\title{
DEVELOPMENT OF A BICYCLE LEVEL OF SERVICE METHODOLOGY FOR TWO-WAY STOP-CONTROLLED (TWSC) INTERSECTIONS
}

\author{
A Thesis \\ presented to \\ the Faculty of California Polytechnic State University \\ San Luis Obispo
}

\author{
In Partial Fulfillment \\ of the Requirements for the Degree \\ Master of Science in Civil and Environmental Engineering
}

by

Nathan Johnston

March 2014 
(C2014

Nathan Johnston

ALL RIGHTS RESERVED 


\section{COMMITTEE MEMBERSHIP}

TITLE: Development of a Bicycle Level of Service Methodology for Two-Way Stop-Controlled (TWSC) Intersections

AUTHOR: Nathan Johnston

DATE SUBMITTED: $\quad$ March 2014

COMMITTEE CHAIR: Anurag Pande, PhD

Associate Professor of Civil and Environmental

Engineering

COMMITTEE MEMBER: Cornelius Nuworsoo, PhD

Professor of City and Regional Planning

COMMITTEE MEMBER: Kimberley Mastako, PhD

Associate Professor of Civil and Environmental

Engineering 


\section{ABSTRACT}

Development of a Bicycle Level of Service Methodology for Two-Way StopControlled (TWSC) Intersections

\section{Nathan Johnston}

This thesis fills a missing piece in research on multimodal performance measures for traffic on streets and highways. The Highway Capacity Manual (HCM) published by the Transportation Research Board (TRB) provides Level of Service (LOS) methodologies which enable engineers and planners to evaluate the overall performance of roadways and highways based on the physical characteristics of facilities. This allows for the evaluation of those facilities and offers a means for recognizing issues and planning, designing, implementing, and ultimately assessing improvements. Originally, level of service was developed for automotive traffic only, but with recent developments as part of the complete streets movement, the performance of infrastructure for alternative transportation modes have also started being assessed in this fashion. There are methodologies in HCM 2010 for bicycle traffic at signalized intersections, allway stop-controlled intersections, roadway and highway segments, but as of yet, no bicycle level of service methodology exists for two-way stop-controlled intersections. This work attempts to fill this gap. The methodology utilized for this report includes video collection of sample two-way stop-controlled intersections throughout California, collection of survey responses from viewers of video, and linear regression of collected survey responses with physical 
attributes of each sample intersection as the explanatory variables. Data was analyzed from both combined and individual street movements to determine the final equation set. The final methodology involves two separate procedures for major and minor streets at TWSC intersections. Final factors deemed significant in bicycle level of service analysis include sight distances, speed limits, presence of bus stops, presence and type of bicycle infrastructure, street widths and types of lanes present, pavement quality, and traffic flows.

Keywords: Highway Capacity Manual, Level of Service, HCM, Bicycle, Two Way Stop Controlled, Intersection 


\section{ACKNOWLEDGMENTS}

I would like to thank Dr. Anurag Pande for his countless help, work, and effort; Dr. Cornelius Nuworsoo for his help with initial funding applications and final review of the thesis; Dr. Kimberley Mastako for her help in obtaining survey responses and conducting the final review. I would also like to thank Kittelson \& Associates for providing me with their past research on level of service which provided a guideline for the processes conducted in this research; Dowling \& Associates for providing their past research on level of service; and Sprinkle Consulting for providing their data on past level of service methodologies and samples of the video they collected and information on the equipment used for the procedure. Thanks to Xi Shen for his help in obtaining the equipment used in this report. Special thanks to James Loy and Jeffrey Johnston for their help and generosity in video recording. Thanks to Dr. John Walker for his help in analyzing the data. Also, I would like to extend a thank you to those who responded to our surveys and provided the much needed feedback necessary for this research including Cycling Connection Bike Group, Cycle Claremont Bike Group, Claremont Senior Bike Group, Psycholist Bike Club, and Cal Poly Students, Faculty, and Staff not only for their participation in the surveys but for all their miscellaneous support, approvals, and involvement.

\section{Thank You}




\section{TABLE OF CONTENTS}

LIST OF TABLES ........................................................

LIST OF FIGURES.........................................................

CHAPTER

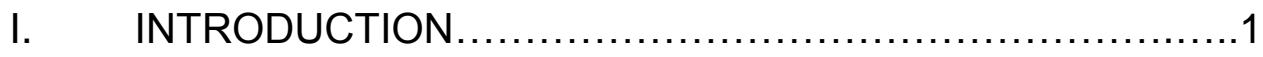

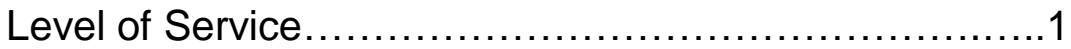

Modes.......................................................

Differences from Cyclist's Perception to Driver's

Perception.................................................. 4

Problem Statement......................................... 6

II. CHARACTERISTICS OF BICYCLE TRAFFIC ...............

Demand Fluctuation..................................... 8

Paved Bicycle Facility Types.............................10

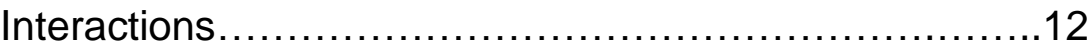

Bicycle Flow................................................

Existing Level of Service Methodologies...................19

Bicycle Level of Service for Signalized

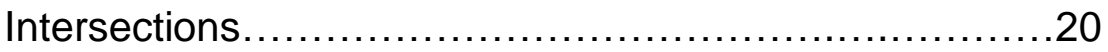

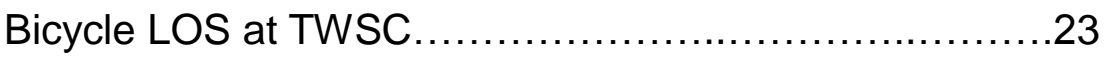

Bicycle Level of Service for All Way Stop-Controlled

Intersections .....................................................

Bicycle Level of Service for Urban Street

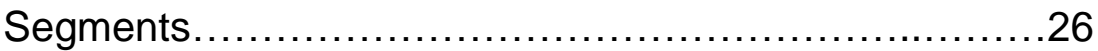


Bicycle Level of Service for Urban Street

Facilities. 28

Bicycles Level of Service for Uninterrupted Flow

Facilities. 29

Automobile Level of Service for Two Way Stop

Controlled Intersections 30

III. DATA COLLECTION AND PROCEDURES......................33

Roadway Design and Environmental Characteristics

Possibly Affecting Two Way Stop-Controlled

Intersection Bicycle Level of Service.......................33

Consideration in Data Collection Procedures...............34

Data Collection Methods....................................35

Sampled Two Way Stop-controlled Intersections...........39

Potential Problems with the Data Collection Method.......42

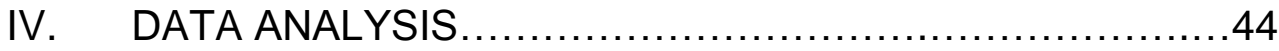

Applying Signalized Intersection Models....................44

All-Way Stop-Controlled Intersection........................45

Two-Way Stop-Controlled Automobile.....................46

Methodology Comparison Figures.........................46

Validation of the Existing Signalized Intersection

Methodology with Data from this Research.................52

Further Considerations...................................52

Expectations............................................. 
Resultant Equations

TWSC Combined LOS Resultant Equation..................61

TWSC Major Street LOS Resultant Equation................63

TWSC Minor Street LOS Resultant Equation...............66

Comparative Evaluation of LOS Estimation at

Approach Level vs. Aggregating All Approaches...........68

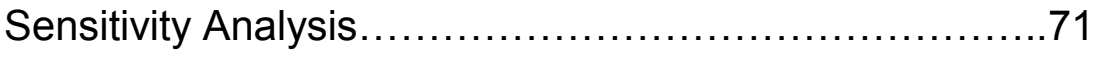

Goodness of Fit........................................... 73

Threshold Recommendation and Improving

Goodness of Fit........................................ 73

Interesting Issues Affecting Bicycle Operation...............76

V. CONCLUSIONS AND SUBJECTS FOR

FUTURE RESEARCH.................................... 82

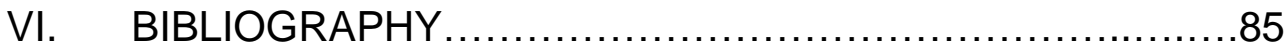

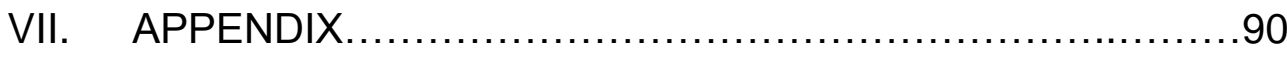

Appendix A: The following is a detailed list of the procedures for several related existing level of service methodologies

Appendix B: Sample calculations for comparing existing level of service methodologies with collected survey responses are provided in the following

Appendix C: The following is a sample calculation for data validation of collected responses by comparing accepted signalized intersection level of service equations to collected signalized intersection level of services.

Appendix D: The following is a list of American League of Bicyclists approved Bicycle Friendly Communities and Universities for 2012. All sites surveyed in this report were selected from this list 
Appendix E: The following images are maps of the selected survey sites shown on the official Bike Maps of the cities selected for data collection. These maps are the ones submitted to the American League of Bicyclists by the individual communities at the time of application for 2012 recognition as Bicycle Friendly Communities. Locations of selected survey intersections are denoted by a large star.

Appendix F: The following are the scanned field data collection pages collected on-site at each survey location

Appendix G: The following is a summary of the collected field data sheets (please note that not all information from the sheets may be listed here, but the majority is).

Appendix $\mathrm{H}$ : The following pages are sample public survey sheets upon which cyclist perception scores were collected by in-person interviews with video recording viewers. Please note that not all data pages collected are included in this appendix due to the large volume of data collected. A summary of all data collected is also included in this appendix to address the excluded data pages

Appendix I: The following is a sample survey response that was provided by a Cal Poly Student in Dr. Mastako's CE 421 Class 302

Appendix $\mathrm{J}$ : The following is a sample survey response that was provided by a member of the general public 305

Appendix $\mathrm{K}$ : The following is a summary of the collected level of service feedback based on the experience of the providers.

Appendix L: The following are the Minitab outputs for the final equations. Results for the tests that were conducted prior to these being determined are not included due to the sheer volume of that data.

Appendix M: The following images are Google Earth ${ }^{\mathrm{TM}}$ screen shots of each surveyed intersection to clarify any confusion with the crude field drawings shown in the field data sheets provided in the above section. Please note that these images are only updated to the most recent Google Earth feed and some intersection images are out of date and do not show all current bicycle facilities present

Appendix N: The following is a poster that was drawn up requesting volunteers to provide feedback on the collected videos. 


\section{LIST OF TABLES}

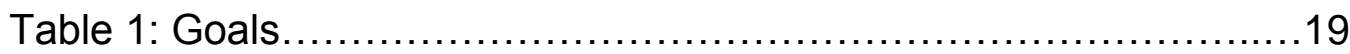

Table 2: LOS Criteria for Bicycles at Signalized

Intersections: Exhibit 18-5 (Highway capacity manual, 2010)...........21

Table 3: Pavement Quality Ratings: Exhibit 17-7

(Highway capacity manual, 2010).....................................27

Table 4: Signalized Intersections Paired T Test Results.................52

Table 5: Paired T Test Results..........................................57

Table 6: Combined LOS Equation Coefficients.........................62

Table 7: Major Street LOS Regression Coefficients......................63

Table 8: Minor Street LOS Regression Coefficients......................66

Table 9: Resulting Variation in Minor Approach Bicycle

LOS Score Based on Increase in Conflicting Automobile Flow..........72

Table 10: Equation Paired T Test Results...............................73

Table 11: TWSC Intersection Major Street Suggested LOS..............74

Table 12: TWSC Intersection Minor Street Suggested LOS...............74

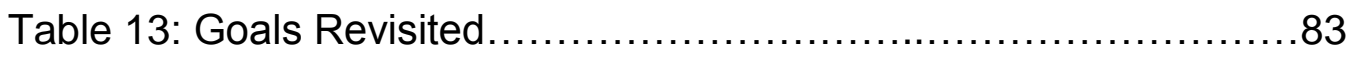




\section{LIST OF FIGURES}

Figure 1: Portland, Oregon, and Copenhagen Travel Demand...........9

Figure 2: Types of Common Bicycle Facilities..........................11

Figure 3: Age versus Speed of Cyclists...............................15

Figure 4: Diagram of Two-Way Stop-Controlled Intersection.............17

Figure 5: Two-Way Stop-Controlled Movement Diagram 1:

Exhibit 19-6 (Highway Capacity Manual, 2010) ..........................31

Figure 6: Semi-Tandem Bicycle Used for Previous Bicycle Level of

Service Methodologies: Image courtesy of Sprinkle Consulting

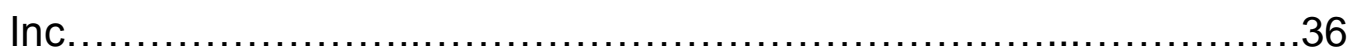

Figure 7: Tandem Bicycle Used for Data Collection for Two-

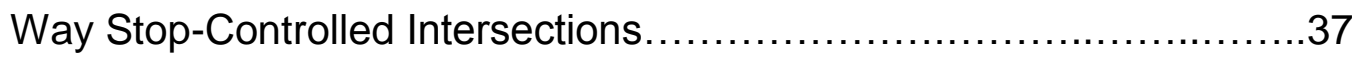

Figure 8: Through Movement Existing Methodology Comparison .......47

Figure 9: Left Turn Movement Existing Methodology

Comparison

Figure 10: Right Turn Movement Existing Methodology Comparison....47

Figure 11: All-Way Stop-Controlled Equation vs. Minor

Street Movements .48 
Figure 12: Uninterrupted Flow Equation vs. Major

Street Movements

Figure 13: TWSC Automobile Method Left Turn..........................49

Figure 14: TWSC Automobile Method Through...........................49

Figure 15: TWSC Automobile Method Right Turn........................49

Figure 16: AWSC Automobile Method Left Turn...........................50

Figure 17: AWSC Automobile Method Through..........................50

Figure 18: AWSC Automobile Method Right Turn........................50

Figure 19: Signalized Automobile Method Left Turn......................51

Figure 20: Signalized Automobile Method Through......................51

Figure 21: Signalized Automobile Method Right Turn...................51

Figure 22: Sight Distance Diagram for TWSC

Intersection Bicycle Approach.......................................53

Figure 23: Original Residuals versus Predicted Values Plot..............58

Figure 24: Combined Methodology Two-Way Stop-Controlled

Movement Diagram: Exhibit 19-6

(Highway capacity manual, 2010)....................................63 
Figure 25: Major Methodology Two-Way Stop-Controlled

Movement Diagram: Exhibit 19-6 (Highway

capacity manual, 2010) .66

Figure 26: Minor Methodology Two-Way Stop-Controlled

Movement Diagram: Exhibit 19-6 (Highway capacity manual, 2010) 67

Figure 27: Bicycle Boulevard. 69

Figure 28: Minor Street Conflicting Volume Sensitivity.... .72

Figure 29: Major Street Equation .75

Figure 30: Minor Street Equation .75

Figure 31: Goleta Comparison .75

Figure 32: Trucks Parking In Bike Lane in Claremont, California. .76

Figure 33: Pavement Quality Discrepancy..... .78

Figure 34: Median Presence in Riverside, California .81 


\section{CHAPTER 1: INTRODUCTION}

There are many components to a transportation network. There are links and all manner of classifications within that category such as streets, highways, freeways, arterials, connectors, etc. Where the links meet, there are intersections, with varying level of traffic controls such as signalized, all-way stop control, TWSC, and roundabouts etc. There are the individual components that are part of these traffic controls as well. A traffic signal, a loop detector, or, perhaps, a video detection system. Each component is important for insuring that the network does not breakdown and each is part of that overall system. If one component fails then it is likely to cause other parts of the system to fail. If one route on a roadway network becomes congested, it is probable that the alternative pathways of travel on that network will also become congested as users try to find alternative paths to their destinations. To ensure that a network and its components function as smoothly as intended, a method must be determined to evaluate how well each is performing and to predict future performance.

\section{Level of Service}

The 2010 Highway Capacity Manual, published by the Transportation Research Board, outlines a methodology for evaluating transportation networks and determining how well each part is functioning with the idea of a "Level of Service"(Highway capacity manual, 2010). This is a grading system that considers the various qualities of a particular part of a network, such as a 
roadway segment, for example, and assigns it a simple letter grade $A$ through $F$ ( $A$ being the best operating conditions and $\mathrm{F}$ being the worst). This method allows for a simple way to determine which components are in need of improvement and which are, or will be, functioning within acceptable parameters. The LOS system is a quantitative method for calculating the performance measures or quality of service of a transportation facility. The measures used to calculate the level of service are referred to as "service measures." Due to extensive costs, roadways are not usually designed up to " $A$ " level standards but may yet experience those conditions during off-peak periods.

Normally, the level of service evaluation is performed for a specific roadway or highway segment, intersection, or direction of travel. Usually the evaluation process examines each traffic movement at that facility individually to identify within the facility its strengths and weaknesses, then use that information to summarize the facility as a whole. Level of service is an important feature of a traffic impact study for future developments as it determines how well a particular transportation facility will work under a given flow rate. Usage of the LOS methodology or the level of service criteria can help a designing engineer determine how best to reasonably accommodate the increase in traffic flow and increase the level of service.

The LOS system is used to designate a physical measurement (e.g., density in case of automobiles on the freeway) that can map to human perception. The simple $\mathrm{A}$ through $\mathrm{F}$ result hides the complex nature behind the measurements. There are a number of inputs that go into the series of equations associated with 
each facility. LOS is a step function which was devised as a way to quickly convey the conditions of a transportation facility to someone who was not familiar with the facility. However, it tends to oversimplify some aspects of the facility and may hide or exaggerate certain specific flaws in the facility. Some have criticized its use saying that it is not fully representative of the overall transportation network, but for the time being it is a well-accepted practice. One reason for this is because it makes for an easy way to communicate roadway performance to lay persons and decision makers that, despite their inability to fully comprehend the technical nature of the situation, are key stakeholders in addressing the transportation related issues.

\section{Modes}

There are different varieties of modes available for travelers to utilize in their travel. The most common of these include the automobile, walking, bicycle, and public transit. The level of service system requires different procedures and set of equations for each. This paper focuses primarily on level of service for bicycle mode choice.

Bicycles are often selected by travelers for a variety of different types of trips including commutes to school or work, recreation, shopping, errands, exercise, or social gatherings and events. Bicycles allow users to travel about five times faster (or more, depending on the cyclist) than an average pedestrian and can extend the range of a local trip. Cycling in the United States is currently less common than in other countries worldwide, but it is increasing in popularity due to a number of reasons both economic and political. Several cities, like Portland, 
Oregon, are becoming increasingly famous for their bicycle friendly infrastructure and attractive locations for potential businesses and residents (Highway capacity manual, 2010).

The existing HCM bicycle level of service equations were developed from survey data on a series of existing bicycle paths. The routes and intersections selected where analyzed in terms of their physical dimensions, characteristics, and flow rates. Then volunteers were asked to give those routes and intersections a letter grade that reflected their own opinion of that facility. Then, the opinion surveys were used to create and calibrate the series of equations that are presented in the 2010 manual (Kang \& Lee, 2012; Dowling et al, 2008). The idea being that these statistical models can now estimate what level of service the cyclists would claim to experience from a given bicycle facility.

\section{Differences from Cyclist's Perception to Driver's Perception}

Many measures that apply to vehicle level of service also apply to bicycle level of service, e.g., delay. Some measures, however, are different, like vehicle density, for example. Cyclists often travel very tightly packed in groups and even travel side by side. Unlike motorists, who experience a higher level of service when densities are low and distances between vehicles are very high, cyclists are more tolerant or even prefer higher densities. But, at the same time, faster cyclists often wish to, but may be unable to, pass slower groups of cyclists due to inadequate maneuvering room with a high density of cycling traffic. This kind of situation makes density a very unstable measure of level of service for bicycles. Capacity is also a difficult measure as it usually depends on the flow speed of the 
traffic. Bicycle speeds vary from cyclist to cyclist, sometimes by up to four times the slower cyclist's speed. It has been noted that, when facilities become too congested, some less experienced cyclists will even dismount and start walking before the facility reaches capacity (Highway capacity manual, 2010).

Some factors have more weight in determining a cyclist's perceived level of service than a motorist's level of service. The pavement quality (and/or presence of roadway debris), for example, often affects a cyclist much more directly than the motorist both due to comfort and the likelihood of mechanical issues like the possibility of getting a flat tire. The percentage of heavy vehicles on a route also may impact cyclists' level of service significantly. Large vehicles can intimidate cyclists, especially when passing in close proximity with a high speed differential. The existence of on-street parking is important to cyclists as pedestrians become more likely to step into the cyclist's path of travel and drivers are more likely to open their doors into the bike lane. On street parking often forces cyclists to slow down and move closer to the main traffic flow in order to avoid a collision with the parking lane.

Environmental factors may play a much heavier role on cyclists' level of service than on motorized vehicle transit. Cyclists often feel more satisfied with a scenic area. This is where the cyclist's perception of safety plays a role as they do not have a locked door between them and someone else standing on a street corner. The weather is also a concern as cyclists are comparatively more concerned than motorists about wet and slick conditions. 


\section{Problem Statement}

Among the existing modal choices, active modes of transportation, i.e., walking and bicycling, can provide significant benefits for physical well-being in addition to the environment. Increased bicycle usage also has the added benefit of making transit more attractive as a mode since a bicyclist can traverse significantly more distance to and from a transit stop compared to a pedestrian. Cycling is not only more economical but also is more equitable alternative to the automobile due to its affordability. In spite of the benefits mentioned here, there are significant challenges to widespread use of bicycles in the US. Infrastructure is designed largely for the automobile not only as the dominant mode but in some jurisdictions as the only mode of travel. In addition, bicycle users are more sensitive to inclement weather conditions and the environment, in general. Also, cyclists are more vulnerable on the road compared to drivers. These challenges to bicycle usage require that the needs of bicyclists on the road are adequately identified and addressed. A level of service (LOS) score can be a valuable tool to help traffic engineers and planners do just that. Although Dowling et al. (2008) tied the LOS measures for bicycle users to user satisfaction for street segments and signalized intersections, the concept is not well defined for some of the other facilities and one of the missing links is the LOS for bicycles at two-way stopcontrolled (TWSC) intersections (Dowling et al, 2008). As of yet, there is no bicycle LOS method for TWSC intersections. The HCM states the following on the subject: 
As of the publication date of this edition of the HCM, no methodology specific to bicyclists has been developed to assess the performance of bicyclists at TWSC intersections, as few data are available in the United States to support model calibration or LOS definitions. (Highway capacity manual, 2010)

This study addresses these challenges and is organized as follows: the next chapter provides characteristics of the bicycle traffic followed by the data details. The chapter after that describes the statistical analysis of the data followed by results and conclusions. 


\section{CHAPTER 2: CHARACTERISTICS OF BICYCLE TRAFFIC}

\section{Demand Fluctuation}

The amount of bicycle travel, and demand for bicycle facilities, varies significantly by time. Bicycle travel is heaviest on an average day during the morning and during the evening as people either commute or have the ability to partake in recreational activities. Bicycle travel is generally higher in the summer time of the year than in the winter as cyclists are exposed to the elements and experience a far lower comfort level when exposed to bad weather, low light levels for bad visibility, and extreme cold. Even over the course of a week, the number of cyclists on a roadway varies from day to day. See Figure 1 below which depicts fluctuations in time for bicycles reproduced from the HCM 2010 (Highway capacity manual, 2010). 

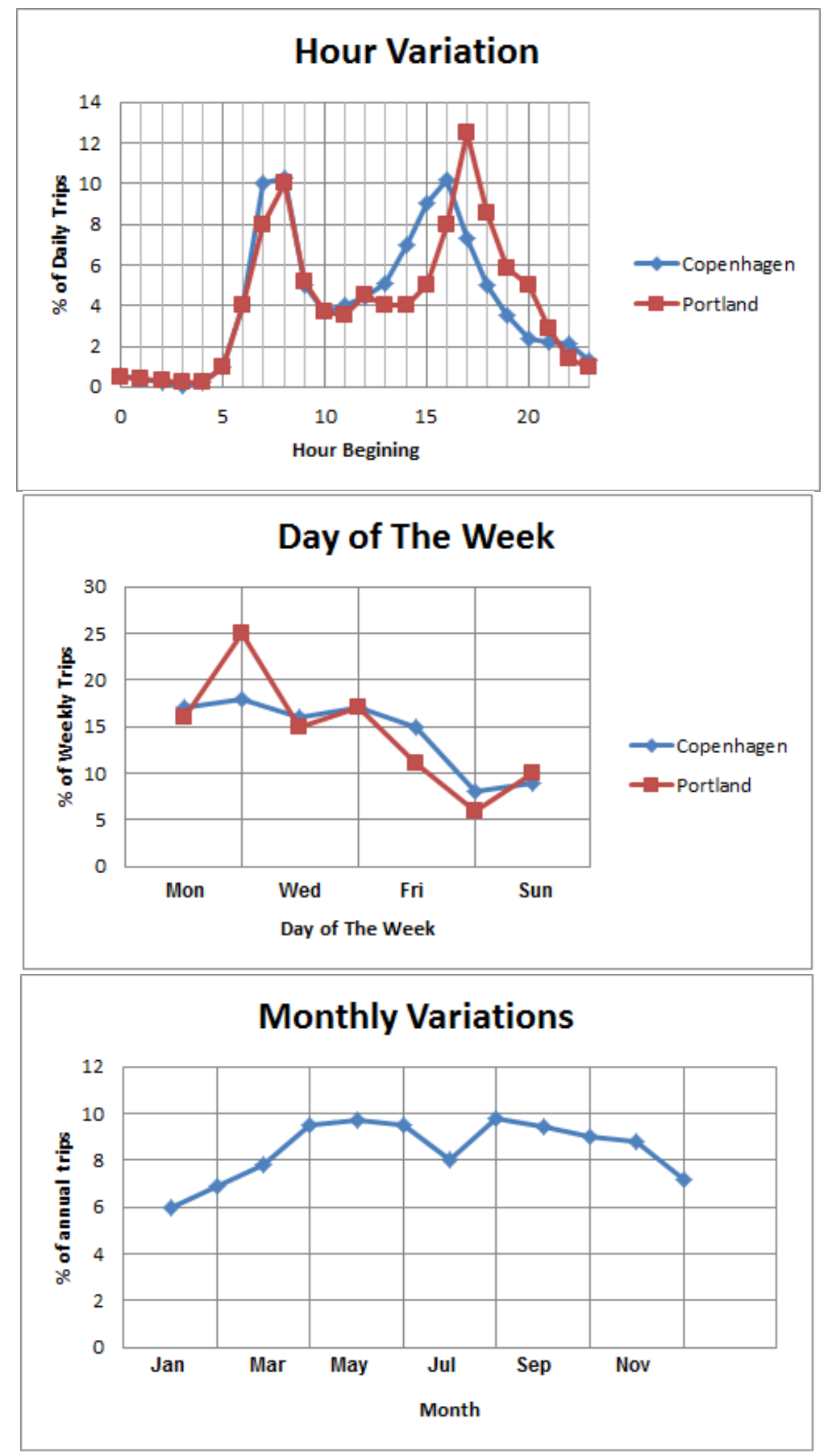

Figure 1: Portland, Oregon, and Copenhagen Travel Demand; (Highway capacity manual, 2010) 


\section{Paved Bicycle Facility Types}

Bicycle facilities may or may not follow, or even be part of, the main roadway network. Those that are part of the existing roadway are considered on-street and those that are not part of the roadway are considered off-street. On-street facilities include (but are not limited to) shared lane paths (also known as Sharrows), bicycle lanes, shoulder bikeways, and bicycle tracks. In some cases a bicycle path may exist on a roadway, but may not be stripped or marked or may have some intermediate method of announcing the presence of cyclists. A class three bike path, for example, refers to a highway that has signage for a "Bike Route," but in which no roadway markings are present and cyclists are expected to ride in the primary travel lanes with other vehicles. For on-street facilities, cyclists share the roadway with motor vehicles but may or may not have separate lanes. These are fairly common in both rural and urban areas with low financial resources. Off-street facilities include sidepaths and exclusive bike pathways, usually offering bi-directional flow. Some facilities may be for bicycle use only whereas some allow for pedestrian travel on these paths, as well, however, such mixed use paths can cause congestion and safety issues when experiencing high flow volumes. Sidepaths in particular can also cause conflicts or concerns with adjacent properties, driveways, or intersecting roadways but the 2010 Highway Capacity Manual level of service methodology does not take this into account. Whatever facility type is utilized, all function with the primary purpose of transporting travelers from point $A$ to point $B$ and can either be constructed on or parallel to a normal vehicle roadway. 


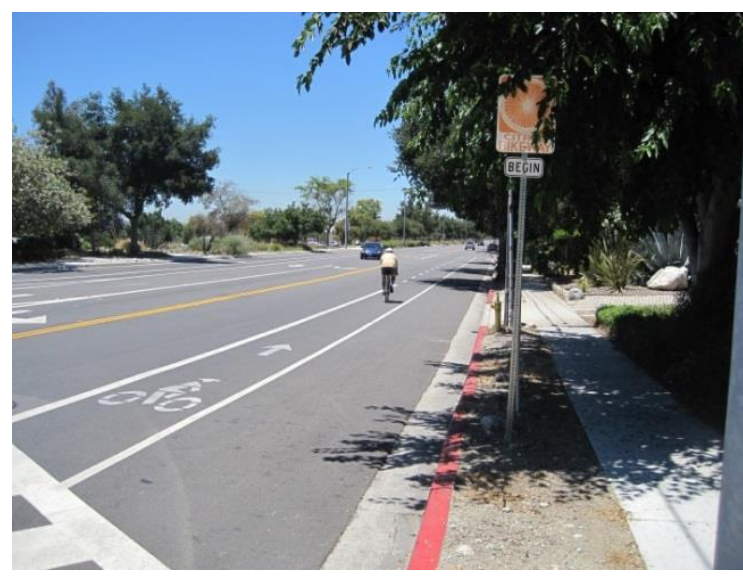

Bike Lane

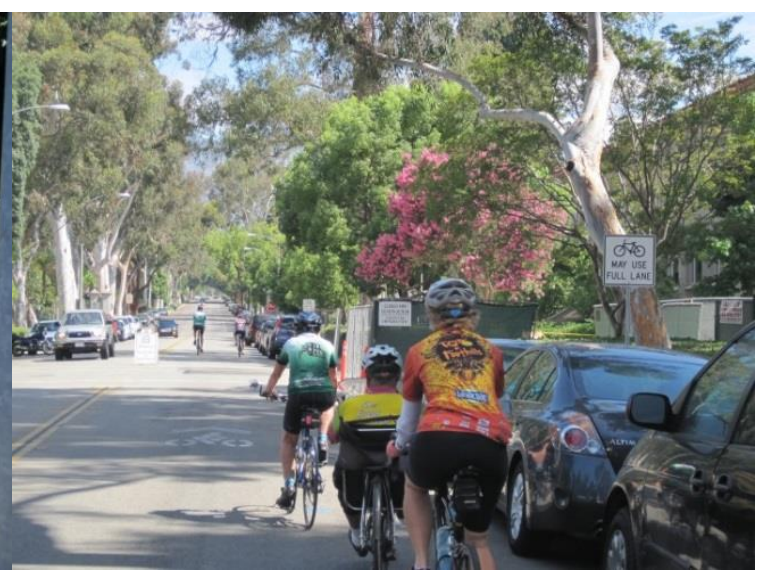

Shared Lane (Sharrows)

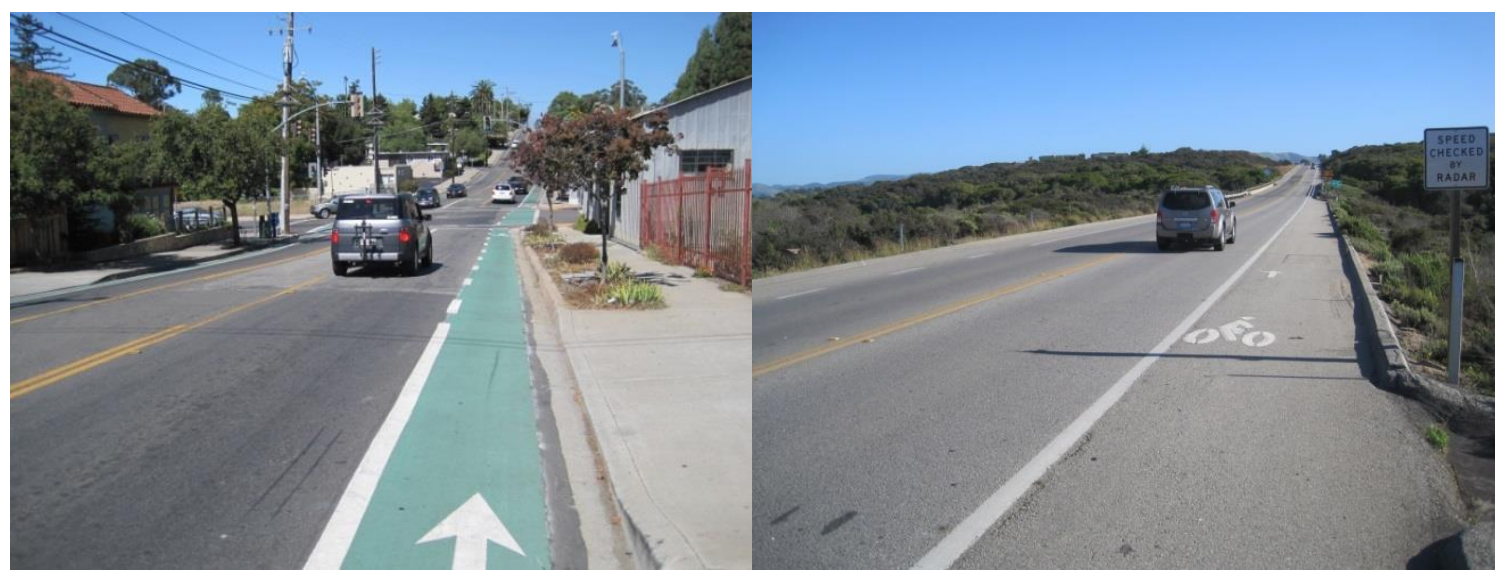

Bike Track

Shoulder Bikeway

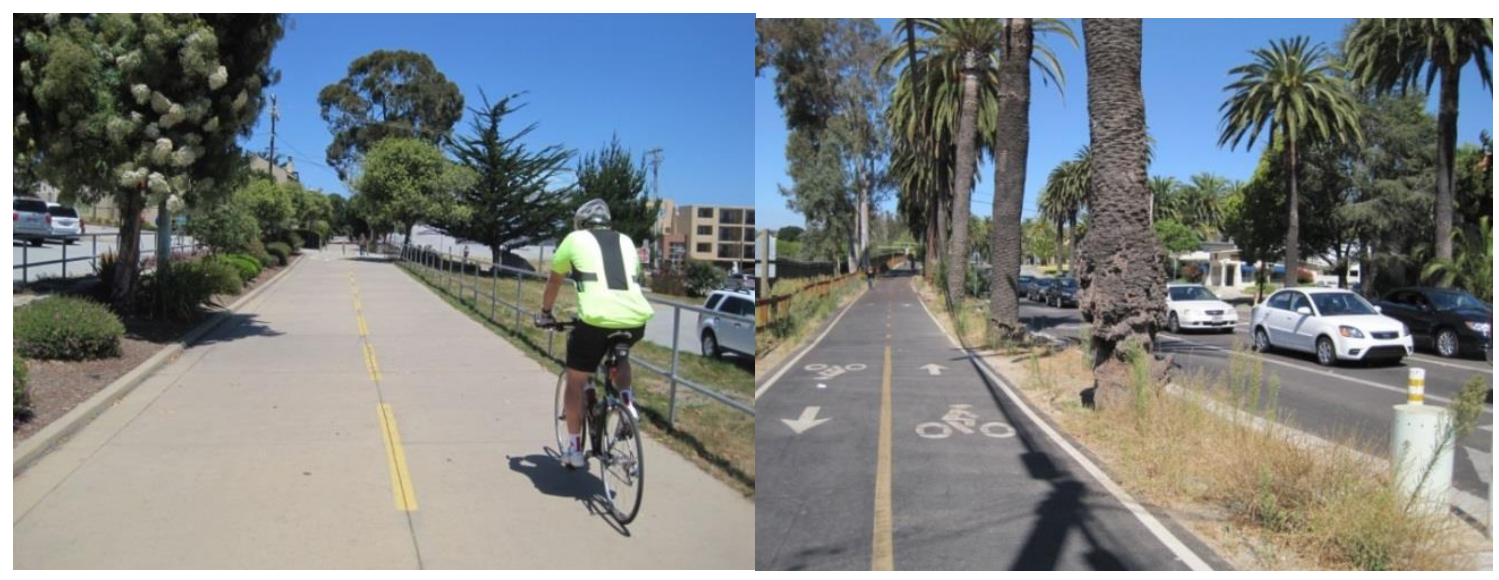

Exclusive Pathway

Side Path

Figure 2: Types of Common Bicycle Facilities 


\section{Interactions}

The volumes of automobile and heavy vehicle flow on or adjacent to a bicycle pathway affect the ride quality of the cyclist. Parked vehicles increase the chances of bicycle collisions, not only with the parked vehicles or pedestrians, but with normal vehicle traffic as the existence of roadside parking often forces cyclists further into the lane of travel than they would otherwise go if no vehicles were parked. Turning vehicles often cross the path of cyclists and right turning vehicles especially often do not even notice the bicycle before cutting into its travel lane. The distance kept between a cyclist and a vehicle is a key aspect in a cyclists' view of the level of service of a facility as well as the speed of the passing vehicle. (On a side note: A proposed piece of legislation that is currently being supported, at the time of this paper being written, is to require vehicles on a roadway to keep a minimum of three feet away from cyclists. If this legislation were to be implemented (as it will be, starting September 2014, in California), and be enforced, the cyclists' level of service perception of each facility may automatically increase without actual physical improvement of the facility.) Transit vehicles such as buses react similarly with cyclists as heavy vehicles except that they often cut into bicycle travel paths in order to pick up or drop off passengers. This adds increasing delay and decreasing safety to the cyclist's ride quality. The 2010 Highway Capacity Manual does not yet account for this in its level of service methods (Highway capacity manual, 2010). In a related manner, transit that allows for a cyclist to bring his or her bike on board can extend the range, ease, and comfort of the ride and increase the perceived 
level of service for a route. In reality, all of these play a role in the cyclists' perception of level of service with respect to vehicles.

Pedestrians also affect cyclists and usually add to the delay with their presence. Pedestrians often travel in groups, typically side by side, at low speeds and have a tendency to block cyclists travel path (even if against the law). They often are more maneuverable than bicycles in close quarters and act in unexpected ways when encountering a bicycle on the same pathway. Similar to motor vehicles, bicycles must yield to pedestrians and also wait for them to travel across their path when heading perpendicular to the bikeway.

\section{Bicycle Flow}

Bicycles tend to act in ways similar to motor vehicles, being legally obligated to adhere to the same rules and regulations. They operate in distinct lanes or paths with widths that are easily measured or determined and the capacity of the facility depends on the number of these lanes that are available. In general, a bicycle lane is around 3 to 5 feet in width but sizes do vary depending on a multitude of factors. (The American Association of State Highway Transportation Officials recommends 10 feet total width for off-street bike paths (Do, 2006). Shared lane facilities are the most common and usually only have one lane in each direction, but there are other paths that have bike shoulders, passing lanes, or tracks that bikes can take to increase their flow. Not all of these lanes may be in use for riders, however, so it may be difficult to determine which should be considered its own lane and which should not. Usually a field evaluation is in order when this ordeal is encountered. The HCM 2010 recommends three lane bike paths (two 
one directional lanes and one passing lane) as being the most efficient bike path layout (Highway capacity manual, 2010). These offer increased maneuverability for cyclists (and pedestrians when allowed) to pass slower groups without conflict, which reduces delay and increases the safety of the path.

As with other vehicles, as the density of the cyclists becomes very large the average speed of the cyclist drops as congestion occurs. Collisions between cyclists are fairly frequent under these circumstances, but rarely do significant damage to person or property, unless a motor vehicle is involved. The majority of bicycle facilities in America are shared with motor vehicles and as the density of each increases, the delay of each increases.

The average free flow speed of the cyclist under ideal conditions also affects the flow significantly. The speed is affected by several factors including skill level, bicycle type, age, and physical capability. A road bike rider is more likely to travel at a faster rate than a mountain bike or "beach cruiser" rider. The personal characteristics of the bicycle and its rider affect the speed and flow just as much as the characteristics of a vehicle and its driver affect its speed and flow. (Note: Please recall that flow is in units of volume per time whereas speed is in units of distance per time.) 


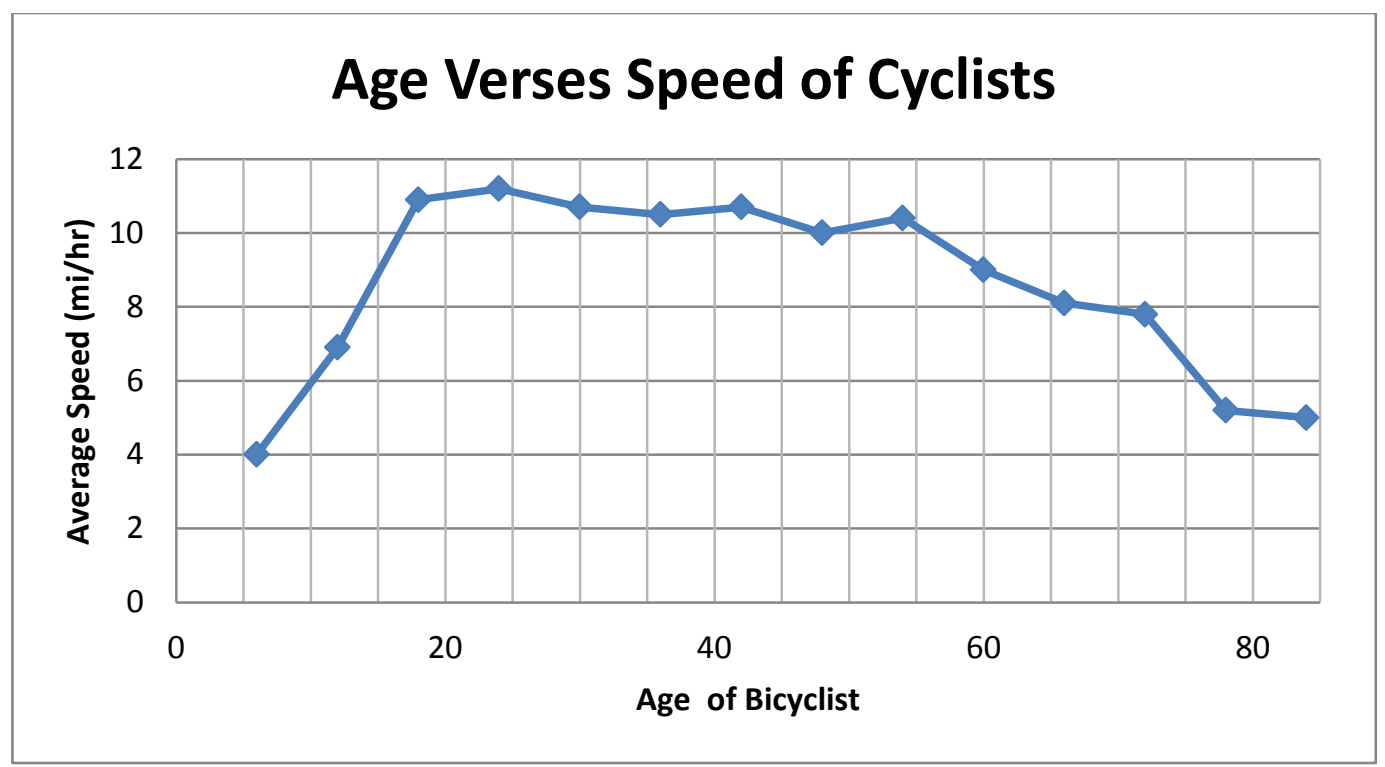

Figure 3: Age versus Speed of Cyclists (Highway capacity manual, 2010)

Flow rates for bicycles usually vary with time over the course of an hour and a day. As cyclists become more exhausted they typically slow down. The HCM usually recommends examining the peak 15 minute flow during the peak hour for measuring the level of service (Highway capacity manual, 2010). (If necessary, the peak hour factor can be used to obtain this value from an hourly rate. Peak hour factors typically range between 0.7 to 1 or 0.85 on average.)

Unfortunately, as highlighted above, the concept of capacity is not the best measurement for level of service or maximum bicycle flow rate. Capacity values depend on factors that have too much variation when applied to bicycles and cannot usually be trusted. The HCM suggests that capacity is only important when dealing with bicycles at signalized intersections but then offers a rule of thumb value of 1000 bicycles/hour/lane to use as a default and a saturation flow rate of 2000 bicycles/hour/lane (Highway capacity manual, 2010). This is 
inconsistent as it claims individual evaluation to be important, then recommends ignoring it altogether in favor of a default value. Delay may serve as a better judgment characteristic than capacity for bicycles. Delay represents the overall travel time, an important factor both for the initial mode choice and for the facility, and accounts for the cyclist's willingness and patience with a system. A cyclist who experiences delay has to exert themselves more than a cyclist that does not experience delay. A cyclist that gets stopped at a traffic signal has to brake and then accelerate again as opposed to a cyclist who coasts through an intersection without extra effort because they were not required to stop. This plays an important part of the perceived satisfaction the cyclist experiences as the one who had to stop no doubt felt a little less happy with the facility than did the cyclist that was allowed to coast through unhindered. Even when the purpose of the bike rider is to exercise, unnecessary physical exertion caused by excess starting and stopping of a bicycle results in increased stress on the rider and decreases their satisfaction with the bicycle facility.

Delay actually may have some components because of this effect. A cyclist that has to start and stop several times along a route will probably feel more upset than a cyclist that only has to stop one or two times. A cyclist, like a normal vehicle driver, that has to wait a long time at an intersection will probably feel more upset than if they only had to wait a few seconds. This indicates that it is necessary to consider not only how long the total delay is in seconds, but also how many times the rider is required to stop. Not only would this apply to routes, but when analyzing a particular intersection the distance to nearby upstream and 
downstream intersections or stops should be considered as well as their cycle lengths.

Bicycle level of service methodologies exist for signalized intersections, but not for the more common TWSC intersections. (A two-way stop-controlled intersection is a roadway intersection in which one or more direction of traffic flows pass through uninhibited while conflicting traffic flows are held back by a stop sign.)

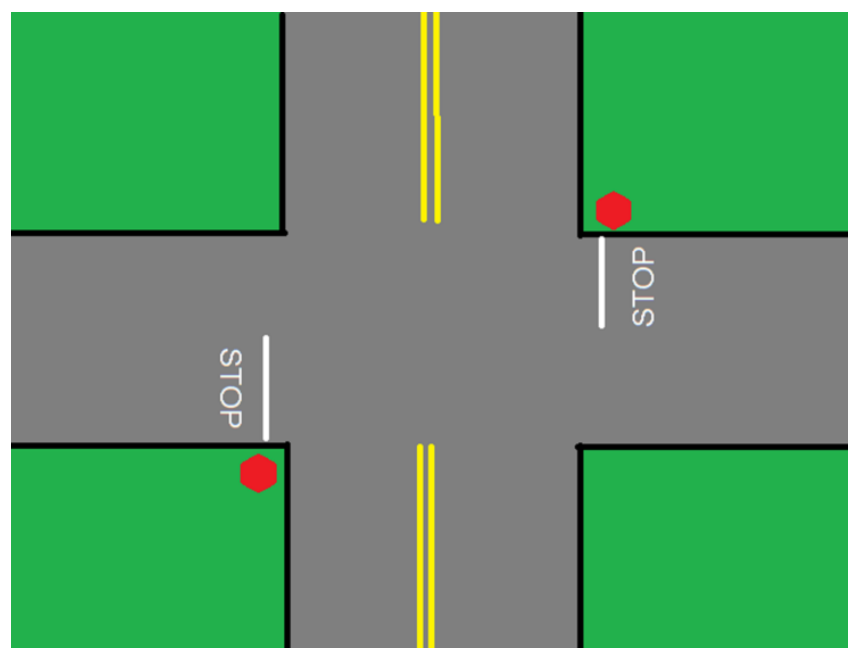

Figure 4: Diagram of Two-Way Stop-Controlled Intersection

TWSC intersections are critical and frequently encountered elements of a street network. One needs to address the LOS for bicyclists at these intersections to obtain a better assessment of the bicycle travel experience. The expansion of LOS procedures by incorporating this critical roadway element will help cities make street networks more bicycle friendly and lead to increased bicycle usage. Literature written about bicycle infrastructure reports significant evidence that providing adequate roadway designs and addressing the needs of bicyclists 
leads to increased bicycle usage (Dill and Voros, 2007; Pucher, Dill, \& Handy, 2010).

Increased bicycling can result in reduced greenhouse gas and pollutants being released into the environment. Bicycles are typically considered to be one of the most economical and sustainable modes of transportation. In addition to being an active mode of transportation they can enhance access to transit services at bus and rail stops. Commuters on bicycles can commute to transit centers located much farther than commuters who walk. Ultimately enhancing the multi modal LOS procedure with this crucial roadway element will make the HCM methodology more complete. Wider applications with a more complete methodology can allow communities to make better decisions with respect to the enhancements that are needed to improve user perception of bicycle facilities. A list of the necessary procedures for providing this level of service methodology is outlined in table 1 below. 
Table 1: Goals

\begin{tabular}{|c|}
\hline Goal \\
\hline $\begin{array}{c}\text { Collection of Data on Physical Characteristics of Sample } \\
\text { Two-Way Stop-Controlled Intersections }\end{array}$ \\
\hline $\begin{array}{c}\text { Collection of Video Footage of Two-Way Stop-Controlled } \\
\text { Intersection Turn Movements from Cyclist' Perspective }\end{array}$ \\
\hline $\begin{array}{c}\text { Collection of Video Footage of Signalized Intersection Turn } \\
\text { Movements for Validation of Viewers Feedback }\end{array}$ \\
\hline $\begin{array}{c}\text { Collection of Video Viewer's Feedback as Perceived Level of } \\
\text { Service Ratings }\end{array}$ \\
\hline $\begin{array}{c}\text { Consolidate Viewers Feedback into a Single Average LOS } \\
\text { Score for Each Turn Movement }\end{array}$ \\
\hline $\begin{array}{c}\text { Split Data into Three Sets for Analysis: Major Street, Minor } \\
\text { Street, and Combined }\end{array}$ \\
\hline Perform Linear Regression on Data and Confirm with \\
Reserved Survey Intersections \\
\hline Provide details on significance of Results and Future \\
Research Possibilities
\end{tabular}

\section{Existing Level of Service Methodologies}

The first step in developing a new level of service methodology is to examine the other methodologies that have already been created and to see what aspects may be important for TWSC (two-way stop-controlled) intersections. It is also possible that an already existing methodology for a similar manner of roadway configuration may work just as well for two-way stop-controlled intersections. This is something that should be tested with data collected from the field at twoway stop-controlled intersections (and is tested later on in this report). Brief descriptions of each method are outlined below. A much more detailed format for each level of service methodology is listed in the appendix. 


\section{Bicycle Level of Service for Signalized Intersections}

Currently, the HCM requires intersection performance to be calculated individually for each intersection approach (direction of travel) unless otherwise stated (Highway capacity manual, 2010). Bicycles are assumed to travel in an on-street facility in the same direction as adjacent motor vehicles. The methodology looks at the intersection from the cyclists' point of view, as the data calibration for the model was done specifically from feedback of cyclists on selected real-life intersections.

There are three main steps in the bicycle level of service for a signalized intersection:

- Determine Bicycle Delay

- Determine Bicycle Level of Service Score for the Intersection

- Determine the Level of Service

These are done separately for each approach to the intersection and repeated for each approach of interest. If a bicycle lane or shoulder does not exist, the bicycle delay is assumed to be the same value for bicycles as it is for vehicles as they both use the same lane. This does cause some room for error as the presence of bicycles in the vehicle lane usually slows down the main traffic flow, so there may be increased delay that is not accounted for by the LOS calculation under these circumstances.

The last step is to use the above bicycle level of service score to look up the actual level of service in exhibit $18-5$ from the HCM: 
Table 2: LOS Criteria for Bicycles at Signalized Intersections: Exhibit 18-5 (Highway capacity manual, 2010)

\begin{tabular}{|c|c|}
\hline LOS & LOS Score \\
\hline A & $<2.00$ \\
\hline B & $2.00-2.75$ \\
\hline C & $2.75-3.50$ \\
\hline D & $3.50-4.25$ \\
\hline E & $4.25-5.00$ \\
\hline F & $>5.00$ \\
\hline
\end{tabular}

For example, if $I_{b \text {,int }}$ was found to equal 3.76 , that particular travel direction in the intersection would have a level of service rating "D." This would imply that modifications may be necessary to improve the experience for cyclists at such an intersection.

Something that is noteworthy in this approach is that, although the delay is calculated, it does not actually factor into the level of service calculation. This may or may not be a flaw in this particular methodology as a high level of delay in the field should indicate a lower level of service. As the HCM mentions, cyclists will not normally tolerate oversaturated conditions or areas with high delay and will select alternate routes or even ignore traffic laws in order to avoid unnecessary delays (Highway capacity manual, 2010). In general, most delay at a signalized intersection is caused by the signal itself. However, right turning vehicles also require cyclists to slow down in order to avoid a collision and cyclists are often delayed whether right turning vehicles are present or not simply because the cyclist has to check for them before entering an intersection. Large dips at intersections, common for streets with high quantities of drainage capacity, also are known to cause delay as cyclists must reduce speed in order 
to safely pass over these hazards. However, these are not directly addressed in the signalized intersection methodology for bicycle level of service.

Two-way stop-controlled intersection bicycle behavior may function in similar respects to this particular level of service method. However, the HCM only looks at what it considers to be the effective bicycle widths without taking into consideration whether or not this space is shared by bicycles with other vehicles. Inexperienced cyclists are often not comfortable with riding in automotive traffic and even experienced cyclists prefer the safety of being separated (Highway capacity manual, 2010). The type of bicycle facility present is not reflected in this method. In addition, signalized intersection delay is estimated based off of the signal timing, but a TWSC intersection has no signal timing. Delay for a two-way stop-controlled intersection may be much more difficult to accurately estimate as it would depend on the individual intersection configuration, traffic flow, sight distance, and possibly other factors we would not normally consider. Another key element in the signalized intersection bicycle level of service methodology is the saturation flow rate. The saturation flow rate is the rate at which vehicles (bicycles in this case) traverse an intersection during a green signal with a full queue. It measures how many vehicles can go through an intersection under perfect conditions (never actually achieved in reality). This can be very difficult to determine as the saturation flow rate varies depending on the experience, age, and skill level of the cyclists (as mentioned in the previous sections). This may be another flaw for the signalized intersection level of service method. 


\section{Bicycle LOS at TWSC}

As mentioned in the introduction, the HCM 2010 states the following in regards to two-way stop-controlled intersection bicycle level of service: "As of the publication date of this edition of the HCM, no methodology specific to bicyclists has been developed to assess the performance of bicyclists at TWSC intersections, as few data are available in the United States to support model calibration or LOS definitions“ (Highway capacity manual, 2010). In other notes, the HCM mentions concerns with bicycle follow up times and headways as cyclists often ride side-by-side rather than single file as an automobile would. There has been some discussion as to whether it is best to model a bicycle more as a vehicle or as a pedestrian instead. (Note that the pedestrian method for level of service at a two-way stop-controlled intersection applies only to pedestrians crossing the major street because the delay for pedestrians crossing the minor street is assumed to be negligible as vehicles already have to stop and wait for conflicting flows to pass by.)

\section{Bicycle Level of Service for All-Way Stop-Controlled Intersections}

For all-way stop-controlled intersections, bicycles are modeled in exactly the same way as vehicles. The HCM recognizes that bicycles do not queue in a single file or linear fashion, but this fact is not reflected in the methodology chosen for LOS estimation (Highway Capacity Manual, 2010). It is stated in the HCM that bicycle delay will be slightly less than the vehicle delay because of this effect, but by exactly how much is unknown. The exception to this is with left turning bicycles who must queue with motorized vehicles in order to safely 
complete their turns. In general, where bike lanes are present, bicycles are not delayed by other vehicles until they reach the stop bar and must wait for their turn to pass through the intersection. Bicycles can pass through an intersection at the same time as the adjacent vehicle traffic where bike lanes are present, so the bike lane, in effect, serves as an additional lane of traffic allowing multilane operations at the intersection. It has been observed that these effects may still occur in areas without a striped bike lane where bicycles simply pass vehicles on the right side, resulting in lower delay for the cyclists.

The methodology for bicycle level of service at all-way stop-controlled intersections is considerably longer than the methodology previously discussed for signalized intersections. The steps include the following:

- Convert movement demand volumes to flow rates

- Determine lane flow rates

- Determine geometry group for each approach

- Determine the saturation headway adjustments

- Determine initial departure headway

- Calculate initial degree of utilization

- Compute probability states

- Compute probability adjustment factors

- Compute saturation headways

- Compute departure headways

- Check for convergence 
- Compute capacity

- Compute service times

- Compute control delay for each lane

- Compute control delay and determine level of service for each approach and the intersection

- Compute queue lengths

Please note that the HCM offers contradictory information between pages $20-3$ and 20-19 and notes that the bicycle delay, capacity, and level of service may be inaccurate for all-way stop-controlled intersections because it uses the model primarily for vehicular behavior (Highway capacity manual, 2010).

This method of determining the level of service does account for directionality, but does not account for the existence of bicycle facilities. It is designed mainly for the determination of automobile level of service and may often present a poor representation of cycling level of service. It does not consider the pavement quality, the separation distance between cyclists and other vehicles, the lane widths, or most of the other factors that are important to a bicycle rider. In addition to not being responsive, this is a fairly complicated method to use, involving multiple iterations of probabilities for each approach and is not userfriendly. It is the calculation intensiveness with the ease of making an error along the way that disrupts the overall estimate of level of service. The all-way stop- 
controlled intersection level of service methodology is highly flawed and does not represent a good model for two-way stop-controlled intersections.

\section{Bicycle Level of Service for Urban Street Segments}

Now let's examine the determination of bicycle level of service for urban street

segments. This method also considers the directional movement of the cyclist at the intersection. The cyclist is assumed to travel in on-street facilities for this method and in the same direction as the adjacent vehicles. This method consists of the following steps depending on the specific information one is interested in:

- Determination of Bicycle Running Speed

- Determine Bicycle Delay at the Intersection

- Determine Bicycle Travel Speed

- Determine Bicycle Level of Service Score for the Intersection

- Determine Bicycle Level of Service Score for the Link

- Determine Level of Service Score for the Link

- Determine Bicycle Level of Service Score for the Segment

- Determine Segment Level of Service

One important part of this methodology that may be very useful for other bicycle level of service methodologies (including two-way stop-controlled intersections) is the use of pavement quality ratings as established by the Federal Highway Administration. A copy of the rating scale details is reproduced below from chapter 17 in the HCM 2010 (Highway capacity manual, 2010). 
Table 3: Pavement Quality Ratings: Exhibit 17-7 (Highway capacity manual, 2010)

\begin{tabular}{|c|c|c|}
\hline $\begin{array}{l}\text { Pavement Condition } \\
\text { Rating }\end{array}$ & Pavement Description & $\begin{array}{l}\text { Motorized Vehicle Ride } \\
\text { Quality and Traffic Speed }\end{array}$ \\
\hline 4 to 5 & $\begin{array}{l}\text { New or nearly new } \\
\text { superior pavement. Free } \\
\text { of cracks and patches }\end{array}$ & Good Ride \\
\hline 3 to 4 & $\begin{array}{l}\text { Flexible pavements may } \\
\text { begin to show evidence } \\
\text { of rutting and fine cracks. } \\
\text { Rigid pavements may } \\
\text { begin to show evidence } \\
\text { of minor cracking }\end{array}$ & Good Ride \\
\hline 2 to 3 & $\begin{array}{l}\text { Flexible pavements may } \\
\text { show rutting and } \\
\text { extensive patching. Rigid } \\
\text { pavements may have a } \\
\text { few joint fractures, } \\
\text { faulting, or cracking. }\end{array}$ & $\begin{array}{c}\text { Acceptable ride for low- } \\
\text { speed traffic but barely } \\
\text { tolerable for high speed } \\
\text { traffic }\end{array}$ \\
\hline 1 to 2 & $\begin{array}{l}\text { Distress occurs over } 50 \% \\
\text { or more of the surface. } \\
\text { Flexible pavement may } \\
\text { have large potholes and } \\
\text { deep cracks. Rigid } \\
\text { pavement distress } \\
\text { includes joint spalling } \\
\text { patching and cracking. }\end{array}$ & $\begin{array}{l}\text { Pavement deterioration } \\
\text { affects the speed of free } \\
\text { flow traffic. Ride quality } \\
\text { not acceptable. }\end{array}$ \\
\hline 0 to 1 & $\begin{array}{l}\text { Distress occurs over } 75 \% \\
\text { or more of the surface. } \\
\text { Large potholes and deep } \\
\text { cracks exist. }\end{array}$ & $\begin{array}{l}\text { Passably only at reduced } \\
\text { speed and considerable } \\
\text { rider discomfort. }\end{array}$ \\
\hline
\end{tabular}

These methods do account for a variety of factors that influence cyclist perception of the true level of service experience, but rely on reaching out to other methods (such as signalized intersection level of service) to fill in missing pieces of the level of service puzzle. In a way, this is a wise thing to do as it breaks down the method into its individual components (intersection, street segment, another intersection, etc.), but at the same time it seems to almost lose 
sight of the fact that it is all part of the same route. The final equation (step seven) combines all of the components into a single equation but only looks at a single route in a single direction. It does not account for bicycles that make a turn along the route. It also does not reflect bicycle facility type (apart from noting that it is assumed to be an on-street facility).

\section{Bicycle Level of Service for Urban Street Facilities}

Now we shall look at a level of service methodology that combines the above methods. Urban street facilities are also looked at in the individual direction of travel (Chapter 16 of the $2010 \mathrm{HCM}$ ) (Highway capacity manual, 2010). This method has only three steps although they require the other methods to be calculated before these can be completed:

- Determine the Bicycle Travel Speed

- Determine the Bicycle Level of Service Score

- Determine the Bicycle Level of Service

This method uses the bicycle travel speed (which, again, varies from cyclist to cyclist) and can offer different level of services for the same facility to different riders. It uses the level of service scores of the individual components that make up that facility (possibly including several intersections, when appropriate) and is more of a global level of service tool than a methodology for a specific site facility location. It would not be useful for two-way stop-controlled intersection analysis. 


\section{Bicycles Level of Service for Uninterrupted Flow Facilities}

For uninterrupted traffic flow, there are three main types of facilities: freeways, multilane highways, and two lane highways. Bicycles are not allowed on freeways, however, and for a cyclist, multilane highways have much the same effect as a two-lane highway. This means that, essentially, there is only one form of uninterrupted flow methodology for bicycles.

The HCM lists the process as being five main steps, however, since one of the steps is simply to gather data, there are effectively only four steps (Highway capacity manual, 2010):

- Calculate the Directional Flow Rate in the Outside Lane

- Calculate the Effective Width

- Calculate the Effective Speed Factor

- Determine the Level of Service

This method takes into account the lane widths (including the shoulder), the motorized vehicle traffic, the number of directional lanes, the percentage of heavy vehicles, the speeds of the vehicles, roadside parking, and the pavement quality. As level of service methodologies go, this is one of the better ones as it accounts for numerous factors and is still fairly simple to use. Simplicity is an important factor in these models because, if a methodology is not simple, no one will want to use it and, if they do, the chances of the engineer using it incorrectly increase dramatically. 


\section{Automobile Level of Service for Two-Way Stop-Controlled Intersections}

The methodology for automobile level of service at two-way stop-controlled intersections depends on a number of factors including intersection geometry, priority of movements, capacities, and delay. The steps for calculation involve the following:

- Determine and Label Movement Priorities

- Convert Movement Demand Volumes to Flow Rates

- Determine Conflicting Flow Rates

- Determine Critical Headways and Follow-up Headways

- Compute Potential Capacities

- Compute Movement Capacities by Rank

- Determine Capacity Adjustments

- Compute Movement Control Delay

- Compute Approach and Intersection Control Delay

- Compute the $95^{\text {th }}$ percentile queue lengths

This methodology examines each turn movement separately, ranking them in order of importance, and even considers whether or not the driver completes their movement in one or multiple stages. (For example, a scenario in which a driver pulls out from the minor street and seeks refuge in a center median on the major street before completing the turn would be considered a two stage movement.) Because this methodology considers each turn movement separately, turn designations are provided that may serve well for discussing and 
analyzing bicycle level of service. The equations utilize the labeling shown in the diagram below which is taken from the HCM 2010 (exhibit 19-6).

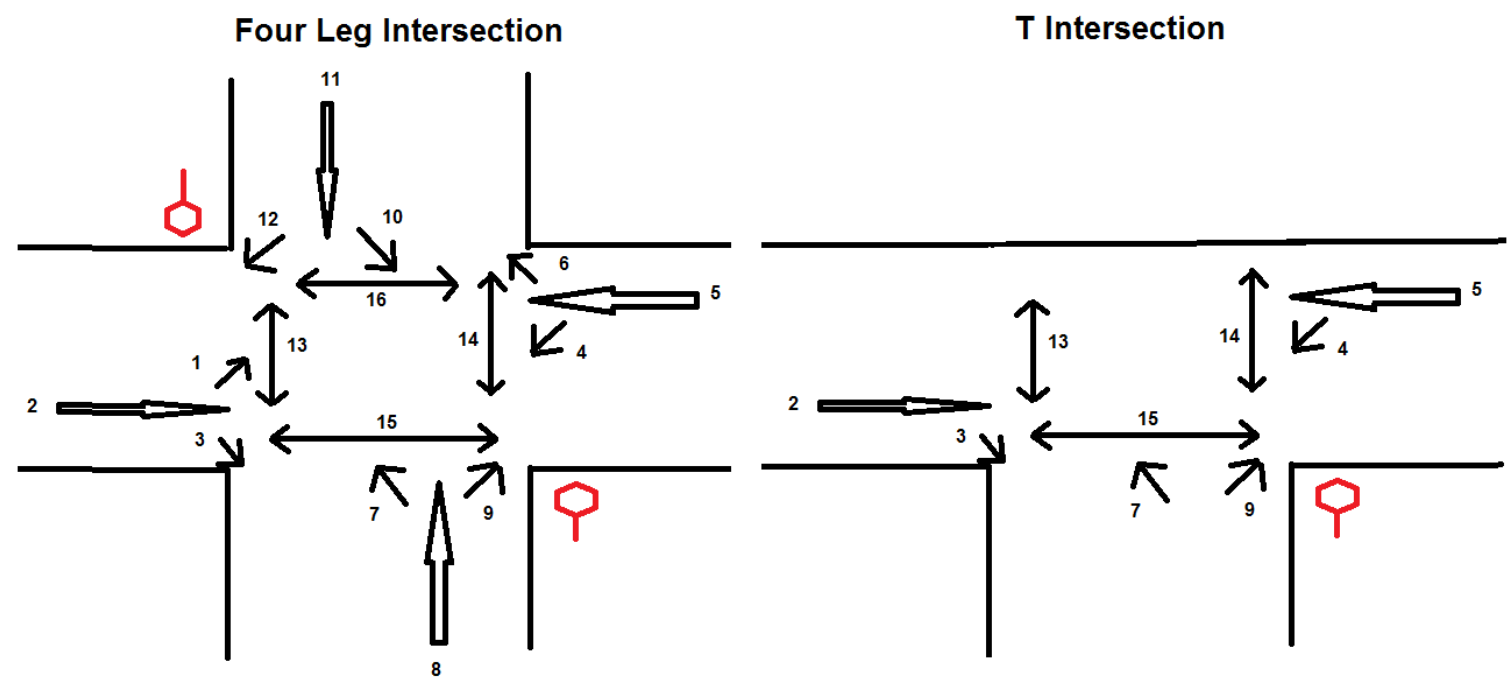

Figure 5: Two-Way Stop-Controlled Movement Diagram 1: Exhibit 19-6 (Highway Capacity Manual, 2010)

Notes: vc\# = Conflicting Volume for \# direction v13 through v16 are pedestrian volumes

Step four in this method is to determine the critical and follow-up headways for the movements. These may not actually apply to bicycle level of service and may be an indication of a separate format being required for bicycle traffic. The effects of upstream signalized intersections are also accounted for, and may make the methodology much more accurate, but severally complicate the nature of the methodology and, unfortunately, inhibits the idea of being "user friendly." To make this procedure even more complex, it must also consider the effects of multiple stage movements (mentioned earlier in this paper) in which the act of 
traversing a single intersection takes place in multiple phases. A positive aspect of this methodology is that it considers the effects of large curb returns, which is something very few methodologies do, even though such physical attributes are fairly common and can greatly affect a user's perception of the quality of an intersection or street segment. 


\section{CHAPTER 3: DATA COLLECTION AND PROCEDURES}

After reviewing the methodologies that were developed for level of service, a list of common roadway elements that were anticipated to possibly have an effect on a cyclist's quality of service perception for an intersection was developed. The list is provided below.

\section{Roadway Design and Environmental Characteristics Possibly Affecting Two-Way Stop-Controlled Intersection Bicycle Level of Service:}

- Number/width of Lanes in each Direction

- Type of Bike Facilities present and in which direction/location at the intersection (Bike Lanes, Sharrows, Signage, etc.)

- Speed Limits (including estimates of bicycle speed)

- Volume of Traffic in each Direction (Vehicle, Bicycle, and Pedestrian)

- Number of Heavy Vehicles

- Grades in each direction

- Pavement Quality

- Presence of Bicycle/Pedestrian Detectors

- Ease of Use for Detection Devices

- Sight distances in each direction (intersection geometry)

- Presence of Shared Turn Lanes

- Presence of Dedicated Vehicular Lanes 
- Presence of Hazards (Dips, storm drains, etc.)

- Proximity to nearest intersection, signalized or other, in each direction.

- Saturation flow rates

- Observed Delay

- Street Lighting

- ADA ramps or other accessibility elements (particularly important if offroad bike facilities)

\section{Consideration in Data Collection Procedures}

A noteworthy concept regarding methods for collecting data that was brought up by Dowling et al. (2008) was the issue of biased field ratings from cyclists (Dowling et al., 2008). Those present at an intersection will tend to rate it as higher than the real perception since the cyclists who like the locations will be over-represented at the intersection. Those who don't like the intersection will tend to avoid it. Therefore, in conducting field interviews for bicycle level of service data, only a skewed sample group is obtained. A better approach that is recommended is to video tape the intersection (from a cyclist's experience of passing through it) and then show the video to a group of people and have them rate the intersection from that. This method attempts to address any biased input that may otherwise be received. 


\section{Data Collection Methods}

In early 2012, Kang et. al. (2012) conducted a survey of bicycle level of service similar to this one for bicycle level of service for rural roadways and did not attempt to obtain video recording (Kang \& Lee, 2012). The method of data collection that was employed in this case was the simple one of stopping passing cyclists and asking them to rate the intersection. However, they did not use the regular A-F rating system and instead used an $\mathrm{A}-\mathrm{C}$ grading rubric. This resulted in a less detailed level of service methodology than those reviewed previously in this thesis and provides less information to traffic engineers and planners. The overall accuracy of this particular research project is a matter of some dispute and it is believed that the methods used by Sprinkle Consulting in 2010 provide a better image of bicycle level of service.

Various methods of capturing video footage have been tried in the past for the Highway Capacity Manual (Dowling et al., 2008). The following is a list of various methods attempted by Sprinkle Consulting Inc. in coordination with the Florida Department of Transportation:

- Fixed Camera Mounted Roadside

- Moving Motor Vehicle Mounted Camera

- Bicycle Helmet Mounted Camera

- Suspended Mountain Bike with Frame Mounted Camera

- Front Suspended Tandem Bicycle with Rear Rider (Stoker) Operating a Camera Mounted on a Glidecam ${ }^{\mathrm{TM}}$ Stabilization System

- Two-person Adult Tricycle with the Videographer in the Left Side Seat 
- Viewpoint Bicycle with Front Rider (Stoker) Operating a Hand Held Camera

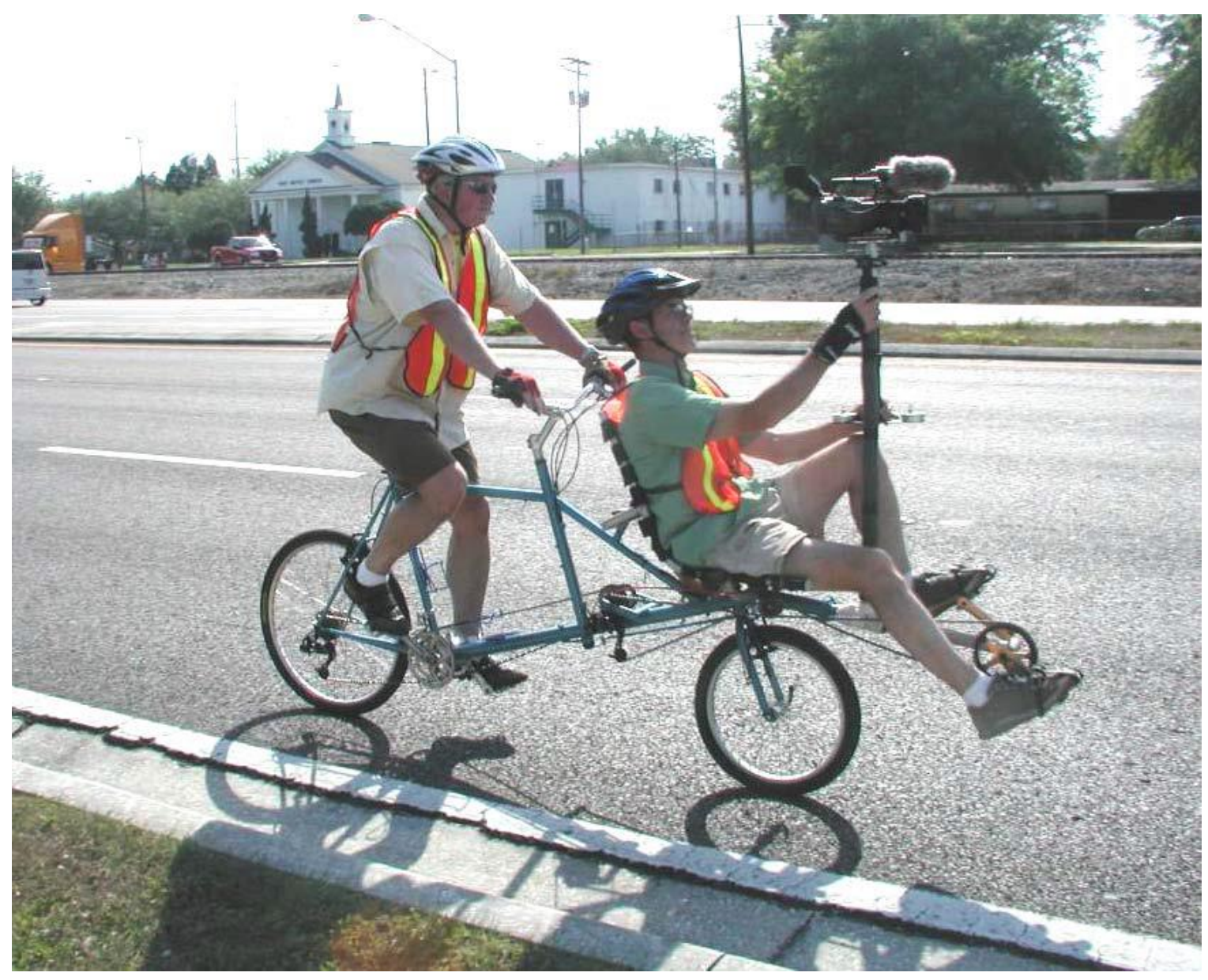

Figure 6: Semi-Tandem Bicycle Used for Previous Bicycle Level of Service Methodologies: Image courtesy of Sprinkle Consulting Inc.

For this research, initially an attempt was made to acquire and deploy a viewpoint style bicycle as recommended by Dowling et al. (2008) and Sprinkle Consulting for data collection. However, due to cost and availability concerns procurement of such a specialized bicycle was not feasible for this particular effort. 
A compromise was made to obtain a regular tandem bicycle and attach a pole mounted camera in a position where the rear cyclist could operate the camera while the lead cyclist steers the bicycle. The bike used for data collection was a 2013 Kent Dual Drive as seen in the Figure 7.

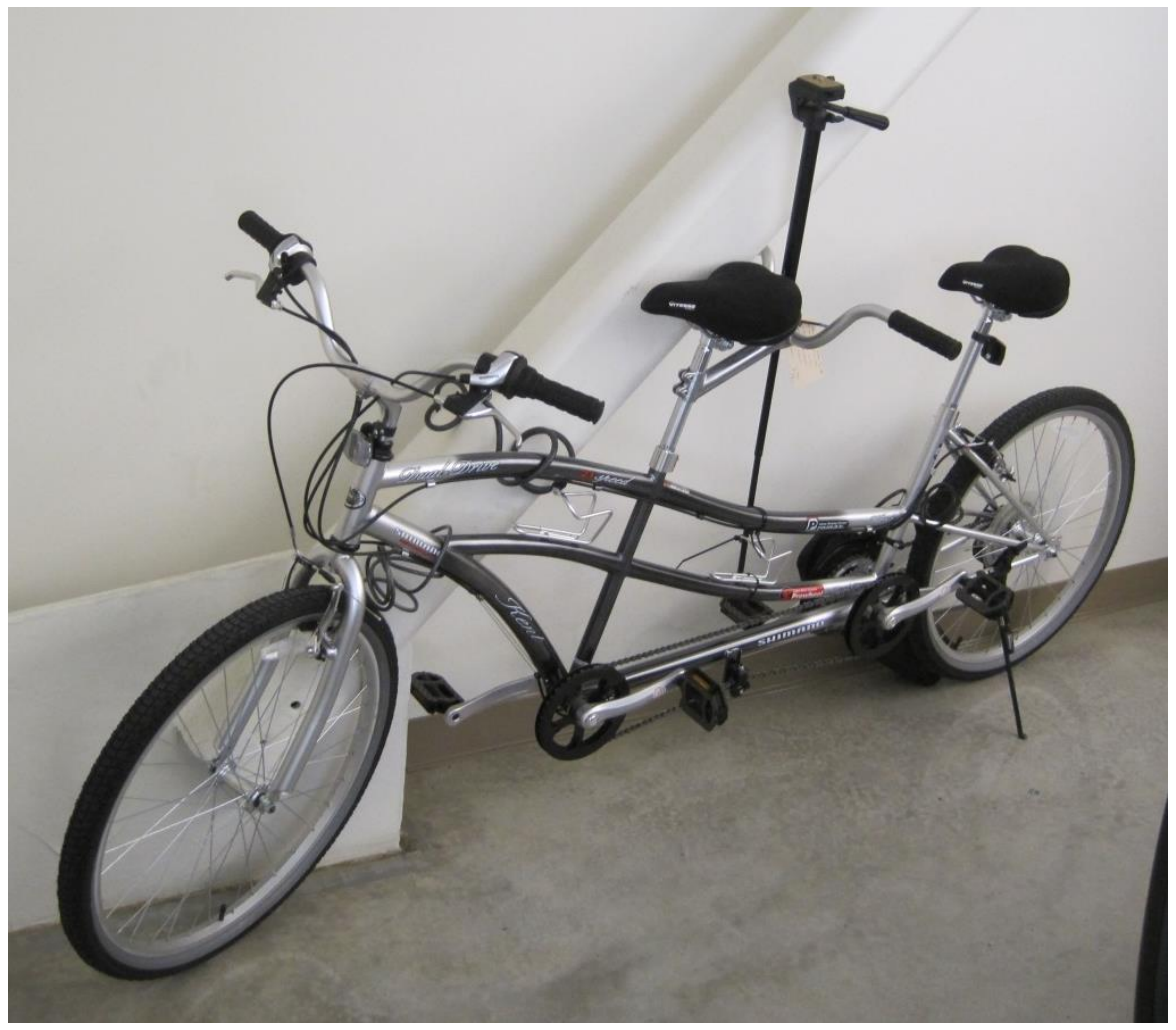

Figure 7: Tandem Bicycle Used for Data Collection for Two-Way Stop-Controlled Intersections

The pole seen here mounted on the bicycle is an extendable monopod which, when in operation, extends up over the heads of the cyclists. This enables the camera to have a view of both the roadway and a live cyclist reacting to realworld conditions. A GoPro Hero3 action camera was attached to the monopod to capture video footage of various survey intersections in California. This camera was operated by the cyclist seated on the rear of the bicycle while the lead cyclist 
steered and powered the bike. Please note that the lead cyclist did not wear a helmet in the video due to issues with blocking the camera's view, but the rear cyclist followed standard roadway safety procedures (including signaling to other vehicles for turns when appropriate). As mentioned in a previous section, some more experienced cyclists often ride in tightly packed groups. The effect of cyclists riding in close proximity to one another unfortunately cannot be adequately estimated from a camera mounted on this type of a bicycle due to the bulky and slow nature of the bike, making it difficult for the riders to keep up with other experienced cyclists. Any information obtained from these surveys will apply to bicycles traveling independently of one another rather than as a uniform group. The total equipment cost for this project was approximately $\$ 700$.

In order for the data collection process to provide an accurate estimate of level of service, a range of sample data intersections from multiple cities, ideally in different regions would need to be collected.

Sample cities that were surveyed had to be relatively well used by cyclists in order to provide sufficient feedback for cycling facility performance. Communities with few bicycle facilities or accommodations will provide only poor information on how to adequately meet the needs of cyclists. The feedback may be offset by the fact that the riders don't have any point of reference for adequately designed intersection for bicyclists. Data collected must provide both good and bad feedback on bicycle facilities in order to be properly utilized. In order to meet this 
objective, only areas that are nationally recognized as Bicycle Friendly Communities by the American League of Bicyclists were examined.

41 Intersections that have been surveyed for cyclist facilities and performance ratings are listed below. Copies of the original field data sheets can be found in the appendix. Please note that not all information regarding these intersections may be on these sheets and may be recorded elsewhere.

These intersections provide samples of several different varieties of bicycle facilities including, but not limited to, Shared Lane Markings, Bike Lanes, Bike Boulevards, Bikes May Use Full Lane Signs, Share the Road Signs, Separated Bike Lanes, and Bike Lanes with Parking Lanes. All sampled cities are in Southern California.

\section{Sampled Two Way Stop-controlled Intersections:}

- San Luis Obispo (14 TWSC intersections)

> Broad Street/Chorro Street/ Sandercock Street

$>$ Broad Street/lslay Street

$>$ Cerro Romaldo/Patricia Drive

> Grand Avenue/McCollum Street

$>$ Higuera Street/ Garden Street

> Johnson Avenue/Sydney Street 
> Los Osos Valley Road/ Diablo Drive

> Los Osos Valley Road/Prefumo Canyon Road

> Marsh Street/ Beach Street

$>$ Monterey Street/Pepper Street

$>$ Monterey Street/Toro Street

$>$ Morro Street/ISlay Street

$>$ Morro Street/ Pismo Street

> Tank Farm Road/Poinsettia Avenue

- Goleta/University of California Santa Barbara (5 TWSC Intersections)

$>$ Cathedral Oaks Road/Ellwood Ridge Road

> Cathedral Oaks Road/North La Patera Lane

$>$ Cathedral Oaks Road/Placer Drive

> Lagoon Road/ Harold Frank Road

> North La Patera Lane/Covington Way

- Claremont (8 TWSC Intersections)

$>$ Baseline Road/Grand Avenue

> Bonita Avenue/Cornell Avenue

$>$ Cambridge Avenue/Wharton Drive

$>$ College Avenue $/ 2^{\text {nd }}$ Street

$>$ College Avenue $/ 4^{\text {th }}$ Street

> Mills Avenue/First Street 
$>$ Mountain Avenue/Butte Street

> Vanderbilt Avenue/Butte Street

- Riverside (7 TWSC Intersections)

$>$ California Avenue/Shelby Drive

> Colorado Avenue/Dundee Road

> Magnolia Avenue/Hoover Street

$>$ Victoria Avenue/Grace Street

> Victoria Avenue/Saint Lawrence Street

> Victoria Avenue/ Boundary Lane

$>$ West Linden Street/Douglass Avenue

- Irvine (5 TWSC Intersections)

> Deerfield Avenue/Fawn Glen East

> McGaw Avenue/Armstrong Avenue

> Michelson Drive/Sequoia Tree Lane

$>$ Northwood/Savannah

> Turtle Rock Drive/Sycamore Creek

To validate collected data and the methodology developed herein, two signalized intersections were also sampled and analyzed with the already established and accepted level of service methodology for bicycles at signalized intersections. These two intersections are also located in Claremont, California:

> Baseline Road/Mountain Avenue 
$>$ Claremont Boulevard/First Street

Videos of each of these intersections were made available online at:

http://g0o.gl/7fyp65 and online surveys were posted at: http://goo.gl/KYiwnN via which viewers could submit feedback from the videos. Once all field video was collected, the obtained video footage was compared with a series of video footage that had been captured by Sprinkle Consulting Inc. for use in the prior Transportation Research Board bicycle level of service methodologies development later adopted in the HCM 2010 (Dowling et al., 2008).

It was found from viewing these two groups of videos that the only noticeable difference was that in the camera view from the videos for two-way stopcontrolled intersections, the back of the head of the lead cyclist was visible, whereas in Sprinkle Consulting Inc.'s videos the cyclist was behind the camera and not directly in view. However, this is a very minor discrepancy that should not severely influence the collected feedback either negatively or positively.

\section{Potential Problems with the Data Collection Method}

A problem with the data collection process involving video viewers, however, is that some aspects (such as pavement quality) may be downplayed in the received level of service feedback because a focus group that provides ratings from a safe and comfortable room does not experience the exact same elements that a cyclist would. Even aspects such as temperature and weather may play a role in the comfort level a cyclist feels with a particular intersection in addition to other more deterministic factors of traffic safety. A focus group may not fear 
adjacent street traffic as much as a cyclist, and may even feel different levels of safety depending on the skill of the rider who captured the video footage. As Kang et al. described it: "They did not calibrate their video-based findings to bicyclists riding on the roadways, and they only validated viewpoints from stillstanding respondents, i.e. not obtaining realistic perspectives of bicyclists." Despite this drawback, this is the method that was used for previous bicycle LOS research and is the method that was determined for the project so as to best follow previously accepted practices. In the next chapter the survey data collected from respondents watching the videos were analyzed.

Another issue is that of bicycle delay. The HCM LOS methodology for signalized intersections estimates bicycle delay at the intersection based off of the signal timing. However, this delay factor is not included in the actual LOS estimation. The pedestrian LOS at signalized intersections computes ped delay and includes it in the LOS calculations. This indicates that delay may offer different levels of importance for bicycles than for pedestrians. For Two-Way Stop-Controlled Intersections, calculating bicycle delay was deemed to be extremely difficult to accurately model due to differences in cyclist behavior towards acceptable vehicle gap time. For this thesis, the focus was decided to be based on the nondelay aspects of bicycle LOS at TWSC intersections. Future research may provide more insight on the delay-based aspects of bicycle LOS at TWSC intersections. 


\section{CHAPTER 4: DATA ANALYSIS}

The first step in the analysis was to make comparisons with existing procedures by inputting the physical characteristics data from this study to existing equations from the HCM 2010. This was done to assess the possibility that the LOS on two-way stop-controlled intersections is governed by the same or similar relationships as the signalized intersections. This assumption was likely to be incorrect, but the output from these equations was valuable to assess the usability of existing models as a starting point for this analysis.

\section{Applying Signalized Intersection Models}

The Signalized Intersection Method proposed in the Highway Capacity Manual 2010 (HCM 2010) utilizes the following formula:

$$
\begin{gathered}
\mathrm{lb}, \text { int }=4.1324+\mathrm{Fw}+\mathrm{Fv} \\
\mathrm{Fw}=0.0153 \mathrm{Wcd}-0.2144 \mathrm{Wt} \\
\mathrm{Fv}=0.0066[\mathrm{vlt}+\mathrm{vth}+\mathrm{vrt}] /(4 \mathrm{Nth}) \\
\mathrm{Wt}=\mathrm{Wol}+\mathrm{Wbl}+\mathrm{IpkWos}{ }^{*}
\end{gathered}
$$

Where:

$\mathrm{lb}$,int $=$ bicycle LOS score for intersection

Wcd $=$ curb-to-curb width of the cross street (ft)

$\mathrm{Wt}=$ total width of the outside through lane, bicycle lane, and paved shoulder (ft)

Vlt $=$ left turn demand flow rate $(\mathrm{veh} / \mathrm{hr})$

Vth $=$ through demand flow rate $(\mathrm{veh} / \mathrm{hr})$

Vrt = right turn demand flow rate $(\mathrm{veh} / \mathrm{hr})$ 
Nth $=$ Number of through lanes (shared or exclusive) (In)

Wol $=$ width of the outside lane $(\mathrm{ft})$

$\mathrm{Wbl}=$ width of the bicycle lane $=0$ if bicycle lane not provided $(\mathrm{ft})$

Ipk $=$ indicator variable for on street parking occupancy $=0$ of $p \mathrm{pk}<0 ; 1$

Otherwise

Wos $=$ width of paved outside shoulder (ft)

Wos $^{*}=$ adjusted with of paved outside shoulder; if curb is present $\mathrm{W}$ os ${ }^{*}=\mathrm{W}$ os

$-1.5>0$; otherwise $\mathrm{W}$ os ${ }^{*}=\mathrm{W}$ os

Unfortunately, applying the signalized intersection equation resulted in almost all approaches to receive a level of service rating " $A$ " for bicycle travel which does not match the collected survey data for the intersections. It was apparent from these results that there are significant differences between the relationships affecting signalized intersection LOS and those governing the bicyclist perceptions and hence the LOS at TWSC. A different LOS methodology may provide a closer formula set to use as a starting point for developing models for TWSC.

\section{All-Way Stop-Controlled Intersections}

Next the all-way stop-controlled bicycle level of service method was tested with the assumption that our survey intersections were all-way stop-controlled. A sample calculation for this application is also provided in the appendix. This method also provided significant differences between the expected level of service values and the survey responses indicating the need for model 
estimation for the TWSC intersections. Examples of the results are shown in Figures 9 through 12 below.

\section{Two-Way Stop-Controlled Automobile}

In comparing bicycle LOS to automobile LOS at TWSC, there is a problem that

presents itself. The Automobile LOS is based off of the delay experienced by the driver at the TWSC intersection and, as is mentioned earlier in this thesis, delay for bicyclists varies depending on behavior. This is, of course, also true for automobile drivers, but is more so for cyclists due to the increased level of risk involved if a collision were to occur. The overall effect of this is that automobile LOS and bicycle LOS cannot be accurately modeled using the same equations.

\section{Methodology Comparison Figures}

To better illustrate the findings from the series of calculations described above, a series of graphs were generated to provide a visual example of the findings. These graphs show the ratings these intersections would have provided for bicycle level of service if the sampled intersections were modeled as the type of intersection labeled on each graph. These are compared with the average survey responses that were obtained for each individual turn movement. 


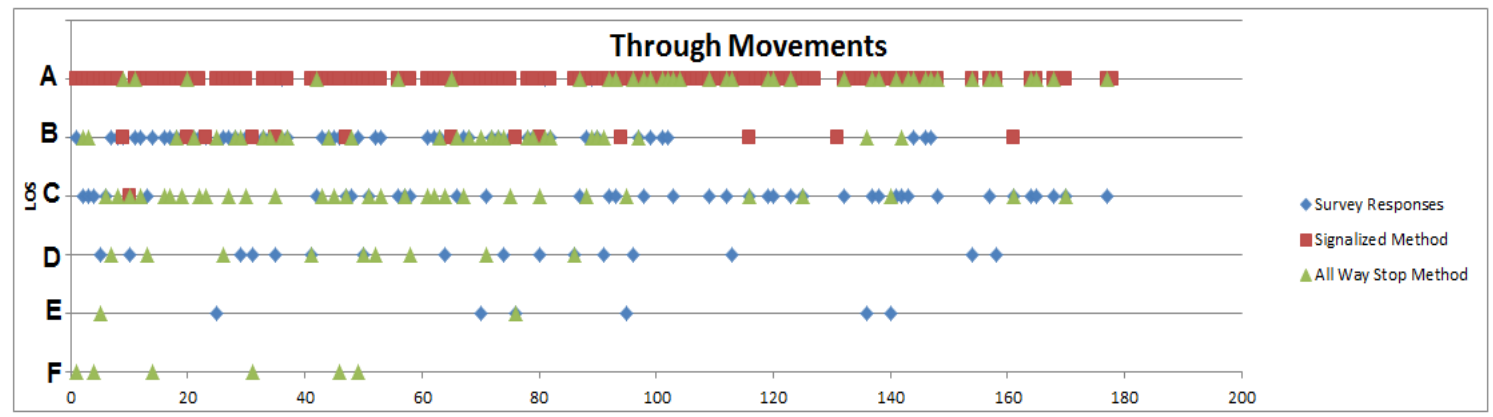

Figure 8: Through Movement Existing Methodology Comparison

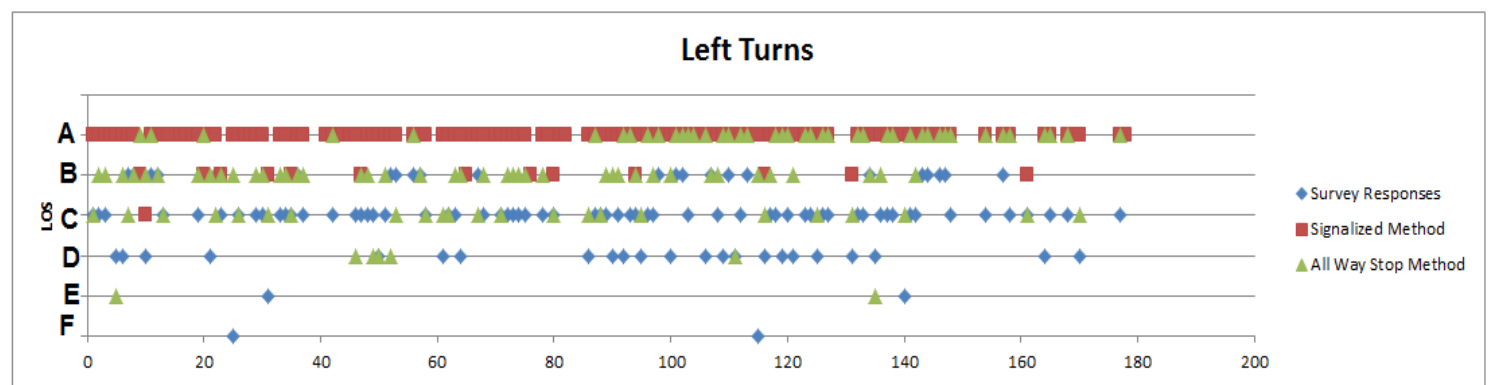

Figure 9: Left Turn Movement Existing Methodology Comparison

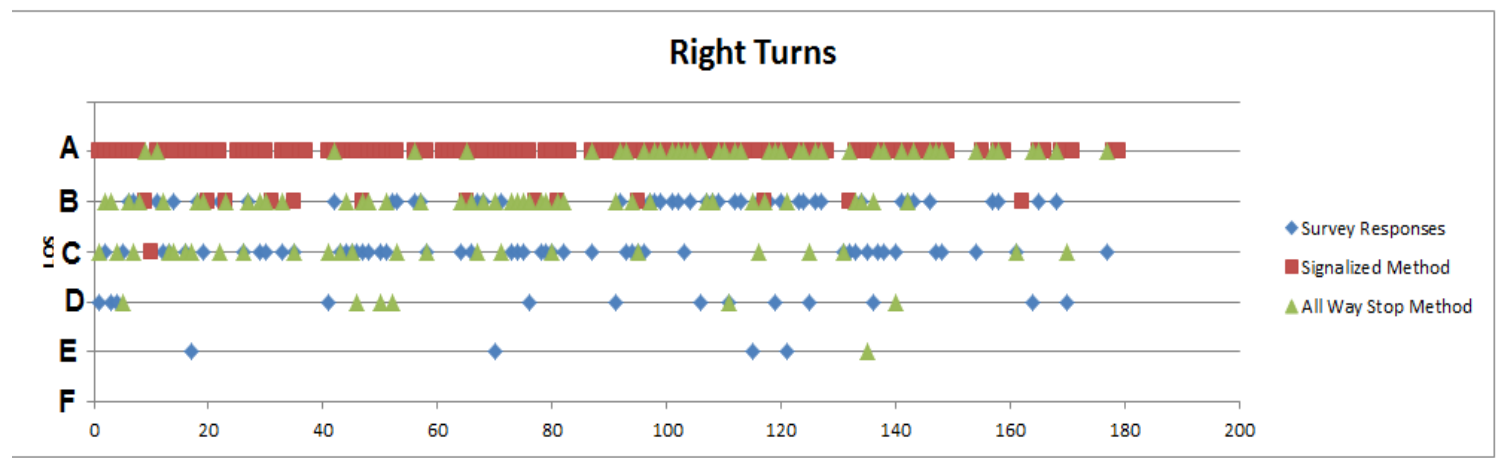

Figure 10: Right Turn Movement Existing Methodology Comparison 


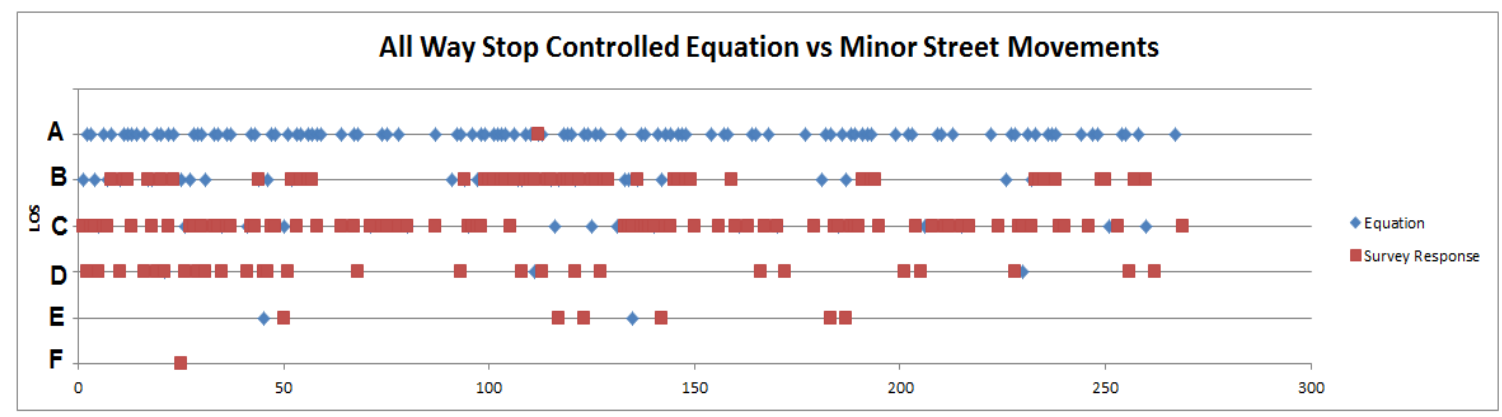

Figure 11: All-Way Stop-Controlled Equation vs. Minor Street Movements

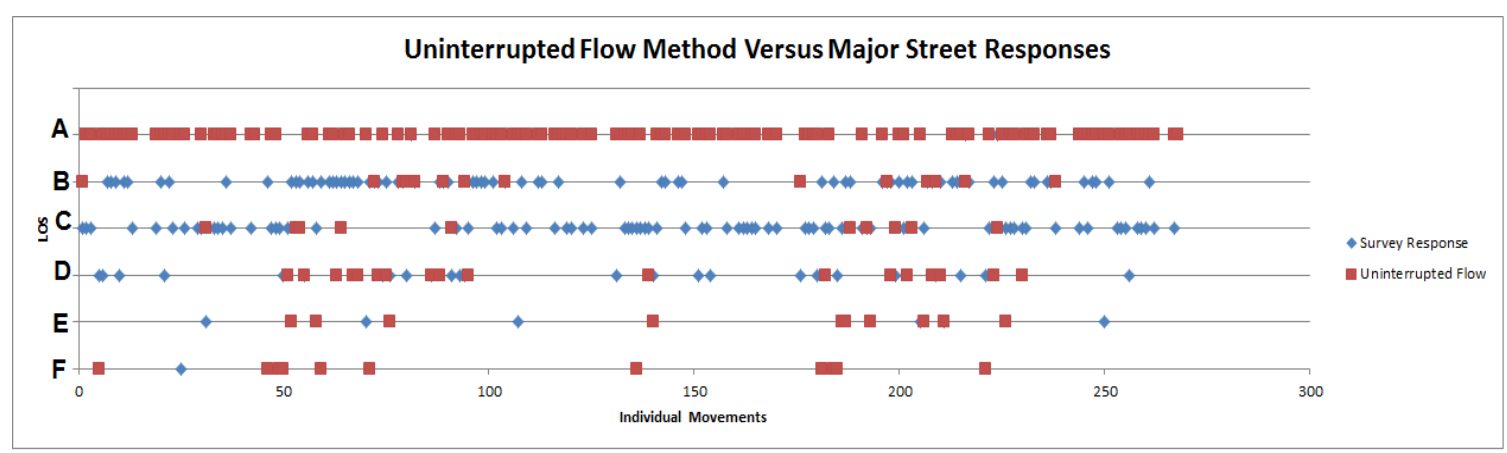

Figure 12: Uninterrupted Flow Equation vs. Major Street Movements

The next set of graphs compare the responses and the equations based off of an increasing (across the $\mathrm{x}$-axis) difference in the ratings to see if there were any trends in why some turn movements had such significantly different values from the theoretical responses than did other turn movements. 


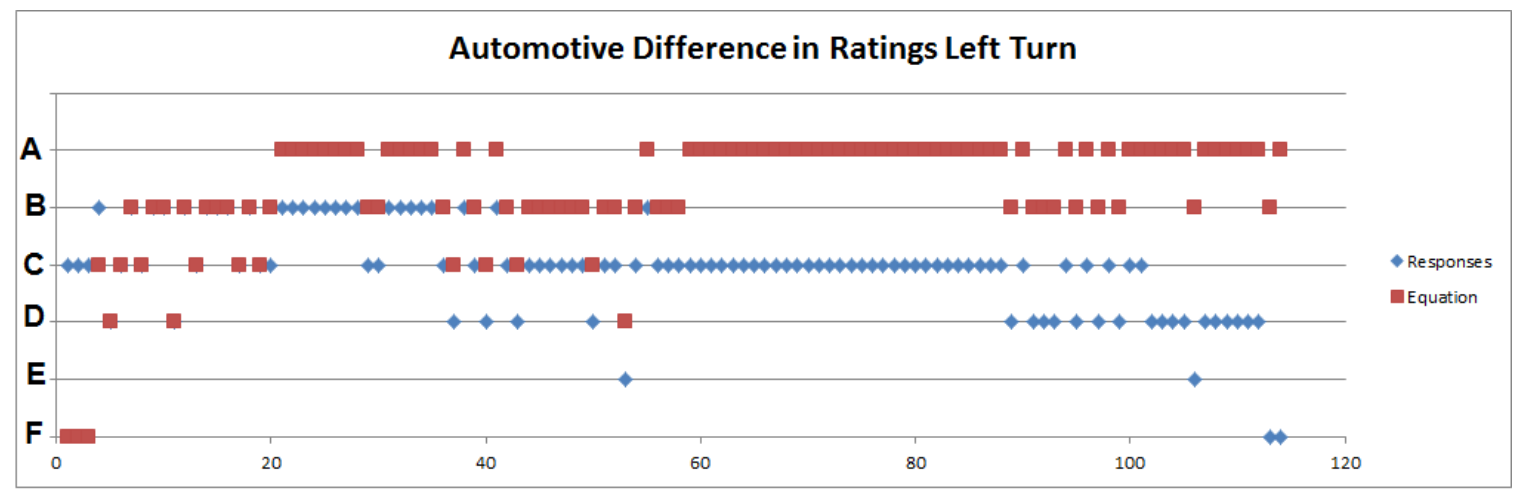

Figure 13: TWSC Automobile Method Left Turn

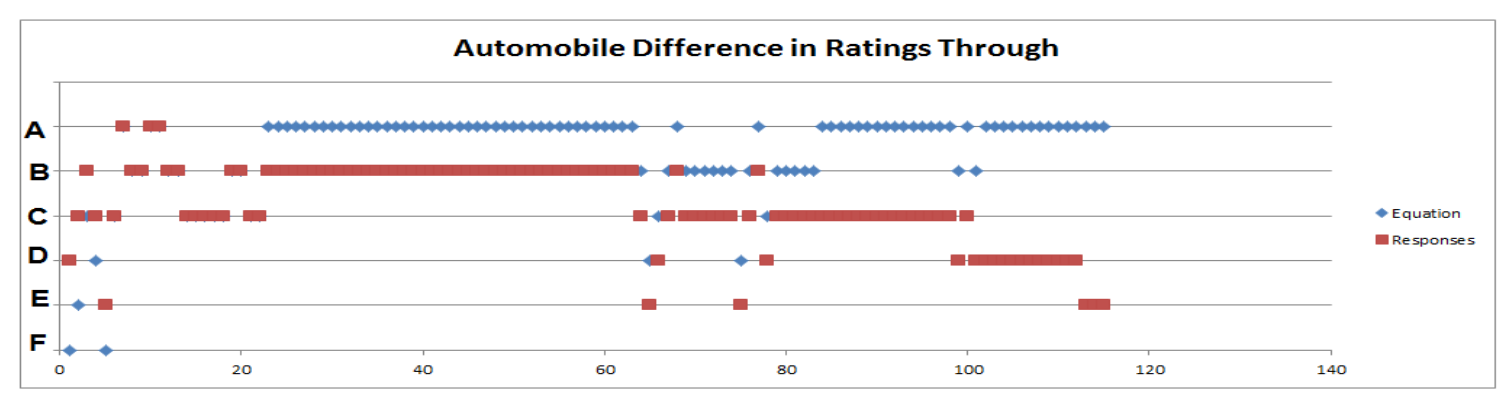

Figure 14: TWSC Automobile Method Through

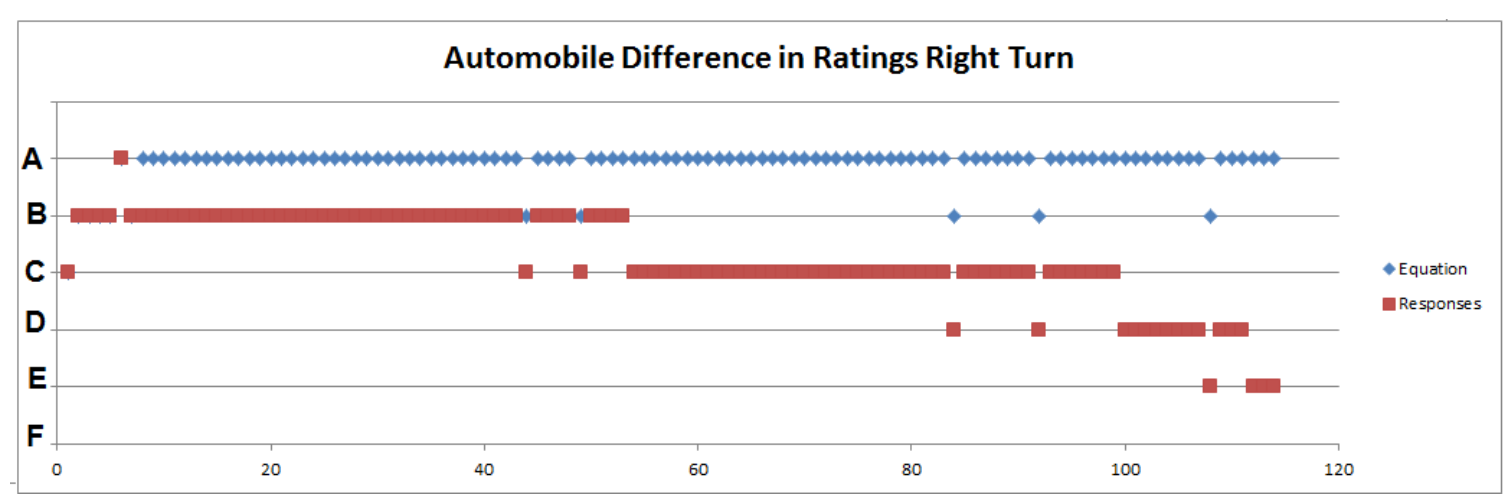

Figure 15: TWSC Automobile Method Right Turn 


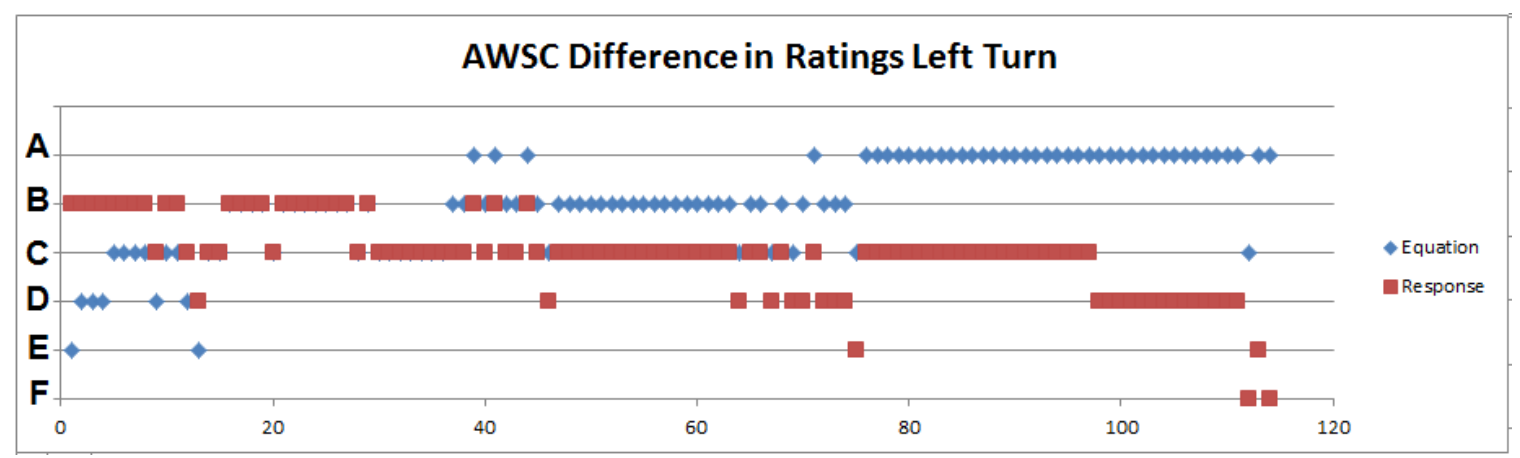

Figure 16: AWSC Automobile Method Left Turn

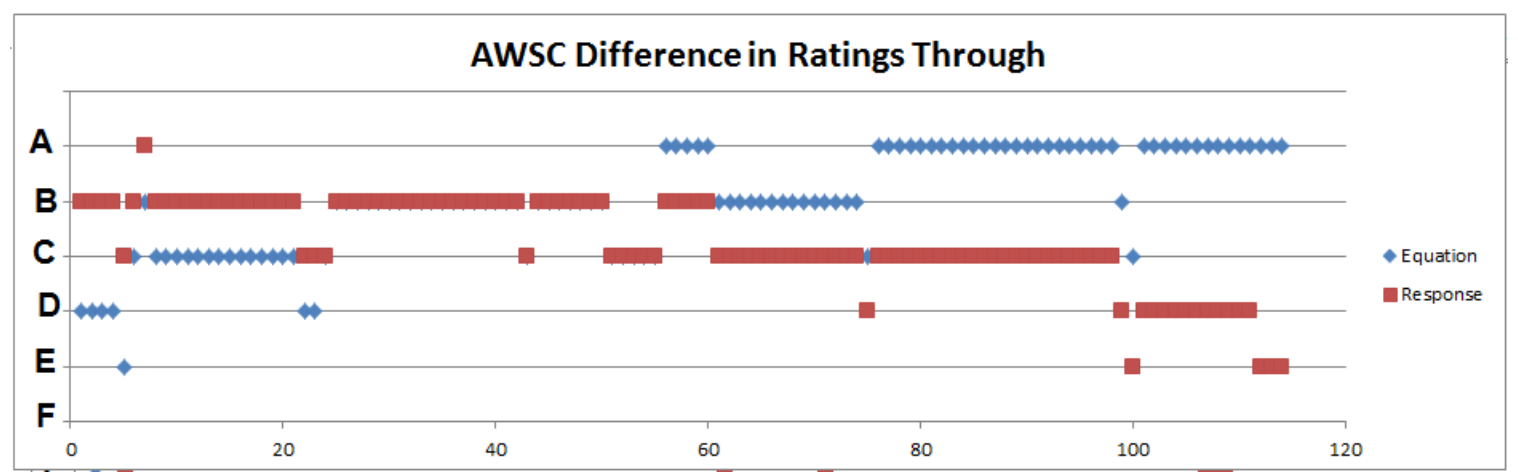

Figure 17: AWSC Automobile Method Through

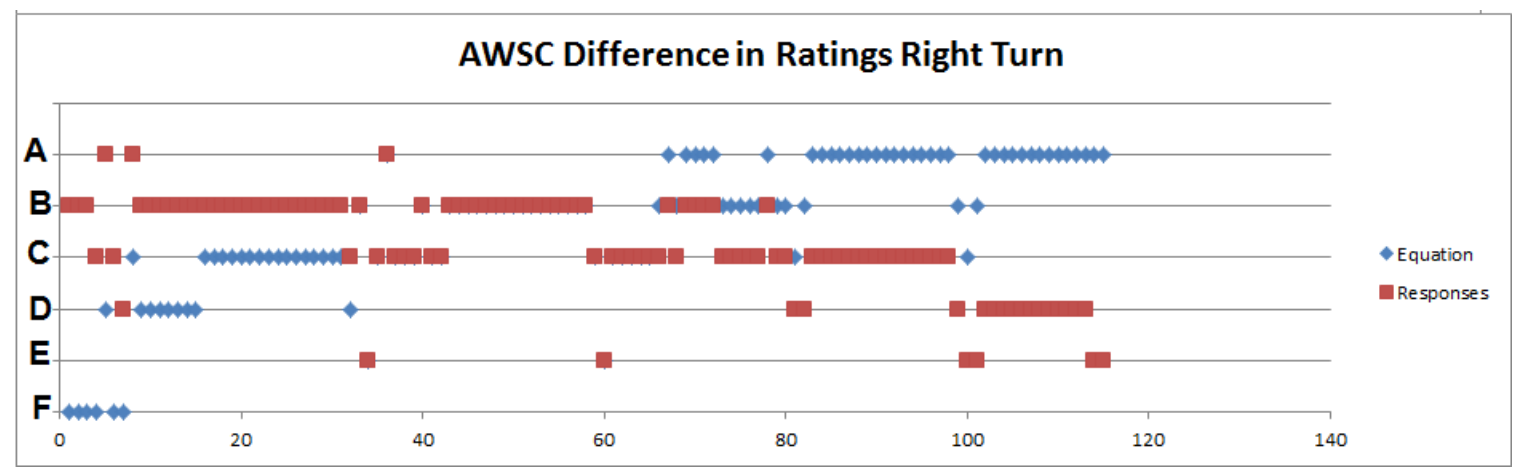

Figure 18: AWSC Automobile Method Right Turn 


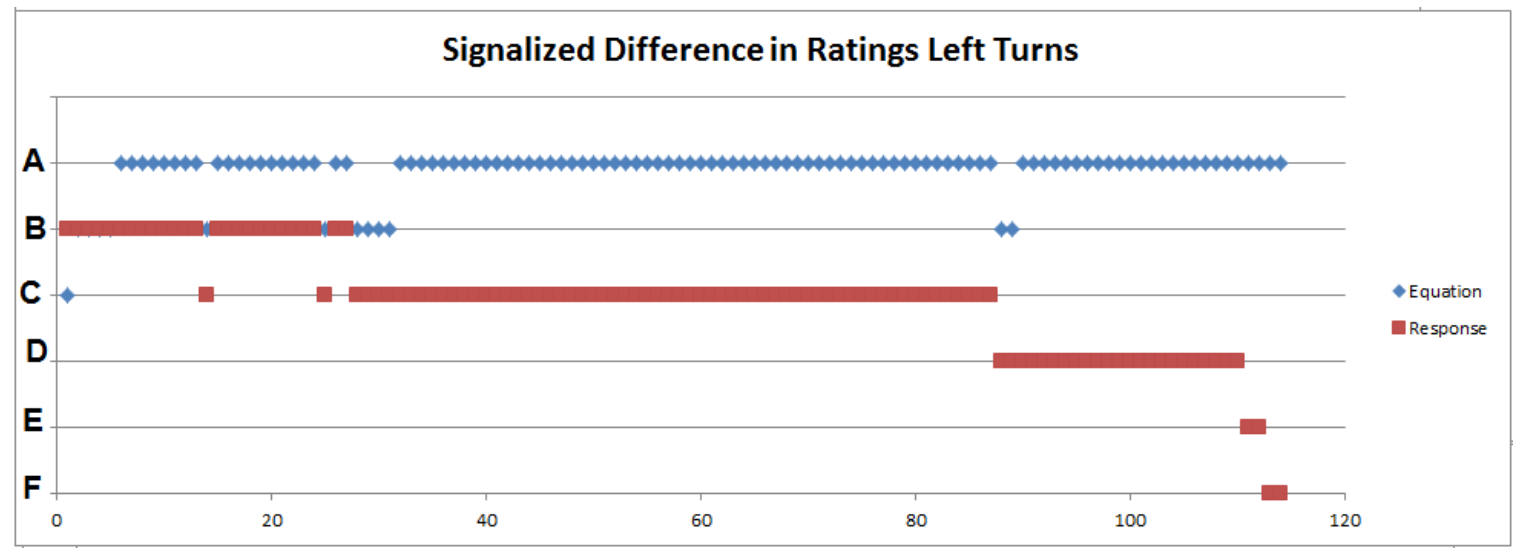

Figure 19: Signalized Automobile Method Left Turn

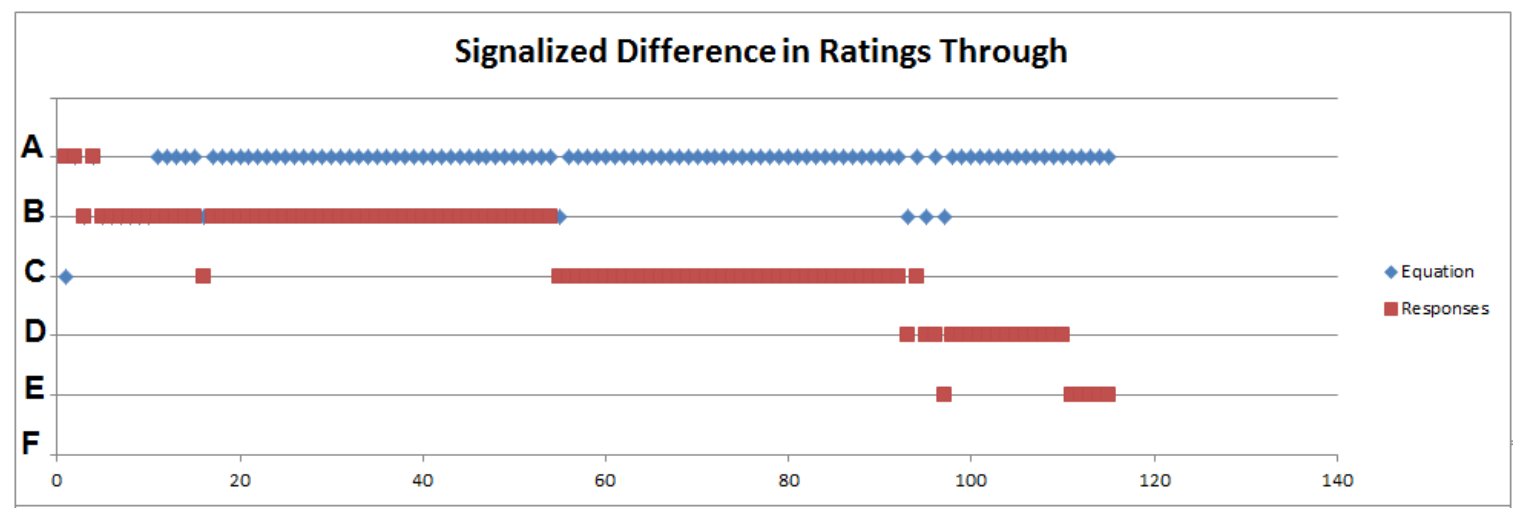

Figure 20: Signalized Automobile Method Through

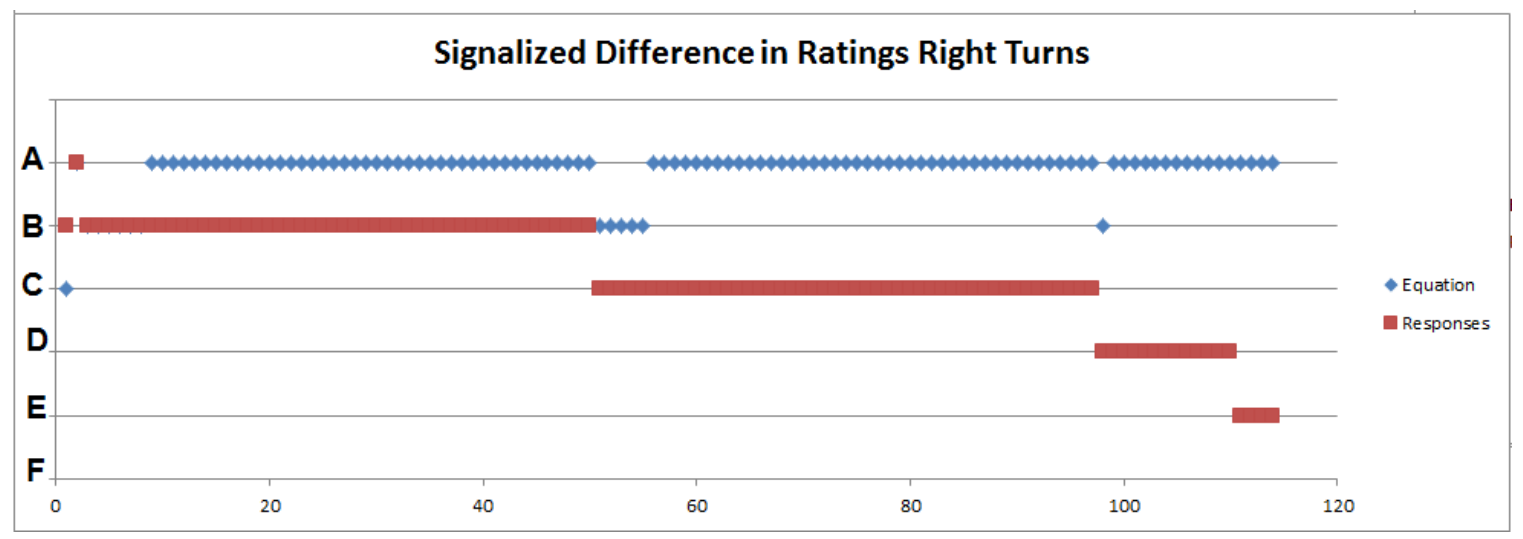

Figure 21: Signalized Automobile Method Right Turn 


\section{Validation of the Existing Signalized Intersection Methodology with Data from this Research}

In order to validate the Level of Service methodology for two-way stop-controlled intersections, two signalized intersections were also included in the survey set and reviewed by the same feedback providers as all other two-way stop-control data. The bicycle level of service for signalized intersections is already established and documented in HCM 2010. The responses for the signalized intersections were compared to the estimated LOS through model from HCM 2010 to evaluate the fit. Collected responses were concluded to have insignificant differences between values and obtained response values. Sample calculations are provided in the appendix. Data listed in Table 4 is a simplified representation of the $t$ tests and presents the results by overall intersection rather than by approach. Individual approach t tests were also calculated but provided similar results and are not reproduced below.

Table 4: Signalized Intersections Paired T Test Results

\begin{tabular}{|c|c|c|c|c|c|}
\hline Intersection & $\begin{array}{l}\text { Average } \\
\text { Score from } \\
\text { the Model }\end{array}$ & $\begin{array}{c}\text { Average Score for } \\
\text { Respondents }\end{array}$ & St Dev & $\begin{array}{c}\mathrm{T} \\
\text { Value }\end{array}$ & $\begin{array}{c}\mathrm{P} \\
\text { Value }\end{array}$ \\
\hline Claremont/First & 3.75 & 3.75 & 0.739 & 0.00 & 1.00 \\
\hline Baseline/Mnt & 4.50 & 4.42 & 0.289 & 1.00 & 0.34 \\
\hline
\end{tabular}

\section{Further Considerations}

Now let's examine a few of the characteristics that may affect a bicyclist's perception of two-way stop-controlled intersections. The first characteristic we will assess is sight distance. Cyclists feel more at-risk at intersections if they 
have insufficient sight distance. It is not as much the sight distance they are really concerned about as the amount of time that they have after they first see another vehicle and before it could theoretically collide with them. This time can be approximated by taking the distance to the intersection from the point where a vehicle would first become visible to a bicycle and dividing that distance by the speed limit on the major road (of TWSC). This time can also be directly measured in the field with a stopwatch. To better clarify, please see Figure 13 below.

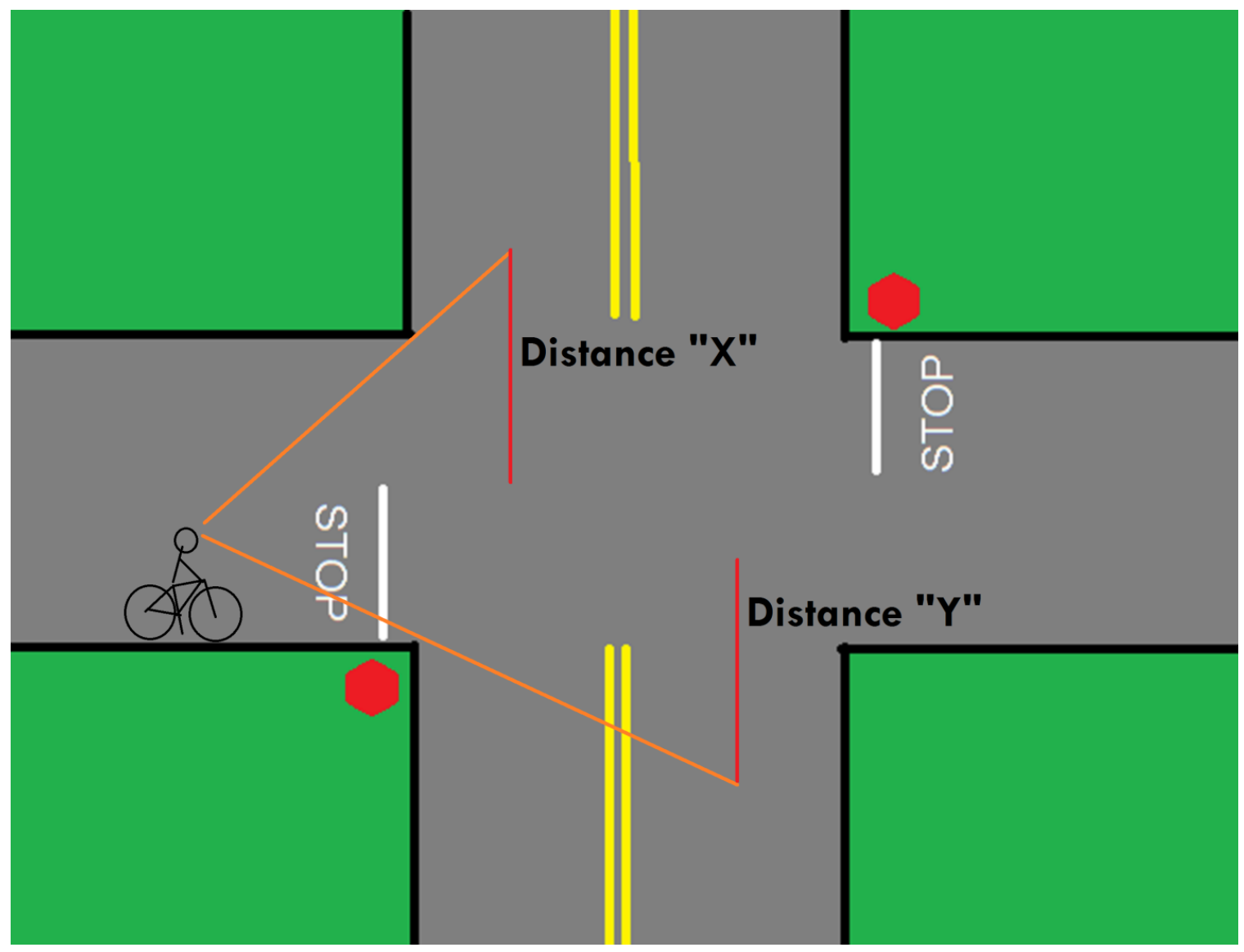

Figure 22: Sight Distance Diagram for TWSC Intersection Bicycle Approach 
The orange lines represent the cyclist's line of sight and the red lines represent the distance a vehicle would have to travel in order to collide with the cyclist's own travel path. These distances (Distances " $X$ " and "Y") can be easily obtained using simple geometry and then divided by the posted speed limit to provide the potential time before a collision.

Data analysis for past level of service equation development was performed using three different statistical methods: Linear Regression, Ordered Logit, or Ordered Probit models. However, it was concluded by the past research that "The results and interpretations [...] were notably similar" (Kang \& Lee, 2012) and "The choice between [methods] is typically an analyst's preference because [the chosen method] does not influence conclusions drawn from the model's results" (Kang \& Lee, 2012). Similar effects were also noted by three other texts: Dowling et al., (2008), and Dixon, (1996), and Landis, (1997). Due to these conclusions, linear regression was decided to be the method of choice for TWSC intersection analysis.

The software selected for analysis of the data in this research paper was Minitab 16 (Minitab, 2013). Analysis was done considering each turn movement at the intersection as a separate data set. This was to keep the existing practice of using the final LOS model to estimate values for each individual bicycle movement. A list of all types of variables considered is the following:

- Individual Directional Traffic Counts (including bikes and pedestrian movements) 
- Sight Distances

- Speed Limits (all directions)

- Widths of Individual Lanes

- Width of Bike Lanes (if present)

- Shared Lane Markings (categorical variable: present or not)

- Striped Parking Lane Adjacent to Bike Lane(categorical variable: present or not)

- Total Street Widths

- Bus Stop(s) Nearby (categorical variable: present or not)

- Percent Heavy Vehicle Traffic

- Grades/Slope of Roadway near Intersection

- On Street Parking Present (categorical variable: present or not) (Separate variables for major and minor roads)

- Bicycle Signage (categorical variable: present or not)

- Number of Lanes each Roadway

- Median/Barrier Near Intersection (categorical variable: present or not)

- Parking Allowed In Bike Lane (categorical variable: present or not)

- Signalized Intersection Nearby (categorical variable: present or not)

- Bicycle Boulevard (categorical variable: present or not)

- Pavement Quality (FHWA rating system)

- Designated Right Turn Lane (categorical variable: present or not)

- Designated Left Turn Lane (categorical variable: present or not)

- Center Storage Lane (categorical variable: present or not) 
- Separated Bike Lane Present (categorical variable: present or not)

- One Way Street (categorical variable: present or not)

- Large Curb Return Radius (categorical variable)

In Minitab, data from each turn movement at each intersection was listed as a separate row of data. Survey responses on perceived level of service were averaged into a single value for each movement and recorded in a column with the row corresponding to the turn movement each represented. During the course of this project there were three different survey datasets that were collected. These datasets identify different stages of the research and the survey questionnaire went through minor modifications during each stage. The first data set "1" was collected from members of cycling clubs in Southern California, the second survey data set "2" was collected from Dr. Kimberley Mastako's CE 421 Fall 2013 class, and the third set "3" was collected from the public via YouTube videos and a SurveyMonkey survey. Survey questions were the same in intent but were revised in wording in each of these datasets with the survey conducted via the online tool, Survey Monkey being the most reliable one. To use each data set, confirmation had to be made that the discrepancy between the responses in each survey type were minimal. Samples of each survey type are provided in the appendix. This was evaluated using a t-test and paired t-test in Minitab and the results are reproduced in Table 5 below: 
Table 5: Paired T Test Results

\begin{tabular}{|c|c|c|c|}
\hline Data Set A & Data Set B & T Value & P Value \\
\hline 2 & 3 & 0.62 & 0.536 \\
\hline 1 & 3 & -0.82 & 0.415 \\
\hline 1 & 2 & -0.84 & 0.401 \\
\hline
\end{tabular}

In each situation, a large $p$-value $(>0.1)$ would indicate that there is not a significant difference between the two survey datasets tested in each run. This essentially means that the three datasets were not statistically different from each other in terms of the respondent's average response to the LOS questions.

Separate tests were generated based on three sets of data: A set of turn movements originating from minor streets, a set of turn movements originating from major streets, and a combined data set that looked at all turn movements. This was meant to address the following concern: two-way stops may have two bicycle levels of service; one for the stopping street, the other for the through street. If the research chose to focus only on the stopping street bike LOS, it may ignore that there are also bicyclists on the through street with their own perceived LOS for the two-way stop intersection. This concern was conceived as a valid point that may imply that separate methodologies for different approaches within the same intersection may be most appropriate. The behavior of cyclists can be expected to differ significantly if their movement originated from the major or the minor street because of the difference in uncontrolled and controlled traffic flows that they are a part of. In order to test this hypothesis, the data were analyzed as three separate sets rather than just one. 
The level of service scores where converted into numeric format where a score of "F" corresponded to a 0 , and a score of "A" corresponded to a 5 . This scaling is essentially the same as past level of service methodologies where a higher range was used (e.g., 0 to 35 or more).

When the tests were first run using multivariate linear regression in Minitab, the diagnostic tests resulted in violations of some assumptions. In a linear regression model there are four main assumptions that must be validated in order for the results to be accepted as accurate (Field \& Miles, 2010):

- The residual errors must have constant (equal) variances

- The residual errors must follow a normal distribution

- The data must be independent in nature

- The response variable and the explanatory variables must be linearly related

In this scenario, the assumption was violated (as was determined from the patterns present in the residuals versus predicted values plot).

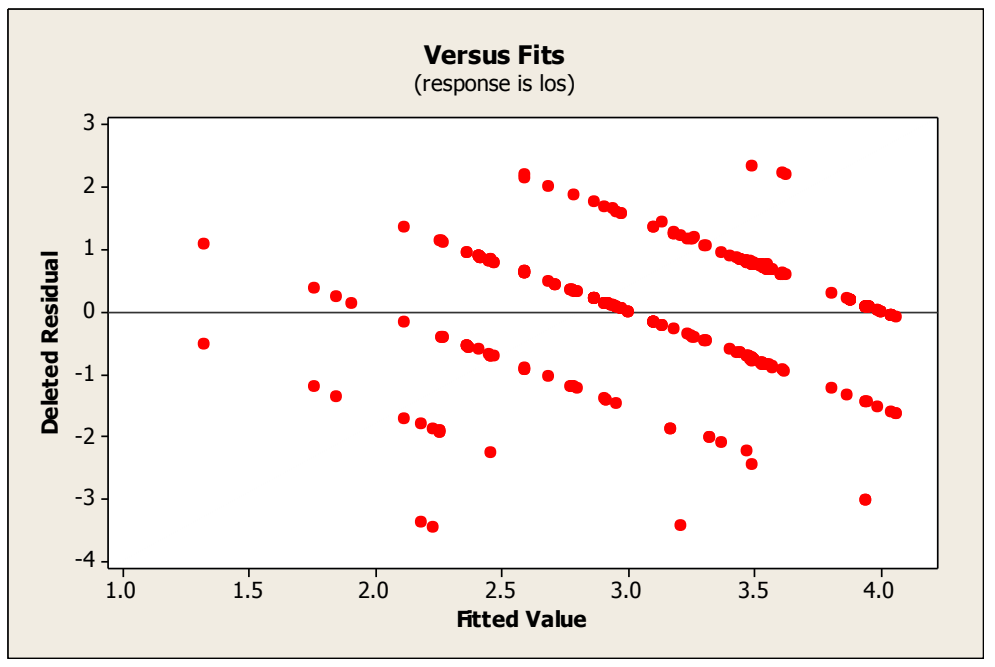

Figure 23: Original Residuals versus Predicted Values Plot 
To help rectify the situation, the case was brought to the attention of Dr. John Walker in the Statistics Department at Cal Poly San Luis Obispo. He proposed taking the log (base 10) of the level of service scores and the traffic volumes to transform the data. Following the transformation the residual plot patterns were consistent with the assumptions for linear regression.

A large number of regression models were estimated for each of the three types of data sets and refined by using the "Best Subsets" feature on Minitab which calculates all possible arrangements of all variables and provides the standard deviations, $\mathrm{R}^{2}$ adjusted, and error values for the different variable combinations; from which can be determined the optimal variables to be included in the model to provide the best fitted equation to the data. Once the variables that should be included are determined, a regression is run to provide the coefficients for those variables. These results are then, of course, checked for any violation of assumptions or possible presence of large error, such as effects of multicollinearity (in which the value of one explanatory variable deeply correlates with the value of another explanatory variable). Once all foreseeable causes of error have been rectified, the equation that is found to provide the best fit to the data is selected. This resulted in three equations from the three data sets.

The data sets that were used to generate the equations included the intersections from San Luis Obispo, Irvine, Riverside and Claremont. The data from Goleta was not used in the original equation generation but was instead 
used to verify the accuracy of the estimated equations and validate the final results.

\section{Expectations}

I would expect, without having done the calculations, that the presence of bicycle signage, shared lane markings, or a bicycle boulevard would have a positive correlation with the level of service for bicycles as they alert motor vehicle drivers to the presence of bicycles and attempt to regulate both traffic forms in a safe manner. An increase in conflicting vehicle traffic along the roadway should correlate to a decrease in the LOS as situations typically become more hazardous to bicycles when more vehicles are present and delays are typically increased, as well. The presence of nearby bus stops should decrease the level of service as bicycles have to enter normal traffic lanes in order to maneuver around parked buses in the bike lane. This increases the likelihood of a bicycle being struck by a motor vehicle. Similar effects are expected where parking is allowed in the bike lane. LOS should increase with increasing sight distance and decrease with increasing speed limits as the reaction time for conflicting traffic is likely to be a factor. Pavement quality is expected to affect LOS and a good pavement should produce a higher LOS than a poor pavement. However, whether or not the video will effectively portray this is uncertain. Large street widths are expected to decrease the LOS as bicycles have further to travel across conflicting traffic flows in order to complete their movement. Medians, center storage lanes, and designated turn lanes are expected to increase the 
LOS as they separate out some conflicting traffic and can provide refuge for bicycles during stages of their movement.

\section{Resultant Equations}

Each of the three final generated equations are outlined in Tables 6, 8 and 10 below. Also provided are suggested LOS ratings ranges that correspond to possible outputs from the equation. These do not necessarily have to be used, but do offer useful suggestions for practical use. 
TWSC Combined LOS Resultant Equation

Table 6: Combined LOS Equation Coefficients

\begin{tabular}{|c|c|c|c|c|c|}
\hline Term & Description & Coef & $\begin{array}{l}\text { Standard } \\
\text { Error } \\
\text { Coef }\end{array}$ & T Stat & P Stat \\
\hline Constant & & 0.3879 & 0.0604 & 6.4141 & $<0.0001$ \\
\hline $\begin{array}{l}\text { SD/(MJSL } x \\
1.467)\end{array}$ & $\begin{array}{c}\text { SD = Sight Distance } \\
\text { MJSL = Major Street } \\
\text { Speed Limit }\end{array}$ & -0.0051 & 0.0043 & -1.2077 & 0.028 \\
\hline MNSL & Minor Street Speed Limit & 0.0044 & 0.0014 & 3.0516 & 0.003 \\
\hline PAV & $\begin{array}{c}\text { Pavement Quality Score } \\
\text { (see Table 3) }\end{array}$ & 0.0054 & 0.0071 & 0.7579 & 0.049 \\
\hline SHAR & $\begin{array}{c}=1 \text { if Shared Lane } \\
\text { Markings are Present } \\
\text { Near Intersection; SHAR = } \\
0 \text { Otherwise }\end{array}$ & 0.1342 & 0.0132 & 10.1346 & $<0.0001$ \\
\hline SIGN & $\begin{array}{l}=1 \text { if Bicycle Signage is } \\
\text { Present Near Intersection; } \\
\text { SIGN = } 0 \text { Otherwise }\end{array}$ & 0.0219 & 0.0091 & 2.4000 & 0.017 \\
\hline BB & $\begin{array}{c}=1 \text { if Bicycle Boulevard; } \\
\text { BB = } 0 \text { Otherwise }\end{array}$ & 0.1332 & 0.0190 & 7.0053 & $<0.0001$ \\
\hline PBL & $\begin{array}{c}=1 \text { if Parking is Allowed in } \\
\text { the Bike Lane; } P B L=0 \\
\text { Otherwise (and if no bike } \\
\text { lane is present) }\end{array}$ & -0.0293 & 0.0171 & -1.7099 & 0.088 \\
\hline WBL & Width of Bike Lane (feet) & 0.0171 & 0.0015 & 10.8786 & $<0.0001$ \\
\hline DRTL & $\begin{array}{l}=1 \text { if Designated Right } \\
\text { Turn Lane is Present; } \\
\text { DRTL = 0 Otherwise }\end{array}$ & -0.0009 & 0.0215 & -0.0422 & 0.066 \\
\hline DLTL & $\begin{array}{c}=1 \text { if Designated Left Turn } \\
\text { Lane is Present; DLTL }=0 \\
\text { Otherwise }\end{array}$ & -0.0285 & 0.0103 & -2.7427 & 0.007 \\
\hline M & $\begin{array}{c}=1 \text { if Median or Barrier } \\
\text { Present Near Intersection; } \\
M=0 \text { Otherwise }\end{array}$ & -0.0489 & 0.0112 & -4.3578 & $<0.0001$ \\
\hline MNW & $\begin{array}{l}\text { Minor Street Curb to Curb } \\
\text { Width (feet) }\end{array}$ & 0.0015 & 0.0006 & 2.3890 & 0.018 \\
\hline LC & $\begin{array}{l}\text { Log(Sum of peak hour } \\
\text { traffic volumes conflicting } \\
\text { with approach) }\end{array}$ & -0.0558 & 0.0140 & -3.9671 & $<0.0001$ \\
\hline
\end{tabular}

$\mathrm{R}-\mathrm{Sq}(\operatorname{adj})=57.08 \%$ 

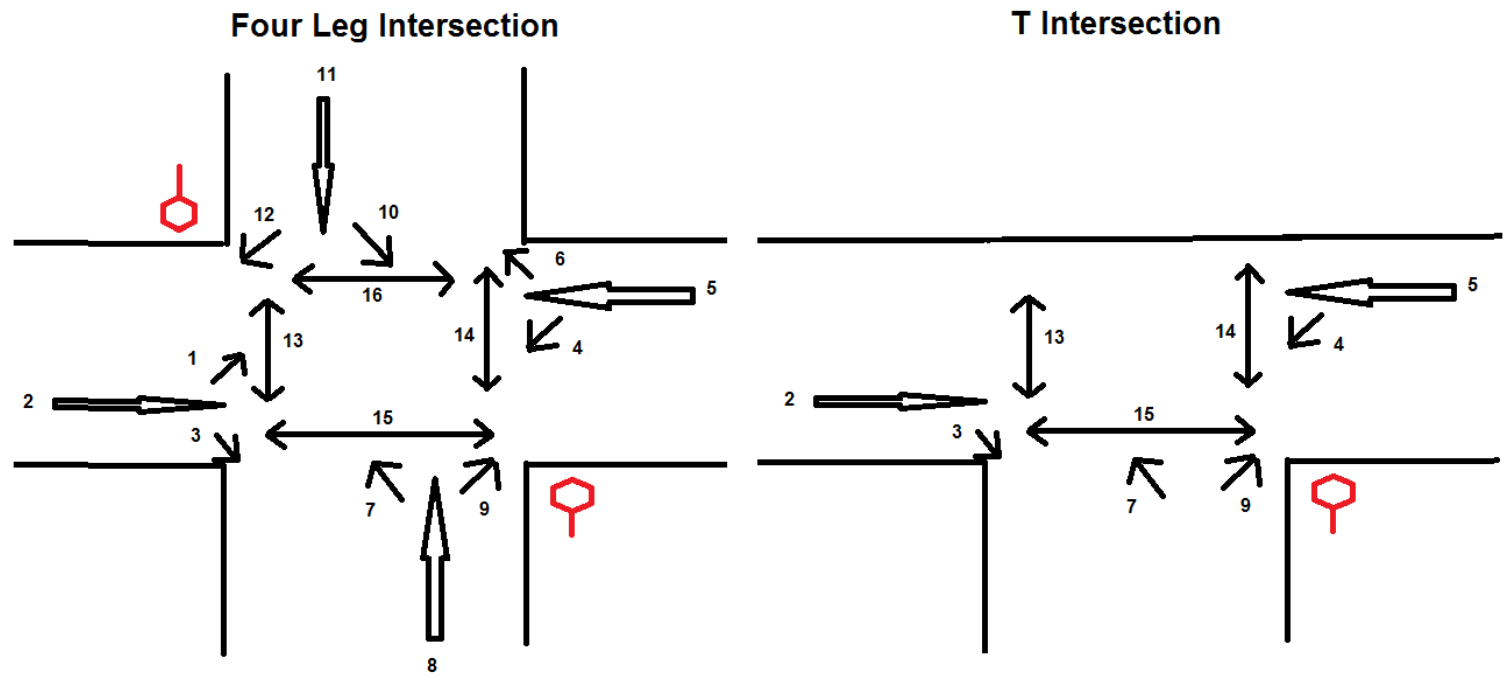

Figure 24: Combined Methodology Two-Way Stop-Controlled Movement Diagram: Exhibit 19-6 (Highway capacity manual, 2010)

TWSC Major Street LOS Resultant Equation

Table 7: Major Street LOS Regression Coefficients

\begin{tabular}{|c|c|c|c|c|c|}
\hline Term & Description & Coef & $\begin{array}{l}\text { Standard } \\
\text { Error } \\
\text { Coef }\end{array}$ & T Stat & P Stat \\
\hline Constant & & 2.9549 & 0.1218 & 2.0212 & 0.045 \\
\hline SD/(MJSL*1.467) & $\begin{array}{c}\text { SD }=\text { Sight } \\
\text { Distance } \\
\text { MJSL }= \\
\text { Major Street } \\
\text { Speed Limit }\end{array}$ & 0.0028 & 0.0060 & 0.4778 & 0.034 \\
\hline MNSL & $\begin{array}{l}\text { Minor Street } \\
\text { Speed Limit }\end{array}$ & 0.0067 & 0.0020 & 3.2200 & 0.002 \\
\hline BS & $\begin{array}{c}1 \text { if Bus } \\
\text { Stop } \\
\text { Present } \\
\text { Near } \\
\text { Intersection; } \\
\text { BS = 0 } \\
\text { Otherwise }\end{array}$ & 0.0216 & 0.0155 & 1.3906 & 0.066 \\
\hline SHAR & $=1$ if & 0.1272 & 0.0191 & 6.6617 & $<0.0001$ \\
\hline
\end{tabular}




\begin{tabular}{|c|c|c|c|c|c|}
\hline & $\begin{array}{c}\text { Shared } \\
\text { Lane } \\
\text { Markings } \\
\text { are Present } \\
\text { Near } \\
\text { Intersection; } \\
\text { SHAR = 0 } \\
\text { Otherwise }\end{array}$ & & & & \\
\hline SIGN & $\begin{array}{c}=1 \text { if } \\
\text { Bicycle } \\
\text { Signage is } \\
\text { Present } \\
\text { Near } \\
\text { Intersection; } \\
\text { SIGN }=0 \\
\text { Otherwise }\end{array}$ & 0.0416 & 0.0134 & 3.0963 & 0.002 \\
\hline BB & $\begin{array}{c}=1 \text { if } \\
\text { Bicycle } \\
\text { Boulevard; } \\
\text { BB = } 0 \\
\text { Otherwise }\end{array}$ & 0.1029 & 0.0308 & 3.3414 & 0.001 \\
\hline PBL & $\begin{array}{l}=1 \text { if } \\
\text { Parking is } \\
\text { Allowed in } \\
\text { the Bike } \\
\text { Lane; PBL = } \\
0 \text { Otherwise } \\
\text { (and if no } \\
\text { bike lane is } \\
\text { present) }\end{array}$ & -0.0438 & 0.0236 & -1.8566 & 0.065 \\
\hline OPMN & $\begin{array}{c}=1 \text { if } \\
\text { Parking is } \\
\text { Allowed on } \\
\text { Minor } \\
\text { Street; } \\
\text { OPMN = } 0 \\
\text { Otherwise }\end{array}$ & -0.0918 & 0.0252 & -3.6428 & $<0.0001$ \\
\hline WBL & $\begin{array}{l}\text { Width of } \\
\text { Bike Lane } \\
\text { (feet) }\end{array}$ & 0.0165 & 0.0024 & 6.7505 & $<0.0001$ \\
\hline MNW & $\begin{array}{c}\text { Minor Street } \\
\text { Curb to } \\
\text { Curb Width } \\
\text { (feet) }\end{array}$ & 0.0016 & 0.0009 & 1.6079 & 0.11 \\
\hline MJW & Major Street & 0.0002 & 0.0005 & 0.4904 & 0.025 \\
\hline
\end{tabular}




\begin{tabular}{|c|c|c|c|c|c|}
\hline & $\begin{array}{c}\text { Curb to } \\
\text { Curb Width } \\
\text { (feet) }\end{array}$ & & & & \\
\hline DRTL & $\begin{array}{c}=1 \text { if } \\
\text { Designated } \\
\text { Right Turn } \\
\text { Lane is } \\
\text { Present; } \\
\text { DRTL }=0 \\
\text { Otherwise }\end{array}$ & -0.0134 & 0.0337 & -0.3993 & 0.69 \\
\hline DLTL & $\begin{array}{l}=1 \text { if } \\
\text { Designated } \\
\text { Left Turn } \\
\text { Lane is } \\
\text { Present; } \\
\text { DLTL = } 0 \\
\text { Otherwise }\end{array}$ & -0.0378 & 0.0150 & -2.5083 & 0.013 \\
\hline LM & $\begin{array}{l}\text { Log(Sum of } \\
\text { peak hour } \\
\text { traffic } \\
\text { volumes } \\
\text { with } \\
\text { direction of } \\
\text { approach) }\end{array}$ & -0.1749 & 0.0896 & -1.9506 & 0.053 \\
\hline LC & $\begin{array}{l}\text { Log(Sum of } \\
\text { peak hour } \\
\text { traffic } \\
\text { volumes } \\
\text { conflicting } \\
\text { with } \\
\text { approach) }\end{array}$ & -0.7692 & 0.0636 & -1.7159 & 0.088 \\
\hline PAV & $\begin{array}{l}\text { Pavement } \\
\text { Quality } \\
\text { Score (see } \\
\text { Table 3) }\end{array}$ & 0.0135 & 0.0107 & 1.2636 & 0.008 \\
\hline M & $\begin{array}{l}=1 \text { if } \\
\text { Median or } \\
\text { Barrier } \\
\text { Present } \\
\text { Near } \\
\text { Intersection; } \\
M=0 \\
\text { Otherwise }\end{array}$ & -0.0525 & 0.0174 & -3.0112 & 0.003 \\
\hline
\end{tabular}


$R-S q(\operatorname{adj})=58.93 \%$
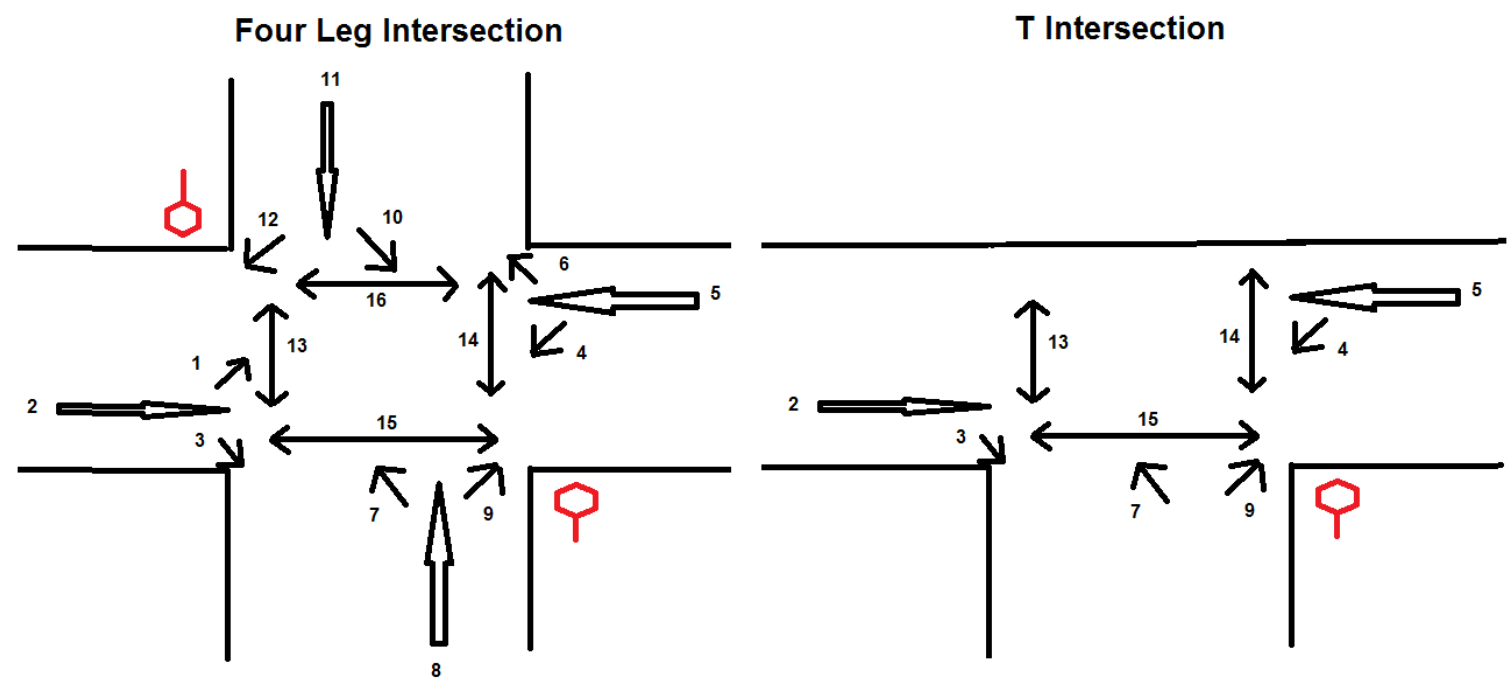

Figure 25: Major Methodology Two-Way Stop-Controlled Movement Diagram:

Exhibit 19-6 (Highway capacity manual, 2010)

\section{TWSC Minor Street LOS Resultant Equation}

Table 8: Minor Street LOS Regression Coefficients

\begin{tabular}{|l|l|l|l|l|l|}
\hline Term & Description & Coef & $\begin{array}{l}\text { Standard } \\
\text { Error } \\
\text { Coef }\end{array}$ & T Stat & P Stat \\
\hline Constant & SD = Sight Distance & 0.6187 & 0.1066 & 5.8020 & $<0.0001$ \\
\hline $\begin{array}{l}\text { SD/(MJSL } x \\
1.467)\end{array}$ & $\begin{array}{c}\text { MJSL Major Street } \\
\text { Speed Limit }\end{array}$ & -0.0040 & 0.0094 & -0.4244 & 0.072 \\
\hline MNSL & $\begin{array}{c}\text { Minor Street Speed } \\
\text { Limit }\end{array}$ & 0.0041 & 0.0029 & 1.4184 & 0.059 \\
\hline SHAR & $\begin{array}{c}\text { =1 if Shared Lane } \\
\text { Markings are Present } \\
\text { Near Intersection; } \\
\text { SHAR = O Otherwise }\end{array}$ & 0.1471 & 0.0189 & 7.7720 & $<0.0001$ \\
\hline BB & $\begin{array}{c}1 \text { if Bicycle Boulevard; } \\
\text { BB = 0 Otherwise }\end{array}$ & 0.1336 & 0.0292 & 4.5690 & $<0.0001$ \\
\hline PBL & $\begin{array}{c}=1 \text { if Parking is Allowed } \\
\text { in the Bike Lane; PBL }= \\
\text { 0 Otherwise (and if no }\end{array}$ & -0.0805 & 0.0272 & -2.9509 & 0.004 \\
\hline
\end{tabular}




\begin{tabular}{|c|c|c|c|c|c|}
\hline & bike lane is present) & & & & \\
\hline WBL & $\begin{array}{l}\text { Width of Bike Lane } \\
\text { (feet) }\end{array}$ & 0.0195 & 0.0029 & 6.7374 & $<0.0001$ \\
\hline LT & $\begin{array}{l}\text { Log(Sum of peak hour } \\
\text { traffic volumes for all } \\
\text { approaches) }\end{array}$ & -0.0972 & 0.0332 & -2.9236 & 0.004 \\
\hline LM & $\begin{array}{l}\text { Log(Sum of peak hour } \\
\text { traffic volumes with } \\
\text { direction of approach) }\end{array}$ & 0.0222 & 0.0268 & 0.8296 & 0.08 \\
\hline M & $\begin{array}{c}=1 \text { if Median or Barrier } \\
\text { Present Near } \\
\text { Intersection; } M=0 \\
\text { Otherwise }\end{array}$ & -0.0090 & 0.0196 & -0.4575 & 0.048 \\
\hline MJW & $\begin{array}{l}\text { Major Street Curb to } \\
\text { Curb Width (feet) }\end{array}$ & -0.0011 & 0.0007 & -1.5570 & 0.022 \\
\hline SLOPE & $\begin{array}{l}\text { Steepest Grade Cyclist } \\
\text { Encounters during } \\
\text { Movement (integer) }\end{array}$ & 0.0013 & 0.0030 & 0.4596 & 0.047 \\
\hline $\mathrm{HV}$ & Percent Heavy Vehicles & -0.0156 & 0.0027 & -5.6652 & $<0.0001$ \\
\hline CR & $\begin{array}{c}=1 \text { if Curb Return } \\
\text { Radius }>9 \text { feet; CR }=0 \\
\text { if Curb Return Radius < } \\
9 \text { feet }\end{array}$ & -0.0308 & 0.0128 & -2.3879 & 0.019 \\
\hline
\end{tabular}

$\mathrm{R}-\mathrm{Sq}(\operatorname{adj})=56.70 \%$
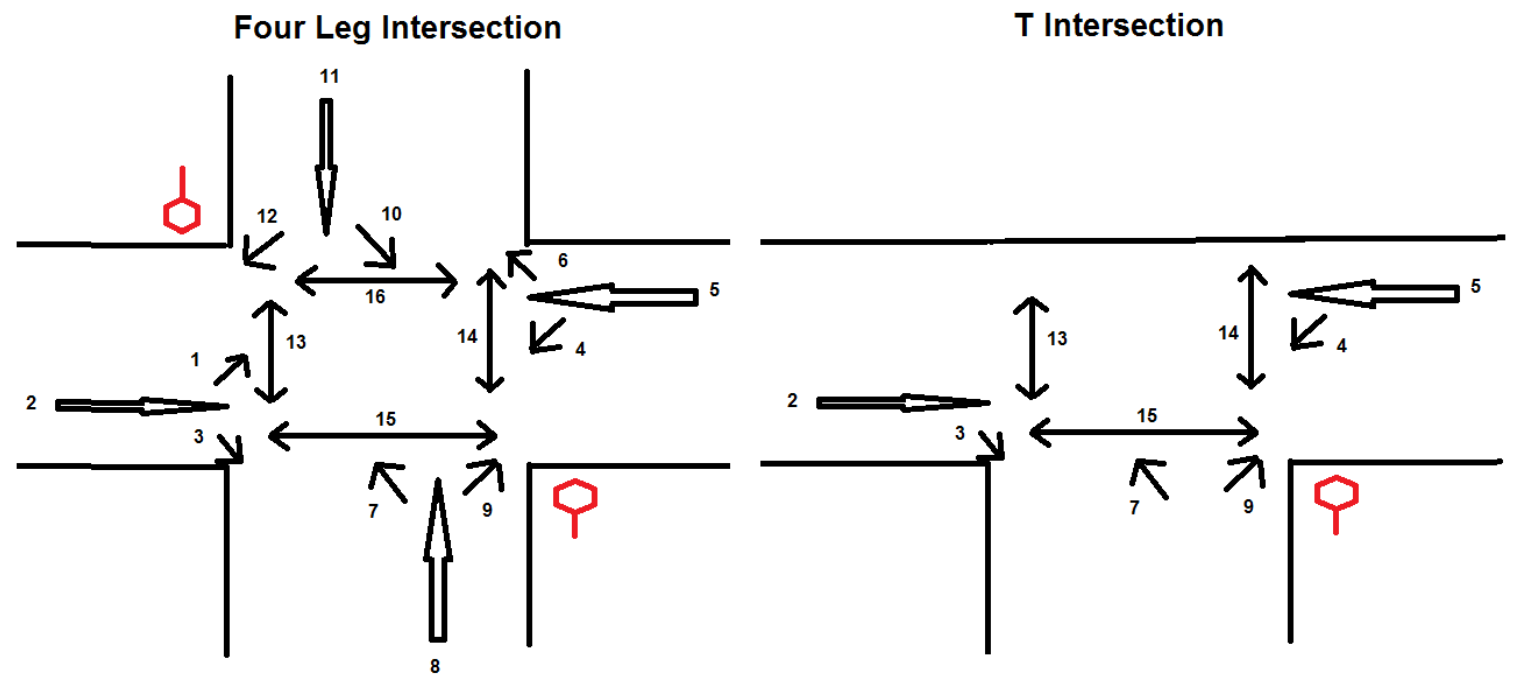

Figure 26: Minor Methodology Two-Way Stop-Controlled Movement Diagram:

Exhibit 19-6 (Highway capacity manual, 2010) 


\section{Comparative Evaluation of LOS Estimation at Approach Level vs. Aggregating All Approaches}

Which method is better? It is recommended that the individual data equations are utilized due to the increased accuracy that these equations provide in estimating level of service values (note that these equations also have the slightly higher $\mathrm{R}^{2}$ adjusted values and provide a better fit for the data). The other method, which provides a single equation for major and minor street movements separately is, perhaps, slightly simpler to use and may provide similar results to the individual data equations, but will probably not prove quite as accurate.

As may be seen in the above resultant equations, whether or not shared lane markings and signage are present at an intersection does affect the level of service. This will be a way that agencies in the future can improve the quality of their roadway networks. Somewhat surprisingly, the presence of a designated left turn lane does appear to have a negative impact on level of service. This may be because of the higher traffic volumes that correspond with roadways that require a designated left turn lane. Also, for major street level of service, the presence of a bus stop was correlated with higher level of service ratings than intersections that did not have a bus stop. This is likely an issue that is due to insufficient data on intersections with bus stops (only six sampled intersections had bus stops present). The presence of parking both on the major and minor roads was also found to be fairly significant, but in opposite ways. Parking on the minor roadways led to a lower level of service score, whereas parking on the major roadways led to a higher level of service score. This could be in part due to the speed of traffic being lower on the major roads that allowed parking or could 
more likely be due to the fact that the traffic flows stayed farther away from the side of the road when parking was adjacent than when no parking was provided.

Another result was that bicyclists perceived the level of service to be higher if the intersection had a bicycle boulevard on it. A bicycle boulevard is defined by Walker et al. (2009) as "low volume and low speed streets that have been optimized for bicycle travel through treatments such as traffic calming and traffic reduction, signage and pavement markings, and intersection crossing treatments. These treatments allow through movements for cyclist while discouraging similar through trips by non-local motorized traffic." Walker et al., 2009)

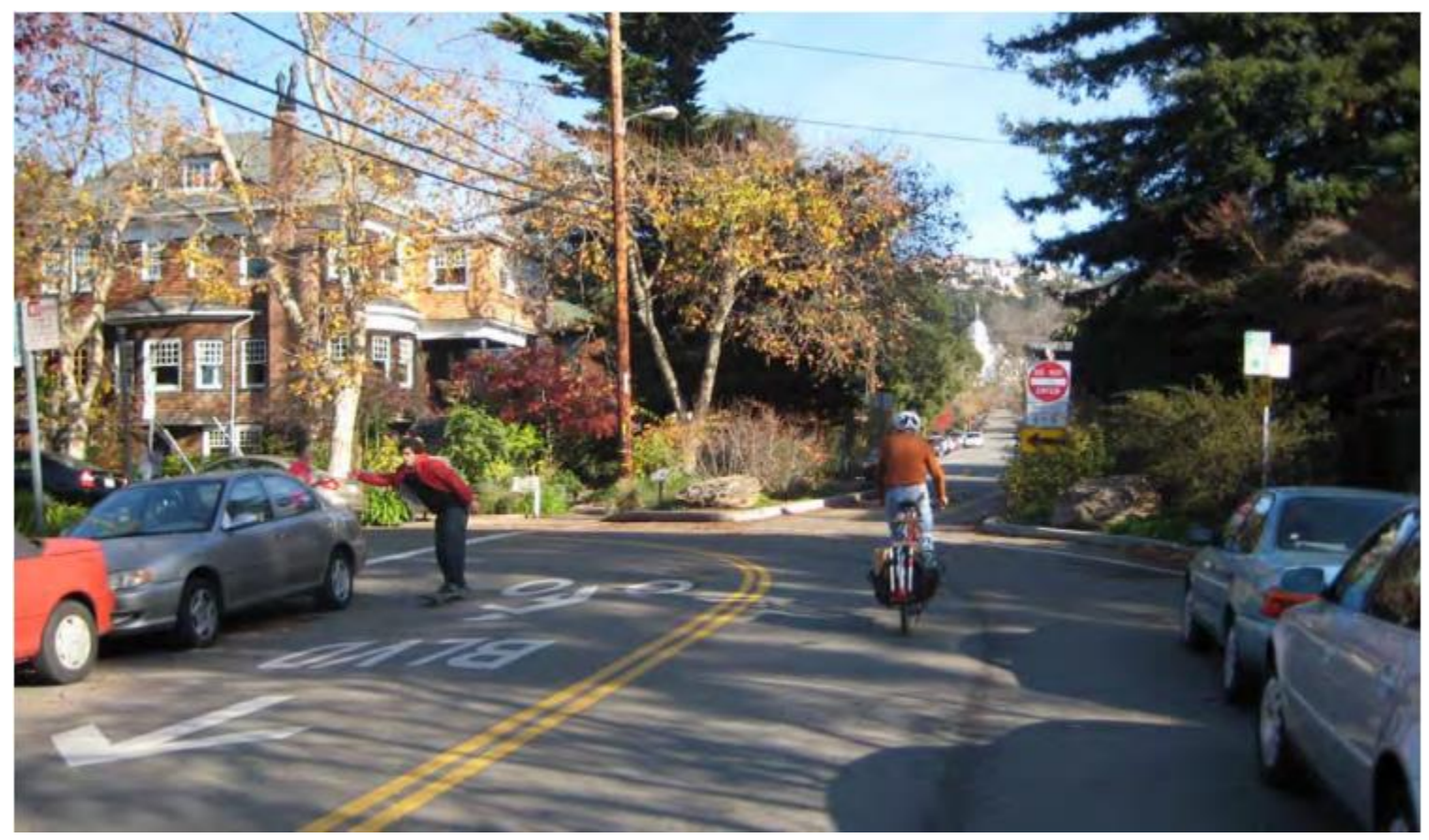

Figure 27: Bicycle Boulevard (Walker et al., 2009) 
This is another factor that can be considered by traffic engineers and planners to improve the level of service of roadway networks for bicycles in low traffic areas.

The data collected for this research was based on video based ratings. These videos were of sample intersections that were recorded at times that may not have been the peak hours for those specific intersections, but because traffic counts and video collection for each individual intersection occurred during approximately the same time of day, the data is reflective of the conditions that the roadway was experiencing during the survey time. The intersections themselves may have different actual levels of service during their own peak hour times, but because this research is to evaluate a level of service methodology and not the intersections themselves, this manner of data collection was deemed acceptable. Respondents to the surveys viewed the traffic volumes as a normal cyclist on the road would, that is by judging for themselves based on how many vehicles are present in the video as to what the relative traffic volumes were at the time of data collection. It is based on this perspective that respondents provided their responses.

Once all variables were entered into the Minitab 16 software, the computer analyzed the patterns to try to determine the best linear regression for the data. It provided, as can be seen in the results tables, different signs for the coefficients of the logs of the traffic volumes. This was done by the software to best enhance the relationship between the data and the best-fit equation. The significance of this is that the conflicting vehicle traffic flows and the vehicle traffic 
flows that are traveling in the same direction as the bicycle experience different levels of significance in determining the overall LOS.

Physical aspects of the intersections that did not appear to influence the level of service equations included the width and number of the lanes, however, these qualities were most likely already accounted for by the curb-to-curb dimension variables (as was suggested by the diagnostic results). Also, the presence of a designated right turn only lane or a center storage lane was determined to be insignificant, as well. This may be because a bicycle has to deal with these traffic flows whether the designated lanes are present or not.

\section{Sensitivity Analysis}

This section presents the results from the equation (estimated bicycle LOS score) based on change in the major road conflicting automobile flow while all other variables are kept constant. This analysis is represented in order to clearly show the correspondence between the well-established automobile LOS methodology and the bicycle LOS methodology. Table 13 and Figure 25 clearly show that the LOS score decreases (i.e., LOS becomes worse as one would expect) for LOS the same way as the conflicting flows on the major street increased. 
Table 9: Resulting Variation in Minor Approach Bicycle LOS Score Based on Increase in Conflicting Automobile Flow

\begin{tabular}{|r|r|r|c|c|c|c|}
\hline $\begin{array}{c}\text { Main } \\
\text { Flow }\end{array}$ & $\begin{array}{c}\text { Opposing } \\
\text { Flow }\end{array}$ & $\begin{array}{c}\text { Conflicting } \\
\text { Flow }\end{array}$ & $\begin{array}{c}\text { Log(Total } \\
\text { Flow) }\end{array}$ & $\begin{array}{c}\text { Log(Main } \\
\text { Flow) }\end{array}$ & Log(los) & LOS \\
\hline 200 & 300 & 200 & 2.845098 & 2.30103 & 0.554265 & 3.58315 \\
\hline 200 & 300 & 400 & 2.954243 & 2.30103 & 0.521827 & 3.325273 \\
\hline 200 & 300 & 600 & 3.041393 & 2.30103 & 0.495926 & 3.132754 \\
\hline 200 & 300 & 800 & 3.113943 & 2.30103 & 0.474364 & 2.981015 \\
\hline 200 & 300 & 1200 & 3.230449 & 2.30103 & 0.439739 & 2.752572 \\
\hline 200 & 300 & 2000 & 3.39794 & 2.30103 & 0.38996 & 2.454485 \\
\hline
\end{tabular}

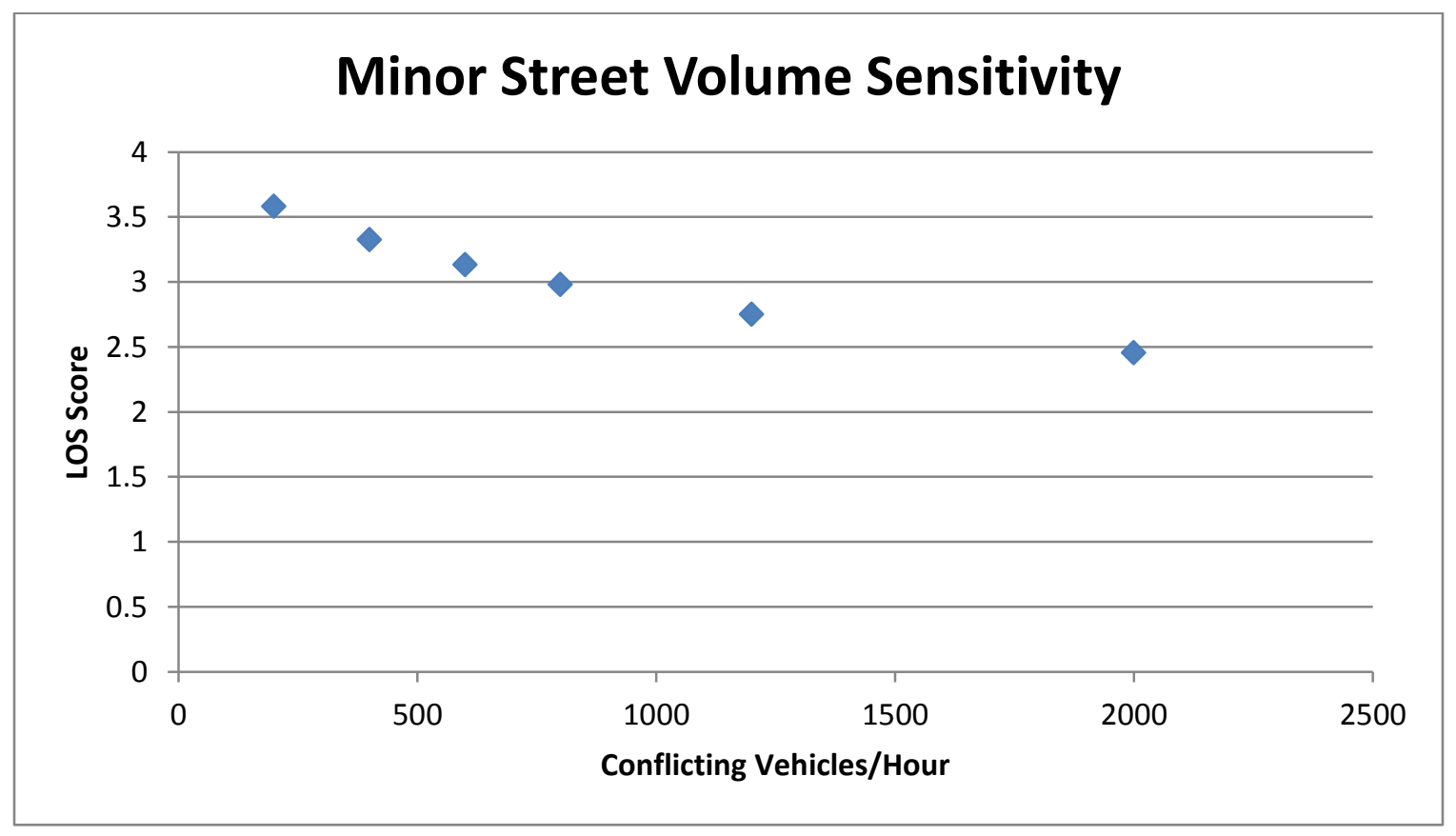

Figure 28: Minor Street Conflicting Volume Sensitivity 


\section{Goodness of Fit}

The Goleta intersection user perception and intersection design data was used to statistically test if the LOS score from the equation for each approach was the same as the average of the ratings from all users. The analysis was conducted using a paired t-test. The results are shown in Table 12.

Table 10: Equation Paired T Test Results

\begin{tabular}{|c|c|c|c|c|}
\hline Equation & $\begin{array}{c}\text { Mean } \\
\text { Difference }\end{array}$ & Std Dev & T Value & P Value \\
\hline Major & 0.137 & 0.710 & -0.90 & 0.378 \\
\hline Minor & 0.143 & 0.535 & -1.00 & 0.336 \\
\hline Combined & 0.25 & 0.692 & -2.17 & 0.037 \\
\hline
\end{tabular}

As you can see from the above results, the individual major and minor street equations provide a much better fit for the Goleta intersection turn movements than does the combined equation. This is one of the main reasons why the individual turn movement equations are being recommended by this report as the best methodology over the single combined equation.

\section{Threshold Recommendation and Improving Goodness of Fit}

To further show how well each equation fits its data set, a series of graphs are created below that show for each individual turn movement (on the $\mathrm{x}$ axis) what the equation predicts the level of service to be versus what the actual survey response was. Data for both Goleta validation intersections and other intersections are provided below in different formats. For each graph, the blue points represent the average of all survey respondents and the purple lines represent the numerical value directly provided by the equation. This time, 
however, a threshold has been applied to convert the raw score into a LOS. The thresholds are provided in Tables 11 and 12. Note that these thresholds were used here to maximize the correspondence between the predicted and estimated LOS category. The author is aware of the concept of over-fitting in statistical modeling and these thresholds are not recommended for assigning LOS for all scenarios. If the proposed methodology is adopted as the standard bicycle LOS methodology for TWSC standard thresholds could be developed and adopted.

Table 11: TWSC Intersection Major Street Suggested LOS

\begin{tabular}{|c|c|}
\hline RATE & LOS \\
\hline $5+$ & A \\
\hline $3.6-5.0$ & B \\
\hline $2.5-3.6$ & C \\
\hline $2.4-2.5$ & D \\
\hline $2.2-2.4$ & E \\
\hline$<2.2$ & F \\
\hline
\end{tabular}

Table 12: TWSC Intersection Minor Street Suggested LOS

\begin{tabular}{|c|c|}
\hline RATE & LOS \\
\hline $4.8+$ & $\mathrm{A}$ \\
\hline $3.5-4.8$ & $\mathrm{~B}$ \\
\hline $2.7-3.5$ & $\mathrm{C}$ \\
\hline $1.7-2.7$ & $\mathrm{D}$ \\
\hline $1.5-1.7$ & $\mathrm{E}$ \\
\hline$<1.5$ & $\mathrm{~F}$ \\
\hline
\end{tabular}




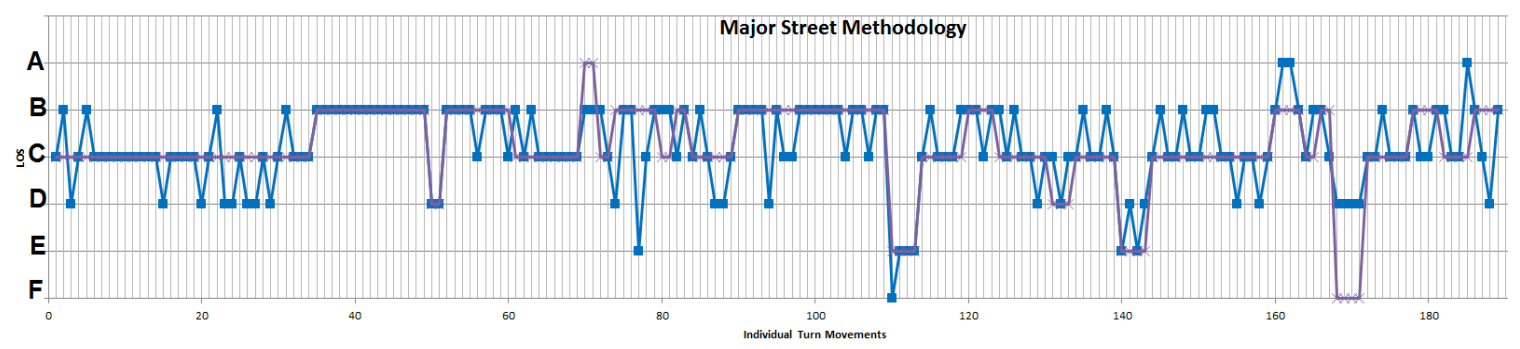

Figure 29: Major Street Equation

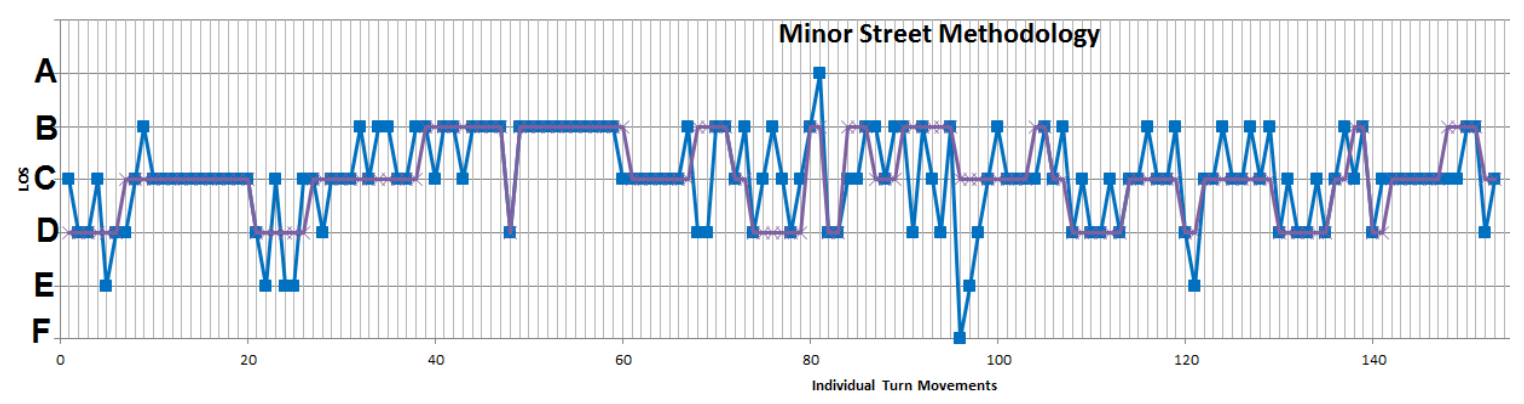

Figure 30: Minor Street Equation

Please note that for each of the above graphs, about the last fifth of the individual turn movements (x axis) are movements from Goleta, California which was used to help confirm the validity of the equations and were not considered during the original development of the equations. The Goleta data is reproduced alone below.
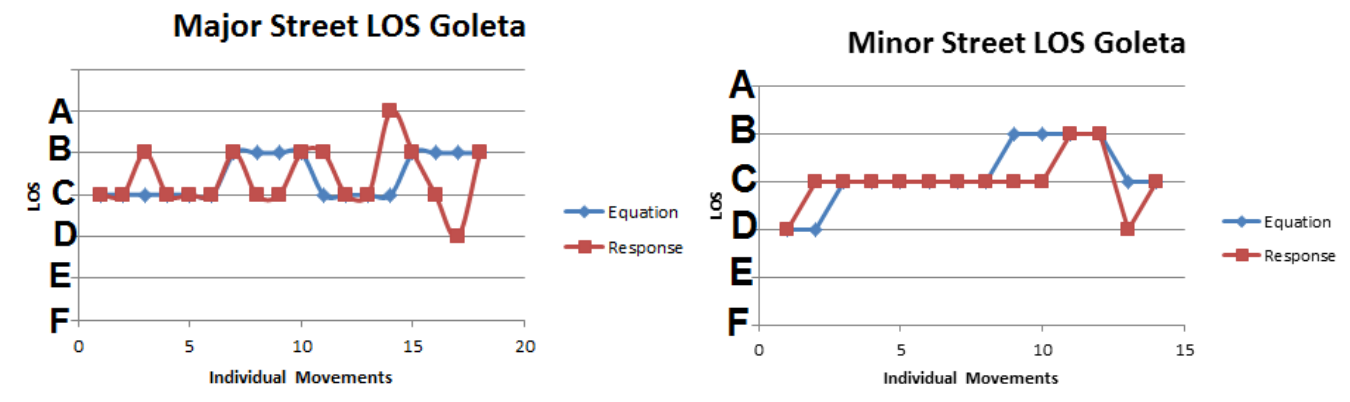

Figure 31: Goleta Comparison 


\section{Interesting Issues Affecting Bicycle Operation}

\section{Enforcement}

From the field research, there were several concerns that presented themselves that were not included in previous research and could not be explored for this research either. For example, in multiple cases of the reviewed sample intersections, "No Parking Bike Lane" signs were posted on the sides of the street, but vehicles would ignore these signs and park in the bike lane anyway, forcing cyclists to leave the safety of their designated lane and enter the normal traffic lanes in order to get around them. This brings into play the importance of police enforcement in maintaining street facilities and level of service. Even if the facilities, such as signage and striping, from an engineering standpoint are present, they become meaningless if they are not enforced. This was discovered to be a very serious concern.

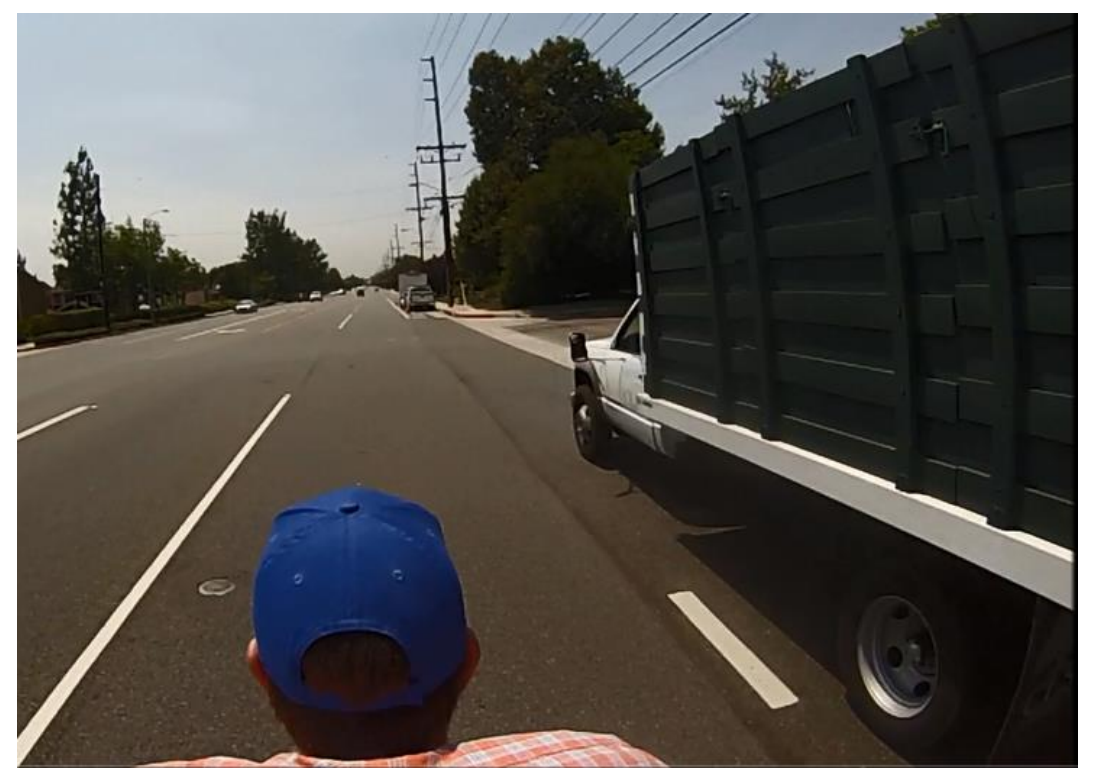

Figure 32: Trucks Parking in Bike Lane in Claremont, California 
Not only parking laws were ignored, but normal traffic laws as well. Multiple times during the captured video that was shown to a review panel for feedback, vehicles break traffic laws to swerve around the cyclist on all sides in order to pass the slower cyclist while he is still traversing the intersection (even blocking off the oncoming traffic in order to complete their pass). Movements such as these are prohibited, but lack of enforcement and/or driver knowledge of rules of the road make such legal matters void in the field. This would lead to a lower level of comfort and safety as well as level of service for the cyclist, but cannot easily be addressed by good bicycle infrastructure without completely separating bicycles and other vehicular traffic.

\section{Pavement Quality Discrepancy between Intersecting Roads}

Another field condition that presented itself is that of inconsistent pavement quality. On many intersections one of the two intersecting roadways has a better pavement quality than the other intersecting roadway. This results in an opinion to average a pavement quality score approximately midway between the two individual roadway scores. For example, a roadway with a pavement quality corresponding to a level two, which intersects with a roadway with a pavement quality of a level four, will usually average to an overall pavement quality of approximately level three to the eye of the cyclist. This often appears to occur because the cyclist's movement across the intersection requires him or her to interact with both pavement qualities as they traverse the intersection. 


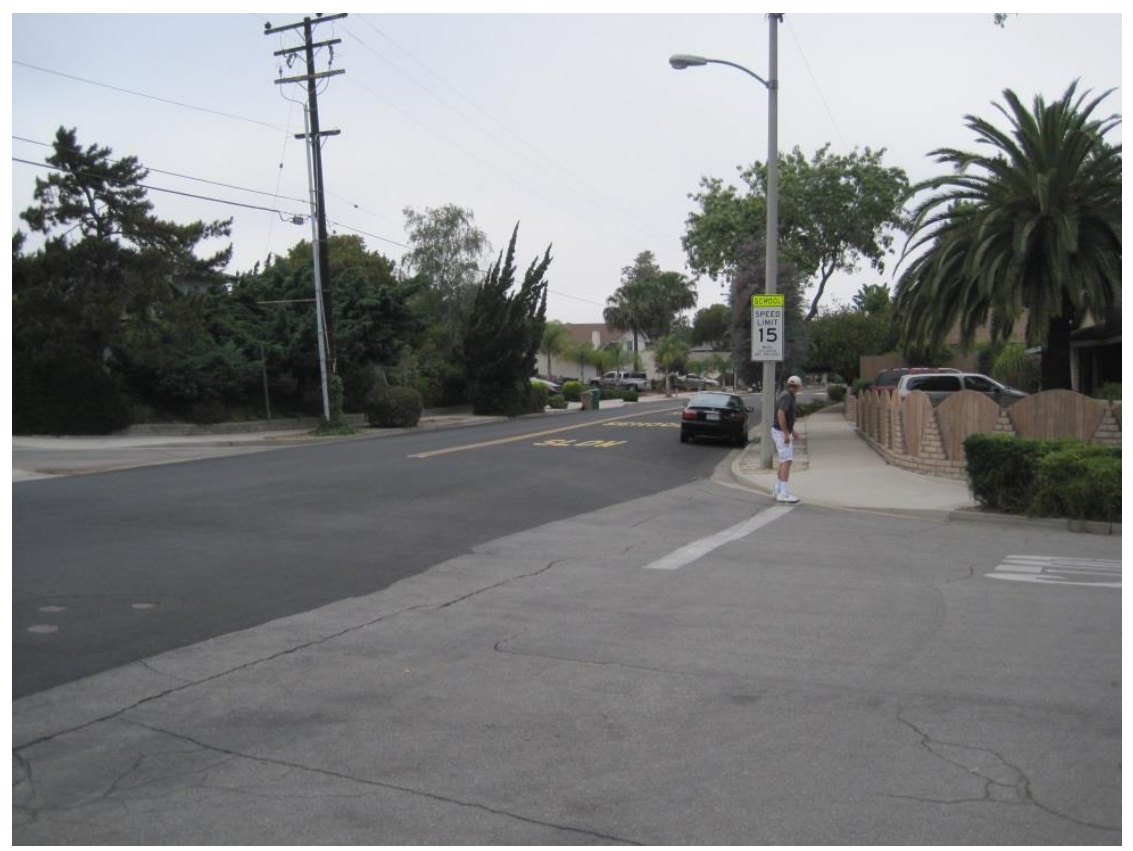

Figure 33: Pavement Quality Discrepancy

Shared Lane Markings

A separate finding was that involving sharrows (shared-lane markings) and bike lanes. For small traffic volumes, painted sharrows were found to provide higher levels of service for cyclists than bike lanes. However, once motor vehicle traffic volumes became sizable (over approximately 160 vehicles per hour) bike lanes started becoming more and more desired by cyclists for adequate safety. This trend was determined from a combination of direct questioning on the internet surveys and manipulation of the overall LOS scores estimated by computer when traffic volumes and presence of sharrows are altered. The California Manual on Uniform Traffic Control Devices addresses this using the speed limit of the roadway, suggesting in Section 9C.07 that the Shared Lane Marking is used only on roadways with a speed limit of 35 miles per hour or lower (California Manual on Uniform Traffic Control, 2012). Signage alerting vehicles to the presence of 
cyclists and improved pavement quality were both found to have a positive effect no matter what the traffic volumes were. Painted parking lanes placed between a bike lane and a curb were actually less desirable than just a lone bike lane UPON THE CONDITION that no parking was allowed in the bike lane and that this was properly enforced. If parking in the bike lane was allowed, then this provided a lower level of service than if there had been a separate striped parking lane.

When a roadway had no bicycle facilities on it but had on street parking, the level of service decreased significantly. From the reviewers' comments, this was primarily because of the lack of painted sharrows without which the cyclist is supposed to legally stay as far to the right as practical. However, on narrower streets, cyclists were at risk of hitting doors that open from adjacently parked vehicles and, if a door is open while a vehicle behind the approaching cyclist tries to pass the bicycle, the cyclist is forced to stop completely and wait for the other vehicles to complete their maneuvers. Very narrow streets make sharrows almost a necessity for bicycle safety even though the California Manual on Uniform Traffic Control Devices, 2012 states that sharrows should not be placed within 11 feet of the curb when on-street parking is present (California Manual on Uniform Traffic Control, 2012). 


\section{Medians}

Previous research on medians has so far showed positive feedback on the presence of solid barriers in the center of the roadway. Dixon et al. (1996) stated the following:

"Medians Present: The medians must be restrictive, raised medians with or without turn bays. The presence of medians should be noted only if the medians are a dominant feature throughout the corridor segment or at least in those portions of the segment where vehicle turning movements are most frequent. These medians are considered a benefit to bicyclists because they limit left-turn conflicts. Turn lanes in a median can also be a benefit because they allow traffic flow to continue without backing up behind a turning vehicle. When this back-up occurs motorists are often tempted to use the bicycle lanes or paved shoulders to pass on the right. However, continuous turn lanes are not to be credited in this category because the benefit of reducing back-ups is greatly offset by the increase in turning movements at random locations." (Dixon, 1996)

However, in the survey information collected for this thesis the medians generally led to reduced sight distance. Planted or exceptionally raised medians in particular decreased the sight distance of cyclists approaching an intersection and made it difficult to see opposing traffic. This resulted in a decrease in level of service at intersections where a restrictive median is present (see results table listed above). This could be offset if medians and barriers ended about 200 feet or so before and intersection, so that cyclists could see traffic within that range, 
but most of the locations observed had medians that went right up to the intersection before breaking. This posed problems especially on roadways with high speed and traffic volumes.

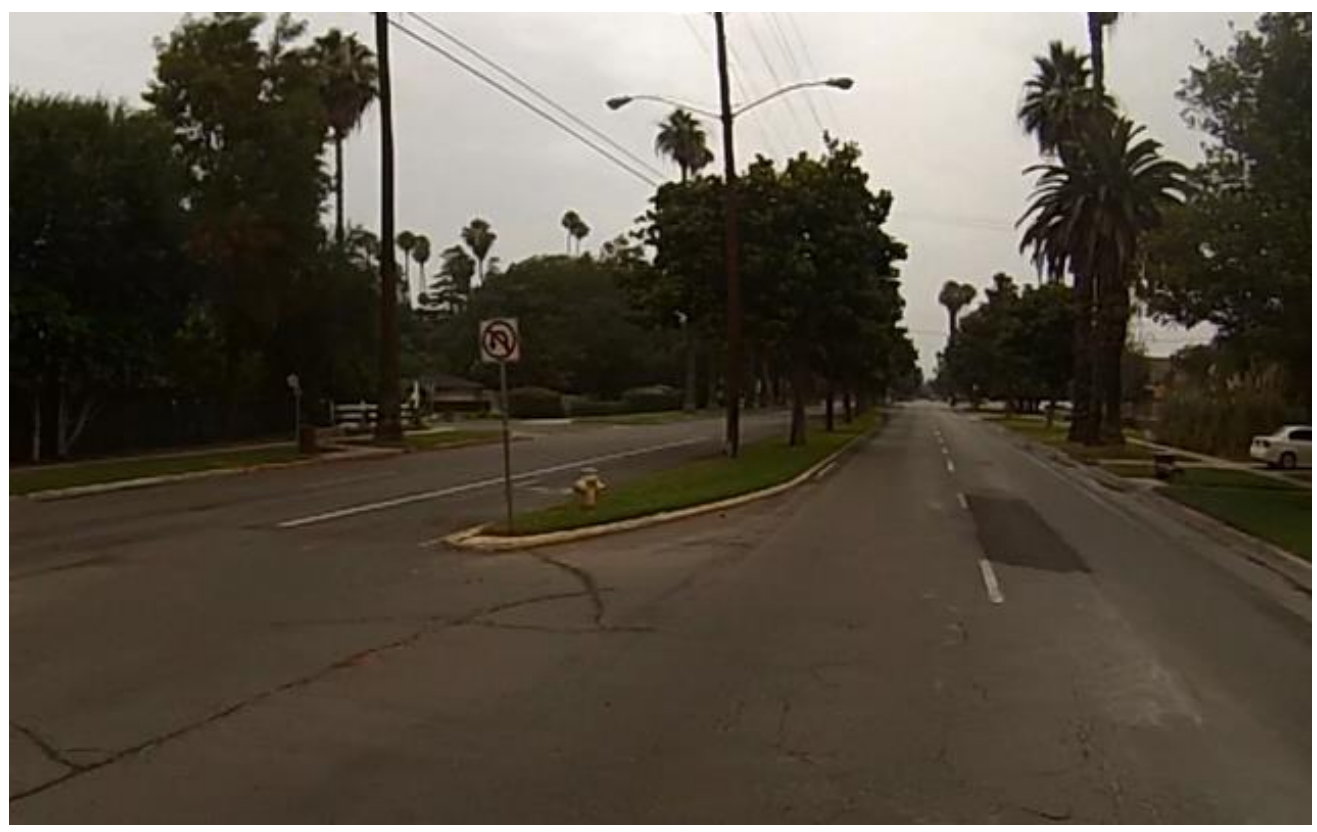

Figure 34: Median Presence in Riverside, California 


\section{CHAPTER 5: CONCLUSIONS AND SUBJECTS FOR FUTURE RESEARCH}

Although all steps necessary to create a level of service model at TWSC intersections were undertaken (See Table 13 below), a key difference between this study and past Transportation Research Board research projects on level of service is the number and range of surveyed sites. Prior studies that have been conducted had significantly larger budgets and staff and were thus able to consider approximately double the number of surveyed locations and those locations were spaced over a greater geographical range that provides a more certain representation of the United States (and other parts of the world depending on the individual study) whereas data from this thesis was collected only in California. Future studies, like the one currently being developed by Kittelson \& Associates for the HCM 2020, will probably benefit from having a larger number of sample intersections and a wider geographical range so as to make the resultant calculations more applicable for agencies in different locations. This is partially the reasoning for why the combined level of service method that was estimated in this research may not have provided an accurate evaluation technique for TWSC LOS. Such a system may only provide a "ballpark" estimate of the true level of service because only 34 intersections where actually used to create the model (with an additional 7 more to validate). There may be a significant amount of error in the model due to the relatively small number of sample survey intersections and future research could help to rectify this issue. In the meantime, the method of analyzing TWSC intersections using two different aspects (major and minor street turn movements) should serve as 
the most accurate means of LOS estimation. Also, in addition to a wider range of survey intersections, it may be advisable to survey the same intersection at multiple times and under different traffic conditions. This may provide further insight on the effects of traffic volume on LOS.

Surveyed intersections in this research were all collected from areas that are recignised at a national level as being "bicycle friendly." It may also prove valuable to survey some sites that are not bicycle friendly to see if there are differences in vehicle and bicycle behavior and/or LOS between the two types of areas. It is possible that the data collected for this research in terms of collected perception scores was skewed due to increased vehicular awareness and friendliness towards cyclists. This validation is a subject for future research.

Table 13: Goals Revisited

\begin{tabular}{|c|c|}
\hline Goal & Completed? \\
\hline $\begin{array}{c}\text { Collection of Data on Physical Characteristics of Sample } \\
\text { Two-Way Stop-Controlled Intersections }\end{array}$ & \\
\hline $\begin{array}{l}\text { Collection of Video Footage of Two-Way Stop-Controlled } \\
\text { Intersection Turn Movements from Cyclist' Perspective }\end{array}$ & \\
\hline $\begin{array}{c}\text { Collection of Video Footage of Signalized Intersection Turn } \\
\text { Movements for Validation of Viewers Feedback }\end{array}$ & \\
\hline $\begin{array}{c}\text { Collection of Video Viewer's Feedback as Perceived Level } \\
\text { of Service Ratings }\end{array}$ & \\
\hline $\begin{array}{c}\text { Consolidate Viewers Feedback into a Single Average LOS } \\
\text { Score for Each Turn Movement }\end{array}$ & \\
\hline $\begin{array}{l}\text { Split Data into Three Sets for Analysis: Major Street, Minor } \\
\text { Street, and Combined }\end{array}$ & \\
\hline $\begin{array}{c}\text { Perform Linear Regression on Data and Confirm with } \\
\text { Reserved Survey Intersections }\end{array}$ & \\
\hline $\begin{array}{c}\text { Provide details on significance of Results and Future } \\
\text { Research Possibilities }\end{array}$ & $\mathrm{Q}$ \\
\hline
\end{tabular}


The resultant equations from this thesis and related insights provided about the other field observed variables such as medians, sharrows etc. should serve as a fair estimate of the bicycle level of service for TWSC intersections. Even within the data used in this study there is still significant variance in the level of service survey response data and the equations' fit, which indicates that there may be no perfect fit, and that the equations represent an estimate only, and that individual situations may offer actual field LOS that could not be fully predicted by such models. Other aspects that should be topics of future research include emerging technologies. For example, flashing lights that activate either by push button or other detection system that alert drivers to the presence of bicycles at an intersection. Such configurations are very rare at current conditions, but within the near future that may change. Technologies similar to bike boxes may also present themselves. Although the bike box itself is only for signalized intersections currently and would most likely serve little purpose at a two-way stop-controlled intersection, it is possible that a similar means of providing a safe haven for bicycle traffic at different types of intersections may be developed in the future. Painted bike lanes, for example, are slowly being introduced to areas of high bicycle incidents and could be subject to further review for level of service analyses. 


\section{BIBLIOGRAPHY:}

Anne Vernez, Moudon and Chanam, Lee (2003). Walking and Bicycling: An

Evaluation of Environmental Audit Instruments. American Journal of Health

Promotion: September/October 2003, Vol. 18, No. 1, pp. 21-37.

Bhuyan, P.K. and Nayak, Minakshi Sheshadri (2013). "A Review on Level of Service Analysis of Urban Streets." Transport Reviews: A Transnational Transdisciplinary Journal. Taylor and Francis Online. Feb 21, 2013. Retrieved April 22, 2013 from:

http://www.tandfonline.com/doi/abs/10.1080/01441647.2013.779617

C. Fuchs, W.D. Berg (1983). Evaluating the need for Accident Reduction Experiments. Transportation Research Record 905. Transportation Research Board. Washington D.C.

Caltrans (2012). California Manual on Uniform Traffic Control Devices. State of California, Business, Transportation and Housing Agency, Department of Transportation. Sacramento, California.

Dill, J., \& Voros, K. (2007). Factors affecting bicycling demand: initial survey findings from the Portland, Oregon, region. Transportation Research Record: Journal of the Transportation Research Board, 2031(1), 9-17. 
Dixon, L. B. (1996). Bicycle and pedestrian level-of-service performance measures and standards for congestion management systems. Transportation Research Record: Journal of the Transportation Research Board, 1538(1), 1-9.

Do, Ann (2006). Evaluation of Safety, Design, and Operation of Shared-Use Paths. The Pedestrain and Bicycle Saftey Research Program. Federal Highway Administration. FHWA-HRT-05-137.

Dowling, R. G., Reinke, D. B., Flannery, A., Ryus, P., Vandehey, M., Petritsch, T. A. Bonneson, J. (2008). NCHRP Report 616: Multimodal Level of Service Analysis for Urban Streets. Transportation Research Board of the National Academies, Washington, DC.

Dowling, Richard (2009). NCHRP Document 128: Multimodal Level of Service Analysis for Urban Streets: Users Guide, Appendix D to Contractor's Final Report for NCHRP Project 3-70. Dowling Associates, Inc. Oakland, CA. National Cooperative Highway Research Program. Transportation Research Board of the National Academies.

E.J. Barenberg and W.D. Berg (1967). Analysis of Data from Route U.S. 66 Field Condition Survey. Department of Civil Engineering, Engineering Experiment Station, University of Illinois, Urbana Illinois.

Field, Andy, Miles, Jeremy (2010). Discovering Statistics Using SAS. SAGE Publications Inc. 2455 Teller Road Thousand Oaks, California 91320. 
Florida Department of Transportation Office of Roadway Design (2013). Florida Intersection Design Guide 2013. State of Florida Department of Transportation. http://transoftsolutions.com/offers/fidg.pdf.

H.A.J. Kuhn, W.D. Berg (1973). Undergraduate Civil Engineering and Transportation Engineering Needs. Highway Research Record No. 462. Highway Research Board. Pp. 27-31.

Harkey, David L. and Reinfurt, Donald W. and Knuiman, Matthew and Stewart, J. Rachard and Sorton, Alex. "Development of the Bicycle Compatibility Index: A Level Of Service Concept." University of North Carolina, Highway Safety and Research Center. Chapel Hill, NC. December, 1998.

HCM. (2000). Washington D.C.: Transportation Research Board, National Research Council.

HCM. (2010). Washington D.C.: Transportation Research Board, National Research Council. lacono, Michael, Krizek, Kevin J., El-Geneidy, Ahmed (2010). Measuring nonmotorized accessibility issues, alternatives, and execution. Journal of Transport Geography. 18: 133-140

Kang, Kyungwoo and Lee, Kyeora, (2012). Development of a Bicycle Level of Service Model from the User's Perspective. KSCE Journal of Civil Engineering (2012). 16(6):1032-1039 
League of American Bicyclists * Bicycle Friendly America. (n.d.). Retrieved May 6, 2013, from http://www.bikeleague.org/programs/bicyclefriendlyamerica/

Landis, Bruce W. and Vattikuti, Venkat R. and Brannick, Michael T. "Real Time Human Perceptions: Toward a Bicycle Level Of Service." Transportation Research Record: Journal of the Transportation Research Board. Transportation Research Board of the National Academies. ${ }^{1}$ Sprinkle Consulting Engineers, Inc. 18115 U.S. Highway 41 North, Suite 600, Lutz, Fla. 33549. ${ }^{2}$ Department of Psychology, University of South Florida. 4202 E. Fowler Ave., BEH 339, Tampa, Fla. 33620. Vol 1578. 1997.

http://trb.metapress.com/content/n118452647112qg6/

Minitab (2013). "Minitab 16 Support Documentation." http://www.minitab.com/enus/support/documentation/

Pucher, J., Dill, J., \& Handy, S. (2010). Infrastructure, programs, and policies to increase bicycling: an international review. Preventive Medicine, 50, S106-S125.

S.B. Lee, W.D. Berg (1998) Development of Safety Based Level of Service Parameters for Two Way Stop-controlled Intersections. Transportation Research Record 1635. Transportation Research Board. Washington D.C. 
Transportation Research Board Executive Committee. (2010). Highway Capacity Manual 2010. Transportation Research Board of the National Academies. Washington DC.

Walker, Lindsay, Tresidder, Mike, Birk, Mia (2009). Fundamentals of Bicycle Boulevard Planning \& Design. Initiative for Bicycle and Pedestrain Innovation Center for Transportation Studies Center for Urban Studies. Portland State University, Portland, Oregon.

http://www.pdx.edu/ibpi/sites/www.pdx.edu.ibpi/files/BicycleBoulevardGuidebook( optimized).pdf

W.D. Berg, H.A.J. Kuhn, R.D. Paris (1972). Final Report on the Problem Defitinition Seminar on Transportation Planning and Management. University of Wisconsin, Institute for Environmental Studies. Madison, Wisconsin.

W.D. Berg (1972). A Review of Techniques of Transportation Planning. The Engineering Economist. American Society for Engineering Education. Vol 17, No. 3.

W.D. Berg (1996). A Methodology for the Study of Causal Factors in Highway Traffic Accidents. The First Road Traffic Safety Association International Symposium. Seoul, Korea. 


\section{Appendix}

Appendix A: The following is a detailed list of the procedures for several related existing level of service methodologies

Appendix B: Sample calculations for comparing existing level of service methodologies with collected survey responses are provided in the following

Appendix C: The following is a sample calculation for data validation of collected responses by comparing accepted signalized intersection level of service equations to collected signalized intersection level of services.

Appendix D: The following is a list of American League of Bicyclists approved Bicycle Friendly Communities and Universities for 2012. All sites surveyed in this report were selected from this list .149

Appendix E: The following images are maps of the selected survey sites shown on the official Bike Maps of the cities selected for data collection. These maps are the ones submitted to the American League of Bicyclists by the 
individual communities at the time of application for 2012 recognition as Bicycle Friendly Communities. Locations of selected survey intersections are denoted by a large star 159

Appendix F: The following are the scanned field data collection pages collected on-site at each survey location 165

Appendix G: The following is a summary of the collected field data sheets (please note that not all information from the sheets may be listed here, but the majority is) 289

Appendix $\mathrm{H}$ : The following pages are sample public survey sheets upon which cyclist perception scores were collected by in-person interviews with video recording viewers. Please note that not all data pages collected are included in this appendix due to the large volume of data collected. A summary of all data collected is also included in this appendix to address the excluded data pages 297

Appendix I: The following is a sample survey response that was provided by a Cal Poly Student in Dr. Mastako's CE 421 Class .302

Appendix $\mathrm{J}$ : The following is a sample survey response that was provided by a member of the general public 305 
Appendix K: The following is a summary of the collected level of service feedback based on the experience of the

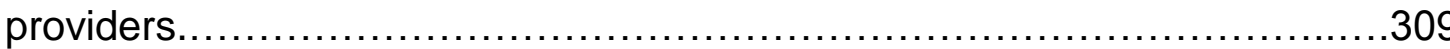

Appendix L: The following are the Minitab outputs for the final equations. Results for the tests that were conducted prior to these being determined are not included due to the sheer volume of that data

Appendix M: The following images are Google Earth ${ }^{\mathrm{TM}}$ screen shots of each surveyed intersection to clarify any confusion with the crude field drawings shown in the field data sheets provided in the above section. Please note that these images are only updated to the most recent Google Earth feed and some intersection images are out of date and do not show all current bicycle facilities present.

Appendix N: The following is a poster that was drawn up requesting volunteers to provide feedback on the collected videos 377 


\section{Appendix A}

The following is a detailed list of the procedures for several related existing level of service methodologies. 


\section{Bicycle Level of Service for Signalized Intersections:}

The first step (Determine Bicycle Delay) begins with determining the bicycle lane capacity. This is done using the following equation:

$C_{b}=\left(S_{b} \times g_{b}\right) / C$

Where

$\mathrm{C}_{\mathrm{b}}=$ capacity of the bike lane (bicycles/hour)

$S_{b}=$ saturation flow rate of the bicycle lane (default $=2,000$ bicycles/hour)

$g_{b}=$ effective green time for the bicycle lane

$\mathrm{C}=$ cycle length

(Source: HCM 2010)

$S_{b}$ has been found in some areas to be as high as 2,600 bicycles per hour but the standard of 2,000 is recommended. If high levels of right turning vehicles are present, even this value may be unachievable in some locations. If possible, field conditions should be measured to determine the exact saturation flow rate of the site being evaluated. The saturation flow rate is the rate at which vehicles (bicycles in this case) traverse an intersection during a green light with a full queue. It measures how many vehicles can go through an intersection under perfect conditions (never actually achieved in reality). 
The cycle length is the time the signal takes to go through a complete cycle (the time a bicycle would have to wait if it was stopped the moment the light turned red, plus the green time)

The effective green time is equal to the actual green time for the direction of travel of interest minus the combination of the time lost at the beginning of the cycle from cyclists starting back up and the time lost from cyclists slowing down as the light begins to turn yellow and/or red.

The second step in this procedure is to determine the bicycle delay using equation 1879 from the HCM:

$$
d_{b}=0.5 C\left(1-g_{b} / C\right)^{2} /\left[1-\min \left(v_{b i c} / c_{b}, 1.0\right) g_{b} / C\right]
$$

$d_{b}=$ Bicycle Delay

$\mathrm{v}_{\text {bic }}=$ Bicycle Flow Rate (bicycles per hour)

The next step is to calculate the bicycle level of service score for the intersection. This is done using the following equations from HCM 2010:

$$
\begin{gathered}
I_{b, \text { int }}=4.1324+F_{w}+F_{v} \\
F_{w}=0.0153 W_{c d}-0.2144 W_{t} \\
F_{v}=0.0066\left[v_{l t}+V_{t h}+v_{r t}\right] /\left(4 N_{t h}\right) \\
W_{t}=W_{o l}+W_{b l}+I_{p k} W_{o s^{*}}
\end{gathered}
$$

Where: 
$I_{b, \text { int }}=$ bicycle LOS score for intersection

$\mathrm{W}_{\mathrm{cd}}=$ curb-to-curb width of the cross street (ft)

$\mathrm{W}_{\mathrm{t}}=$ total width of the outside through lane, bicycle lane, and paved shoulder (ft)

$\mathrm{V}_{\mathrm{It}}=$ left turn demand flow rate $(\mathrm{veh} / \mathrm{hr})$

$\mathrm{V}_{\mathrm{th}}=$ through demand flow rate $(\mathrm{veh} / \mathrm{hr})$

$\mathrm{V}_{\mathrm{rt}}=$ right turn demand flow rate $(\mathrm{veh} / \mathrm{hr})$

$\mathrm{N}_{\mathrm{th}}=$ Number of through lanes (shared or exclusive) (In)

$\mathrm{W}_{\mathrm{ol}}=$ width of the outside lane $(\mathrm{ft})$

$\mathrm{W}_{\mathrm{bl}}=$ width of the bicycle lane $=0$ if bicycle lane not provided (ft)

$I_{p k}=$ indicator variable for on street parking occupancy $=0$ of $p_{p k}<0 ; 1$ Otherwise

$\mathrm{P}_{\mathrm{pk}}=$ proportion of on street parking occupied (decimal)

$\mathrm{W}_{\mathrm{os}}=$ width of paved outside shoulder (ft)

$\mathrm{W}_{\mathrm{os}^{*}}=$ adjusted with of paved outside shoulder; if curb is present $\mathrm{W}_{\mathrm{os}^{*}}=\mathrm{W}_{\mathrm{os}}-1.5>0$;

otherwise $\mathrm{W}_{\mathrm{os}^{*}}=\mathrm{W}_{\mathrm{os}}$

The last step is to use the above bicycle level of service score to look up the actual level of service in exhibit $18-5$ from the HCM: 
Table: Exhibit 18-5 from HCM 2010

\begin{tabular}{|c|c|}
\hline LOS & LOS Score \\
\hline A & $<2.00$ \\
\hline B & $2.00-2.75$ \\
\hline C & $2.75-3.50$ \\
\hline D & $3.50-4.25$ \\
\hline E & $4.25-5.00$ \\
\hline F & $>5.00$ \\
\hline
\end{tabular}

\section{Bicycle Level of Service for All Way Stop Controlled Intersections:}

The first step is to convert the movement demand volume into a flow rate (remembering that the level of service is calculated for a specific vehicle movement).

$$
\mathrm{V}_{\mathrm{i}}=\mathrm{V}_{\mathrm{i}} / \mathrm{PHF}
$$

where:

$v_{i}=$ the demand flow rate for a movement (vehicles/ hour)

$V_{i}=$ the demand volume for the movement (vehicles/hour)

PHF $=$ Peak Hour Factor

The second step is determined if there are multiple lanes that travel in the same direction. If there is only one lane per movement, the first step values are equal to the second step values. Next, the geometry group for each approach must be determined. This is done using exhibit $20-10$ of the HCM and our knowledge of the intersection's configuration. 
Table: Exhibit 20-10 from HCM 2010

\begin{tabular}{|c|c|c|c|c|}
\hline $\begin{array}{c}\text { Intersection } \\
\text { Configuration }\end{array}$ & $\begin{array}{c}\text { Subject } \\
\text { Approaches }\end{array}$ & $\begin{array}{c}\text { Opposing } \\
\text { Approaches }\end{array}$ & $\begin{array}{c}\text { Conflicting } \\
\text { Approaches }\end{array}$ & $\begin{array}{c}\text { Geometry } \\
\text { Group }\end{array}$ \\
\hline Four leg or T & 1 & 0 or 1 & 1 & 1 \\
\hline Four leg or T & 1 & 0 or 1 & 2 & 2 \\
\hline Four leg or T & 1 & 2 & 1 & $3 \mathrm{a} / 4 \mathrm{a}$ \\
\hline T & 1 & 2 & 2 & $3 \mathrm{~b}$ \\
\hline Four leg & 1 & 2 & 2 & $4 \mathrm{~b}$ \\
\hline Four leg or T & 1 & 0 or 1 & 3 & 5 \\
& 1 & 3 & 1 & \\
& 2 & 0,1, or 2 & 1 or 2 & \\
& 3 & 0 or 1 & 1 & \\
& 3 & 0 or 1 & 2 or 3 & \\
& 3 & 2 or 3 & 1 & \\
& 1 & 3 & 2 & 3 \\
& 1 & 2 & 3 & \\
& 2 & 3 & 1,2 , or 3 & \\
& 2 & $0,1,2$, or 3 & 2 or 3 & \\
& 3 & 2 or 3 & \multicolumn{3}{|c}{} \\
\hline
\end{tabular}

The forth step involves calculating the saturation headway adjustments using equation 20-13.

$$
H_{\text {adj }}=h_{\text {It,adj }} P_{I t}+h_{r t} P_{r t}+h_{h v, \text { adj }} P_{h v}
$$

Where:

$\mathrm{H}_{\mathrm{adj}}=$ headway adjustment (s)

$\mathrm{H}_{\mathrm{It}, \mathrm{adj}}=$ headway adjustment for left turns(s)

$\mathrm{H}_{\mathrm{rt}, \mathrm{adj}}=$ headway adjustment for right turns (s)

$\mathrm{H}_{\mathrm{hv}, \mathrm{adj}}=$ headway adjustment for heavy vehicles (s)

$\mathrm{P}_{\mathrm{It}}=$ proportion of left turning vehicles in the lane 
$\mathrm{P}_{\mathrm{rt}}=$ proportion of right turning vehicles in the lane

$\mathrm{P}_{\mathrm{hv}}=$ proportion of heavy vehicles in the lane

The adjustments listed here can be obtained from exhibit 20-11:

Table: Exhibit 20-11 from HCM 2010: Saturation Headway Adjustment

\begin{tabular}{|c|c|c|c|c|c|c|c|c|}
\hline Group & 1 & 2 & $3 a$ & $3 b$ & $4 a$ & $4 b$ & 5 & 6 \\
\hline Factor & & & & & & & & \\
\hline LT & 0.2 & 0.2 & 0.2 & 0.2 & 0.2 & 0.2 & 0.5 & 0.5 \\
\hline RT & -0.6 & -0.6 & -0.6 & -0.6 & -0.6 & -0.6 & -0.7 & -0.7 \\
\hline HV & 1.7 & 1.7 & 1.7 & 1.7 & 1.7 & 1.7 & 1.7 & 1.7 \\
\hline
\end{tabular}

Step five is the first part of an iterative process in which the departure headways are assumed to be 3.2 seconds until a more accurate estimate can be determined. Step six is to calculate the initial degree of utilization using equation $20-14$ :

$$
X=v_{d} / 3600
$$

Where

$\mathrm{X}=$ Degree of utilization

$h_{d}=$ Assumed departure headway (step five)

$V=$ Lane flow rate (step two) 
Step seven is a complicated and fairly confusing one to understand at first glance. The probability state of each combination is found by multiplying all individual probabilities together. The individual probabilities can be determined using exhibits 20-12 and/or 2013. It may be advisable to simply read the value from exhibit $20-13$ if you are uncertain as to how best to utilize the data in exhibit 20-12.

$\mathrm{J}=\mathrm{O} 1$ (opposing approach, Lane 1), O2 (opposing approach, Lane 2), CL1 (conflicting left approach, Lane 1), CL2 (conflicting left approach, Lane 2), CR1 (conflicting right approach, Lane 1), and CR2 (conflicting right approach, Lane 2) for a two-lane, two-way AWSC intersection

$P\left(a_{j}\right)=$ probability of $a_{j}$, computed on the basis of Exhibit 20-12, where $V_{j}$ is the lane flow rate

$A_{j}=1$ (indicating a vehicle present) or 0 (indicating no vehicle present in the lane) (values of $a_{j}$ for each lane in each combination I are listed in Exhibit 20-13).

Table: Exhibit 20-12 from HCM 2010

\begin{tabular}{|c|c|c|}
\hline$A_{j}$ & $V_{j}$ & $P\left(a_{j}\right)$ \\
\hline 1 & 0 & 0 \\
\hline 0 & 0 & 1 \\
\hline 1 & $>0$ & $X_{j}$ \\
\hline 0 & $>0$ & $1-x_{j}$ \\
\hline
\end{tabular}


Table: Exhibit 20-13 from HCM 2010

\begin{tabular}{|c|c|c|c|c|c|c|c|c|}
\hline $\mathrm{i}$ & $\begin{array}{l}\text { DOC } \\
\text { Case }\end{array}$ & $\begin{array}{c}\# \\
\text { Vehicles }\end{array}$ & $\begin{array}{c}\text { Op } \\
\text { Approach } \\
\text { L1 }\end{array}$ & $\begin{array}{c}\text { Op } \\
\text { App } \\
\text { L2 }\end{array}$ & $\begin{array}{c}\text { Conf } \\
\text { App } \\
\text { L1 }\end{array}$ & $\begin{array}{l}\text { Conf } \\
\text { App } \\
\text { L2 }\end{array}$ & $\begin{array}{l}\text { Conf } \\
\text { App } \\
\text { R1 }\end{array}$ & $\begin{array}{c}\text { Conf } \\
\text { App } \\
\text { R2 }\end{array}$ \\
\hline 1 & 1 & 0 & 0 & 0 & 0 & 0 & 0 & 0 \\
\hline $\begin{array}{l}2 \\
3\end{array}$ & 2 & 1 & $\begin{array}{l}1 \\
0\end{array}$ & $\begin{array}{l}0 \\
1\end{array}$ & 0 & 0 & 0 & 0 \\
\hline 4 & 2 & 2 & 1 & 1 & 0 & 0 & 0 & 0 \\
\hline $\begin{array}{l}5 \\
6 \\
7 \\
8\end{array}$ & 3 & 1 & 0 & 0 & $\begin{array}{l}1 \\
0 \\
0 \\
0\end{array}$ & $\begin{array}{l}0 \\
1 \\
0 \\
0\end{array}$ & $\begin{array}{l}0 \\
0 \\
1 \\
0\end{array}$ & $\begin{array}{l}0 \\
0 \\
0 \\
1\end{array}$ \\
\hline $\begin{array}{c}9 \\
10\end{array}$ & 3 & 2 & 0 & 0 & $\begin{array}{l}1 \\
0\end{array}$ & $\begin{array}{l}1 \\
0\end{array}$ & $\begin{array}{l}0 \\
1\end{array}$ & $\begin{array}{l}0 \\
1\end{array}$ \\
\hline $\begin{array}{l}11 \\
12 \\
13 \\
14 \\
15 \\
16 \\
17 \\
18 \\
19 \\
20 \\
21 \\
22\end{array}$ & 4 & 2 & $\begin{array}{l}0 \\
0 \\
0 \\
0 \\
0 \\
1 \\
0 \\
1 \\
0 \\
0 \\
1 \\
1\end{array}$ & $\begin{array}{l}0 \\
0 \\
0 \\
0 \\
1 \\
0 \\
1 \\
0 \\
1 \\
1 \\
0 \\
0\end{array}$ & $\begin{array}{l}0 \\
1 \\
1 \\
0 \\
0 \\
1 \\
0 \\
0 \\
1 \\
0 \\
0 \\
0\end{array}$ & $\begin{array}{l}1 \\
0 \\
0 \\
1 \\
1 \\
0 \\
0 \\
1 \\
0 \\
0 \\
0 \\
0\end{array}$ & $\begin{array}{l}0 \\
0 \\
1 \\
1 \\
0 \\
0 \\
1 \\
0 \\
0 \\
0 \\
1 \\
0\end{array}$ & $\begin{array}{l}1 \\
1 \\
0 \\
0 \\
0 \\
0 \\
0 \\
0 \\
0 \\
1 \\
0 \\
1\end{array}$ \\
\hline $\begin{array}{l}23 \\
24 \\
25 \\
26 \\
27 \\
28 \\
29 \\
30 \\
31 \\
32 \\
33 \\
34\end{array}$ & 4 & 3 & $\begin{array}{l}0 \\
0 \\
0 \\
1 \\
1 \\
1 \\
1 \\
0 \\
1 \\
0 \\
1 \\
0\end{array}$ & $\begin{array}{l}0 \\
0 \\
0 \\
0 \\
1 \\
1 \\
1 \\
1 \\
0 \\
0 \\
1 \\
1\end{array}$ & $\begin{array}{l}0 \\
1 \\
1 \\
1 \\
1 \\
0 \\
0 \\
1 \\
0 \\
1 \\
0 \\
0\end{array}$ & $\begin{array}{l}1 \\
1 \\
1 \\
1 \\
0 \\
0 \\
0 \\
1 \\
0 \\
0 \\
1 \\
0\end{array}$ & $\begin{array}{l}1 \\
0 \\
1 \\
0 \\
0 \\
1 \\
0 \\
0 \\
1 \\
1 \\
0 \\
1\end{array}$ & $\begin{array}{l}1 \\
1 \\
0 \\
0 \\
0 \\
0 \\
1 \\
0 \\
1 \\
1 \\
0 \\
1\end{array}$ \\
\hline $\begin{array}{l}35 \\
36 \\
37\end{array}$ & 4 & 4 & $\begin{array}{l}1 \\
0 \\
1\end{array}$ & $\begin{array}{l}1 \\
0 \\
1\end{array}$ & $\begin{array}{l}0 \\
1 \\
1\end{array}$ & $\begin{array}{l}0 \\
1 \\
1\end{array}$ & $\begin{array}{l}1 \\
1 \\
0\end{array}$ & $\begin{array}{l}1 \\
1 \\
0\end{array}$ \\
\hline $\begin{array}{l}38 \\
39 \\
40\end{array}$ & 5 & 3 & $\begin{array}{l}0 \\
1 \\
0\end{array}$ & $\begin{array}{l}1 \\
0 \\
1\end{array}$ & $\begin{array}{l}0 \\
0 \\
1\end{array}$ & $\begin{array}{l}1 \\
1 \\
0\end{array}$ & $\begin{array}{l}0 \\
1 \\
1\end{array}$ & $\begin{array}{l}1 \\
0 \\
0\end{array}$ \\
\hline
\end{tabular}




\begin{tabular}{|l|l|l|l|l|l|l|l|l|}
\hline 41 & & & 0 & 1 & 0 & 1 & 1 & 0 \\
42 & & & 0 & 1 & 1 & 0 & 0 & 1 \\
43 & & & 1 & 0 & 1 & 0 & 0 & 1 \\
44 & & & 1 & 0 & 0 & 1 & 0 & 1 \\
45 & & & 1 & 0 & 1 & 0 & 1 & 0 \\
\hline 46 & 5 & 4 & 1 & 0 & 0 & 1 & 1 & 1 \\
47 & & & 0 & 1 & 1 & 1 & 1 & 0 \\
48 & & & 0 & 1 & 1 & 1 & 0 & 1 \\
49 & & & 1 & 0 & 1 & 0 & 1 & 1 \\
50 & & & 1 & 0 & 1 & 1 & 1 & 0 \\
51 & & & 0 & 1 & 0 & 1 & 1 & 1 \\
52 & & & 1 & 1 & 1 & 0 & 0 & 1 \\
53 & & & 1 & 0 & 1 & 1 & 0 & 1 \\
54 & & & 0 & 1 & 1 & 0 & 1 & 1 \\
55 & & & 1 & 1 & 0 & 1 & 1 & 0 \\
56 & & & 1 & 1 & 0 & 1 & 0 & 1 \\
57 & & & 1 & 1 & 1 & 0 & 1 & 0 \\
\hline 58 & 5 & 5 & 1 & 0 & 1 & 1 & 1 & 1 \\
59 & & & 1 & 1 & 0 & 1 & 1 & 1 \\
60 & & & 1 & 1 & 1 & 0 & 1 & 1 \\
61 & & & 0 & 1 & 1 & 1 & 1 & 1 \\
62 & & & 1 & 1 & 1 & 1 & 1 & 0 \\
63 & & & 1 & 1 & 1 & 1 & 0 & 1 \\
\hline 64 & 5 & 6 & 1 & 1 & 1 & 1 & 1 & 1 \\
\hline
\end{tabular}

The probabilities of no opposing conflict, no conflict from the left, and no conflict from the right are computed using 1-(values from step six). Each of these are then used to calculate the probability of each scenario from the above table, usually through straight multiplication.

Step eight is to compute the probability adjustment factors using the values from step seven.

$$
\begin{gathered}
P\left(C_{1}\right)=P(1) \\
P\left(C_{2}\right)=\sum_{i=2}{ }^{4} P(i) \\
P\left(C_{3}\right)=\sum_{i=5}{ }^{10} P(i)
\end{gathered}
$$




$$
\begin{gathered}
P\left(C_{4}\right)=\sum_{i=11}{ }^{37} P(i) \\
P\left(C_{5}\right)=\sum_{i=38}{ }^{64} P(i) \\
\text { AdjP(1) }=\alpha\left[P\left(C_{2}\right)+2 P\left(C_{3}\right)+3 P\left(C_{4}\right)+4 P\left(C_{5}\right)\right] / 1 \\
\text { AdjP(2)through AdjP(4) }=\alpha\left[P\left(C_{3}\right)+2 P\left(C_{4}\right)+3 P\left(C_{5}\right)-P\left(C_{2}\right)\right] / 3 \\
\text { AdjP(5) through AdjP(10) }=\alpha\left[P\left(C_{4}\right)+2 P\left(C_{5}\right)-3 P\left(C_{3}\right)\right] / 6 \\
\text { AdjP(11) through AdjP(37) }=\alpha\left[P\left(C_{5}\right)-6 P\left(C_{4}\right)\right] / 27 \\
\text { AdjP(38) through AdjP(64) }=\alpha\left[10 P\left(C_{5}\right)\right] / 27 \\
\alpha=0.01 \text { or } 0 \text { if no correlation between saturation headways } \\
P^{\prime}(i)=P(i)+\operatorname{AdjP}(i)
\end{gathered}
$$

Step nine is to compute the saturation headways using $h_{s i}=h_{\text {base }}+h_{\text {adj }}$ and exhibit 20-

14. Table: Exhibit 20-14 from HCM 2010: Base Saturation Headways

\begin{tabular}{|c|c|c|c|c|c|c|c|c|c|}
\hline Case & \# Veh & Gr 1 & Gr 2 & Gr 3a & Gr 3b & Gr 4a & Gr 4b & Gr 5 & Gr 6 \\
\hline 1 & 0 & 3.9 & 3.9 & 4 & 4.3 & 4 & 4.5 & 4.5 & 4.5 \\
\hline 2 & 1 & 4.7 & 4.7 & 4.8 & 5.1 & 4.8 & 5.3 & 5.0 & 6.0 \\
& 2 & & & & & & & 6.2 & 6.8 \\
& $3+$ & & & & & & & & 7.4 \\
\hline 3 & 1 & 5.8 & 5.8 & 5.9 & 6.2 & 5.9 & 6.4 & 6.4 & 6.6 \\
& 2 & & & & & & & 7.2 & 7.3 \\
& $3+$ & & & & & & & & 7.8 \\
\hline 4 & 2 & 7 & 7 & 7.1 & 7.4 & 7.1 & 7.6 & 7.6 & 8.1 \\
& 3 & & & & & & & 7.8 & 8.7 \\
& 4 & & & & & & & 9.0 & 9.6 \\
& $5+$ & & & & & & & & 12.3 \\
\hline 5 & 3 & 9.6 & 9.6 & 9.7 & 10 & 9.7 & 10.2 & 9.7 & 10 \\
& 4 & & & & & & & 9.7 & 11.1 \\
& 5 & & & & & & & 10 & 11.4 \\
& $6+$ & & & & & & & 11.5 & 13.3 \\
\hline
\end{tabular}


Step ten is to compute the departure headways. This is done with the following formula:

$$
h_{d}=\sum_{i=1}{ }^{64} P^{\prime}(i) h_{i s}
$$

Step eleven is to check for convergence. Check the calculated $h_{d}$ values from the last step with the initial assumed values in step 5. If there is a change bigger than 0.1 second, repeat procedures 5-10 until the values do not change significantly. (This may take a lot of work.)

Step twelve is to compute the capacity of each approach assuming that the flows are constant on the opposing and conflicting directions. The flow rate of the subject lane is increased and departure headways are computed for each approach with the degree of utilization set equal to 1 .

Step thirteen is to determine the service times in order to calculate control delay.

$$
\begin{gathered}
t_{s}=h_{d}-m \\
t_{s}=\text { service time } \\
h_{d}=\text { departure headway (step 10) } \\
m=\text { move up time }(2.0 \text { sec for geo groups } 1-4 ; 2.3 \mathrm{sec} \text { for geo groups } 5-6)
\end{gathered}
$$

Step fourteen is to compute control delay for each lane.

$$
d=t_{s}+900 T\left[(x-1)+\left((x-1)^{2}+\left(h_{d} x / 450 T\right)\right)^{0.5}\right]+5
$$




$$
\begin{gathered}
\mathrm{d}=\text { average control delay } \\
\mathrm{x}=\mathrm{vh} / \mathrm{d} / 3600=\text { degree of utilization } \\
\mathrm{t}_{\mathrm{s}}=\text { service time }(\mathrm{sec}) \\
\mathrm{h}_{\mathrm{d}}=\text { departure headway (sec) } \\
\mathrm{T}=\text { length of analysis period (hour) }
\end{gathered}
$$

Step fifteen is to determine the control delay for each approach and find the level of service for each approach and the intersection as a whole.

$$
\begin{gathered}
d_{\text {approach }}=\sum d_{i} v_{i} / \sum v_{i} \\
d_{\text {approach }}=\text { control delay for each approach (sec/veh) } \\
d_{i}=\text { control delay for the lane (sec/veh) } \\
v_{i}=\text { flow rate for the lane } i(v e h / h r) \\
d_{\text {intersection }}=\sum d_{\text {approach }} V_{i} / \sum V_{i} \\
d_{\text {intersection }}=\text { control delay for the intersection } \\
V_{i}=\text { flow rate for the approach } \mathrm{i}
\end{gathered}
$$

The level of service can then be determined from exhibit 20-2 and the above computed values. 
Table: Exhibit 20-2 from HCM 2010

\begin{tabular}{|c|c|}
\hline Control Delay (sec/veh) & LOS $(\mathrm{v} / \mathrm{c}<1)$ \\
\hline $0-10$ & $\mathrm{~A}$ \\
\hline $10-15$ & $\mathrm{~B}$ \\
\hline $15-25$ & $\mathrm{C}$ \\
\hline $25-35$ & $\mathrm{D}$ \\
\hline $35-50$ & $\mathrm{E}$ \\
\hline$>50$ & $\mathrm{~F}$ \\
\hline
\end{tabular}

If the volume to capacity ratio is greater than 1 , the level of service is automatically an "F" grade.

The last step in the process applies more to automotives than to bicycles, but shall be included in these notes just for completeness. Step sixteen involves the computation of queue lengths.

$$
\begin{gathered}
Q_{95}=900 T\left[(x-1)+\left((x-1)^{2}+\left(h_{d} x / 150 T\right)\right)^{0.5}\right] / h_{d} \\
Q_{95}=95^{\text {th }} \text { percentile queue (veh) } \\
x=\text { degree of utilization } \\
h_{d}=\text { departure headway (sec) } \\
T=\text { length of analysis period (hour) }
\end{gathered}
$$




\section{Bicycle Level of Service for Urban Street Segments:}

Step one is to determine the average running speed. This is best done in the field looking at the speed of cyclists between signalized intersections. If a speed cannot be determined, it is recommended that a speed of $15 \mathrm{mi} / \mathrm{hr}$ is used. Many factors influence bicycle speed including roadway volumes and conditions as well as cyclist demographics.

Step two is to determine bicycle delay at the intersection. This is done using one of three ways depending on the intersection configuration. If the intersection is uncontrolled, delay is assumed to be zero (although it may not be in reality). If the intersection is signalized or stop controlled, the delay is calculated in the same respective manner as listed in the previous sections of this paper. (See all way stop controlled intersections and/or signalized intersections.)

Step three is to determine the bicycle travel speed using a formula that accounts for downstream delay and the time required to travel through the length of the segment. This value is typically lower than the running speed. In general, we want this speed to be greater than $10 \mathrm{mi} / \mathrm{hr}$. If it is less than 5 , that suggests there is a problem with the street segment or the calculations.

$$
\begin{gathered}
\qquad S_{\text {Tbseg }}=3600 \mathrm{~L} /\left(5280 \mathrm{t}_{\mathrm{Rb}}+5280 \mathrm{~d}_{\mathrm{b}}\right) \\
\mathrm{S}_{\text {Tbseg }}=\text { travel speed of bicycles in through direction along the segment } \\
\mathrm{L}=\text { segment length }
\end{gathered}
$$


$t_{R b}=$ segment running time of bicycles in through direction $\left(3600 \mathrm{~L} / 5280 \mathrm{~S}_{\mathrm{b}}\right)(\mathrm{sec})$

$$
\begin{gathered}
S_{b}=\text { bicycle running speed (mi/hr) (step 1) } \\
d_{b}=\text { bicycle control delay (sec/bicycle) }
\end{gathered}
$$

Step four is to determine the bicycle level of service score for the intersection. This is done in the same manner as in the signalized intersection section of this paper and will not be repeated here. Step five is to determine the bicycle level of service score for the link.

$$
\begin{gathered}
I_{\text {blink }}=0.76+F_{W}+F_{v}+F_{S}+F_{p} \\
F_{W}=-0.005 W_{e}^{2} \\
F_{v}=0.507 \ln \left(v_{m a} / 4 N_{t h}\right) \\
F_{S}=0.199\left[1.1199 \ln \left(S_{R a}-20\right)+0.8103\right]\left(1+0.1038 P_{H V a}\right)^{2} \\
F_{p}=7.066 / P_{c}{ }^{2} \\
I_{b l i n k}=\text { bicycle level of service score for the link } \\
F_{W}=\text { cross section adjustment factor } \\
F_{v}=\text { motorized vehicle volume adjustment factor } \\
F_{S}=\text { motorized vehicle speed adjustment factor } \\
F_{P}=\text { pavement condition adjustment factor } \\
W_{e}=\text { effective width of outside through lane }
\end{gathered}
$$




$$
\mathrm{V}_{\mathrm{ma}}=\text { adjusted midsegment demand flow rate (veh/hr) }
$$

$\mathrm{N}_{\mathrm{th}}=$ number of through lanes on the segment in the subject direction of travel

$$
S_{\mathrm{Ra}}=\text { adjusted motorized vehicle running speed }(\mathrm{mi} / \mathrm{hr})
$$

$\mathrm{P}_{\mathrm{HVa}}=$ adjusted percent heavy vehicles in midsegment demand flow rate (\%)

$$
P_{c}=\text { pavement condition rating (exhibit 17-7) }
$$

\begin{tabular}{|c|c|c|}
\hline $\begin{array}{c}\text { Pavement Condition } \\
\text { Rating }\end{array}$ & Pavement Description & $\begin{array}{l}\text { Motorized Vehicle Ride } \\
\text { Quality and Traffic Speed }\end{array}$ \\
\hline 4 to 5 & $\begin{array}{l}\text { New or nearly new } \\
\text { superior pavement. Free } \\
\text { of cracks and patches }\end{array}$ & Good Ride \\
\hline 3 to 4 & $\begin{array}{l}\text { Flexible pavements may } \\
\text { begin to show evidence } \\
\text { of rutting and fine cracks. } \\
\text { Rigid pavements may } \\
\text { begin to show evidence } \\
\text { of minor cracking }\end{array}$ & Good Ride \\
\hline 2 to 3 & $\begin{array}{l}\text { Flexible pavments may } \\
\text { show rutting and } \\
\text { extensive patching. Rigid } \\
\text { pavements may have a } \\
\text { few joint fractures, } \\
\text { faulting, or cracking. }\end{array}$ & $\begin{array}{l}\text { Acceptable ride for low- } \\
\text { speed traffic but barely } \\
\text { tolerable for high speed } \\
\text { traffic }\end{array}$ \\
\hline 1 to 2 & $\begin{array}{l}\text { Distress occurs over } 50 \% \\
\text { or more of the surface. } \\
\text { Flexible pavement may } \\
\text { have large potholes and } \\
\text { deep cracks. Rigid } \\
\text { pavement distress } \\
\text { includes joint spalling } \\
\text { patching and cracking. }\end{array}$ & $\begin{array}{l}\text { Pavement deterioration } \\
\text { affects the speed of free } \\
\text { flow traffic. Ride quality } \\
\text { not acceptable. }\end{array}$ \\
\hline 0 to 1 & $\begin{array}{l}\text { Distress occurs over } 75 \% \\
\text { or more of the surface. } \\
\text { Large potholes and deep } \\
\text { cracks exist. }\end{array}$ & $\begin{array}{l}\text { Passably only at reduced } \\
\text { speed and considerable } \\
\text { rider discomfort. }\end{array}$ \\
\hline
\end{tabular}

Table: Exhibit 17-7 from HCM 2010 
Step six is to find the link level of service using the bicycle level of service score from step five. This is done using exhibit $17-4$ reproduced here:

Table: Exhibit 17-4 from HCM 2010

\begin{tabular}{|c|c|}
\hline Level of Service & Level of Service Score \\
\hline A & $<2.0$ \\
\hline B & $2.0-2.75$ \\
\hline C & $2.75-3.5$ \\
\hline D & $3.5-4.25$ \\
\hline E & $4.25-5$ \\
\hline F & $5<$ \\
\hline
\end{tabular}

There are conditions that go along with these values however. Please see the following exhibit 17-21 to check for special conditions.

Table: Exhibit 17-21 from HCM 2010

\begin{tabular}{|c|c|c|}
\hline Condition & $\begin{array}{c}\text { Variable When Condition } \\
\text { Is Satisfied }\end{array}$ & $\begin{array}{c}\text { Variable When Condition } \\
\text { Is Not Satisfied }\end{array}$ \\
\hline$P_{p k}=0$ & $\mathrm{~W}_{\mathrm{t}}=\mathrm{W}_{\mathrm{ol}}+\mathrm{W}_{\mathrm{bl}}+\mathrm{W}_{\mathrm{os}^{*}}$ & $\mathrm{~W}_{\mathrm{t}}=\mathrm{W}_{\mathrm{ol}}+\mathrm{W}_{\mathrm{bl}}$ \\
\hline $\begin{array}{c}V_{m}>160 \text { veh/hr or street } \\
\text { is divided }\end{array}$ & $W_{v}=W_{t}$ & $W_{v}=W_{t}\left(2-0.005 v_{m}\right)$ \\
\hline $\mathrm{W}_{\mathrm{bl}}+\mathrm{W}_{\mathrm{os}^{*}<4 \mathrm{ft}}$ & $W_{e}=W_{v}-10 p_{p k}>0$ & $\begin{array}{c}W_{e}=W_{v}+W_{b l}+W_{o s^{*}-} \\
20 p_{p k}>0\end{array}$ \\
\hline $\begin{array}{l}V_{m}\left(1-0.01 P_{h v}\right)<200 \\
\text { veh/hr and } p_{h v}>50 \%\end{array}$ & $P_{\text {hva }}=50 \%$ & $\mathrm{P}_{\mathrm{hva}}=\mathrm{P}_{\mathrm{hv}}$ \\
\hline $\mathrm{S}_{\mathrm{r}}<21 \mathrm{mi} / \mathrm{hr}$ & $\mathrm{S}_{\mathrm{Ra}}=21 \mathrm{mi} / \mathrm{hr}$ & $S_{R a}=S_{R}$ \\
\hline $\mathrm{V}_{\mathrm{m}}>4 \mathrm{~N}_{\text {th }}$ & $\mathrm{V}_{\mathrm{ma}}=\mathrm{V}_{\mathrm{m}}$ & $\mathrm{V}_{\mathrm{ma}}=4 \mathrm{~N}_{\mathrm{th}}$ \\
\hline
\end{tabular}


$\mathrm{V}_{\mathrm{m}}=$ midsegment demand flow rate $(\mathrm{veh} / \mathrm{hr})$

$S_{R}=$ motorized vehicle running speed $(\mathrm{mi} / \mathrm{hr})$

Step seven is to calculate the bicycle level of service score for the street segment.

$$
\begin{gathered}
I_{\text {bseg }}=0.16 I_{\text {blink }}+0.011 \mathrm{~F}_{b i} e^{\text {Ibint }}+\left[0.035 \mathrm{~N}_{\text {aps }} /(L / 5280)\right]+2.85 \\
I_{b s e g}=\text { bicycle level of service score for the segment } \\
I_{\text {blink }}=\text { bicycle level of service score for the link }
\end{gathered}
$$

$\mathrm{F}_{\mathrm{bi}}=1$ if signalized intersection, $=0$ if two way stop controlled intersection

$$
I_{\text {bint }}=\text { bicycle level of service score for the intersection }
$$

$\mathrm{N}_{\text {aps }}=$ number of access point approaches on the right side in the subject direction of travel

Step eight is to simply plug the value obtained from step seven back into exhibit 17-4 (shown above in step six) to obtain the final level of service rating. 


\section{Bicycle Level of Service for Urban Street Facilities:}

The first step, bicycle travel speed, is found using the following equation:

$$
\begin{gathered}
S_{\mathrm{TbF}}=\left(\sum_{\mathrm{i}=1}{ }^{m} L_{i}\right) /\left(\sum_{\mathrm{i}=1}{ }^{m} L_{i} / S_{\text {Tbsegi }}\right) \\
S_{T b F}=\text { travel speed of through bicycles for the facility (mi/hr) } \\
L_{i}=\text { length of segment (ft) } \\
M=\text { number of segments on the facility } \\
S_{\text {Tbsegi }}=\text { travel speed of through bicycles for segment } i
\end{gathered}
$$

Step two is to determine the bicycle level of service score using the following:

$$
\begin{gathered}
\mathrm{I}_{\mathrm{bF}}=\left(\sum \mathrm{I}_{\text {bsegi }} \mathrm{L}_{\mathrm{i}}\right) / \Sigma \mathrm{L}_{\mathrm{i}} \\
\mathrm{I}_{\mathrm{bF}}=\text { bicycle level of service score for the facility } \\
\mathrm{I}_{\mathrm{bsegi}}=\text { bicycle level of service score for the segment } \mathrm{i} \\
\mathrm{L}_{\mathrm{i}}=\text { length of segment }(\mathrm{ft})
\end{gathered}
$$

Step three is to simply plug the value obtained in step two into exhibit 17-4 to determine the level of service for the urban street facility. 
Table: Exhibit 17-4 from HCM 2010

\begin{tabular}{|c|c|}
\hline Level of Service & Level of Service Score \\
\hline A & $<2.0$ \\
\hline B & $2.0-2.75$ \\
\hline C & $2.75-3.5$ \\
\hline D & $3.5-4.25$ \\
\hline E & $4.25-5$ \\
\hline F & $5<$ \\
\hline
\end{tabular}

\section{Bicycles Level of Service for Uninterrupted Flow Facilities:}

The flow in the outside travel lane affects the perception of the cyclist and must be determined in the first step.

$$
\begin{gathered}
\qquad \mathrm{V}_{\mathrm{OL}}=\mathrm{V} /(\mathrm{PHF} \times \mathrm{N}) \\
\mathrm{V}_{\mathrm{OL}}=\text { directional demand flow rate in the outside lane }(\mathrm{veh} / \mathrm{hr}) \\
\mathrm{V}=\text { hourly directional volume }(\mathrm{veh} / \mathrm{hr}) \\
\mathrm{PHF}=\text { Peak Hour Factor } \\
\mathrm{N}=\text { number of directional lanes }(1 \text { for two lane highways })
\end{gathered}
$$


The second step is to calculate the effective width (factor) that is available to the bicycle. This depends on the outside through lane and the shoulder or bike lane. On highway parking, if present, reduces the effective width of the highway.

$$
\begin{gathered}
W_{e}=\text { effective width } \\
W_{s}=\text { width of paved shoulder } \\
\text { If } W_{s}>8 f t: \quad W_{e}=W_{v}+W_{s}-(\% O H P \times 10 f t) \\
\text { If } 4 \mathrm{ft}<W_{s}<8 f t: \quad W_{e}=W_{v}+W_{s}-2\left(\% O H P\left(2 f t+W_{s}\right)\right) \\
\text { If } W_{s}<4 \mathrm{ft}: \quad W_{e}=W_{v}+\left(\% O H P\left(2 f t+W_{s}\right)\right) \\
\text { If } V>160 \text { veh/hr: } W_{v}=W_{O L}+W_{s} \\
\text { If } V_{<} 160 \text { veh/hr: } W_{v}=\left(W_{O L}+W_{s}\right) \times(2-0.005 V) \\
W_{v}=\text { effective width as a function of traffic volume (ft) } \\
\text { WOHP }=\text { outside lane width } \\
V=\text { hourly directional volume }
\end{gathered}
$$

Step three is to calculate the effective speed factor which represents the effects of motor vehicle speed on the cyclist quality of service.

$$
S_{t}=1.1199 \ln \left(S_{p}-20\right)+0.8103
$$




$$
\begin{gathered}
S_{t}=\text { effective speed factor } \\
S_{p}=\text { posted speed limit (mi/hr) }
\end{gathered}
$$

The final step is to calculate and determine the bicycle level of service using the following equation and exhibit 15-4.

$$
\begin{gathered}
\text { BLOS }=0.507 \ln \left(V_{O L}\right)+0.1999 S_{t}(1+10.38 H V)^{2}+7.066(1 / P)^{2}-0.005 W_{e}^{2}+0.057 \\
\text { BLOS }=\text { bicycle level of service score }
\end{gathered}
$$

$\mathrm{HV}=$ percentage of heavy vehicles (decimal)(max of 0.5 if $\mathrm{V}<200 \mathrm{veh} / \mathrm{hr})$

$\mathrm{P}=\mathrm{FHWA}$ 's 5 point pavement surface condition rating (see below chart)

\section{Table: Exhibit 15-4 from HCM 2010}

\begin{tabular}{|c|c|}
\hline Level of Service & Level of Service Score \\
\hline A & $<1.5$ \\
\hline B & $1.5-2.5$ \\
\hline C & $2.5-3.5$ \\
\hline D & $3.5-4.5$ \\
\hline E & $4.5-5.5$ \\
\hline F & $5.5<$ \\
\hline
\end{tabular}


Table: FHWA Pavement Quality Ratings

\begin{tabular}{|c|c|}
\hline Rating & Quality \\
\hline 1 & Very Poor \\
\hline 2 & Poor \\
\hline 3 & Fair \\
\hline 4 & Good \\
\hline 5 & Very Good \\
\hline
\end{tabular}

\section{Automobile Level of Service for Two Way Stop Controlled Intersections:}

The first step is to determine the priority of each direction of travel. This is to allow the engineer to determine what are the most likely areas in an intersection to have conflicts arise. The priorities are listed in order below:

1. Left Turns from the Major Street

2. Right Turns from the Minor Street

3. U Turns from the Major Street

4. Through Movements from the Minor Street

5. Left Turns From the Minor Street

6. Any other Movement

Step two is to convert the movement demand volumes into flow rates. This is done simply by dividing the peak hour demand volume by the peak hour factor. 


$$
\begin{gathered}
\qquad V_{i}=V_{i} / \text { PHF } \\
v_{i}=\text { demand flow rate for movement } i(v e h / h r) \\
V_{i}=\text { demand volume for movement } i(v e h / h r) \\
\text { PHF }=\text { Peak Hour Factor }
\end{gathered}
$$

Step three is to determine conflicting flow rates for the movement of interest. These include pedestrian and bicycle flows, as well. The equations for some of these conflicting movements are listed below either because they are common and serve as a good example for calculating the conflicting rates of other directions or because some of the equations listed have unique multipliers that account for driver behavior. The equations utilize the labeling shown in the below diagram which is taken from the $\mathrm{HCM}$ 2010 (exhibit 19-6).

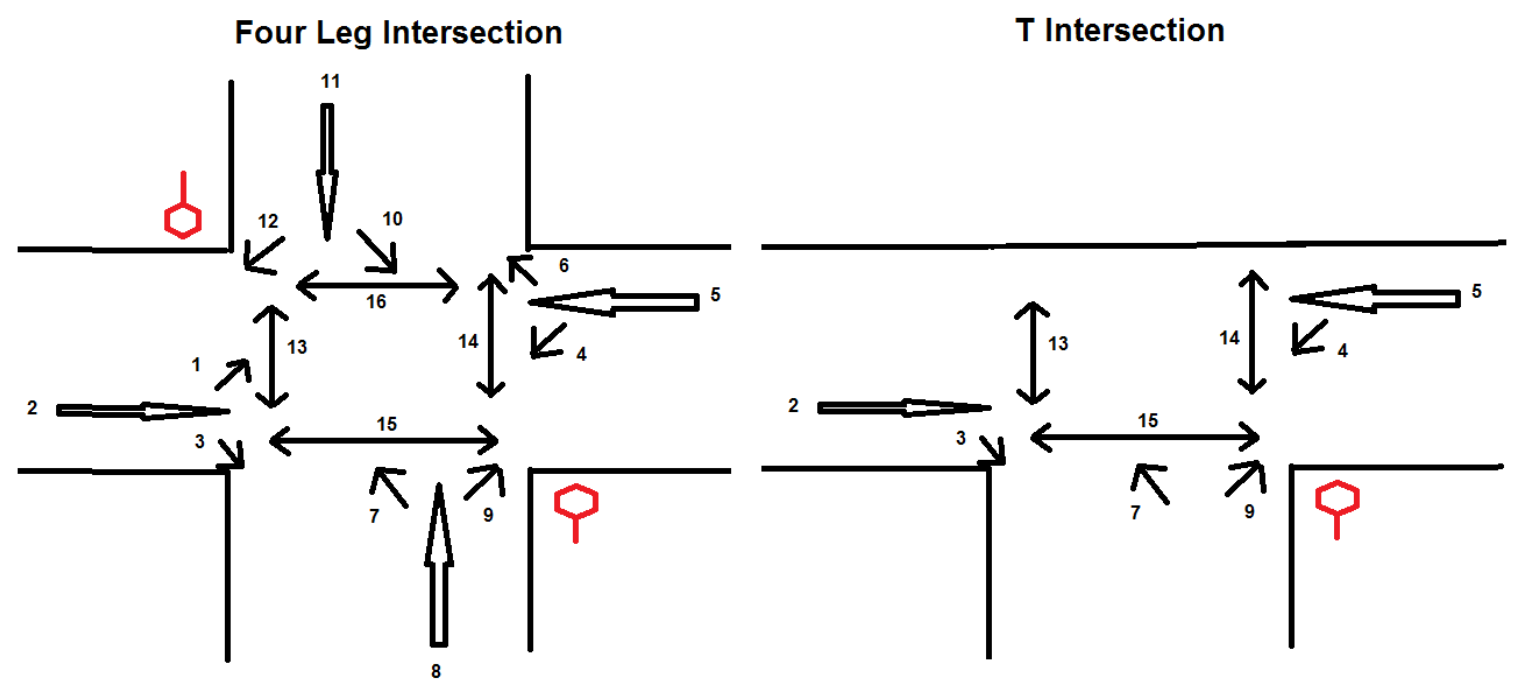

Figure: Exhibit 19-6 from HCM 2010

Notes: vc\# = Conflicting Volume for \# direction 
$\mathrm{vc \# u}=$ Conflicting Volume for $U$ Turn from \# direction

v13 through v16 are pedestrian volumes

$$
\begin{aligned}
& \mathrm{vc} 1=\mathrm{v} 5+\mathrm{v} 6+\mathrm{v} 16 \\
& \mathrm{vc} 4=\mathrm{v} 2+\mathrm{v} 3+\mathrm{v} 15
\end{aligned}
$$

For Two Lane Major Streets:

$$
\begin{aligned}
& \mathrm{vc} 9=\mathrm{v} 2+0.5 \mathrm{v} 3+\mathrm{v} 14+\mathrm{v} 15 \\
& \mathrm{vc} 12=\mathrm{v} 5+0.5 \mathrm{v} 6+\mathrm{v} 13+\mathrm{v} 16
\end{aligned}
$$

For Four Lane Major Streets:

$$
\begin{gathered}
\mathrm{vc9}=0.5 \mathrm{v} 2+0.5 \mathrm{v} 3+\mathrm{v} 14+\mathrm{v} 15 \\
\mathrm{vc12}=0.5 \mathrm{v} 5+0.5 \mathrm{v} 6+\mathrm{v} 13+\mathrm{v} 16 \\
\mathrm{vc1} u=v 5+\mathrm{v} 6 \\
\mathrm{vc4u}=\mathrm{v} 2+\mathrm{v} 3
\end{gathered}
$$


For Six Lane Major Streets:

$$
\begin{gathered}
V_{c} 9=0.5 v 2+0.5 v 3+v 14+v 15 \\
V_{c 12}=0.5 v 5+0.5 v 6+v 13+v 16 \\
V_{c} 1 u=0.73 v 5+0.73 v 6 \\
V_{c} 4 u=0.73 v 2+0.73 v 3
\end{gathered}
$$

Some other movements are more complicated and, in effect, take place in more than one phase. Vehicles crossing the intersection may enter an intersection and stay in the intersection for a length of time, waiting for an acceptable gap in conflicting traffic to complete their turn. This behavior results in multiple equations for what is essentially the same vehicular movement.

Note: vc $\$, \#=$ Conflicting Flow in Phase $\$$ and Direction \#

$$
\begin{gathered}
\mathrm{vcl}, 8=2(\mathrm{v} 1+\mathrm{v} 1 \mathrm{u})+\mathrm{v} 2+0.5 \mathrm{v} 3+\mathrm{v} 15 \\
\mathrm{vcll}, 8=2(\mathrm{v} 4+\mathrm{v} 4 \mathrm{u})+\mathrm{v} 5+\mathrm{v} 6+\mathrm{v} 16 \\
\mathrm{vcl}, 11=2(\mathrm{v} 4+\mathrm{v} 4 \mathrm{u})+\mathrm{v} 5+0.5 \mathrm{v} 6+\mathrm{v} 16 \\
\mathrm{vcll}, 11=2(\mathrm{v} 1+\mathrm{v} 1 \mathrm{u})+\mathrm{v} 2+\mathrm{v} 3+\mathrm{v} 15
\end{gathered}
$$

For Two Lane Major Streets: 


$$
\begin{gathered}
\mathrm{vcl}, 7=2 \mathrm{v} 1+\mathrm{v} 2+0.5+\mathrm{v} 15 \\
\mathrm{vcll}, 7=2 \mathrm{v} 4+\mathrm{v} 5+0.5 \mathrm{v} 6+0.5 \mathrm{v} 12+0.5 \mathrm{v} 11+\mathrm{v} 13 \\
\mathrm{vcl}, 10=2 \mathrm{v} 4+\mathrm{v} 5+0.5 \mathrm{v} 6+\mathrm{v} 16 \\
\mathrm{vcll}, 10=2 \mathrm{v} 1+\mathrm{v} 2+0.5 \mathrm{v} 3+0.5 \mathrm{v} 9+0.5 \mathrm{v} 8+\mathrm{v} 14
\end{gathered}
$$

For Four Lane Major Streets:

$$
\begin{gathered}
\mathrm{vcl}, 7=2(\mathrm{v} 1+\mathrm{v} 1 \mathrm{u})+\mathrm{v} 2+0.5 \mathrm{v} 3+\mathrm{v} 15 \\
\mathrm{vcll}, 7=2(\mathrm{v} 4+\mathrm{v} 4 \mathrm{u})+0.5 \mathrm{v} 5+0.5 \mathrm{v} 11+\mathrm{v} 13 \\
\mathrm{vcl}, 10=2(\mathrm{v} 4+\mathrm{v} 4 \mathrm{u})+\mathrm{v} 5+0.5 \mathrm{v} 6+\mathrm{v} 16
\end{gathered}
$$$$
v c l l, 10=2(v 1+v 1 u)+0.5 v 2+0.5 v 9+0.5 v 8+v 14
$$

For Six Lane Major Streets:

$$
\begin{gathered}
\mathrm{vcl}, 7=2(\mathrm{v} 1+\mathrm{v} 1 \mathrm{u})+\mathrm{v} 2+0.5 \mathrm{v} 3+\mathrm{v} 15 \\
\mathrm{vcll}, 7=2(\mathrm{v} 4+\mathrm{v} 4 \mathrm{u})+0.4 \mathrm{v} 5+0.5 \mathrm{v} 11+\mathrm{v} 13 \\
\mathrm{vcl}, 10=2(\mathrm{v} 4+\mathrm{v} 4 \mathrm{u})+\mathrm{v} 5+0.5 \mathrm{v} 6+\mathrm{v} 16 \\
\mathrm{vcll}, 10=2(\mathrm{v} 1+\mathrm{v} 1 \mathrm{u}) 0.4 \mathrm{v} 2+0.5 \mathrm{v} 8+\mathrm{v} 14
\end{gathered}
$$


Step four is to determine the critical and follow-up headways for the movements. The critical headway can be estimated using the following equation:

$$
T c x=t c b a s e+t c H V^{*} P H V+t^{*}{ }^{*} G-t 3 L T
$$

Where: tcx $=$ critical headway for movement $x(\mathrm{sec})$

tcbase $=$ base critical headway (from Exihibit 19-10 reproduced below from HCM 2010)

tcHV = Heavy Vehicle Factor (Equals 1 if major street has one lane in each direction; Equals 2 if major street has multiple lanes in each direction.)

$$
\text { PHV = Percent Heavy Vehicles (decimal) }
$$

$\operatorname{tcg}=$ Grade Factor (Equals 0.1 for movements 9 and 12; Equals 0.2 for movements 7 ,

$$
\begin{gathered}
\text { 8, 10, and 11) } \\
\mathrm{G}=\text { Percent Grade (integer) }
\end{gathered}
$$

$\mathrm{t} 3 \mathrm{LT}=$ Intersection Geometry Factor (0.7 if minor street left turn movement at $\mathrm{T}$ intersection; 0 for all other scenarios) 
Table: Exhibit 19-10: Base Critical Headway

\begin{tabular}{|c|c|c|c|}
\hline Vehicle Movement & Two Lanes & Four Lanes & Six Lanes \\
\hline $\begin{array}{l}\text { Left turn from } \\
\text { major }\end{array}$ & 4.1 & 4.1 & 5.3 \\
\hline$U$ turn from major & NA & $\begin{array}{r}6.4 \text { (wide) } \\
6.9 \text { (narrow) }\end{array}$ & 5.6 \\
\hline $\begin{array}{l}\text { Right Turn from } \\
\text { minor }\end{array}$ & 6.2 & 6.9 & 7.1 \\
\hline $\begin{array}{l}\text { Through traffic on } \\
\text { minor }\end{array}$ & $\begin{array}{c}\text { 1-stage: } 6.5 \\
\text { 2-stage, stage 1: } \\
5.5 \\
\text { Stage 2: } 5.5\end{array}$ & $\begin{array}{c}\text { 1-stage: } 6.5 \\
\text { 2-stage, stage 1: } \\
5.5 \\
\text { Stage 2: } 5.5\end{array}$ & $\begin{array}{c}\text { 1-stage: } 6.5 \\
\text { 2-stage, stage 1: } \\
5.5 \\
\text { Stage 2: } 5.5\end{array}$ \\
\hline $\begin{array}{l}\text { Left turn from } \\
\text { minor }\end{array}$ & $\begin{array}{c}\text { 1-stage: } 7.1 \\
\text { 2-stage, stage 1: } \\
6.1 \\
\text { Stage } 2: 6.1\end{array}$ & $\begin{array}{c}\text { 1-stage: } 7.5 \\
\text { 2-stage, stage 1: } \\
6.5 \\
\text { Stage 2: } 6.5\end{array}$ & $\begin{array}{c}\text { 1-stage: } 6.4 \\
\text { 2-stage, stage 1: } \\
7.3 \\
\text { Stage 2: } 6.7\end{array}$ \\
\hline
\end{tabular}

The follow-up headway can be determined from a separate equation:

$$
\mathrm{tfx}=\mathrm{tfbase}+\mathrm{tfHV} \text { PHV }
$$

Where: $\mathrm{tfx}=$ follow-up headway for movement $\mathrm{x}(\mathrm{sec})$

tfbase $=$ base follow up headway (from Exhibit 19-11 reproduced below from HCM 2010)

$\mathrm{tfHV}=$ Heavy Vehicle Factor (Equals 0.9 if major street has one lane in each direction; Equals 1 otherwise)

PHV $=$ Percent Heavy Vehicles for movement $x$ 
Table: Exhibit 19-11 from HCM 2010: Base Follow Up Headway

\begin{tabular}{|c|c|c|c|}
\hline Vehicle Movement & 2 Lanes & 4 Lanes & 6 Lanes \\
\hline $\begin{array}{c}\text { Left Turn from } \\
\text { Major }\end{array}$ & 2.2 & 2.2 & 3.1 \\
\hline $\begin{array}{c}\text { U Turn from Major } \\
\text { Right Turn from } \\
\text { minor }\end{array}$ & 3.3 & $\begin{array}{c}2.5 \text { (wide) } \\
3.1 \text { (narrow) }\end{array}$ & 3.3 \\
\hline $\begin{array}{c}\text { Through traffic on } \\
\text { minor }\end{array}$ & 4 & 3.3 & 4 \\
\hline $\begin{array}{c}\text { Left Turn from } \\
\text { minor }\end{array}$ & 3.5 & 3.5 & 3.8 \\
\hline
\end{tabular}

The fifth step in this procedure is to evaluate the potential capacities of the roadways.

The capacities are determined from the following equation:

$$
C_{p, x}=v_{c, x}\left[e^{-v c, x t c, x / 3600} /\left(1-e^{-v c, x t, x / 3600}\right)\right]
$$

Where: $C_{p, x}=$ the potential capacity of movement $x(v e h / h r)$

$$
\begin{gathered}
\mathrm{V}_{\mathrm{c}, \mathrm{x}}=\text { the conflicting flow rate for movement } \mathrm{x}(\mathrm{veh} / \mathrm{hr}) \\
\mathrm{t}_{\mathrm{c}, \mathrm{x}}=\text { the critical headway for the minor movement } \mathrm{x}(\mathrm{sec}) \\
\mathrm{t}_{\mathrm{f}, \mathrm{x}}=\text { the follow-up headway for the minor movement } \mathrm{x}(\mathrm{sec})
\end{gathered}
$$

Now we get to the point where we must examine the effects of upstream signals or coordinated signals on our intersection. To make this procedure even more complex, we must remember to consider the effects of multiple stage movements (mentioned 
earlier in this paper) in which the act of traversing a single intersection takes place in multiple phases. The proportion of time blocked is designated by $p_{x, \#}$. A list of which of these factors apply to what movement is detailed in Exhibit 19-12.

Table: Exhibit 19-12 from HCM 2010: Proportion Blocked for Movement

\begin{tabular}{|c|c|c|c|}
\hline Movement & 1 Stage & $1^{\text {st }}$ Stage & $2^{\text {nd }}$ Stage \\
\hline $1,1 \mathrm{U}$ & $\mathrm{P}_{\mathrm{B}, 1}$ & $\mathrm{NA}$ & $\mathrm{NA}$ \\
\hline $4,4 \mathrm{U}$ & $\mathrm{P}_{\mathrm{B}, 4}$ & $\mathrm{NA}$ & $\mathrm{NA}$ \\
\hline 7 & $\mathrm{P}_{\mathrm{B}, 7}$ & $\mathrm{P}_{\mathrm{B}, 4}$ & $\mathrm{P}_{\mathrm{B}, 1}$ \\
\hline 8 & $\mathrm{P}_{\mathrm{B}, 8}$ & $\mathrm{P}_{\mathrm{B}, 4}$ & $\mathrm{P}_{\mathrm{B}, 1}$ \\
\hline 9 & $\mathrm{P}_{\mathrm{B}, 9}$ & $\mathrm{NA}$ & $\mathrm{NA}$ \\
\hline 10 & $\mathrm{P}_{\mathrm{B}, 10}$ & $\mathrm{P}_{\mathrm{B}, 1}$ & $\mathrm{P}_{\mathrm{B}, 4}$ \\
\hline 11 & $\mathrm{P}_{\mathrm{B} 11}$ & $\mathrm{P}_{\mathrm{B}, 1}$ & $\mathrm{P}_{\mathrm{B}, 4}$ \\
\hline 12 & $\mathrm{P}_{\mathrm{B}, 12}$ & $\mathrm{NA}$ & $\mathrm{NA}$ \\
\hline
\end{tabular}

The conflicting flow for each movement during the period of time that is unblocked can be determined with the equation: $v_{c, u, x}=\left[v_{c, x}-1.5 v_{c, m i n} p_{b, x}\right] /\left[1-p_{b, x}\right]$ However, this applies only if $\mathrm{v}_{\mathrm{c}, \mathrm{x}}$ is greater than $1.5 \mathrm{v}_{\mathrm{c}, \min } \mathrm{p}_{\mathrm{b}, \mathrm{x}}$ so that the numerator is positive. If this is not the case, then the conflicting flow is taken to be zero.

Note: $v_{c, u, x}=$ conflicting flow for movement $x$ during the unblocked period (veh/hr)

$\mathrm{v}_{\mathrm{c}, \mathrm{x}}=$ the total conflicting flow for movement $\mathrm{x}$ that was determined from step 3 above (veh/hr)

$\mathrm{v}_{\mathrm{c}, \min }=$ minimum platooned flow rate $(\mathrm{veh} / \mathrm{hr}) ;$ Equals $1000 \mathrm{~N}$

$\mathrm{N}=$ Number of through lanes in each direction on the major street

$\mathrm{p}_{\mathrm{b}, \mathrm{x}}=$ the proportion of time the movement $\mathrm{x}$ is blocked by the major street platoon (Exhibit 19-12) 
Now, with the upstream signal effects we use the following equations to determine the effective capacities of the intersection.

$$
\begin{gathered}
C_{p, x}=\left(1-p_{b, x}\right) c_{t, x} \\
C_{t, x}=v_{c, u, x}\left[e^{-v c, u, x t c, x / 3600} /\left(1-e^{-v c, u, x t f, x / 3600}\right)\right]
\end{gathered}
$$

Where: $C_{p, x}=$ the potential capacity of movement $x(v e h / h r)$

$$
p_{p, x}=\text { the proportion of time that movement } x \text { is blocked by a platoon }
$$

$\mathrm{C}_{r, \mathrm{x}}=$ the capacity of movement $\mathrm{x}$ with unplatooned flow during the unblocked period

This equation is then used individually for all possible movements at the intersection.

U-turn movements are considered with a few extra steps beyond this equation.

$$
\begin{gathered}
F_{1 u}=p_{0,12}=1-v_{12} / c_{m, 12} \\
F_{4 u}=p_{0,9}=1-v_{9} / c_{m, 9}
\end{gathered}
$$

Where:

$F_{\text {iu }}=$ capacity adjustment factor for rank 2 major street $u$ turn movements

$\mathrm{P}_{0, \mathrm{j}}=$ probability that conflicting rank 2 minor street right turn movment $\mathrm{j}$ will operate in a queue free state

$V_{j}=$ flow rate of movement $j$ 
$\mathrm{C}_{\mathrm{m}, \mathrm{j}}=$ capacity of movement $\mathrm{j}$

$\mathrm{J}=9$ and 12 (minor street movements of rank 2)

The movement capacity for major street $u$ turn movements is then computed with equation 19-40:

$$
C_{m, j u}=\left(C_{P, J u}\right) F_{J U}
$$

Where:

$\mathrm{C}_{\mathrm{m}, \mathrm{ju}}=$ movement capacity for movements $1 \mathrm{u}$ and $4 \mathrm{u}$

$\mathrm{C}_{\mathrm{p}, \mathrm{ju}}=$ potential capacity for movments $1 \mathrm{u}$ and $4 \mathrm{u}$

$F_{j u}=$ capacity adjustment factor for movements $1 \mathrm{u}$ and $4 \mathrm{u}$

Since the left turn and $u$ turn movments are typically conducted from the same lane, their shared lane capacity is computed with equation 19-41:

$$
\mathrm{C}_{\mathrm{sh}}=\operatorname{Sum}\left[\mathrm{v}_{\mathrm{y}}\right] / \operatorname{Sum}\left[\mathrm{v}_{\mathrm{y}} / \mathrm{C}_{\mathrm{m}, \mathrm{y}}\right]
$$

Where: $\mathrm{C}_{\mathrm{SH}}=$ the capacity of the shared lane $(\mathrm{veh} / \mathrm{hr})$

$$
\mathrm{v}_{\mathrm{y}}=\text { flow rate of the } \mathrm{y} \text { movement in the shared lane }(\mathrm{veh} / \mathrm{hr})
$$

$c_{m, y}=$ movement capacity of the $y$ movement in the shared lane $(\mathrm{veh} / \mathrm{hr})$ 
If the major street has does not have a left lane that is a shared left turn and through lane or a designated left turn lane, then the probability of not having a queue build up in that lane is expressed as:

$$
P_{o, j}=1-v_{j} / c_{m, j}
$$

Note: j usually equals 1 or 4

On the opposite scenario, if a left turn pocket or shared left turn lane exists, then the following equation is used to calculate the probability of having no queue waiting on the street:

$$
\begin{gathered}
\mathrm{P}^{*}{ }_{0, \mathrm{j}}=1-\left(1-\mathrm{p}_{0, \mathrm{j}}\right)\left[(\mathrm{nl}+1)\left(1+\mathrm{X}_{\mathrm{i}, 1+2}{ }^{\mathrm{nl}+1} /\left(1-\mathrm{x}_{\mathrm{i}, 1+2}\right)\right)^{\wedge}(1 / 2)\right] \\
\mathrm{X}_{\mathrm{i}, 1+2}=\mathrm{v}_{\mathrm{i} 1} / \mathrm{s}_{\mathrm{i} 1}+\mathrm{v}_{\mathrm{i} 2} / \mathrm{s}_{\mathrm{i} 2}
\end{gathered}
$$

Where:

$P_{0, j}=$ probability of queue free state for movement $j$ assuming an exclusive left turn lane on the major street

$\mathrm{J}=1$ and 4 (major street turn movements)

$11=2$ and 5 (major street through movements)

12 = 3 and 6 (major street right turning movements)

$\mathrm{X}_{\mathrm{i}, 1+2}=$ combined degree of saturation for the major street through and right turn movements 
$S_{i 1}=$ saturation flow rate for the major street through movements (default assumed to be $1800 \mathrm{veh} / \mathrm{hr}$, however, this parameter can be measured in the field

$S_{i 2}=$ saturation flow rate for the major right turn movements (default assumed to be $1500 \mathrm{veh} / \mathrm{hr}$, however, this parameter can be measured in the field

$\mathrm{V}_{\mathrm{i} 1}=$ major street through movement $(\mathrm{veh} / \mathrm{hr})$

$\mathrm{V}_{\mathrm{i} 2}=$ major street right turn flow rate $(\mathrm{veh} / \mathrm{hr})(0$ if an exclusive right turn lane is provided)

$N_{I}=$ storage places in the left turn pocket

For shared lanes, the equation becomes:

$$
P^{*}{ }_{0, j}=1-\left(1-p_{0, j}\right) /\left(1-x_{i, 1+2}\right)
$$

Step eight is to compute the next rank of movement capacities. These are the minor street left and through movements which must yield to the major street movements. These capacities are determined from the product of all probabilities of the possible movements experiencing a queue free scenario.

$$
\begin{gathered}
\mathrm{F}_{\mathrm{k}}=\prod \mathrm{p}_{\mathrm{o}, \mathrm{j}} \\
\mathrm{F}_{\mathrm{k}}=\text { The capacity adjustment factor for all rank } 3 \text { movements }
\end{gathered}
$$


$\mathrm{p}_{\mathrm{o}^{\prime j}}=$ The Probability that rank 2 movements will operate in a queue free manner to allow a break in traffic for movement 3 vehicles to complete their transgression of the intersection.

$F_{k}$ is then multiplied by $C_{p, k}$ to obtain the adjusted capacity. If there is a two stage movement style action undertaken by a vehicle in the intersection for a rank 3 movement, then a different formula is used to calculate the adjusted capacity.

$$
\begin{gathered}
A=1-0.32 e^{-1.3(n m)^{\wedge} / 2} \text { for } n m>0 \\
Y=\left[c_{i}-c_{m, x}\right] /\left(c_{\|}-v_{L}-c_{m, x}\right)
\end{gathered}
$$

Where:

$\mathrm{Nm}=$ number of storage spaces in the median

$C_{j}=$ movement capacity for the stage 1 process $(v e h / h r)$

$\mathrm{C}_{\|}=$movement capacity for the stage 2 process $(\mathrm{veh} / \mathrm{hr})$

$V_{1}=$ major left turn or $u$ turn flow rate, either $v_{1}+v_{1 u}$ or $v_{4}+v_{4 u}(v e h / h)$

$\mathrm{C}_{\mathrm{m}, \mathrm{x}}=$ capacity of subject movement, considering the total conflicting flow rate for both stages of a two stage gap acceptance process

For y not equal to $1: c_{t}=a /\left(y^{n m+1}-1\right)\left[y\left(y^{n m}-1\right)\left(c_{h}-v_{l}\right)+(y-1) c_{m, x}\right]$

For $y=1: c_{t}=a /\left(n_{m}+1\right)\left[n_{m}\left(c_{\|}-v_{l}\right)+{ }_{c} m, x\right]$ 
Step nine is to compute the rank 4 movement type capacities. Once again, these depend on the probability of operating in a queue free state, and, queuing in one traffic direction can induce queuing in one of the lesser priority travel directions so we have to be careful to account for multiple causes of vehicle delay from queuing.

$$
P^{\prime}=0.65 p^{\prime \prime}-p^{\prime \prime} /\left(p^{\prime \prime}+3\right)+0.6\left(p^{\prime \prime}\right)^{(1 / 2)}
$$

Where:

$\mathrm{P}^{\prime}=$ adjustment to the major street left, minor street through impedance factor

$P^{\prime \prime}=\left(p_{0, j}\right)\left(p_{0, k}\right)$

$P_{0, j}=$ probability of a queue free state for the conflicting major street left turning traffic

$P_{0, k}=$ probability of a queue free state for the conflicting minor street crossing traffic

When determining p' for rank 4 movement 7 in equation 19-53:

$P^{\prime \prime}=\left(p_{0,1}\right)\left(p_{0,4}\right)\left(p_{0,11}\right)$ Likewise when determining $p^{\prime}$ for rank 4 movement 10

$P^{\prime \prime}=\left(p_{0,1}\right)\left(p_{0,4}\right)\left(p_{0,8}\right)$

The relationship between p' and p" can be determined graphically from Exhibit 19-14 of the HCM, reproduced below: 


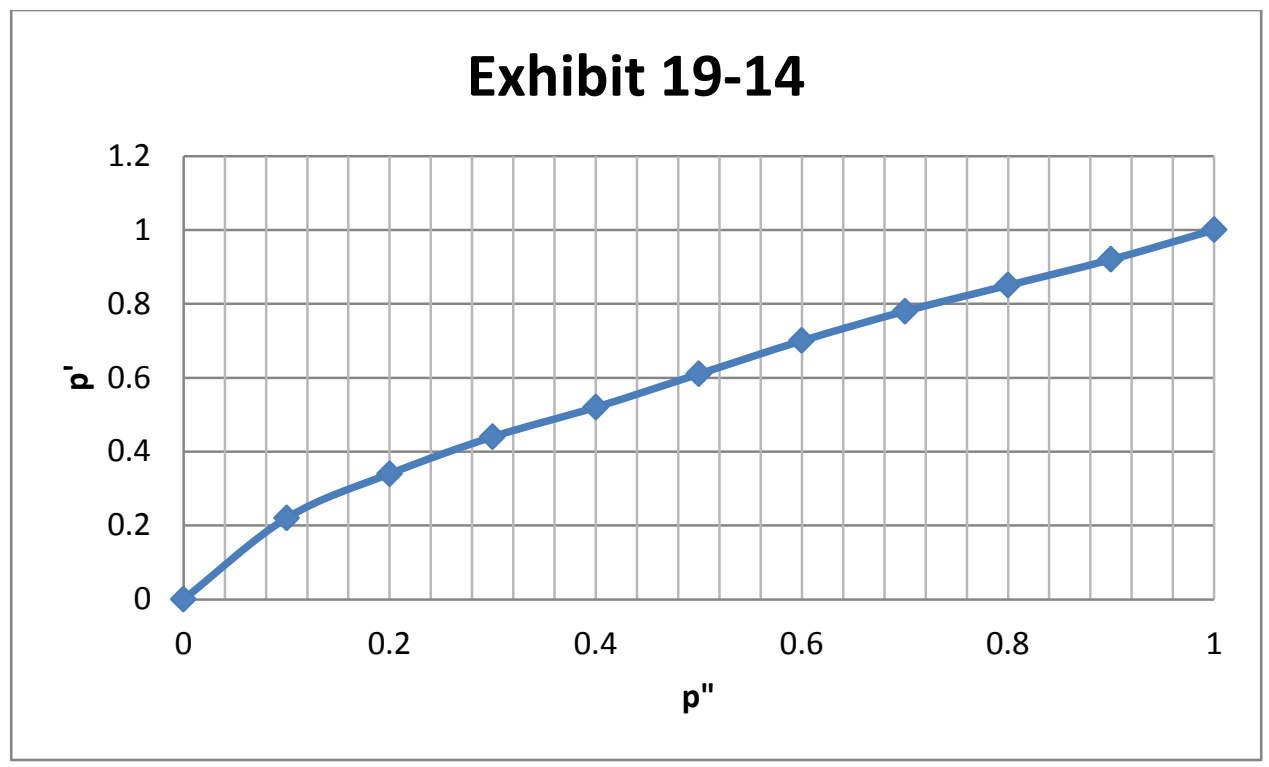

Figure 6: Exhibit 19-14 from HCM 2010

The adjustment factor $F_{p, l}$ is calculated by multiplying $p^{\prime}$ by $p_{0, j} . \quad F_{p, l}$ is then multiplied by $\mathrm{C}_{p, \mathrm{I}}$ to determine the adjusted capacity for rank 4 movements. If a two stage behavior is observed, then the capacity must be calculated using a similar process from step eight (essentially the same set of equations).

$$
\begin{gathered}
A=1-0.32 e^{-1.3(n m)^{\wedge}(1 / 2)} \text { for } n m>0 \\
Y=\left(c_{i}-c_{m, x}\right) /\left(c_{\|}-V_{l}-c_{m, x}\right)
\end{gathered}
$$

Where:

$\mathrm{N}_{\mathrm{m}}=$ number of storage spaces in the median

$C_{i}=$ movement capacity for the stage 1 process $(v e h / h r)$

$\mathrm{C}_{\|}=$movement capacity for the stage 3 process $(\mathrm{veh} / \mathrm{hr})$

$V_{1}=$ major left turn or $u$ turn flow rate, either $v_{1}+v_{1 u}$ or $v_{4}+v_{4 u}(v e h / h r)$ 
$\mathrm{C}_{\mathrm{m}, \mathrm{x}}=$ capacity of subject movement, considering the total conflicting flow rate for both stages of a two stage gap acceptance process

$$
\begin{aligned}
& \text { For y not equal to } 1: c_{t}=a /\left(y^{n m+1}-1\right)\left[y\left(y^{n m}-1\right)\left(c_{\|}-v_{L}\right)+(y-1) c_{m, x}\right] \\
& \qquad \text { For } y=1: c_{t}=a /\left(n_{m}+1\right)\left[n_{m}\left(c_{\|}-v_{L}\right)+c_{m, x}\right]
\end{aligned}
$$

Step ten is to perform the final capacity adjustments to the model. If different movements share the same lane, this must be accounted for using the equation:

$$
\mathrm{C}_{\mathrm{sh}}=\operatorname{Sum}\left[\mathrm{v}_{\mathrm{y}}\right] / \operatorname{Sum}\left[\mathrm{v}_{\mathrm{y}} / \mathrm{c}_{\mathrm{m}, \mathrm{y}}\right]
$$

$$
\begin{gathered}
\text { Where: } \mathrm{C}_{\mathrm{SH}}=\text { the capacity of the shared lane }(\mathrm{veh} / \mathrm{hr}) \\
\mathrm{v}_{\mathrm{y}}=\text { flow rate of the } \mathrm{y} \text { movement in the shared lane }(\mathrm{veh} / \mathrm{hr}) \\
\mathrm{c}_{\mathrm{m}, \mathrm{y}}=\text { movement capacity of the } \mathrm{y} \text { movement in the shared lane }(\mathrm{veh} / \mathrm{hr})
\end{gathered}
$$

If a right turn lane has a flared style corner, this must also be accounted for in the queue length estimate. 

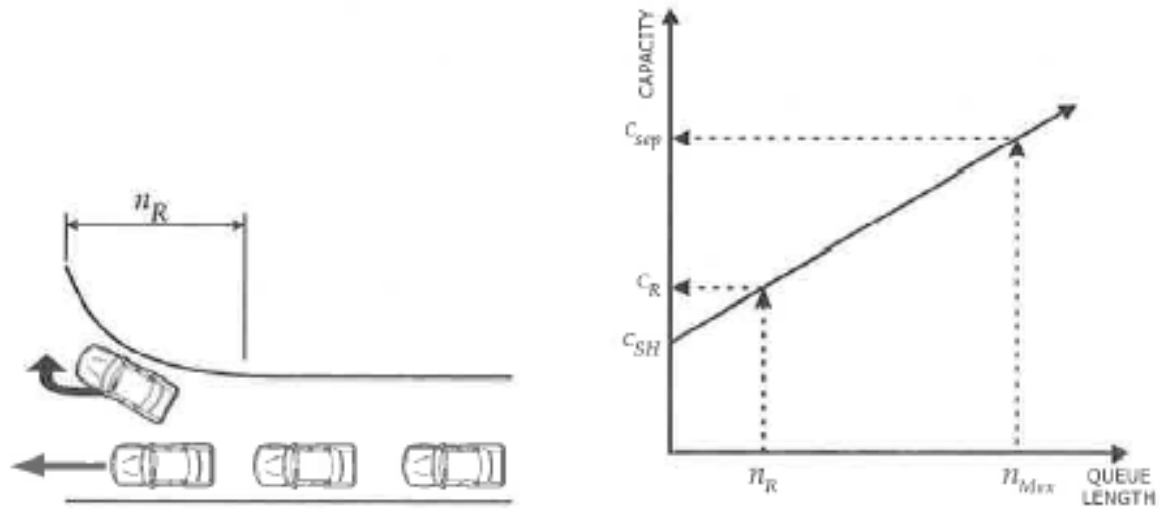

Figure: Exhibit 19-15 from HCM 2010

$$
Q_{\text {sep }}=d_{\text {sep }} v_{\text {sep }} / 3600
$$

$Q_{\text {sep }}=$ average queue length for the movement considered as a separate lane (veh/hr)

$D_{\text {sep }}=$ control delay for the movement considered as a separate lane

$\mathrm{V}_{\mathrm{sep}}=$ flow rate for the movement $(\mathrm{veh} / \mathrm{hr})$

The next part of this procedure is to determine the necessary length of the vehicle storage area that is needed to allow for effective operation of the intersection.

$$
N_{\max }=\operatorname{Max}\left[\operatorname{round}\left(Q_{\text {sep }}+1\right)\right]
$$

Where:

$Q_{\text {sep }}=$ average queue length for movement I considered as a separate lane

Round = round off operator, rounding the quantity in parentheses to the nearest integer 
$\mathrm{N}_{\text {Max }}$ = length of the storage area such that the approach would operate as separate lanes

To compare, the capacity of an additional theoretical lane is then calculated to see how well the median storage area operates at containing vehicular flow.

$$
\mathrm{C}_{\text {sep }}=\operatorname{Min}\left[\mathrm{C}_{\mathrm{r}}\left(1+\mathrm{v}_{1+\mathrm{th}} / \mathrm{v}_{\mathrm{r}}\right), \mathrm{C}_{1+\mathrm{th}}\left(1+\mathrm{v}_{\mathrm{r}} / \mathrm{V}_{1+\mathrm{th}}\right)\right]
$$

Where:

$\mathrm{C}_{\text {sep }}=$ sum of the capacities of the right turning traffic operating as a separate lane and the capacity of the other traffic in the right lane (upstream of the flare) operating in the separate lane $(\mathrm{veh} / \mathrm{hr})$

$\mathrm{C}_{\mathrm{r}}=$ capacity of the right turn movment $(\mathrm{veh} / \mathrm{hr})$

$\mathrm{C}_{\mathrm{I}_{+} \text {th }}=$ capacity of the through and left turn movements as a shared lane (veh/hr)

$\mathrm{V}_{\mathrm{r}}=$ right turn movement flow rate $(\mathrm{veh} / \mathrm{hr})$

$\mathrm{V}_{1+\text { th }}=$ through and left turn movement combined flow rate (veh/hr)

Then the capacity of the lane is computed taking all of these above factors into account.

$$
\begin{gathered}
\mathrm{C}_{\mathrm{r}}=\left(\mathrm{c}_{\text {sep }}-\mathrm{C}_{\text {sh }}\right)\left(\mathrm{n}_{\mathrm{r}} / \mathrm{n}_{\max }\right)+\mathrm{C}_{\text {sh }} \text { if } \mathrm{n}_{\mathrm{r}}<\mathrm{n}_{\max } \\
\mathrm{C}_{\mathrm{r}}=\mathrm{c}_{\text {sep }} \text { if } \mathrm{n}_{\mathrm{r}}>\mathrm{n}_{\max }
\end{gathered}
$$


Where:

$\mathrm{C}_{\mathrm{r}}=$ actual capacity of the flared lane $(\mathrm{veh} / \mathrm{hr})$

$\mathrm{C}_{\text {sep }}=$ capacity of the lane if both storage areas were infinitely long

$\mathrm{C}_{\text {sh }}=$ capacity of the lane when all traffic is sharing one lane

$\mathrm{N}_{\mathrm{r}}=$ actual storage are for right turning vehicles

The actual capacity $c_{n e t}$ must be greater than $c_{s h}$ but less than or equal to $c_{\text {sep }}$.

Step eleven is to calculate the movement control delay. This consist of the time a driver experiences in decelerating, waiting, and then accelerating again back to the free flow speed at the intersection. It is first calculated for the rank 2 through 4 movements using the following equation from the $\mathrm{HCM}$ :

$$
\mathrm{D}=3600 / \mathrm{c}_{\mathrm{m}, \mathrm{x}}+900 T\left[\left(\mathrm{v}_{\mathrm{x}} / \mathrm{c}_{\mathrm{m}, \mathrm{x}}\right)-1+\left(\left(\mathrm{v}_{\mathrm{x}} / \mathrm{c}_{\mathrm{m}, \mathrm{x}}-1\right)^{2}+\left(\left(3600 / \mathrm{c}_{\mathrm{m}, \mathrm{x}}\right)\left(\mathrm{v}_{\mathrm{x}} / \mathrm{c}_{\mathrm{m}, \mathrm{x}}\right) / 450 \mathrm{~T}\right)\right)^{(1 / 2)}\right]+5
$$

Where:

$\mathrm{D}=$ control delay $(\mathrm{s} / \mathrm{veh})$

$V_{x}=$ flow rate for movement $x(v e h / h r)$

$\mathrm{C}_{\mathrm{m}, \mathrm{x}}=$ capacity of movement $\mathrm{x}(\mathrm{veh} / \mathrm{hr})$

$\mathrm{T}=$ analysis time period $(=0.25$ for 15 minute period $)$ 
Please note that the +5 on the end of this equation is to account for vehicle deceleration and acceleration. It is an assumed constant and may differ from the specific field scenario depending on the location. If possible, a field analysis of the intersection in question is desired to provide this constant, but it can be very difficult to estimate even in the field.

Now the rank 1 movement control delay can be estimated using a separate equation:

$$
\begin{gathered}
D_{\text {rank1 }}=\left(1-\mathrm{p}^{*}{ }_{0, j}\right) \mathrm{d}_{\mathrm{M}, \mathrm{LT}}\left(\mathrm{v}_{\mathrm{i}, 1} / \mathrm{N}\right) /\left(\mathrm{v}_{\mathrm{i}, 1}+\mathrm{v}_{\mathrm{i}, 2}\right) \text { for } \mathrm{N}>1 \\
D_{\text {rank1 }}=\left(1-\mathrm{p}^{*}{ }_{0, \mathrm{j}}\right) \mathrm{d}_{\mathrm{M}, \mathrm{LT}} \text { for } \mathrm{N}=1
\end{gathered}
$$

Where:

$D_{\text {rank1 }}=$ delay to rank 1 vehicles $(\mathrm{s} /$ veh $)$

$\mathrm{N}=$ number of through lanes per direction on the major street

$\mathrm{P}^{*}{ }_{0, \mathrm{j}}=$ proportion of rank 1 vehicles not blocked

$D_{M, L T}=$ delay to major left turning vehicles

$\mathrm{V}_{\mathrm{i}, 1}=$ major street through vehicles in shared lane

$\mathrm{V}_{\mathrm{i}, 2}=$ major street turning vehicles in shared lane

The twelfth step is to compute the approach and intersection control delay. These are handled respectively by the following two equations:

$$
D_{a}=\left(d_{r} v_{r}+d_{t} v_{t}+d_{l} v_{l}\right) /\left(v_{r}+v_{t}+v_{l}\right)
$$




$$
D_{i}=\left(d_{a, 1} v_{a, 1}+d_{a, 2} v_{a, 2}+d_{a, 3} v_{a, 3}+d_{a, 4} v_{a, 4}\right) /\left(v_{a, 1}+v_{a, 2}+v_{a, 3}+v_{a, 4}\right)
$$

Where:

$\mathrm{D}_{\mathrm{a}}=$ control delay on the approach (s/veh)

$D_{r}, d_{t}, d_{l}=$ computed control delay for the right turn, through and left turn movements $V_{r}, V_{t}, V_{l}=$ volume or flow rate of right turn, through, and left turn traffic on the approach $\mathrm{D}_{\mathrm{a}, \mathrm{x}}=$ control delay on approach $\mathrm{x}(\mathrm{s} / \mathrm{veh})$

$\mathrm{V}_{\mathrm{a}, \mathrm{x}}=$ volume or flow rate on approach $\mathrm{x}(\mathrm{veh} / \mathrm{hr})$

Please note that the delay for all major street rank 1 movements is assumed to be zero seconds per vehicle. Total intersection delay is usually only used to compare the intersection in question to others similar to it or to evaluate different traffic control alternatives. Movement delays are, of course, used to determine the level of service rating from Exhibit 19-1 (reproduced below)

Table: Exhibit 19-1 from HCM 2010: LOS

\begin{tabular}{|c|c|c|}
\hline Control Delay & V/C $<1$ & v/C 1 \\
\hline $0-10$ & A & F \\
\hline $10-15$ & B & F \\
\hline $15-25$ & C & F \\
\hline $25-35$ & D & F \\
\hline $35-50$ & E & F \\
\hline $50+$ & F & \\
\hline
\end{tabular}


Step thirteen is to compute the queue lengths. This is done for the estimated $95^{\text {th }}$ percentile queue.

$$
Q_{95}=900 T\left[\left(v_{x} / c_{m, x}\right)-1+\left(\left(v_{x} / c_{m, x}-1\right)^{2}+\left(3600 / c_{m, x}\right)\left(v_{x} / c_{m, x}\right) / 150 T\right)^{0.5}\right]\left(c_{m, x} / 3600\right)
$$

Where:

$Q_{95}=95^{\text {th }}$ percentile queue (veh)

$V_{x}=$ flow rate for movement $x$

$\mathrm{C}_{\mathrm{m}, \mathrm{x}}=$ capacity of movement $\mathrm{x}$

$\mathrm{T}=$ analysis time period 


\section{Appendix B}

Sample calculations for comparing existing level of service methodologies with collected survey responses are provided in the following. 


\section{Signalized Intersection:}

Intersection: West Linden Street and Douglass Avenue, Riverside California

Signalized Intersection Method- Eastbound Through Movement

$$
\text { Lane width }=18^{\prime}
$$

No bike lane or shoulder present.

$$
\begin{gathered}
\text { Wt }=18^{\prime}+0^{\prime} \\
\text { Total Width }=36^{\prime} \\
\text { FW }=0.0153^{\star} 36^{\prime}-0.2144^{\star} 18^{\prime}=-3.4922 \\
\text { Vleft }=0 \\
\text { Vthrough }=107 \text { veh } / h^{\prime} \\
\text { Vright }=19 \text { veh } / h^{\prime} \\
\text { Nlanes }=1 \\
\text { Fv }=0.0066^{*}(107+19+0) /\left(4^{*} 1\right)=0.051975 \\
\text { lb,int }=4.1324+0.051975-3.4922=0.676088 \\
\text { LOS }=\text { A } \\
\text { LOS obtained from survey }=\mathrm{E}
\end{gathered}
$$

Answers do not match. 


\section{All Way Stop Controlled Intersection:}

Sample Calculation:

Intersection: West Linden Street and Douglass Avenue, Riverside California

All Way Stop Controlled Intersection Method- Eastbound Through Movement

$$
\begin{gathered}
\mathrm{Vi}=\mathrm{V} / \mathrm{PHF} \\
107 / 0.85=125.8
\end{gathered}
$$

Group Geometry = Group 1for this movement

$$
\begin{gathered}
\mathrm{Plt}=0.0 \\
\mathrm{Prt}=0.15 \\
\mathrm{Phv}=0.03 \\
\mathrm{Hlt}=0.2 \\
\mathrm{Hrt}=-0.7 \\
\mathrm{Hhv}=1.7 \\
\mathrm{Hadj}=\mathrm{Plt}{ }^{*} \mathrm{HIt}+\mathrm{Prt}{ }^{*} \mathrm{Hrt}+\mathrm{Phv}{ }^{*} \mathrm{Hhv}=5.01 \\
\mathrm{X}=\mathrm{vh} / 3600 \\
\mathrm{X}=125.8{ }^{*} 3.2 / 3600=0.1119 \\
\text { His }=\text { Hbase }+ \text { Hadj }
\end{gathered}
$$


(skipping writing out the individual probability iteration which was done in Microsoft Excel)

$$
\begin{gathered}
\text { Hbase }=3.9 \text { for Group } 1 \\
\text { His }=5.01+3.9=8.91 \\
\text { Hd } \sim \text { His } \\
\text { Ts }=\text { Hd }-\mathrm{m} \\
\mathrm{m}=2 \\
\text { Ts }=8.91-2=6.91 \\
\mathrm{~d}=\mathrm{t}_{\mathrm{s}}+900 \mathrm{~T}\left[(\mathrm{x}-1)+\left((\mathrm{x}-1)^{2}+\left(\mathrm{h}_{\mathrm{d}} \mathrm{x} / 450 \mathrm{~T}\right)\right)^{0.5}\right]+5 \\
\mathrm{~T}=1 \\
\mathrm{~d}=6.91+900 \text { * }\left[(0.1119-1)+\left((0.1119-1)^{2}+\left(8.91{ }^{*} 0.1119 / 450\right)\right)^{0.5}\right]+5=13.03 \\
\text { Number of Lanes }=1 \\
\text { Movement LOS }=\mathrm{B} \\
\text { Average Reviewers' LOS }=\mathrm{E} \\
\text { Answers Do Not Match }
\end{gathered}
$$




\section{Uninterrupted Flow Facilities:}

Intersection: West Linden Street and Douglass Avenue, Riverside California Uninterrupted Flow Facility Method- Eastbound Through Movement

$$
\begin{gathered}
\mathrm{V}_{\mathrm{OL}}=\mathrm{V} /(\mathrm{PHF} \times \mathrm{N}) \\
107 /\left(0.85^{\star} 1\right)=125.8 \mathrm{veh} / \mathrm{hr}
\end{gathered}
$$

If $\mathrm{V}>160 \mathrm{veh} / \mathrm{hr}: \mathrm{W}_{\mathrm{v}}=\mathrm{W}_{\mathrm{OL}}+\mathrm{W}_{\mathrm{s}}$

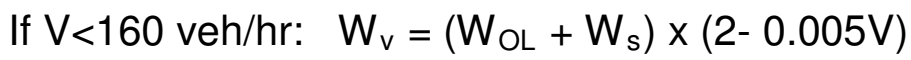

$$
\begin{gathered}
\mathrm{W}_{\mathrm{OL}}=18 \\
\mathrm{~W}_{\mathrm{s}}=0
\end{gathered}
$$

$W_{v} 18^{\prime}{ }^{*}(2-0.005(125.8))=26.37$

If $W_{s}<4 \mathrm{ft}: \quad W_{e}=W_{v}+\left(\% O H P\left(2 f t+W_{s}\right)\right)$

$\% \mathrm{OHP}=100 \%$ at this intersection

$$
\begin{gathered}
26.37+1(2)=28.37=W_{e} \\
S_{t}=1.1199 \ln \left(S_{p}-20\right)+0.8103 \\
S_{p}=30 \\
1.1199 \ln (30-20)+0.8103=3.389=S_{t}
\end{gathered}
$$

BLOS $=0.507 \ln \left(V_{O L}\right)+0.1999 S_{t}(1+10.38 H V)^{2}+7.066(1 / P)^{2}-0.005 W_{e}{ }^{2}+0.057$ 


$$
\begin{gathered}
\mathrm{HV}=0.03 \\
\mathrm{P}=2 \\
0.507 \ln (125.8)+0.1999(3.389)(1+10.38(0.03))^{2}+7.066(1 / 2)^{2}-0.005(28.37)^{2}+0.057 \\
=1.4158 \\
\text { LOS }=\mathrm{A} \\
\text { Survey LOS }=\mathrm{E}
\end{gathered}
$$

Answers do not match.

\section{Automobile Level of Service Methodology:}

Intersection: West Linden Street and Douglass Avenue, Riverside California

Two Way Stop Controlled Intersection Automotive Method- Eastbound Through

$$
\begin{gathered}
\text { Movement } \\
\text { Vi = V/PHF } \\
107 / 0.85=125.8
\end{gathered}
$$

Conflicting Volume for Major Street Through Movement $=0$ veh/hr

$$
\begin{gathered}
\text { Tcx }=\text { Tc, base }+ \text { Tc, } H^{*}{ }^{*} \mathrm{HV}+\mathrm{Tc}, \mathrm{g}^{*} \mathrm{G}-\mathrm{T} 3 \mathrm{LT} \\
\text { Tc,base }=4.1 \\
\mathrm{Tc}, \mathrm{HV}=1
\end{gathered}
$$




$$
\begin{aligned}
& \mathrm{PHV}=0.03 \\
& \mathrm{TC}, \mathrm{g}=0 \\
& \mathrm{~T} 3 \mathrm{LT}=0 \\
& \operatorname{Tcx}=4.1+1^{*} 0.03=4.13 \\
& t f x=t f b a s e+t f H V^{*} P H V \\
& \text { tfbase }=2.2 \\
& \mathrm{tfHV}=0.9 \\
& \mathrm{PHV}=0.03 \\
& \mathrm{tfx}=2.2+0.9^{*} 0.03=2.227 \\
& C_{p, x}=v_{c, x}\left[e^{-v c, x t c, x / 3600} /\left(1-e^{-v c, u, x t f, x / 3600}\right)\right] \\
& \mathrm{Vc}, \mathrm{x}=0 \sim 1 \\
& \mathrm{Cp}, \mathrm{x}=1^{*}\left(\mathrm{e}^{-1^{*} 4.13 / 3600} /\left(1-\mathrm{e}^{-1^{*} 2.227 / 3600}\right)\right)=1615 \mathrm{veh} / \mathrm{hr}
\end{aligned}
$$

No nearby signals at this location.

$$
D=3600 / c_{m, x}+900 T\left[\left(v_{x} / c_{m, x}\right)-1+\left(\left(v_{x} / c_{m, x}-1\right)^{2}+\left(\left(3600 / c_{m, x}\right)\left(v_{x} / c_{m, x}\right) / 450 T\right)\right)^{(1 / 2)}\right]+5
$$

Where:

$\mathrm{D}=$ control delay $(\mathrm{s} / \mathrm{veh})$ 
$V_{x}=$ flow rate for movement $x(v e h / h r)$

$\mathrm{C}_{\mathrm{m}, \mathrm{x}}=$ capacity of movement $\mathrm{x}(\mathrm{veh} / \mathrm{hr})$

$\mathrm{T}=$ analysis time period $(=0.25$ for 15 minute period $)$

$$
\begin{gathered}
\mathrm{T}=1 \mathrm{hr} \\
\text { Cp, } \mathrm{x} \sim \mathrm{Cm}, \mathrm{x} \\
\mathrm{d}=(3600 / 1615)+900^{*} 1^{*}\left[(125.8 / 1615)-1+\left((125.8 / 1615-1)^{2}+\right.\right. \\
\left.\left.(3600 / 1615)^{*}(125.8 / 1615) /\left(450^{*} 1\right)\right)^{\wedge}(1 / 2)\right]+5=7.41724 \\
\operatorname{LOS}=\mathrm{A}
\end{gathered}
$$

Average Survey Response LOS from our Data Collection $=\mathrm{E}$

Answers do not match. 


\section{Appendix C}

The following is a sample calculation for data validation of collected responses by comparing accepted signalized intersection level of service equations to collected signalized intersection level of services. 
Intersection: Claremont Boulevard and First Street, Claremont, California

Signalized Intersection Method- Southbound Through Movement

$$
\text { Lane width }=12^{\prime}
$$

No bike lane or shoulder present.

$$
\begin{aligned}
& \mathrm{Wt}=12^{\prime}+0^{\prime} \\
& \text { Total Width }=87^{\prime} \\
& F w=0.0153^{*} 87^{\prime}-0.2144^{*} 12^{\prime}=-1.2417 \\
& \text { Vleft }=4 \\
& \text { Vthrough }=203 \mathrm{veh} / \mathrm{hr} \\
& \text { Vright }=26 \mathrm{veh} / \mathrm{hr} \\
& \text { Nlanes }=2 \\
& F v=0.0066^{*}(4+203+26) /\left(4^{\star} 2\right)=0.192225 \\
& \mathrm{lb}, \text { int }=4.1324+0.192225-1.2417=3.082925 \\
& \mathrm{LOS}=\mathrm{C}
\end{aligned}
$$

Average LOS Survey Score $=$ C

Survey Average Appears Approximately Valid. 


\section{Appendix D}

The following is a list of American League of Bicyclists approved Bicycle Friendly Communities and Universities for 2012. All sites surveyed in this report were selected from this list. 


\section{Current Bicycle Friendly Communities 2012}

Click on the name of the community to learn more

\begin{tabular}{|c|c|c|c|c|}
\hline Community & State & Award Level & Population & Fall 2012 \\
\hline Boulder & $\mathrm{CO}$ & Platinum & 101,500 & \\
\hline Davis & $\mathrm{CA}$ & Platinum & 63,722 & \\
\hline Portland & OR & Platinum & 533,492 & \\
\hline Breckenridge & $\mathrm{CO}$ & Gold & 4,540 & \\
\hline Corvallis & OR & Gold & 53,165 & \\
\hline Durango & $\mathrm{CO}$ & Gold & 16,887 & \\
\hline Eugene & OR & Gold & 142,681 & \\
\hline Fort Collins & $\mathrm{CO}$ & Gold & 118,652 & \\
\hline Jackson and Teton County & WY & Gold & 18,251 & \\
\hline Madison & WI & Gold & 221,551 & \\
\hline Minneapolis & $\mathrm{MN}$ & Gold & 379,499 & \\
\hline Missoula & MT & Gold & 66,788 & \\
\hline Palo Alto & CA & Gold & 64,403 & \\
\hline San Francisco & CA & Gold & 739,426 & \\
\hline Scottsdale & $A Z$ & Gold & 217,385 & \\
\hline Seattle & WA & Gold & 563,374 & \\
\hline Stanford University & CA & Gold & 13,315 & \\
\hline Steamboat Springs & $\mathrm{CO}$ & Gold & 12,088 & \\
\hline Tucson \& East Pima Region & $A Z$ & Gold & 512,023 & \\
\hline Ada County & ID & Silver & 392,365 & Moved Up \\
\hline Ann Arbor & MI & Silver & 114,028 & \\
\hline Arcata & CA & Silver & 17,321 & \\
\hline Arlington & VA & Silver & 210,280 & \\
\hline Aspen & $\mathrm{CO}$ & Silver & 6,100 & \\
\hline Austin & TX & Silver & 681,804 & \\
\hline Bellingham & WA & Silver & 73,460 & \\
\hline Bend & OR & Silver & 80,995 & \\
\hline Bloomington & IN & Silver & 69,107 & \\
\hline Boston & MA & Silver & 645,169 & \\
\hline Bozeman & MT & Silver & 37,280 & New \\
\hline Burlington & VT & Silver & 42,417 & \\
\hline Charlottesville & VA & Silver & 43,475 & \\
\hline Carrboro & NC & Silver & 18,162 & \\
\hline Chicago & $\mathrm{IL}$ & Silver & $2,896,016$ & \\
\hline Chico & CA & Silver & 79,000 & Moved Up \\
\hline Claremont & CA & Silver & 36,612 & Moved Up \\
\hline Colorado Springs & $\mathrm{CO}$ & Silver & 360,890 & \\
\hline Columbia & MO & Silver & 102,324 & \\
\hline
\end{tabular}




\begin{tabular}{|c|c|c|c|c|}
\hline \multicolumn{2}{|l|}{ Bicycle Friendly Community } & \multicolumn{3}{|c|}{ Current Bicycle Friendly Communitie } \\
\hline Community & State & Award Level & Population & Fall 2012 \\
\hline Denver & $\mathrm{CO}$ & Silver & 598,707 & \\
\hline Evanston & $\mathrm{IL}$ & Silver & 74,486 & New \\
\hline Flagstaff & $A Z$ & Silver & 57,391 & \\
\hline Folsom & $\mathrm{CA}$ & Silver & 63,960 & Moved Up \\
\hline Gainesville & $\mathrm{FL}$ & Silver & 117,182 & \\
\hline Gunnison & $\mathrm{CO}$ & Silver & 5,854 & \\
\hline Hilton Head Island & SC & Silver & 33,862 & \\
\hline La Crosse & WI & Silver & 51,818 & \\
\hline Long Beach & $\mathrm{CA}$ & Silver & 466,520 & \\
\hline Longmont & $\mathrm{CO}$ & Silver & 87,461 & \\
\hline Mountain View & $\mathrm{CA}$ & Silver & 70,708 & Moved Up \\
\hline New York & NY & Silver & $8,143,197$ & \\
\hline Olympia & WA & Silver & 44,460 & \\
\hline Park City and Snyderville Basin & UT & Silver & 20,671 & \\
\hline Philadelphia & $\mathrm{PA}$ & Silver & $1,454,382$ & Moved Up \\
\hline Port Townsend & WA & Silver & 8,334 & \\
\hline Presidio of San Francisco & $\mathrm{CA}$ & Silver & 3,000 & \\
\hline Redmond & WA & Silver & 49,637 & \\
\hline Sacramento & $\mathrm{CA}$ & Silver & 456,394 & \\
\hline Salt Lake City & UT & Silver & 181,743 & \\
\hline San Luis Obispo & $\mathrm{CA}$ & Silver & 43,766 & \\
\hline Santa Cruz & CA & Silver & 54,593 & \\
\hline Sisters & OR & Silver & 1,925 & \\
\hline Tempe & $A Z$ & Silver & 172,589 & \\
\hline Venice & $\mathrm{FL}$ & Silver & 22,146 & New \\
\hline Washington & $\mathrm{DC}$ & Silver & 599,657 & \\
\hline Wood River Valley & ID & Silver & 12,506 & \\
\hline Alameda & $\mathrm{CA}$ & Bronze & 73,812 & \\
\hline Albany & OR & Bronze & 48,770 & \\
\hline Albuquerque & NM & Bronze & 448,607 & \\
\hline Alexandria & VA & Bronze & 140,024 & \\
\hline Anchorage & AK & Bronze & 284,994 & \\
\hline Arlington & MA & Bronze & 42,844 & \\
\hline Arvada & $\mathrm{CO}$ & Bronze & 107,050 & \\
\hline Ashland & OR & Bronze & 19,522 & \\
\hline Asheville & $\mathrm{NC}$ & Bronze & 83,393 & \\
\hline Athens-Clarke County & GA & Bronze & 115,000 & \\
\hline Auburn & $A L$ & Bronze & 52,205 & \\
\hline Bainbridge Island & WA & Bronze & 20,300 & \\
\hline Baltimore & MD & Bronze & 631,000 & \\
\hline
\end{tabular}


Current Bicycle Friendly Communities 2012

\begin{tabular}{|c|c|c|c|c|}
\hline Community & State & Award Level & Population & Fall 2012 \\
\hline Baton Rouge & LA & Bronze & 428,360 & \\
\hline Beaverton & OR & Bronze & 79,350 & \\
\hline Bemidji & MN & Bronze & 13,431 & New \\
\hline Bentonville & $\mathrm{AR}$ & Bronze & 35,301 & New \\
\hline Bethesda & MD & Bronze & 57,319 & New \\
\hline Billings & MT & Bronze & 100,147 & \\
\hline Boca Raton & $\mathrm{FL}$ & Bronze & 83,960 & \\
\hline Brentwood & $\mathrm{CA}$ & Bronze & 40,007 & \\
\hline Brunswick & ME & Bronze & 21,820 & \\
\hline Calistoga & $\mathrm{CA}$ & Bronze & 5,300 & \\
\hline Carbondale & $\mathrm{CO}$ & Bronze & 5,196 & \\
\hline Carmel & IN & Bronze & 70,000 & \\
\hline Cary & $\mathrm{NC}$ & Bronze & 119,745 & \\
\hline Castle Rock & $\mathrm{CO}$ & Bronze & 50,028 & New \\
\hline Cedar Falls & IA & Bronze & 36,145 & \\
\hline Cedar Rapids & $\mathrm{IA}$ & Bronze & 12,6498 & \\
\hline Chandler & $A Z$ & Bronze & 252,257 & \\
\hline Chapel Hill & $\mathrm{NC}$ & Bronze & 55,616 & \\
\hline Charleston & SC & Bronze & 124,000 & \\
\hline Charlotte & NC & Bronze & 648,387 & \\
\hline Chattanooga & TN & Bronze & 167,674 & \\
\hline Cincinnati & $\mathrm{OH}$ & Bronze & 297,000 & \\
\hline Coeur d'Alene & ID & Bronze & 41,983 & \\
\hline Columbia & SC & Bronze & 116,278 & \\
\hline Columbus & IN & Bronze & 44,061 & \\
\hline Columbus & $\mathrm{OH}$ & Bronze & 748,000 & \\
\hline Concord & $\mathrm{NH}$ & Bronze & 43,225 & \\
\hline Conway & $A R$ & Bronze & 59,511 & \\
\hline Cottonwood & $A Z$ & Bronze & 12,426 & \\
\hline Cupertino & $\mathrm{CA}$ & Bronze & 50,479 & \\
\hline Davidson & $\mathrm{NC}$ & Bronze & 10,300 & \\
\hline Dayton & $\mathrm{OH}$ & Bronze & 154,200 & \\
\hline Decatur & GA & Bronze & 19,335 & New \\
\hline Des Moines & $\mathrm{IA}$ & Bronze & 203,433 & \\
\hline Durham & $\mathrm{NC}$ & Bronze & 212,789 & \\
\hline Eau Claire & WI & Bronze & 101,353 & \\
\hline Emeryville & CA & Bronze & 10,080 & New \\
\hline Fayetteville & $A R$ & Bronze & 67,158 & \\
\hline Fitchburg & WI & Bronze & 25,260 & New \\
\hline Fort Wayne & IN & Bronze & 253,691 & \\
\hline
\end{tabular}


Bicycle Friendly Community

$\begin{array}{ll}\text { Community } & \\ \text { Franklin } & \\ \text { Frederick } & \\ \text { Fresno } & \\ \text { Gilbert } & \\ \text { Golden } & \\ \text { Goshen } & \\ \text { Grand Rapids } & \\ \text { Greater Mankato } & \\ \text { Greensboro } & \\ \text { Gresham } & \\ \text { Harrisonburg } & \\ \text { Hoboken } & \\ \text { Houghton } & \\ \text { Huntington Beach } & \end{array}$

Indianapolis \& Marion County IN

lowa City IA

Irvine CA

Juneau AK

Kansas City MO

Keene $\quad \mathrm{NH}$

Knoxville TN

Lakeland $\quad F L$

Lakewood CO

Lansing Ml

Las Cruces NM

Lawrence KS

Lee's Summit MO

Lewes DE

Lexington-Fayette County KY

Lincoln NE

Los Altos

Los Angeles

Louisville

Manhattan

Marquette

Menlo Park

Mesa

Miami

Midland

Current Bicycle Friendly Communities 2012

Award Level

Bronze

Bronze

Bronze

Bronze

Bronze

Bronze

Bronze

Bronze

Bronze

Bronze

Bronze

Bronze

Bronze

Bronze

Bronze

Bronze

Bronze

Bronze

Bronze

Bronze

Bronze

Bronze

AZ

FL

MI
Population Fall 2012

7,212

65,239

500,121

196,000

18,026

31,719

688,937

52,703

258,671

57,400

101,537

48,814

$50,005 \quad$ New

8,238

202,250

872,842

65,219

186,220

30,711

482,228

24,769

177,646
New

New
New
Bronze

Bronze

Bronze

Bronze

Bronze

Bronze

Bronze

Bronze

Bronze

Bronze

Bronze

Bronze

Bronze

Bronze

Bronze

97,422

146,000

111,304

92,235

88,664

92,188

2,747

246,800

258,379

27,483

$3,792,621$

700,030

52,281

21,000

30,648

437,454

418,480

41,863

New

New

Bronze

Bronze

Bronze 
Bicycle Friendly Community

\begin{tabular}{|c|c|c|c|c|}
\hline Community & State & Award Level & Population & Fall 2012 \\
\hline Milwaukee & WI & Bronze & 554,965 & \\
\hline Morgantown & WV & Bronze & 29,660 & \\
\hline Napa & $\mathrm{CA}$ & Bronze & 75,000 & \\
\hline Naperville & IL & Bronze & 128,358 & \\
\hline Nashville-Davidson County & $\mathrm{TN}$ & Bronze & 601,222 & New \\
\hline Newark & DE & Bronze & 29,886 & \\
\hline New Orleans & LA & Bronze & 343,829 & \\
\hline Norman & OK & Bronze & 112,551 & \\
\hline North Little Rock & $A R$ & Bronze & 60,433 & \\
\hline Northampton & MA & Bronze & 28,978 & \\
\hline Oakland & $\mathrm{CA}$ & Bronze & 365,875 & \\
\hline Ocean City & NJ & Bronze & 11,701 & New \\
\hline Oceanside & CA & Bronze & 174,925 & \\
\hline Omaha & NE & Bronze & 408,958 & \\
\hline Orange County & CA & Bronze & $3,010,232$ & New \\
\hline Orlando & $\mathrm{FL}$ & Bronze & 205,648 & \\
\hline Oxford & MS & Bronze & 16,727 & \\
\hline Pittsburgh & PA & Bronze & 316,718 & \\
\hline Portage & MI & Bronze & 46,143 & \\
\hline Provo & UT & Bronze & 117,489 & New \\
\hline Raleigh & $\mathrm{NC}$ & Bronze & 405,612 & \\
\hline Redding & CA & Bronze & 89,470 & \\
\hline Reno-Sparks Washoe County & NV & Bronze & 421,407 & \\
\hline Richmond & VA & Bronze & 205,533 & New \\
\hline Ridgeland & MS & Bronze & 22,809 & \\
\hline River Falls & WI & Bronze & 15,308 & New \\
\hline Riverside & $\mathrm{CA}$ & Bronze & 311,575 & \\
\hline Roanoke & VA & Bronze & 94,911 & \\
\hline Rochester & MN & Bronze & 102,437 & \\
\hline Rochester & NY & Bronze & 210,565 & New \\
\hline Rock Hill & SC & Bronze & 66,154 & New \\
\hline Rockville & MD & Bronze & 61,209 & New \\
\hline Roseville & CA & Bronze & 109,154 & \\
\hline Roswell & GA & Bronze & 85,920 & \\
\hline Saint Paul & MN & Bronze & 281,244 & \\
\hline Salem & OR & Bronze & 152,239 & \\
\hline San Antonio & $\mathrm{TX}$ & Bronze & $1,144,646$ & \\
\hline San Jose & CA & Bronze & 912,332 & \\
\hline Sanibel & $\mathrm{FL}$ & Bronze & 6,064 & \\
\hline Santa Clara & $\mathrm{CA}$ & Bronze & 110,376 & \\
\hline
\end{tabular}

Current Bicycle Friendly Communities 2012 
Bicycle Friendly Community

\begin{tabular}{|c|c|c|c|c|}
\hline Community & State & Award Level & Population & Fall 2012 \\
\hline Santa Fe & NM & Bronze & 67,947 & \\
\hline Santa Monica & $\mathrm{CA}$ & Bronze & 87,400 & \\
\hline Schaumburg & IL & Bronze & 73,346 & \\
\hline Sedona & $A Z$ & Bronze & 10,192 & \\
\hline Shawnee & KS & Bronze & 57,628 & \\
\hline Sheboygan County & WI & Bronze & 115,507 & \\
\hline Shorewood & WI & Bronze & 13,267 & \\
\hline Simsbury & CT & Bronze & 23,256 & \\
\hline Sioux Falls & SD & Bronze & 154,000 & \\
\hline Sitka & AK & Bronze & 8,883 & \\
\hline Snohomish & WA & Bronze & 9,098 & \\
\hline Sonoma & CA & Bronze & 9,128 & \\
\hline Somerville & MA & Bronze & 77,478 & \\
\hline South Bend & IN & Bronze & 100,842 & \\
\hline South Lake Tahoe & $\mathrm{CA}$ & Bronze & 23,609 & \\
\hline South Sioux City & NE & Bronze & 11,925 & \\
\hline South Windsor & СT & Bronze & 24,409 & \\
\hline Spartanburg & SC & Bronze & 39,487 & \\
\hline Spokane & WA & Bronze & 204,428 & \\
\hline Springfield & MO & Bronze & 156,206 & \\
\hline State College - Centre Region & PA & Bronze & 92,096 & \\
\hline Stillwater & OK & Bronze & 45,688 & New \\
\hline St. Louis & MO & Bronze & 350,759 & \\
\hline St. Petersburg & $\mathrm{FL}$ & Bronze & 249,090 & \\
\hline Summit County & $\mathrm{CO}$ & Bronze & 29,626 & \\
\hline Sunnyvale & $\mathrm{CA}$ & Bronze & 131,760 & \\
\hline Tacoma & WA & Bronze & 198,387 & \\
\hline Tallahassee & FL & Bronze & 176,336 & \\
\hline The Woodlands Township & TX & Bronze & 97,023 & \\
\hline Thousand Oaks & CA & Bronze & 127,644 & \\
\hline Tybee Island & GA & Bronze & 3,713 & \\
\hline Traverse City & MI & Bronze & 14,532 & \\
\hline Tulsa & OK & Bronze & 384,037 & \\
\hline University Heights & IA & Bronze & 1,051 & \\
\hline Urbana & IL & Bronze & 40,550 & \\
\hline Vail & $\mathrm{CO}$ & Bronze & 4,806 & \\
\hline Vancouver & WA & Bronze & 156,600 & \\
\hline Westerville & $\mathrm{OH}$ & Bronze & 36,120 & New \\
\hline West Windsor & NJ & Bronze & 27,165 & \\
\hline Wilmington & NC & Bronze & 101,353 & \\
\hline
\end{tabular}

Current Bicycle Friendly Communities 2012
Award Level

ronze

Bronze

Bronze

Bronze

Bronze

Bronze

Bronze

Bronze

Bronze

Bronze

Bronze

Bronze

inze
Population Fall 2012

87,400

10,192

115,507

13,267

154,000

8,883

9,128

77,478

33,609

(3),609

24,409

39,487

156,206

(56,206

92,096

350,759

49,090

131,760

198,387

176,336

97,023

3,713

14,532

84,037$$
4,806
$$

56,600

27,165

101,353 
Community

State

Windsor
CA

$\begin{array}{rc}\text { Population } & \text { Fall } 2012 \\ 26,801 & \text { New }\end{array}$




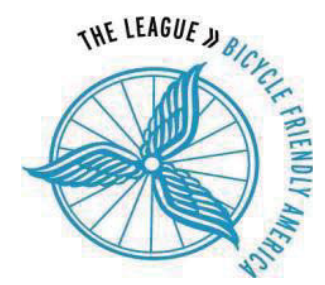

\section{Current Bicycle Friendly Universities Spring 2013}

Go to bikeleague.org/programs/bicyclefriendlyamerica/ to learn more about these universities

\begin{tabular}{|c|c|c|c|}
\hline College/ University Name & Award & Location & Spring 2013 \\
\hline Stanford University & Platinum & Stanford, CA & \\
\hline Portland State University & Gold & Portland, OR & Moved Up \\
\hline University of California & Gold & Davis, CA & \\
\hline University of California & Gold & Santa Barbara, CA & \\
\hline Boise State University & Silver & Boise, ID & \\
\hline California State University & Silver & Long Beach, CA & \\
\hline Colorado State University & Silver & Fort Collins, CO & \\
\hline Georgia Institute of Technology & Silver & Atlanta, GA & \\
\hline Harvard University & Silver & Cambridge, MA & New \\
\hline Lincoln Memorial University & Silver & Harrogate, TN & New \\
\hline Northern Arizona University & Silver & Flagstaff, AZ & \\
\hline Oregon State University & Silver & Corvallis, OR & \\
\hline University of Arizona & Silver & Tucson, AZ & \\
\hline University of California & Silver & Irvine, CA & \\
\hline University of California & Silver & Berkeley, CA & New \\
\hline University of Maryland & Silver & College Park, MD & \\
\hline University of Minnesota & Silver & Twin Cities, MN & \\
\hline University of Nebraska & Silver & Lincoln, NE & New \\
\hline University of Oregon & Silver & Eugene, OR & \\
\hline University of Utah & Silver & Salt Lake City, UT & \\
\hline University of Washington & Silver & Seattle, WA & \\
\hline University of Wisconsin & Silver & Madison, WI & \\
\hline Virginia Commonwealth University & Silver & Richmond, VA & \\
\hline California Institute of Technology & Bronze & Pasadena, CA & New \\
\hline Chatham University & Bronze & Pittsburgh, PA & \\
\hline Clemson University & Bronze & Clemson, SC & New \\
\hline Cornell University & Bronze & Ithaca, NY & \\
\hline Duke University & Bronze & Durham, NC & \\
\hline Eastern Mennonite University & Bronze & Harrisonburg, VA & \\
\hline Emory University & Bronze & Atlanta, GA & \\
\hline
\end{tabular}




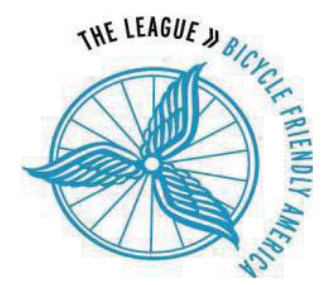

\section{Current Bicycle Friendly Universities Spring 2013}

Go to bikeleague.org/programs/bicyclefriendlyamerical to learn more about these universities

\begin{tabular}{|c|c|c|c|}
\hline College/ University Name & Award & Location & Spring 2013 \\
\hline George Mason University & Bronze & Fairfax, VA & \\
\hline Gustavus Adolphus College & Bronze & Saint Peter. MA & New \\
\hline Indiana University & Bronze & Bloomington, IN & \\
\hline James Madison University & Bronze & Harrisonburg, VA & New \\
\hline Michigan State University & Bronze & East Lansing, MI & \\
\hline Michigan Technological University & Bronze & Houghton, MI & New \\
\hline New Mexico State University & Bronze & Las Cruces, NM & New \\
\hline North Carolina State University & Bronze & Raleigh, NC & \\
\hline Ohio State University & Bronze & Columbus, $\mathrm{OH}$ & \\
\hline Old Dominion University & Bronze & Norfolk, VA & New \\
\hline Pennsylvania State University & Bronze & University Park, PA & \\
\hline Princeton University & Bronze & Princeton, NJ & \\
\hline Rochester Institute of Technology & Bronze & Rochester, NY & \\
\hline State University of New York & Bronze & Buffalo, NY & \\
\hline University of California & Bronze & Los Angeles, CA & \\
\hline University of Denver & Bronze & Denver, CO & \\
\hline University of Illinois & Bronze & Champaign, IL & \\
\hline University of Kentucky & Bronze & Lexington, KY & \\
\hline University of Miami & Bronze & Coral Gables, FL & \\
\hline University of Michigan & Bronze & Ann Arbor, MI & \\
\hline University of Michigan & Bronze & Flint, MI & New \\
\hline University of New England & Bronze & Biddeford, ME & New \\
\hline University of North Carolina & Bronze & Greensboro, NC & \\
\hline University of North Carolina & Bronze & Wilmington, NC & \\
\hline University of South Carolina & Bronze & Columbia, SC & \\
\hline University of Vermont & Bronze & Burlington, VT & \\
\hline Virginia Tech & Bronze & Blacksburg, VA & New \\
\hline Yale University & Bronze & New Haven, CT & \\
\hline
\end{tabular}




\begin{abstract}
Appendix $\mathrm{E}$
The following images are maps of the selected survey sites shown on the official Bike Maps of the cities selected for data collection. These maps are the ones submitted to the American League of Bicyclists by the individual communities at the time of application for 2012 recognition as Bicycle Friendly Communities. Locations of selected survey intersections are denoted by a large star.
\end{abstract}




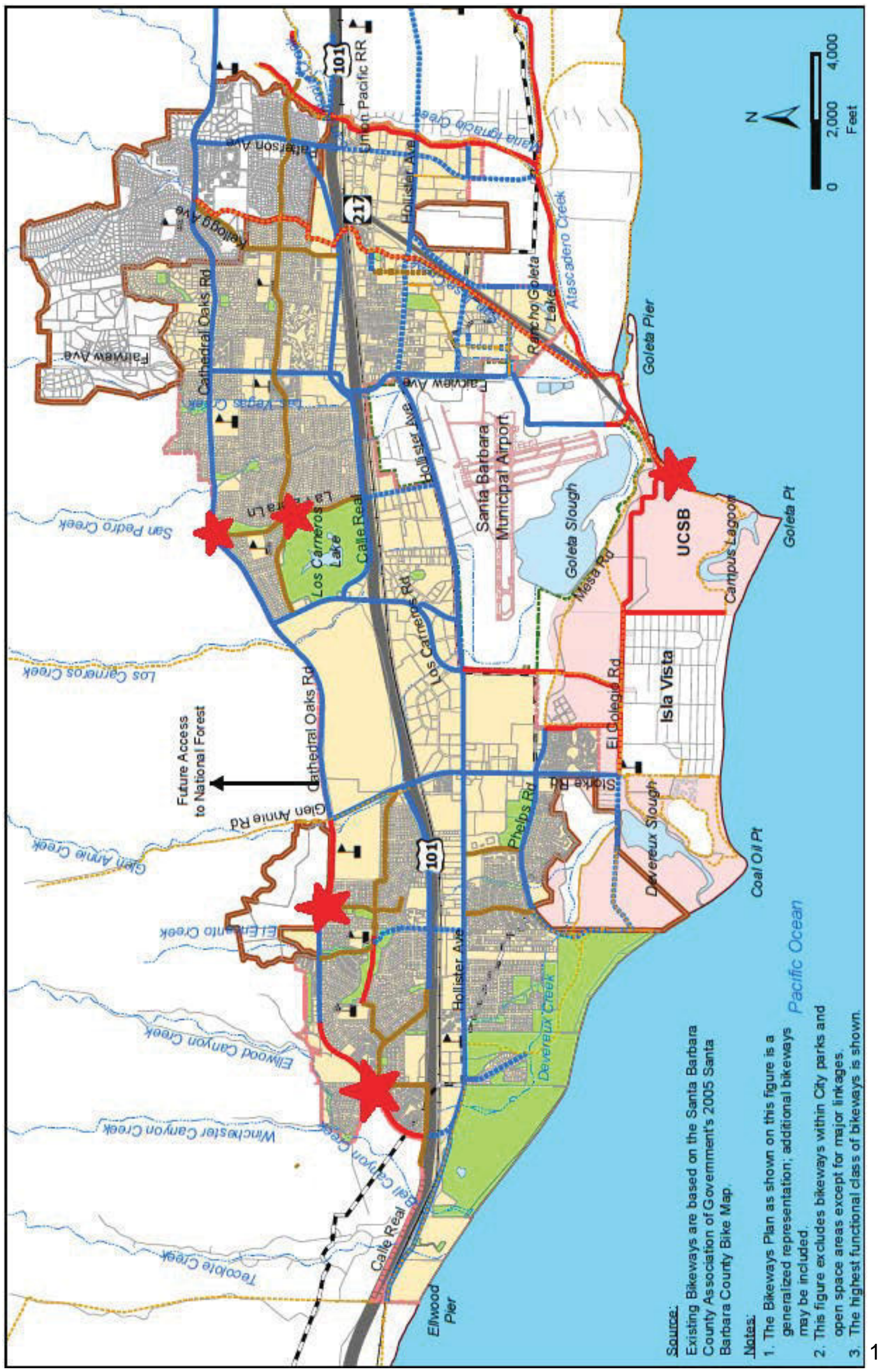




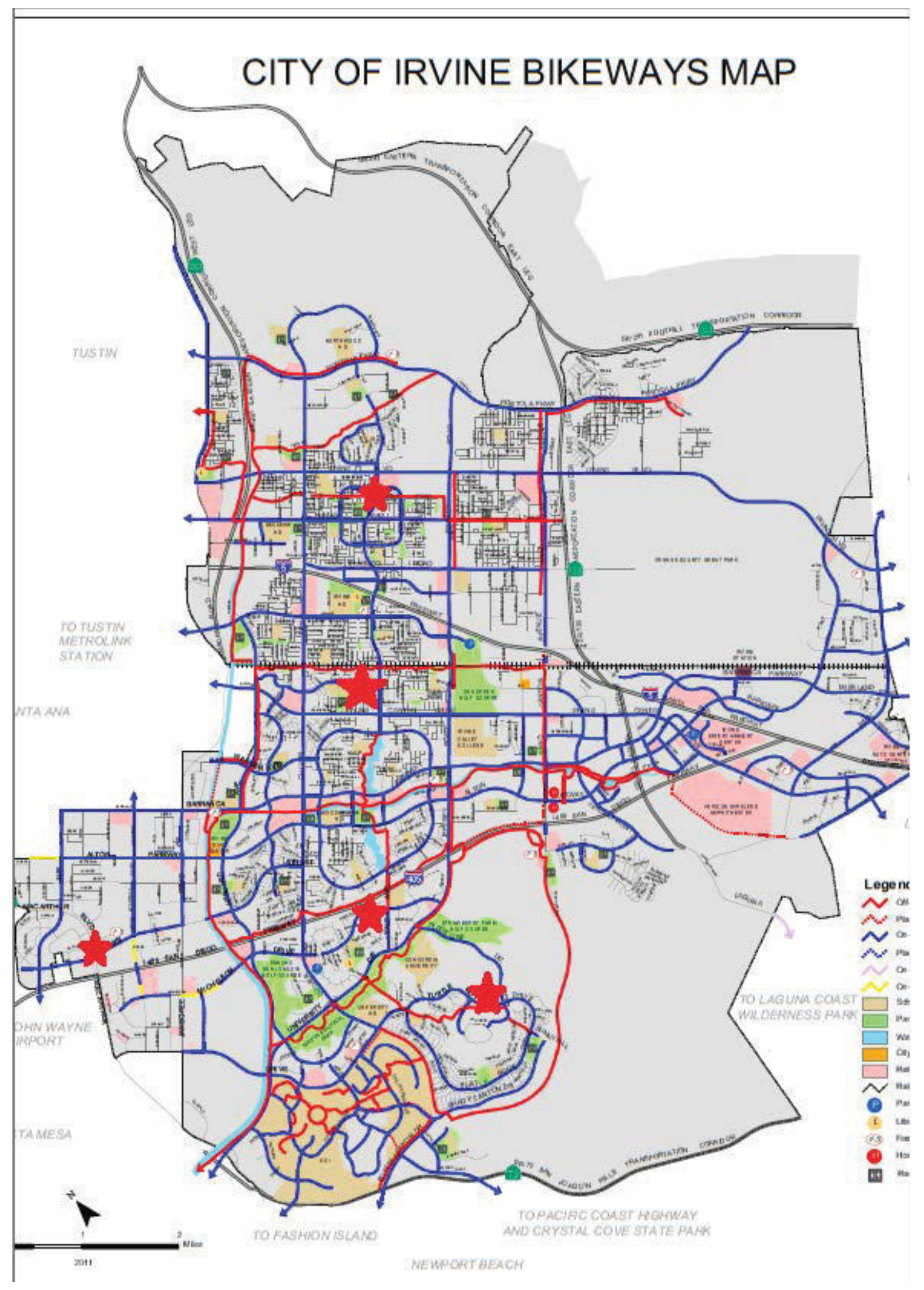




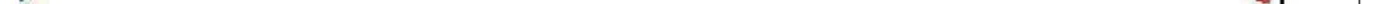




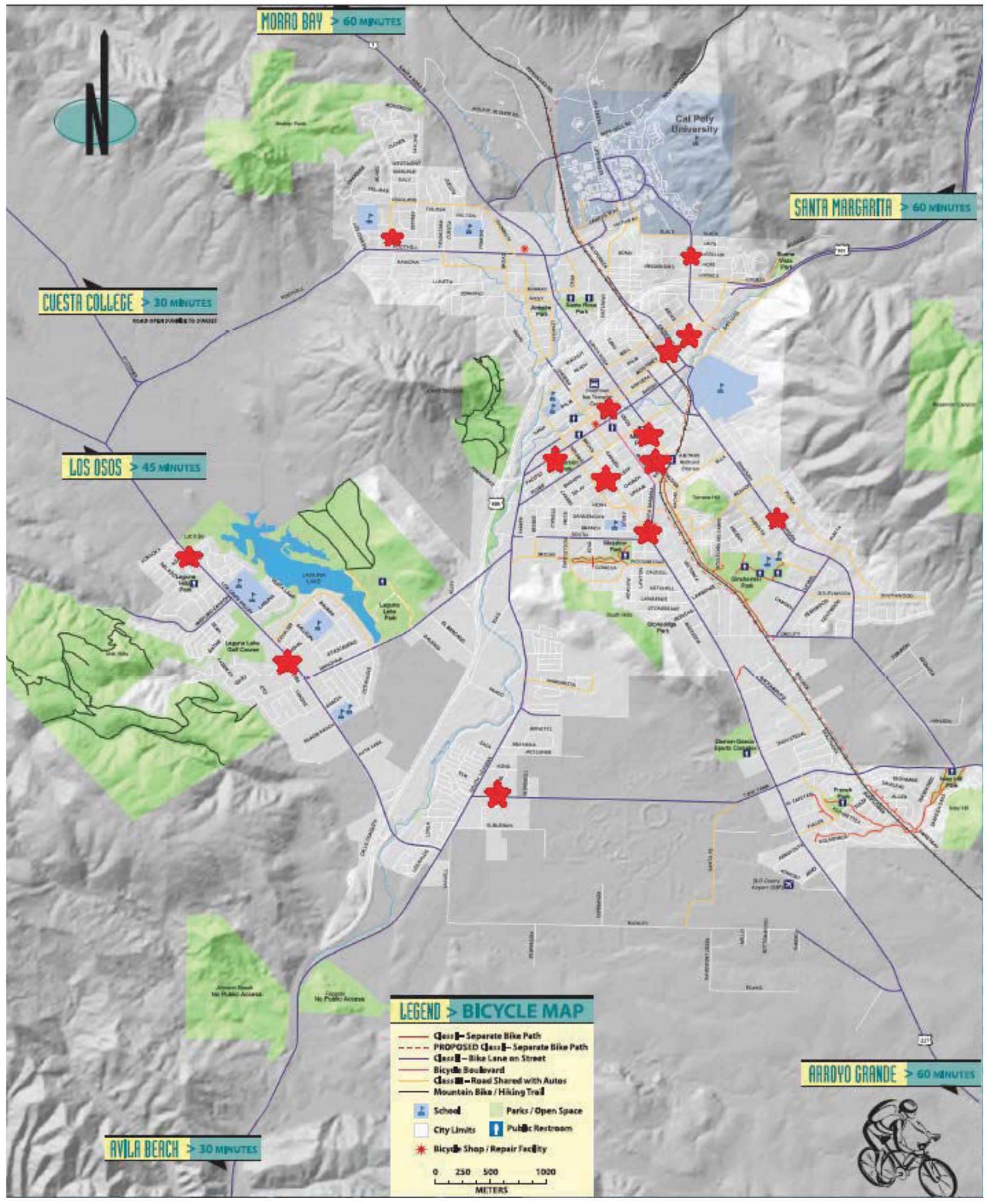




\begin{abstract}
Appendix F
The following are the scanned field data collection pages collected on-site at each survey location.
\end{abstract}


Nathan Johnston

Intersection:

College Avenue/Fonith Street

City:

Claremont

Location: Southern CA Northern CA CentralCA Other Intersection Type: ( +

Data Collection Time:

$8: 00=9: 00$

Intersection Geometry.

North Arrow:

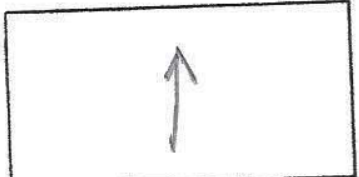

Dist to upstream intersectionisignal

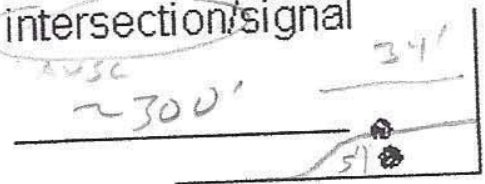

cross wath

$2 \sin i^{n}$

Fourth Street

$\overrightarrow{2 \%} ; 7+5$

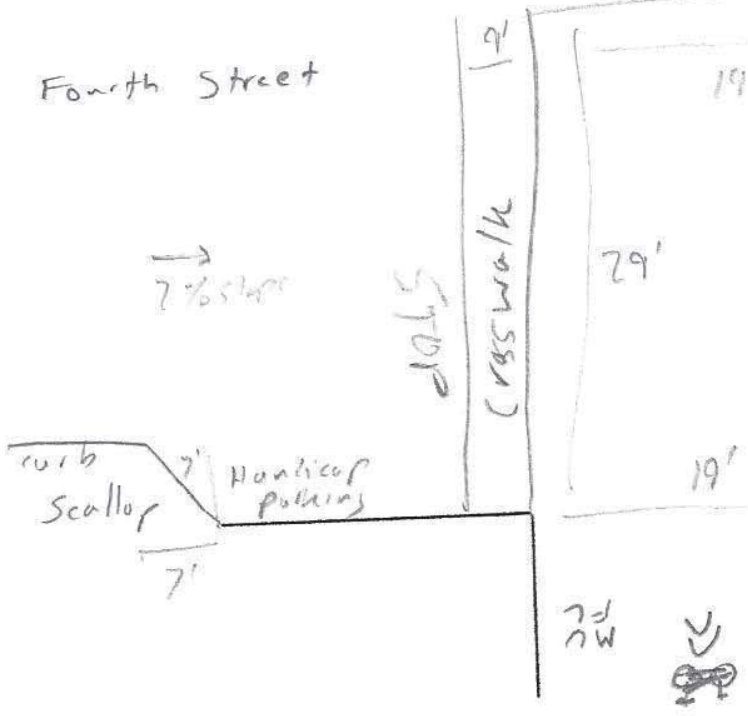

Dist to upstream
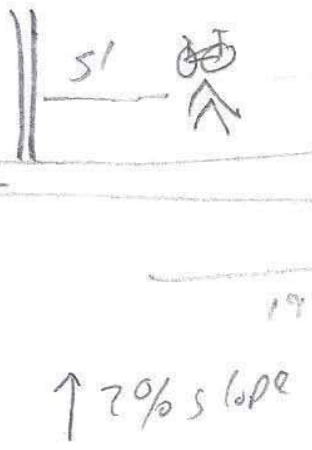

intersection/signal

नus

$-200^{\circ}$

Comments:

Normally, Fourth street does go throesh as t

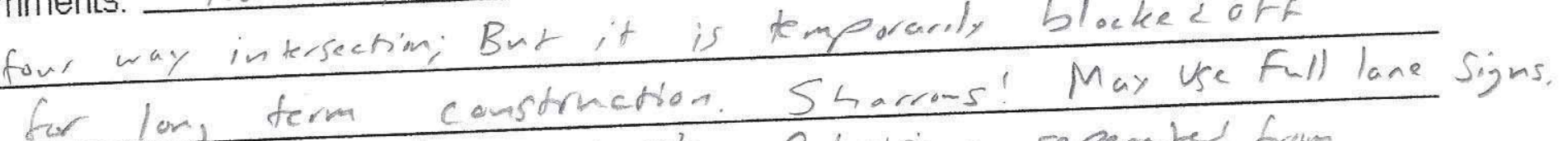
Parking allawed allong spreat side. 1 Pelestrian seperated from

street by large nege $\left(-20^{\prime}\right)$ 
Nathan Johnston

Intersection:

College Avenue / fourth street

Time Period:

$8: 00-9: 00$

Volumes:

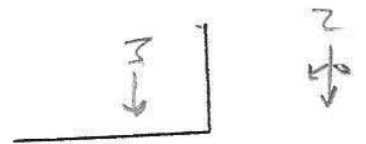

$\int_{1}^{9}$

$v^{132}$

$3 \gamma$

$9 \longrightarrow$

$2 \stackrel{\overrightarrow{5}}{\mathrm{~s}}$

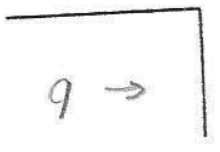

$\uparrow$

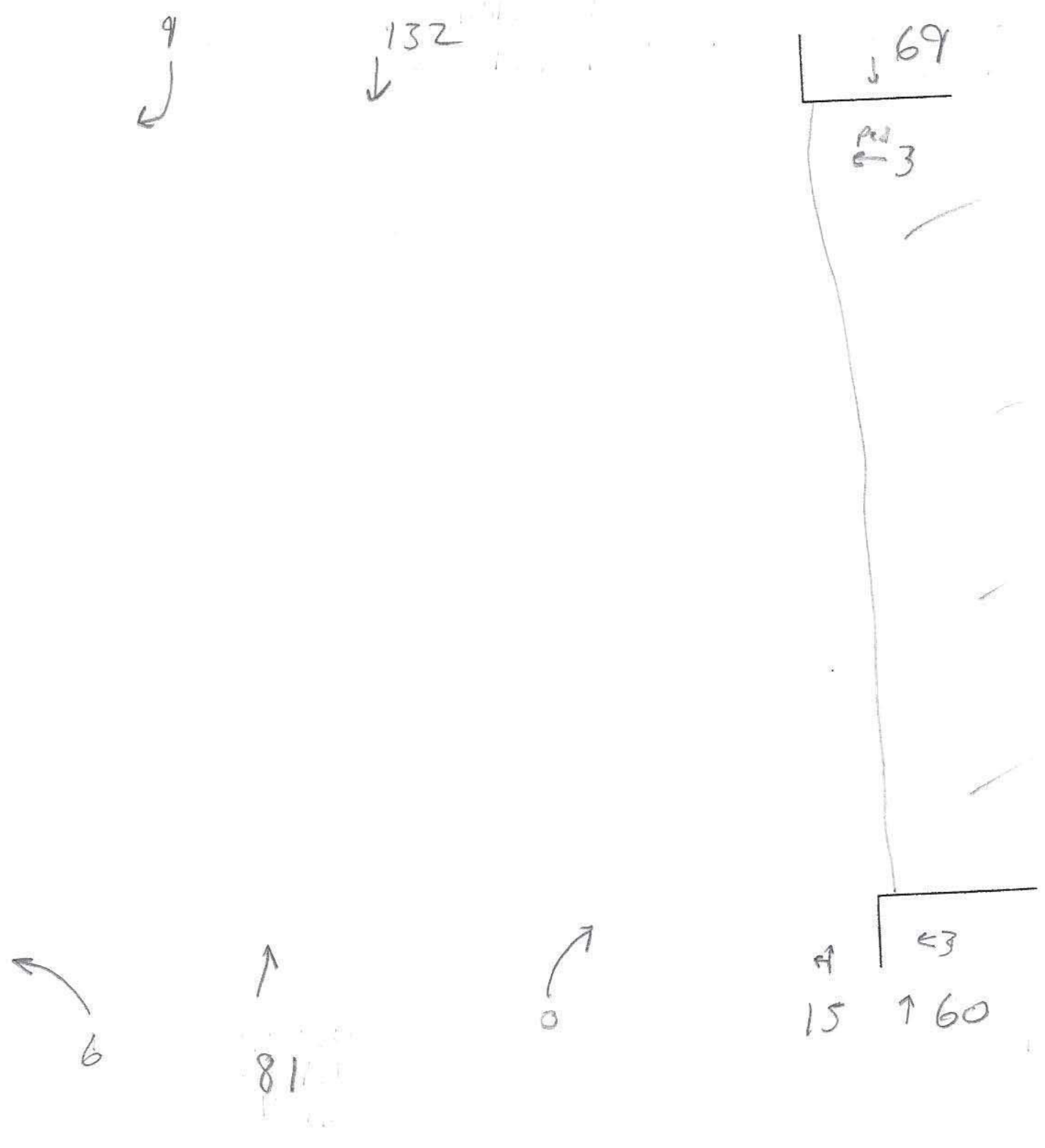


Cal Poly San Luis Obispo

Nathan Johnston

Intersection:

College Areare/Fourth street

Hear vehicles:

$15 \% \mathrm{HU}$

$1 \%$ HO

$5 \% \mathrm{HV}$

Comments:

Trash trucks; Construction trucks, and

normal tractor trainers. College is an approved truck rove through the city.

Funith street has trees that in habit large vehicles.

3

168 
Nathan Johnston

Intersection: College Avenue/Secont Strect

Time Period:

$9: 10-10: 10$

Volumes:

$18 \lambda$

$18-y$

Secont sheet

$\uparrow \leqslant$<smiles>C1C[SiH2]C1</smiles>

66

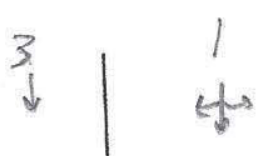

33

$\downarrow$

$\lambda$

4
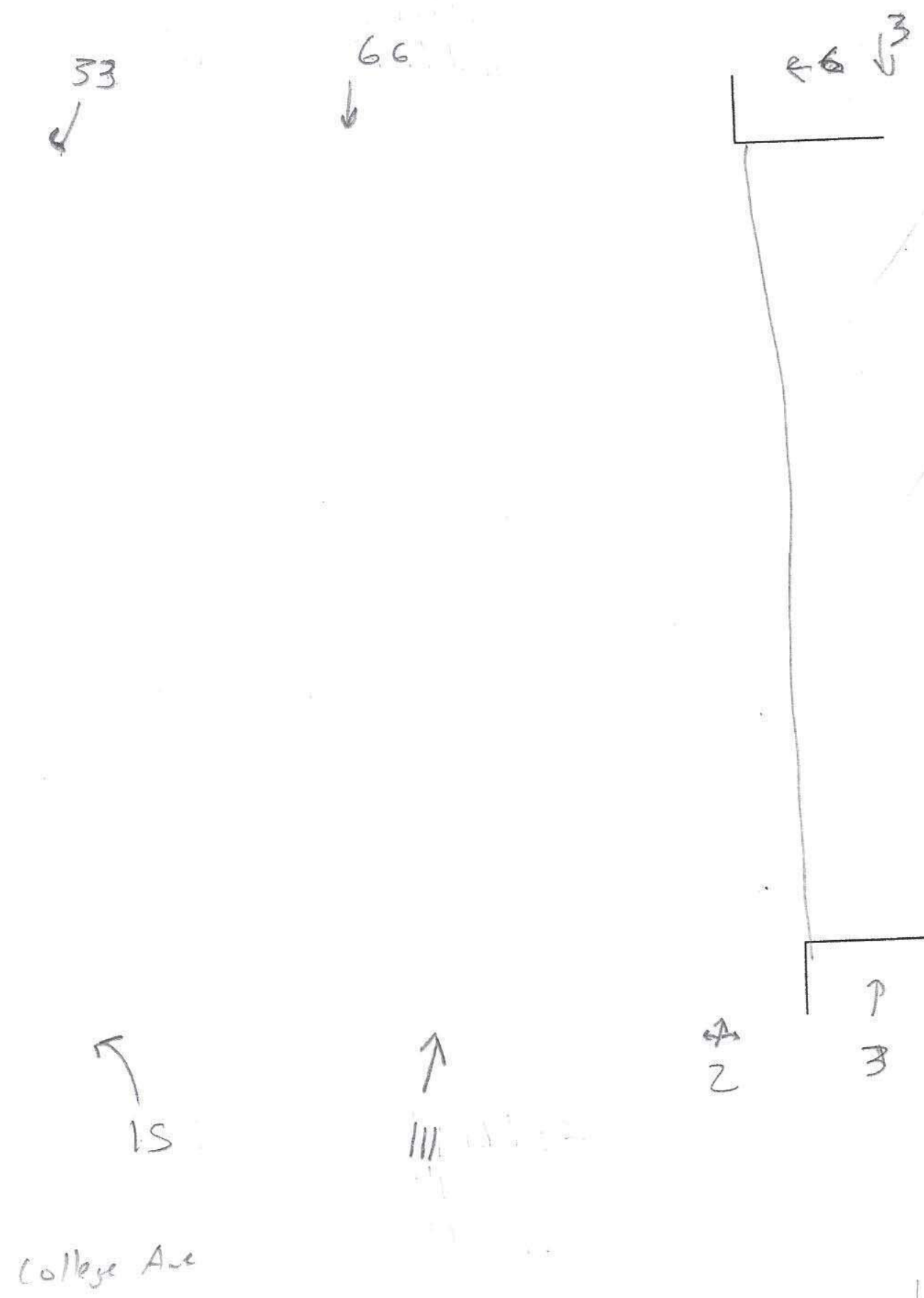

12

III 
Cal Poly San Luis Obispo

Nathan Johnston

Intersection:

College Avenre/Secons Street

Hear Vehicles:

$5 \%$

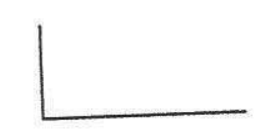

$3 \%$

Second Street

$5 \% \quad$ College Ave

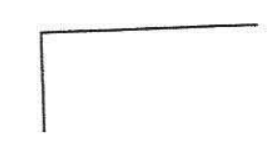

Comments:

Post other

or Seconistrect

3

170 
Nathan Johnston

Cal Poly San Luis Obispo

Intersection:

Collese Avenef Second strect

City:

Claremont

Location Southern CA Northern CA Central CA Other

Intersection Type: ( 1 +

Data Collection Time:

$9: 10-10: 10$

Intersection Geometry.

North Arrow:

$\uparrow$

Dist to upstream intersectionisignal
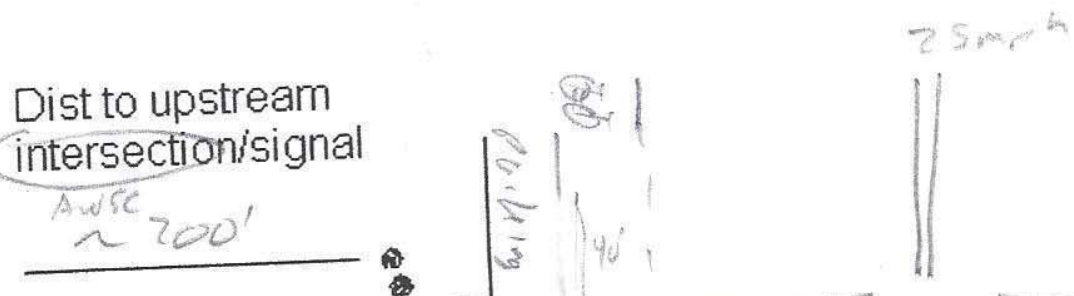

(
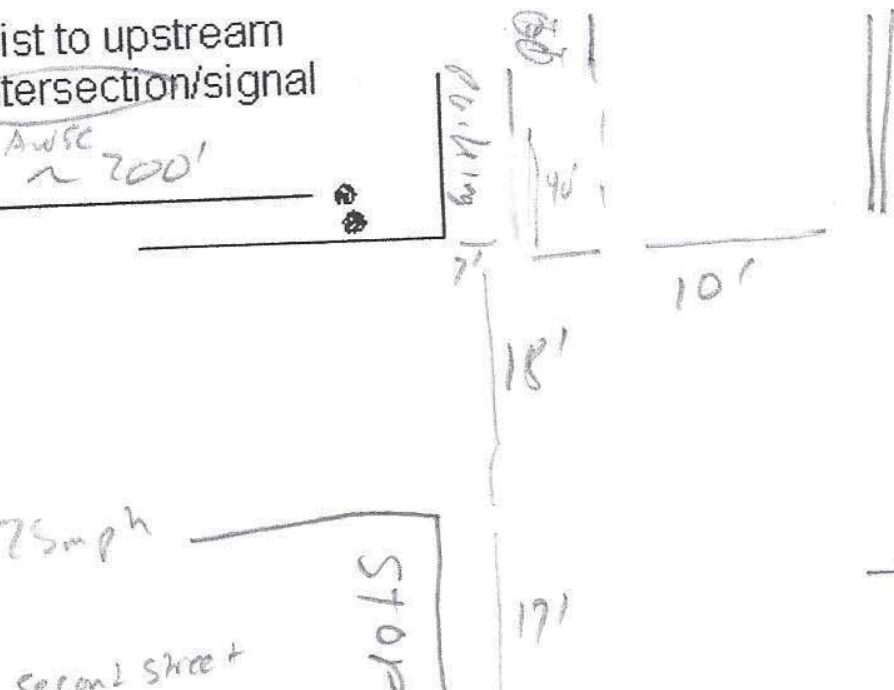

secont sreet

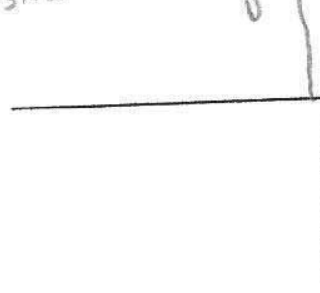

Dist to upstream

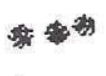

intersection/signal

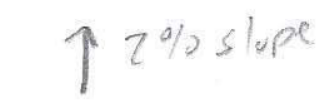

$10^{\prime}$

$\rightarrow 1 \% 5$ lope

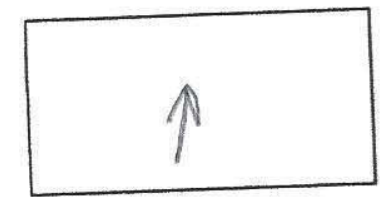

$\sim 750^{\prime}$

Comments:

there is a wolluway that is gated off o- east side of street. Bike and paltes lanes puintel on college. On north ste, parhinglare culs $40^{\prime}$ nothof intergetion. (Notide suoth side) No parking win $40^{\prime}$ or in ergection on college dive to red e 171 b ary casé. 
Nathan Johnston

Cal Poly San Luis Obispo

Intersection:

Time Period:

Volumes:

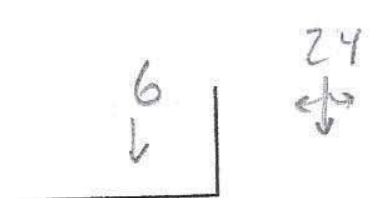

$18-y$

$21 \frac{1}{i}$

159

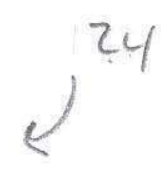

$10: 20-11: 20 \quad 7 / 5 / 13$

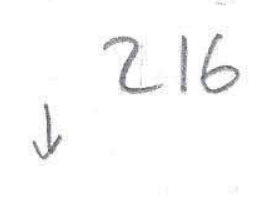

$$
T_{21}
$$
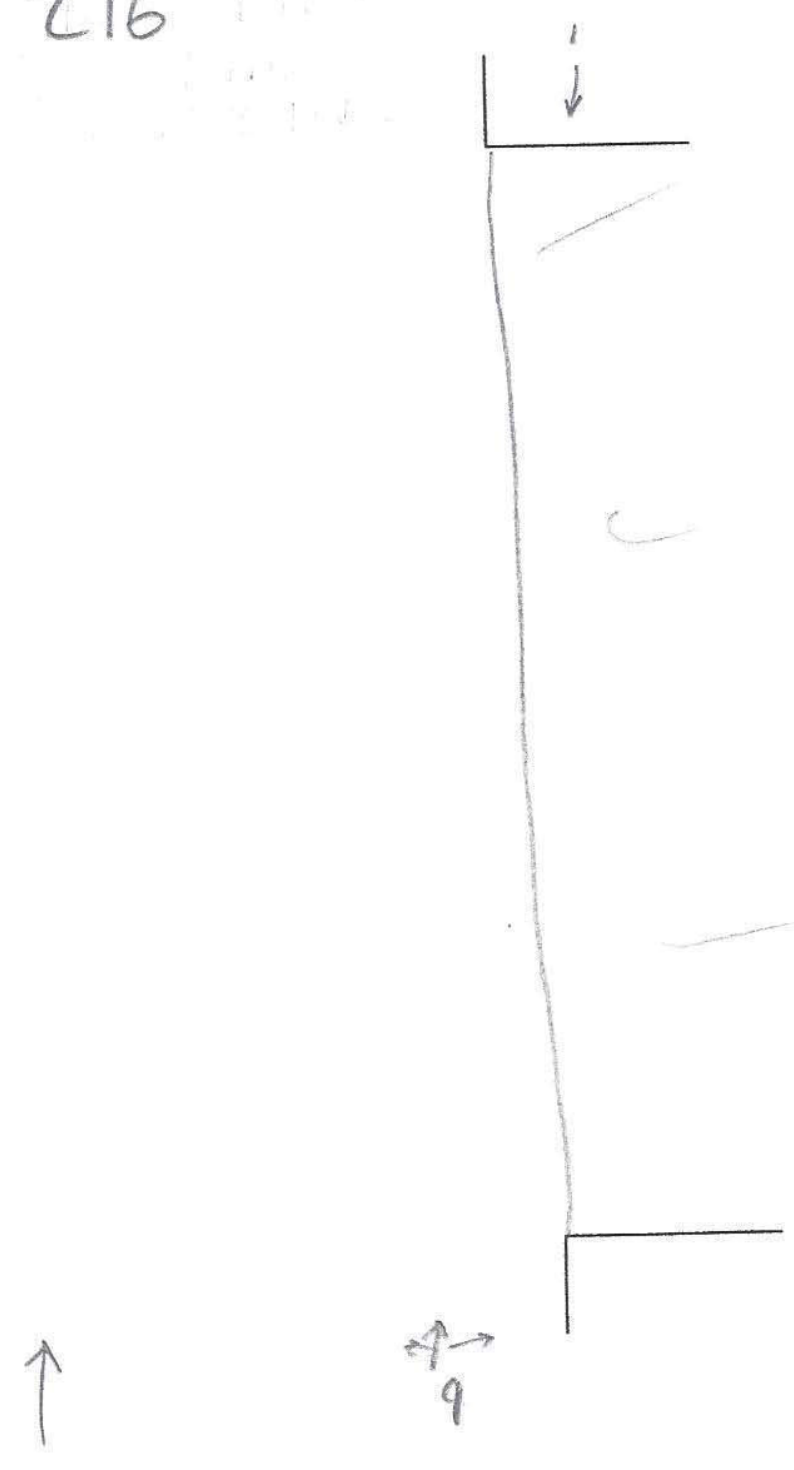

Bonita Ave

174

2

172 
Nathan Johnston

Intersection: Bonita Avenue/Correll Avenne Heaw Vehicles:

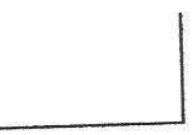

$$
3 \% N V
$$

$3 \% \mathrm{HO}$

1

comments: Comerence that therie the Surc. fire stahon adjacent to pulice station 
Nathan Johnston

Intersection:

Bunita Avenue/Correll Avenue

City:

Claremont

Location: Southern CA Northern CA Central CA Other

Intersection Type: $(T+$

Data Collection Time:

$10: 20-11: 20 \quad 7 / 5 / 13$ (Fritay)

Intersection Geometry:

North Arrow:

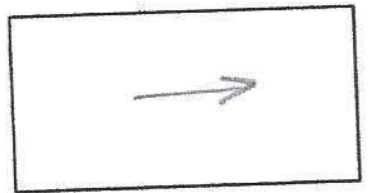

Dist to upstream (intersection/signal

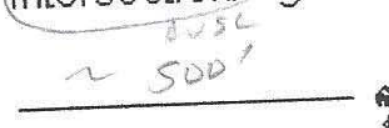

(4)
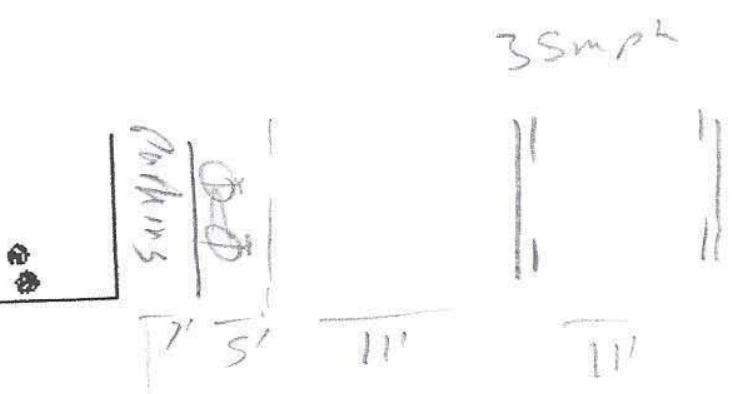

$3 \sin p^{2}$

Corac $\|$ Ave

$20^{\prime}$

$75 m p$
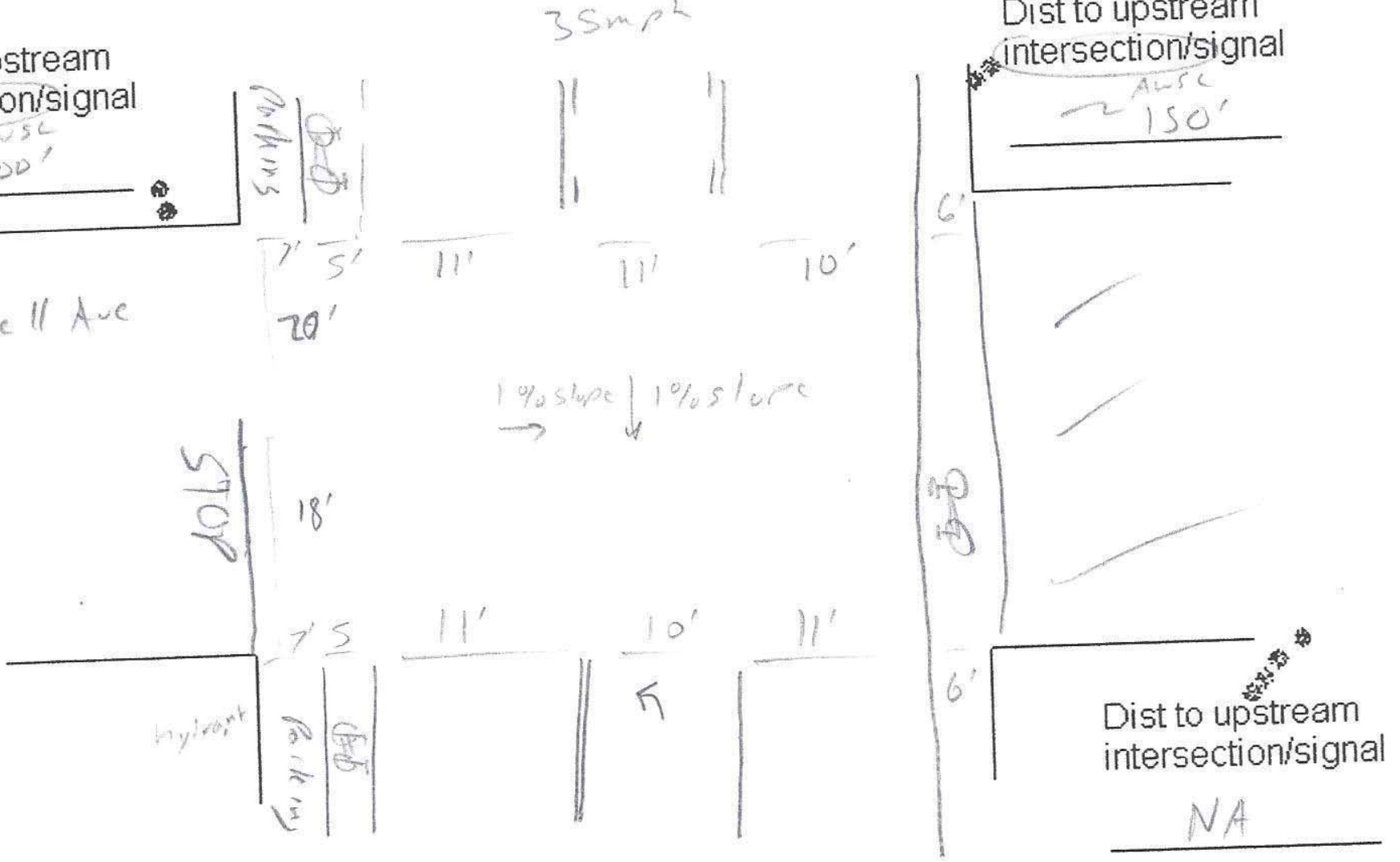

Dist to upstream Bon the $35 \mathrm{smph}$

intersection/signal

2230

comments: Police Station on South west Corne-

Bike Corner - (itwe Bikeway. Bignage)

Bike lares set back $30^{\prime}$ from in hesection, No porking Bixe lave Sust of Norto side of Street. 
Cal Poly San Luis Obispo

Nathan Johnston

Intersection: $\frac{\text { Baseline Ro-2/Grane Avenue }}{11: 30-12: 30 \quad 7 / 5 / 13}$

volumes:
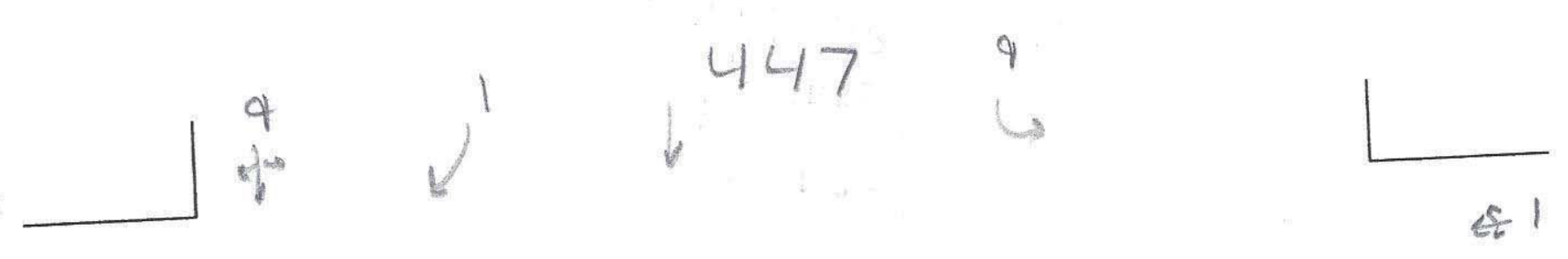

Grant Ave

$+3$

$15^{x}$

$\leftarrow 0$

$1 \rightarrow$

127

$0+4$

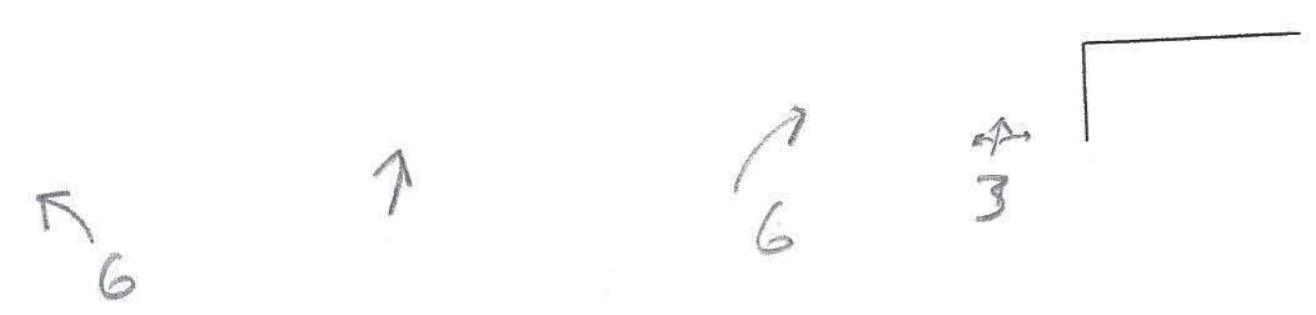

Baseline Rood 510

2

175 
Cal Poly San Luis Obispo

Nathan Johnston

Intersection:

Baseline Rool/Grand. Ave

Hear Vehicles:

$3 \%$

$1 \%$

$3 \%$

Comments:

Baseline is of route 301 is establish e trusts route.

3

176 
Cal Poly San Luis Obispo

Nathan Johnston

Intersection:

City.

Location: Southern CA Northern CA Central CA Other Intersection Type: $T$ (

Data Collection Time:

$11130-12: 30$

$7 / 5 / 13$

Intersection Geometry.

North Arrow:
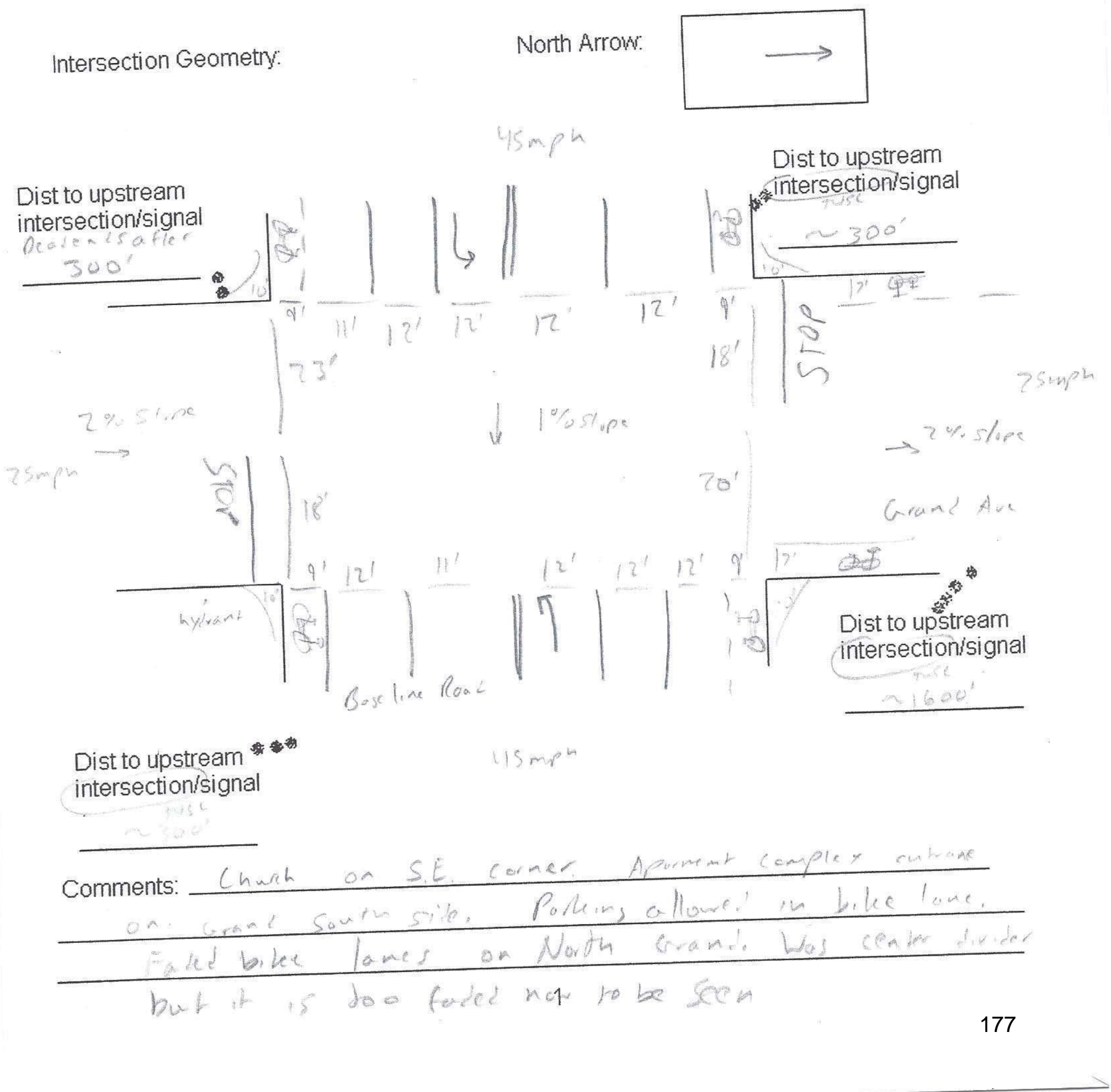
Nathan Johnston

Cal Poly San Luis Obispo

Intersection:

Butte Street/Vanderbilt Ave

City:

Claremont

Location Southern CA Northern CA Central CA Other Intersection Type: (T) +

Data Collection Time:

$8: 30-9: 30$

Intersection Geometry.

North Arrow:

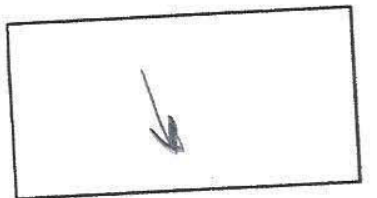

Dist to upstream intersection'signal $2200^{\prime}$

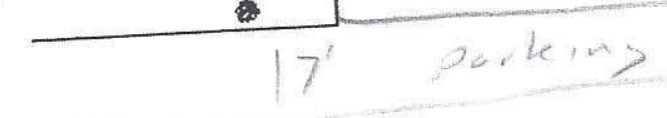

Dist to upstream
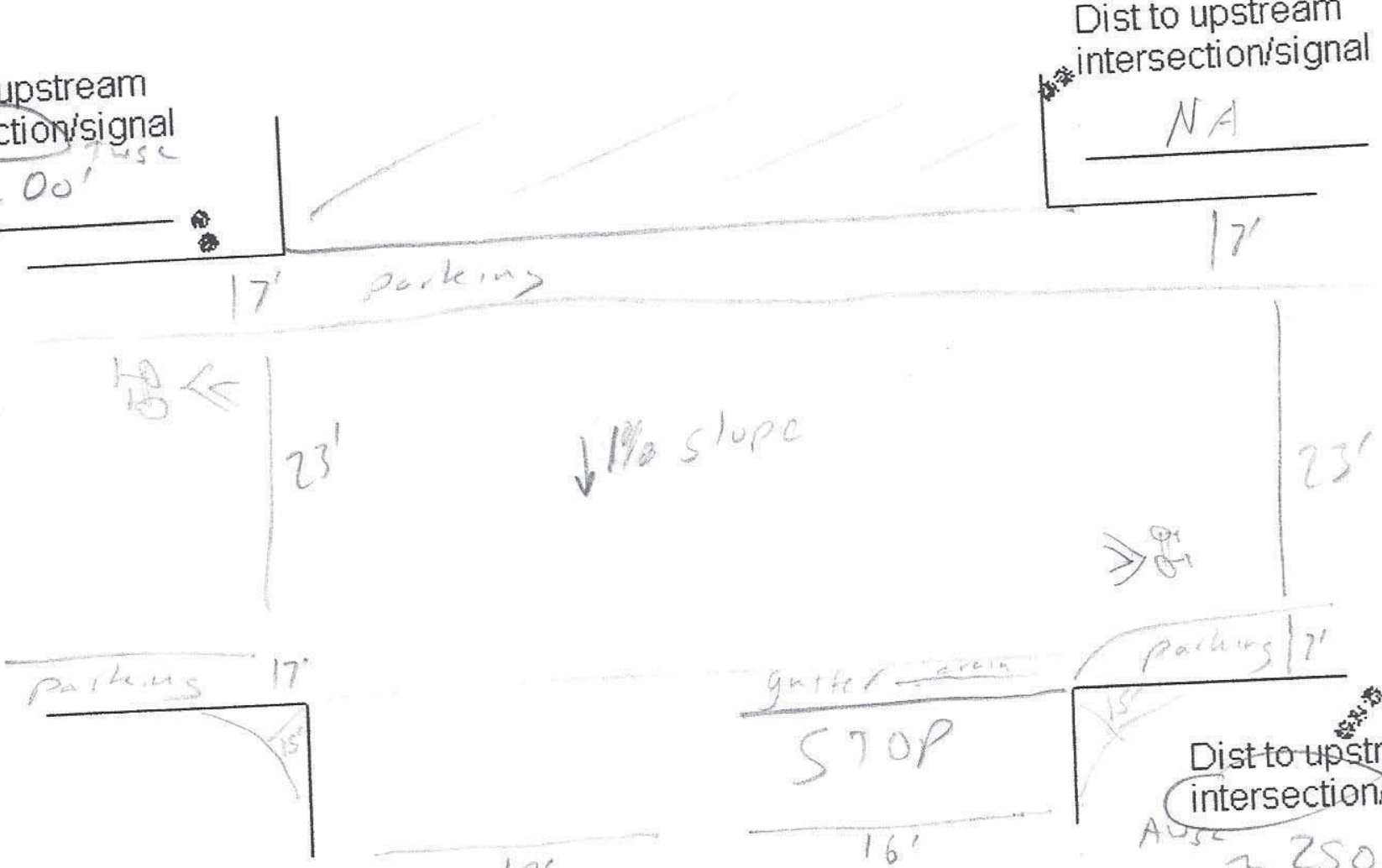

$23^{\prime}$

$v^{180} 5^{10 p e}$

$17^{\prime}$

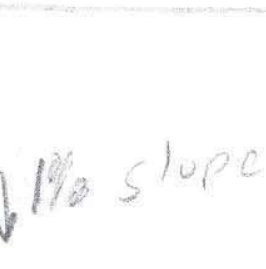

Dist to upstream

*

varderbitt

intersection/signal

$25 \mathrm{mph}$

Tus 2150

Comments:

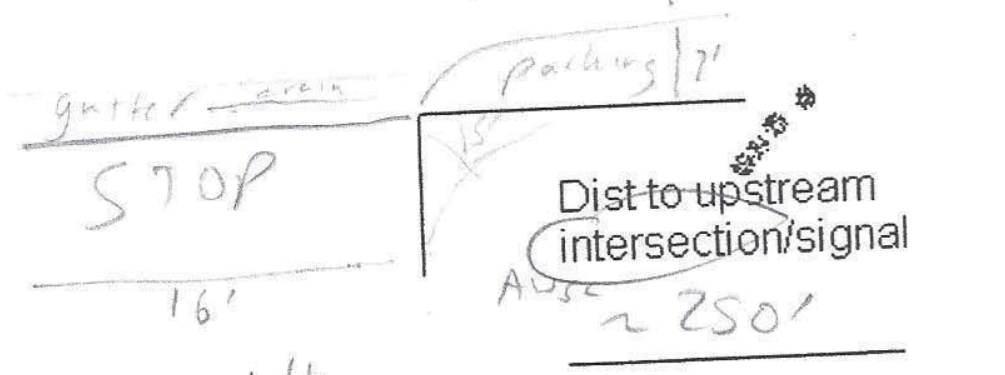

Dist to upstream

Dectionisignal

$2250^{\prime}$ 
Nathan Johnston

Intersection:

Butte Street/Uanderbilt Ave

Time Period:

Volumes:

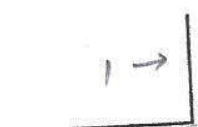

$8: 30-8: 30$ 
Nathan Johnston

Cal Poly San Luis Obispo

Intersection: Vanzerbitt Ave / Butte Streef Heaw Vehicles:
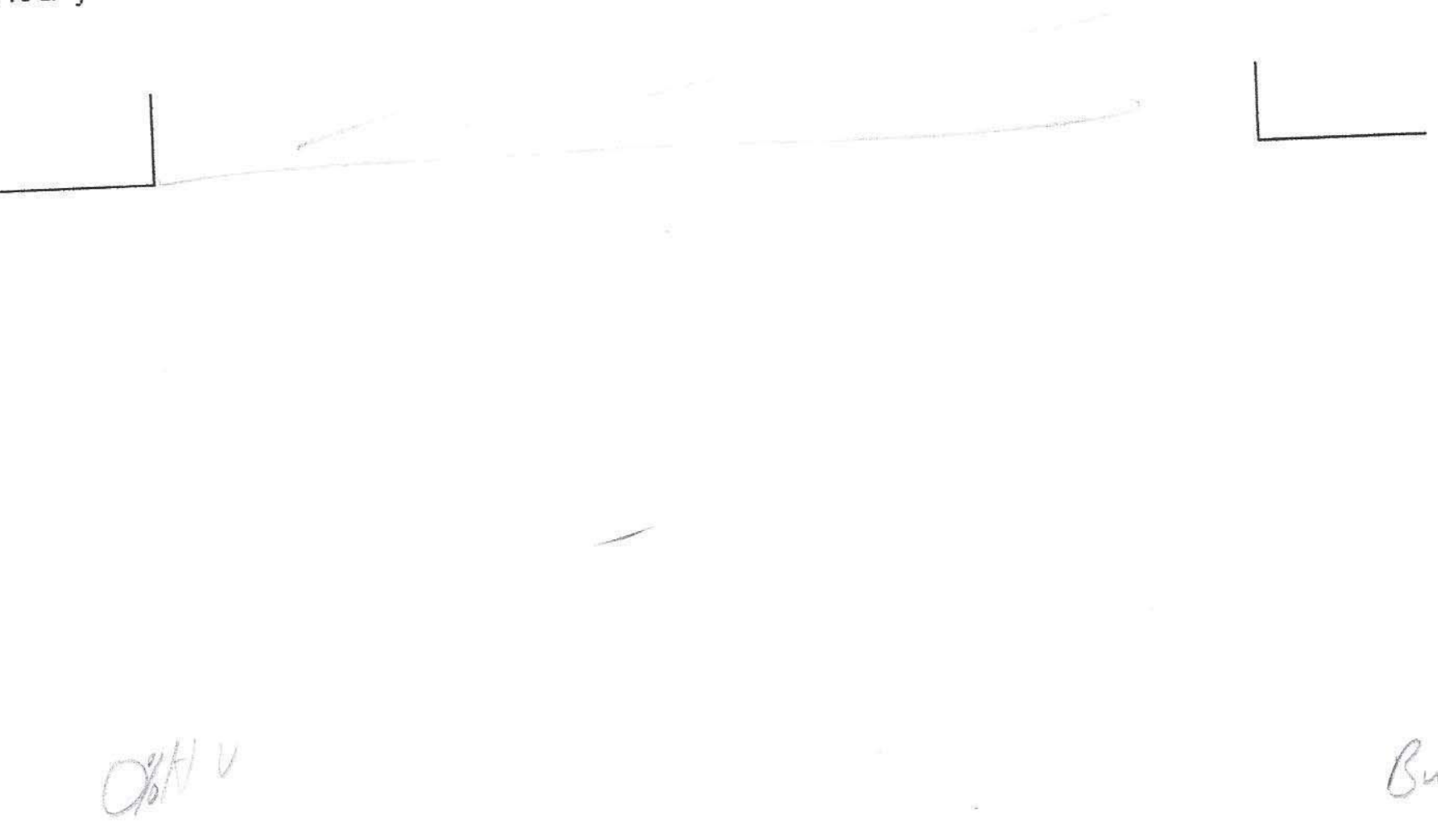

Butte

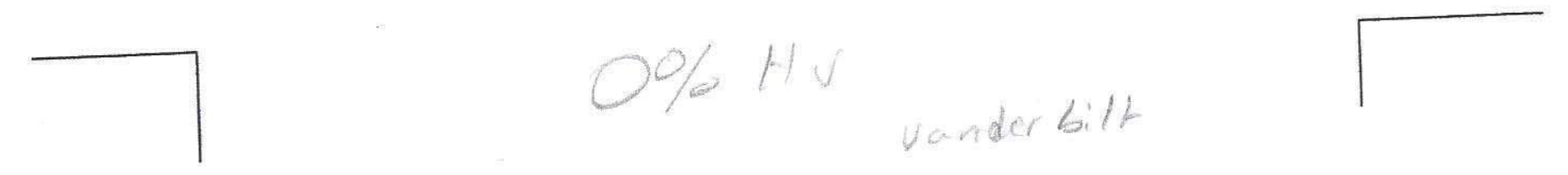

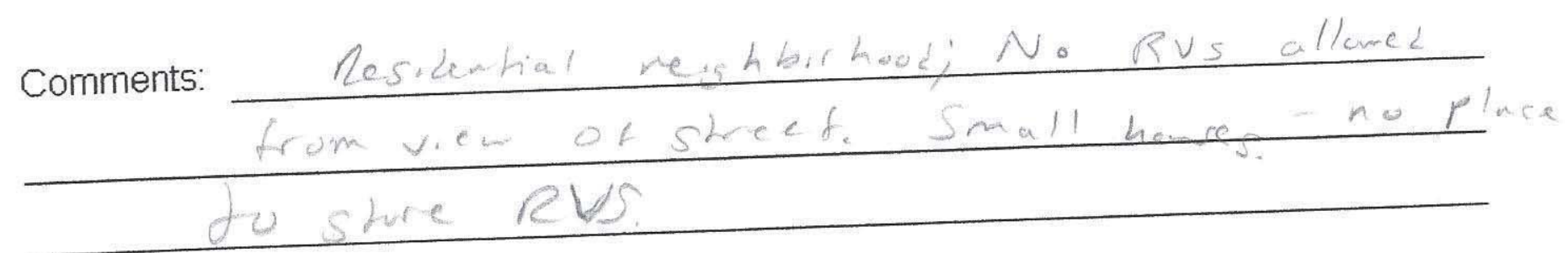


Nathan Johnston

Cal Poly San Luis Obispo

Intersection:

Cambridge Ave
Claremont

City:

Location: Southern CA Northern CA Central CA Other Intersection Type: (T) +

Data Collection Time:

$9: 50-10: 50$

Intersection Geometry:

North Arrow:

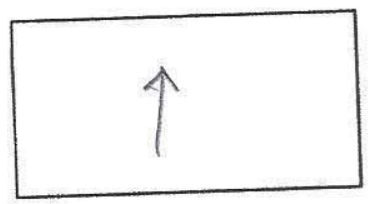

Dist to upstream intersection/signal

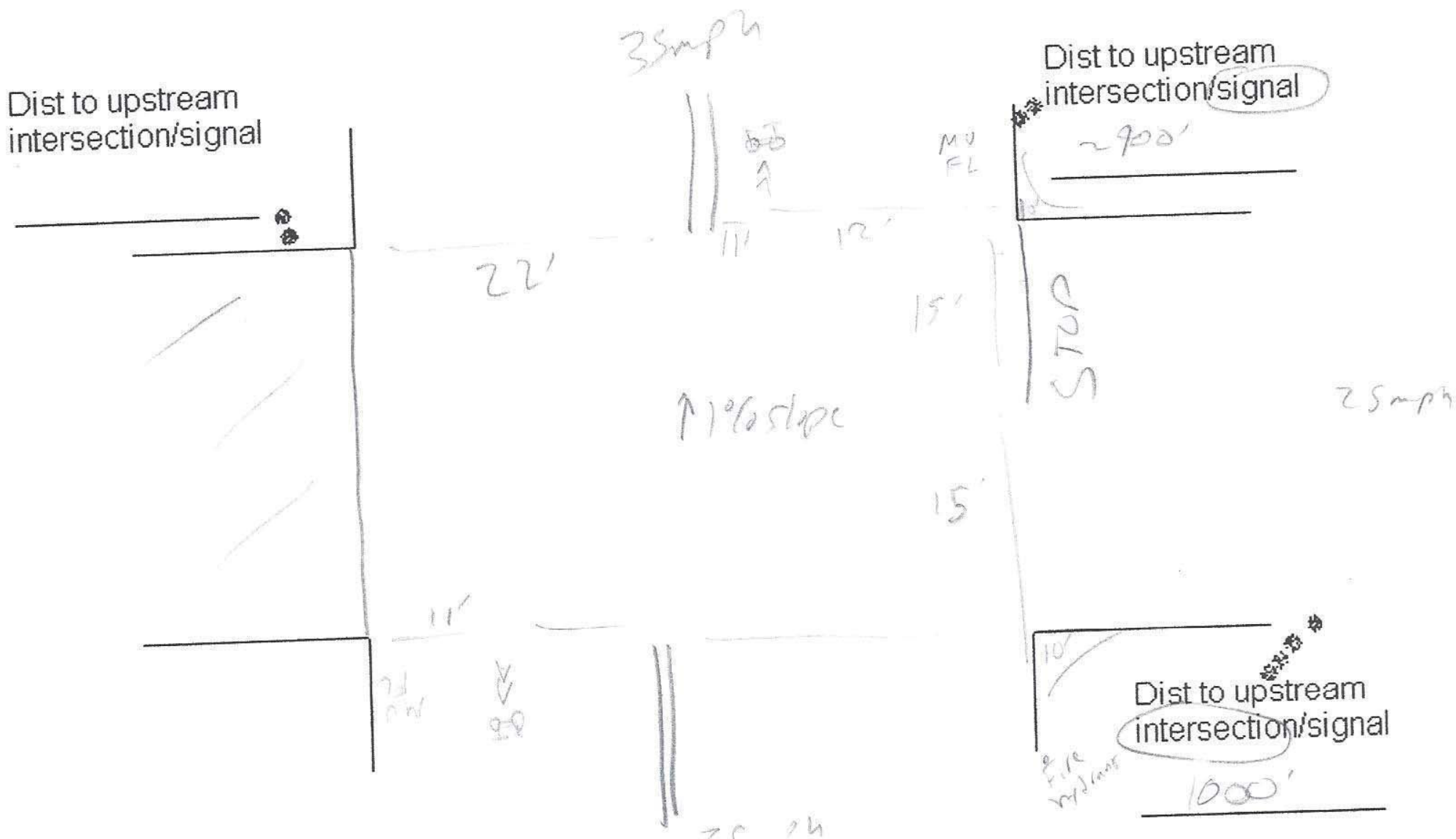

Dist to upstream intersectionisignal

$600^{\circ}$

Comments:

Full

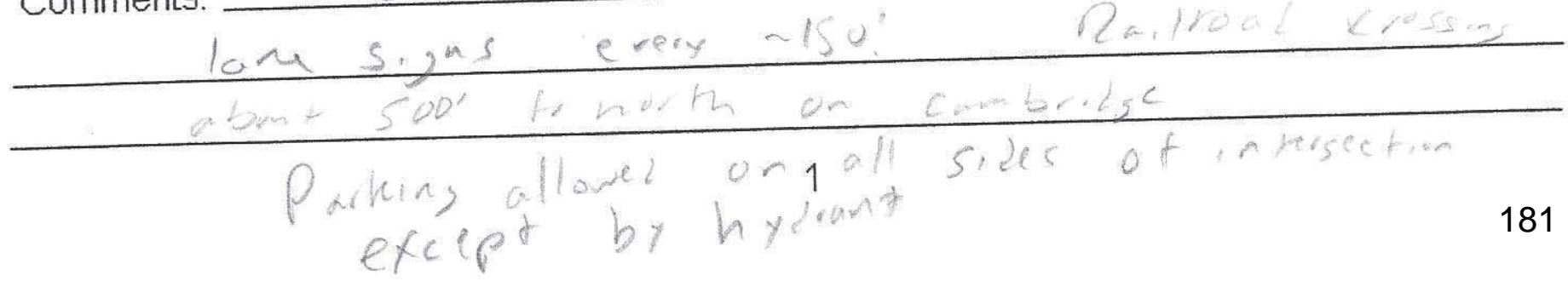


Nathan Johnston

Intersection:

Cambidge Ave/Whardon Prive

Time Period:

$9: 50-10: 50$

Volumes:
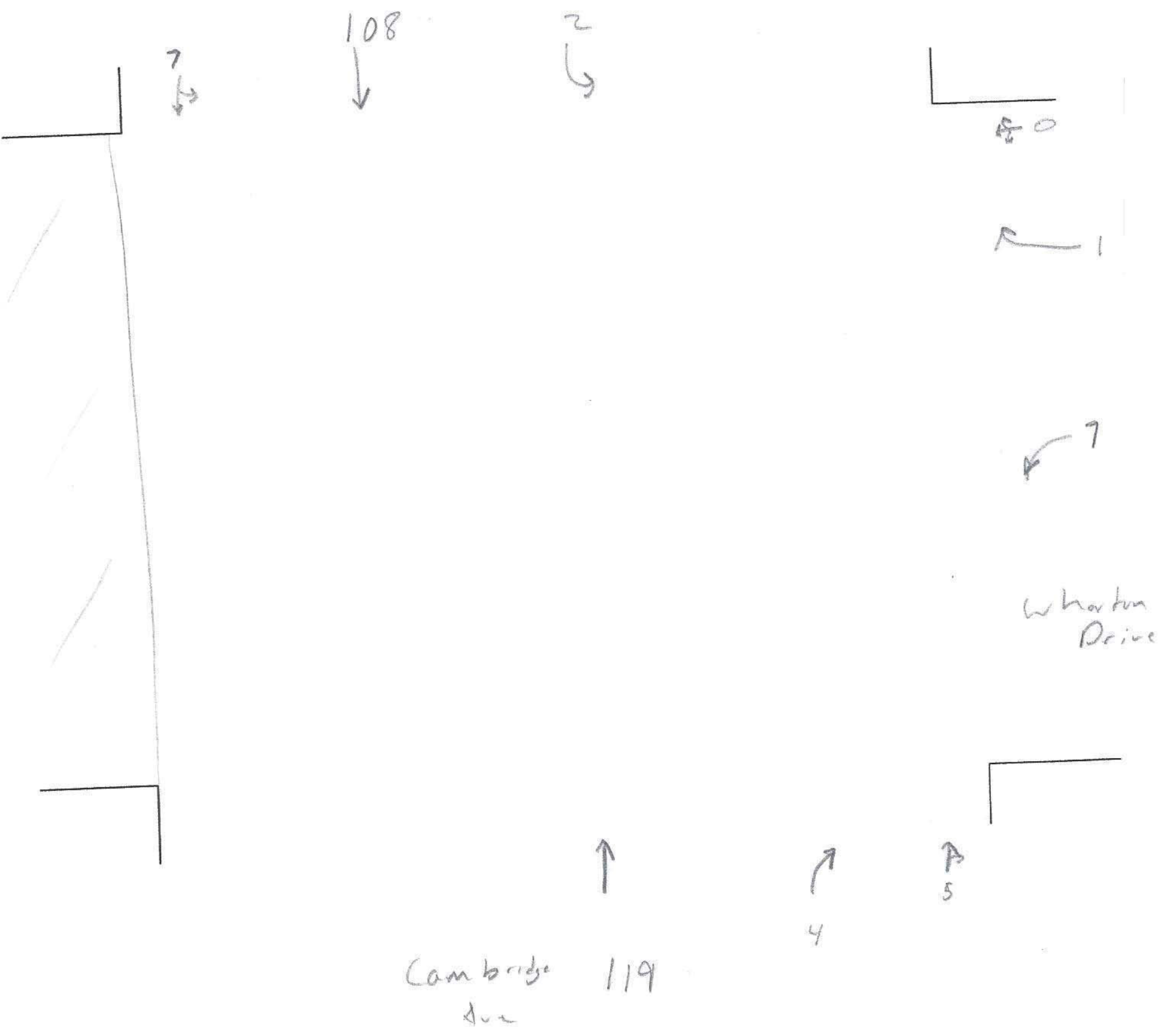
Nathan Johnston

Cal Poly San Luis Obispo

Intersection: Cambricse Ave/Whatton Pnve Heaw Vehicles:
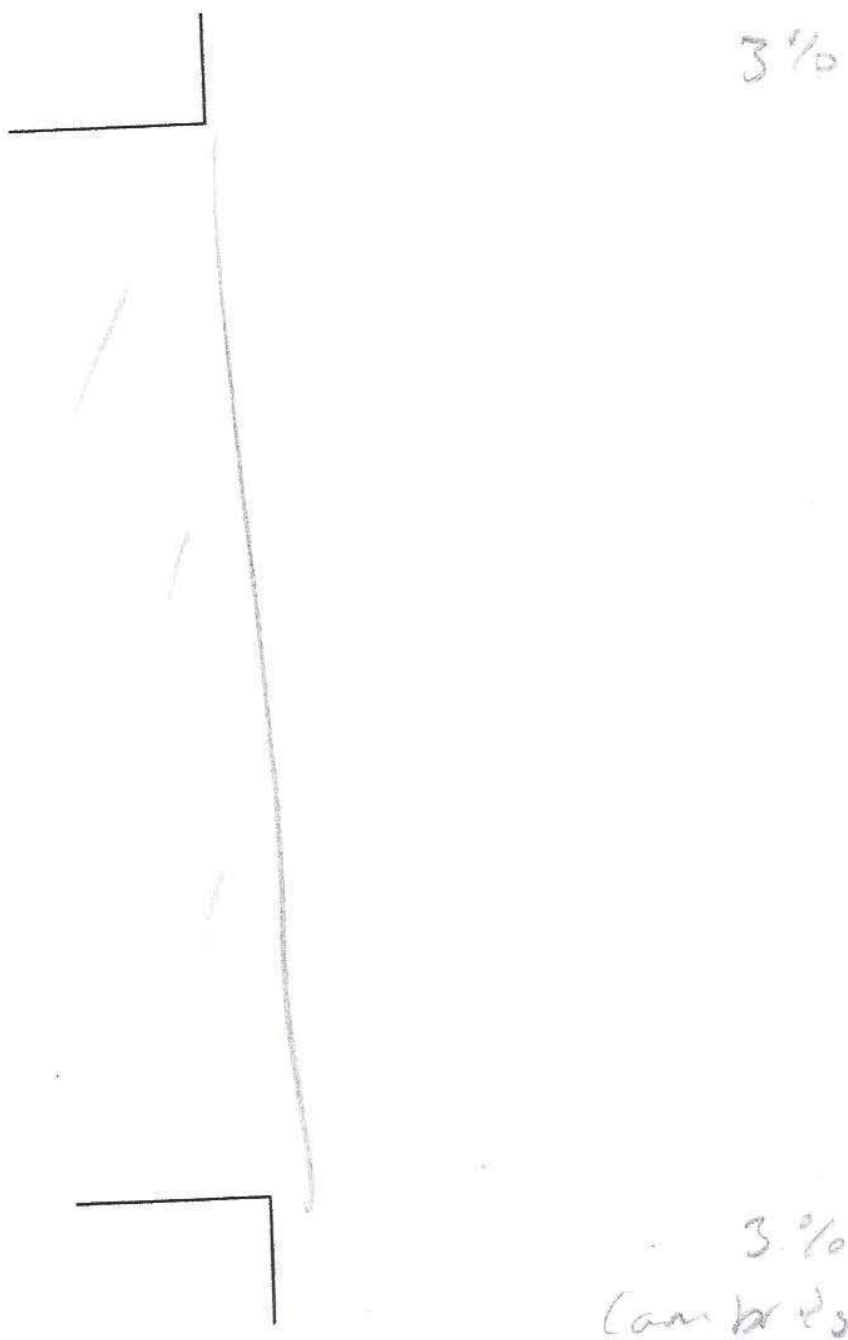

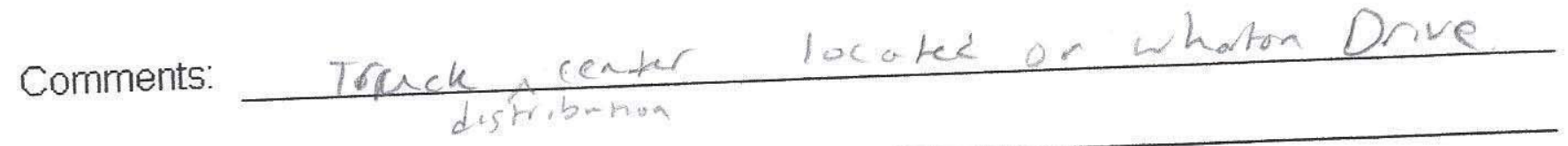


Nathan Johnston

Intersection: $\frac{\text { First street / Mills Ave }}{\text { Time Period: }}$

Volumes:

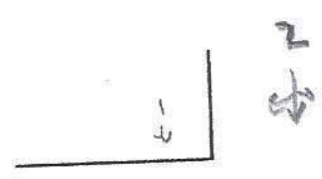

$12 \pi$

$125 \rightarrow$

$3 \longrightarrow$

$16 \div 3$
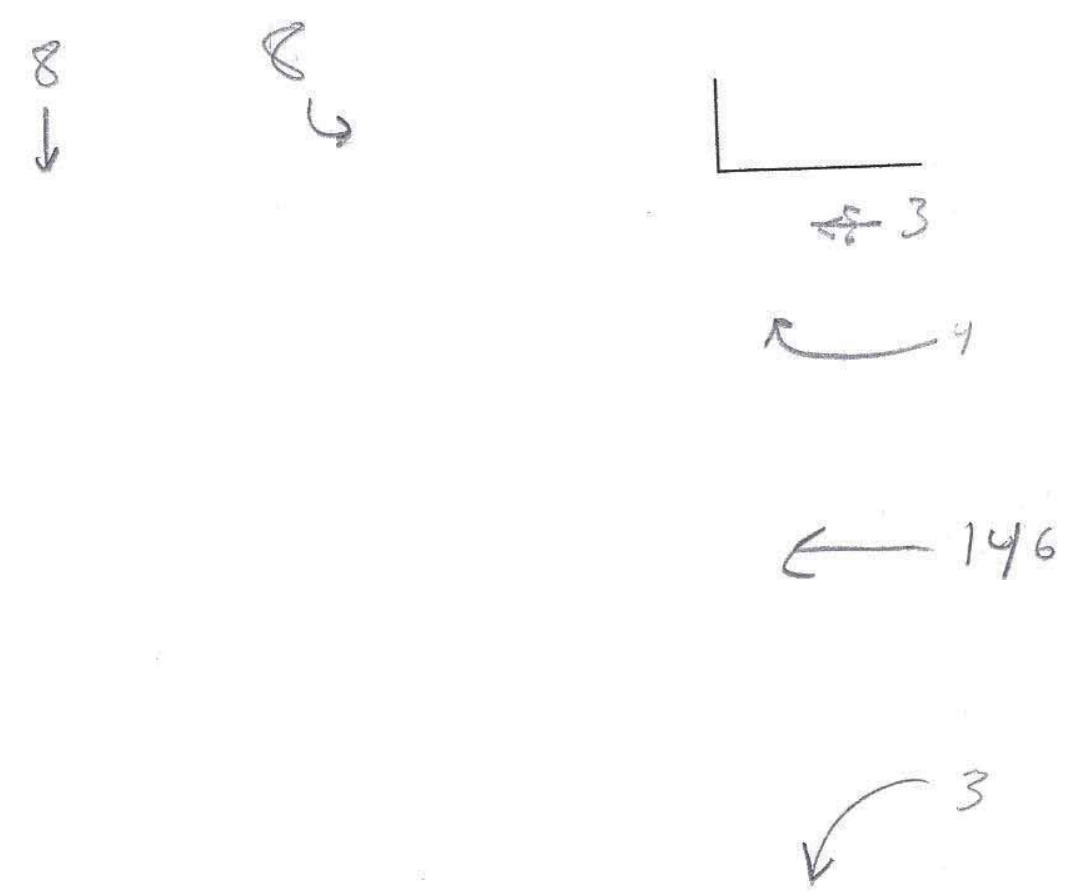

First

$$
\begin{aligned}
& \text { Molls } \\
& \text { Ave }
\end{aligned}
$$

$\pi$

8

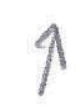

8

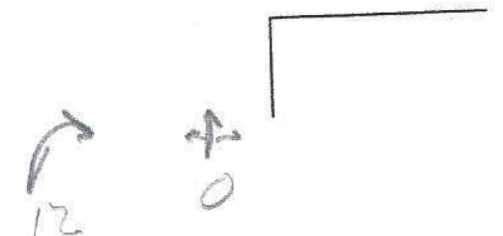


Nathan Johnston

Cal Poly San Luis Obispo

Intersection: First Strut / Mills Are

Heaw Vehicles:
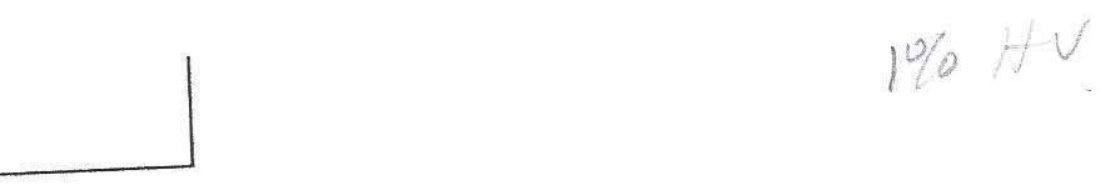

$7 \%$

$7 \% \quad H V$

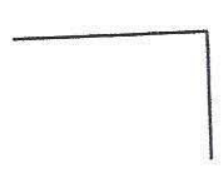

$$
2 \% \mathrm{HU}
$$

comments: Bus route alons 1st street. Bothdirectives 
Nathan Johnston

Cal Poly San Luis Obispo
Intersection:
First street/Mils Ave
City.
Claremont
Location Southern CA Northern CA Central CA Other Intersection Type: $\mathrm{T}+$

Data Collection Time:

$11: 00-12: 00$

Intersection Geometry.

North Arrow:

Dist to upstream intersectionsignal
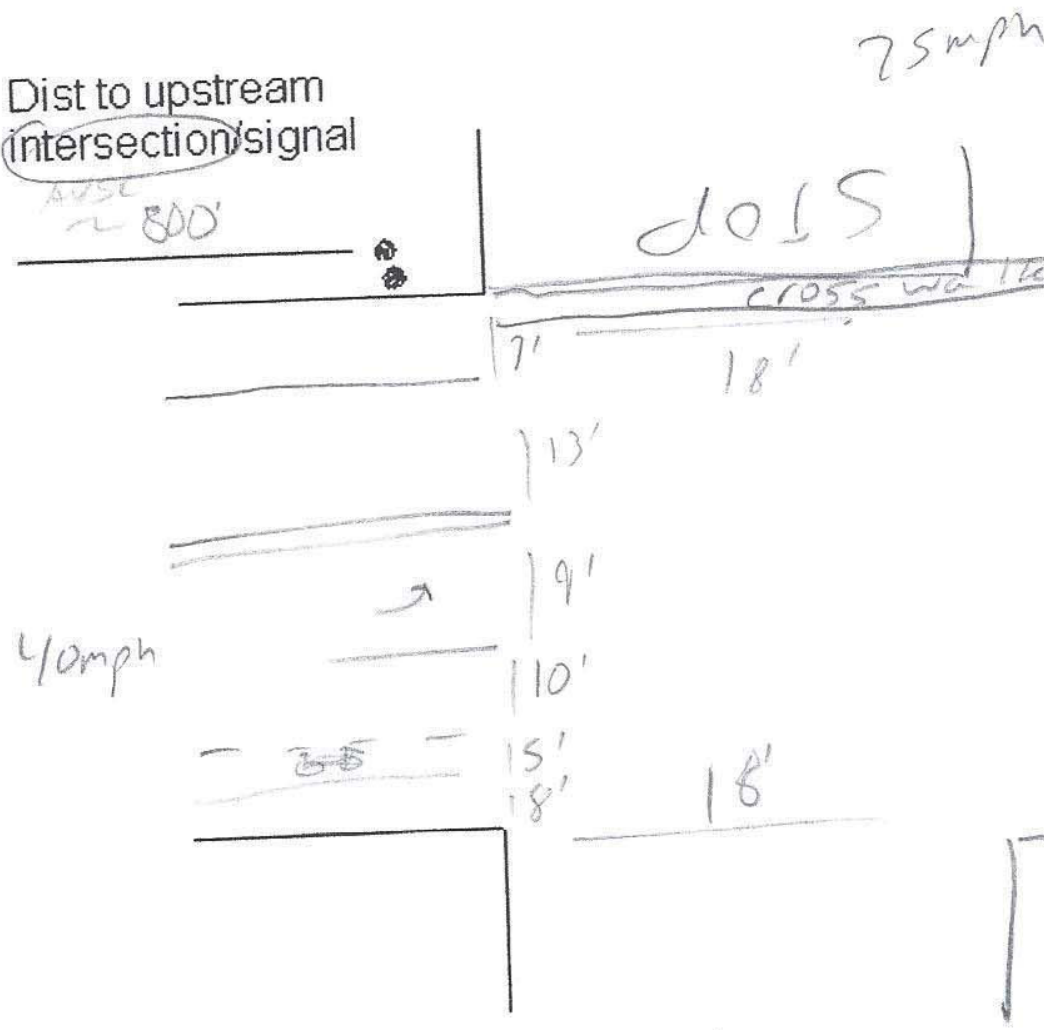

mills

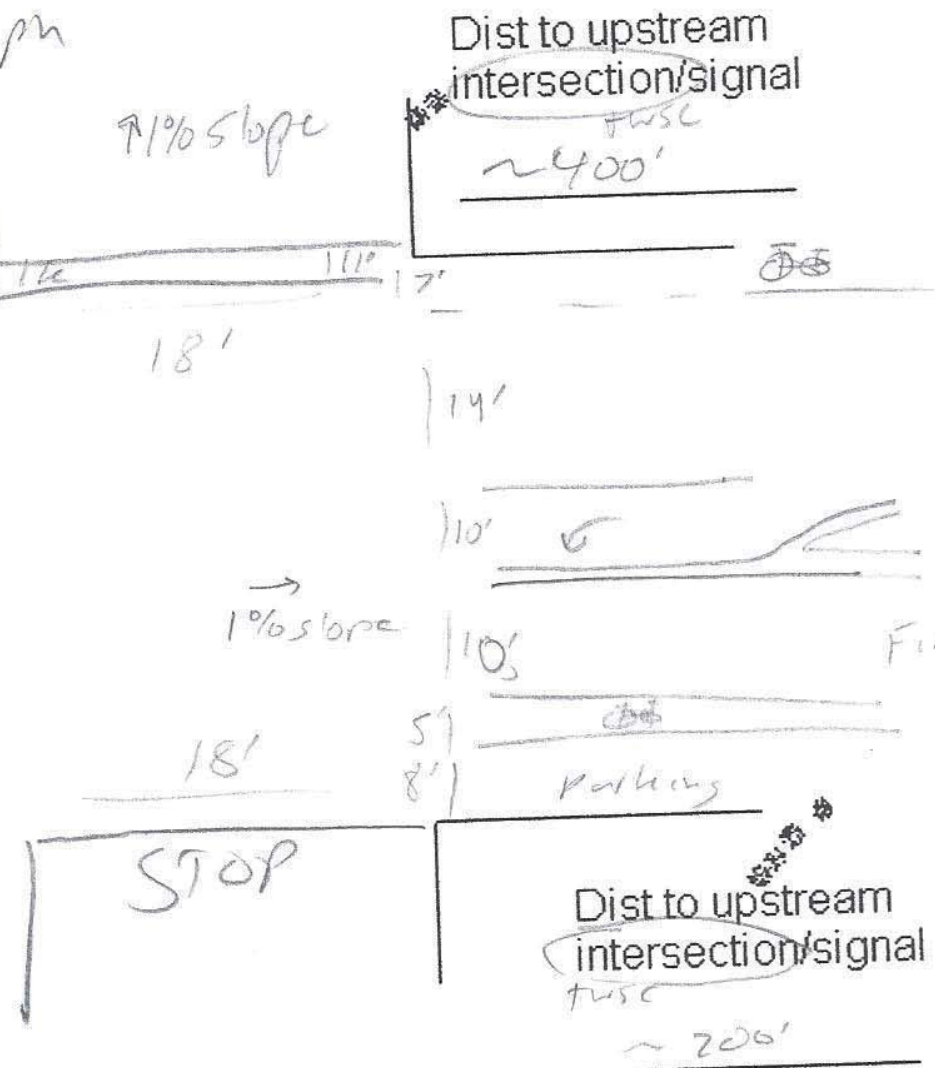

Dist to upstream

*

intersection/signal

Notathrough Street Z150'

Comments:

South side has schuol Almin building pomuna college. Lars come $B$ go from there 
Nathan Johnston

Intersection:

Mountain Avenue/Butie Street/ $8^{\text {th }}$ Street

City.

Claremint

Location: Southern CA Northern CA Central CA Other Intersection Type: $T \notin$

Data Collection Time:

$10,00 \cdot 11: 00$

thes

$7 / 28 / 13$

Intersection Geometry.

North Arrow:

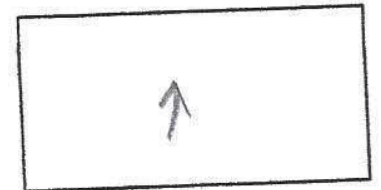

Dist to upstream intersectionisignal

twosc
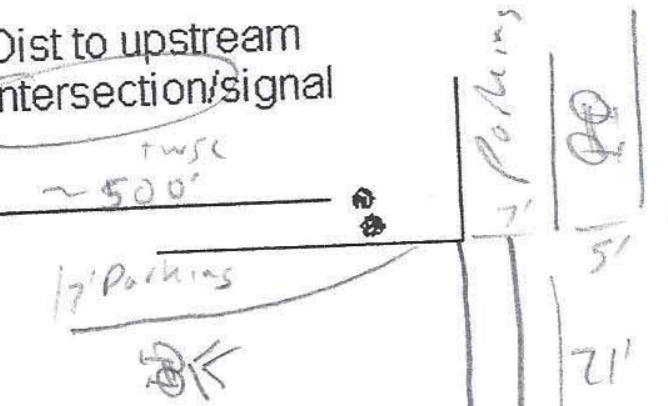

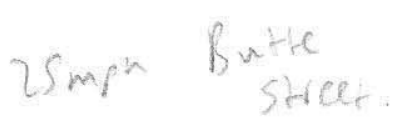

$\overline{\sqrt{7 \text { paining }}}$
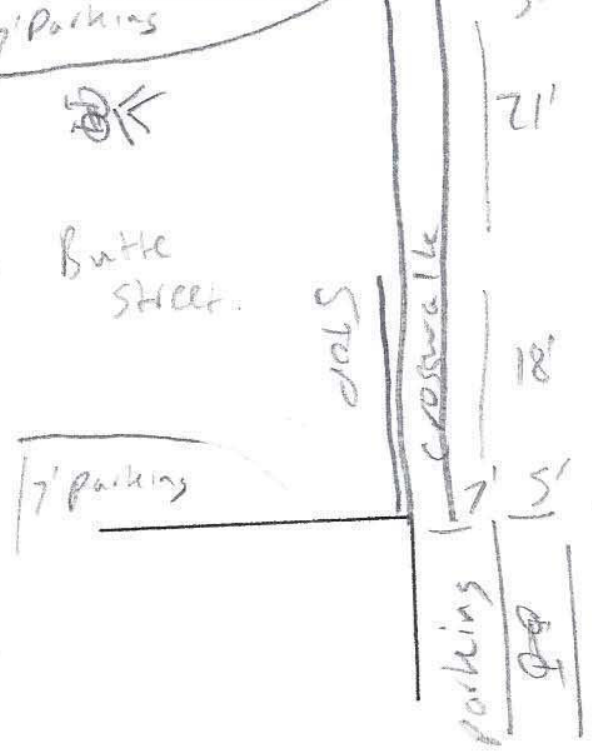

Monarain

$40 m p^{n}$

Dist to upstream

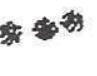

Ave

Yorpen

$\gamma^{\prime}$

Dist to upstream
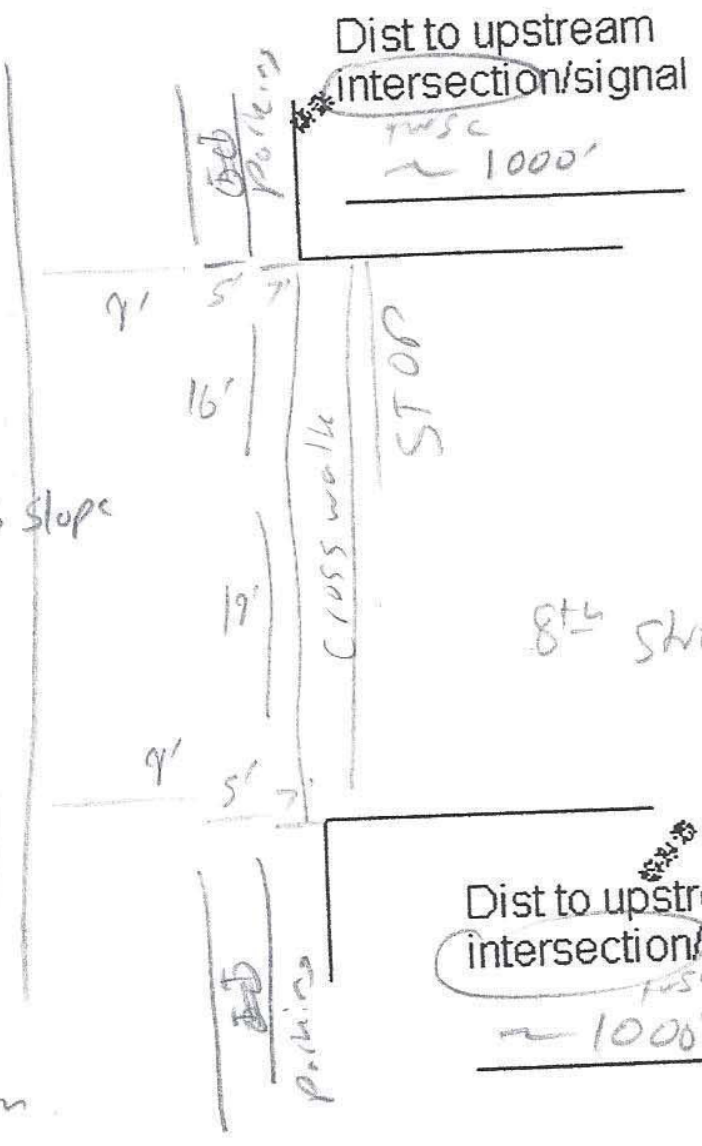

$25 \mathrm{mph}$

intersection/signal

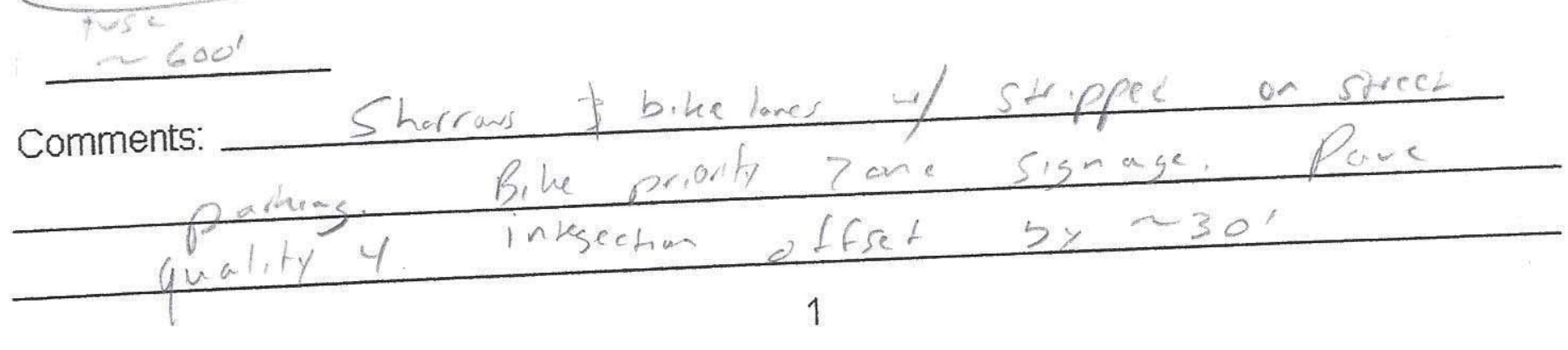


Nathan Johnston

Cal Poly San Luis Obispo

Intersection: Monntain Ave/Butte Sreet/8 $/ 8^{\text {th }}$ strect

Time Period:

$10: 00-11: 00$

Volumes:

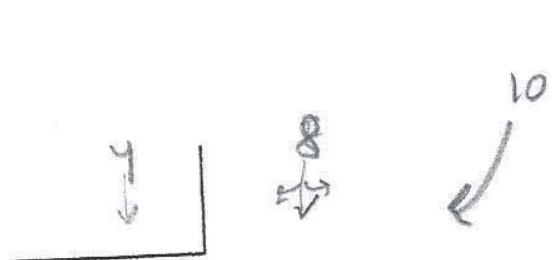

オ

$14 \longrightarrow$

$13-9$

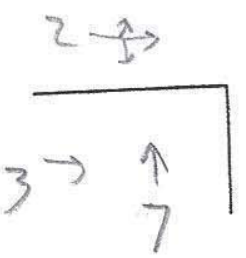

137

$\downarrow$

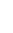

22

$\hookrightarrow$

$\frac{\leftarrow 3}{\leftarrow 1}$

$+12$

$\longleftarrow 13$

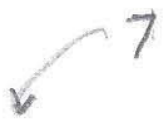

$\uparrow$

$\Gamma$

$\underset{5}{11}$

2

89

4 
Cal Poly San Luis Obispo

Nathan Johnston

Intersection: Mountain Avenuc/Butte Street/8th Street

Hear vehicles:

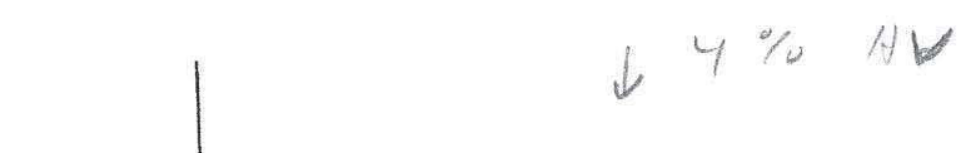

$$
\leftarrow 1 \% \text { H }
$$

$1 \% \mathrm{HV}$

$\uparrow 4 \% \mathrm{Hr}$

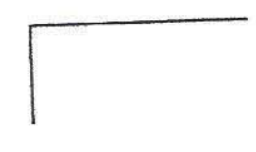

Comments: School a few blocks away or mountain = Buses.

3

189 
Nathan Johnston

Intersection:

Lagoon Road/Harold Frank Roal

City.

$$
\text { Goleta (UCSB) }
$$

Location: Southern CA Northern CA Central CA Other

Intersection Type: $(T+$

Data Collection Time:

$45 \cdot 21457 / 26 / 13$ Fridax

Intersection Geometry:

North Arrow:

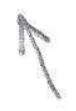

Dist to upstream

intersectionisignal

$2 \operatorname{sim} p^{h}$

$\operatorname{lsm} p^{n}$
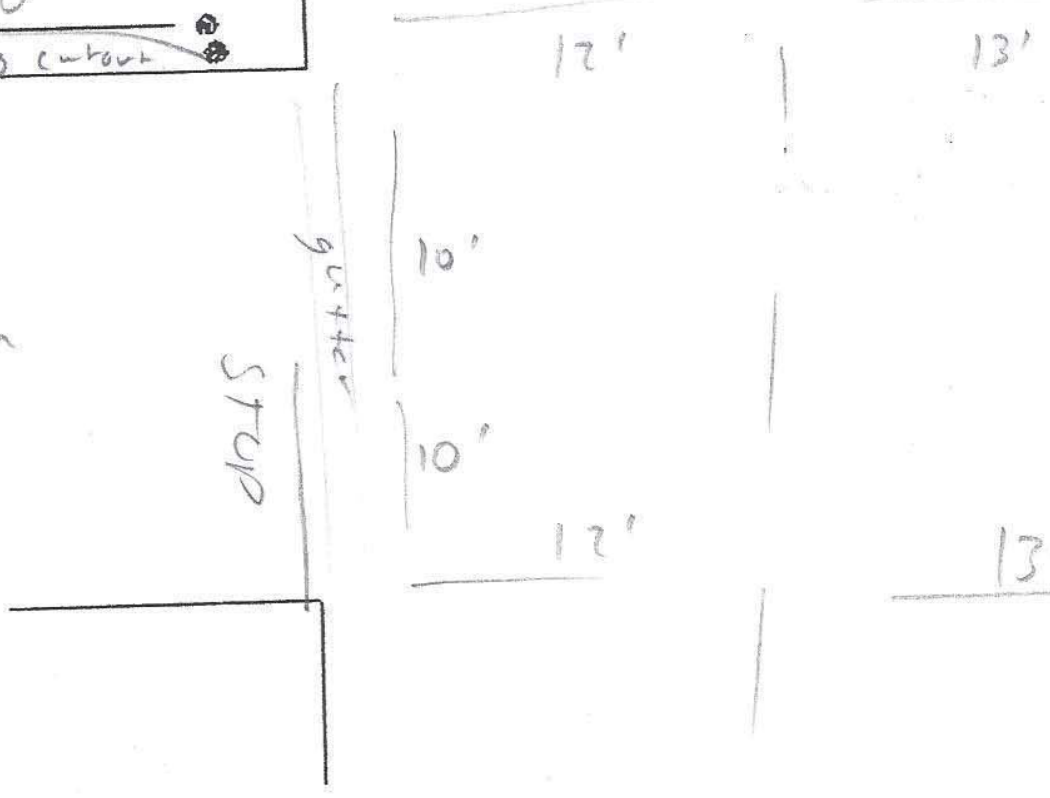

pakiazcurtout

Dist to upstream

intersection/signal
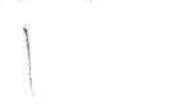
Nathan Johnston

Cal Poly San Luis Obispo

Intersection: Lagoon Roal/Hardl Frank Roar

Time Period: $1: 45-2: 45$

Volumes:
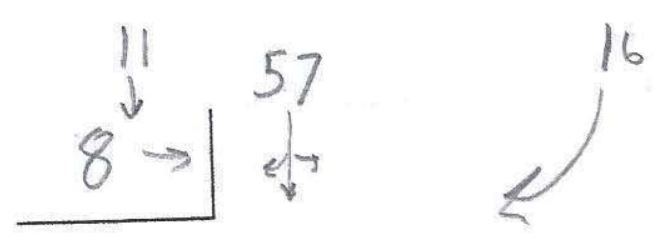

234
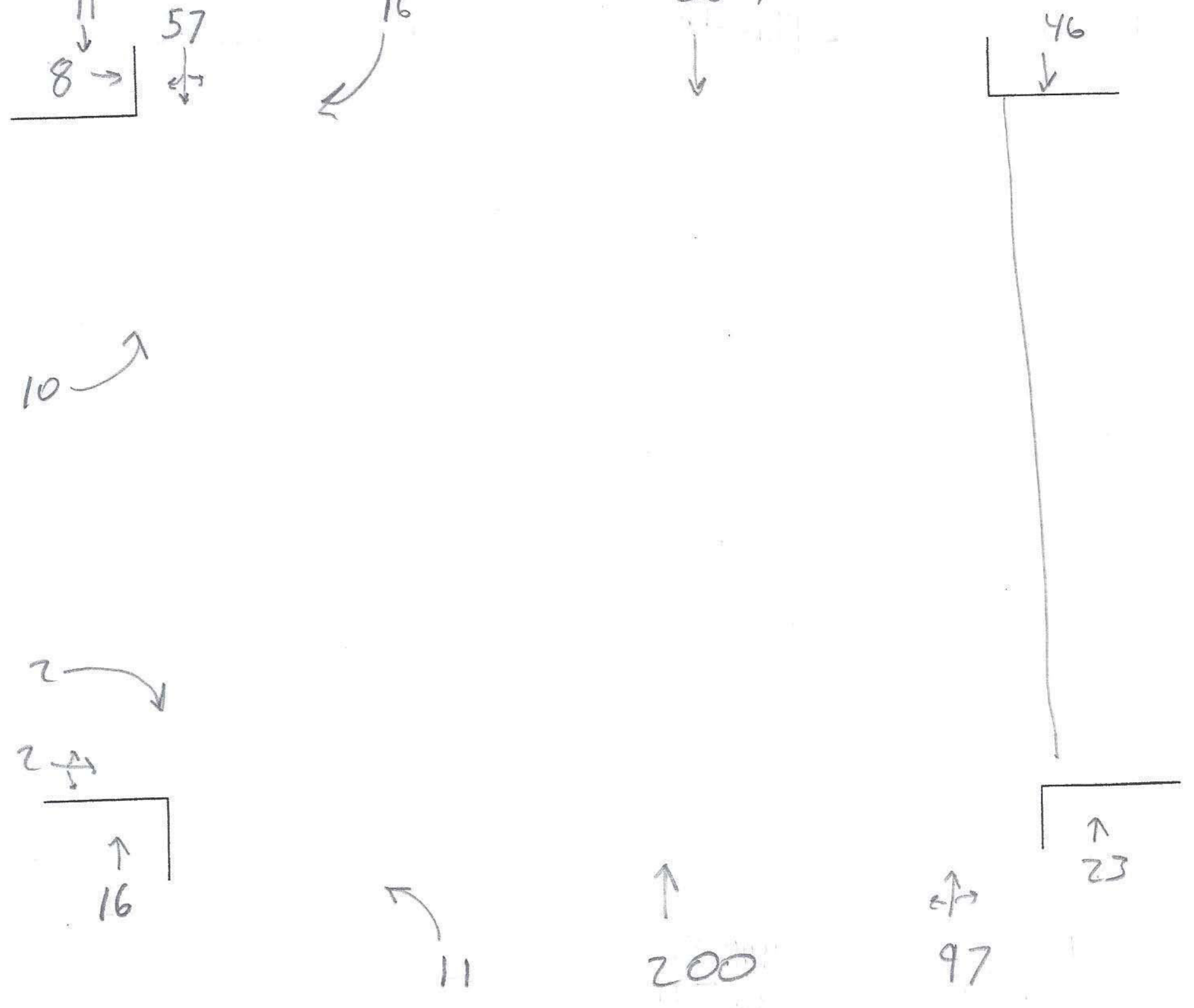

2

191 
Nathan Johnston

Cal Poly San Luis Obispo Intersection: Lagoon Roal/Haroll Franh Rand Heaw Vehicles:

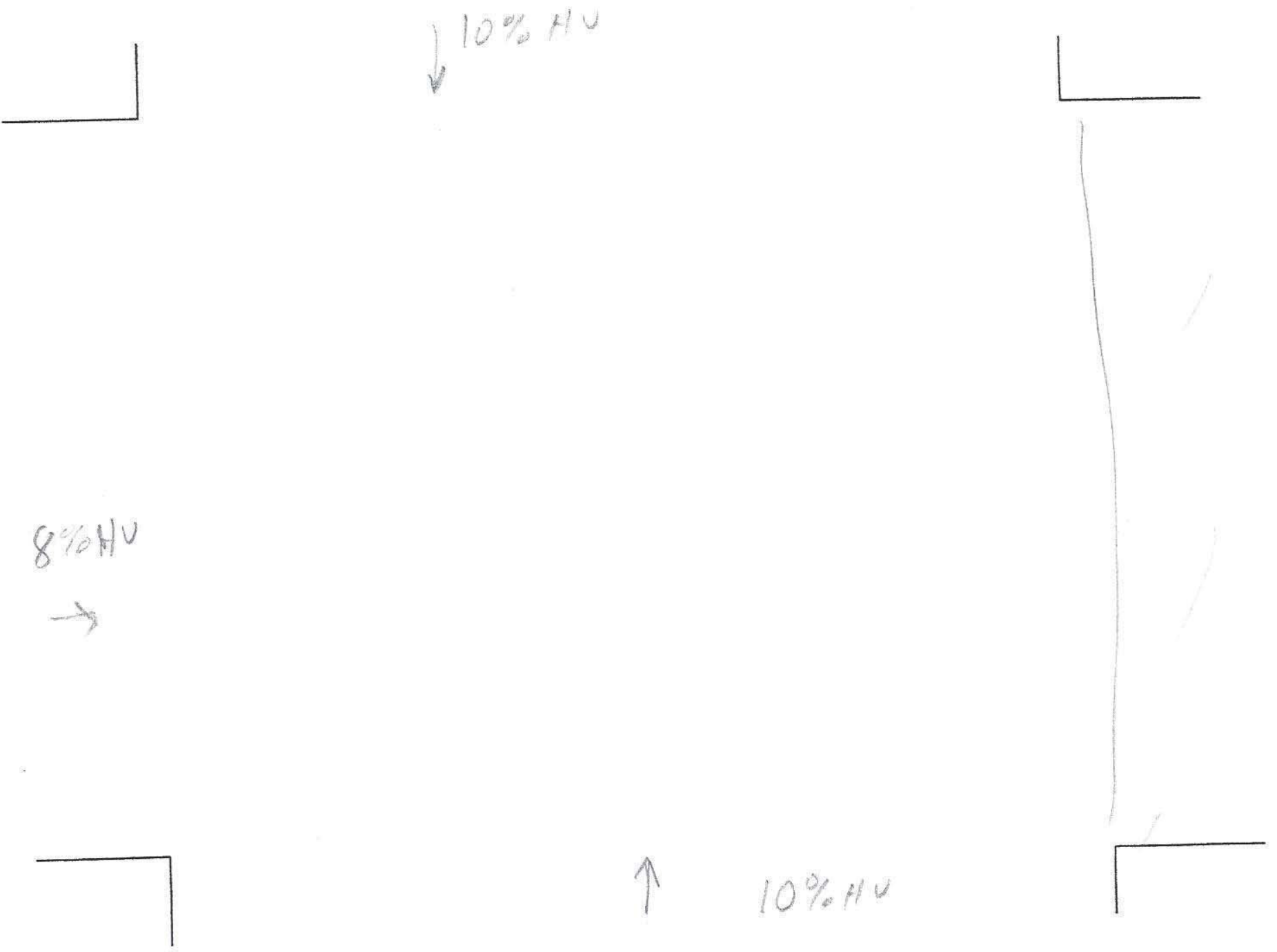

Comments: 
Nathan Johnston

Intersection: North La Patera Lane/Coviegtor Way

City.

Location: Southern CA Northern CA Central CA Other Intersection Type: $T+$

Data Collection Time:

$9: 00-10: 00$

$7 / 26 / 13$

Fricay

Intersection Geometry:

North Arrow:

1

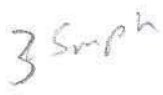

Dist to upstream intersectionisignal

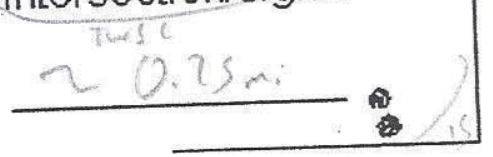

$25 m p$

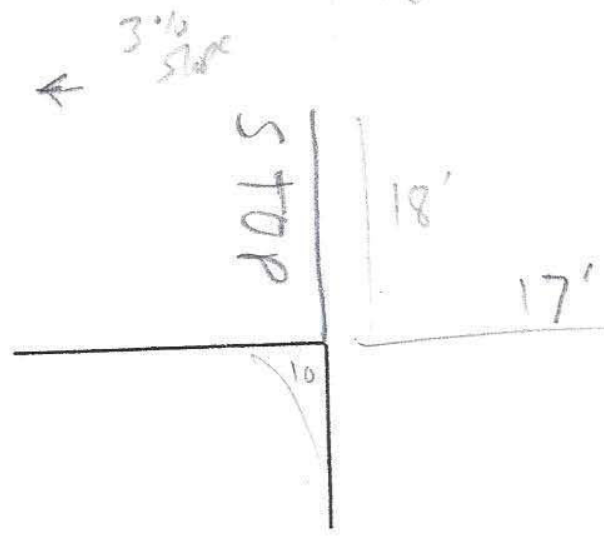

Dist to upstream intersection/signal

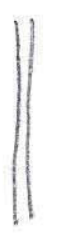

171

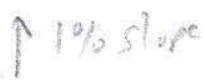

$22^{\prime}$

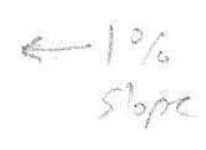

Dist to upstream intersection/signal

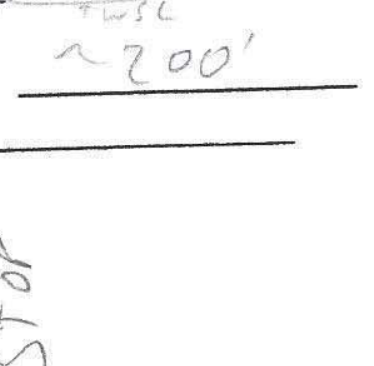

$7^{\operatorname{Sin} \mathrm{ph}^{2}}$ $\sim 1000^{\prime}$

Comments:

Sh houl Signage.

Pavemer. towality 4

On street parking 
Nathan Johnston

Intersection: N.La Pater - Lanc/Coving ton Way

Time Period:

$9: 00-10: 00$

Volumes:
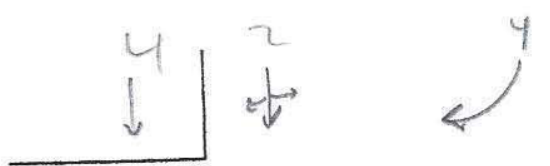

$\downarrow 3$

$\underset{2}{\longrightarrow}$

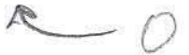

1

2
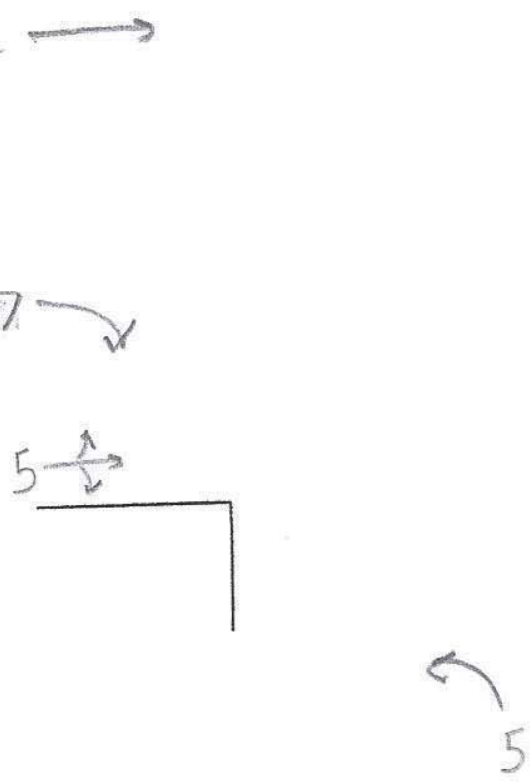

$\uparrow$

17

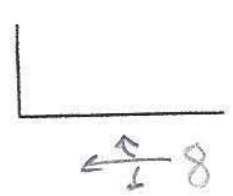

C 0
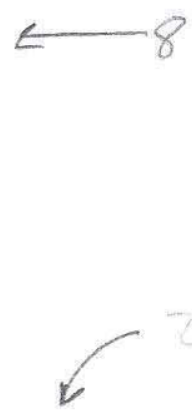

$7 \times$

$5 \stackrel{2}{2}$

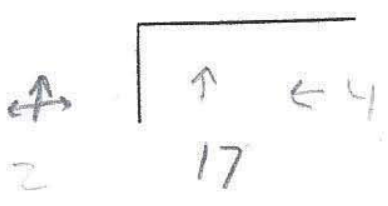


Nathan Johnston

Intersection: N. La Prerr lane/Cosington Way

Heaw vehicles:
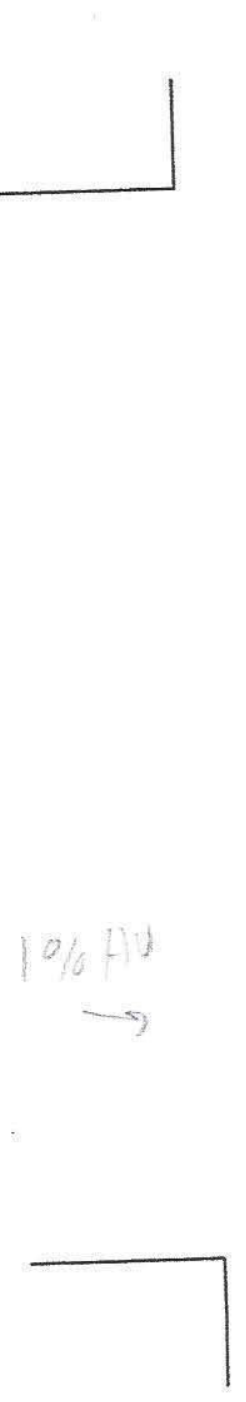

Comments: 
Nathan Johnston

Intersection: Cathedrat Oaks Road/North La Pakera Lane

City.

Goleta

Location: Southern CA Northern CA CentralCA Other Intersection Type: $T+$ Data Collection Time:

Intersection Geometry:

North Arrow:

$40 \mathrm{~min}^{\mathrm{h}}$

Dist to upstream intersectionisignal

$30 \mathrm{mp}^{n}$

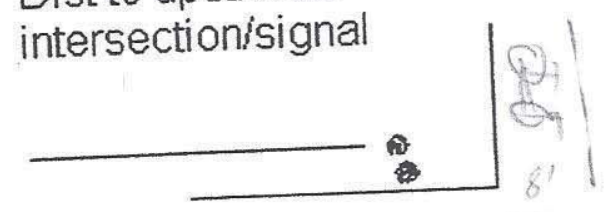

$10: 05-11: 05$

$726 / 13$ Freat

La Priner

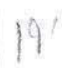

Dist to upstream

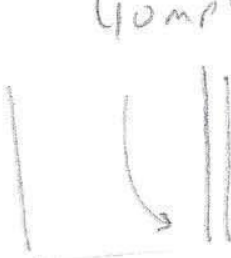

intersectionisignal

$$
\text { Cothedrat oaks }
$$

Dist to upstream intersectionisignal

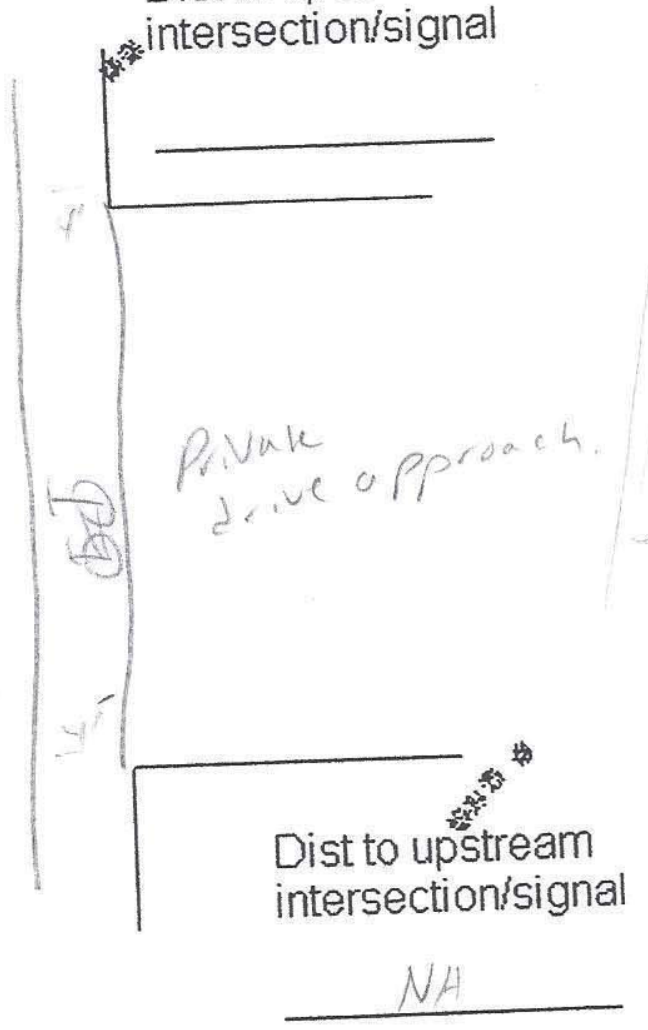

comments:
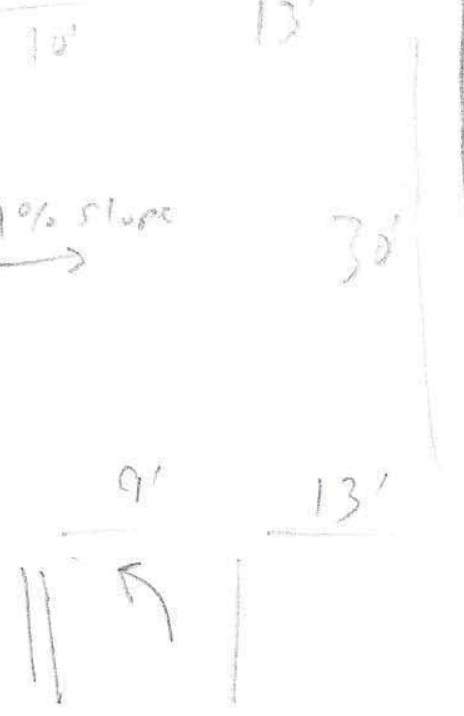
Nathan Johnston

Intersection:

Catuiral ooks Poot/lan Putera lane

Time Period:

$10: 05-11: 05$

Volumes:
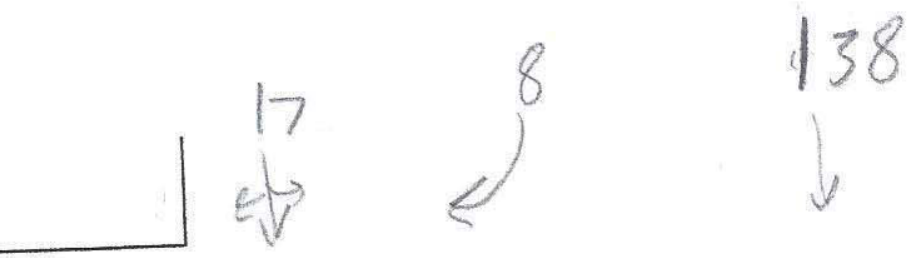

7
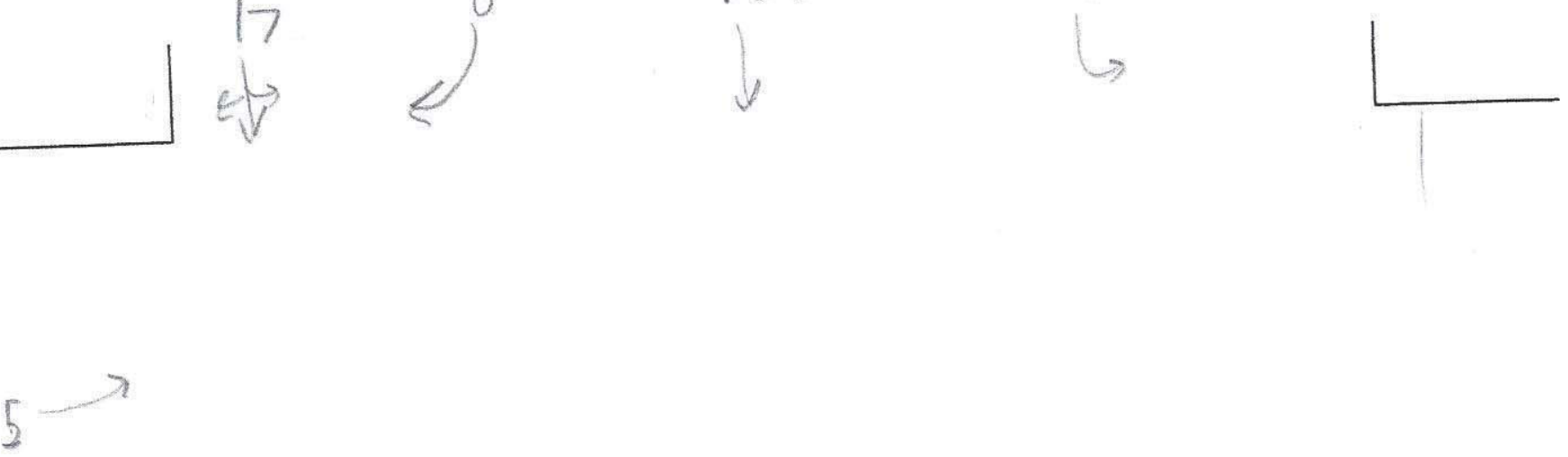

$16-1$
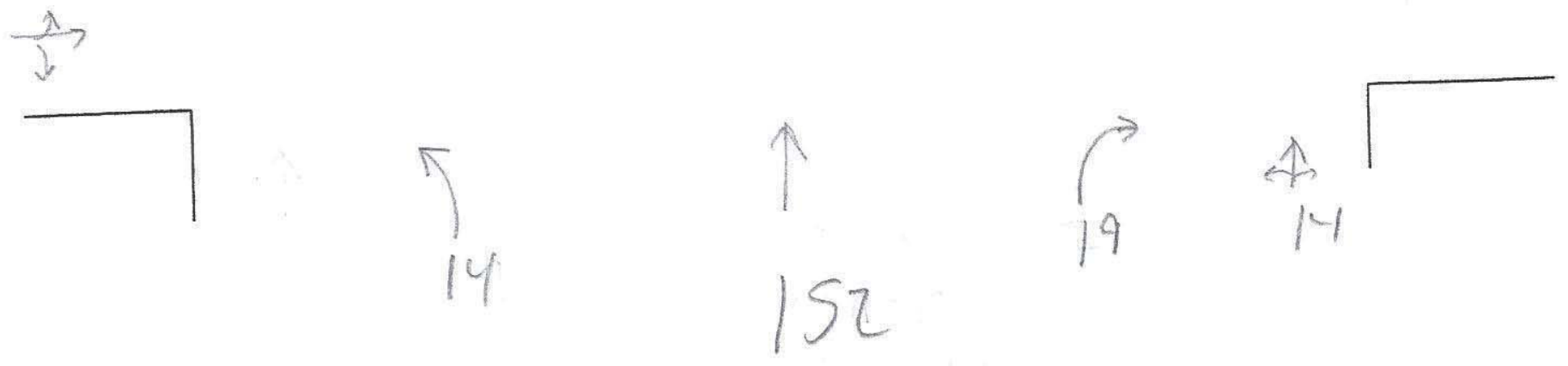
Nathan Johnston

CalPoly San Luis Obispo

Intersection:

Catuedral Ooks Rood) Lo Putera Lanc.

Heaw Vehicles:

$\checkmark 8 \% 40$
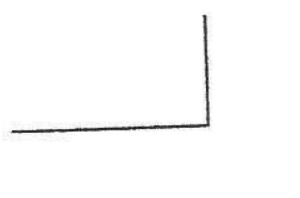

$2 \%+4$

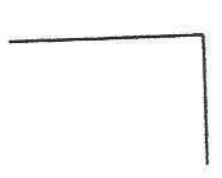

$\Uparrow 7 \%, 4$

Comments: 
Nathan Johnston

City:
Intersection:
Cathe $2 x: 1$
Oales
Roal/
Placer Drive
Goletar

Location: Southern CA Northern CA CentralCA Other Intersection Type $Y+$ Data Collection Time:

Intersection Geometry.

North Arrow:

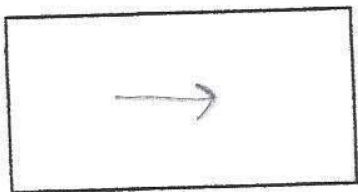

Dist to upstream intersection/signal

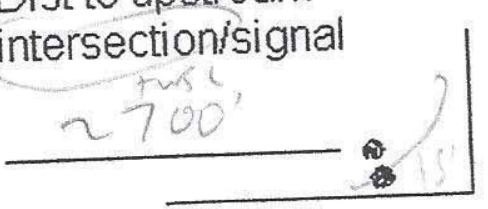

$2 S$ min

Places

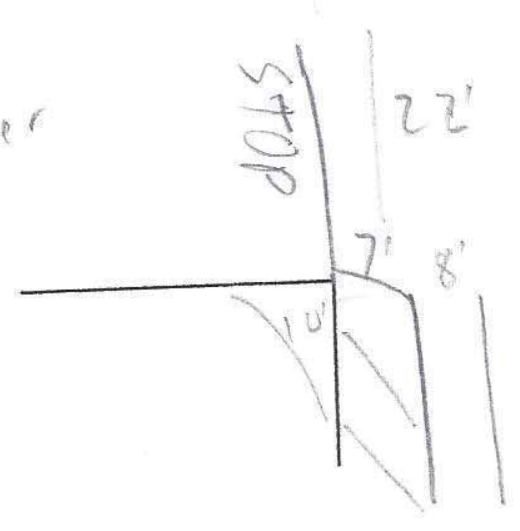

\section{yom th}

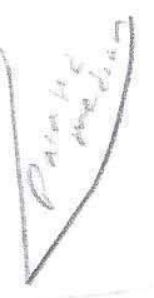

121

$\rightarrow 2 \%$ stope
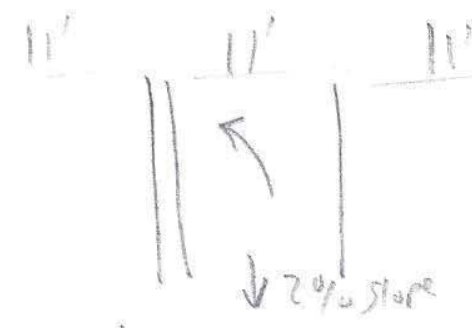

Dist to upstream

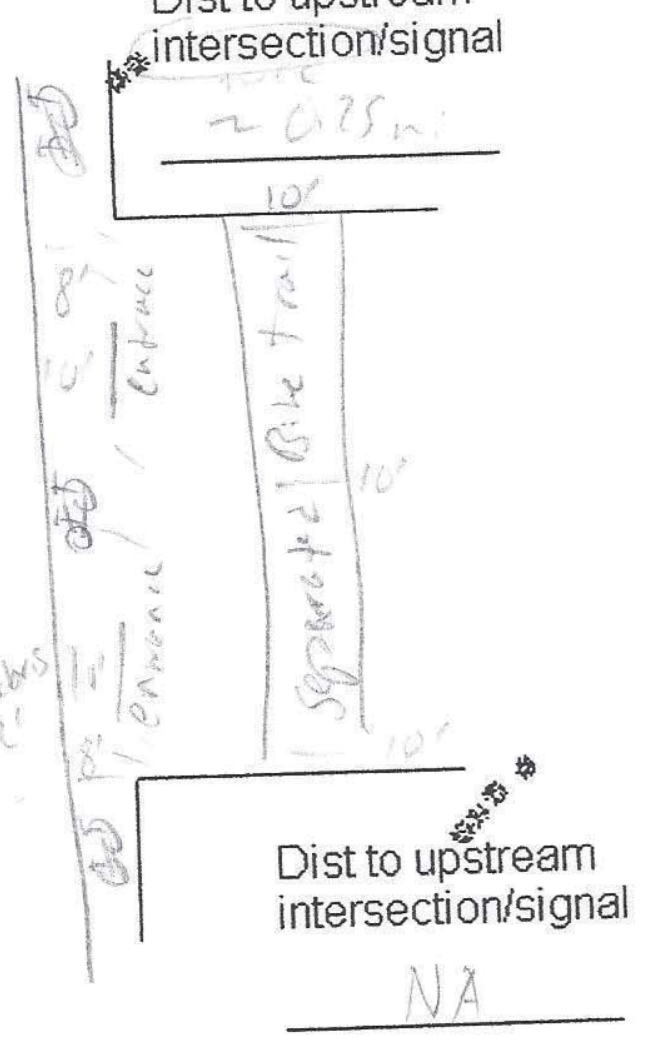

Dist to upstream Caheid intersection/signal

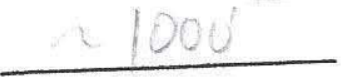

Comments:

School on

Pave quality 22 
Nathan Johnston

Intersection: Catudral Oous Rool/Placer Orive

Time Period:

$11: 15-12: 15$

Volumes:
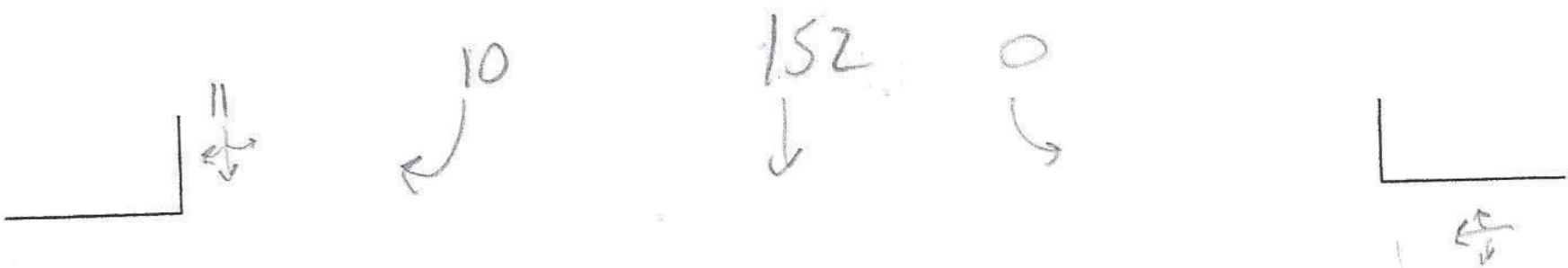

$0 \rightarrow$

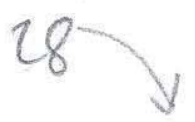

$2-\frac{\lambda}{j}$

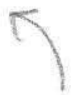

17.

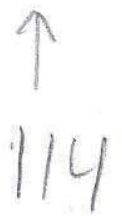

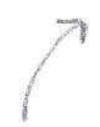

0

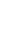


Nathan Johnston

Cal Poly San Luis Obispo

Intersection: Catuderal Oobs Row/Placer Dive

Heaw Vehicles:

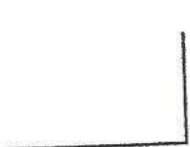

$\checkmark 3 \% \mathrm{Hv}$

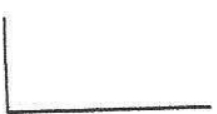

$3 \% \mathrm{H}^{4}$

$\rightarrow$
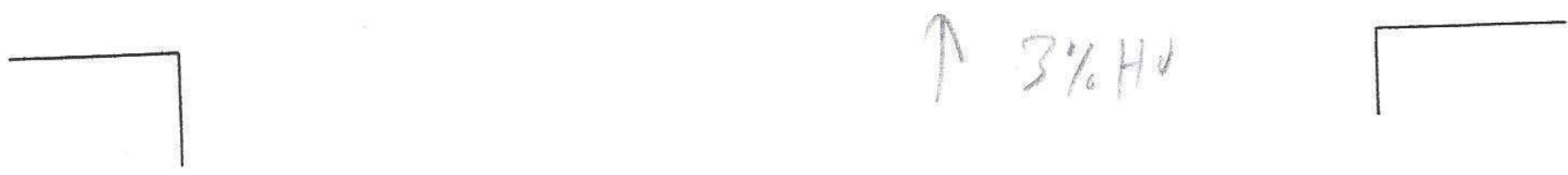

Comments:

Gchol on Placer. 
Nathan Johnston

Intersection:

City.

Goleta

Location: Southern CA Northern CA CentralCA Other Intersection Type T + Data Collection Time:

$12: 30-1: 30$

$7 / 26 / 13$ Frizuy

Intersection Geometry.

North Arrow:

$$
40 \mathrm{~m} / \mathrm{p}^{\mathrm{h}}
$$

$\uparrow$

Dist to upstream intersectionisignal
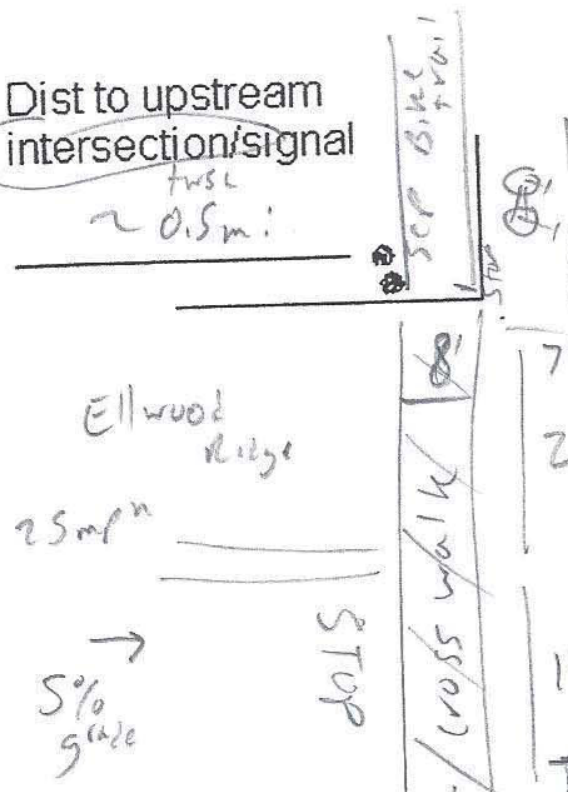

$(81$
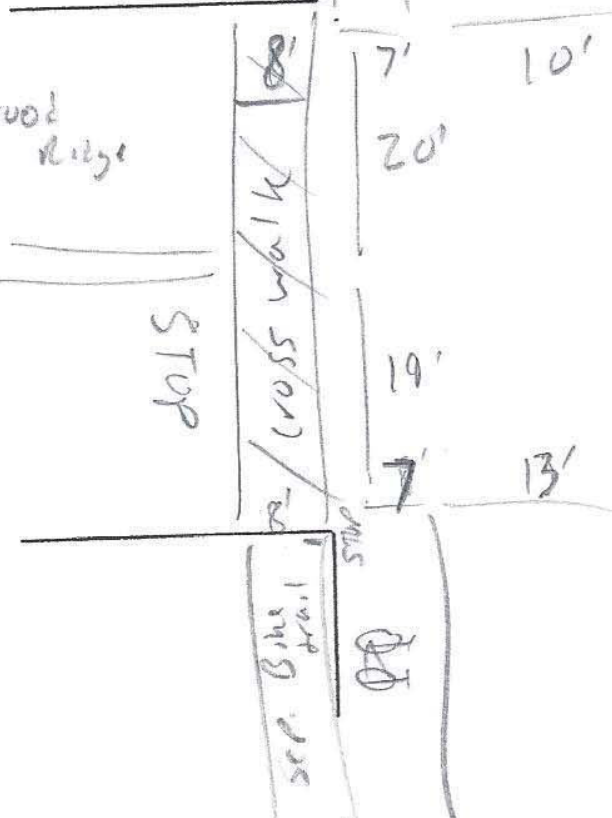

Dist to upstream intersection/signal

tws $\approx 400^{\circ}$

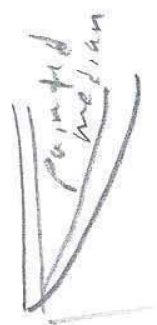

$10^{\prime} \quad 13^{\prime}$

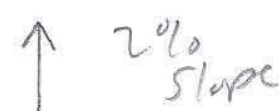

$13^{\prime}$

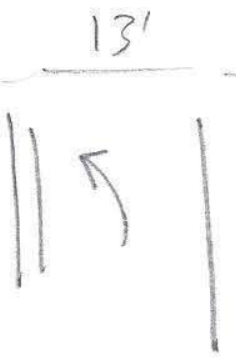

$11^{\prime}$

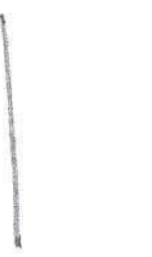

Catheiral

Ouxs

$$
\text { Yompan }
$$

Dist to upstream intersectionisignal

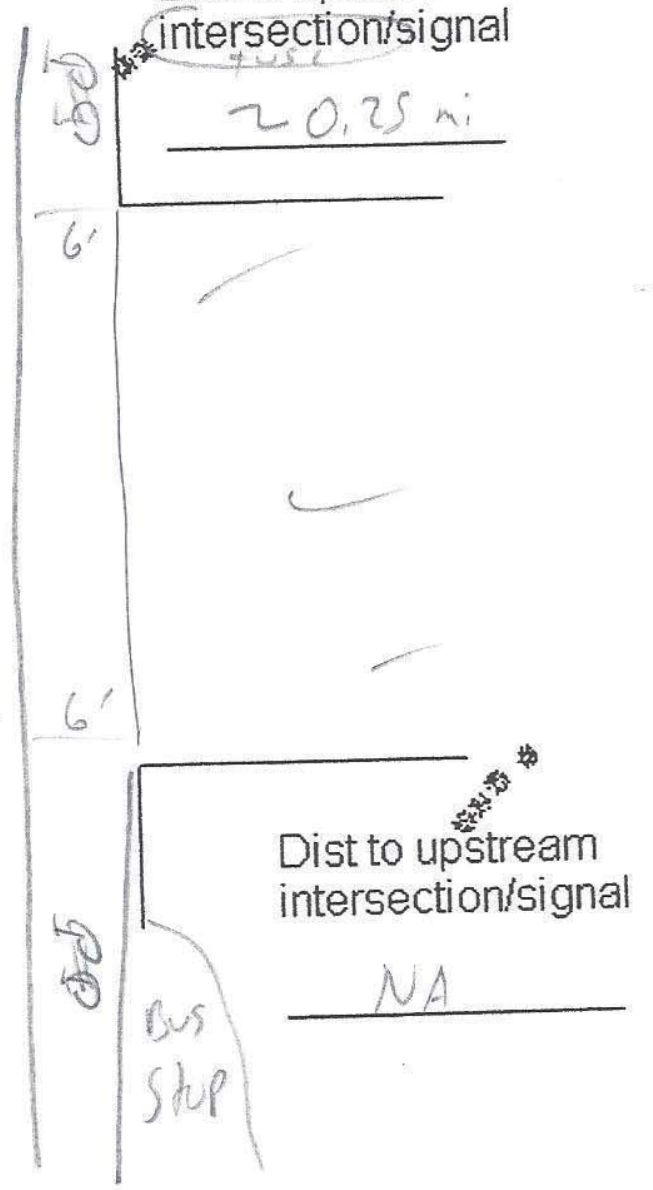

Comments:

Parement Quality $=3$

Signage

present 
Nathan Johnston

Intersection: Cathedral Ooks Rood/Ellwow Ridse Roud

Time Period:

$12: 30-1: 30$

Volumes:
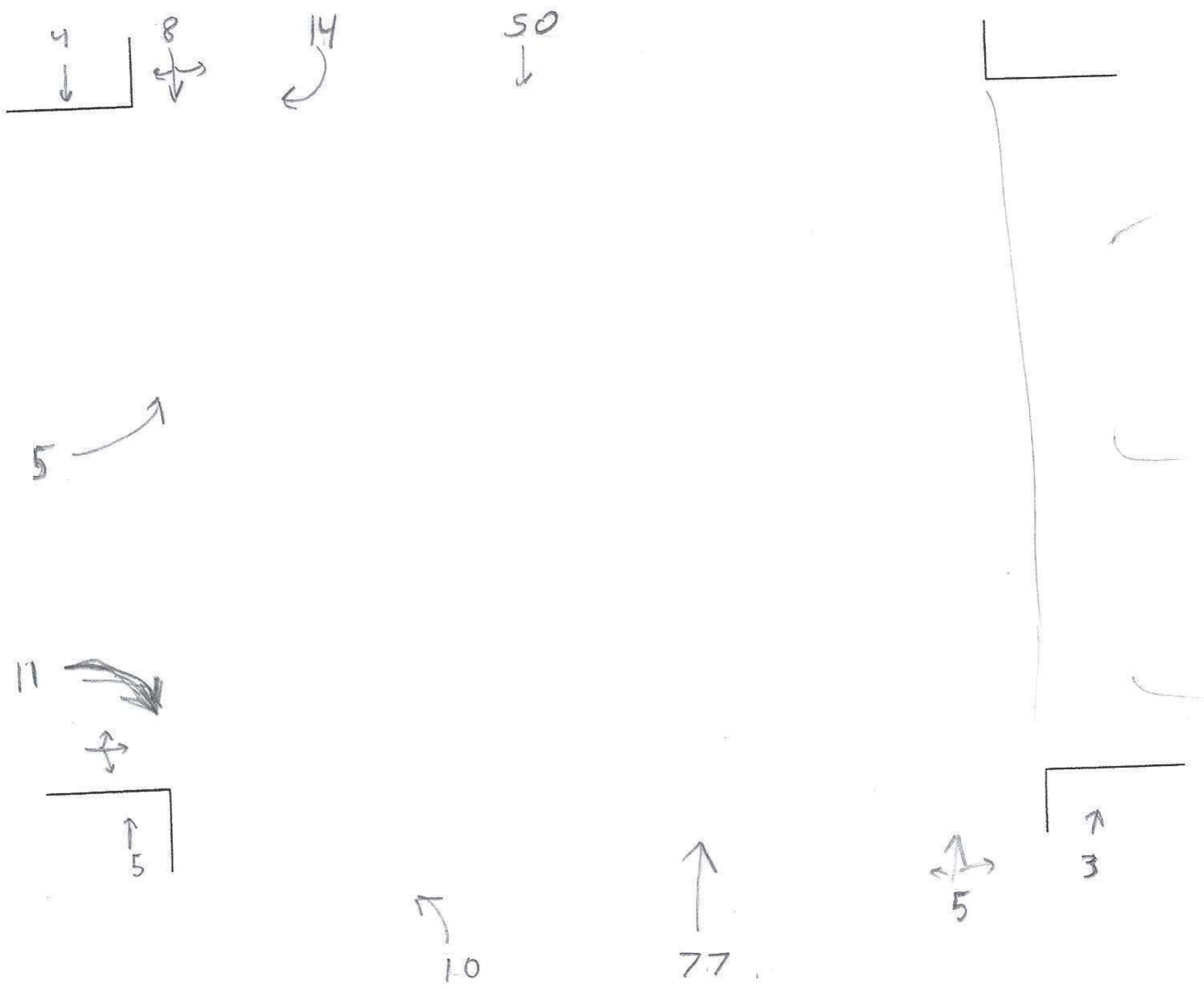
Nathan Johnston

Cal Poly San Luis Obispo

Intersection: Catredal Oous Roal/ Ellwook Ridse Roods.

Heaw Vehicles:

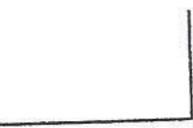

$\downarrow 6 \% \mathrm{HV}$

$25 \% \mathrm{HV}$

$\rightarrow$

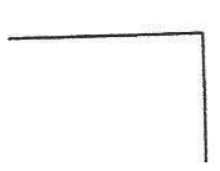

$\uparrow 4 \%, 4 V$

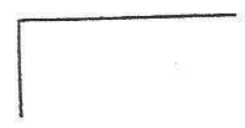

Comments:

Ellwool docsn't go throug, but leats to

a well bose canter w/ heary vehicles. 
n: Northwood/Savannah

Irvine

Location: Southern CA Northern CA Central CA Other Intersection Type: $T+$

Data Collection Time: $10: 00-11: 00$ $7 / 26 / 13$ sat

Intersection Geometry:

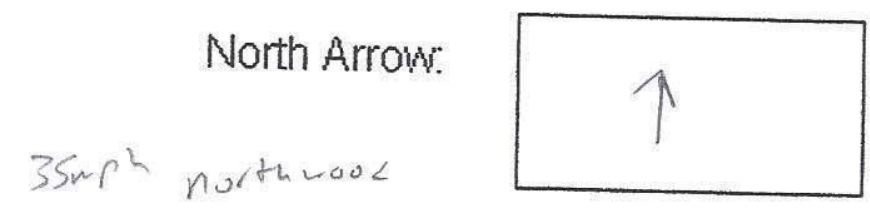

Dist to upstream $\frac{\text { intersection/signal }}{n_{0} \text { contals }}$

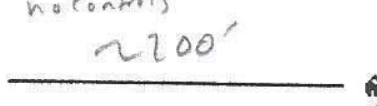

8

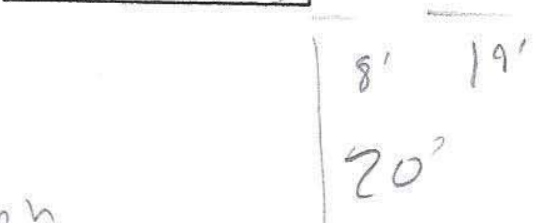

$25 \sin ^{h}$

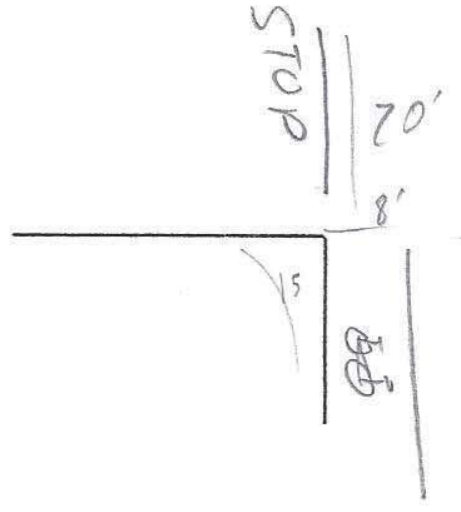

Dist to upstream intersection(signal)

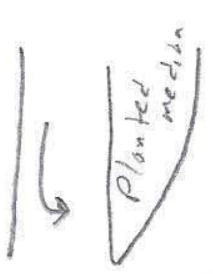

$10^{\prime}$

25

$701^{\prime}$

Comments: School
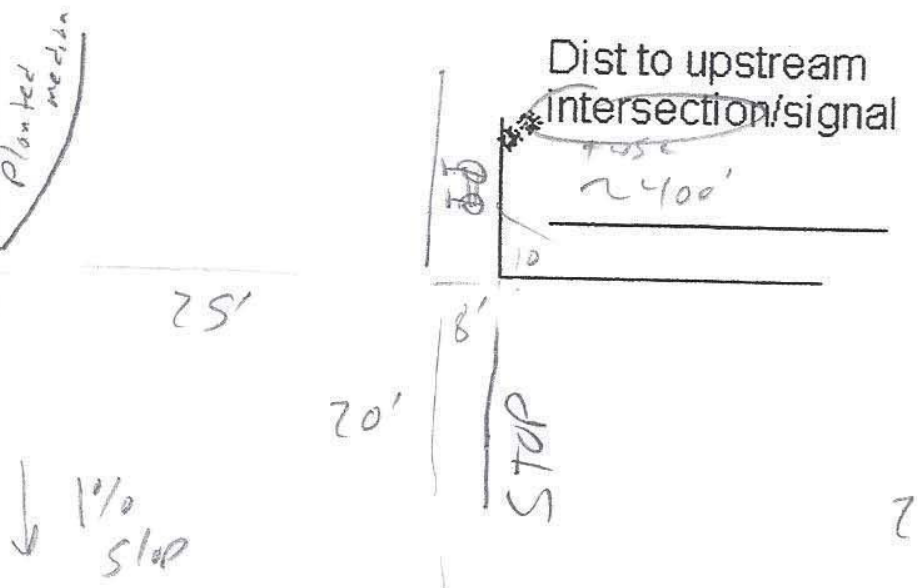

$25 \mathrm{mph}$

Sovanaah

$70^{\prime}$
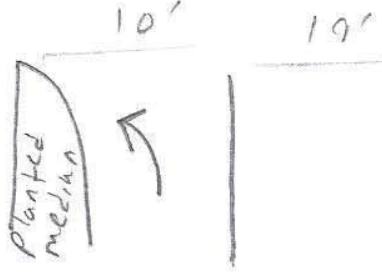

$35 m^{4}$

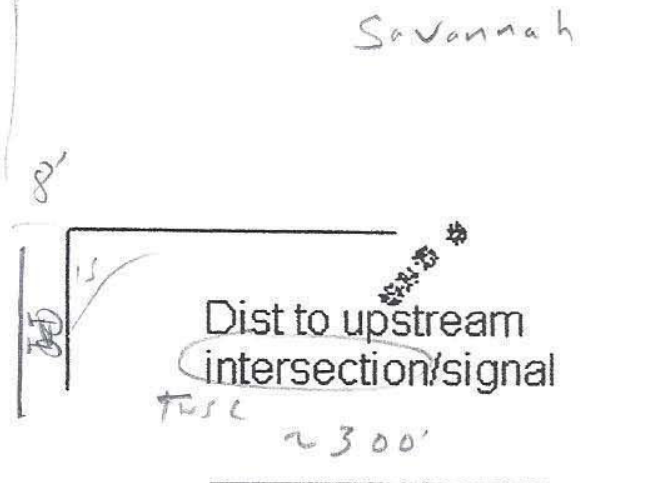

$2300^{\circ}$ 
Nathan Johnston

Intersection:

Northwoos S Savannah

Time Period:

$10: 00-11: 00$

Volumes:

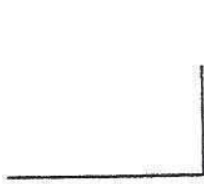

is

$3^{3}$

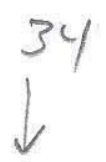

$\zeta^{10}$
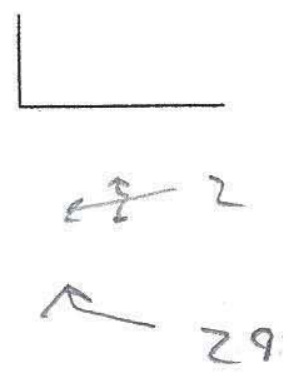

$2-\lambda$

o

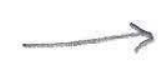

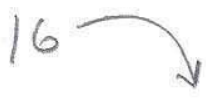

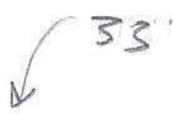

$0 \hat{i}$

$10 \rightarrow$

$\pi$

$\uparrow$

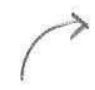

$\hat{\gamma}$

$<1$

y

58

23

4 
Nathan Johnston

Intersection: Northwood/Sovannah

Heaw Vehicles:

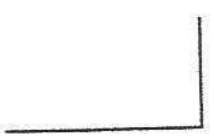

$\downarrow 3 \%$

$\leftarrow$

$\longrightarrow$

$1 \%$

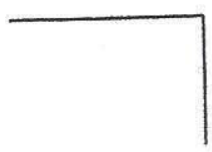

$\uparrow 3 \%$

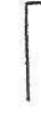

Comments: 
Nathan Johnston

Intersection:

Decrfield/ Fawn Glex East

City.

Irvine

Location: Southern CA Northern CA Central CA Other

Intersection Type: $T+$

Data Collection Time:

$11: 20-12: 20$

Intersection Geometry.

North Arrow:

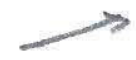

Dist to upstream

intersection/signal

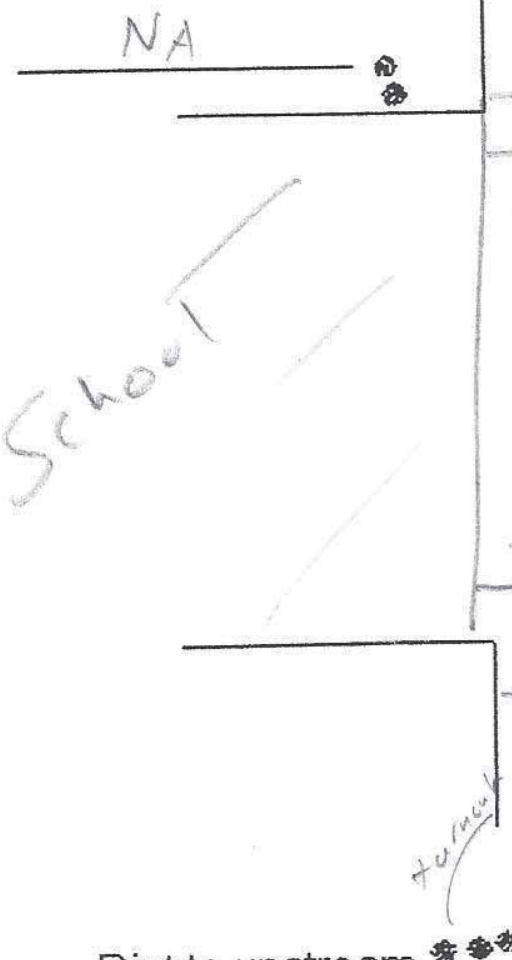

$30 \mathrm{mph}$

Dist to upstream
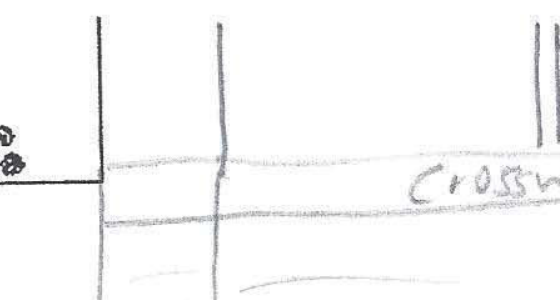

1

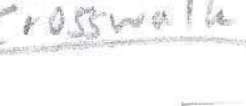

h

Dist to upstream

intersection/signal

tws

$\sim 0.25 \mathrm{ni}_{\mathrm{i}}$

Comments:

Schoul cijocear No patkers ia bike

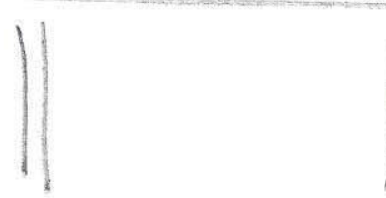

Dist to upstream

intersectionisignal

$\sim 300^{\circ}$

$30 \mathrm{mp} \mathrm{p}^{2}$

$2 \operatorname{Simph}$

Clen

$\cos$ walle

intersectionisignal 
Nathan Johnston

Intersection: Deerfiell/ Fown Clea bost

Time Period:

$11: 20-12: 20$

Volumes:

130

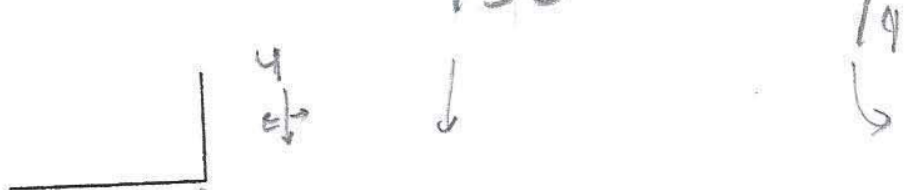


Nathan Johnston

Intersection:

Cal Poly San Luis Obispo

Heaw Vehicles:

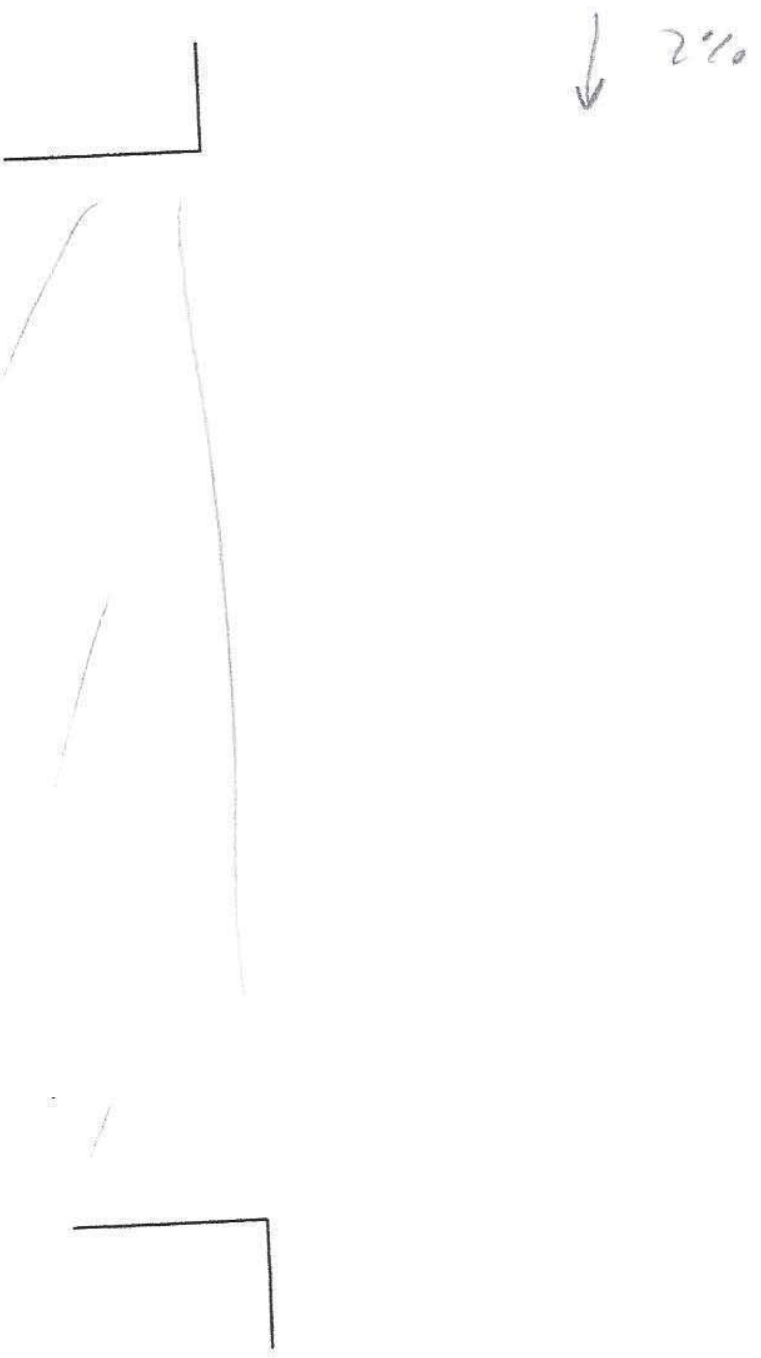

$\uparrow>\%$

$41 \%$

Comments: 
Nathan Johnston

Intersection:

Mc baw Ave/Armstrong Street

City:

trvine

Location: Southern CA Northern CA Central CA Other

Intersection Type: $T+$

Data Collection Time:

$12: 30-1: 30$

$7 / 20 / 13$ Sat

Intersection Geometry:

North Arrow:

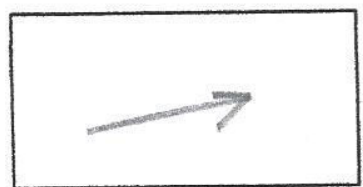

Dist to upstream

intersectionisignal
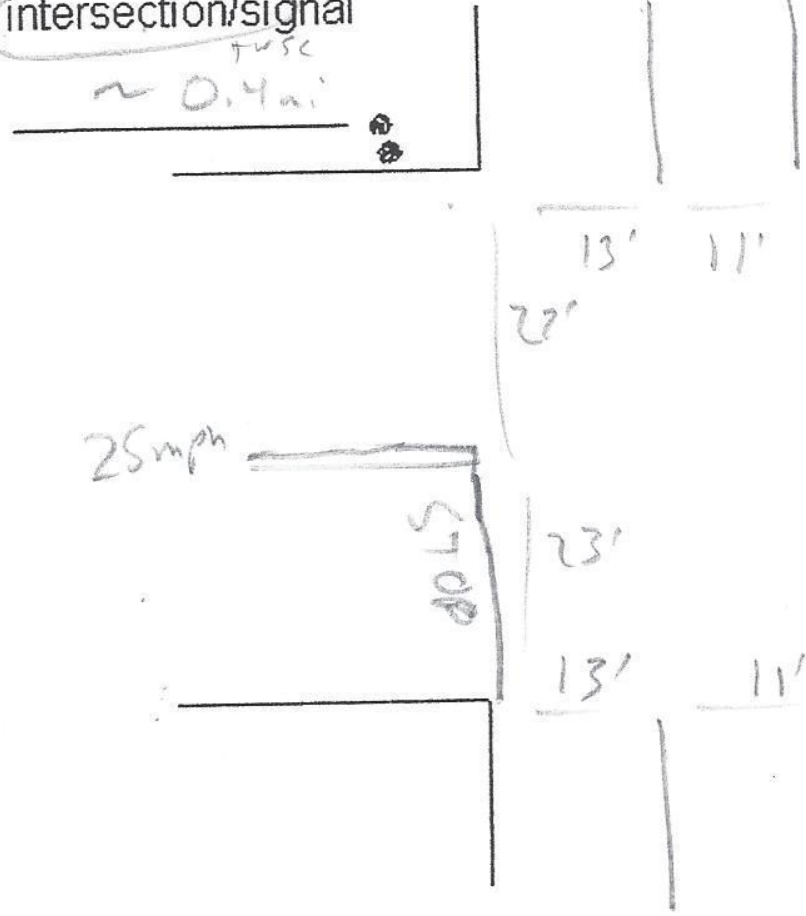

\section{$4 \mathrm{smp}^{4}$}

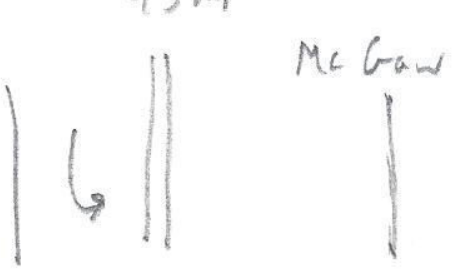

$10^{\prime}$
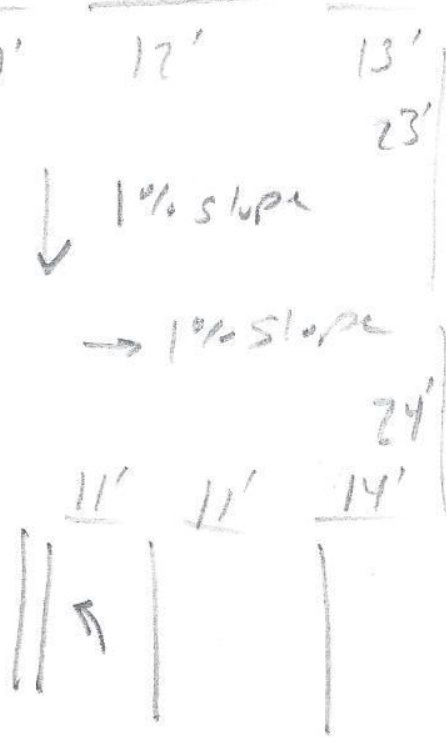

$4 \operatorname{simpa}^{n}$

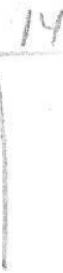

Dist to upstream intersection(signal

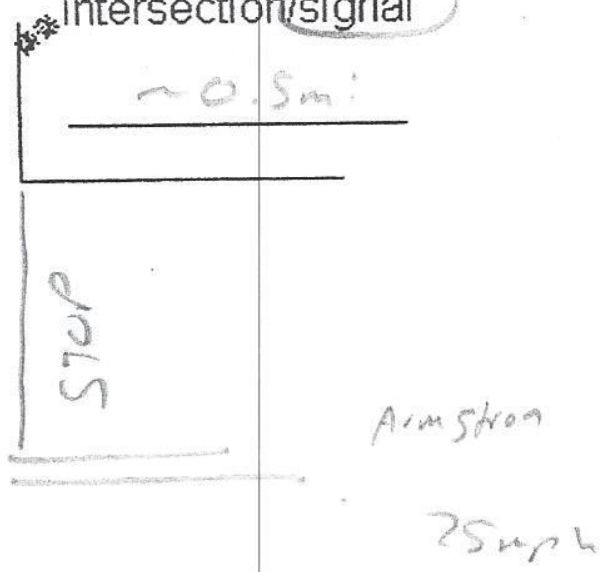

Dist to upstream

intersectionisignal

a $0.4 \mathrm{~m}$

nments:

No bike

Davement 
Nathan Johnston

intersection: Mccraw /Armstiong Street

Time Period:

$12: 30.1: 30$

Volumes:
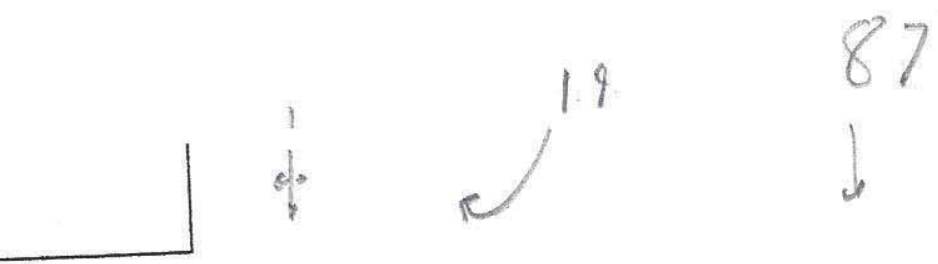

3
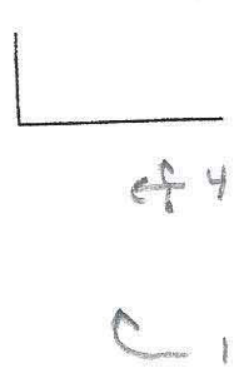

$10-7$

$10 \longrightarrow$

$46-v$
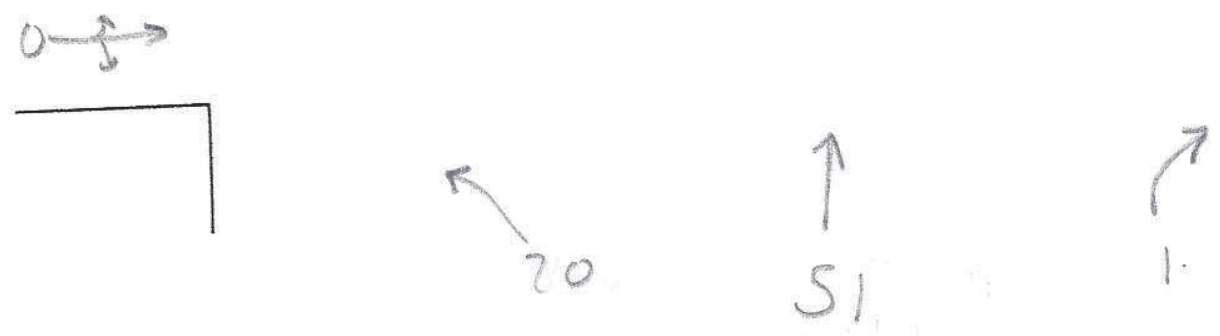

$-4$ 
Nathan Johnston

Intersection:

Me Craw Armstrong sdreet.

Heaw Vehicles:

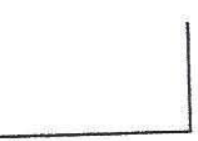

$166^{\circ}$

$5 \%$
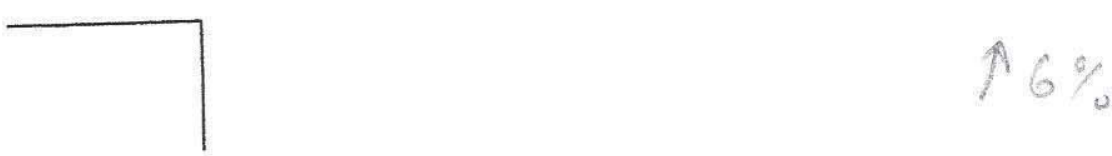

Comments: 
Nathan Johnston

Intersection:

Michelson

LSequoia Tree lane

City:

Irvive

Location: Southern CA Northern CA Central CA Other Intersection Type: $T+$

Data Collection Time:

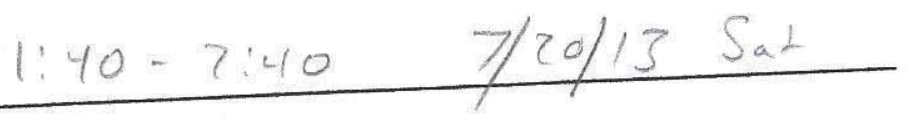

Intersection Geometry:

North Arrow:

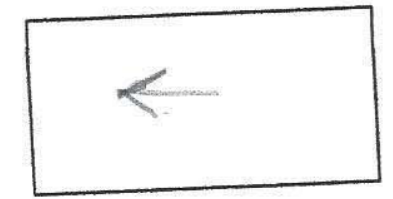

Dist to upstream intersectionisignal

NA
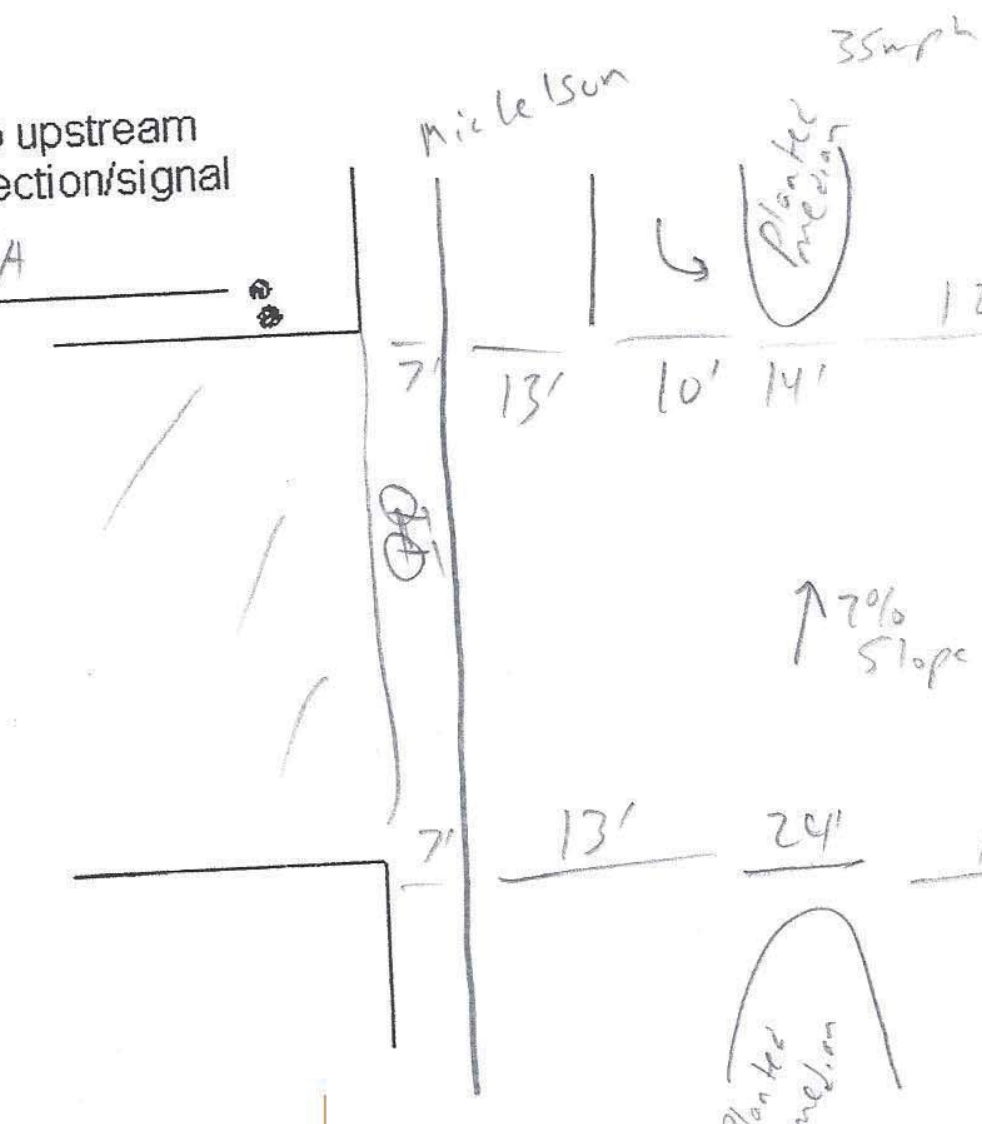

Dist to upstream

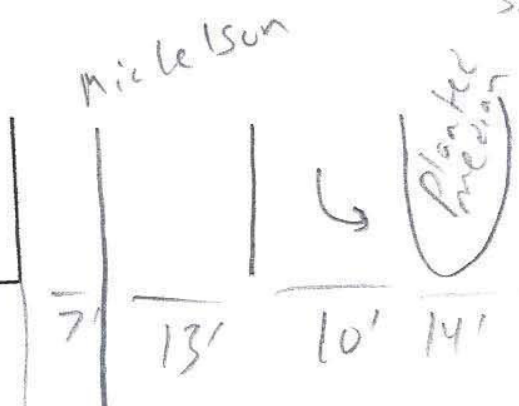

intersection!signal

$$
\text { ' } 250^{\prime}
$$

Comments:

pave guatity 4 no poiteing on

Michelson

Dist to upstream
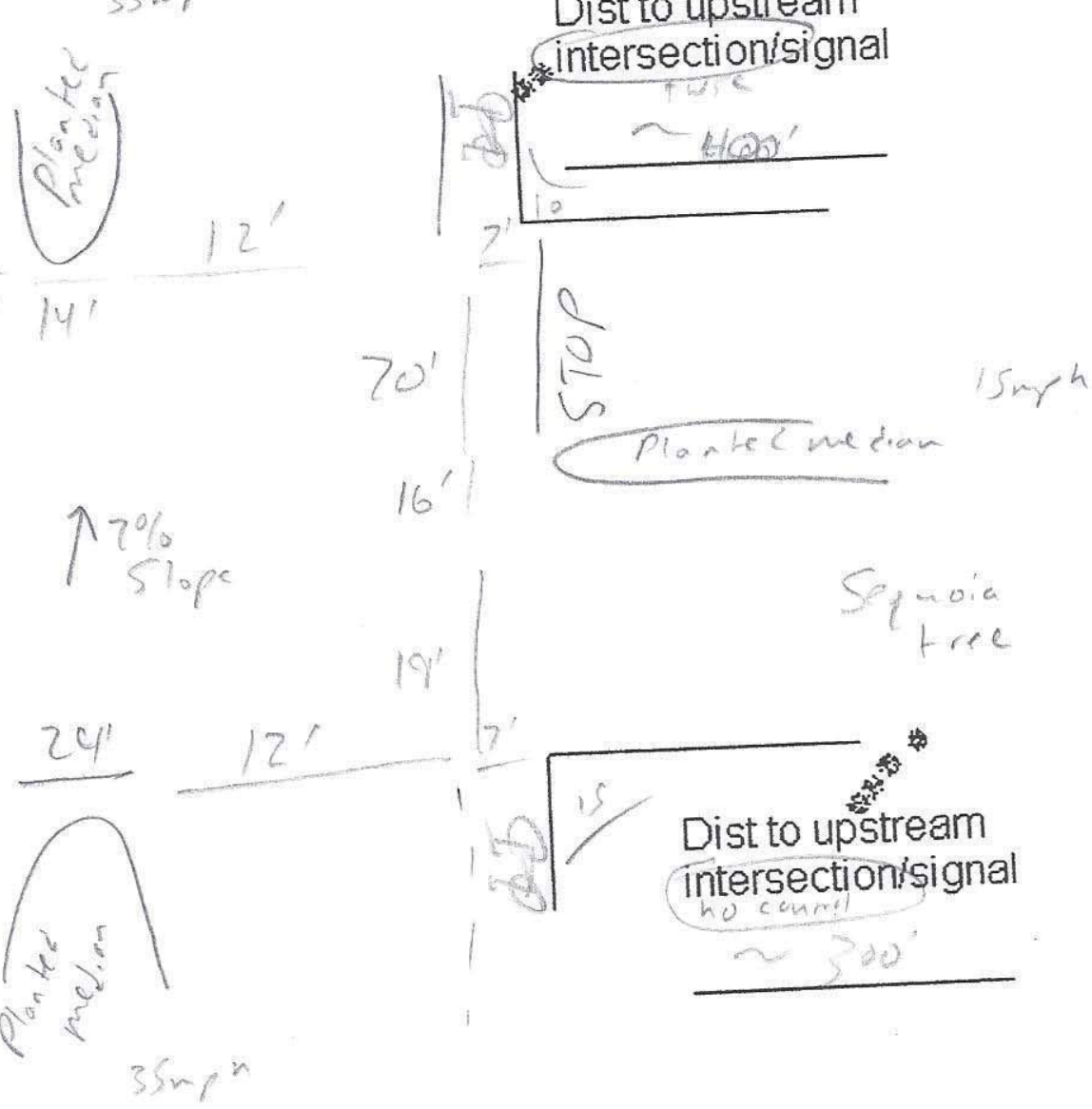

Dist to upstream

intersectionisignal

$\sim 300$ 
Nathan Johnston

Intersection:

Michelson I Sequaia Tree lane

Time Period:

$1: 40 \cdot 2: 40$

Volumes:

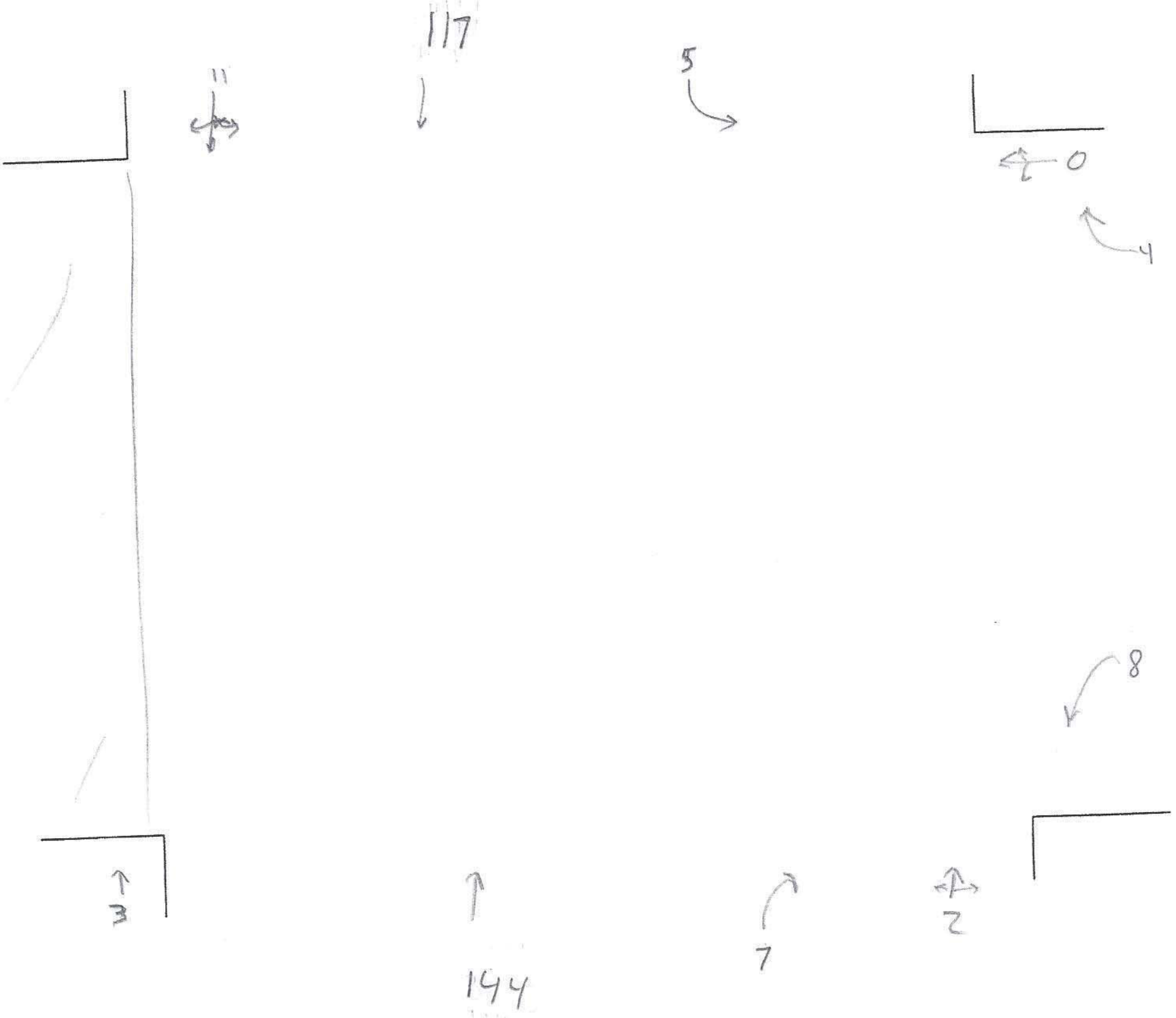


Nathan Johnston

Cal Poly San Luis Obispo

Intersection: Miclelsun / Sequoia Tree Lan

Heaw Vehicles:

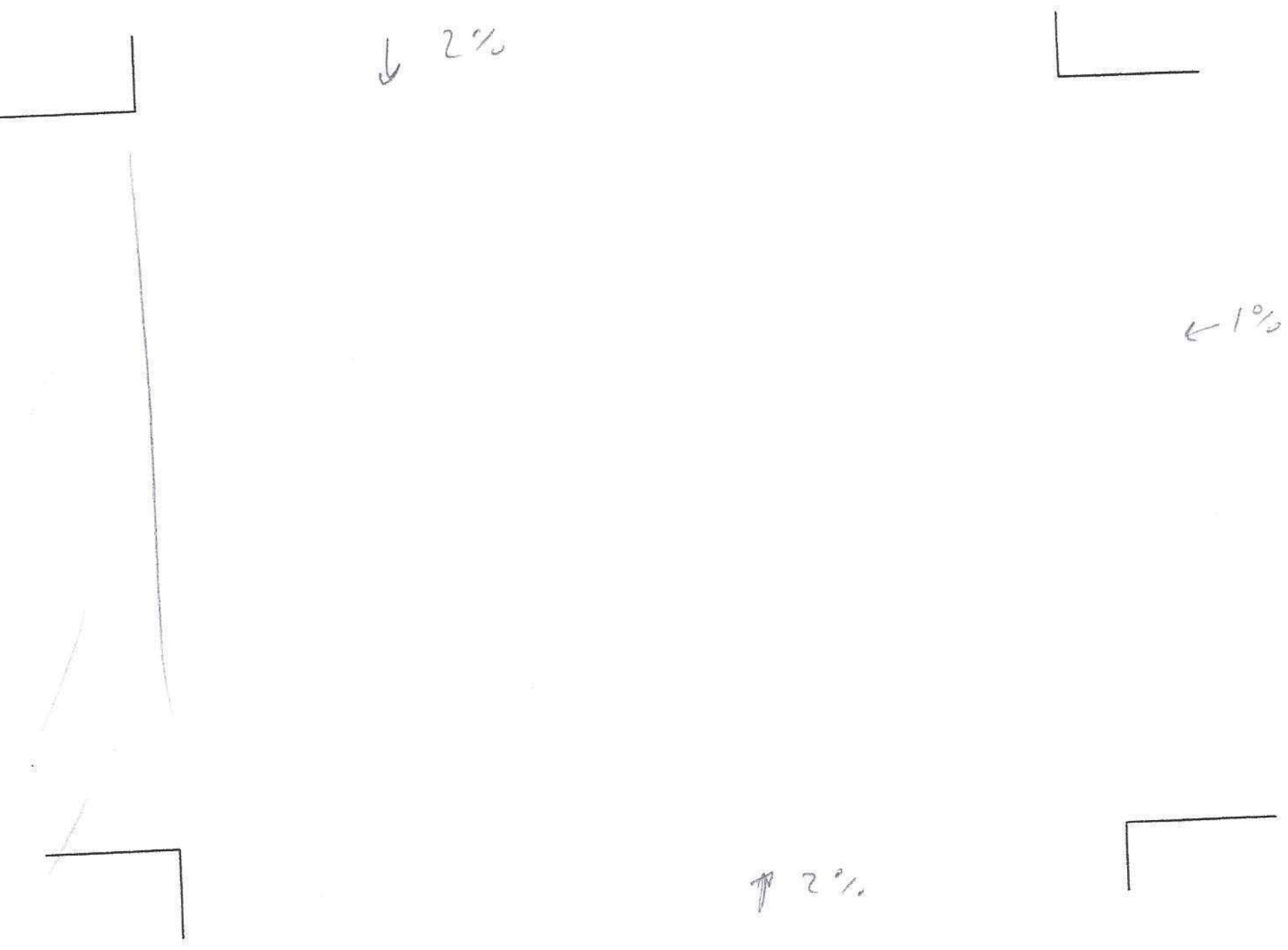

Comments: 
Nathan Johnston

Intersection: tur the

City. Irvine

Location: Southern CA Northern CA. Central CA Other Intersection Typer $T+$

Data Collection Time:

$2: 50-3: 50$

Intersection Geometry:

Dist to upstream intersection/signal
$45 \sin ^{4}$ tritk

Rock

Drive

7/20/13 Sart

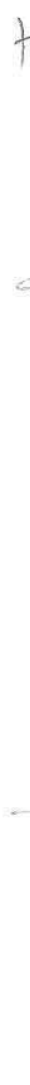

Dist to upstream
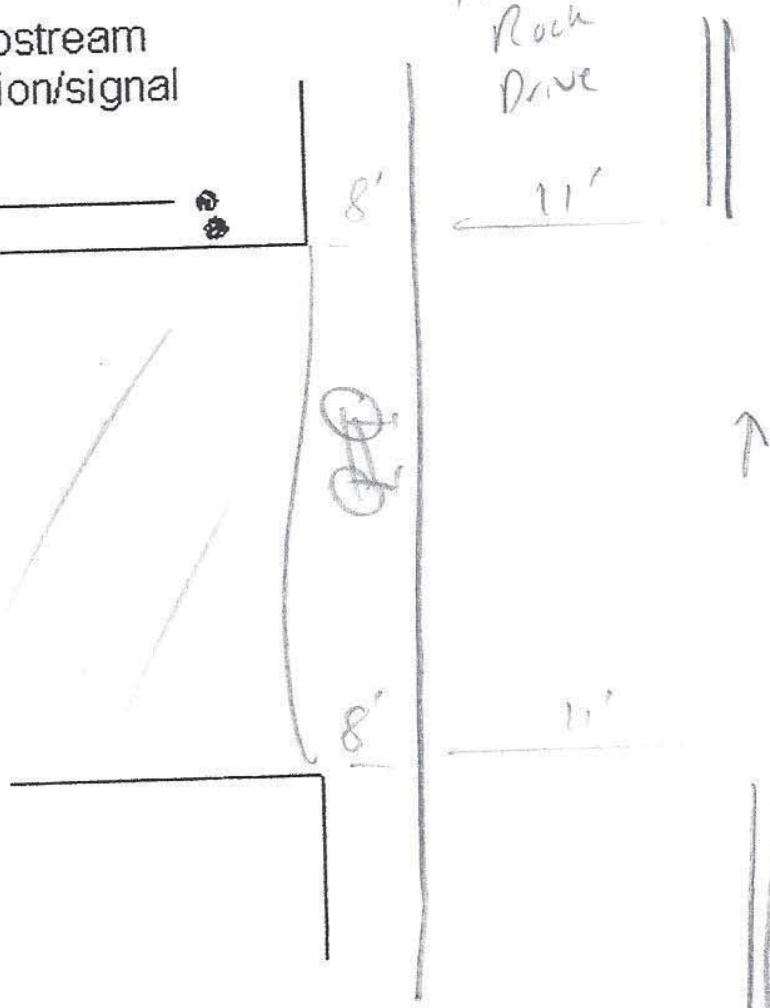

intersection/signal
North Arrow:

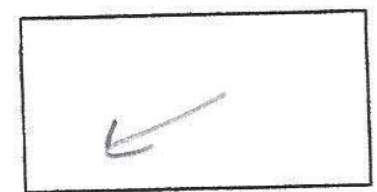

Dist to upstream
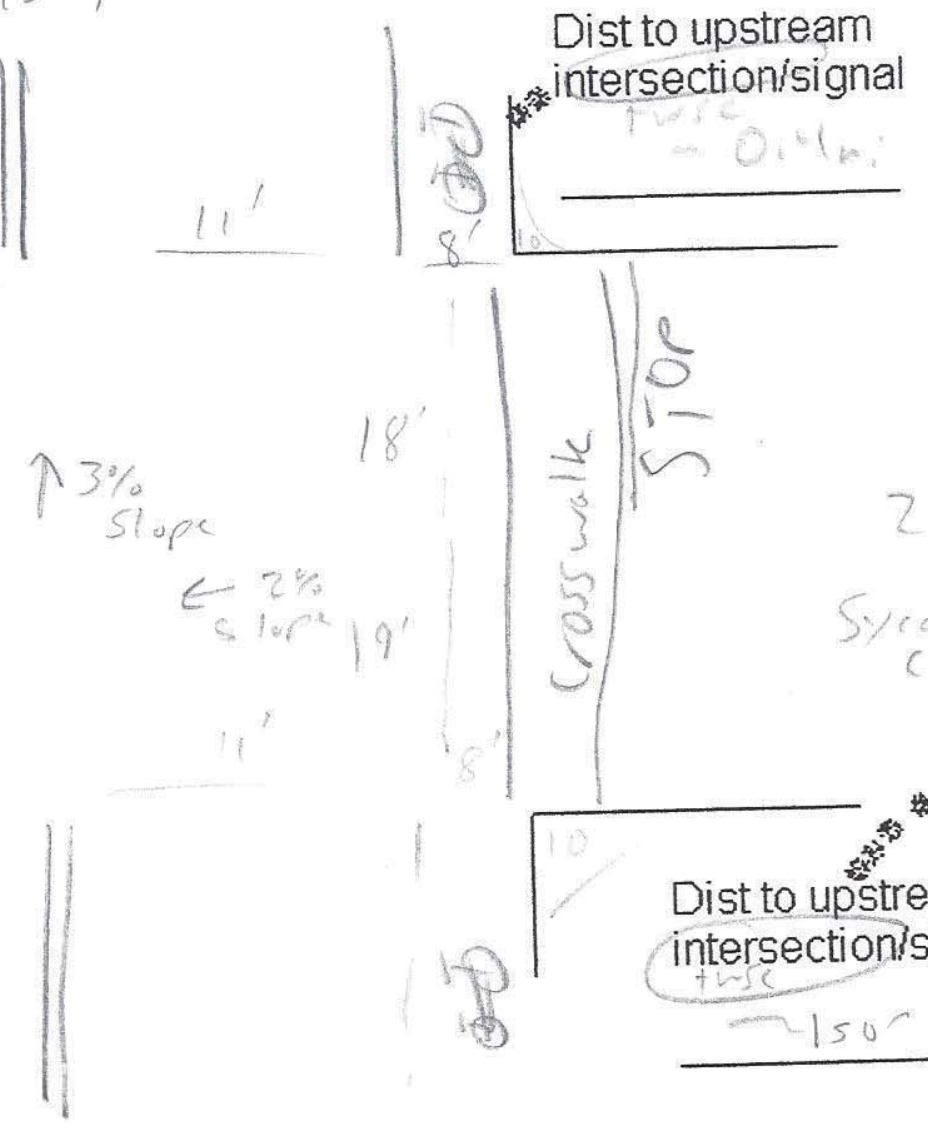

7

$5 \times 6 a m a c$

crek

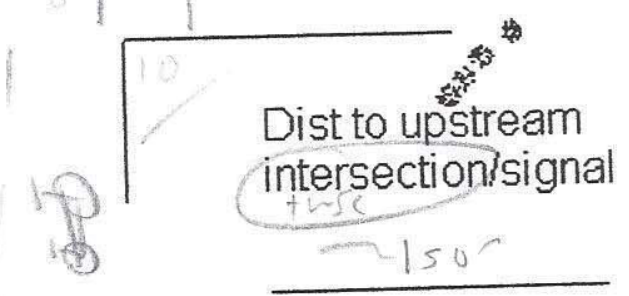

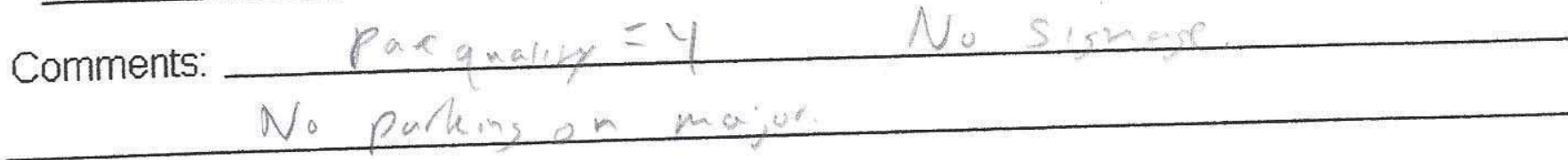

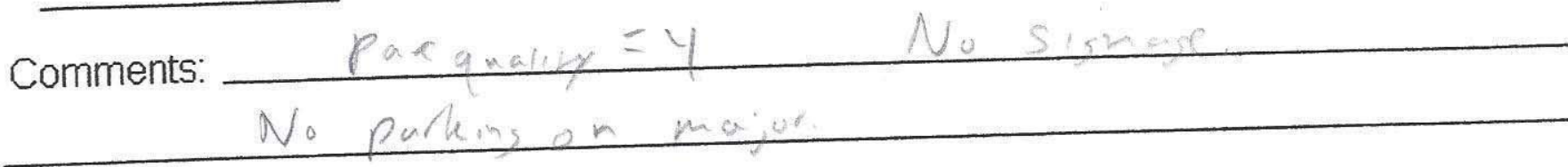
$45 \mathrm{~s} \mathrm{p}^{\mathrm{n}}$ 
Nathan Johnston

Intersection: Turtle Rouk Priv/Sycomene creek

Time Period:

$2: 50-3: 50$

Volumes:

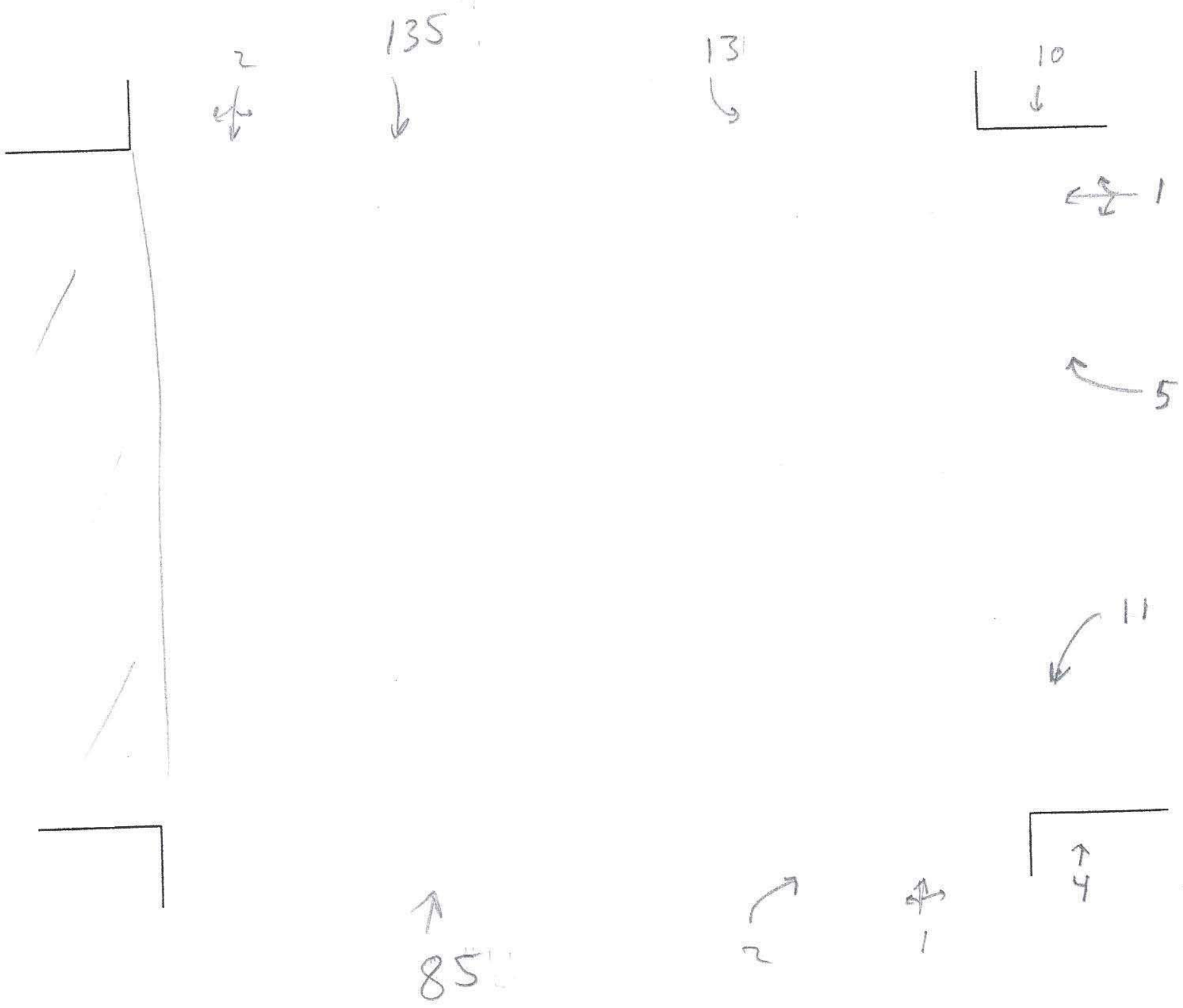


Nathan Johnston Cal Poly San Luis Obispo Intersection: Turtle Roch Drenc/Sycamarc Creek Heaw Vehicles:

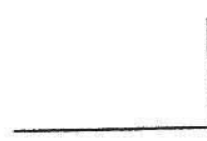

$$
12 \%
$$

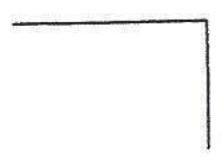

$\uparrow 2 \%$

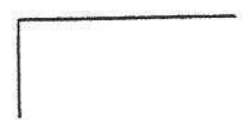

Comments: 
Nathan Johnston

Intersection:

West ciacen Street/ Douglase Avenue

City.

Location: Southern CA Northern CA Central CA Other Intersection Type: (T) + Data Collection Time:

Riveride

Intersection Geometry:

Dist to upstream intersectionisignal

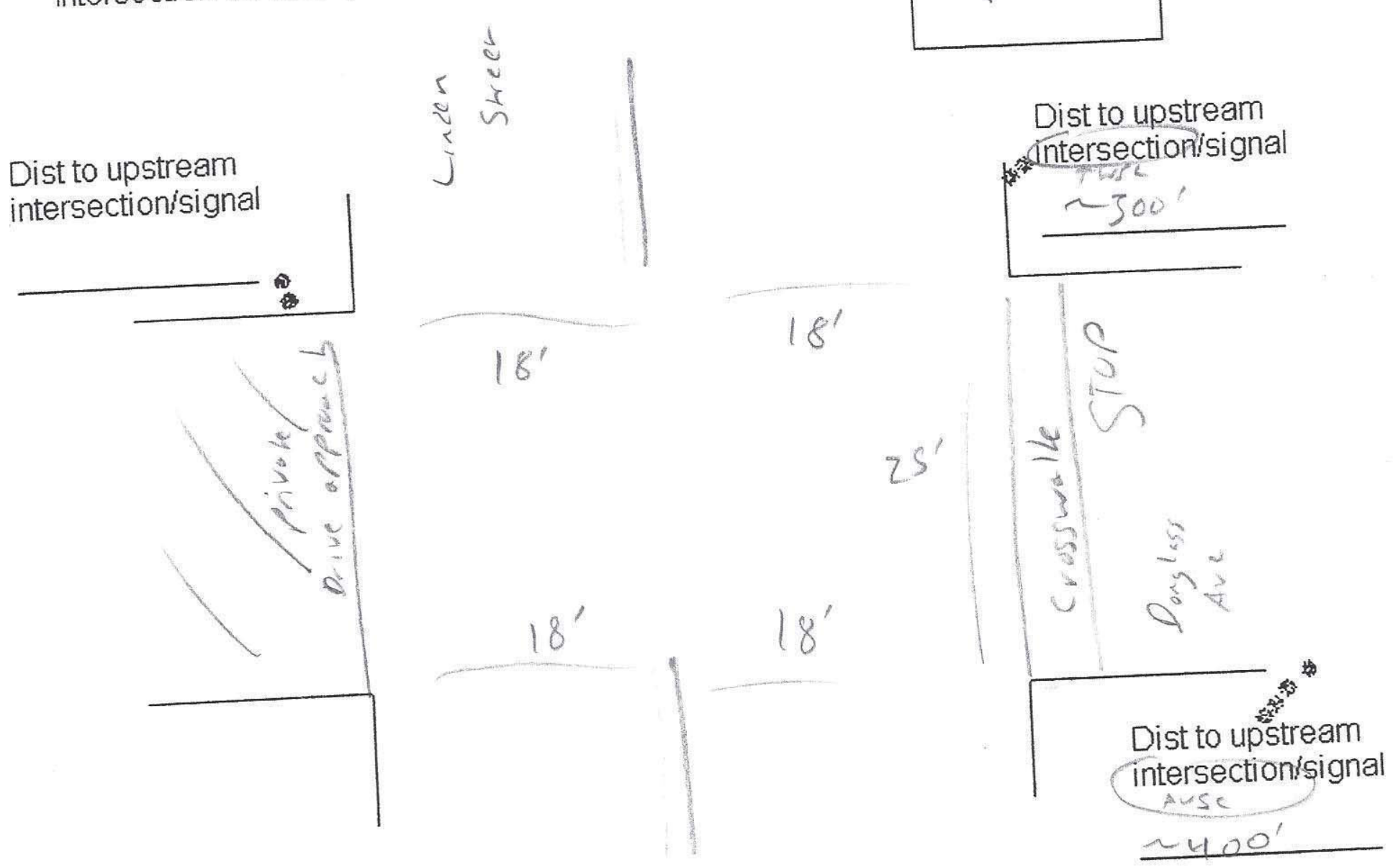

North Arrow:

$7 / 6 / 13$ Twes

Dist to upstream

A usintersection/signal

$2400^{\prime}$

Comments:

Paremear qualing=?

Onsticet purturas on

all

sites

No siganese 
Nathan Johnston

Intersection: WLinden sweet/ Panglos Arenue

Time Period:

$1: 50-2: 50$

$7 / 16 / 17$

Tues

Volumes:

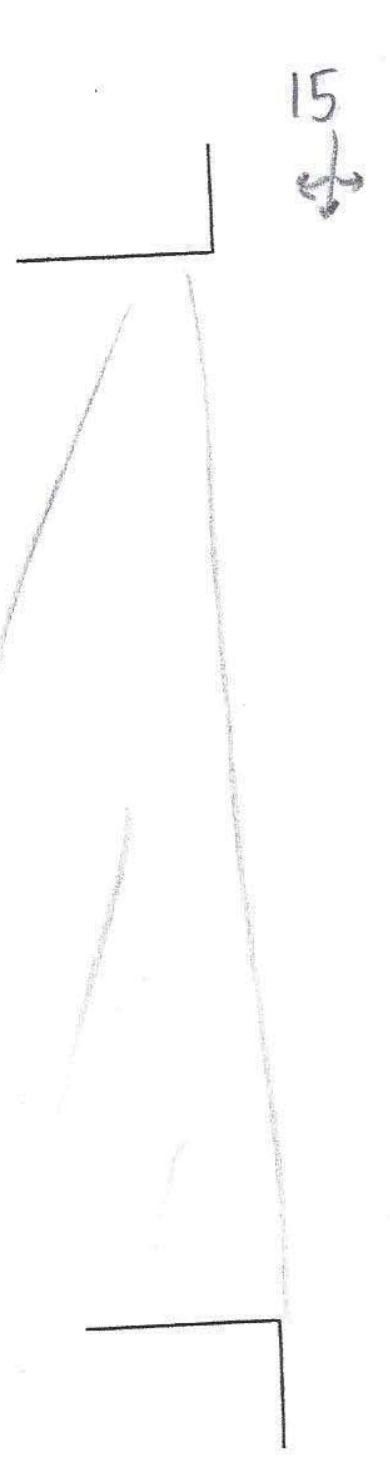

93

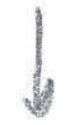

6

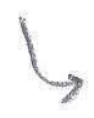

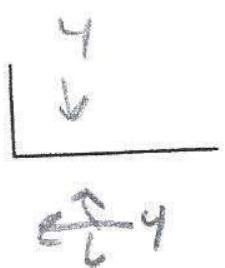

10

21<smiles>C1CCC1</smiles>

$\operatorname{li}_{13} 1$
19 
Cal Poly San Luis Obispo

Nathan Johnston

Intersection: WL Linden Street/Dongloss Avenue Heaw Vehicles:

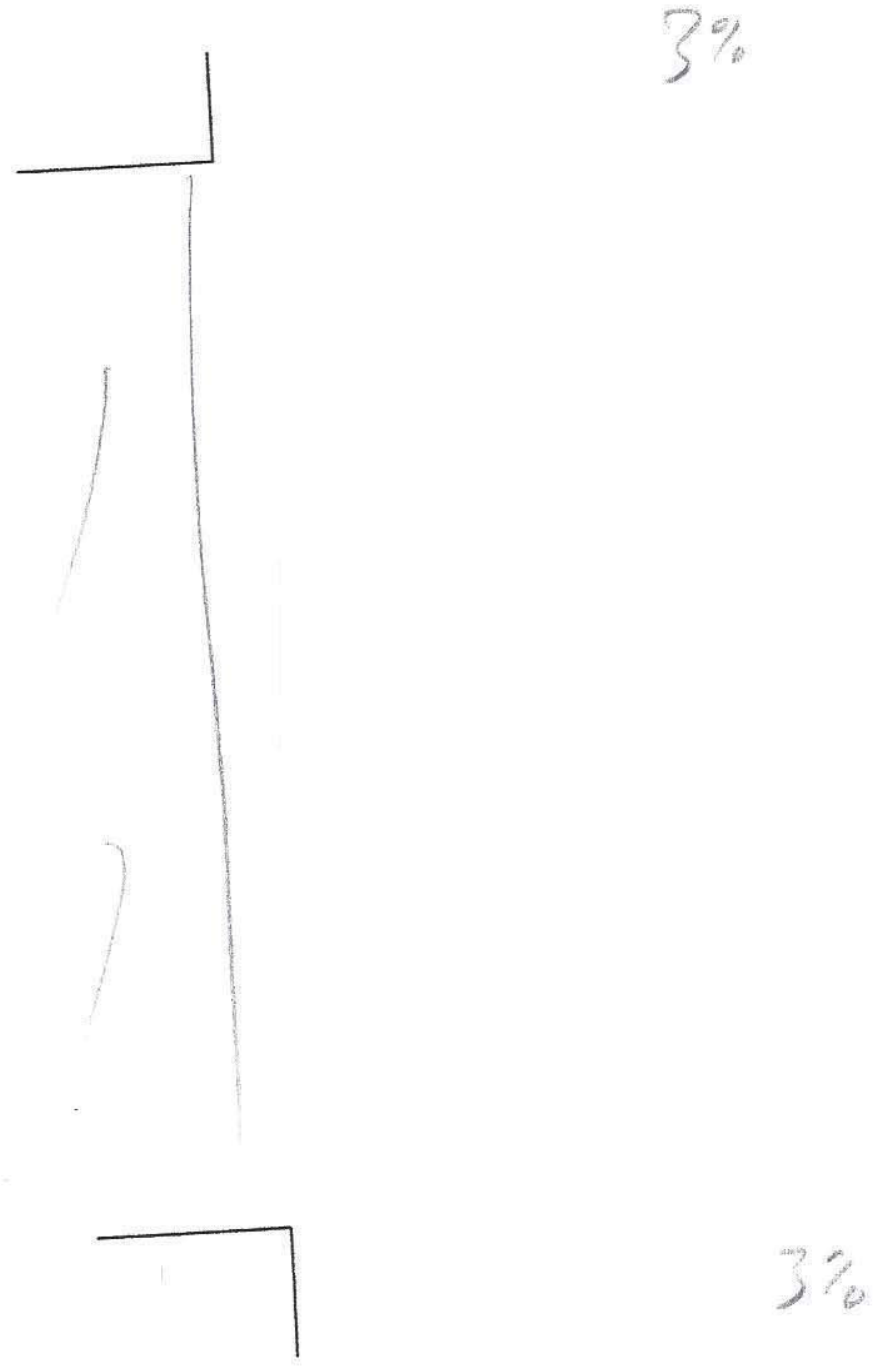

Comments: 
Nathan Johnston

Intersection:

Victoria Ave / Crace Street

City:

Riverside

Location: Southern CA Northern CA Central CA Other

Intersection Type: $T+$

Data Collection Time:

8:00-9:00 $\quad 7 / 16 / 13$ Thes

Intersection Geometry:

North Arrow:

$\pi$

$45 \mathrm{~m} \rho^{h}$

Dist to upstream intersectionisignal

Grace

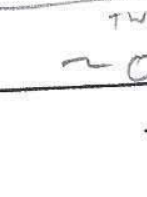

$35 \mathrm{mph}$

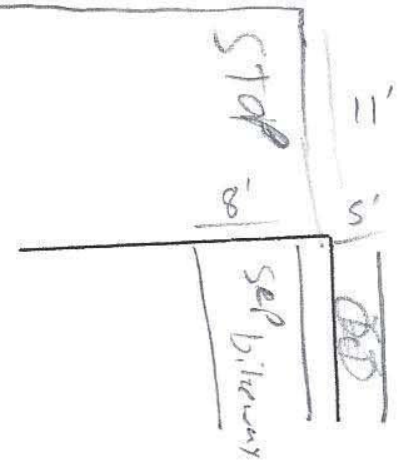

Dist to upstream

intersection'signal

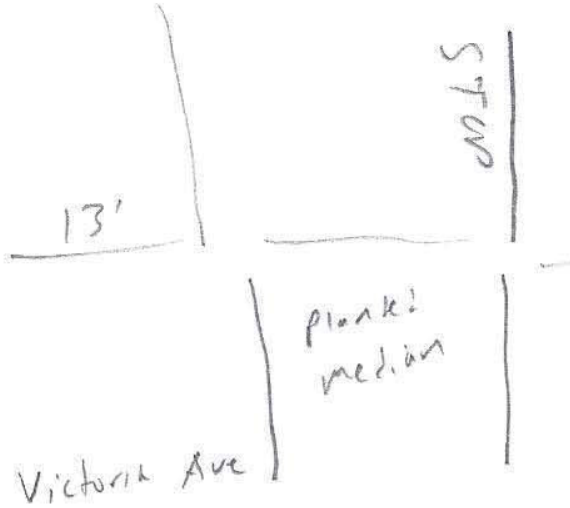

Victuric Ave $\left|\begin{array}{c}\text { plank: } \\ \text { perion }\end{array}\right|$

$\uparrow 1 \%$ s\%pe

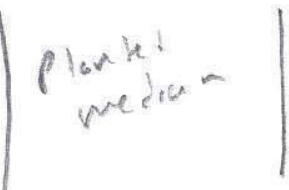

ह

$7 s^{\prime}$

$13^{1}$

$45 m / n$

$\sim 0.3 \mathrm{mi}$

Comments:

Onstreet ane separated bihelancs

median

Planke

c) immelate

cenu-divide-

S.gnise

westorem,

$5+1 m+1$

Dist to upstream

intersection/signal

$\sim 0.75 \mathrm{~m}$ : 
Nathan Johnston

Intersection:

Victoria Avenue/Grace Street

Time Period:

$8: 00-9: 00$

Volumes:
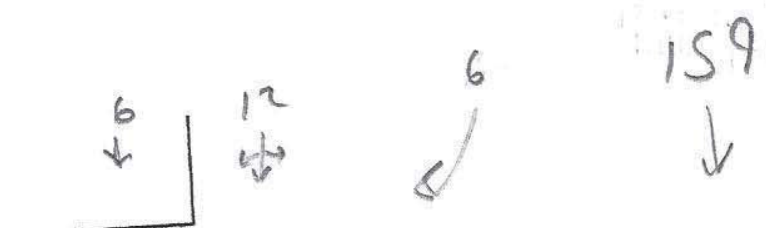

$2 \lambda$

$\longrightarrow$

$3 \stackrel{s}{b}$

$6>v$ $q$ y

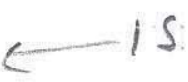

$r^{9}$

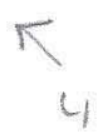

147

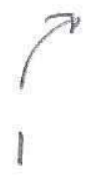

占

18 
Cal Poly San Luis Obispo

Nathan Johnston

Intersection:

Victona Ave/Grace Street

Heaw Vehicles:

$+$

$$
\text { \& } 10 \%
$$

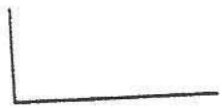

$\longleftarrow 7 \%$

$7 \% \rightarrow$

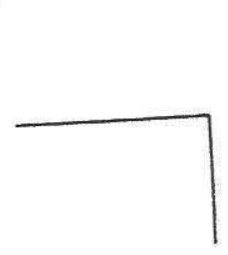

$p q \%$

Comments: Qu,k a few lage Uacks 
Nathan Johnston

Intersection:

Victoria Avenue / Saint Lawerence Street

City.

Riversic

Location Southern CA Northern CA Central CA Other Intersection Type: $(T)+$

Data Collection Time:

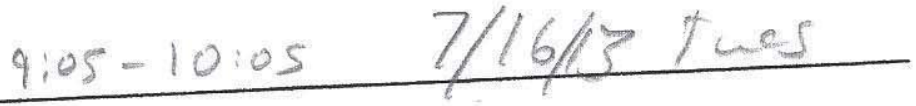

Intersection Geometry.

North Arrow:

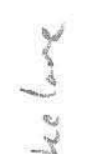

Dist to upstream intersectionisignal

तse

ح $0.25 \mathrm{~m}$ :

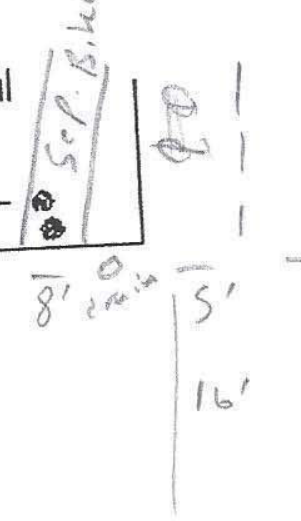

ST tovereace
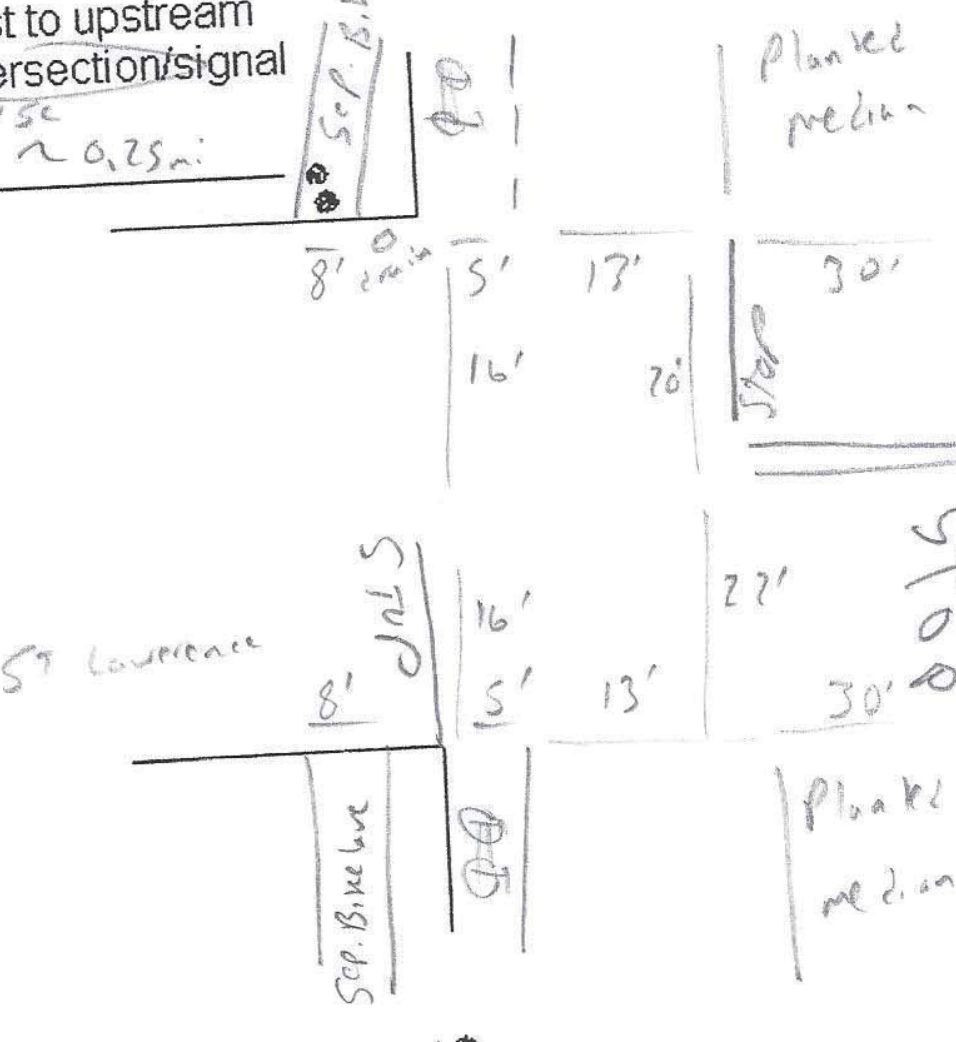

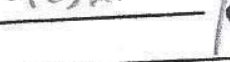

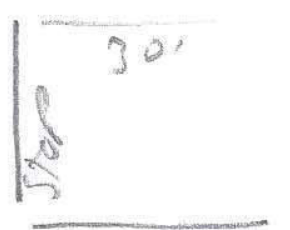

Jichura

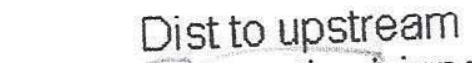

Dist to upstream

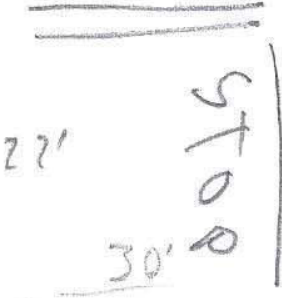

$\left|\begin{array}{l}\text { plomer } \\ \text { melian }\end{array}\right|$

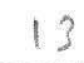

$13^{\prime}$

Private

Driveway

intersectionisignal

Awst

$\sim 0.35 \mathrm{mi}$

Comments:

Siznage present

Doveruat Gualts 5

No parkins, a bike lawes

Planker metian 
Nathan Johnston

Intersection:

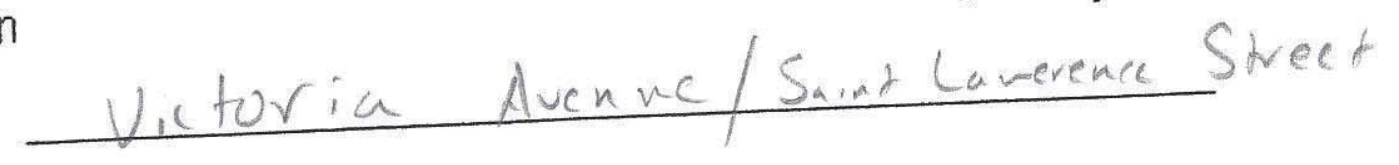

Time Period:

$9105-10105$

Volumes:

127

บ 54

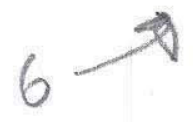

$$
\begin{aligned}
& \text { little } \\
& \text { to no } \\
& \text { tratace }
\end{aligned}
$$

4
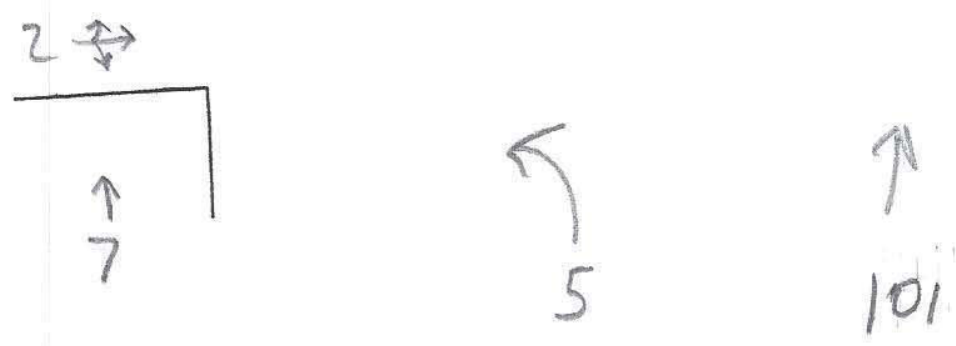
Cal Poly San Luis Obispo

Nathan Johnston

Intersection:

Virhona Ave/Sarat Loncrence Sheet

Heaw Vehicles:

$+$

$\downarrow 4 \%$

$3 \%-8$

$\uparrow 4 \%$

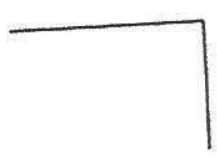


Nathan Johnston

Intersection:

Victoriu Avenuc/Bonadary Lare

City.

Rive sile

Location Southern CA Northern CA Central CA Other Intersection Type: ( + Data Collection Time:

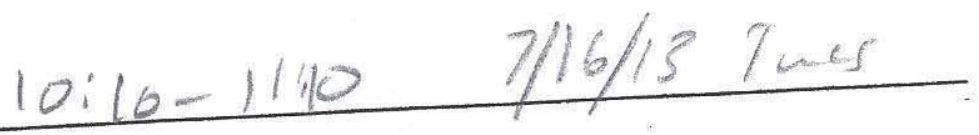

Intersection Geometry:

North Arrow:

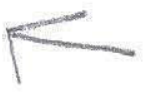

$$
40 m p^{2}
$$

Dist to upstream intersectionisignal

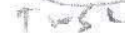
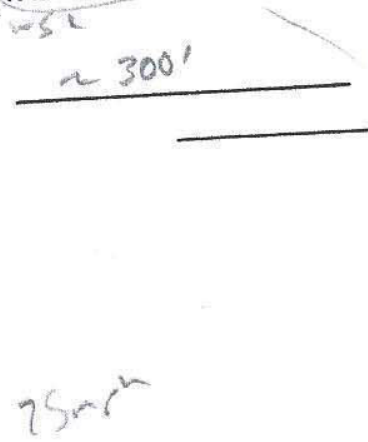

Bunriary

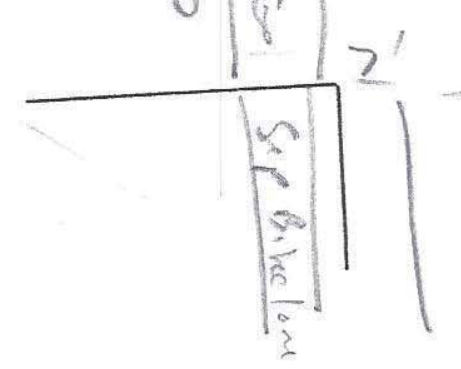

Dist to upstream intersection/signal

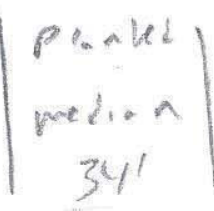

品

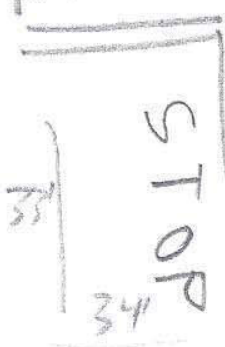

18

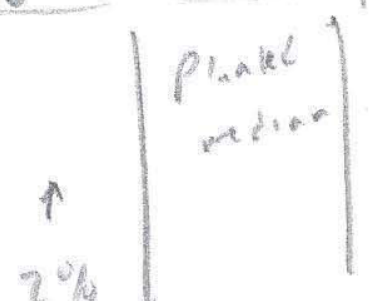

Dist to upstream intersection/signal

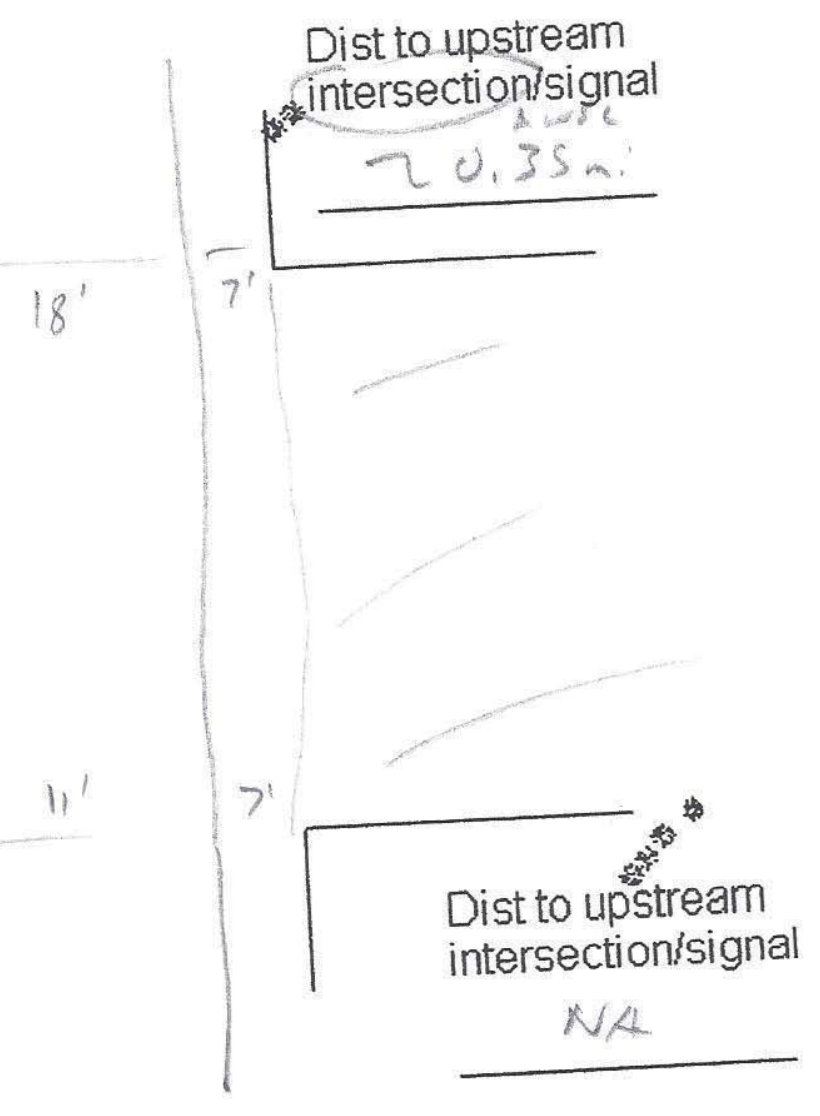

\footnotetext{
$20.4 \mathrm{~m}$
}

Comments: 
Cal Poly San Luis Obispo

Nathan Johnston

Intersection:

Victurat Averue/Bowadory lane

Time Period:

$10: 10-11: 10$

volumes:
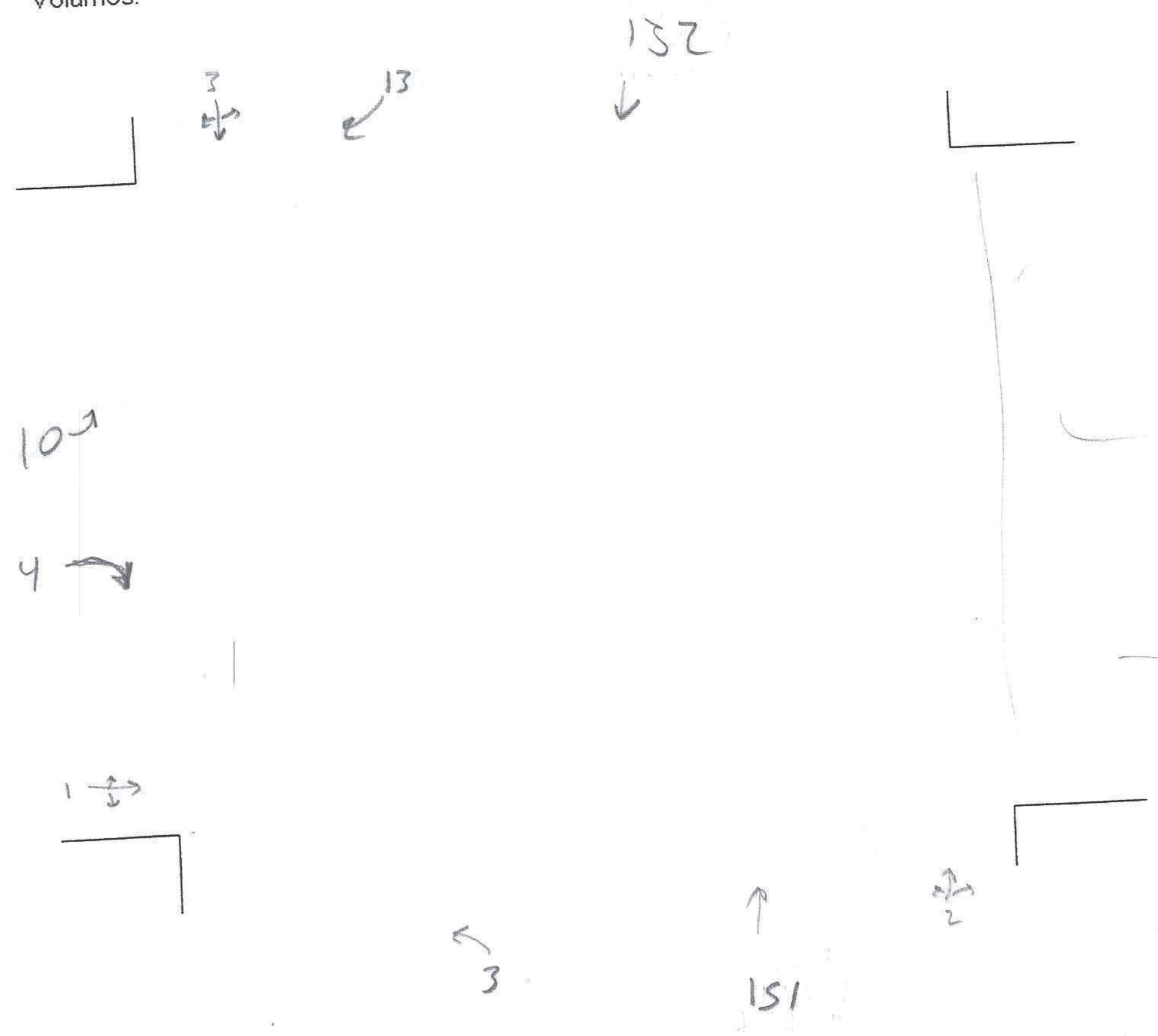

2

230 
Nathan Johnston

Intersection:

Vichora Auen+y/Burdary Lome Heaw Vehicles:
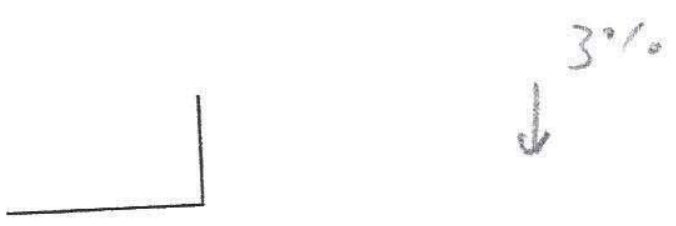

$1 \%,-3$

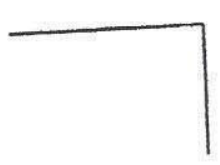

$\uparrow 3 \%$

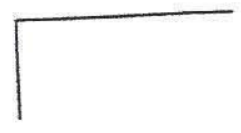

Comments: 
Nathan Johnston

Intersection:

Colorado Avenve/Dundec Roat

City:

Riverside

Location: Southern CA Northern CA Central CA Other Intersection Type: $T+$

Data Collection Time:

Intersection Geometry.

North Arrow:

$7 / 16 / 13$ Tues

Dist to upstream

intersectionisignal

$\simeq 700^{\prime}$

2smph

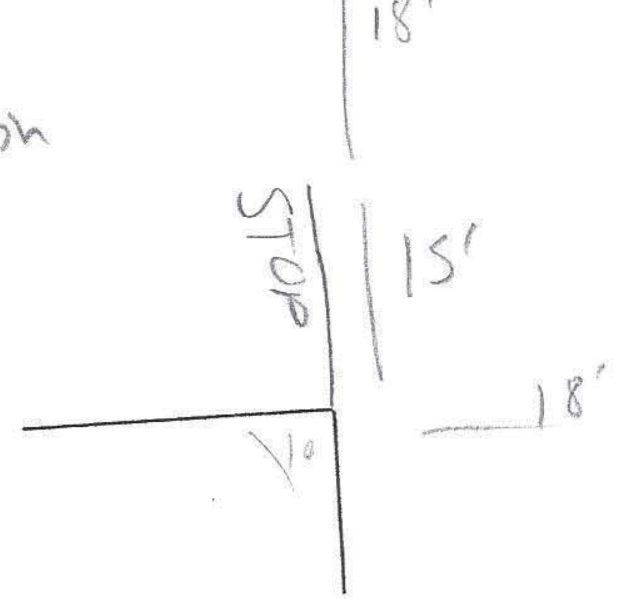

Dist to upstream

$35 m p^{h}$

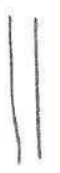

$18^{\prime}$

$18^{1}$

intersection!signal

$\sim 0.25$

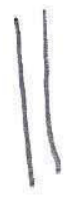

1

slope

$\uparrow 1 \%$ slope

$17^{\prime}$

$K$

Comments: 
Nathan Johnston

Intersection:

Colurado Avenue/Oundec Rdac

Time Period:

Volumes:

$\begin{array}{lllll}1 & 2 & 100 & 0 \\ 4 & j & 1 & b\end{array}$

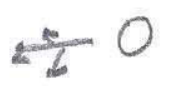

$7-1$

$0 \rightarrow$

167
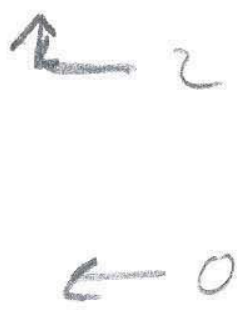

$\angle 0$

$0 \stackrel{2}{\rightarrow}$
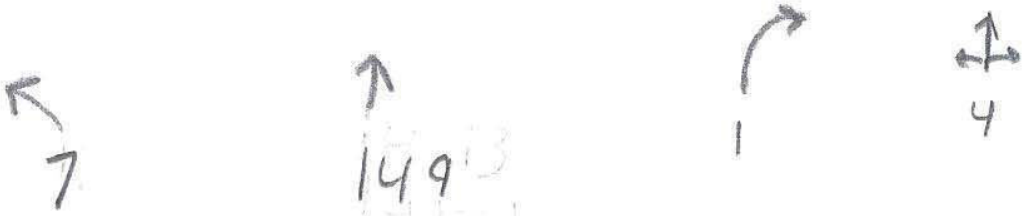
Nathan Johnston

Intersection:

Colorade Avenue /Onndec Rout

Heaw Vehicles:

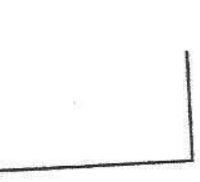

$$
\downarrow 2 \%
$$

$\rightarrow$

$$
12 \%
$$

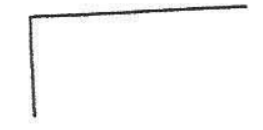

Comments: 
Nathan Johnston

Intersection:

Cal. formia Avenue/Shel by Drive

City:

Location Southern CA Northern CA Central CA Other Intersection Type: $T+$

Data Collection Time:

$12: 20=1: 20 \quad 7 / 16 / 13$ Tass

Intersection Geometry.

North Arrow:

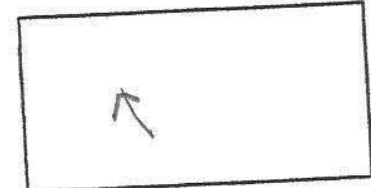

Dist to upstream intersectionisignal r $200^{\prime}$
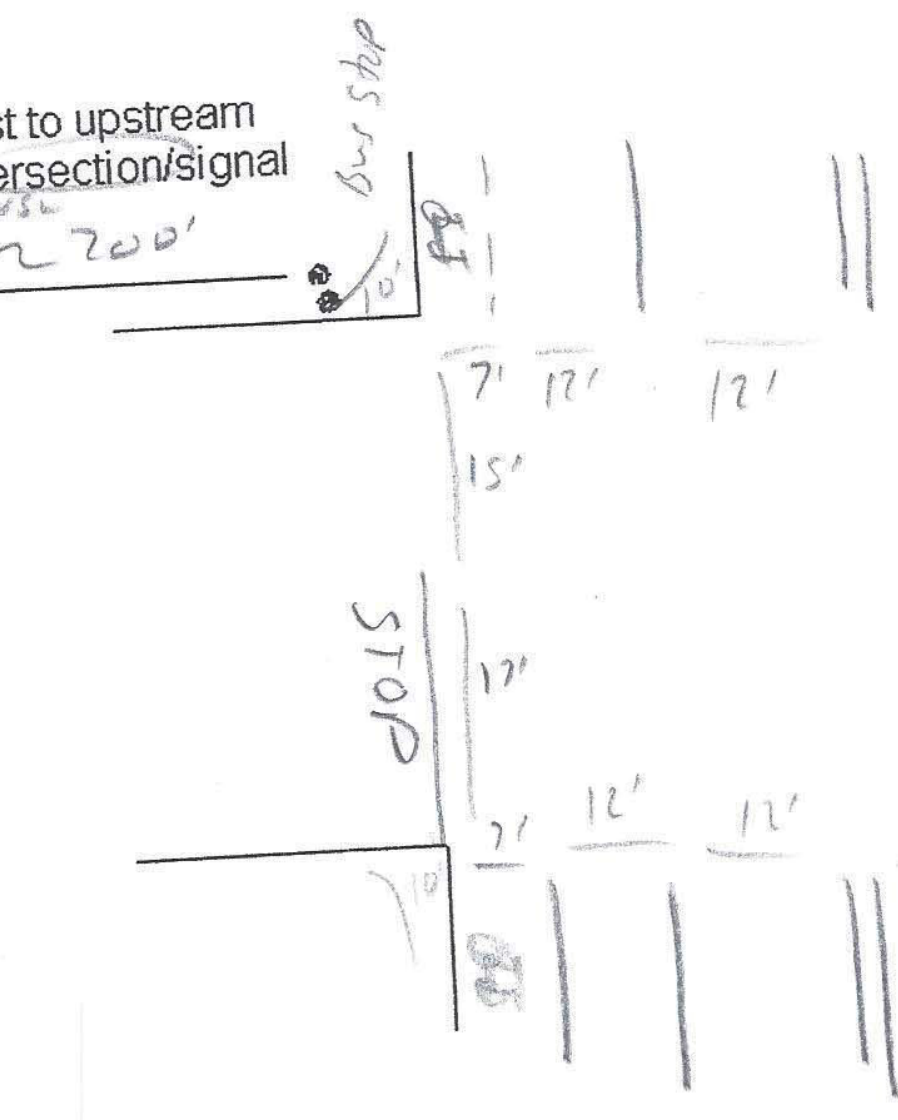

121
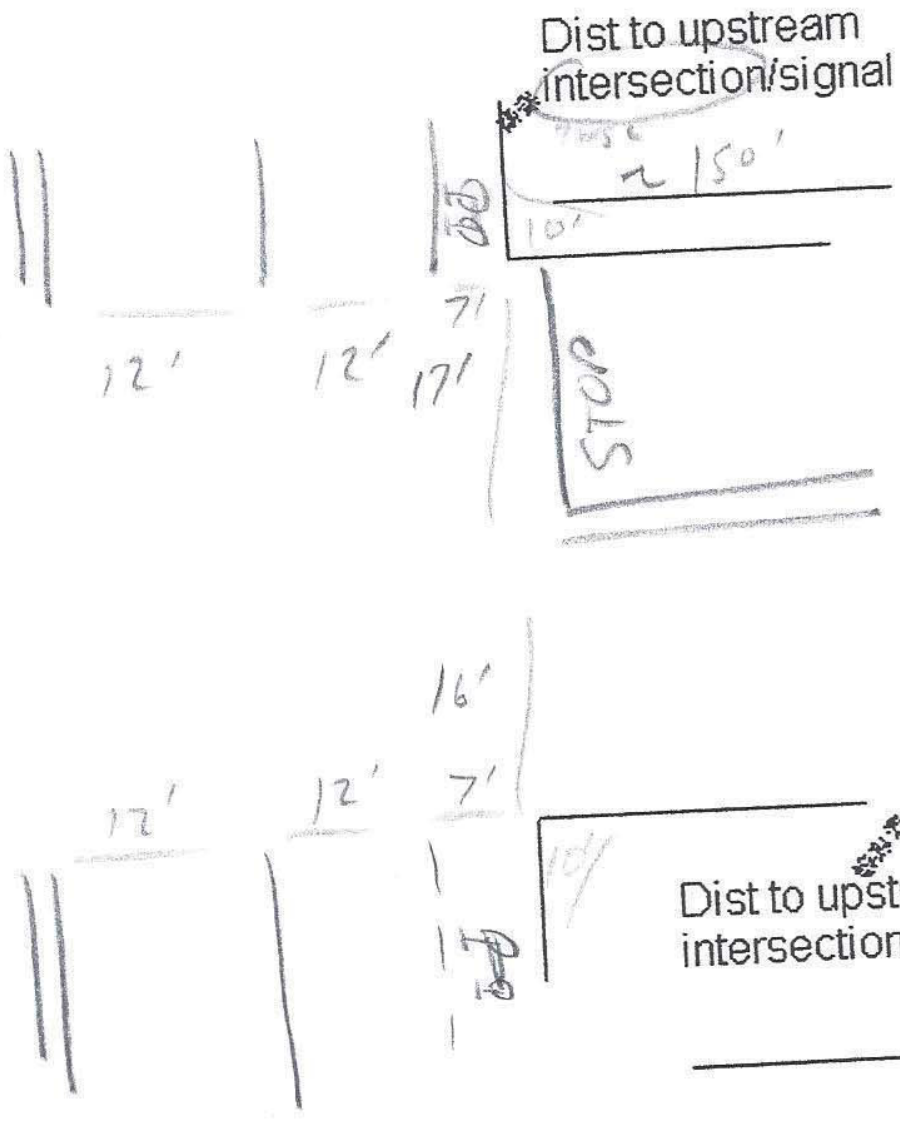

Dist to upstream

Dist to upstream intersection/signal

$$
\sim 0.25 \mathrm{mt}
$$

Comments:

Pavment qualits

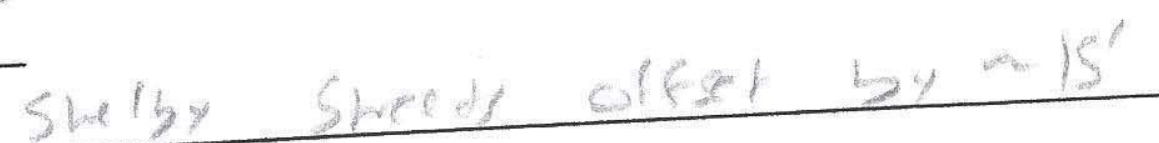


Nathan Johnston

Intersection:

Califormia Avenue/ Shiby Drive

Time Period:

$12120-1: 20$

Volumes:
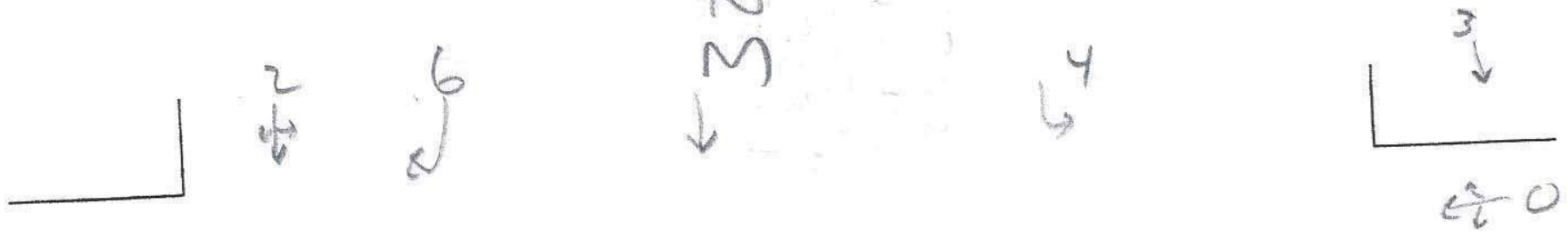

$6 \gamma$

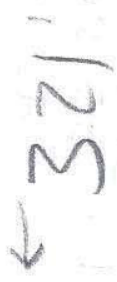

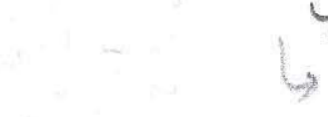
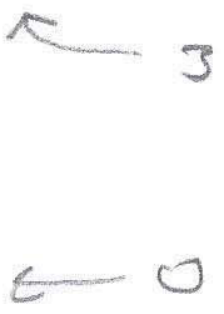

$0 \rightarrow$

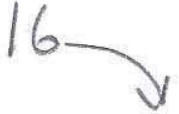

$6 \stackrel{5}{5}$

7

10 $\uparrow$

U

$N$

$M$
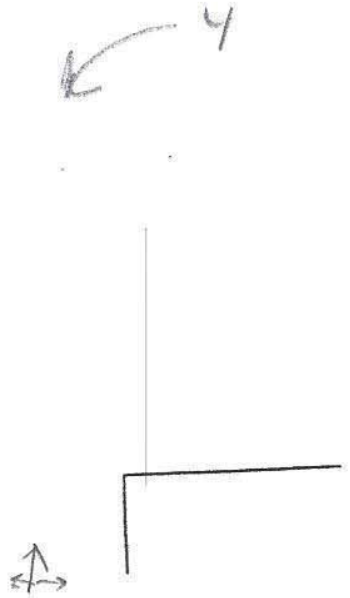
Nathan Johnston

Cal Poly San Luis Obispo

intersection: California Xue/slelby Drive

Heaw vehicles:

$\downarrow \downarrow^{3 / 0}$

10

$\rightarrow$

$+$

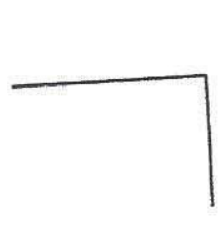

$\uparrow 310$

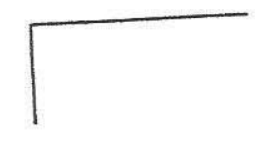

comments: 
Nathan Johnston

Intersection:

city. Riverside

Location: Southern CA Northern CA Central CA Other Intersection Type: (T + Data Collection Time:

Intersection Geometry.

\section{Dist to upstream} intersection/signal NA $1: 30-2: 30 \quad 716 / 13$

Magndia Avenue/tower Street

North Arrow:

Yomph
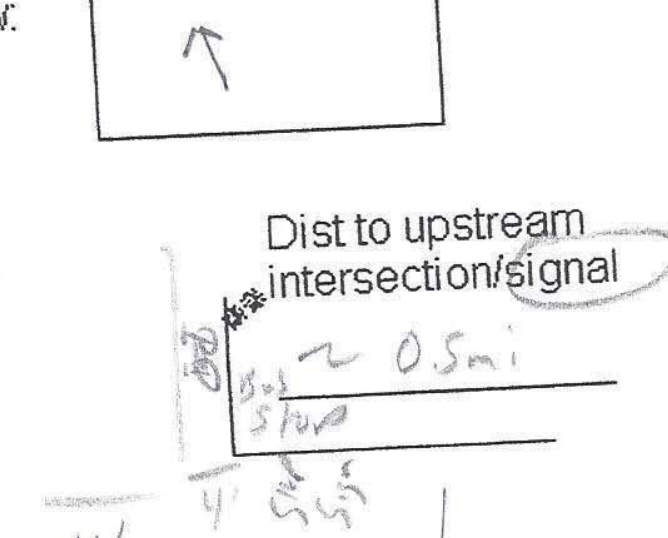
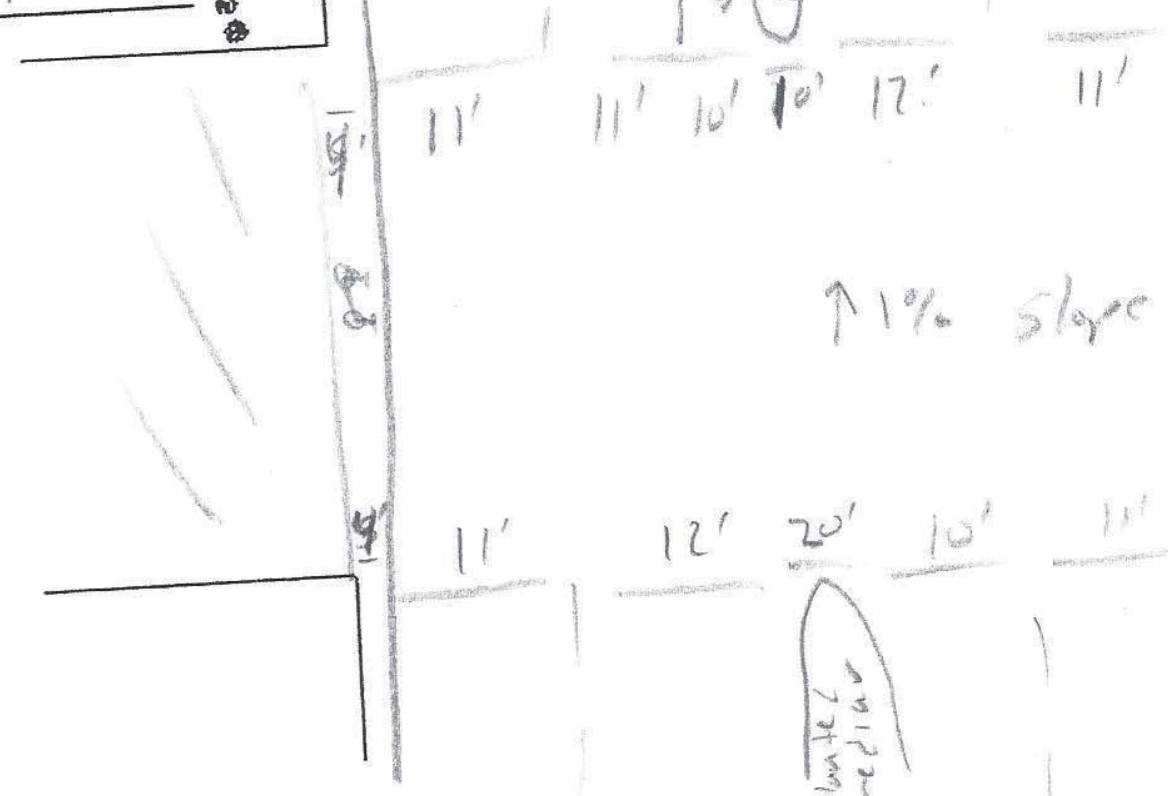

$2 s^{m p h}$
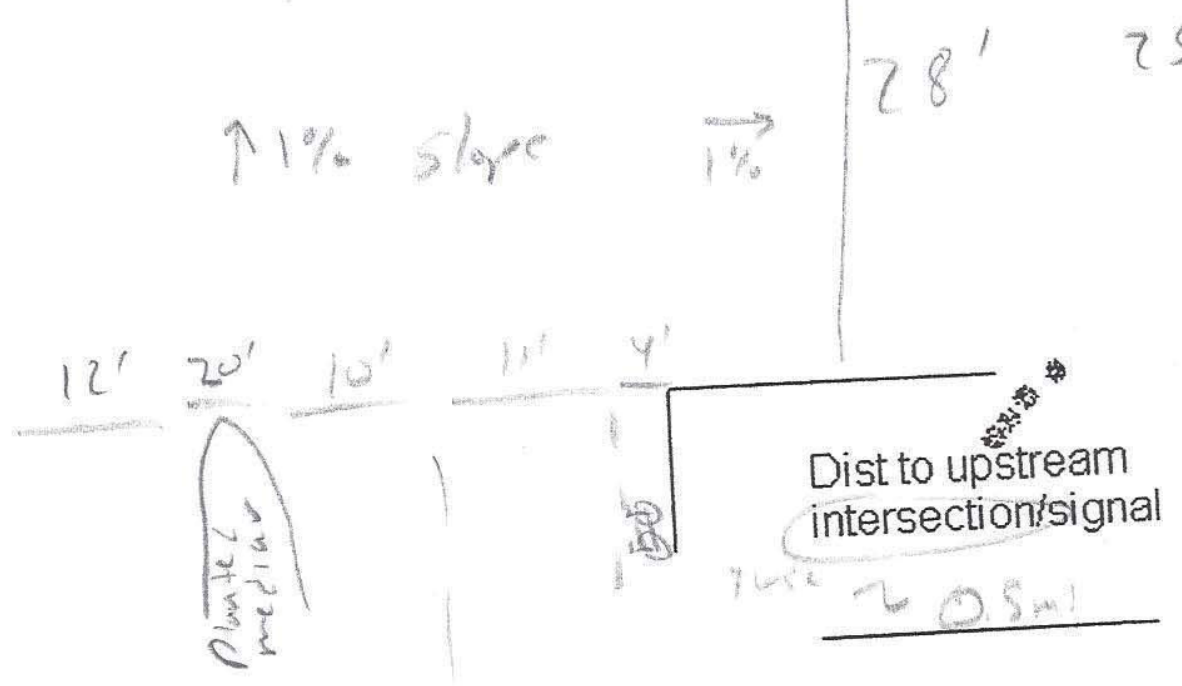

Dist to upstream intersectionsignal

$40 m^{n}$

$0.3 \ldots$

Comments:

No porting

ch

and

Eust side $h=5$

movatable entb. 
Cal Poly San Luis Obispo

Nathan Johnston

Intersection:

Mandolin Avenue/Hower Street

Time Period: $1: 30-2: 30$

Volumes:

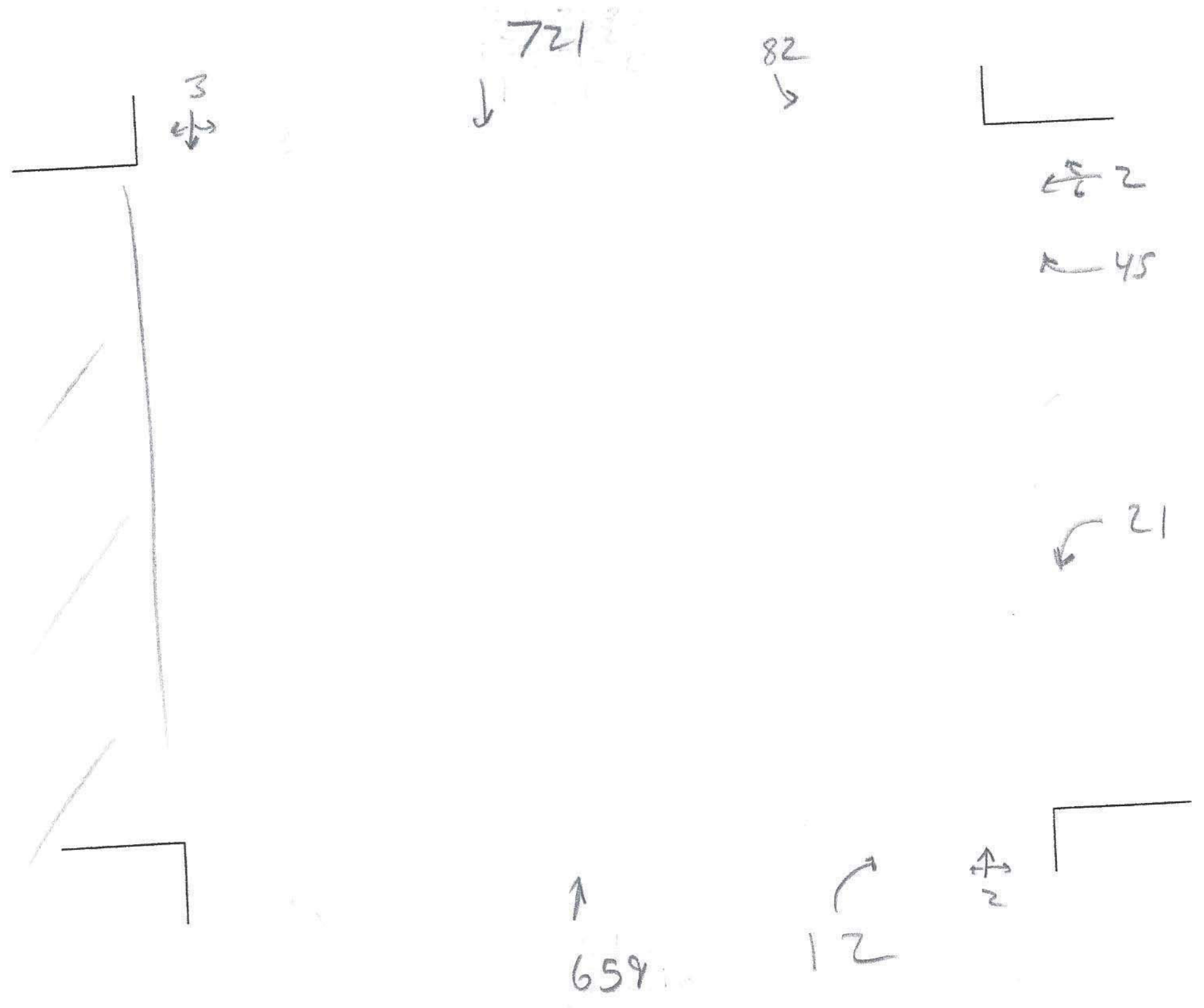

2

239 
Nathan Johnston

Intersection:

Magnolia Avenue/ Hower Sheet

Heaw Vehicles:

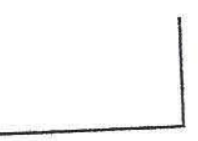

$$
\downarrow 5 \%
$$

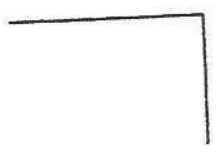

$\uparrow 4 \%$

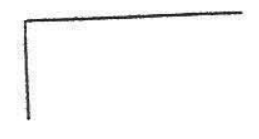

Comments: 
Nathan Johnston

Intersection: Los Osos Valley Roor/Piablo Drive

City:

Sor cus Obispo

Location: Southern CA Northern CA

Central CA

Other

Intersection Type: $\mathrm{T}+$

Data Collection Time:

9:00-10:00 wets

$6 / 19 / 13$

Intersection Geometry:

Dist to upstream

intersection/signal

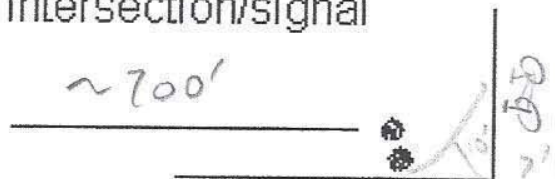

$25 \mathrm{mph}$

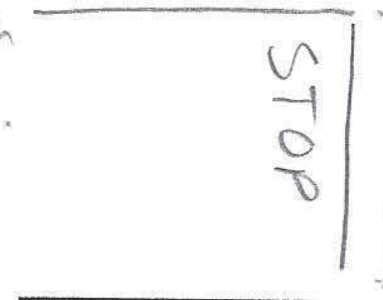

$\prod_{\substack{\text { Bus } \\ \text { stop }}}$

Dist to upstream

intersection/signal

$\sim 1000^{\prime}$
North Arrow:

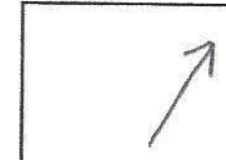

$4 \mathrm{smph}$

Shor Dist to upstream
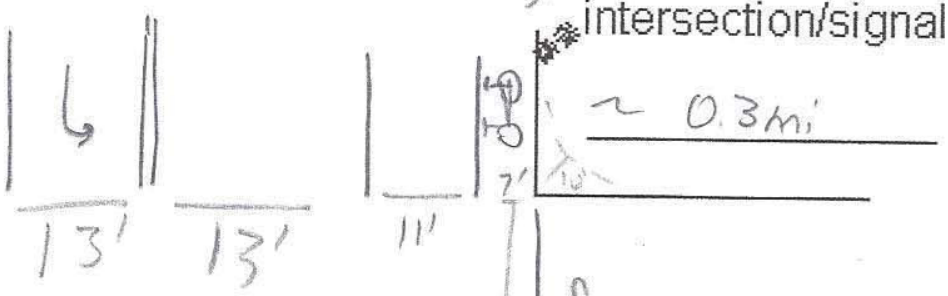

2 smph

Diablo

Dr.

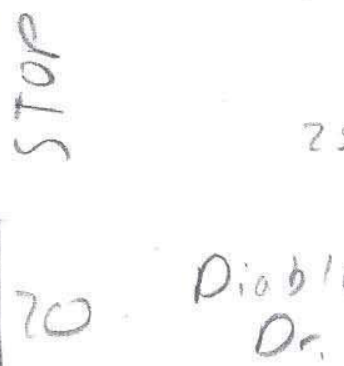

Dist to upstream intersection/signal

$-6001$

Comments: Diablo EB is set back abut to feet frem Louk fur stop bar. Provites space far cyclists to entkr. 
Nathan Johnston

Intersection:

Cos OSas Valley Road / O.ablo Pr.

Time Period:

$9: 00 \cdot 10 ; 00$

Volumes:

$\int_{16}^{15} \quad 46,628,30$

D.abis

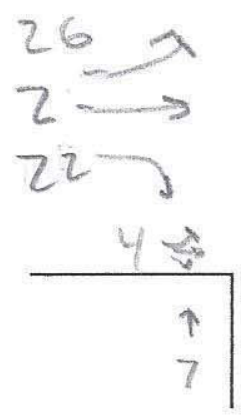

Lour

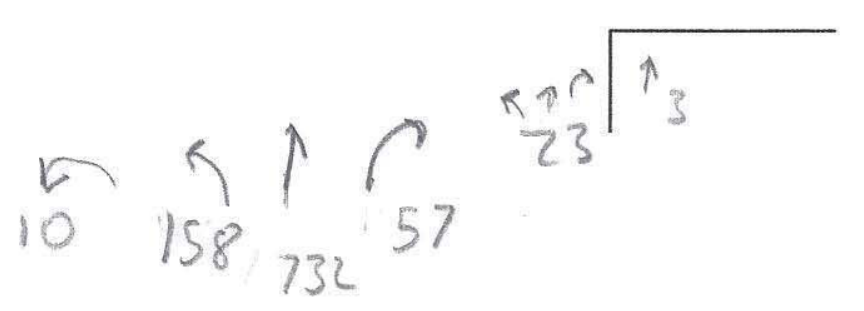


Nathan Johnston

Cal Poly San Luis Obispo Intersection: Los osus Valley Roat/D,ablo Dive

Heaw Vehicles:

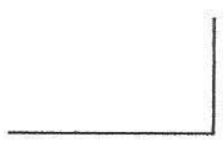

$\downarrow 9 \%$

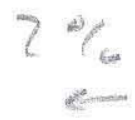

$2 \%$

$\rightarrow$

Dis bia

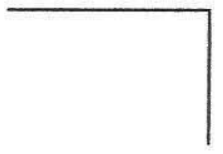

Loun

$12 \%$

$\uparrow$

Comments:

Diablo hat Ru trathic 
Nathan Johnston

Intersection:

Granc Ave / Mccollum st.

City:

Sun Luis Obispo

Location: Southern CA Northern CA

Central CA Other

Intersection Type: $\mathrm{T} \oplus$

Data Collection Time:

$7: 40-8: 40$ Weds $6 / 19 / 13$

Intersection Geometry.

Dist to upstream

intersection/signal

$\sim 200^{\prime}$

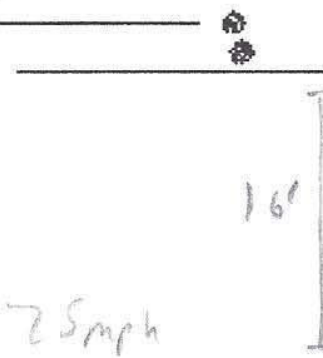

Dist to upstream *

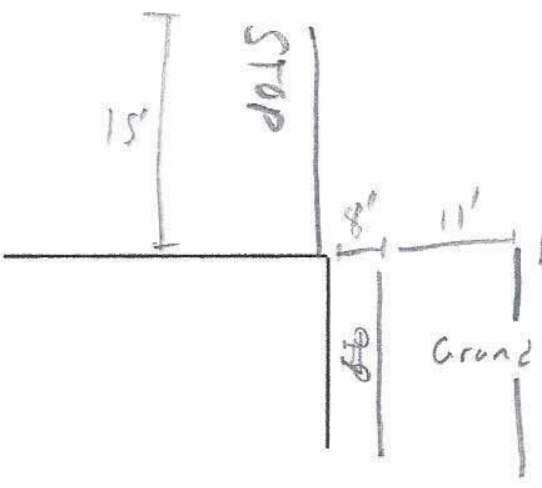

intersection/signal

$\sim 200^{\prime}$
North Arrow:

$35 \mathrm{mph}$

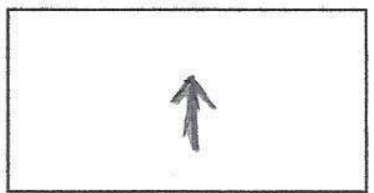

Dist to upstream

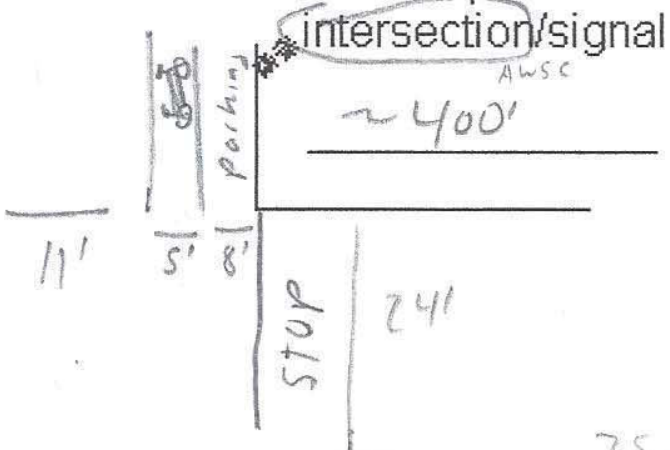

$e-10 \%$ slope

$16^{\prime}+11^{\prime}+11^{\prime}+11^{\prime}+5^{\prime}+8^{\prime} \mid$

zi' MLCollum

Comments: 
Nathan Johnston

Cal Poly San Luis Obispo

Intersection: Grancture/Mccollum St.

Time Period: $7: 40-8: 40$. We $256 / 19 / 13$

Volumes:

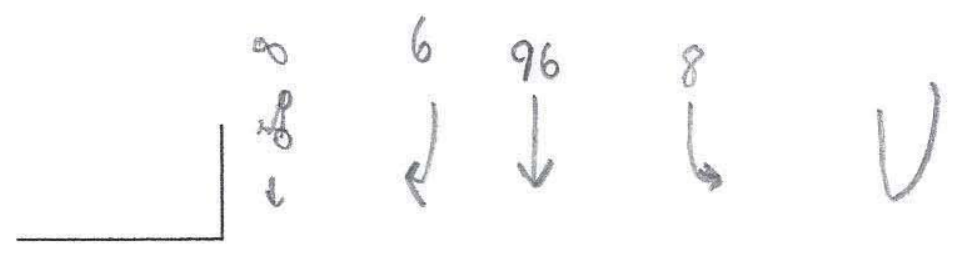

$e^{1 \% \text { slope }} \quad \uparrow 3 \%$ slope
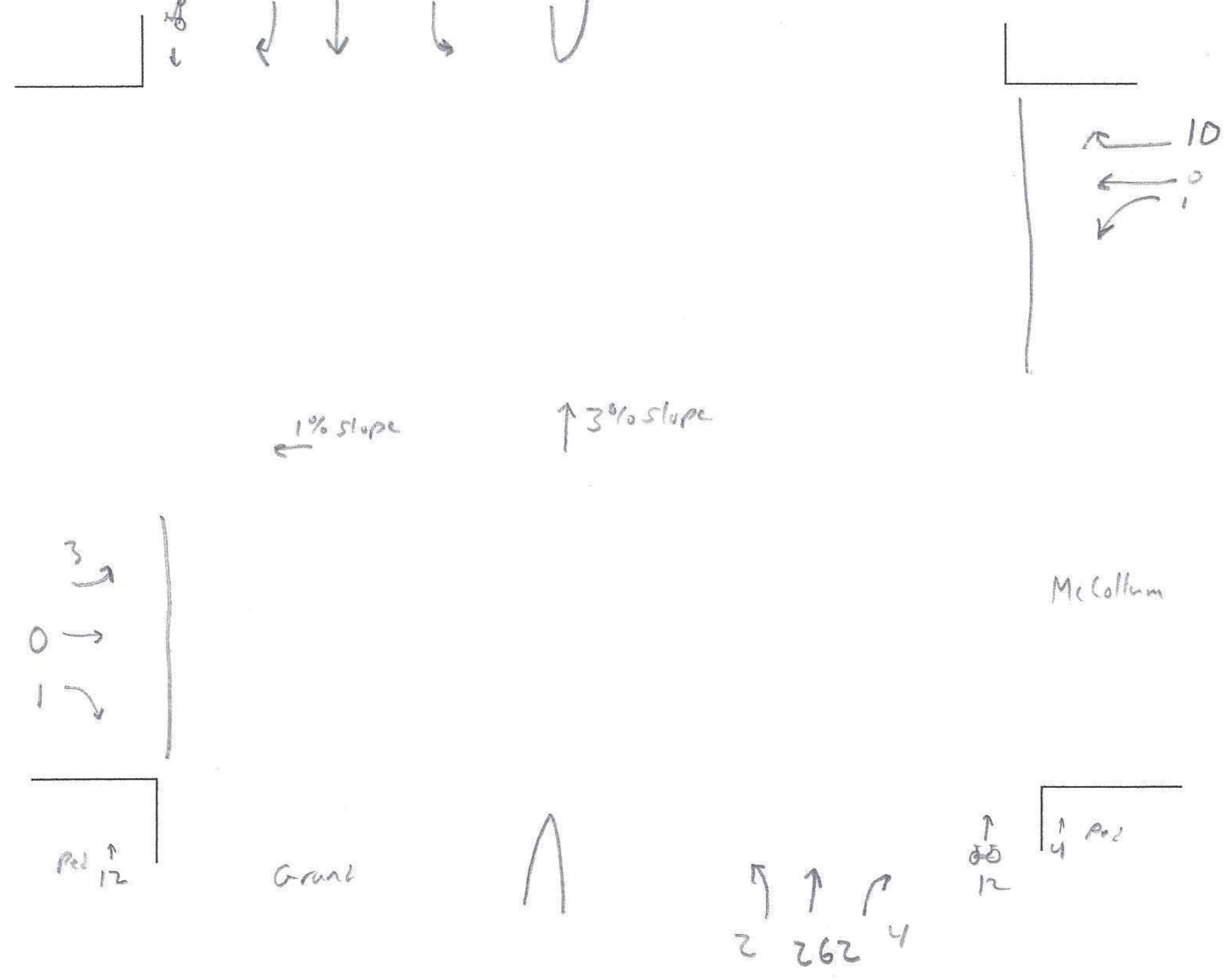

245 
Nathan Johnston

Intersection: Crant Ave $/ M c$ Collum st

Heay Vehicles:

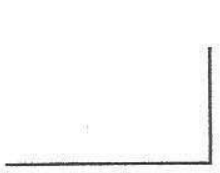

$$
\downarrow^{3 \%}
$$

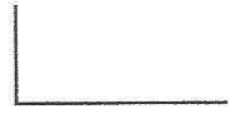

$\varepsilon 1 \%$

Me Collum

$\overrightarrow{1 \%}$

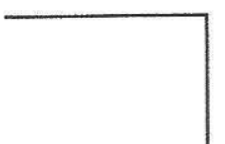

$$
\text { Grant }
$$

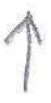

$3 \%$

Comments: 
Nathan Johnston

Intersection: Patricia Dr/ Cerro Romaldo Ave

City.

San Luis Obispo

Location: Southern CA Northern CA CentralCA Other Intersection Type: $\mathrm{T}+$

Data Collection Time:

Weds $6 / 19 / 13$

$\sim 6: 30 \mathrm{~mm}$ Start

Intersection Geometry:

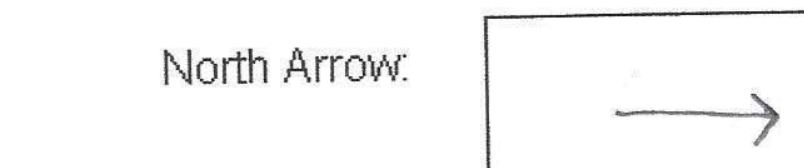

Dist to upstream intersection/signal

$\sim 200$
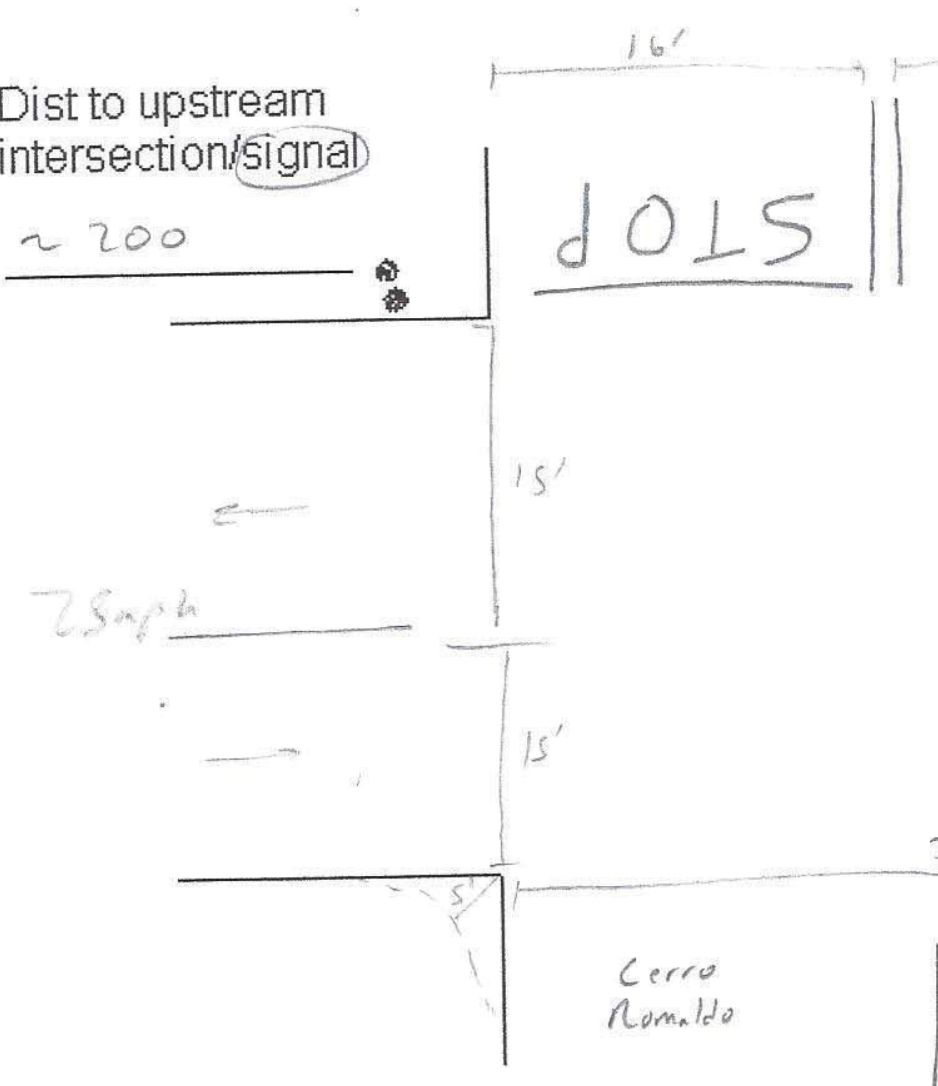

Dist to upstream * * * *

intersection/signal

$32^{\prime}$

$16^{\prime}$

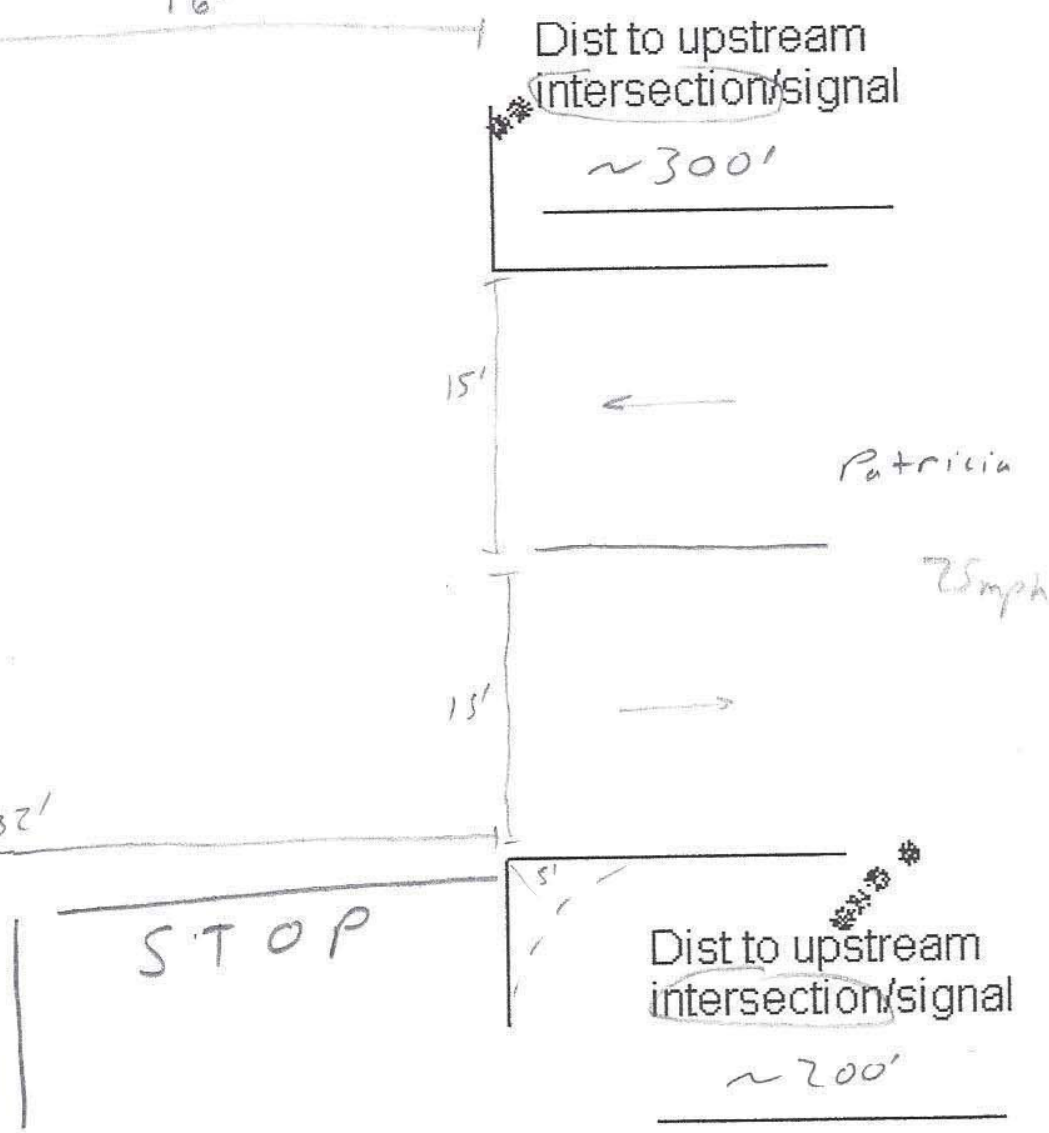
$\sim 800^{\circ}$

Comments: 
Nathan Johnston

Intersection:

Patricia Dr. / Cerro Romallo

Time Period:

$6: 30-7: 30 \mathrm{am}$

veds

Volumes:

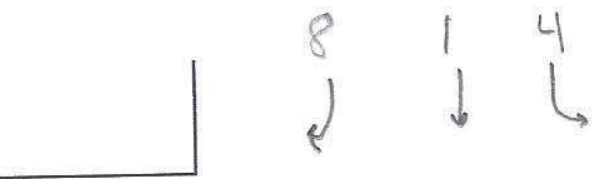

1
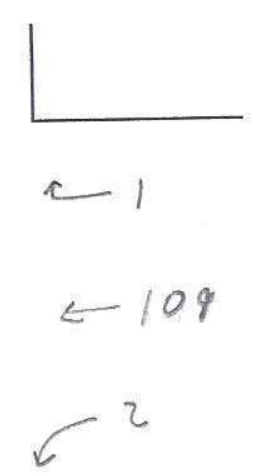

Patricia -

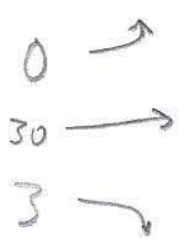

$\prod$ cerro komaldo

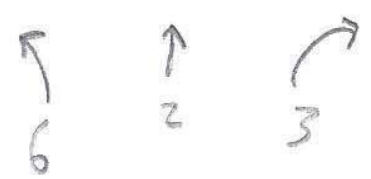


Nathan Johnston

Cal Poly San Luis Obispo

Intersection: Patricia Dr / Cero Romaldo

Heap Vehicles:
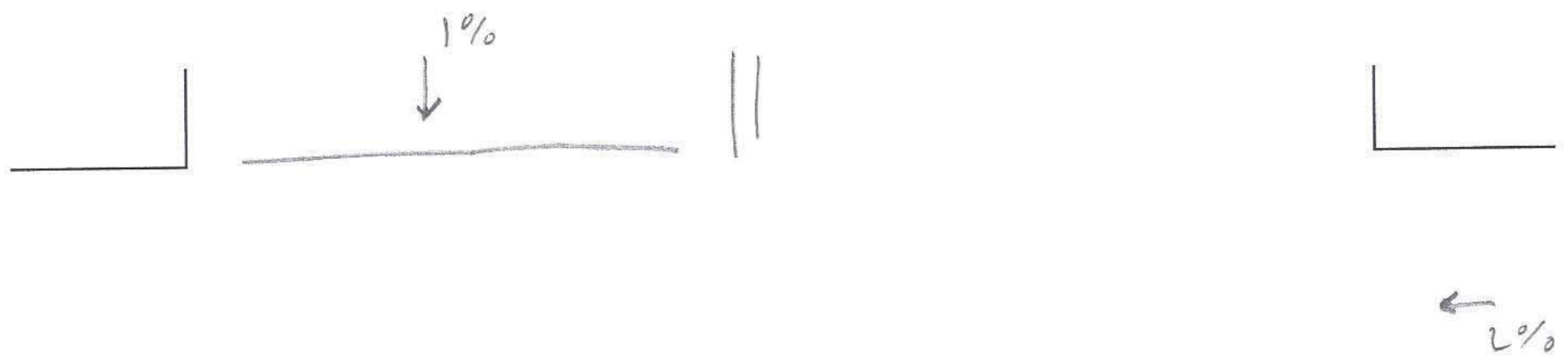

Patricia

$\rightarrow$

cero
normal to

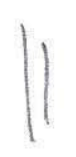

$\uparrow$

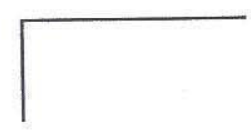

Comments: Near residential neighborhood Only heave vehicles

Were School bases.

249

3 
Nathan Johnston

Intersection: Preformo Canyon Row / Cos OSos valley Row

City San Luis Ob.spa

Location: Southern CA Northern CA Central CA Other

Intersection Type: $(T+$

Data Collection Time:

$10: 10-11: 10$

Intersection Geometry:

North Arrow:

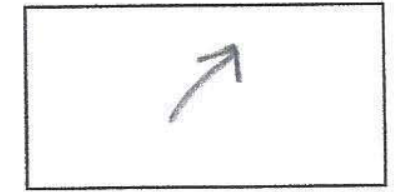

Dist to upstream

intersection/signal

$-300^{\prime}$

$8 \overline{8}$

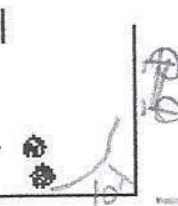

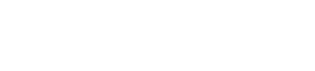

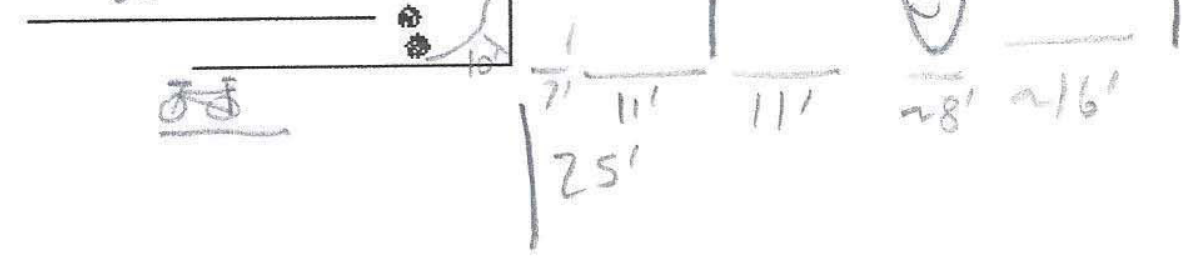

$40 \mathrm{mph}$

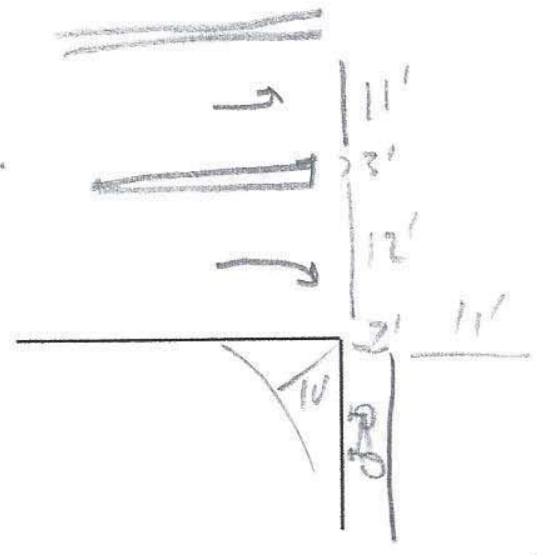

$<2 \%$ slope

L U VR
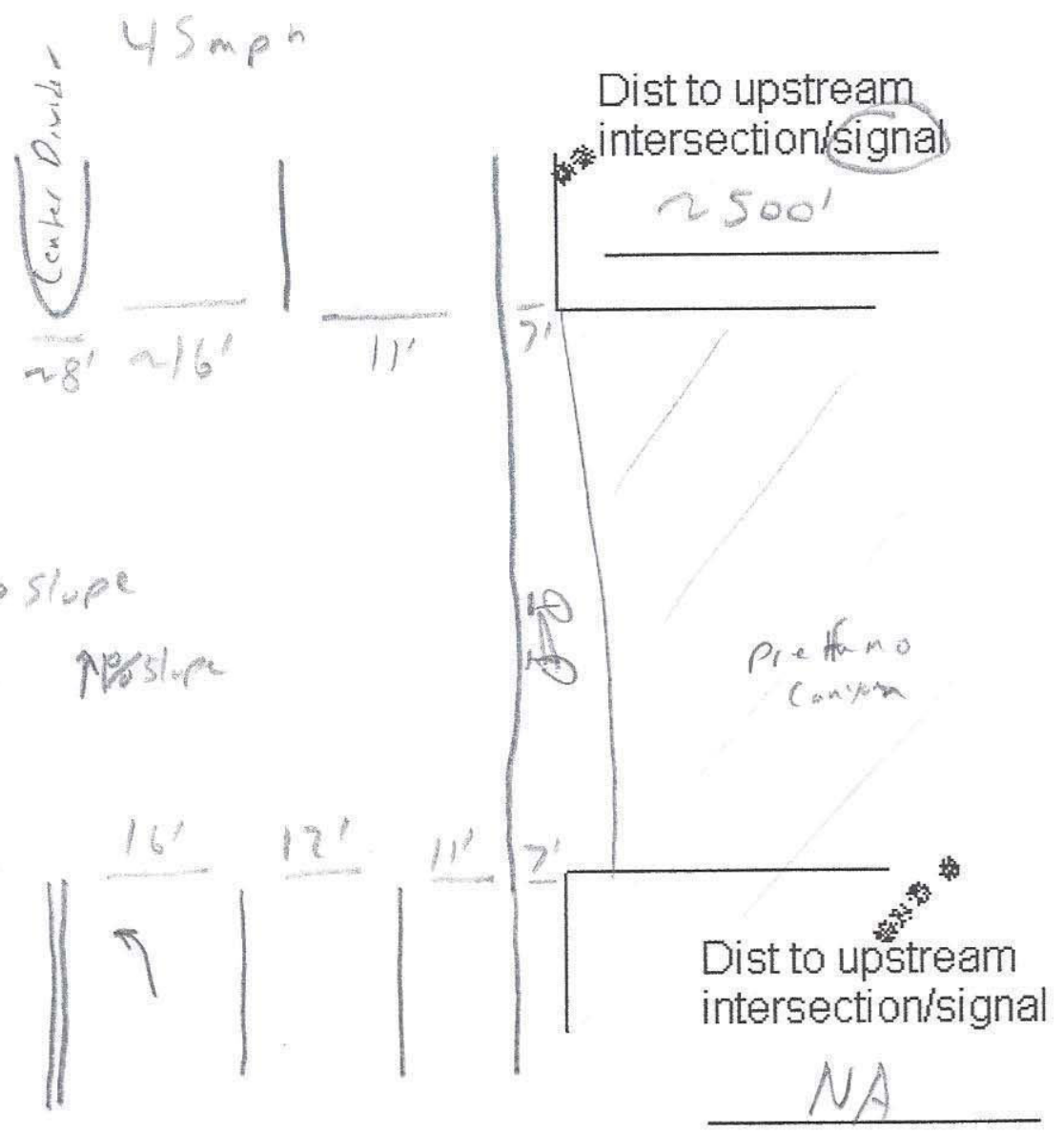

Dist to upstream

intersection/signal
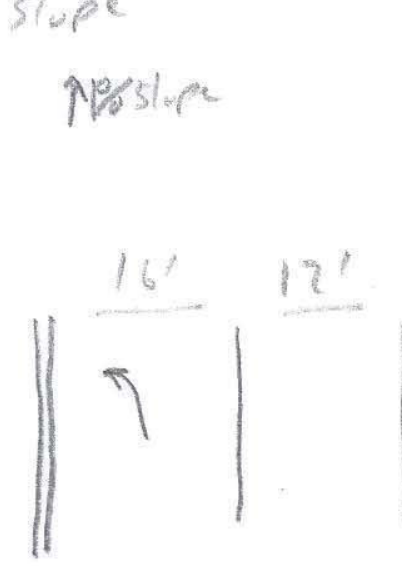

$$
\text { Ysmph }
$$$$
100^{\prime}
$$

Comments:

Deesn't becanc ustble for sol ather inkersection. North center Diveder megese into NB \& 1 lane relueing to 12 later. 
Nathan Johnston

Intersection:

Lovr / Pretumo Canyea Roud

Time Period:

$10: 10-11: 10$

Volumes:

Pichomente

Canyor

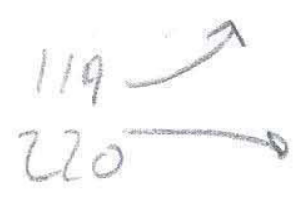

$\frac{17 \geq}{1}$

lovn

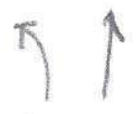

70780

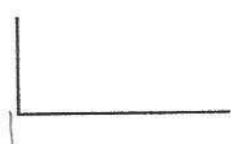

58
38 
Nathan Johnston

Intersection: Los osos Valley Ros /Prefumo Canyur Rous

Heaw Vehicles:

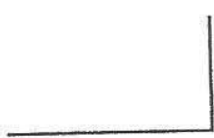

$v^{9 \%}$

$+3 \%$

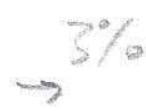

perano

Canyer

Rd

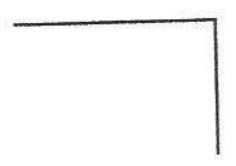

LovR
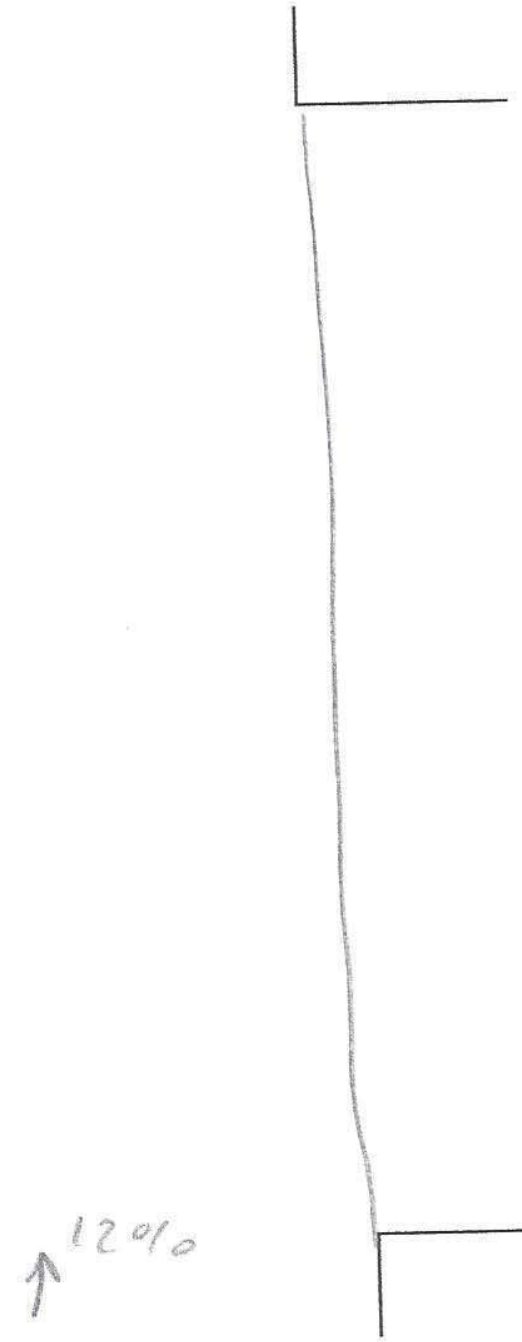

Comments: 
Nathan Johnston

Intersection:

Tank Form Rond Long Strect

City:

San Lu+S

C) $b+5 p$

Location: Southern CA Northern CA CentralCA Other Intersection Type: $T+$

Data Collection Time:

$$
11: 30-12: 30 \text { Vets }
$$

Intersection Geometry.

North Arrow:

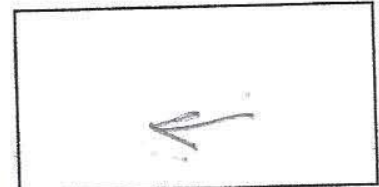

Dist to upstream intersection'signal $\sim 600^{\circ}$

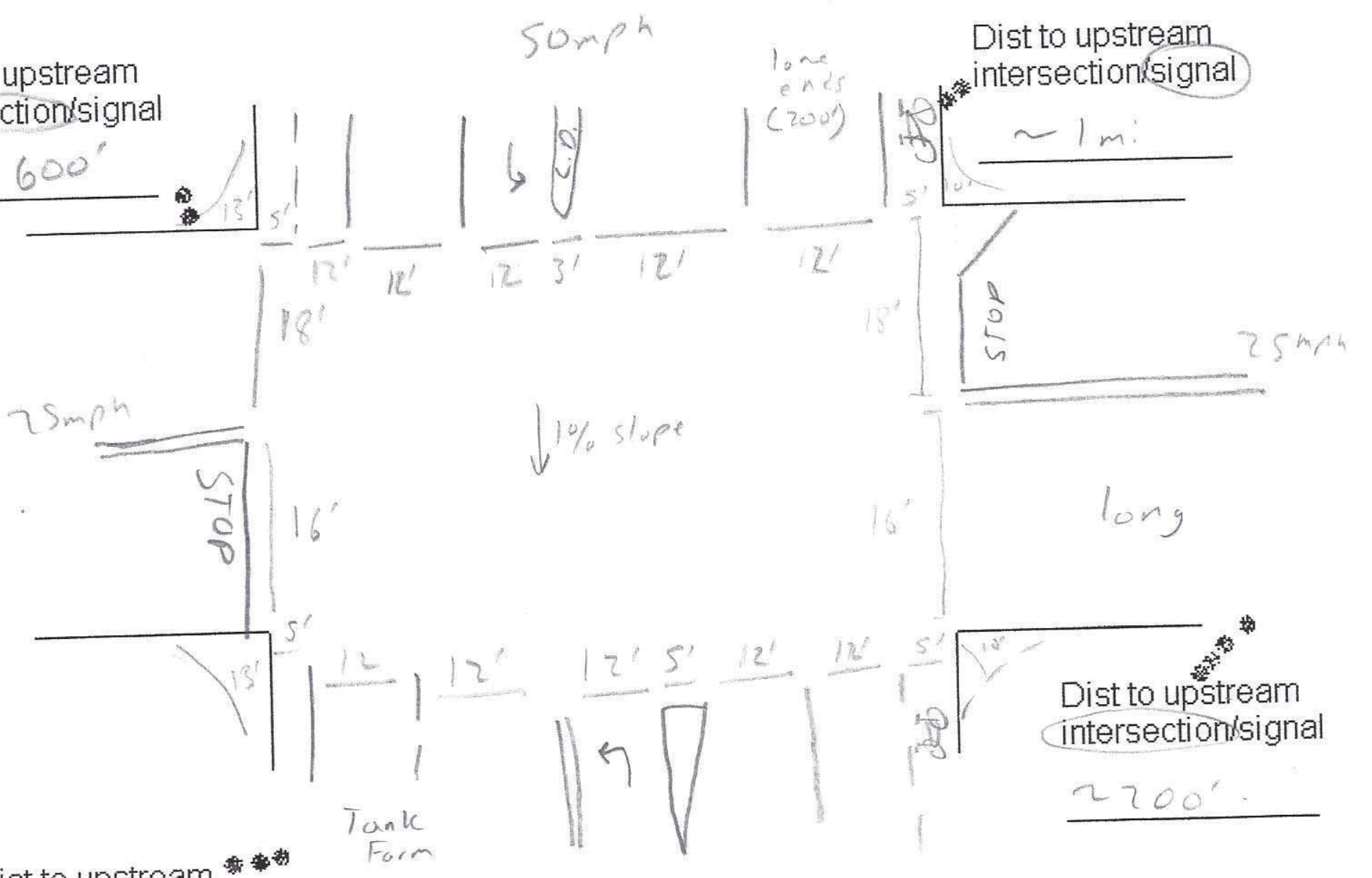

Dist to upstream * intersection/signal $50 \mathrm{mph}$ $\sim 400^{\prime}$

Comments: Very Windy 
Nathan Johnston

Intersection:

Tank farm Rout/lang strect

Time Period:

$11 ; 30-12: 30$

wets $6 / 19 / 13$

Volumes:
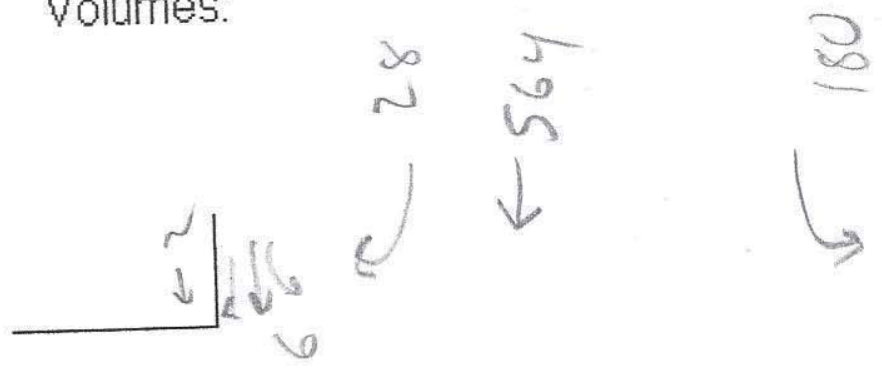

4

닌

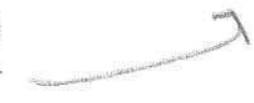

$-\longrightarrow$

$\stackrel{-\infty}{2}$

Tank
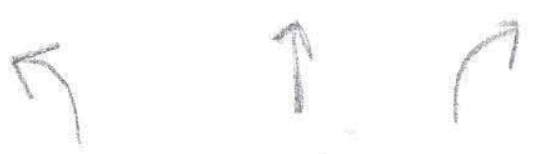

$\sin$

Furpan

$\because \quad \frac{5}{9}$ 
Nathan Johnston

Cal Poly San Luis Obispo

Intersection: Tunh Farm Row/Low Street

Heaw Vehicles:

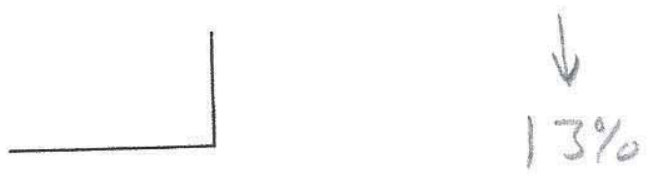

$\rightarrow$

$10 \%$

Comments:
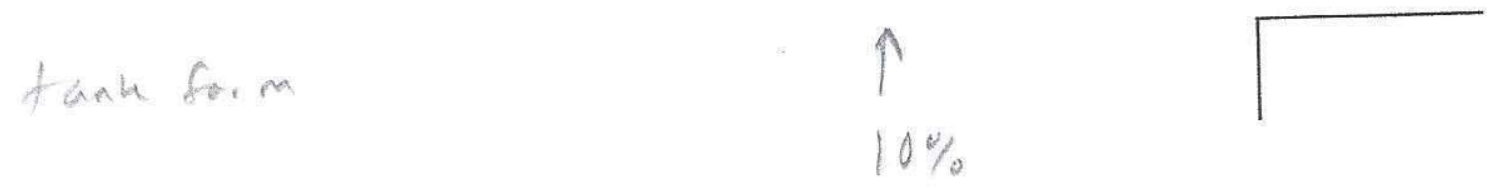
Nathan Johnston

Intersection:

$$
\text { Johason Ave }
$$

Syeney Street

City:

San Luis Obispo

Location: Southern CA

Northern CA Central CA Other

Intersection Type: $T \biguplus$

Data Collection Time:

$12: 50-1: 50$

Intersection Geometry.

North Arrow:

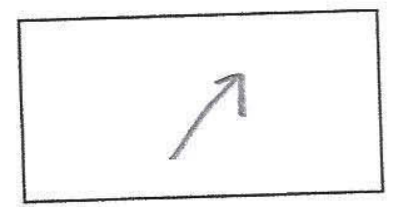

$45 \mathrm{mp}^{h}$

Dist to upstream

intersection/signal n $400^{\prime}$

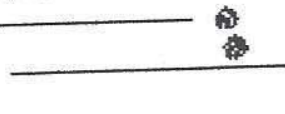

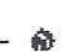

$25 \min ^{6}$

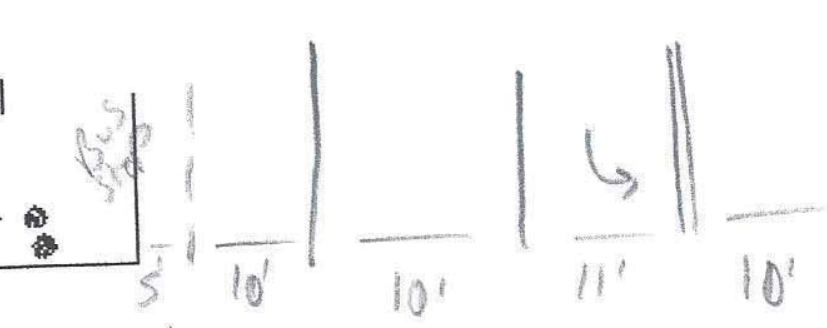

$\overrightarrow{5 \%}$

Dist to upstream

intersection/signal

Jihnson

Cober Crosswalk

$5^{\prime} 10^{\prime}$

10

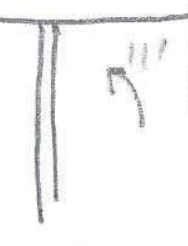

10

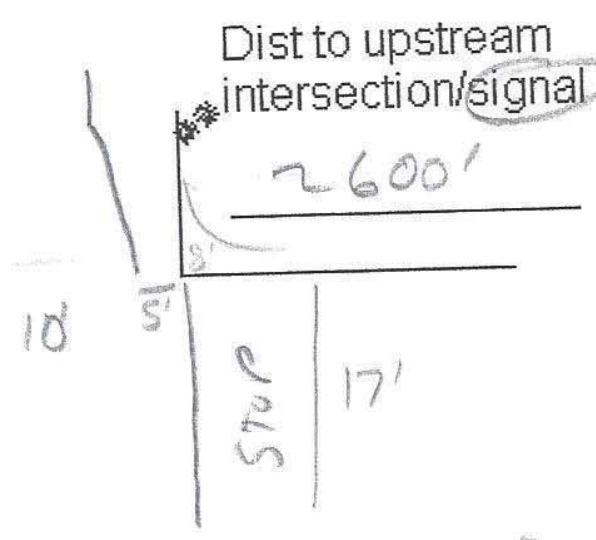

$2 \operatorname{simph}$

$20^{\prime}$ Syeney

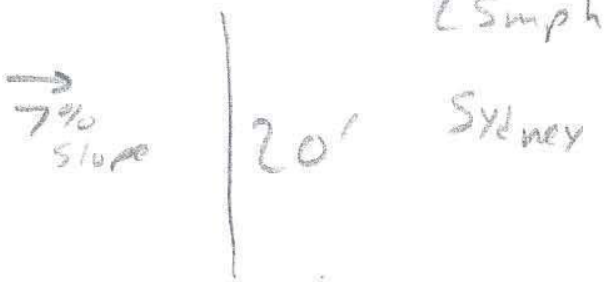

10 is!

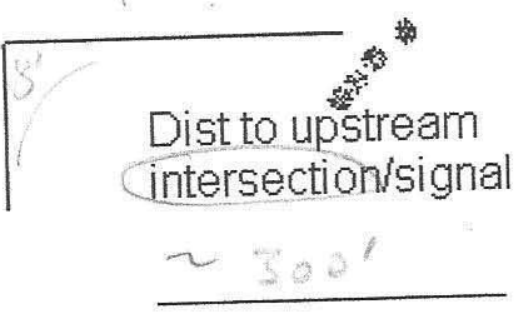

$45 \mathrm{mph}$

Comments:

NB expands to inelude partion laas after 100 ' 
Nathan Johnston

Intersection:

Sohnson Ave/Syeney Street

Time Period:

$12: 30=130$

Volumes:

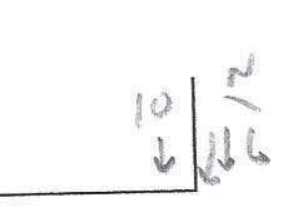

$2_{6}^{\infty}$

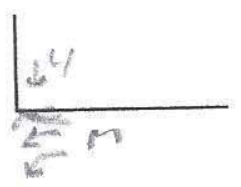

$1+38$
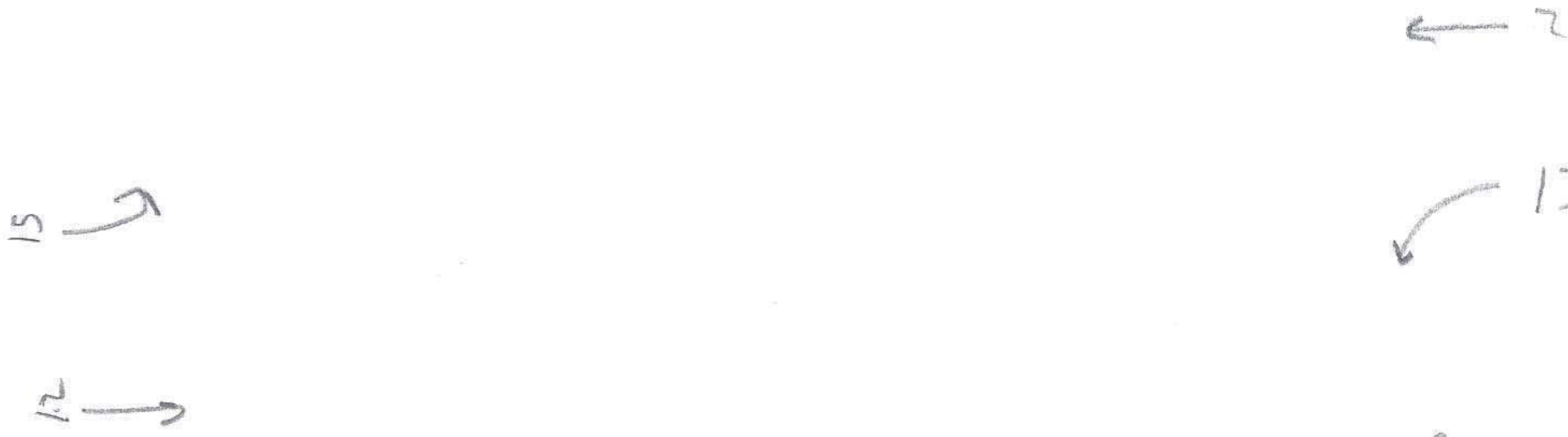

$$
\begin{aligned}
& 6-y
\end{aligned}
$$

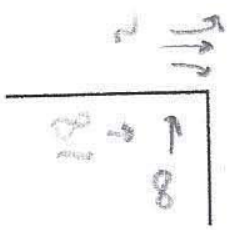

Johnsen

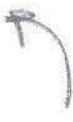

16
1

9

S $\{y=n p y$
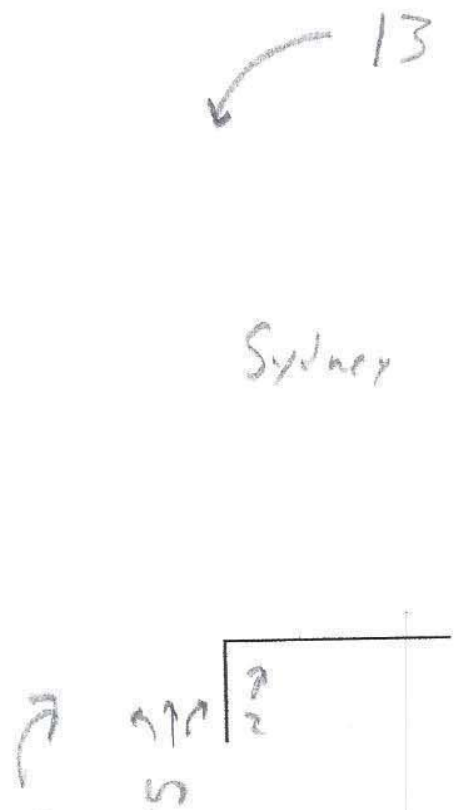
Nathan Johnston

Intersection: Jahnson Ave/Sylmy Sheet

Heaw Vehicles:

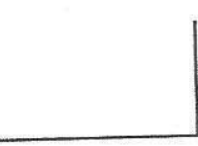

$\int_{10}^{2}$

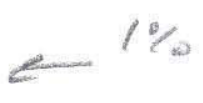

Sydne

$1 \% \rightarrow$

Johason

1

$4 \%$

Comments:

Sydar o resuleatial while Juhiogos is on heaver

roule 
Nathan Johnston

Intersection:

Munterey Street/70ro street.

City.

San Luis ob is po

Location: Southern CA Northern CA Central CA Other Intersection Type: $T \oplus$

Data Collection Time:

Intersection Geometry:

North Arrow:

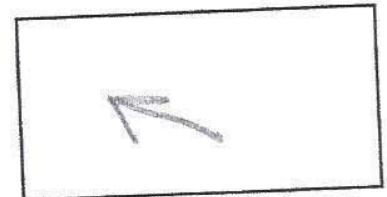

Dist to upstream intersection/signal
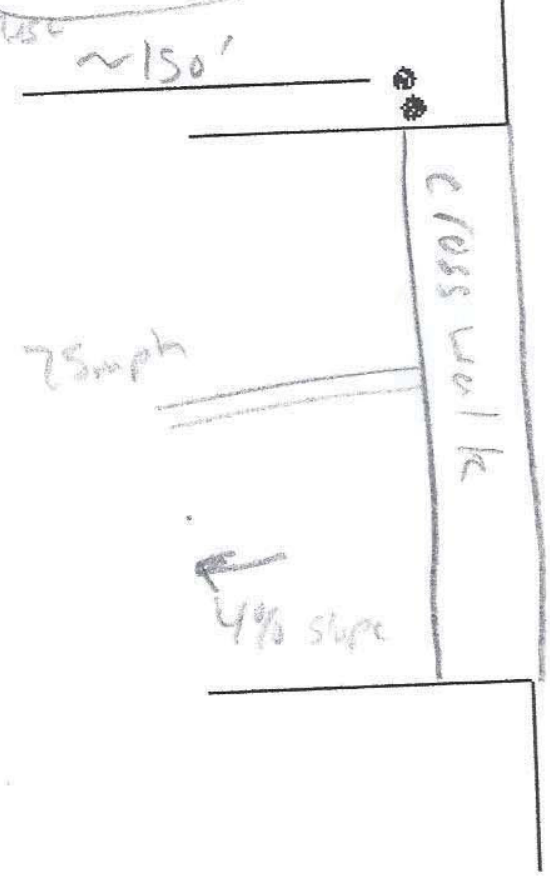

Dist to upstream intersection/signal
$1: 40-2: 40$ wods $6 / 19 / 13$ 
Nathan Johnston

Intersection: Monterex Strect/Toro Street

Time Period:

$1: 40-2: 40$

Volumes:

$\begin{aligned} & 4 \\ & 4\end{aligned} \mid \begin{array}{ll}13 \\ 403\end{array}$<smiles>CCCC</smiles><smiles>[GeH2]</smiles>

$\downarrow$

$3^{32}$

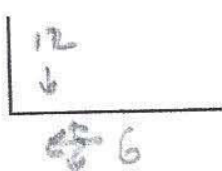

47
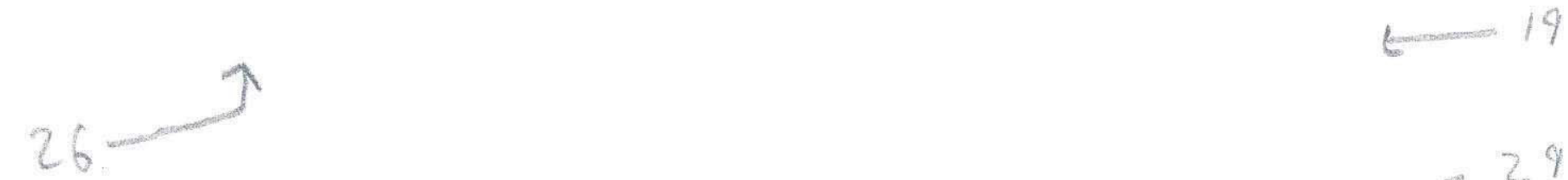

56 menamang

12

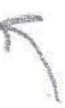

27

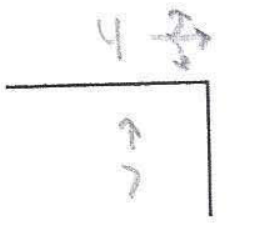

Markey 
Nathan Johnston

Cal Poly San Luis Obispo

Intersection: Montereystrect $/$ tore Street

Heaw Vehicles:

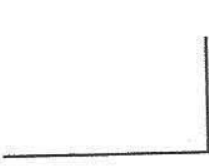

$\downarrow 9 \%$

$\rightarrow 3 \%$

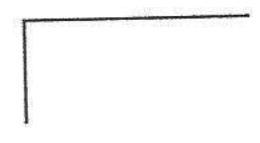

Comments: 
Nathan Johnston

Intersection:

Monterey Itreet / Pepper street

City:

Sar Luis ob.sp:

Location: Southern CA Northern CA Central CA Other Intersection Type: $T+$

Data Collection Time:

$2: 50$ - 3:5o weds $6 / 19 / 13$

Intersection Geometry.

North Arrow:

$$
35 \mathrm{mph}
$$

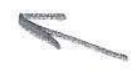

Dist to upstream

intersection'signal

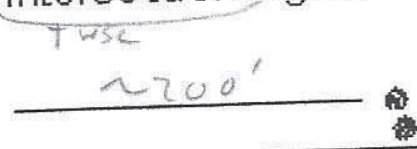

$25 \mathrm{mph}$

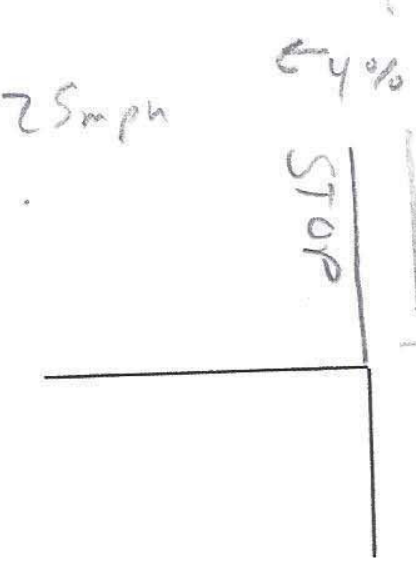<smiles>C1CCCCC1</smiles>
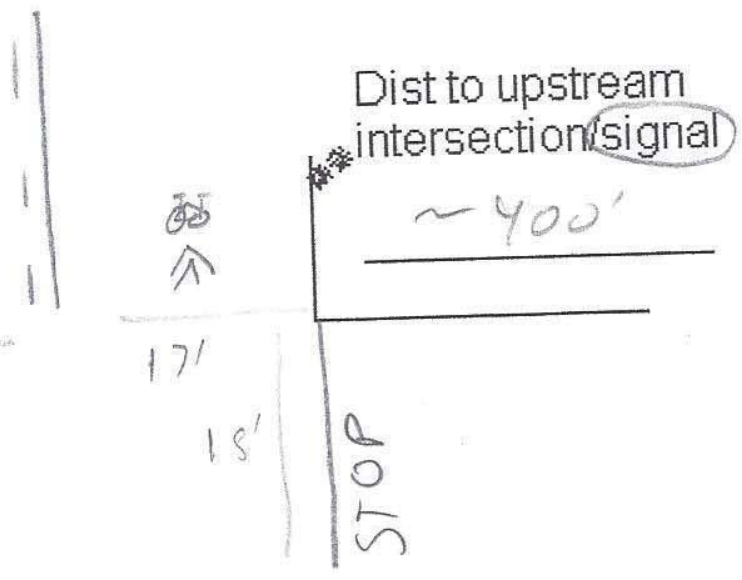

$\rightarrow$ $4 \%$

pepper

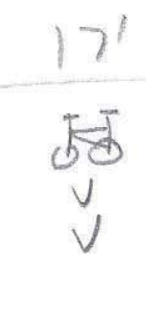

Monterey

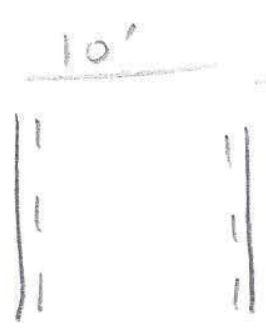

$35 \mathrm{~m} \mathrm{ph}^{\mathrm{h}}$
Dist to upstream intersection/signal

$$
\sim 400^{\prime}
$$

Comments:

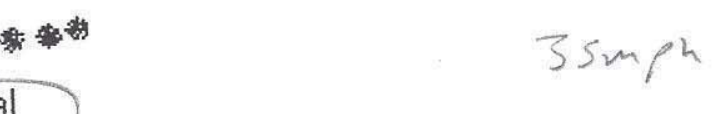

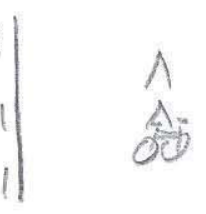

$\Delta$ 
Nathan Johnston

Intersection: Monkrey Street / pepper

Heaw Vehicles:

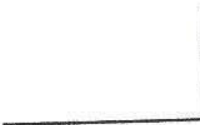

$\downarrow 4 \%$

$1 \%$

$\rightarrow$

Comments: 
Nathan Johnston

Intersection: Monterey Street

Time Period:

$2: 50-3: 50$

Volumes:

$\begin{array}{llll}\overline{\tilde{w}} & \overline{0} & \bar{\omega} & \sim\end{array}$
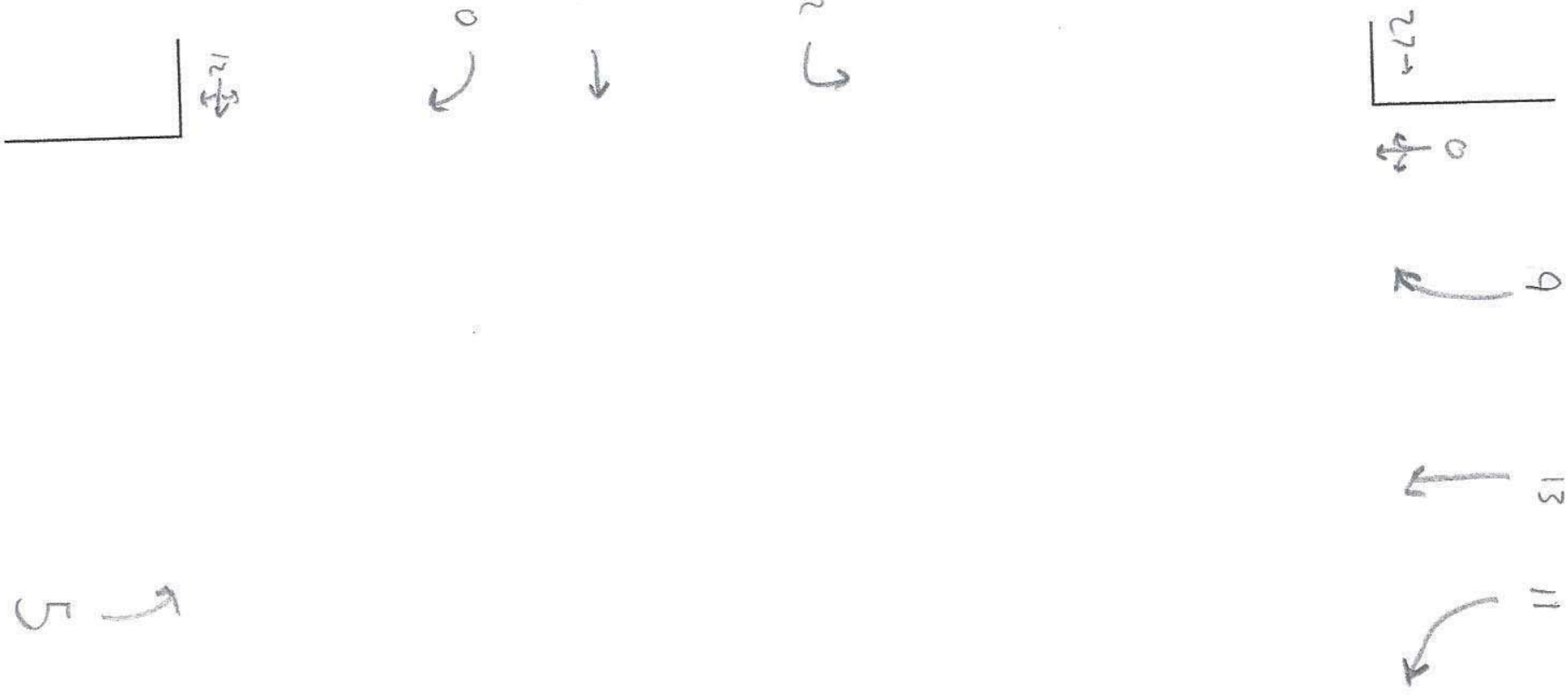

$\mathrm{O} \longrightarrow$
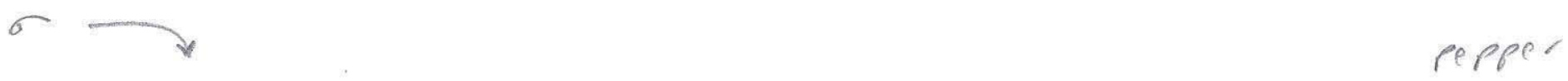

$$
0 \frac{2}{6}
$$

Monterey

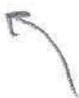

$\checkmark$

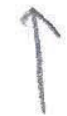

N

us

$\infty$

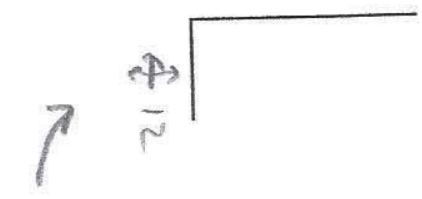


Nathan Johnston

Intersection:

Morro Street I Pismo Street

City:

San Luis Obispo

Location: Southern CA Northern CA Central CA Other Intersection Type: $T$ P

Data Collection Time:

Intersection Geometry:

$3: 55-4: 55$

Dist to upstream

intersection/signal Awse $200^{\circ}$
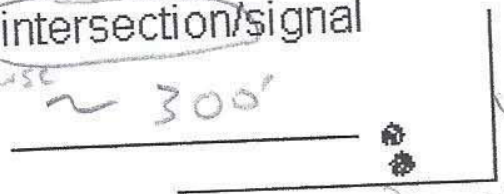

$25 m p^{2}$

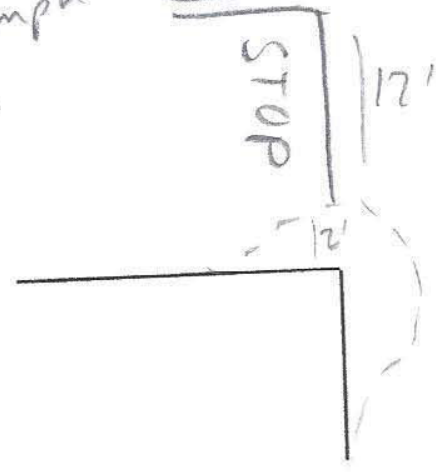

Dist to upstream

intersection/signal

inse $300^{\circ}$
North Arrow:

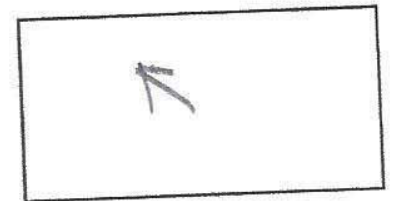

$25 m p^{2}$

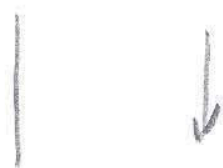

$\uparrow 1 \%$
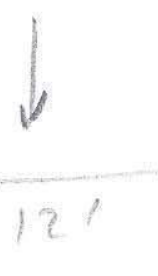

$+91$

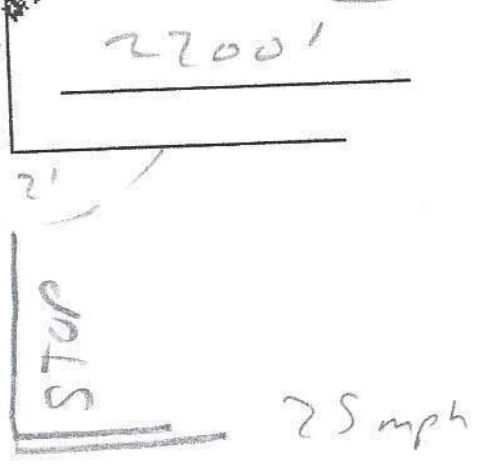

Dist to upstream intersection/signal

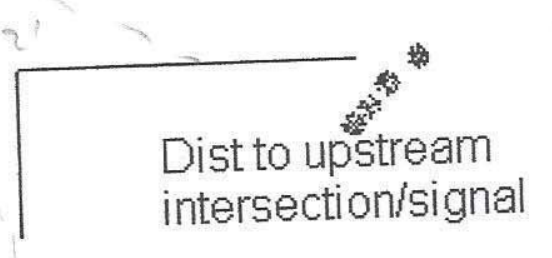

pismo

$25 \mathrm{mp}^{\mathrm{h}}$
Dist to upstream intersection/signa

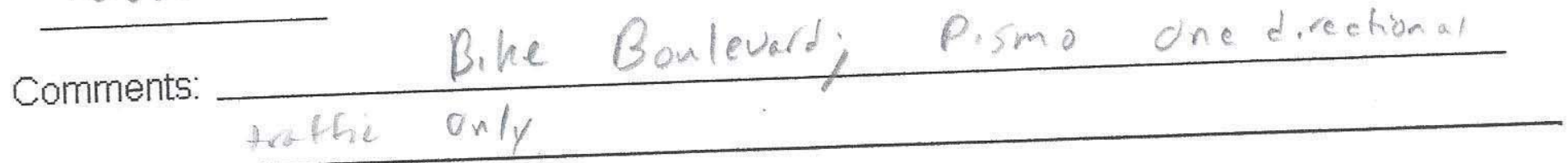


Nathan Johnston

Intersection:

Pismo street/ Morro Street

Time Period:

$3: 55=4: 55$

Volumes:

$x_{\rightarrow \infty} \rightarrow$

$\sqrt{1}$ $\overbrace{i}^{i}$
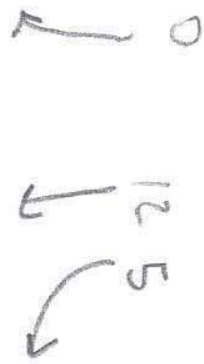

27

Morro

$\frac{\bar{n}-\frac{2}{i}}{\sigma \rightarrow \frac{1}{i}}$ 
Nathan Johnston

Intersection: P.smo strect/Murro Street

Heaw Vehicles:

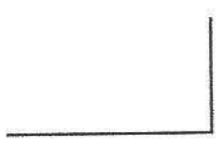

$$
\downarrow 1 \%
$$

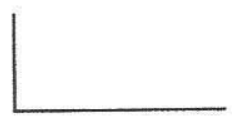

Comments: Very Few heary vehicks, 
Nathan Johnston

Intersection:

Higuere Street/ Garden Street

City.

Sar Luis Obispo

Location: Southern CA Northern CA CentralCA Other Intersection Type: (T) + Data Collection Time:

$5: 05-6: 05$ wees $6 / 19 / 13$

Intersection Geometry.

Dist to upstream intersection/signal
Dist to upstream intersection/signal
NA

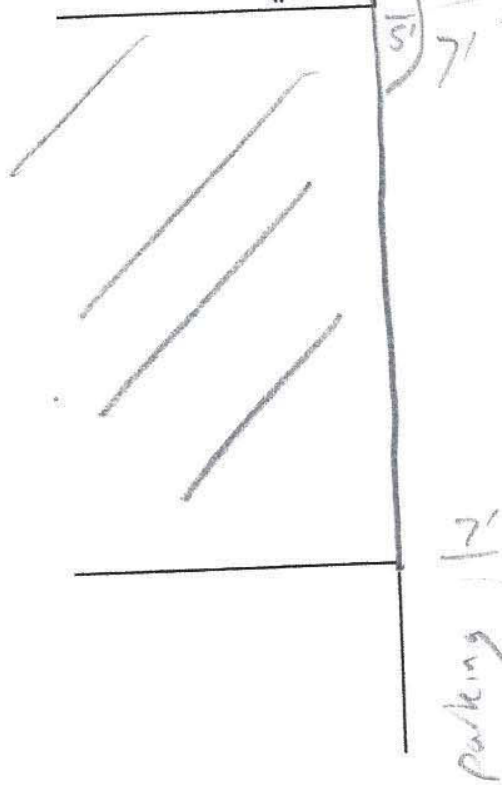

North Arrow:

$35 \mathrm{mp}$

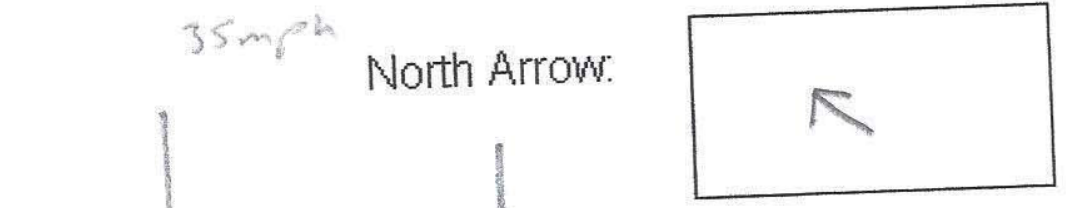

$$
\simeq 150^{\prime}
$$

Comments: 
Nathan Johnston

Intersection:

Higuerastreet/Garden Street

Heaw Vehicles:

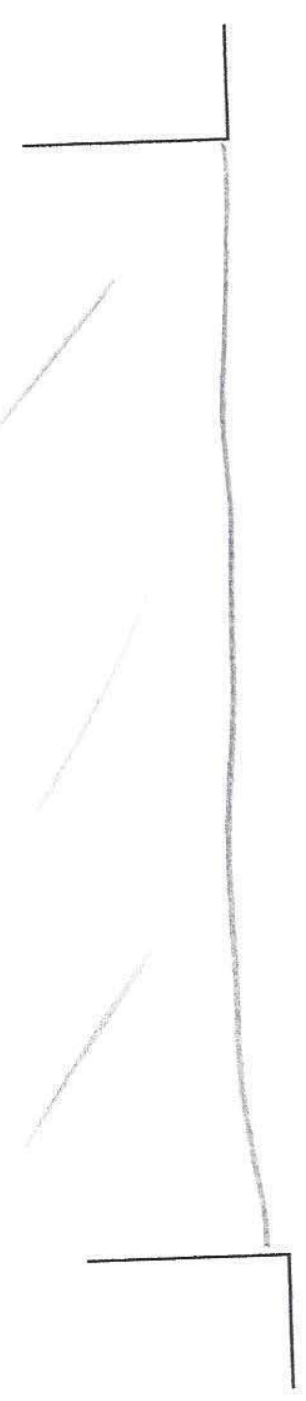

$$
\begin{gathered}
43 \% \\
\text { Hiqura }
\end{gathered}
$$

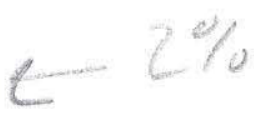

Gar Jem

Comments:

Very ubso area 
Nathan Johnston

Intersection:

Hiquera Street/ baiden street

Time Period:

$5: 05-6: 05$ veds

$6 / 19 / 13$

Volumes:
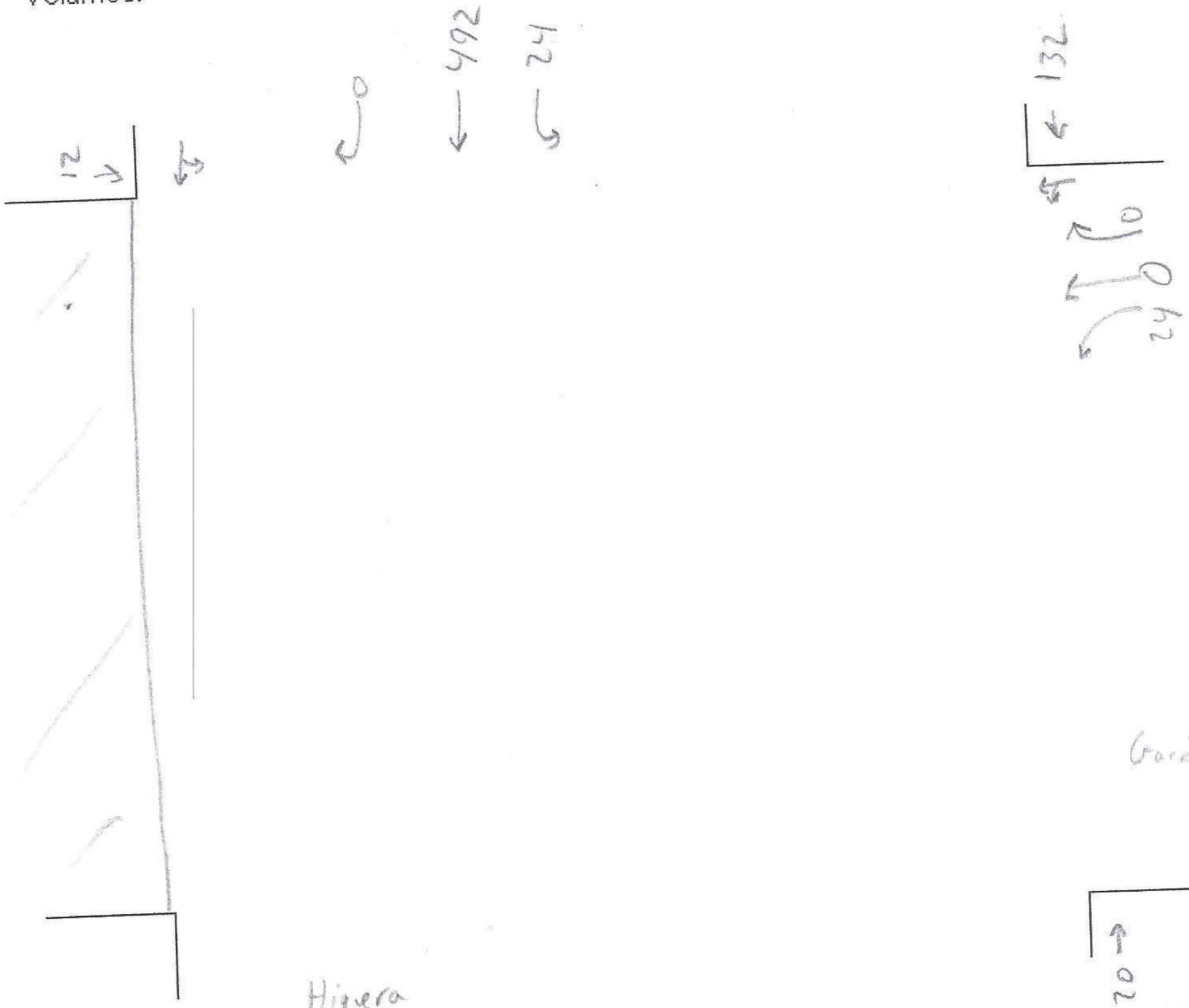

Garto

Hiquera

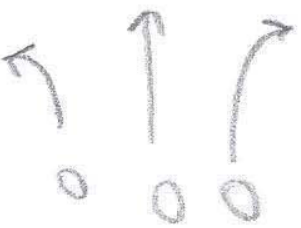

i

$\simeq$ 
Nathan Johnston

Intersection:

$$
\text { Morro Strect / Fslay Street }
$$

City:

San Luis Obspo

Location: Southern CA Northern CA Intersection Type: $T+$

Data Collection Time:

$6: 10-7: 10$

Intersection Geometry:

North Arrow:

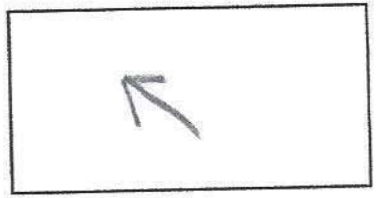

Dist to upstream intersection/signal

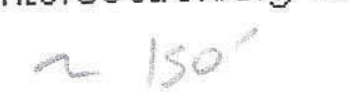

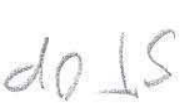

$2 \sin p^{\text {in }}$

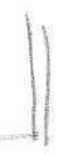

$|q|$

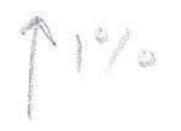

Dist to upstream

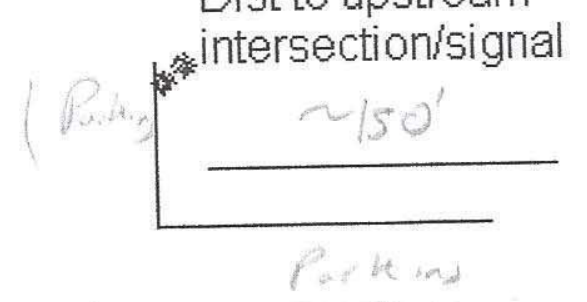

$25 m p h$

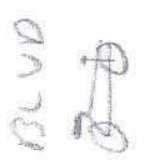

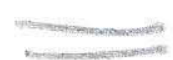
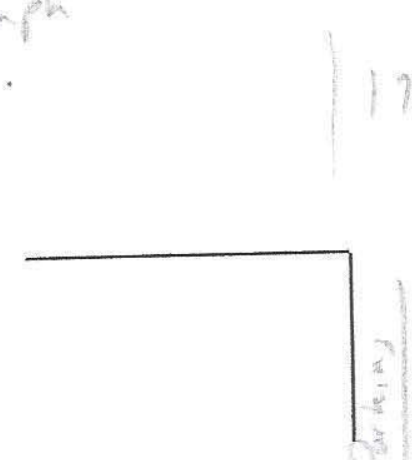

Istay

191
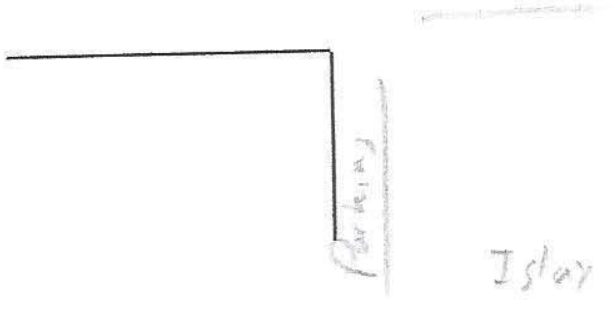

Dist to upstream

*⿻丷木大

intersection/signal

$$
\sim 200^{\circ}
$$

Comments: 
Nathan Johnston

Intersection:

Morrostreet/Islay Strect

Time Period:

$6: 10-7: 10$

Volumes:
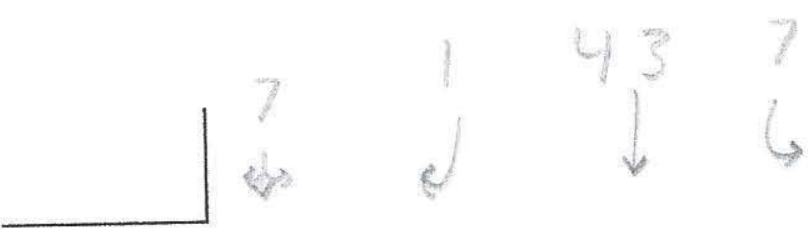

Mares
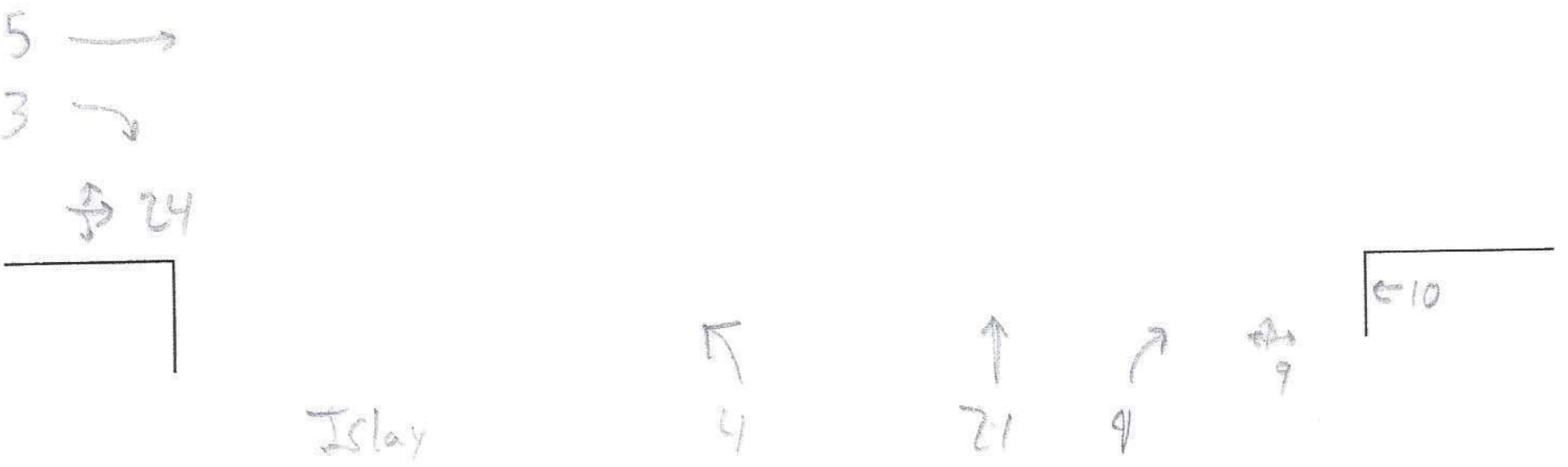
Nathan Johnston

Cal Poly San Luis Obispo

Intersection: Morro Street/ Istay Street

Heaw Vehicles:

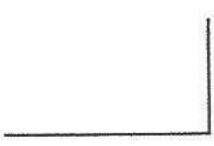

$$
\downarrow^{1 \% \%}
$$
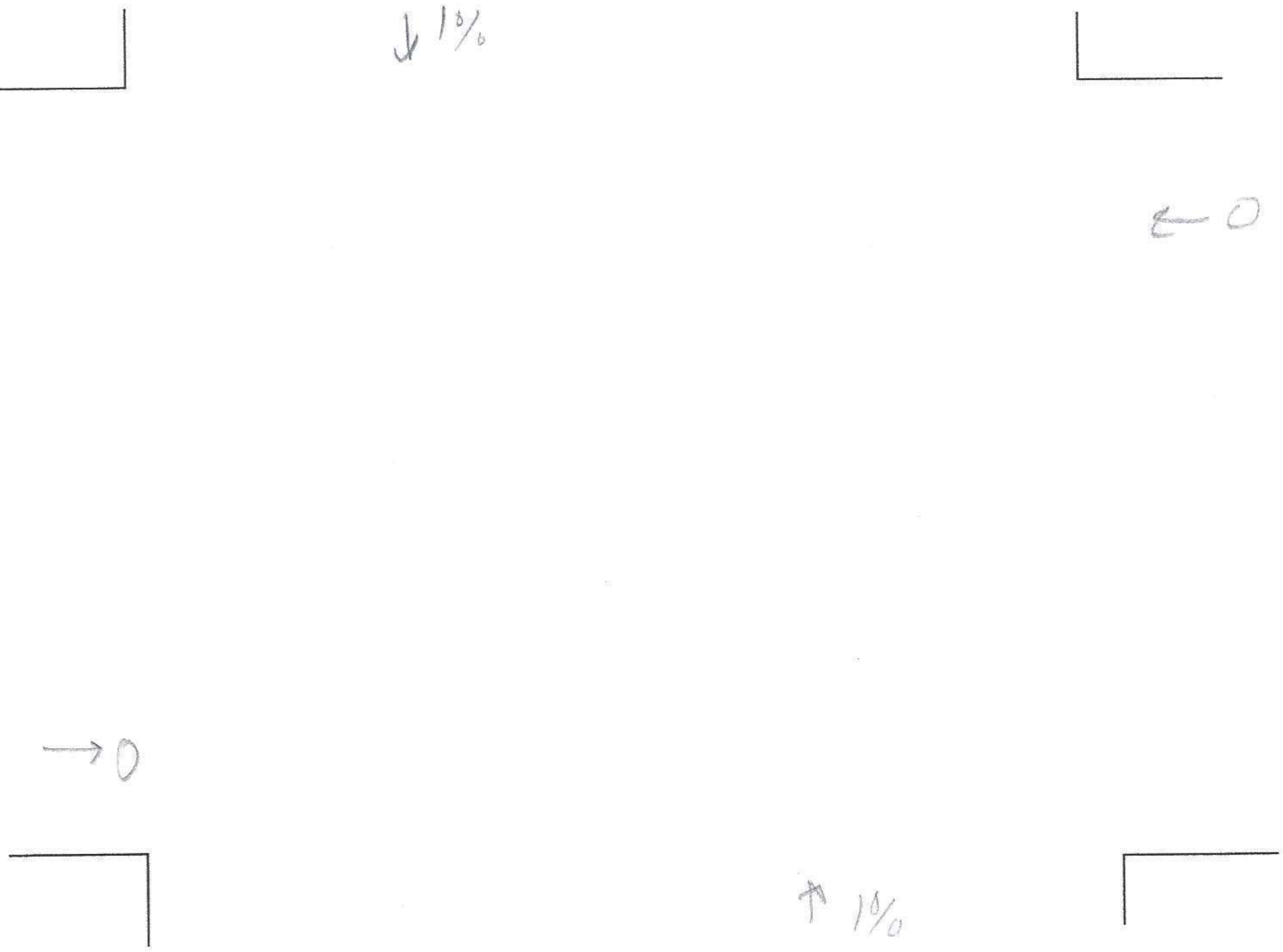

Comments: Lax Vehicles Canat navigate Moro traftic

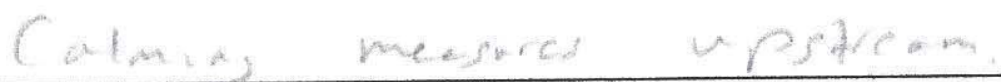


Nathan Johnston

Cal Poly San Luis Obispo

Intersection:

City.

Location: Southern CA

Northern CA

Central CA

Intersection Type: $T \uplus$

Data Collection Time:

Intersection Geometry.
North Arrow:

$25 m p h$

Dist to upstream

intersection/ signal

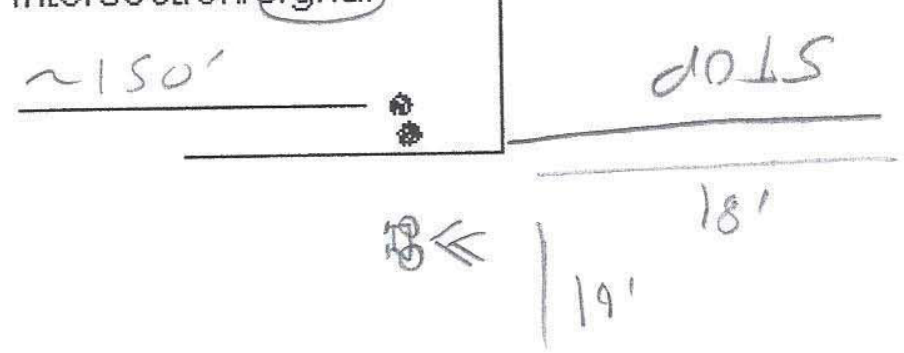

$35 m \rho^{2}=$

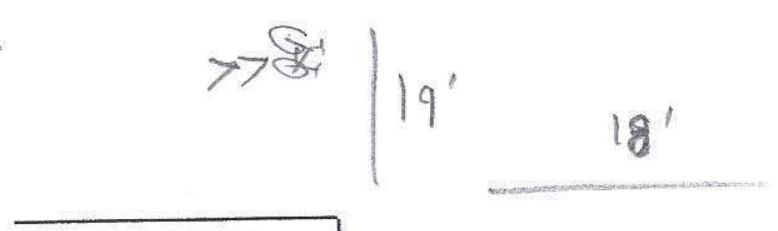

Inlay

Dist to upstream

intersectionssignal

TaWS

2 $200^{\prime}$

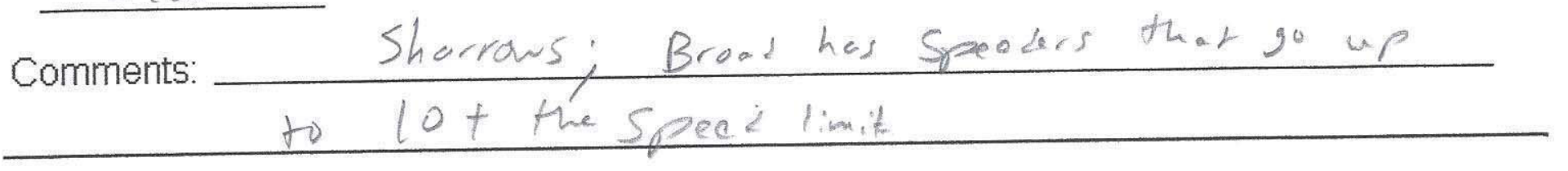

1

274 
Nathan Johnston

Intersection:

Time Periad:

$7: 15-8: 15$

Volumes:

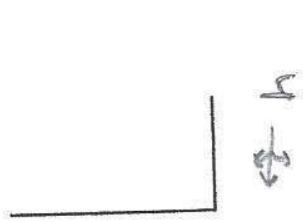

$\stackrel{0}{\infty}$ $\bar{n}$

$\downarrow$ $\checkmark$<smiles></smiles>

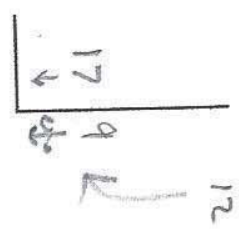

$\varepsilon \frac{\pi}{\sigma}$

$L=$

Broa L

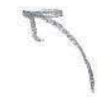

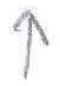

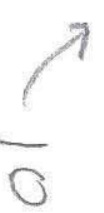

Isluy 
Nathan Johnston

Cal Poly San Luis Obispo

Intersection: Broal street/ Islay Street

Heaw Vehicles:

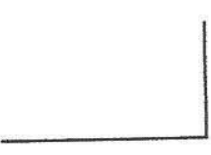

$$
\downarrow^{10 \%}
$$
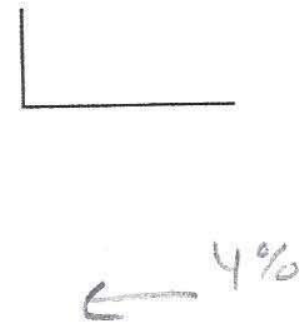

Broal

$\rightarrow$

$4 \%$

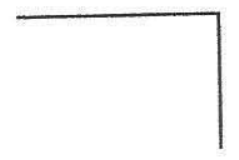

Islay

$\uparrow 1 \%$

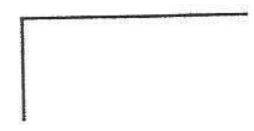

Comments: 
Nathan Johnston

Intersection:

City: San Luis Obispo

Location: Southern CA Northern CA CentralCA Other Intersection Type: $T \oplus$

Data Collection Time:

$7: 30-8: 30 \quad 6 / 18 / 13$ Thes

Intersection Geometry.

North Arrow:

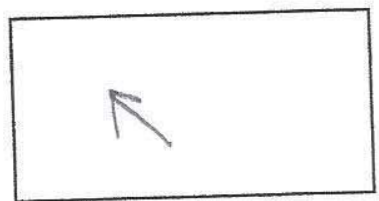

Dist to upstream

intersection/signal

2150, the

需

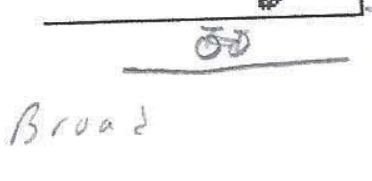

Uom $r^{2}$

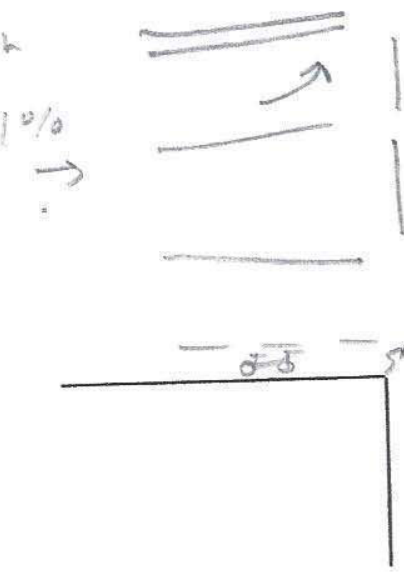

Chorro

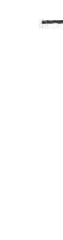

10

121

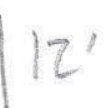

do 15

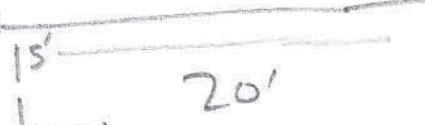

$114^{\prime} 26^{\prime}$

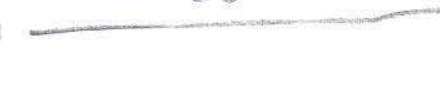

$\uparrow 2 \%$

201

Dist to upstream

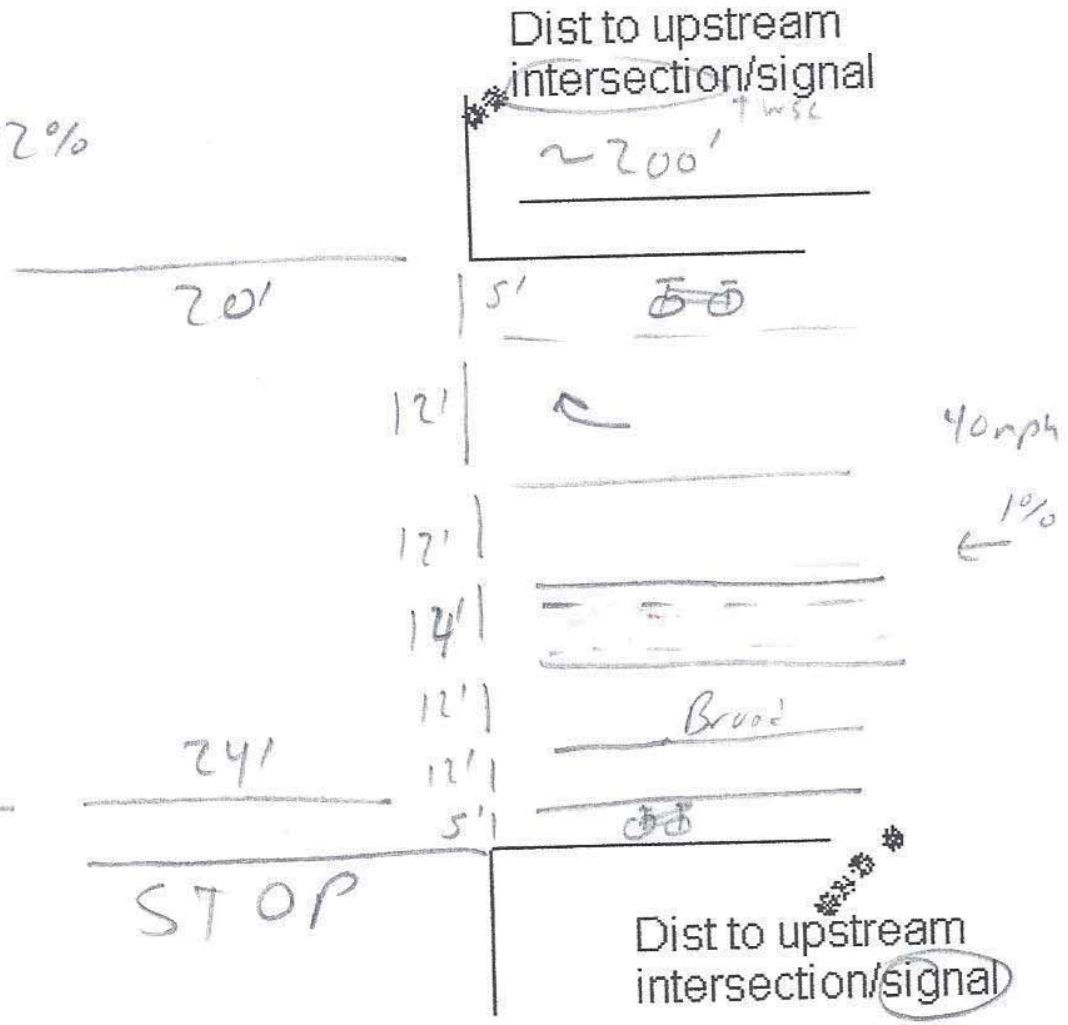

Sandercock

$\uparrow 1 \%$

$2200^{\circ}$

Dist to upstream *

$25 m p^{n}$

intersectionisignal

twse $150^{\circ}$

Comments:

Churo I Somberch Streten to $45^{\circ}$ argle

westwared ather intersection 
Nathan Johnston

Intersection: Broal Street/Chorro Strect / Sondereock Street

Time Period:

$7: 30-8: 30$

$6 / 18 / 13$

Volumes:

69

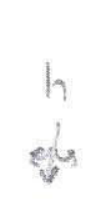

$$
\text { Chorro }
$$<smiles></smiles>

$\downarrow$

21

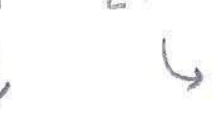

Bro. L

sSh $\longrightarrow$

$n \mid \lambda$

$01>$

Sandreach
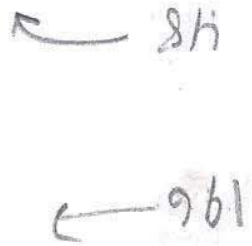

Broa 2

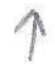

L
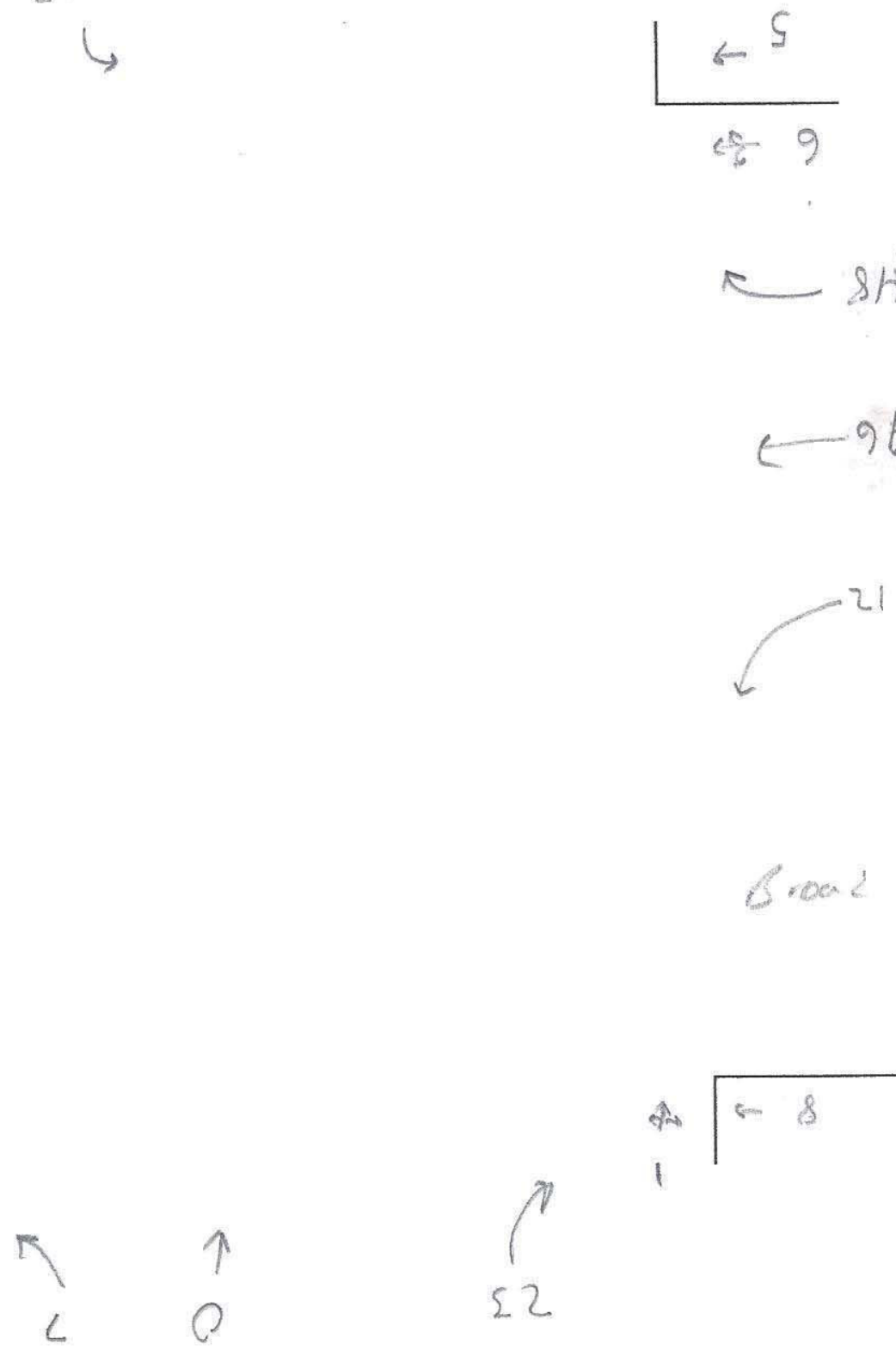

Q 
Nathan Johnston

Intersection: Broud Street/ (horro Street/Sardereck Strect

Heaw Vehicles:

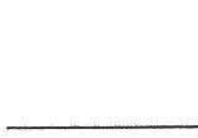

Chorro

$\downarrow 1 \%$

Braaz

$\longrightarrow$

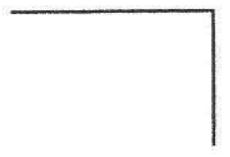

Sanker coen

$\uparrow 1 \%$

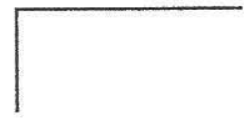

Comments: 
Nathan Johnston

Intersection:

Marsh Streed/Beach Strect

City.

Sin Luis Obispo

Location: Southern CA Northern CA Central CA Other Intersection Type: (1) +

Data Collection Time:

$8: 50-9: 50 \quad 6 / 18 / 13$ thes

Intersection Geometry:

North Arrow:

$N$

Dist to upstream intersection/signal
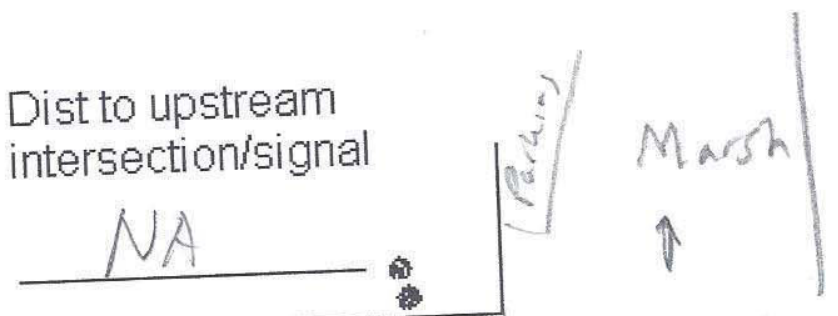

$35 m p^{h}$

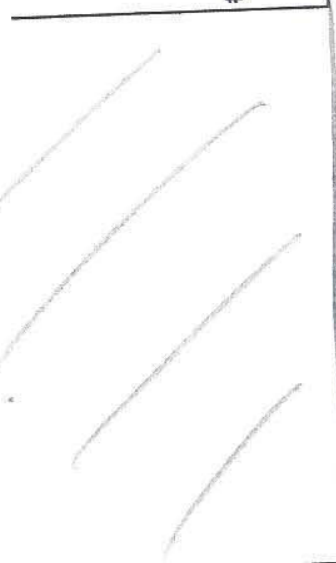

Dist to upstream

$$
x^{2}
$$
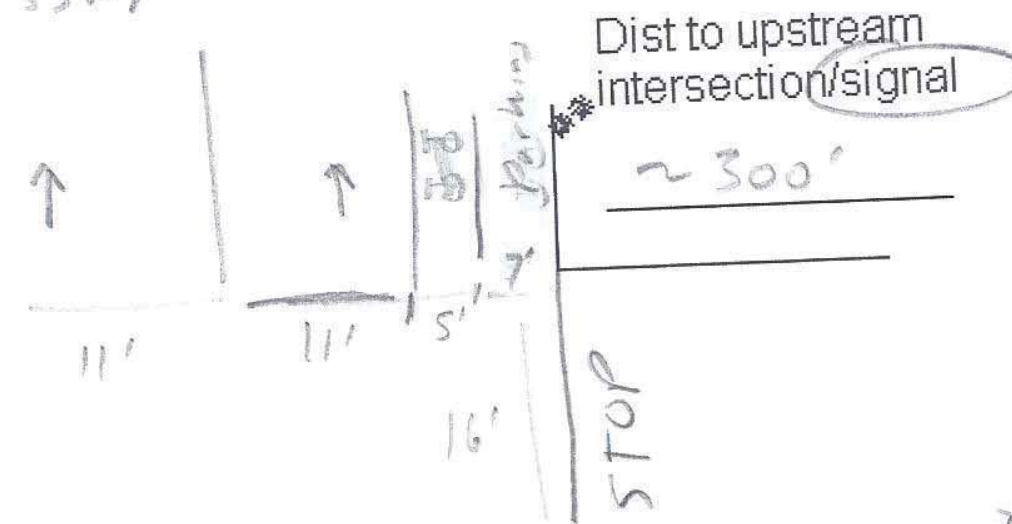

ZSmph

$\overrightarrow{2 \%}$ slope

Beah
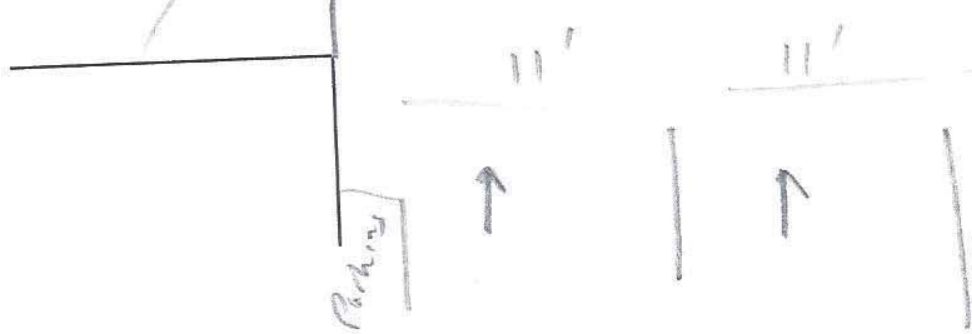

11
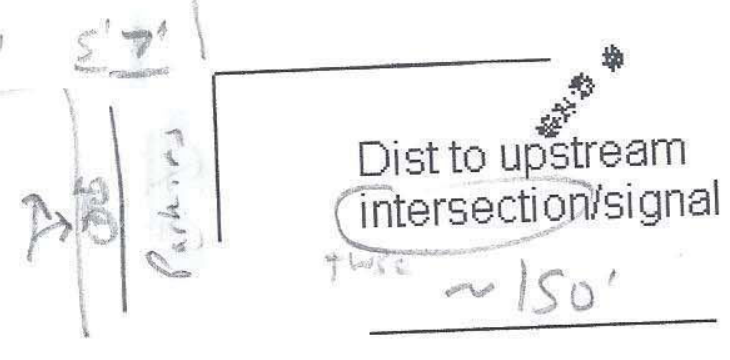

intersectionsignal

$$
+400^{\prime}
$$

Comments:

Mursh is a one directional street 
Nathan Johnston

Intersection:

Time Period:

Marsh street/Bean street

Volumes:

Morsh

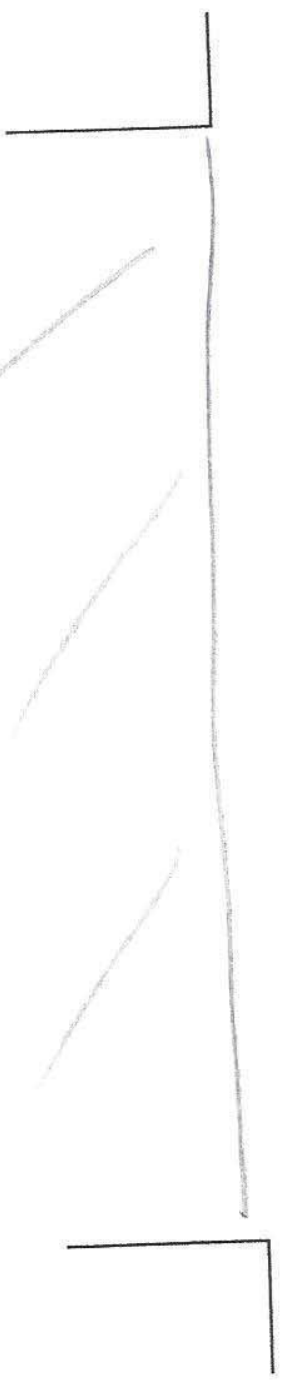

$$
8: 50-9: 50
$$

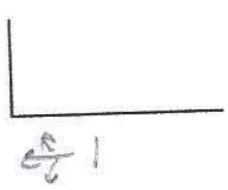

N 
Nathan Johnston

Cal Poly San Luis Obispo

Intersection: Marsh Street/ Beach Street

Heaw Vehicles:
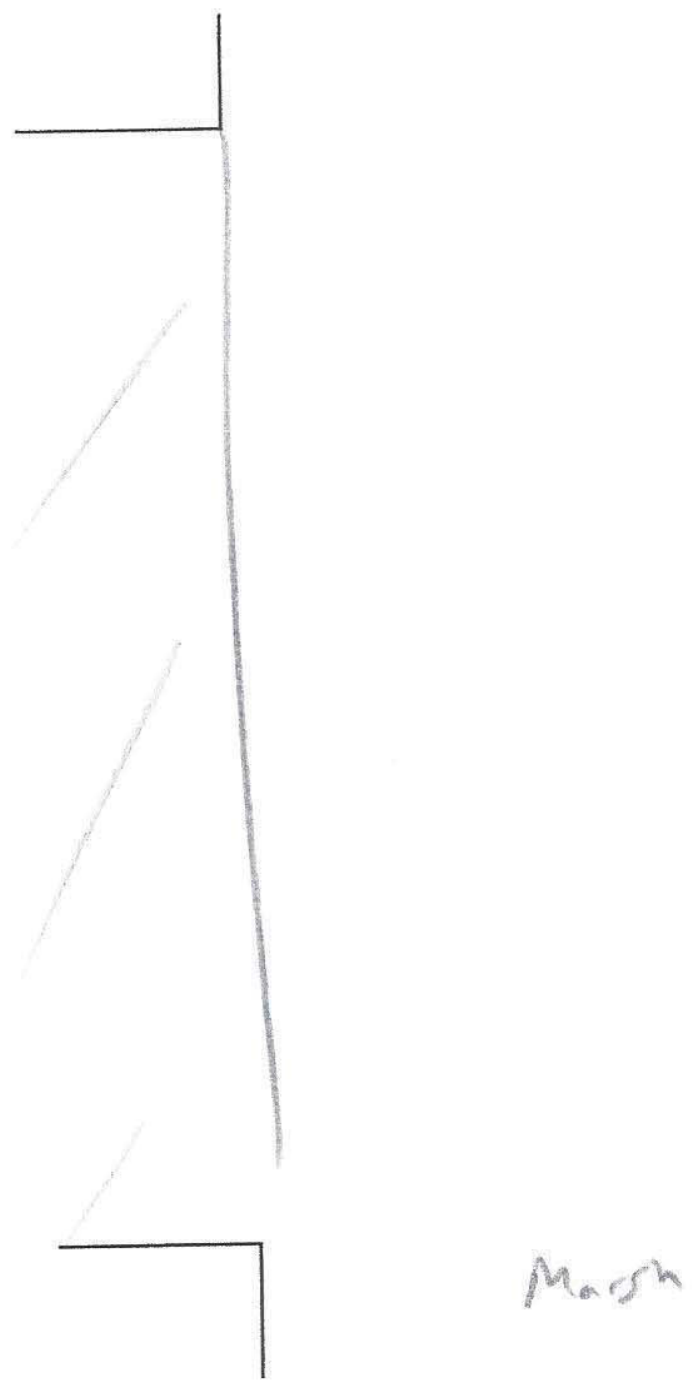

Comments: 
Nathan Johnston

Intersection:

Claremont Boulevord/ First Street

City:

Claremont

Location: Southern CA Northern CA Central CA Other Intersection Type: $T+$ signalized

Data Collection Time:

$2: 00-3: 00 \mathrm{pm}$

Intersection Geometry.

North Arrow:

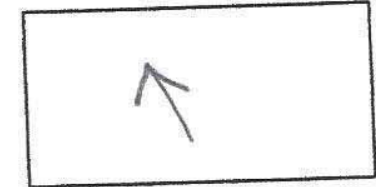

Dist to upstream

intersection/signal

Tws
+300

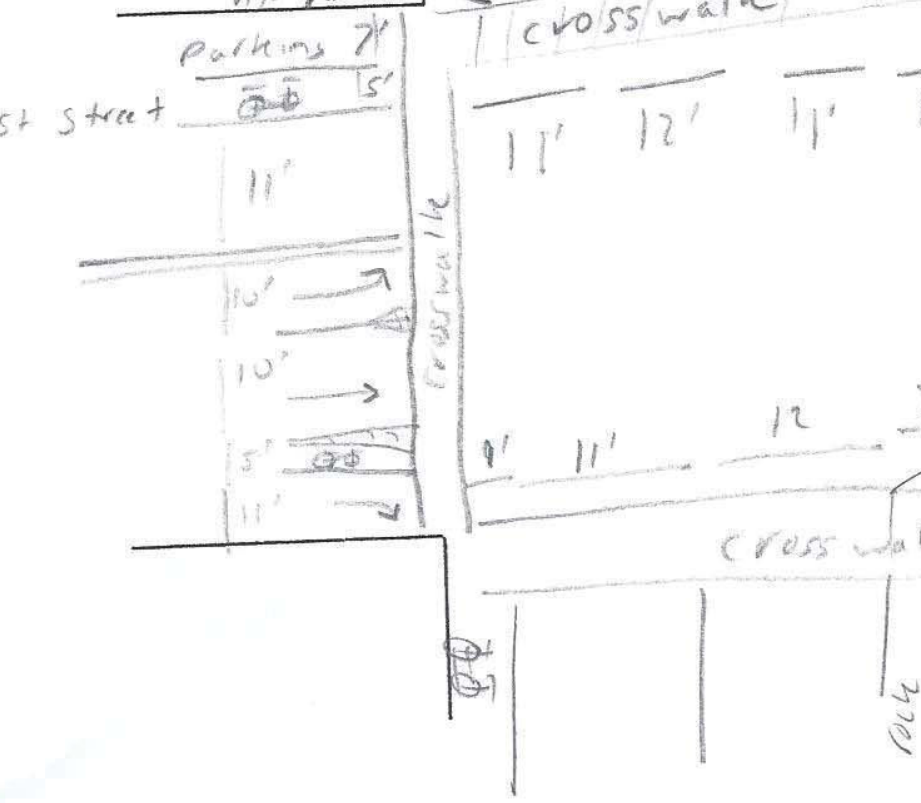

Dist to upstream intersection(signal)

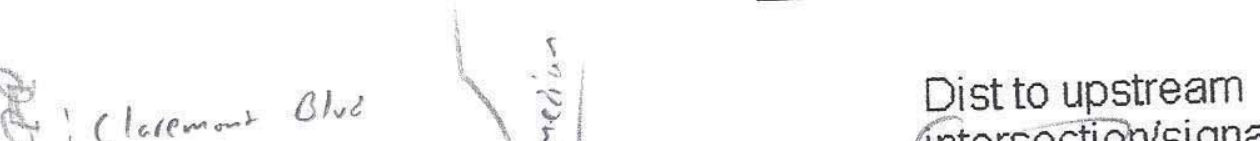

$20.7 s_{m}$ :

$\frac{\text { Comments: } \frac{\text { Pavement }}{\text { Parhing allowed or Claremont bike lane, hot First }}}{\text { Strect }}$ 
Nathan Johnston

Intersection:

Time Period:

$2: 0003100$

Volumes:

$\left.15 \rightarrow\right|_{t} ^{10} j^{26} l^{203}$

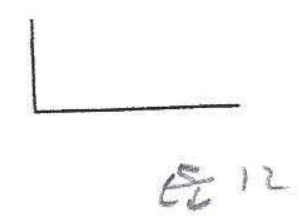

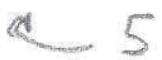

$49-1$

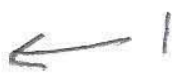

$1 \longrightarrow$

E

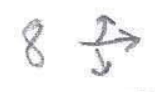

$H_{v}=7 \%$ 
Nathan Johnston

Cal Poly San Luis Obispo

Intersection:

(laremont Blue) First Street

Heat Vehicles:

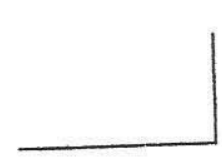

$$
7 \% \downarrow
$$

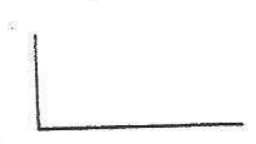

$$
\leftarrow 2 \%
$$

$7 \%$

$\uparrow>\%$

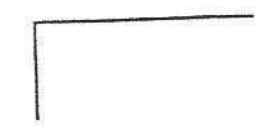

Comments:

East $1^{\text {st }}$ street dead ends a fleer a shout

ways.

3

285 
Nathan Johnston

Intersection:

Bascline Roal/Mountain Avenue

City.

Chemont

Location: Southern CA Northern CA. Central CA Other Intersection Type: $T+$ sigualine

Data Collection Time:

$3: 10-4: 10$

Intersection Geometry.

North Arrow:

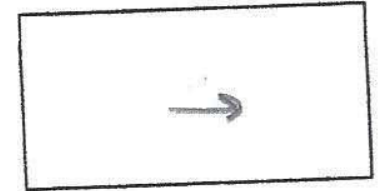

Dist to upstream intersectionisignal

$280^{\prime}$

Dist to upstream
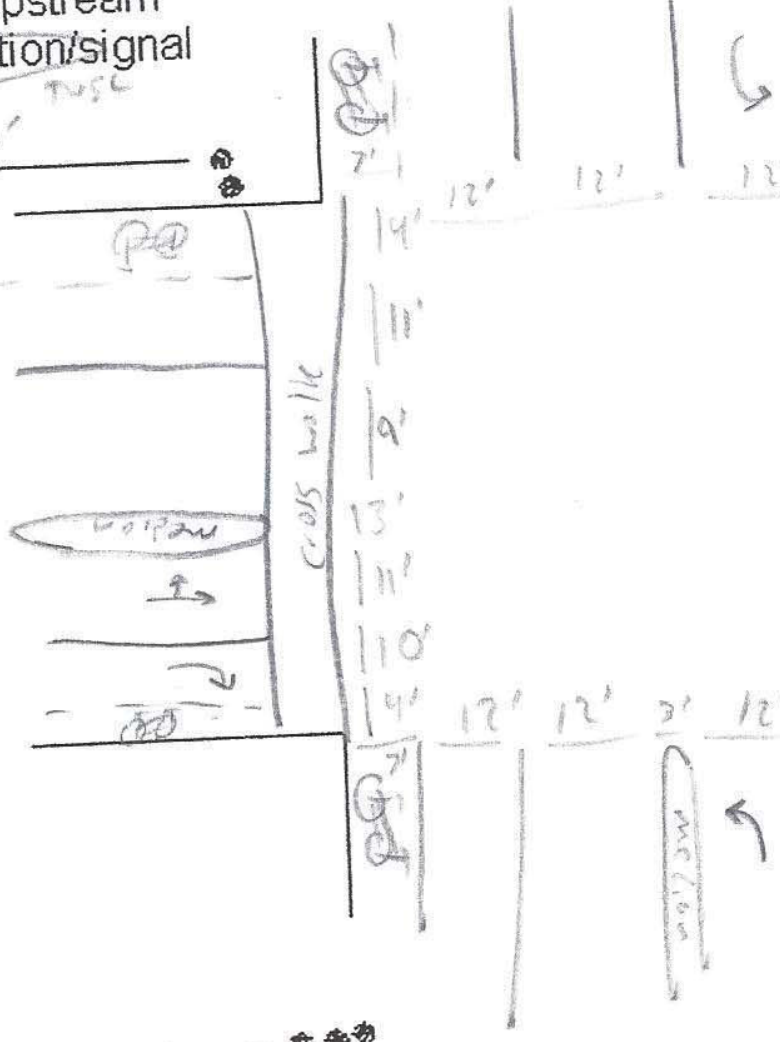

$12^{\prime}$

intersection/signal

$$
v^{2} 200^{\prime}
$$

Comments:

Pavement $=3$

appraches are redcurbel

Dist to upstream intersection/signal

2400 
Nathan Johnston

Intersection:

Monntare Avenne/Boseline Roos

Time Period:

$3: 10-4: 10$

Volumes:
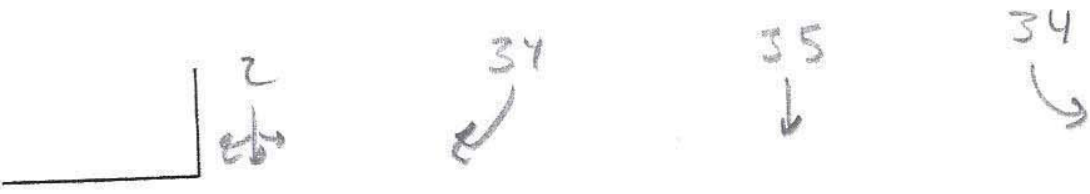

$29+$

$8 \frac{3}{9}$

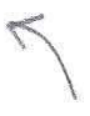

26 $\uparrow$

47

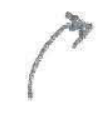

54
^

$-29$

2

677

$2 \frac{5}{23}$

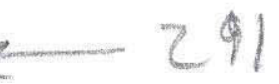

5 
Nathan Johnston

Intersection: Mountain Avenue/Baseline Road

Heaw Vehicles:

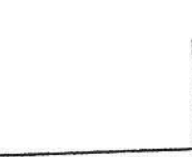

$$
5 \% \downarrow
$$

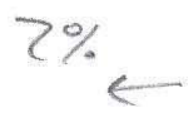

$4 \%$

$\longrightarrow$
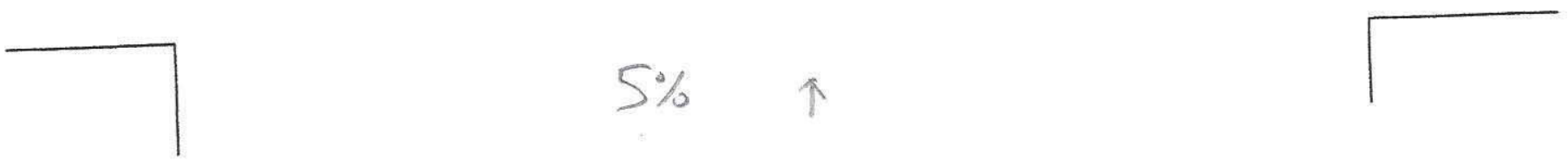

comments: North Mountrin is residention l Area, mainly. 


\section{Appendix $G$}

The following is a summary of the collected field data sheets (please note that not all information from the sheets may be listed here, but the majority is). 


\begin{tabular}{|c|c|c|c|c|c|c|c|c|c|c|c|}
\hline & $\begin{array}{l}\text { Nathan Johnston } \\
\text { Anurag Pande }\end{array}$ & & & & & & & & & & \\
\hline City & Intersection & Time & Day & Intersection Type & Major & Minor & Major Speed limit & Minor Speed Limit & t Nearby signal conflict? & Bus Stop Nearby? & Pavement Quality \\
\hline \multirow{14}{*}{$\begin{array}{l}\text { San Luis Obispo } \\
\text { Silver }\end{array}$} & Los Osos Valley Road/ Diablo Drive & 9-10 & Weds & + & LOVR & Diablo & 4 & & 25 No & Yes & 2 \\
\hline & Grand Avenue/McCollum Street & 7:40-8:40 & Weds & + & Grand & McCollum & & & 25 No & No & 3 \\
\hline & Patricia Drive/ Cerro Romaldo Avenue & 6:30-7:30 & Weds & + & Patricia & Cerro Romaldo & & & 25 Yes & No & 3 \\
\hline & Los Osos Valley Road/ Prefumo Canyon Drive & $10: 10-11: 10$ & Weds & $\mathrm{T}$ & LOVR & Prefumo Canyon & & & 40 No & No & 3 \\
\hline & Tank Farm Road/Long Street & $11: 30-12: 30$ & Weds & + & Tank Farm & Long & & & 25 No & No & 3 \\
\hline & Johnson Avenue/Sydney Street & $12: 50-1: 50$ & Weds & + & Johnson & Sydney & & & 25 No & Yes & 3 \\
\hline & Monterey Street/ Toro Street & 1:40-2:40 & Weds & + & Monterey & Toro & & & 25 No & No & 3 \\
\hline & Monterey Street/ Pepper Street & 2:50-3:50 & Weds & + & Monterey & Pepper & & & 25 No & No & 3 \\
\hline & Morro Street/Pismo Street & 3:55-4:55 & Weds & + & Pismo & Morro & 2 & & 25 Yes & No & 3 \\
\hline & Higuera Street/Garden Street & 5:05-6:05 & Weds & $\mathrm{T}$ & Higuera & Garden & & & 25 Yes & No & 3 \\
\hline & Morro Street/slay Street & 6:10-7:10 & Weds & + & Morro & Islay & 2 & & 25 No & No & 3 \\
\hline & Broad Street/Islay Street & 7:15-8:15 & Weds & + & Broad & Islay & 3 & & 25 No & No & 4 \\
\hline & Broad Street/Chorro Street/Sandercock Street & 7:30-8:30 & Tues & + & Broad & Chorro/Sandercock & & & 25 No & No & 3 \\
\hline & Marsh Street/Beach Street & $8: 50-9: 50$ & Tues & $\mathrm{T}$ & Marsh & Beach & 3 & & 25 No & No & 3 \\
\hline Claremont & College Avenue/Fourth Street & 8:00-9:00 & Friday & $\mathrm{T}$ & College & Fourth & & & 25 No & No & 3 \\
\hline \multirow[t]{7}{*}{ Silver } & College Avenue/Second Street & $9: 10-10: 10$ & Friday & $\mathrm{T}$ & College & Second & & & 25 No & No & 3 \\
\hline & Bonita Avenue/Cornell Avenue & 10:20-11:20 & Friday & $\mathrm{T}$ & Bonita & Cornell & & & 25 No & No & 4 \\
\hline & Baseline Road/Grand Ave & $11: 30-12: 30$ & Friday & + & Baseline & Grand & 4 & & 25 No & No & 3 \\
\hline & Butte Street/ Vanderbilt Avenue & $8: 30-9: 30$ & Tues & $\mathrm{T}$ & Butte & Vanderbilt & 3 & & 25 No & No & 4 \\
\hline & Cambridge Avenue/Wharton Drive & 9:50-10:50 & Tues & $\mathrm{T}$ & Cambridge & Wharton & 3 & & 25 No & No & 3 \\
\hline & First Street/Mills Avenue & $11: 00-12: 00$ & Tues & + & First & Mills & & & 25 No & Yes & 4 \\
\hline & Mountain Avenue/Butte Street/8th Street & $10: 00-11: 00$ & Tues & + & Mountain & Butte/8th & & & 25 No & No & 4 \\
\hline Riverside & West Linden Street/ Douglass Avenue & 2:50-3:50 & Tues & $\mathrm{T}$ & West Linden & Douglass & & & 25 No & No & 2 \\
\hline \multirow{6}{*}{$\begin{array}{l}\text { Bronze } \\
\text { Panze }\end{array}$} & Victoria Avenue/Grace Street & 8:00-9:00 & Tues & + & Victoria & Grace & & & 35 No & No & 3 \\
\hline & Victoria Avenue/Saint Lawerence Street & 9:05-10:05 & Tues & $\mathrm{T}$ & Victoria & Saint Lawerence & & & 30 No & No & 3 \\
\hline & Victoria Avenue/Boundary Lane & 10:10-11:10 & Tues & $\mathrm{T}$ & Victoria & Boundary & & & 25 No & No & 2 \\
\hline & Colorado Avenue/Dundee Road & 11:15-12:15 & Tues & + & Colorado & Dundee & 3 & & 25 No & No & 3 \\
\hline & California Avenue/Shelby Drive & $12: 20-1: 20$ & Tues & + & California & Shelby & & & 25 No & Yes & 3 \\
\hline & Magnolia Avenue/Hoover Street & $1: 30-2: 30$ & Tues & $\mathrm{T}$ & Magnolia & Hoover & 4 & & 25 No & Yes & 3 \\
\hline Irvine & Northwood/Savannah & 10:00-11:00 & Sat & + & Northwood & Savannah & & & 25 No & No & 5 \\
\hline \multirow[t]{4}{*}{ Bronze } & Deerfield/Fawn Glen East & $11: 20-12: 20$ & Sat & $\mathrm{T}$ & Deerfield & Fawn Glen East & & & 25 No & Yes & 3 \\
\hline & McGaw Avenue/Armstrong Street & $12: 30-1: 30$ & Sat & + & McGaw & Armstrong & & & 25 No & No & 4 \\
\hline & Michelson/Sequoia Tree Lane & $1: 40-2: 40$ & Sat & $\mathrm{T}$ & Michelson & Sequoia Tree & 3 & & 25 No & No & 4 \\
\hline & Turtle Rock Drive/Sycamore Creek & 2:50-3:50 & Sat & $\mathrm{T}$ & Turtle Rock & Sycamore Creek & se & & 25 No & No & 4 \\
\hline City & Intersection & Time & Day & Intersection Type & Major & Minor & Major Speed limit & Minor Speed Limit & Nearby signal conflict? & Bus Stop Nearby? & Pavement Quality \\
\hline Goleta/Santa Barbara & Lagoon Road/Harold Frank Road & 1:45-2:45 & Friday & $\mathrm{T}$ & Lagoon & Harold Frank & & & 15 No & No & 2 \\
\hline \multirow[t]{4}{*}{ Gold } & North La Patera Lane/Covington Way & 9:00-10:00 & Friday & + & La Patera & Covington & 3 & & 25 No & No & 4 \\
\hline & Cathedral Oaks Road/North La Patera Lane & 10:05-11:05 & Friday & + & Cathedral Oaks & La Patera & 4 & & 30 No & No & 4 \\
\hline & Cathedral Oaks Road/Placer Drive & 11:15-12:15 & Friday & $\mathrm{T}$ & Cathedral Oaks & Placer & & & 25 No & No & 2 \\
\hline & Cathedral Oaks Road/Ellwood Ridge Road & $12: 30-1: 30$ & Friday & $\mathrm{T}$ & Cathedral Oaks & Ellwood Ridge & 4 & & 25 No & Yes & 3 \\
\hline Claremont & Claremont Boulevard/First Street & 2:00-3:00 & Tues & Signalized & Claremont & First & 4 & & 35 No & No & 4 \\
\hline Signalized Intersections & is Baseline Road/Mountain Avenue & 3:10-4:10 & Tues & Signalized & Baseline & Mountain & & & 45 No & No & 3 \\
\hline
\end{tabular}




\begin{tabular}{|c|c|c|c|c|c|c|c|c|c|c|}
\hline Sharrows? & Signage? & Bike Boulevard? & Bike Lane? & Separated Bike Lane? & Stripped Parking Lane? & Parking in Bike Lane? & $\begin{array}{l}\text { If no stripped parking lane } \\
\text { On Street Parking Major? }\end{array}$ & On Street Parking Minor & Bike Lane Size if present 1 (ft) & Bike Lane Size if present 2 (ft) \\
\hline No & No & No & Yes & No & No & No & No & Yes & & 7 \\
\hline No & No & No & Yes & No & Yes & No & No & Yes & & 8 \\
\hline No & No & No & No & No & No & No & Yes & Yes & & 0 \\
\hline No & No & No & Yes & No & No & No & No & Yes & & 7 \\
\hline No & No & No & Yes & No & No & No & No & Yes & & 5 \\
\hline No & No & No & Yes & No & Yes & No & No & Yes & & 5 \\
\hline Yes & Yes & No & No & No & No & No & Yes & Yes & & 0 \\
\hline Yes & Yes & No & No & No & No & No & Yes & Yes & & 0 \\
\hline No & Yes & Yes & No & No & No & No & Yes & Yes & & 0 \\
\hline No & No & No & No & No & Yes & No & Yes & Yes & & 0 \\
\hline No & Yes & Yes & No & No & Yes & No & Yes & Yes & & 0 \\
\hline Yes & No & No & No & No & No & No & Yes & Yes & & 0 \\
\hline No & No & No & Yes & No & No & No & Yes & Yes & & 5 \\
\hline No & Yes & No & Yes & No & Yes & No & Yes & Yes & & 5 \\
\hline Yes & Yes & No & No & No & No & No & Yes & Yes & & 0 \\
\hline No & Yes & No & Yes & No & Yes & No & Yes & Yes & & 7 \\
\hline No & Yes & No & Yes & No & Yes & No & Yes & Yes & & 7 \\
\hline No & No & No & Yes & No & No & Yes & Yes & Yes & & 9 \\
\hline Yes & Yes & No & No & No & Yes & No & Yes & Yes & & 0 \\
\hline Yes & Yes & No & No & No & No & No & Yes & Yes & & 0 \\
\hline No & Yes & No & Yes & No & Yes & No & Yes & Yes & & 7 \\
\hline Yes & Yes & No & Yes & No & Yes & No & Yes & Yes & & 5 \\
\hline No & No & No & No & No & No & No & Yes & Yes & & 0 \\
\hline No & Yes & No & Yes & Yes & No & No & No & Yes & & 5 \\
\hline No & Yes & No & Yes & Yes & No & No & No & Yes & & 8 \\
\hline No & Yes & No & Yes & Yes & No & No & Yes & Yes & & 8 \\
\hline No & No & No & No & No & No & No & Yes & Yes & & 0 \\
\hline No & No & No & Yes & No & No & No & No & Yes & & 7 \\
\hline No & No & No & Yes & No & No & No & No & Yes & & 4 \\
\hline No & No & No & Yes & No & No & No & No & Yes & & 8 \\
\hline No & No & No & Yes & No & No & No & No & Yes & & 8 \\
\hline No & No & No & No & No & No & No & No & No & & 0 \\
\hline No & No & No & Yes & No & No & No & No & No & & 7 \\
\hline No & No & No & Yes & No & No & No & No & Yes & & 8 \\
\hline Sharrows? & Signage? & Bike Boulevard? & Bike Lane? & Separated Bike Lane? & Stripped Parking Lane? & Parking in Bike Lane? & On Street Parking Major? & On Street Parking Minor & Bike Lane Size if present 1 (ft) & Bike Lane Size if present 2 (ft) \\
\hline No & Yes & No & No & Yes & No & No & No & Yes & & 10 \\
\hline No & Yes & No & No & No & No & No & Yes & Yes & & 0 \\
\hline No & Yes & No & Yes & No & No & No & No & Yes & & 8 \\
\hline No & Yes & No & Yes & Yes & No & No & No & Yes & & 10 \\
\hline No & Yes & No & Yes & Yes & No & No & No & No & & 8 \\
\hline No & Yes & No & Yes & No & Yes & Yes & Yes & Yes & & 7 \\
\hline No & No & No & Yes & No & No & Yes & Yes & Yes & & 7 \\
\hline
\end{tabular}




\begin{tabular}{|c|c|c|c|c|c|c|c|}
\hline \multirow[t]{34}{*}{ Number of through lanes major street (both ways) } & Designated Right Turn Lane? & Designated Left Turn lane? & Center Storage Lane? & Median? & One Way Street? & \multirow{34}{*}{ Number of lanes minor street } & $\begin{array}{l}\text { Large Curb Return? } \\
2 \text { Yes }\end{array}$ \\
\hline & 4 No & $\begin{array}{l}\text { Yes } \\
\text { Yes }\end{array}$ & No & Yes & & & $\begin{array}{l}2 \text { Yes } \\
2 \text { No }\end{array}$ \\
\hline & 4 No & 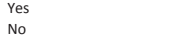 & 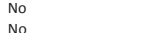 & Yes & (n) & & 2 No \\
\hline & $\begin{array}{l}2 \text { No } \\
4 \text { No }\end{array}$ & Yes & $\begin{array}{l}\text { No } \\
\text { No }\end{array}$ & $\begin{array}{l}\text { No } \\
\text { Yes }\end{array}$ & $\begin{array}{l}\text { No } \\
\text { No }\end{array}$ & & $\begin{array}{l}2 \text { No } \\
3 \text { Yes }\end{array}$ \\
\hline & 4 No & Yes & No & Yes & No & & 2 Yes \\
\hline & 4 No & Yes & No & No & No & & 2 No \\
\hline & 2 No & No & Yes & No & No & & 2 No \\
\hline & 2 No & No & Yes & No & No & & 2 No \\
\hline & 2 No & No & No & No & Yes & & 2 Yes-traffic calming \\
\hline & 3 No & No & No & No & Yes & & 2 No \\
\hline & 2 No & No & No & No & No & & 2 No \\
\hline & 2 No & No & No & No & No & & 2 No \\
\hline & 3 Yes & Yes & Yes & No & No & & 2 No \\
\hline & 3 No & No & No & No & Yes & & 2 No \\
\hline & 2 No & No & No & No & No & & 2 Yes \\
\hline & 2 No & No & No & No & No & & 2 No \\
\hline & 2 No & Yes & Yes & No & No & & 2 No \\
\hline & 4 No & Yes & No & No & No & & 2 Yes \\
\hline & 2 No & No & No & No & No & & 2 Yes \\
\hline & 2 No & No & No & No & No & & 2 Yes \\
\hline & 2 No & Yes & No & No & No & & 2 No \\
\hline & 2 No & No & Yes & No & No & & 2 No \\
\hline & 2 No & No & No & No & No & & 2 No \\
\hline & 2 No & No & Yes & Yes & No & & 2 No \\
\hline & 2 No & No & Yes & Yes & No & & 2 No \\
\hline & 2 No & No & Yes & Yes & No & & 2 Yes \\
\hline & 2 No & No & No & No & No & & 2 Yes \\
\hline & 4 No & No & No & No & No & & 2 Yes \\
\hline & 4 No & Yes & No & Yes & No & & 2 No \\
\hline & 2 No & Yes & No & Yes & No & & 2 Yes \\
\hline & 2 No & No & No & No & No & & 2 No \\
\hline & 4 No & Yes & No & No & No & & 2 No \\
\hline & 2 No & No & No & Yes & No & & 2 Yes \\
\hline & 2 No & No & No & No & No & & 2 Yes \\
\hline \multirow[t]{8}{*}{ Number of through lanes major street (both ways) } & Designated Right Turn Lane? & Designated Left Turn lane? & Center Storage Lane? & Median? & One Way Street? & \multirow[t]{6}{*}{ Number of lanes minor street } & Large Curb Return? \\
\hline & 2 No & No & No & No & No & & 2 No \\
\hline & 2 No & No & No & No & No & & 2 Yes \\
\hline & 2 No & Yes & No & No & No & & 2 No \\
\hline & 2 No & Yes & No & Yes & No & & 2 Yes \\
\hline & 2 No & Yes & No & Yes & No & & 2 No \\
\hline & 4 Yes & Yes & No & Yes & No & & 4 No \\
\hline & 4 Yes & Yes & No & Yes & No & & 3 No \\
\hline
\end{tabular}




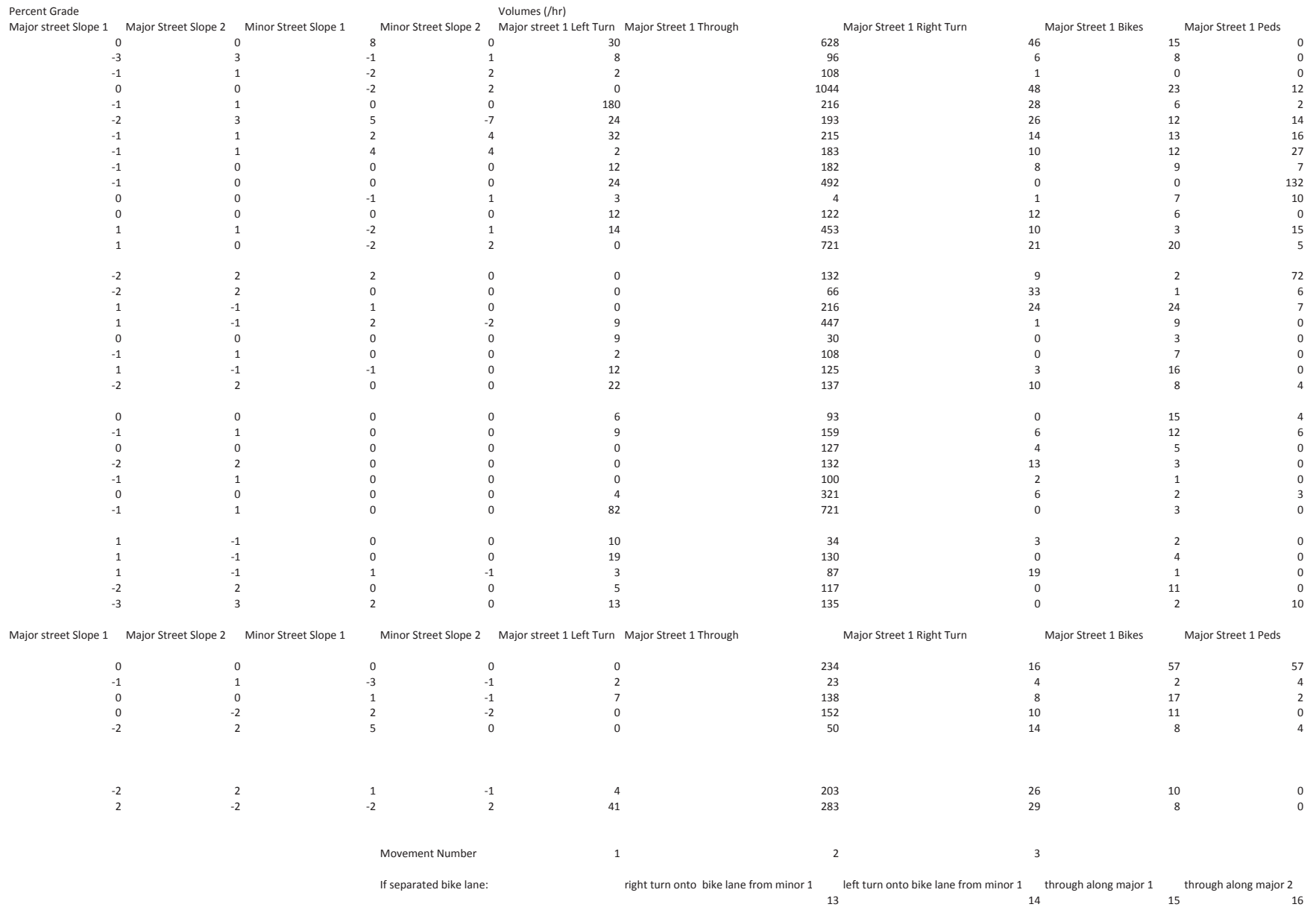




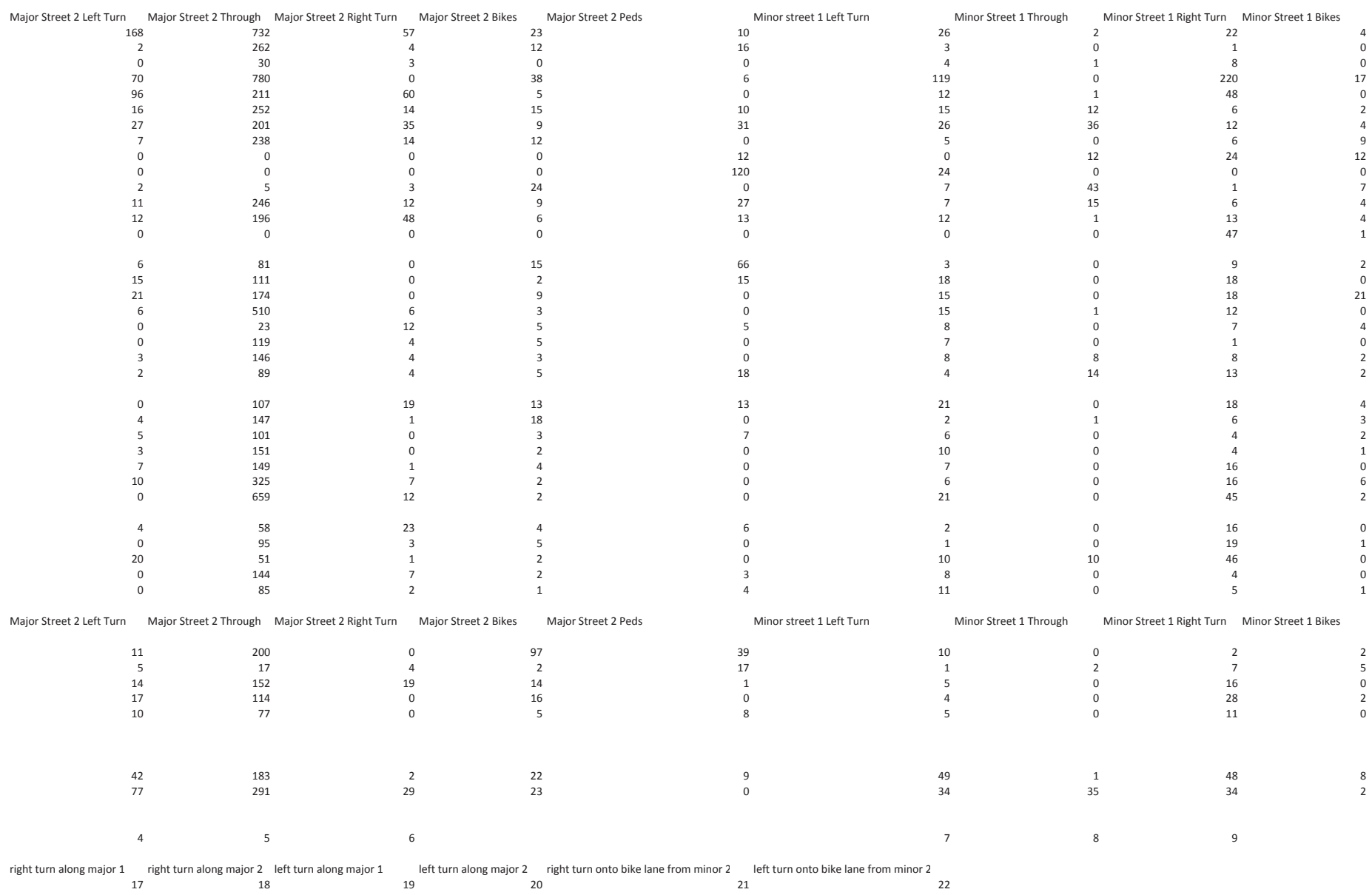



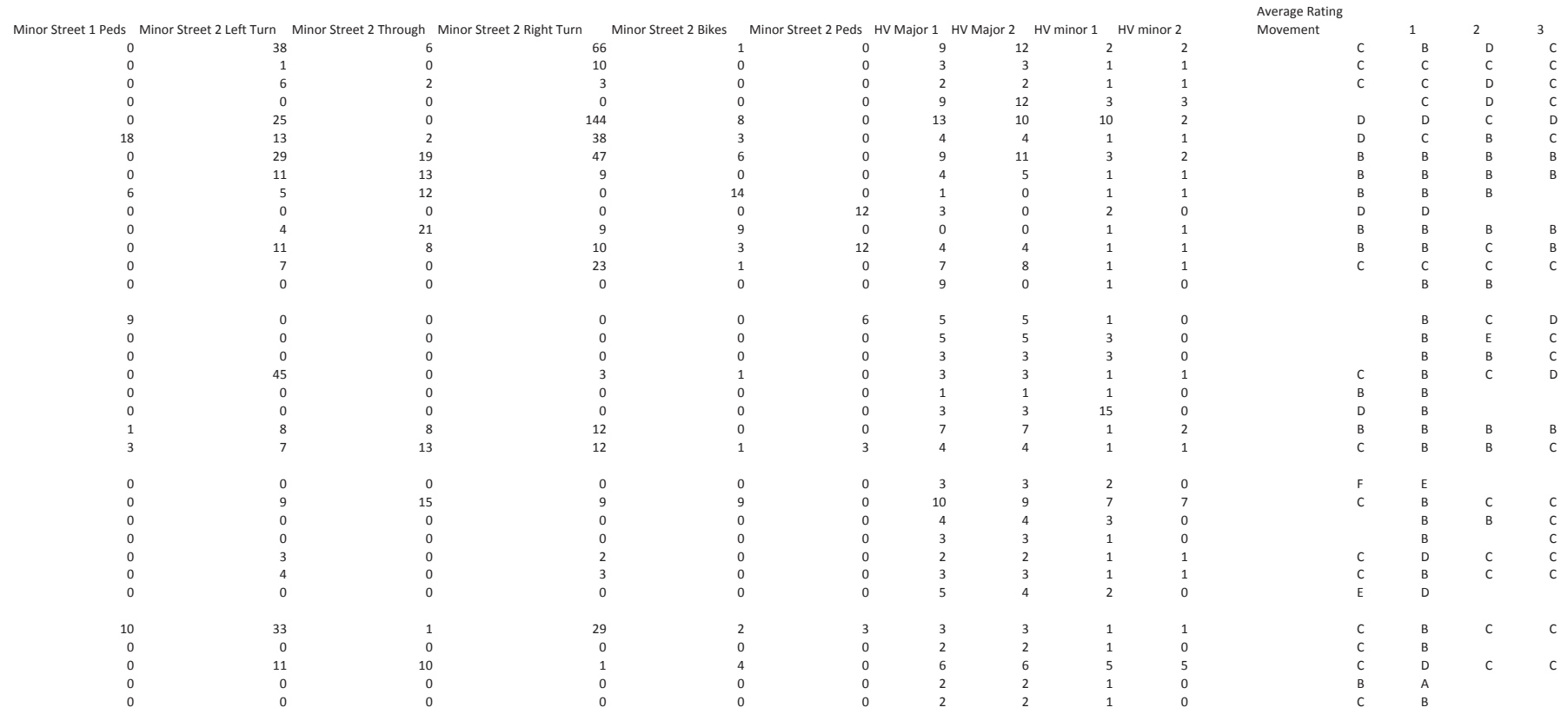

Minor Street 1 Peds $\quad$ Minor Street 2 Left Turn $\quad$ Minor Street 2 Through $\quad$ Minor Street 2 Right Turn $\quad$ Minor Street 2 Bikes $\quad$ Minor Street 2 Peds $\quad$ HV Major $1 \quad$ HV Major 2 HV minor $1 \quad$ HV minor 2
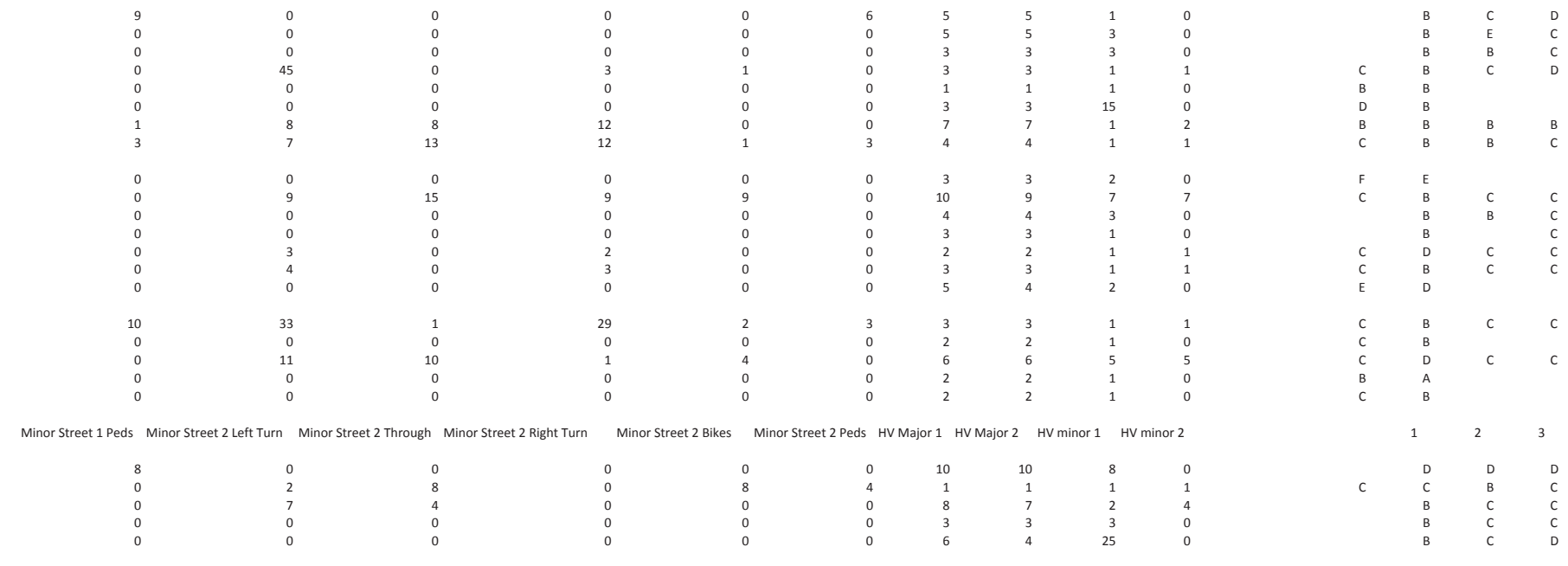

2

10

11

12 


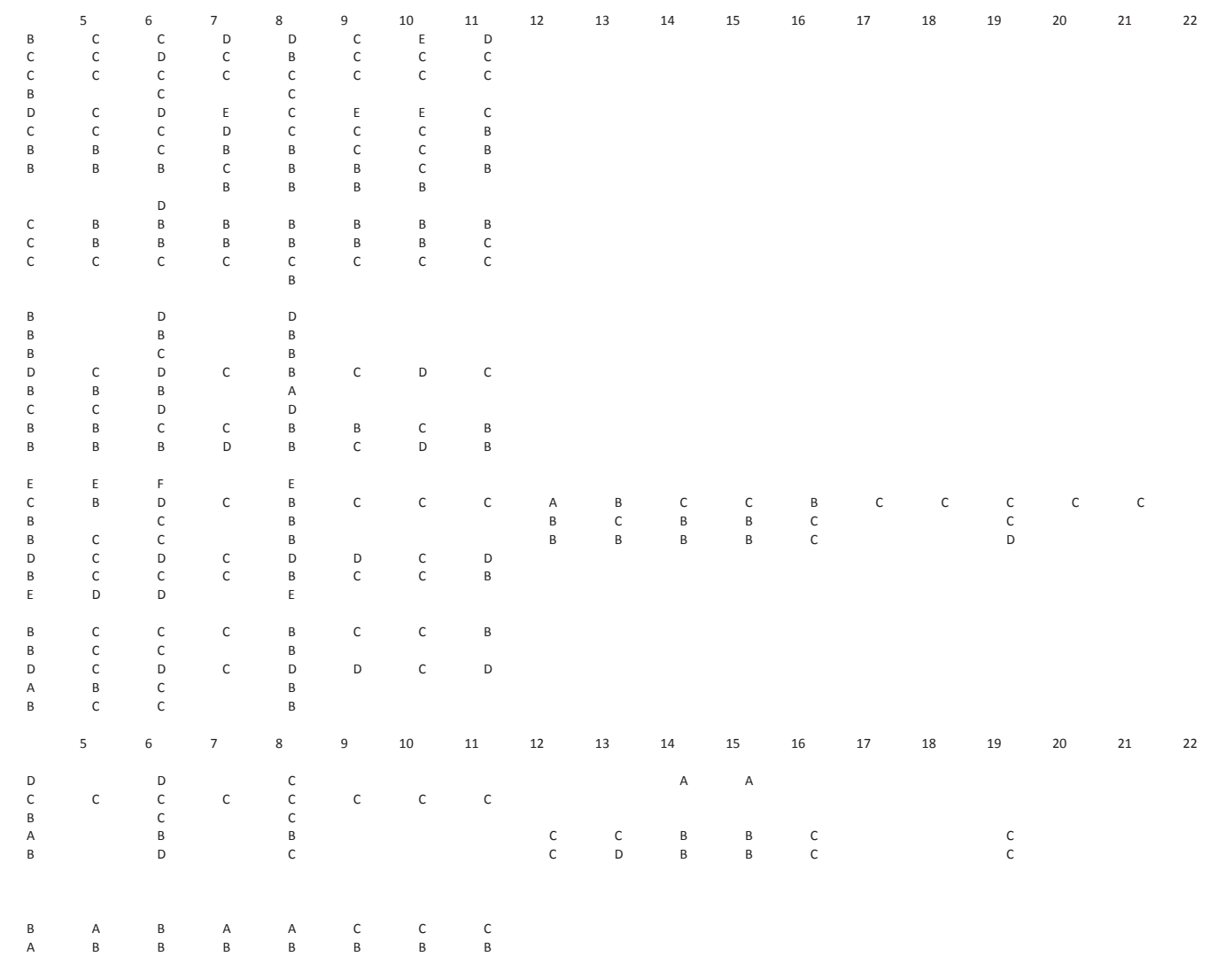




\section{Appendix $\mathrm{H}$}

The following pages are sample public survey sheets upon which cyclist perception scores were collected by in-person interviews with video recording viewers. Please note that not all data pages collected are included in this appendix due to the large volume of data collected. A summary of all data collected is also included in this appendix to address the excluded data pages. 
Intersection: Broad/Islay SLO Scores: ( $A=$ Best $\quad F=$ Worst $)$

\begin{tabular}{|c|c|c|}
\hline Right Turn & Through & Left Turn \\
\hline$C$ & $B$ & $B$ \\
\hline$B$ & $O$ & $B$ \\
\hline$B-$ & $C-($ cars share & $B$ \\
\hline$B$ & $C-$ & $C$ \\
\hline
\end{tabular}

comments: Cars parkod on street, bushem obstruct vien

street is not bus, Bike shocen roud.

street in peor repaie

* Sharing a road with muving emeso parkod cones is not goad. Intersection: Chure Broed / Sander cock

Scores: ( $A=$ Best $\quad F=$ Worst)

\begin{tabular}{|c|c|c|}
\hline Right Turn & Through & Left Turn \\
\hline$C-$ & $\mathrm{C}-7$ not & C \\
\hline$C-$ & $c-\{0,0$ & $c+$ \\
\hline C & 7 t & $c$ \\
\hline C & $\mathrm{C}$ & $C$ \\
\hline
\end{tabular}

Comments: The Rev lave is fefplut but the other lanes should be sharros.

Intersection: Crardewe Higuerom

Scores: ( $A=$ Best $\quad F=$ Worst $)$

\begin{tabular}{|l|l|l|}
\hline Right Turn & Through & \multicolumn{1}{c|}{ Left Turn } \\
\hline & $C$ & $D \rightarrow$ Cross 3 laneas \\
\hline & & $C$ \\
\hline & & \\
\hline
\end{tabular}

Comments: Streots ane narrow - Not sharrow-Yikeo! - Cars parked aling the rine - 


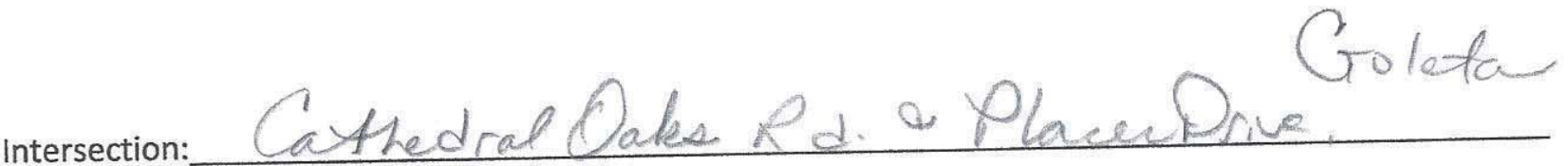
Scores: ( $A=$ Best $\quad F=$ Worst)

\begin{tabular}{|l|l|l|}
\hline$B^{\text {Right Turn }}$ & \multicolumn{1}{|c|}{ Through } & \multicolumn{1}{c|}{ Left Turn } \\
\hline$C$ & $B$ & $C$ \\
\hline
\end{tabular}

comments: Nece-wide bike lanes.

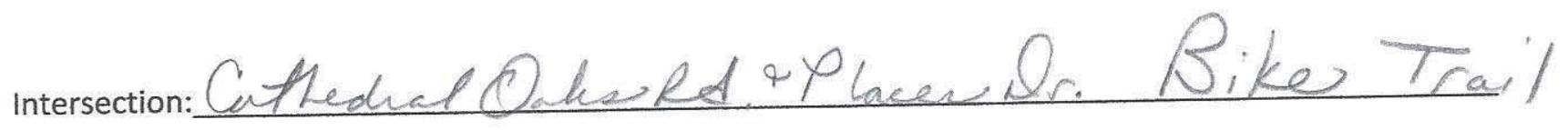
Scores: ( $A=$ Best $F=$ Worst)

\begin{tabular}{|c|c|c|}
\hline Right Turn & Through & Left Turn \\
\hline$C$ & $C$ & \\
\hline$C$ & $C$ & \\
\hline$B *$ & & \\
\hline$B *$ & & \\
\hline
\end{tabular}

comments: * The score would be higheif the bike-lane

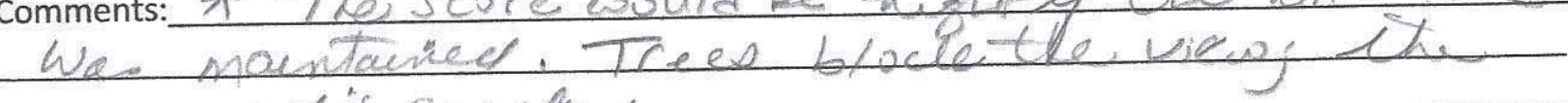
pavement is cuacled.

Intersection: NiLa Patera Lane a Covingtom has Scores: ( $A=$ Best $\quad F=$ Worst $)$

\begin{tabular}{|c|c|c|}
\hline Right Turn & Through & Left Turn \\
\hline$E$ & $D$ & $E$ \\
\hline$c$ & $E$ & $E$ \\
\hline$D$ & $E$ & $D$ \\
\hline$D$ & $D$ & $D$ \\
\hline
\end{tabular}

comments: Cegelist must share narrow road with Omotorist os parbed canes 
Intersection:

Sh

Scores: ( $A=$ Best $F=$ Worst $)$

\begin{tabular}{l|l|l|l|}
\hline Right Turn & Through & Left Turn \\
\hline B & $B$ & $B$ \\
\hline$C$ & $B$ & $C+$ \\
\hline$D$ & $B$ & $B$ \\
\hline$E$ & $B$ & $B$ & $B$ \\
\hline$B$
\end{tabular}

Comments: Sharron makes up fou narrow lanes Parked lars are a problem

Intersection:

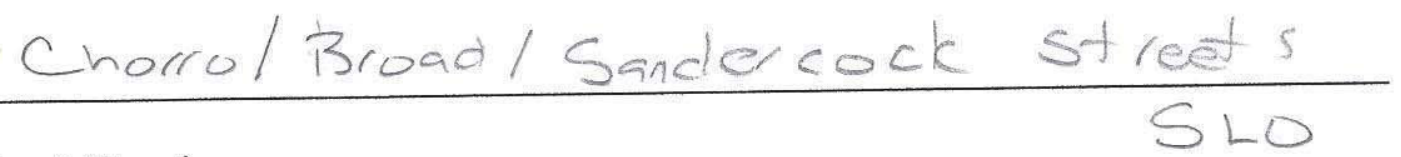

Scores: (A=Best $F=$ Worst)

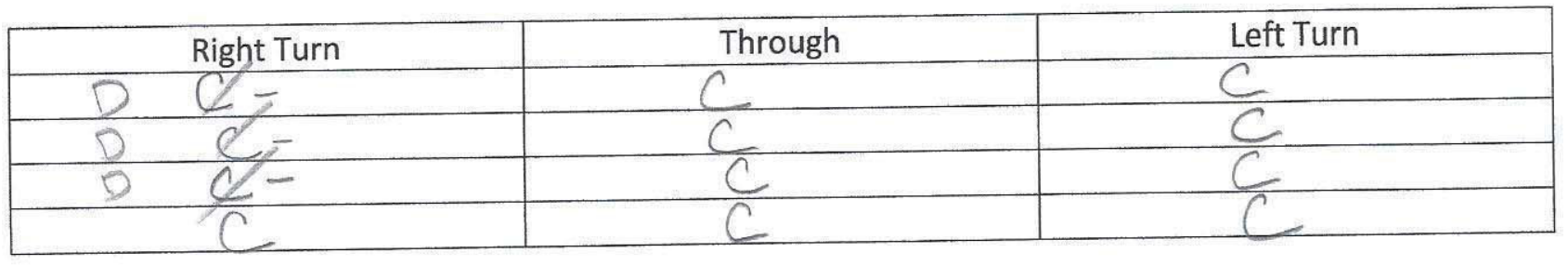

Comments: SIDE STRLEJ SHDFLD BE A ShaRE

Intersection: CACDEN HIGUCS

Scores: $(A=B e s t \quad F=$ Worst $)$

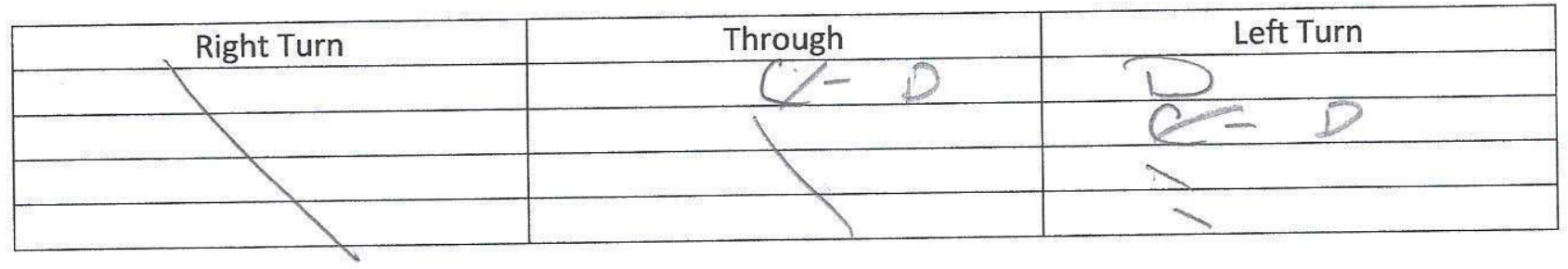

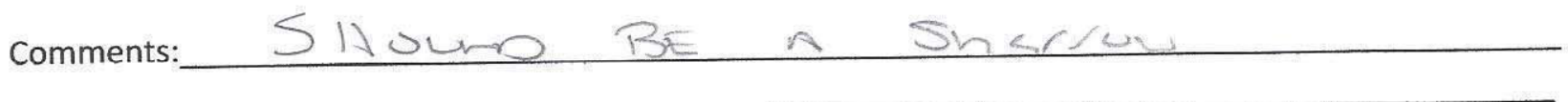

300 
Intersection: Grand \& MCCullom SLO

Scores: ( $A=$ Best $\quad F=$ Worst)

\begin{tabular}{|c|c|c|}
\hline Right Turn & Through & Left Turn \\
\hline C & C & C \\
\hline B & $C$ & $C$ \\
\hline$C$ & $C$ & $C$ \\
\hline$C$ & $C$ & $C$ \\
\hline
\end{tabular}

comments: Island blocks line of sight tack of Signage.

Intersection:

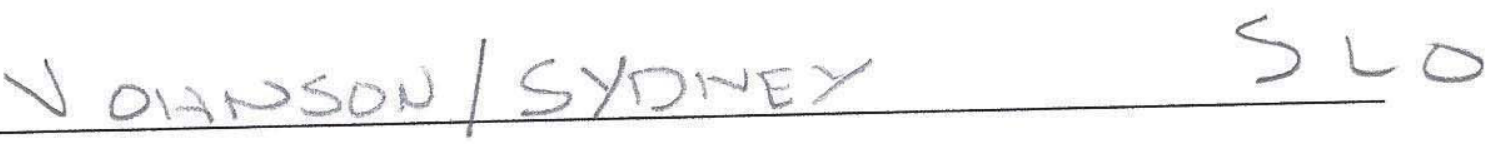

Scores: ( $A=$ Best $\quad F=$ Worst $)$

\begin{tabular}{|c|c|c|}
\hline Right Turn & Through & Left Turn \\
\hline$B$ & $C$ & $C$ \\
\hline$C$ & $C$ & $D$ \\
\hline$C$ & $C$ & $C$ \\
\hline$C$ & $C$ & $C$ \\
\hline
\end{tabular}

Comments:

bushes

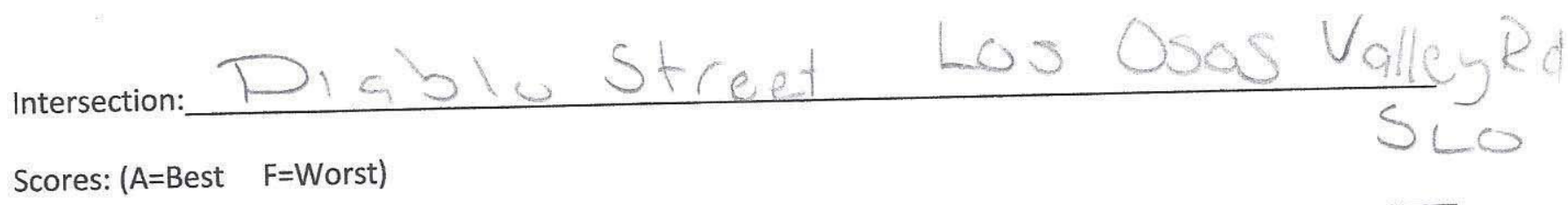

\begin{tabular}{|c|c|c|}
\hline Right Turn & Through & Left Turn \\
\hline$D$ & $D$ & $C$ \\
\hline$C$ & $D$ & $C$ \\
\hline$D$ & $C$ & $D$ \\
\hline$C$ & $C$ & $C$ \\
\hline
\end{tabular}

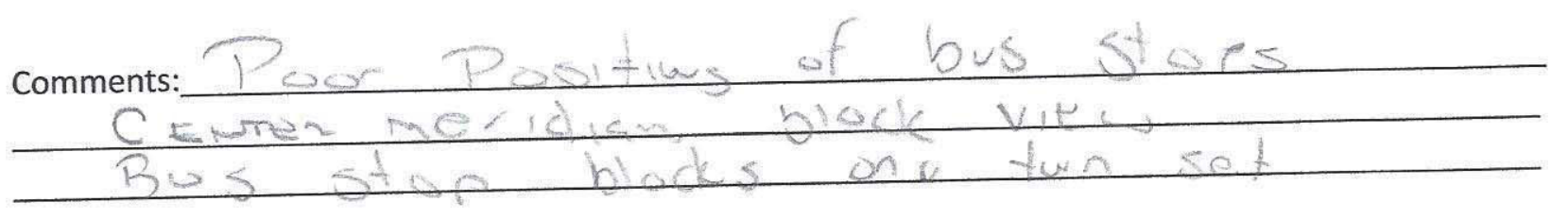

301 


\section{Appendix I}

The following is a sample survey response that was provided by a Cal Poly Student in Dr. Mastako's CE 421 Class. 
Q1: Please rate your own personal level of experience

4- Experienced Biker cycling on a scale of 1 to $5 ; 5$ being very experienced and 1 being not at all experienced.

Q2: For low speed and low traffic roads, do you prefer: Bike Lanes w ith Parking Adjacent?

Q3: Please view each of the videos at http://goo.gl/7fyp65 and 2: Deerfield/Faw n Glen East rate each movement from a cyclist's perspective in the order show $n$ in the video. If fewer movements occur in the video than are listed below, simply leave the extra options blank. What we are looking for in your response is how well the intersection design addresses the needs of the cyclist. It is recommended that you fill this out while you are watching the video rather than after you have completed the video. Please select the intersection you are viewing here:

Q4: You will now be asked to provide two separate values for each turn movement show $\mathrm{n}$ in the video. The first concerns the safety level of the cyclist and the second concerns how well the roadway infrastructure present helps the cyclist. Provide safety ratings in question numbers 4, 5, and 6 and the infrastructure ratings in questions 7,8 , and 9 below: Please rate each movement below in the order show $n$ in the video in terms of how safe the cyclist is on this road.

\section{1st Right Turn Shown 2nd Right Turn Shown}

$\begin{array}{ll}\text { 3rd Right } & \text { 4th Right } \\ \text { Turn } & \text { Turn } \\ \text { Shown } & \text { Shown }\end{array}$

Right A. Little to no danger for the B. Minor danger to the cyclist, but experienced cyclists w ould
Turns cyclist not be concerned

\section{Q5: Through Movements}

\section{1st Through Movement 2nd Through Movement}

3rd

Through

Movement 4th

Through Movement

Throug A. Little to no danger for the C. Some danger to the cyclist, but most bicycle riders w ould hs cyclist attempt the movement

Q6: Left Turns

\section{1st Left Turn Shown}

Left

Turns
B. Minor danger to the cyclist, but experienced cyclists w ould not be concerned 2nd Left Turn Shown

C. Some danger to the cyclist, but most bicycle riders w ould attempt the movement 3rd Left 4th Left

Turn Turn

Shown Shown

cyclists would not be concerned


Q7: Below is the beginning of the second set of responses mentioned in the introduction to question 4 . These relate to how well you think the bicycle infrastructure present at the intersection (bike lanes, signage, speed limit, etc.) helps the cyclist. Please note that some of the videos are of intersections with no bicycle facilities present. You may take this into consideration when rating the $m$. Please rate each movement below in the order show in the video in terms of how well the roadway design helps the cyclist on this road.

\begin{tabular}{|c|c|c|c|}
\hline 1st Right Turn Shown & 2nd Right Turn Shown & $\begin{array}{l}\text { 3rd } \\
\text { Right } \\
\text { Turn } \\
\text { Shown }\end{array}$ & $\begin{array}{l}\text { 4th } \\
\text { Right } \\
\text { Turn } \\
\text { Shown }\end{array}$ \\
\hline
\end{tabular}

$\begin{array}{lll}\text { Right } & \text { A. Great improvement for the cyclist from a } & \text { D. Lack of bike lanes or extremely narrow bike } \\ \text { Turns } & \begin{array}{l}\text { standard roadw ay; inexperienced cyclists w ould } \\ \text { not be concerned }\end{array} & \begin{array}{l}\text { lanes; cyclists of all levels of experience w ould be } \\ \text { uncomfortable }\end{array}\end{array}$

Q8: Through Movements

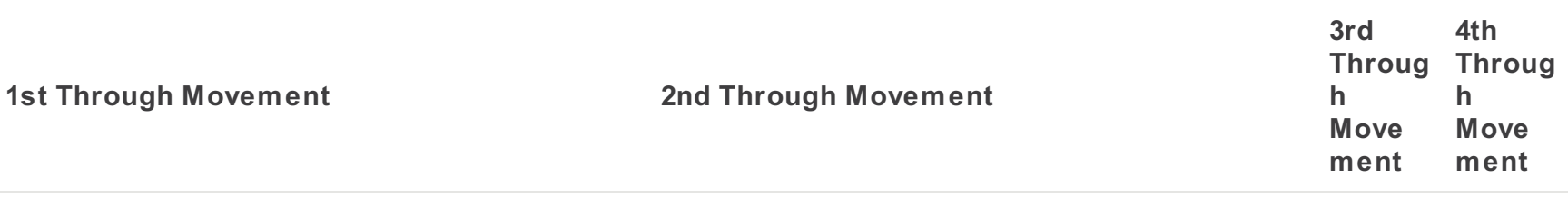
Throug A. Great improvement for the cyclist from a
hs standard roadw ay; inexperienced cyclists w ould not be concerned
B. Some improvement for the cyclist from a standard roadw ay; inexperienced cyclists w ould be mildly concerned

\section{Q9: Left Turns}

\begin{tabular}{|c|c|c|}
\hline 1st Left Turn Shown & 2nd Left Turn Shown & $\begin{array}{l}\text { 3rd } \\
\text { Left } \\
\text { Turn } \\
\text { Shown }\end{array}$ \\
\hline
\end{tabular}

\begin{tabular}{|c|c|c|}
\hline $\begin{array}{l}\text { Left } \\
\text { Turns }\end{array}$ & $\begin{array}{l}\text { B. Some improvement for the cyclist from a } \\
\text { standard roadw ay; inexperienced cyclists w ould } \\
\text { be mildly concerned }\end{array}$ & $\begin{array}{l}\text { C. An average roadw ay w ith bike lanes adjacent to } \\
\text { vehicular traffic; inexperienced cyclists w ould be } \\
\text { gravely concerned }\end{array}$ \\
\hline
\end{tabular}

Q10: Do you have any thoughts or comments on the intersection and/or videos? If so, please enter them here. This could include your thoughts on the type of infrastructure present or needed at a particular intersection, the quality of a roadway, comments on why the video does or does not give a good representation of field conditions, why you rated a particular movement the way you did, why you are confused over something, etc. This is a free section where you can provide open feedback.

Unprotected left turn is alw ays going to have some sort of danger present. 


\section{Appendix J}

The following is a sample survey response that was provided by a member of the general public. 
Q1: Informed Consent Form INFORMED CONSENT TO PARTICIPATE IN A RESEARCH PROJECT, "De velopm ent of a Bicycle Level of Service Methodology for Two Way Stop Controlled Intersections" A research project on the level of service provided to bicyclists is being conducted by $\mathrm{Dr}$. Anurag Pande in the Department of Civil Engineering at Cal Poly, San Luis Obispo. The purpose of the study is to develop a methodology to predict how well bicycle infrastructure at this particular type of intersection affects a cyclist's ride experience and perception of safety. You are being asked to take part in this study by watching a short video of an intersection recorded from a cyclist's point of view and rate each viewed turn movement on an onlinesurvey. Your participation will take approximately10 minutes. Please be aw are that you are not required to participate in this research and you may discontinue your participation at any time without penalty. You may also om it any items on the questionnaire(s) you prefer not to answer. Your responses $w$ ill be provided anonymously to protect your privacy. There are no risks anticipated with participation in this research. Potential benefits include improved roadway infrastructure for bicycle use. If you have questions regarding this study or would like to be informed of the results when the study is completed, please feel free to contact Dr. Anurag Pande at apande@calpoly.edu. If you have concerns regarding the manner in which the study is conducted, you may contact Dr. Steve Davis, Chair of the Cal Poly Hum an Subjects Comm ittee, at (805) 756-2754, sdavis@calpoly.edu, or Dr. Dean Wendt, Interim Dean of Research, at (805) 756-1508, dwendt@calpoly.edu. If you agree to voluntarily participate in this research project as described, please indicate your agreement by completing and submitting the following questionnaire. Please print a copy of this consent form NOW for your reference, and thank you for your participation in this research.

\section{Yes, I Volunteer}

\section{PAGE 2}

Q2: Please indicate your approximate age.

Q3: Please rate your ow $\mathbf{n}$ personal level of experience cycling on a scale of 1 to $5 ; 5$ being very experienced and 1 being not at all experienced. 


\section{Two Way Stop Controlled Intersections}

Q4: Please view each of the videos at http://goo.gl/7fyp65 and 11: Victoria/Boundary

rate each movement from a cyclist's perspective in the order show $n$ in the video. If fewer movements occur in the video than are listed below, simply leave the extra options blank. What we are looking for in your response is how well the intersection design addresses the needs of the cyclist. It is recommended that you fill this out while you are watching the video rather than after you have completed the video.

Please select the intersection you are viewing here:

Q5: You will now be asked to provide two separate values for each turn movement show $n$ in the video. The first concerns the safety level of the cyclist and the second concerns how well the roadway infrastructure present helps the cyclist. Provide safety ratings in question numbers 4, 5, and 6 and the infrastructure ratings in questions 7,8 , and 9 below: Please rate each movement below in the order show $n$ in the video in terms of how safe the cyclist is on this road.

$\begin{array}{lll} & & \text { 3rd } \\ \text { 1st Right Turn Shown } & \text { 4th Right } \\ & \text { 2nd Right Turn Shown } & \text { Rurn } \\ \text { Turn Shown } & \text { Shown }\end{array}$
Right
B. Minor danger to the cyclist, but experienced
C. Some danger to the cyclist, but most bicycle
Turns cyclists would not be concerned riders w ould attempt the movement

Q6: Through Movements

\begin{tabular}{|c|c|c|c|}
\hline 1st Through Movement & 2nd Through Movement & $\begin{array}{l}\text { 3rd } \\
\text { Through } \\
\text { Moveme } \\
\text { nt }\end{array}$ & $\begin{array}{l}\text { 4th } \\
\text { Through } \\
\text { Moveme } \\
\text { nt }\end{array}$ \\
\hline
\end{tabular}

Throug B. Minor danger to the cyclist, but experienced hs cyclists would not be concerned
B. Minor danger to the cyclist, but experienced cyclists w ould not be concerned

Q7: Left Turns

1st Left Turn Shown

Left

Turns
C. Some danger to the cyclist, but most bicycle riders w ould attempt the movement 2nd Left Turn Shown

C. Some danger to the cyclist, but most bicycle riders w ould attempt the movement

Q8: Below is the beginning of the second set of responses mentioned in the introduction to question 4. These relate to how well you think the bicycle infrastructure present at the intersection (bike lanes, signage, speed limit, etc.) helps the cyclist. Please note that some of the videos are of intersections with no bicycle facilities present. You may take this into consideration when rating them. Please rate each movement below in the order show $n$ in the video in terms of how well the roadway design helps the cyclist on this road.

$\begin{array}{lcc} & \text { 3rd } & \text { 4th } \\ \text { 1st Right Turn Shown } & & \text { Right } \text { Right } \\ & \text { 2nd Right Turn Shown } & \text { Turn } \text { Turn } \\ & & \text { Shown Shown }\end{array}$

Right B. Some improvement for the cyclist from a $\quad$ B. Some improvement for the cyclist from a standard

Turns standard roadw ay; inexperienced cyclists would be roadw ay; inexperienced cyclists w ould be mildly mildly concerned

concerned

Q9: Through Movements

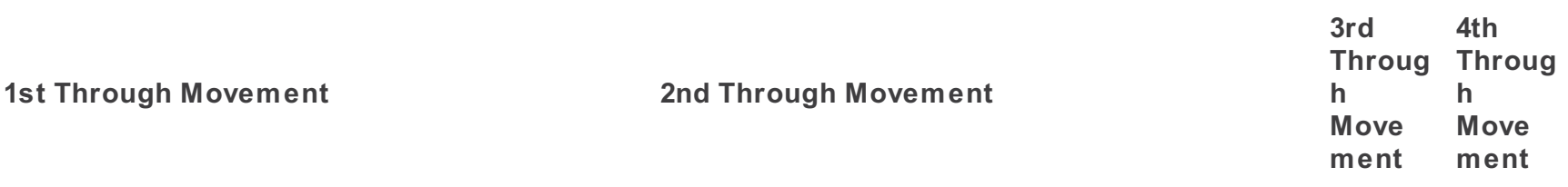

Throug A. Great improvement for the cyclist from a hs standard roadw ay; inexperienced cyclists w ould not be concerned
B. Some improvement for the cyclist from a standard roadw ay; inexperienced cyclists w ould be mildly concerned

$\begin{array}{ll}\text { 3rd Left } & 4 \text { th Left } \\ \text { Turn } & \text { Turn } \\ \text { Shown } & \text { Shown }\end{array}$




\section{Two Way Stop Controlled Intersections}

Q10: Left Turns

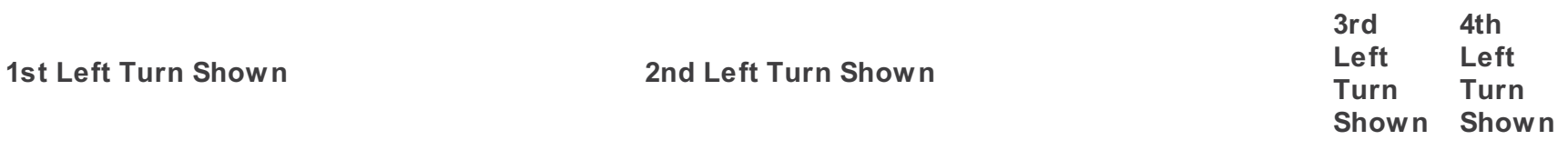

$\begin{array}{lll}\text { Left } & \text { B. Some improvement for the cyclist from a } & \text { C. An average roadw ay w ith bike lanes adjacent to } \\ \text { Turns } & \begin{array}{l}\text { standard roadw ay; inexperienced cyclists w ould } \\ \text { be mildly concerned }\end{array} & \begin{array}{l}\text { vehicular traffic; inexperienced cyclists w ould be } \\ \text { gravely concerned }\end{array}\end{array}$

Q11: Do you have any thoughts or comments on the intersection and/or videos? If so, please enter them here. This could include your thoughts on the type of infrastructure present or needed at a particular intersection, the quality of a roadway, comments on why the video does or does not give a good representation of field conditions, why you rated a particular movement the way you did, why you are confused over something, etc. This is a free section where you can provide open feedback.

The split roadw ay design is rather unusual. Also, the separated bike lane is nice, but may provide problems w ith turning cars. (and other bikes). 


\section{Appendix K}

The following is a summary of the collected level of service feedback based on the experience of the providers. 


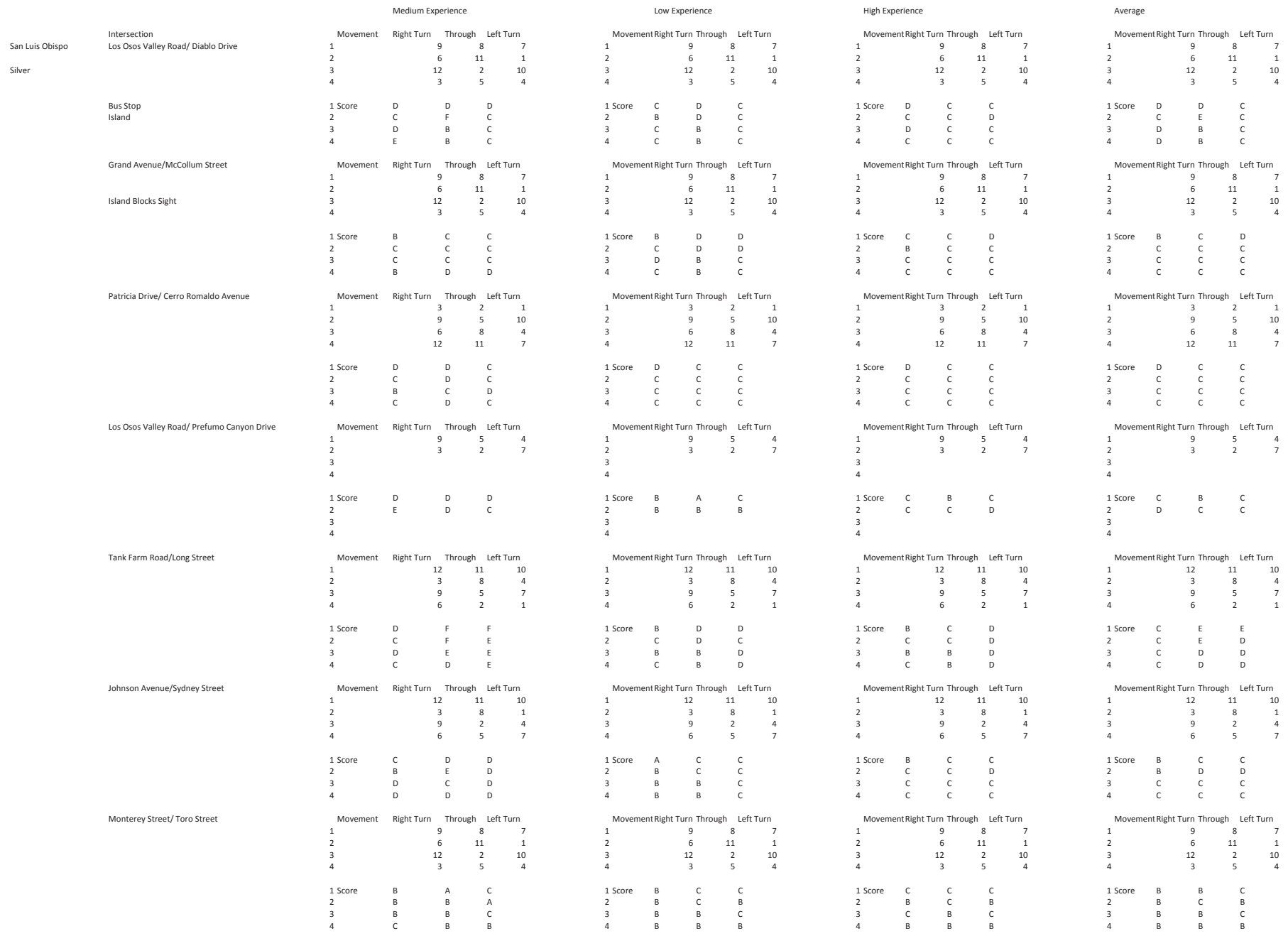




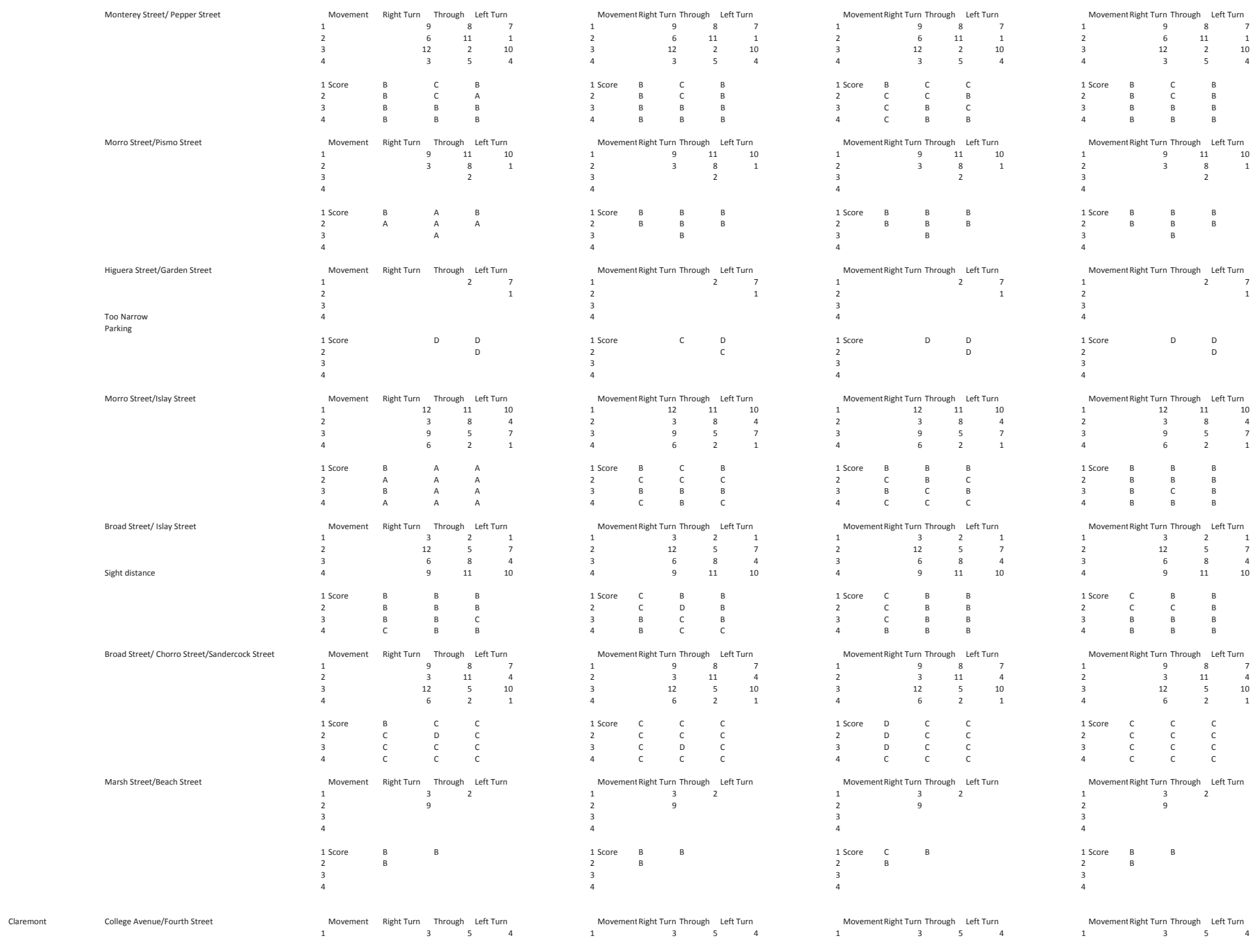


Silver

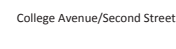

Bonita Avenue/Cornell Avenu

Gaseline Road/Grand Ave

Butte Street/ Vanderbilt Avenue

First Street/Mills Avenue

Bus Stops$$
\begin{aligned}
& 2 \\
& 3 \\
& 4 \\
& 45000 \\
& 2 \\
& 3 \\
& 4 \\
& 4 \\
& 1 \\
& 3 \\
& 3 \\
& 4 \\
& 4 \\
& 2500 \\
& 3 \\
& 4
\end{aligned}
$$

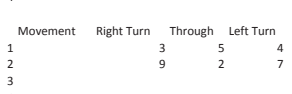$$
\begin{array}{llll}
1 \text { 5core } & \text { A } & \text { A } & \text { B } \\
2 & \text { B } & \text { A } & \text { C } \\
3 & & &
\end{array}
$$

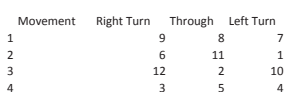$$
\begin{array}{llll}
1 \text { Score } & \text { B } & \text { C } & \text { D } \\
2 & \text { D } & \text { D } & C \\
3 & \text { D } & C & C \\
4 & \text { C } & \text { E } & \text { D }
\end{array}
$$

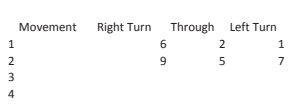

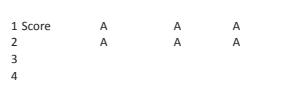

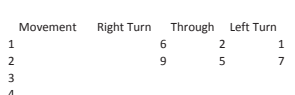

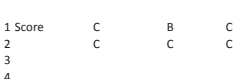
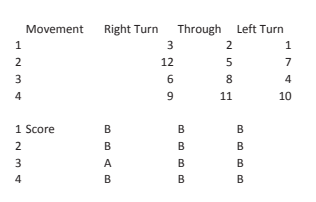

\begin{tabular}{llll} 
& Movement & Right Turn & \multicolumn{2}{c}{ Through } & Left Turn \\
1 & 9 & 8 & 7 \\
2 & 6 & 11 & 1
\end{tabular}
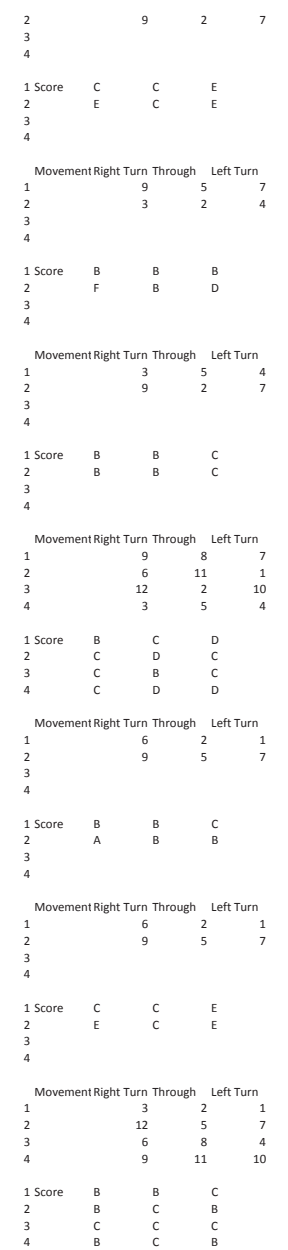

\begin{tabular}{lccc} 
& \multicolumn{2}{c}{ Movement Right Turn Through L Left Turn } \\
1 & 9 & 8 \\
2 & 6 & 11 & 7
\end{tabular}

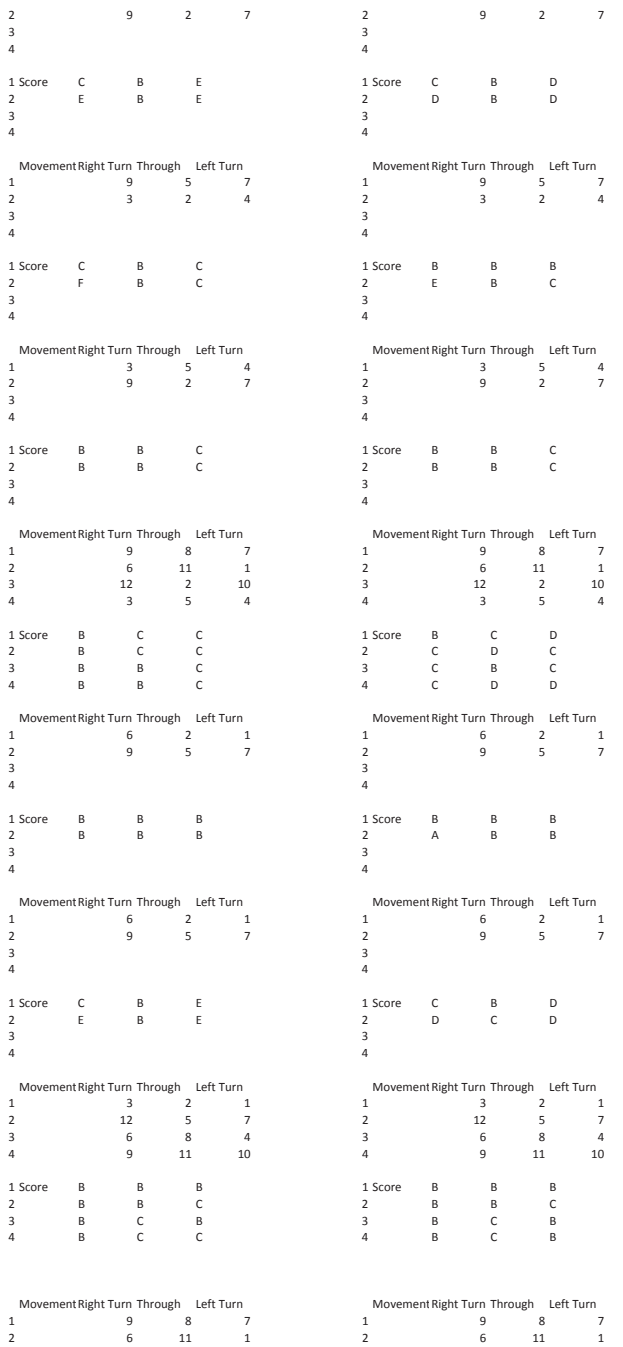


Riverside

West Linden Street/ Douglass Avenue Too Narrow
Parking

Bronze

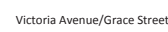

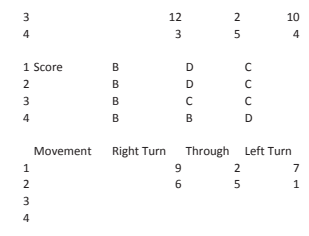

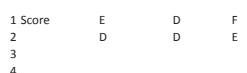

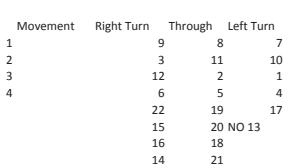

1 Score
2
3
4

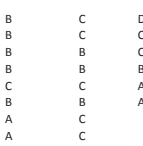

Victoria Avenue/Saint Lawerence Street<smiles>[Li]</smiles>
${ }_{1}^{\text {Mo }}$
2
3
4

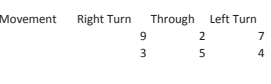
$\begin{array}{ll}17 & 14 \\ 13 & 20 \\ 15 & \\ 16 & \end{array}$

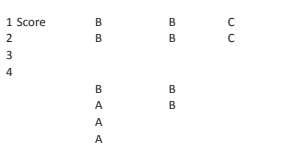

Victoria Avenue/Boundary Lane Colorado Avenue/Dundee Road

$\begin{array}{lcrrr} & \text { Movement } & \text { Right Turn } & \text { Through } & \text { Left Turn } \\ 1 & 9 & 5 & 7 \\ 2 & & 6 & 2 & 4 \\ 3 & & & & \\ 4 & & & & \end{array}$

$$
\begin{array}{ll}
13 & 15 \\
14 & 20 \\
17 & \\
16 &
\end{array}
$$

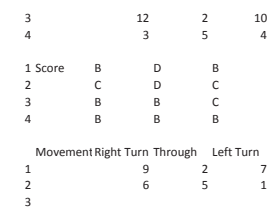$$
\begin{aligned}
& \text { Mo } \\
& 1 \\
& 2 \\
& 3 \\
& 4
\end{aligned}
$$
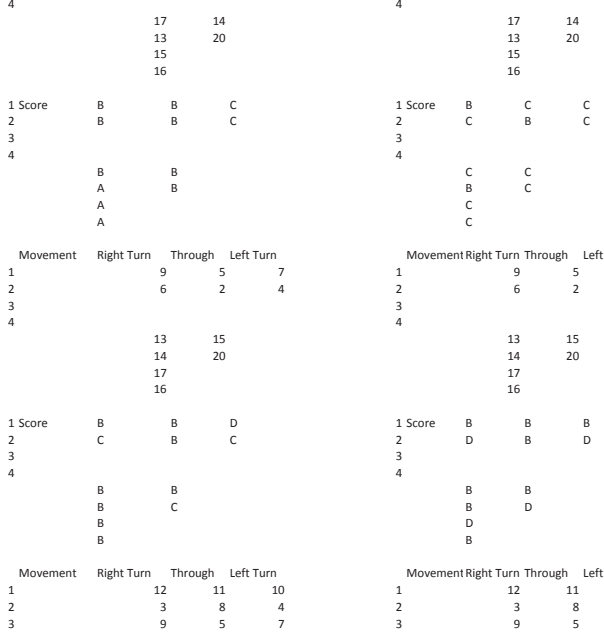
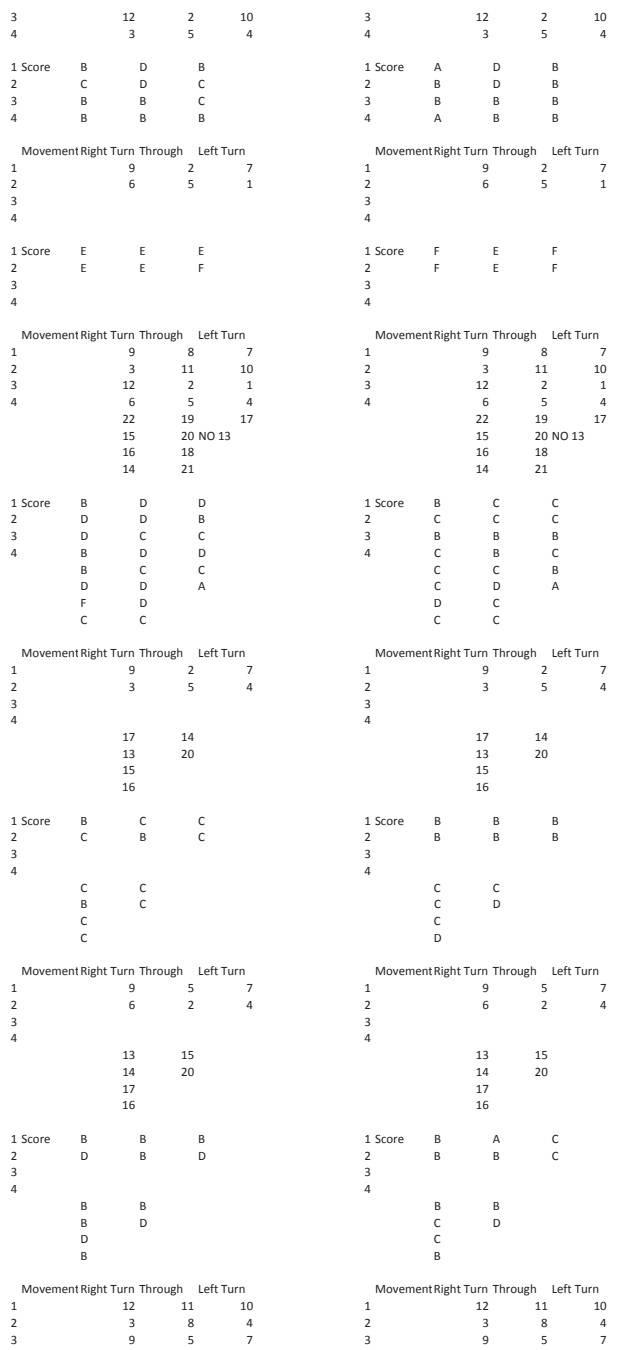
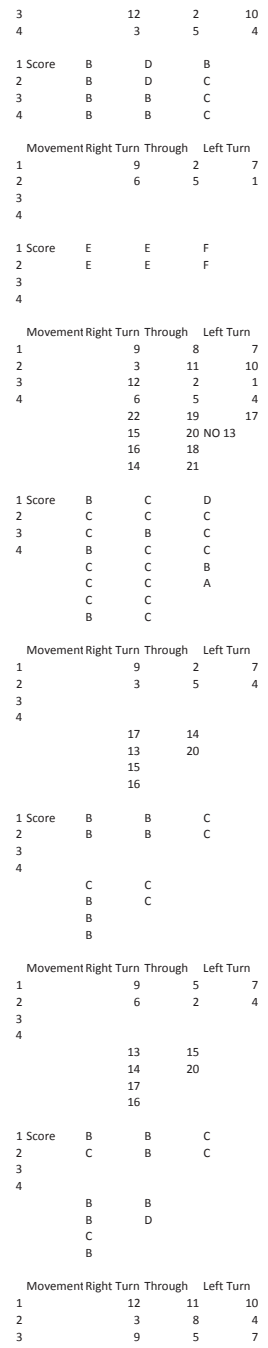


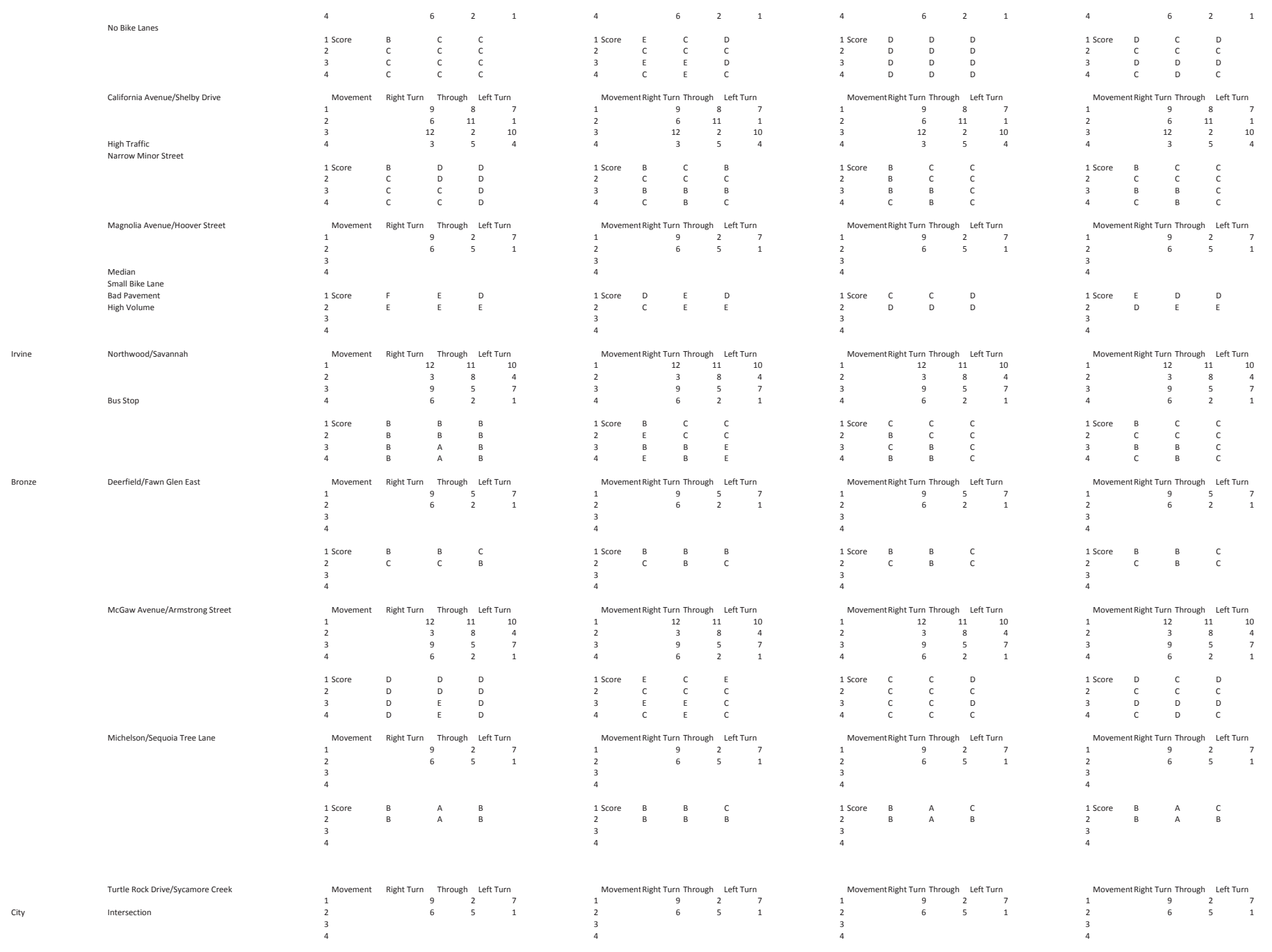


Goleta/Santa Barbara Lagoon Road/Harold Frank Road

$\begin{array}{llll}1 \text { Score } & \text { C } & \text { C } & \text { D } \\ 2 & \text { C } & \text { C } & \text { C } \\ 3 & & & \\ 4 & & & \end{array}$

Gold

North La Patera Lane/Covington Way

Cathedral Oaks Road/North La Patera Lan

Gathedral Oaks Road/Ellwood Ridge Road

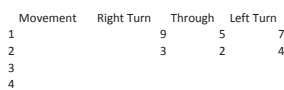
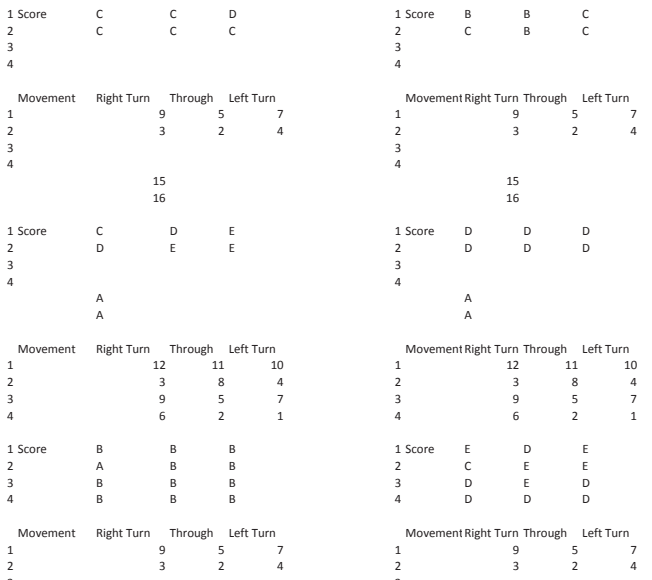

1 score $\quad$ c $\quad c \quad c \quad D$

3
4

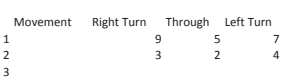

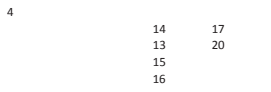

$\begin{array}{llll}1 \text { Score } & \text { C } & \text { C } & \text { D } \\ 2 & \text { C } & \text { C } & \text { D } \\ 3 & & & \\ 4 & & & \end{array}$ $\begin{array}{ll}\text { C } & \text { C } \\ \text { C } & \text { C } \\ \text { A } & \\ \text { A } & \end{array}$

Movement Right Turn Through Left Turn

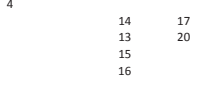

$\begin{array}{llll}1 \text { Score } & \text { B } & \text { A } & \text { B } \\ 2 & \text { C } & \text { B } & \text { C } \\ 3 & & & \end{array}$ $\begin{array}{ll}\text { c } & \text { c } \\ \text { C } & \text { c } \\ \text { B } & \end{array}$

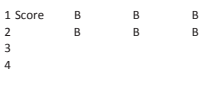

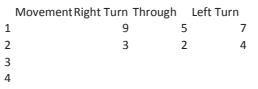

$\begin{array}{llll}1 \text { Score } & \text { B } & \text { B } & \text { C } \\ 2 & \text { C } & \text { B } & \text { C } \\ 3 & & & \end{array}$

Movement Right Turn Through Left Turn
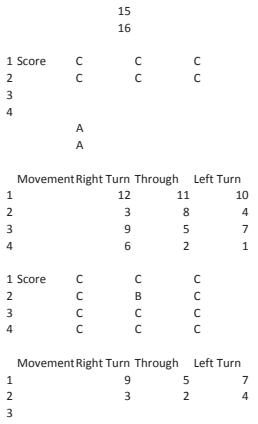

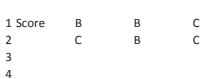

${ }_{1}$ Movement Right Turn Through Left Turn

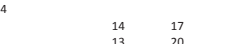

$\begin{array}{ll}14 & 17 \\ 13 & 20 \\ 15 & \\ 16 & \end{array}$

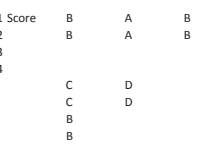

\begin{tabular}{ccc} 
MovementRight Turn Through & Left Turn \\
3 & 5 & 4 \\
9 & 2 & 7 \\
\hline & &
\end{tabular}

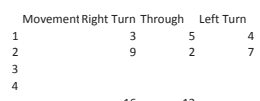


Claremont
Signalized

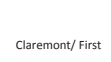

Baseline/Mountain
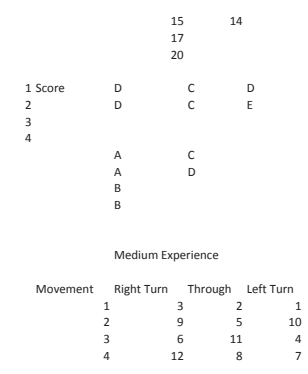

score
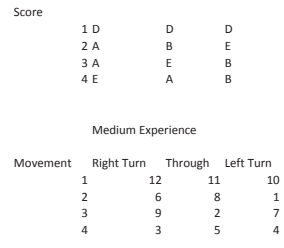

score

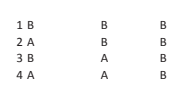

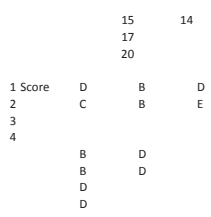

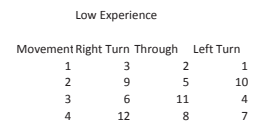

Score
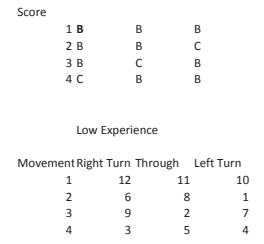

score

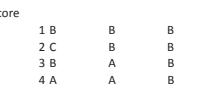

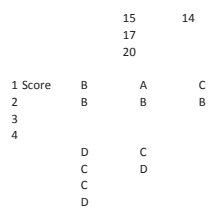

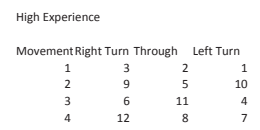

Score $\begin{array}{lll}1 \mathrm{~A} & \mathrm{~A} & \mathrm{~A} \\ 2 \mathrm{~A} & \mathrm{~A} & \mathrm{~A} \\ 3 \mathrm{~A} & \mathrm{~A} & \mathrm{~A} \\ 4 \mathrm{~A} & \mathrm{~A} & \mathrm{~A}\end{array}$

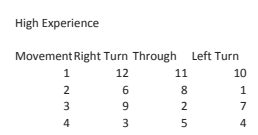

score

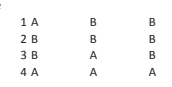

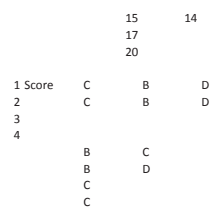

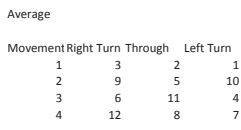

Score $\begin{array}{lll} & & \\ \text { IC } & \text { C } & \text { C } \\ \text { 2A } & \text { B } & \text { C } \\ \text { 3A } & \text { C } & \text { B } \\ 4 C & \text { A } & \text { B }\end{array}$
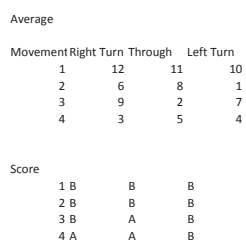


\begin{abstract}
Appendix L
The following are the Minitab outputs for the final equations. Results for the tests that were conducted prior to these being determined are not included due to the sheer volume of that data.
\end{abstract}


Major Street Equation:

Best Subsets Regression: log los versus SD/SL(ft/s), Minor Speed , ...

Response is log los

185 cases used, 3 cases contain missing values

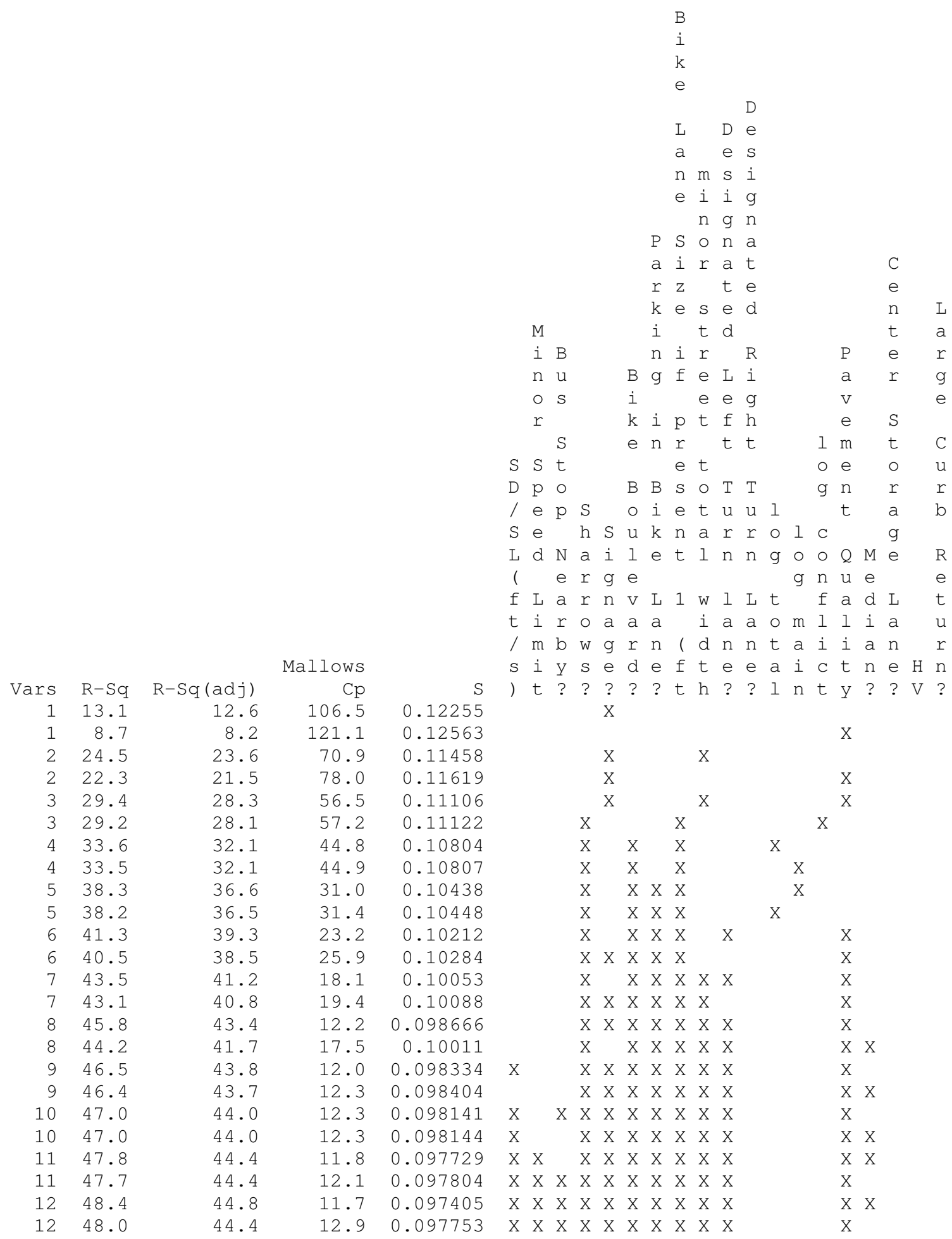




\begin{tabular}{|c|c|c|c|c|c|c|c|c|c|c|c|c|c|c|c|c|c|c|c|c|c|}
\hline 13 & 48.6 & 44.7 & 13.2 & 0.097538 & $\mathrm{X}$ & $\mathrm{X}$ & $x>$ & $x \quad x$ & $x \quad x$ & $\mathrm{X}$ & $\mathrm{X}$ & & & & & & & & & & \\
\hline 13 & 48.5 & 44.6 & 13.3 & 0.097568 & $\mathrm{X}$ & $\mathrm{X}$ & $x>$ & $X \quad x$ & $x \quad x$ & $\mathrm{X}$ & $\mathrm{X}$ & $\mathrm{X}$ & $\mathrm{X}$ & $\mathrm{X}$ & & & & & $\mathrm{X}$ & & \\
\hline 14 & 49.1 & 44.9 & 13.3 & 0.097289 & $\mathrm{X}$ & $\mathrm{X}$ & $x>$ & $X x$ & $x \quad x$ & $\mathrm{X}$ & $\mathrm{X}$ & $\mathrm{X}$ & $\mathrm{X}$ & & $\mathrm{X}$ & $\mathrm{X}$ & X & X & & & \\
\hline 14 & 48.9 & 44.7 & 14.1 & 0.097515 & $\mathrm{X}$ & $\mathrm{X}$ & $\gamma$ & $x \quad x$ & $x \quad x$ & $x$ & $\mathrm{X}$ & X & $\mathrm{X}$ & & $\mathrm{X}$ & $\mathrm{X}$ & X & $X$ & $\mathrm{X}$ & & \\
\hline 15 & 49.9 & 45.5 & 12.7 & 0.096828 & $\mathrm{X}$ & $\mathrm{X}$ & X 2 & $x \quad x$ & $x \quad x$ & $x$ & $\mathrm{X}$ & $\mathrm{X}$ & $\mathrm{X}$ & & $X$ & $\mathrm{X}$ & X & $x$ & $\mathrm{X}$ & & \\
\hline 15 & 49.4 & 44.9 & 14.5 & 0.097340 & $\mathrm{X}$ & $\mathrm{X}$ & $x>$ & $x \quad x$ & $x \quad x$ & $x$ & $\mathrm{X}$ & $\mathrm{X}$ & $\mathrm{X}$ & & $\mathrm{X}$ & $\mathrm{X}$ & X & $\mathrm{X}$ & & & \\
\hline 16 & 50.2 & 45.5 & 13.8 & 0.096843 & $\mathrm{X}$ & $\mathrm{X}$ & $x>$ & $x \times$ & $x \quad x$ & $x$ & $\mathrm{X}$ & $\mathrm{X}$ & $\mathrm{X}$ & $\mathrm{X}$ & $\mathrm{X}$ & $\mathrm{X}$ & X & $\mathrm{x}$ & $\mathrm{X}$ & & \\
\hline 16 & 50.0 & 45.3 & 14.3 & 0.096990 & $\mathrm{X}$ & $\mathrm{X}$ & X 2 & $x \quad x$ & $x \quad x$ & $x$ & $\mathrm{X}$ & $\mathrm{x}$ & $\mathrm{x}$ & & $\mathrm{X}$ & $\mathrm{X}$ & $\mathrm{X}$ & & X & & \\
\hline 17 & 50.3 & 45.2 & 15.6 & 0.097072 & $\mathrm{X}$ & $\mathrm{X}$ & $x>$ & $x \quad x$ & $x \quad x$ & $x$ & $\mathrm{X}$ & $\mathrm{X}$ & $\mathrm{x}$ & $\mathrm{x}$ & $\mathrm{X}$ & $\mathrm{X}$ & $\mathrm{X}$ & $x$ & $\mathrm{X}$ & & \\
\hline 17 & 50.2 & 45.2 & 15.7 & 0.097102 & $\mathrm{X}$ & $\mathrm{X}$ & $x>$ & $x \quad x$ & $x \quad x$ & $x$ & $\mathrm{X}$ & & $\mathrm{X}$ & X & $\mathrm{X}$ & $X$ & $\mathrm{X}$ & & & $\Delta$ & \\
\hline 18 & 50.4 & 45.0 & 17.3 & 0.097268 & $\mathrm{X}$ & $\mathrm{X}$ & X 2 & $x \quad x$ & $x \quad x$ & $x$ & $\mathrm{X}$ & $\mathrm{X}$ & $\mathrm{x}$ & $\mathrm{x}$ & $\mathrm{X}$ & $\mathrm{X}$ & $\mathrm{X}$ & $X$ & & $\lambda$ & \\
\hline 18 & 50.3 & 44.9 & 17.5 & 0.097330 & $\mathrm{X}$ & $\mathrm{X}$ & $x>$ & $x \quad x$ & $x \quad x$ & $x$ & $\mathrm{X}$ & $\mathrm{X}$ & $\mathrm{x}$ & $\mathrm{X}$ & $\mathrm{X}$ & $\mathrm{X}$ & $\mathrm{X}$ & $x$ & $\mathrm{X}$ & & $\mathrm{X}$ \\
\hline 19 & 50.4 & 44.7 & 19.1 & 0.097507 & $\mathrm{X}$ & X & X $>$ & $x \quad x$ & $x \quad x$ & $\mathrm{x}$ & X & 2 & $\mathrm{X}$ & X & $X$ & $\mathrm{X}$ & X & $\Delta$ & $x$ & $2=$ & $\mathrm{X}$ \\
\hline 19 & 50.4 & 44.7 & 19.1 & 0.097523 & $\mathrm{X}$ & $X$ & X 2 & $x \quad x$ & $x \quad x$ & $x$ & $\mathrm{X}$ & $\Delta$ & $\mathrm{X}$ & X & $\mathrm{X}$ & $\mathrm{X}$ & X & & X & $\mathrm{X}$ & \\
\hline 20 & 50.4 & 44.4 & 21.0 & 0.097776 & $\mathrm{X}$ & $\mathrm{X}$ & X 2 & $x \quad x$ & $x \quad x$ & $x$ & $\mathrm{X}$ & $\mathrm{X}$ & $\mathrm{X}$ & $\mathrm{X}$ & $\mathrm{X}$ & $\mathrm{X}$ & $\mathrm{X}$ & $\mathrm{X}$ & $\mathrm{X}$ & $\mathrm{X}$ & $\mathrm{x}$ \\
\hline
\end{tabular}

m

a

j

$r$

S

$r$

e

t

t

o

t

1

W

i

d

Vars h

1

1

3

5

5

6

7

7

8 


\section{General Regression Analysis: log los versus SD/SL(ft/s), Minor Speed , ...}

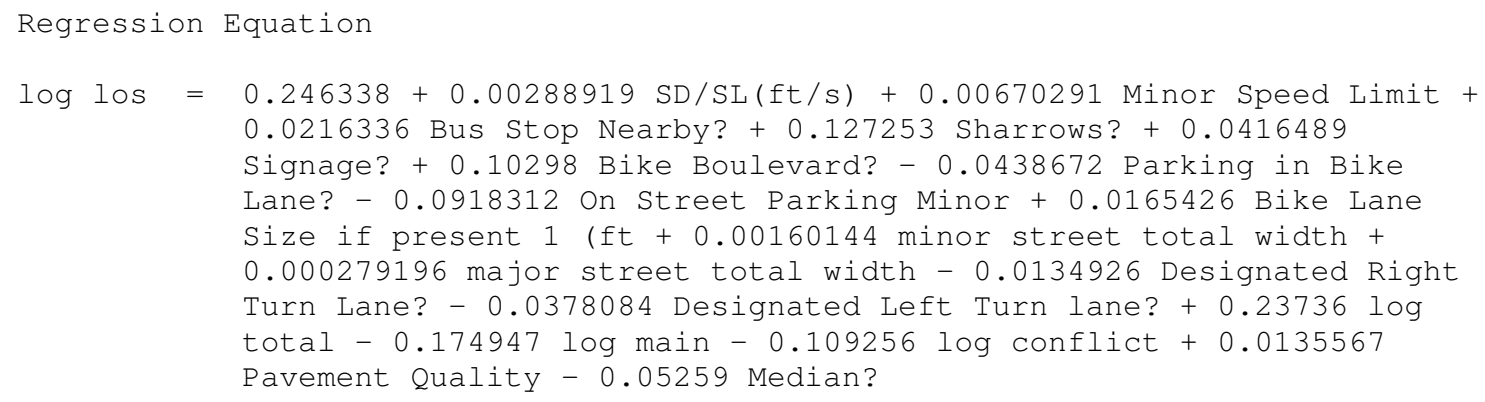

163 cases used, 3 cases contain missing values

Coefficients

Term

Constant

$\mathrm{SD} / \mathrm{SL}(\mathrm{ft} / \mathrm{s})$

Minor speed Limit

Bus Stop Nearby?

Sharrows?

Signage?

Bike Boulevard?

Parking in Bike Lane?

On Street Parking Minor

Bike Lane Size if present 1 (ft

minor street total width

major street total width

Designated Right Turn Lane?

Designated Left Turn lane?

$\log$ total

log main

log conflict

$\begin{array}{rrrr}\text { Coef } & \text { SE Coef } & T & P \\ 0.246338 & 0.121873 & 2.02126 & 0.045 \\ 0.002889 & 0.006047 & 0.47781 & 0.634 \\ 0.006703 & 0.002082 & 3.22003 & 0.002 \\ 0.021634 & 0.015557 & 1.39063 & 0.166 \\ 0.127253 & 0.019102 & 6.66179 & 0.000 \\ 0.041649 & 0.013451 & 3.09635 & 0.002 \\ 0.102980 & 0.030819 & 3.34148 & 0.001 \\ -0.043867 & 0.023627 & -1.85666 & 0.065 \\ -0.091831 & 0.025209 & -3.64282 & 0.000 \\ 0.016543 & 0.002451 & 6.75058 & 0.000 \\ 0.001601 & 0.000996 & 1.60791 & 0.110 \\ 0.000279 & 0.000569 & 0.49040 & 0.625 \\ -0.013493 & 0.033785 & -0.39937 & 0.690 \\ -0.037808 & 0.015073 & -2.50838 & 0.013 \\ 0.237360 & 0.148192 & 1.60170 & 0.111 \\ -0.174947 & 0.089688 & -1.95062 & 0.053 \\ -0.109256 & 0.063670 & -1.71599 & 0.088\end{array}$




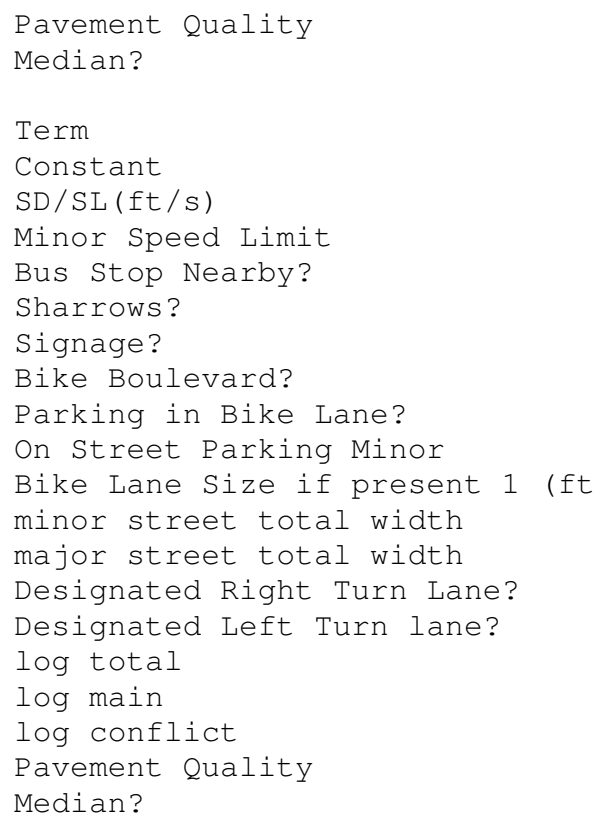

Bus Stop Nearby?

$\begin{array}{rrrr}0.013557 & 0.010728 & 1.26367 & 0.208 \\ -0.052590 & 0.017464 & -3.01125 & 0.003\end{array}$

\begin{tabular}{rrr}
$95 \%$ & \multicolumn{1}{r}{ CI } \\
$(0.005446$, & $0.487230)$ & \\
$(-0.009063$, & $0.014841)$ & 1.752 \\
$(0.002588$, & $0.010817)$ & 2.148 \\
$(-0.009115$, & $0.052383)$ & 2.003 \\
$(0.089497$, & $0.165009)$ & 2.574 \\
$(0.015062$, & $0.068236)$ & 2.022 \\
$(0.042065$, & $0.163895)$ & 2.215 \\
$(-0.090568$, & $0.002833)$ & 1.302 \\
$(-0.141658$, & $-0.042004)$ & 1.636 \\
$(0.011699$, & $0.021386)$ & 3.391 \\
$(-0.000367$, & $0.003570)$ & 2.330 \\
$(-0.000846$, & $0.001405)$ & 4.244 \\
$(-0.080271$, & $0.053286)$ & 1.809 \\
$(-0.067601$, & $-0.008016)$ & 2.408 \\
$(-0.055553$, & $0.530272)$ & 108.907 \\
$(-0.352222$, & $0.002328)$ & 46.260 \\
$(-0.235104$, & $0.016591)$ & 25.668 \\
$(-0.007648$, & $0.034761)$ & 2.325 \\
$(-0.087110$, & $-0.018070)$ & 2.899
\end{tabular}

IF

.574

. 022

.302

1.636

.391

809

.408

907

5.668

2.899

$\begin{array}{rrrrr}\text { DF } & \text { Seq SS } & \text { Adj SS } & \text { Adj MS } & F \\ 18 & 0.91307 & 0.913075 & 0.050726 & 13.9115 \\ 1 & 0.00974 & 0.000832 & 0.000832 & 0.2283 \\ 1 & 0.05069 & 0.037808 & 0.037808 & 10.3686 \\ 1 & 0.04432 & 0.007052 & 0.007052 & 1.9339 \\ 1 & 0.16081 & 0.161824 & 0.161824 & 44.3795 \\ 1 & 0.11150 & 0.034959 & 0.034959 & 9.5874 \\ 1 & 0.03965 & 0.040714 & 0.040714 & 11.1655 \\ 1 & 0.00090 & 0.012570 & 0.012570 & 3.4472 \\ 1 & 0.09718 & 0.048388 & 0.048388 & 13.2701 \\ 1 & 0.19542 & 0.166166 & 0.166166 & 45.5703 \\ 1 & 0.03054 & 0.009427 & 0.009427 & 2.5854 \\ 1 & 0.03545 & 0.000877 & 0.000877 & 0.2405 \\ 1 & 0.00003 & 0.000582 & 0.000582 & 0.1595 \\ 1 & 0.01966 & 0.022943 & 0.022943 & 6.2920 \\ 1 & 0.04662 & 0.009355 & 0.009355 & 2.5655 \\ 1 & 0.00133 & 0.013874 & 0.013874 & 3.8049 \\ 1 & 0.01257 & 0.010737 & 0.010737 & 2.9446 \\ 1 & 0.02358 & 0.005823 & 0.005823 & 1.5969 \\ 1 & 0.03306 & 0.033064 & 0.033064 & 9.0676 \\ 144 & 0.52508 & 0.525077 & 0.003646 & \\ 53 & 0.18349 & 0.183488 & 0.003462 & 0.9223 \\ 91 & 0.34159 & 0.341588 & 0.003754 & \\ 162 & 1.43815 & & & \end{array}$

$\mathrm{P}$

0.000000

0.633511

0.001584

0.166483 


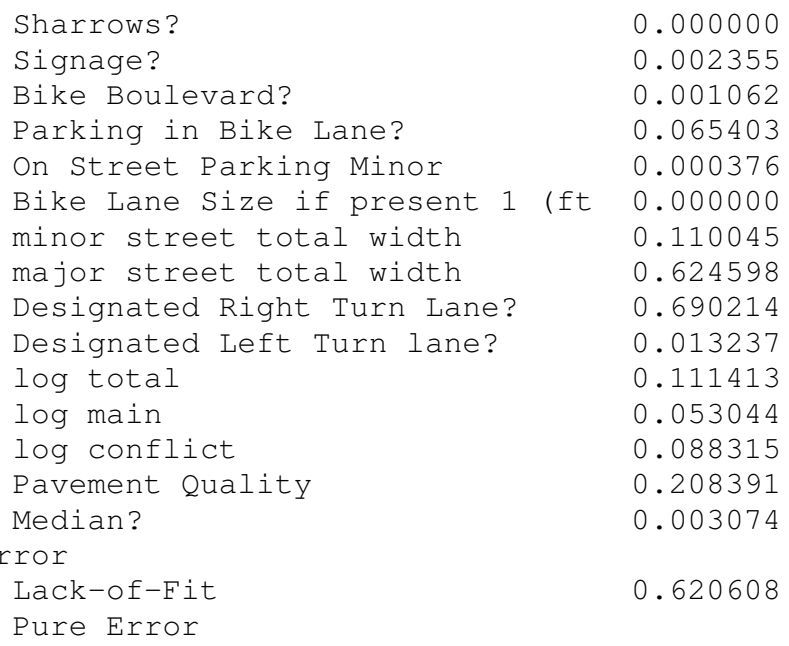

\section{Residual Plots for log los}

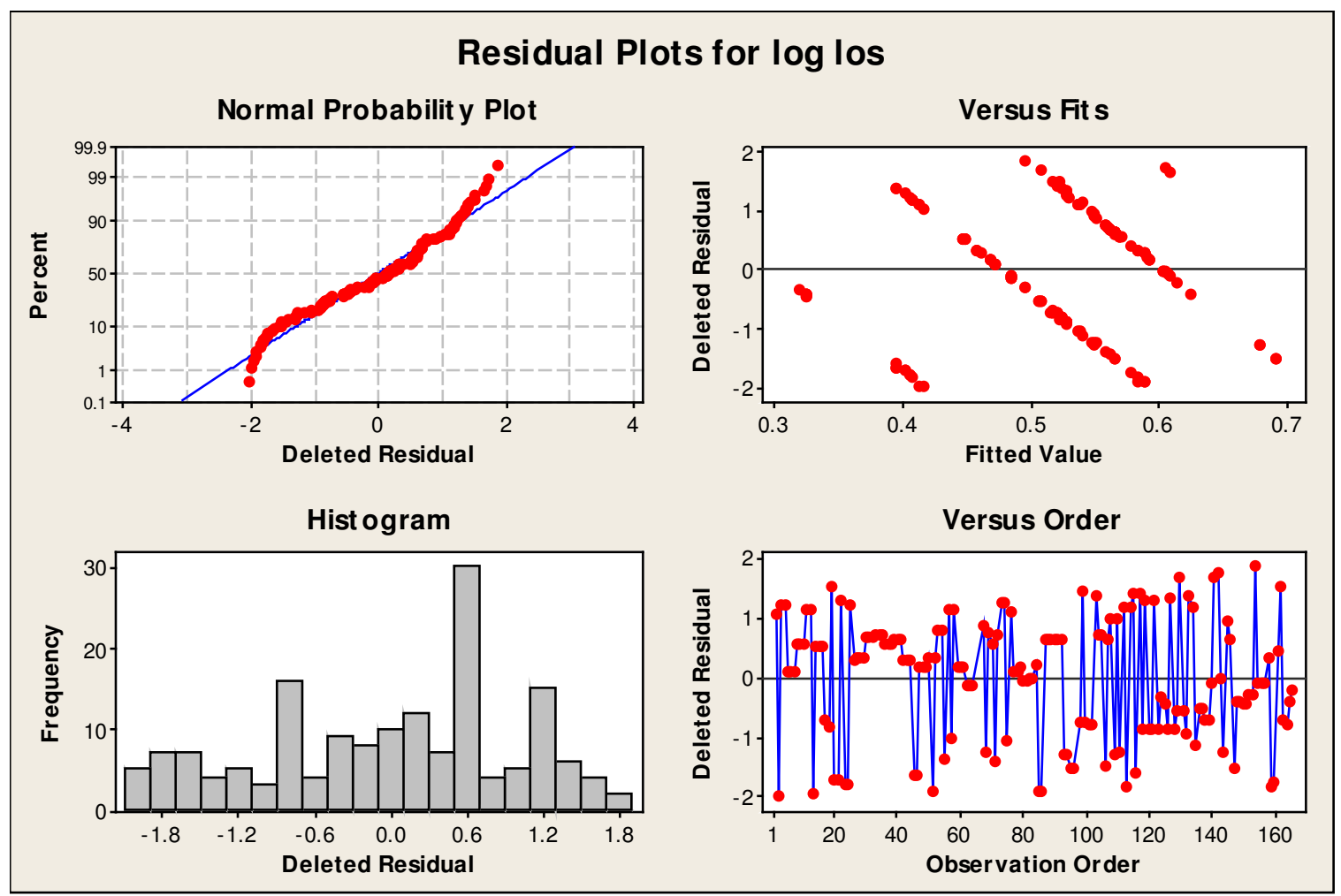


Minor Street Equation:

Best Subsets Regression: log los versus SD/SL(ft/s), Minor Speed , ...

Response is log los

151 cases used, 1 cases contain missing values

\begin{tabular}{|c|c|c|c|c|c|c|c|c|c|c|c|c|c|c|c|c|c|}
\hline & & & & & & & & & $\begin{array}{l}\mathrm{B} \\
\mathrm{i} \\
\mathrm{k} \\
\mathrm{e}\end{array}$ & & & & & & & & \\
\hline & & & & & & & & & L & & & & & & & & \\
\hline & & & & & & & & & a & & & & & & & & \\
\hline & & & & & & & & & $\mathrm{n}$ & & & & $\mathrm{m}$ & 0 & & & \\
\hline & & & & & & & & & e & & & & $\mathrm{a}$ & $\mathrm{n} \mathrm{O}$ & & & \\
\hline & & & & & & & & & & & & & j & $\mathrm{n}$ & & & \\
\hline & & & & & & & & & $P \quad S$ & & & & ○ & S & & & \\
\hline & & & & & & & & & $a i$ & & & & r & $t s$ & & & \\
\hline & & & & & & & & & $r \quad z$ & & & & & $r t$ & : & & \\
\hline & & & & & & & & & $k e$ & & & & S & e $r$ & . & $\mathrm{L}$ & \\
\hline & & & & & & $\mathrm{M}$ & & & i & & & & t & $e e$ & 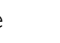 & $a$ & \\
\hline & & & & & & $i$ & & & $n i$ & & & P & $r$ & $t e$ & $S$ & $r$ & \\
\hline & & & & & & $\mathrm{n}$ & & B & $g \mathrm{f}$ & & & a & e & $t$ & L & 9 & \\
\hline & & & & & & O & & i & & & & $\mathrm{V}$ & e & $\mathrm{P}$ & 0 & e & \\
\hline & & & & & & r & & $\mathrm{k}$ & i $p$ & & & e & $t$ & $\mathrm{a} P$ & $P$ & & \\
\hline & & & & & & & 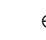 & e r & $n r$ & & 1 & $m$ & & r a & $E$ & $\mathrm{C}$ & \\
\hline & & & & & S & $S$ & & & e & & o & e & $t$ & $\mathrm{k} r$ & 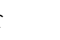 & $\mathrm{u}$ & \\
\hline & & & & & $\mathrm{D}$ & $\mathrm{p}$ & & $\mathrm{B}$ & $B s$ & & $g$ & $\mathrm{n}$ & $\circ$ & i k & $T$ & $r$ & \\
\hline & & & & & / & e & S & o & $i e$ & 1 & & $t$ & $t$ & $\mathrm{n} i$ & $\mathrm{R}$ & $\mathrm{b}$ & \\
\hline & & & & & S & e & h & $a$ ] & $\mathrm{k} n$ & 0 & $1 \mathrm{c}$ & & a & $\mathrm{g} n$ & $A$ & & \\
\hline & & & & & $\mathrm{L}$ & d & $\mathrm{a}$ & $1 \epsilon$ & e $t$ & 9 & $\circ 0$ & Q $M$ & M 1 & g & $\mathrm{N}$ & $\mathrm{R}$ & \\
\hline & & & & & ( & & $r$ & e & & 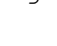 & $g \mathrm{n}$ & u e & e & $\mathrm{M}$ & S & e & \\
\hline & & & & & $\mathrm{f}$ & $\mathrm{L}$ & $r$ & $\mathrm{~V}$ & L 1 & $t$ & $\mathrm{f}$ & $a d$ & $d \quad w$ & $\mathrm{a} M$ & $1 I$ & $t$ & \\
\hline & & & & & $t$ & $i$ & 0 & $a \quad$ & a & o & $\mathrm{m} 1$ & $1 i$ & i i & $j i$ & $T$ & $\mathrm{u}$ & \\
\hline & & & & & / & $\mathrm{m}$ & $\mathrm{w}$ & $r \mathrm{r}$ & n ( & $t$ & a i & $i$ & $\mathrm{a} d$ & o n & $I$ & $r$ & \\
\hline & & & Mallows & & s & i & $\mathrm{s}$ & $d$ & e $f$ & $a$ & i $c$ & $t n$ & $n t$ & $r o$ & 0 & $\mathrm{n}$ & $\mathrm{H}$ \\
\hline Vars & $\mathrm{R}-\mathrm{Sq}$ & $R-S q(a d j)$ & $\mathrm{Cp}$ & S & ) & $t$ & $?$ & ? & $? t$ & 1 & $n t$ & $\mathrm{y}$ ? & ? h & $? r$ & $\mathrm{~N}$ & $?$ & V \\
\hline 1 & 8.8 & 8.2 & 68.0 & 0.13483 & & & & & & & $\mathrm{X}$ & & & & & & \\
\hline 1 & 8.5 & 7.8 & 68.9 & 0.13510 & & & & & & $X$ & & & & & & & \\
\hline 2 & 15.9 & 14.8 & 53.2 & 0.12990 & & & & & & & $\mathrm{X}$ & & & & & & $\mathrm{X}$ \\
\hline 2 & 15.7 & 14.6 & 53.8 & 0.13008 & & & & & & $\mathrm{X}$ & & & & & & & $\mathrm{X}$ \\
\hline 3 & 19.3 & 17.6 & 47.4 & 0.12773 & & & $\mathrm{x}$ & & & & $\mathrm{X}$ & & & & & & $\mathrm{X}$ \\
\hline 3 & 18.9 & 17.3 & 48.2 & 0.12801 & & & $\mathrm{X}$ & & & X & & & & & & & $\mathrm{X}$ \\
\hline 4 & 24.7 & 22.7 & 36.4 & 0.12374 & & & $x_{2} 2$ & $X$ & $\mathrm{X}$ & $x$ & & & & & & & \\
\hline 4 & 24.3 & 22.2 & 37.6 & 0.12413 & & & $\mathrm{X}$ & & $\mathrm{X}$ & & $\mathrm{X}$ & & & & & & $\mathrm{X}$ \\
\hline 5 & 29.4 & 26.9 & 27.5 & 0.12028 & & & $x y$ & $\mathrm{X}$ & $\mathrm{X}$ & $x$ & & $\mathrm{X}$ & $X$ & & & & \\
\hline 5 & 28.8 & 26.4 & 28.8 & 0.12074 & & & $x^{2}$ & $x$ & $\mathrm{X}$ & $x$ & & & & & & & $\mathrm{X}$ \\
\hline 6 & 32.4 & 29.5 & 22.5 & 0.11812 & & & $x$ & $\mathrm{X}$ & $\mathrm{X}$ & $x$ & & $\mathrm{X}$ & $x$ & & $\mathrm{X}$ & & \\
\hline 6 & 31.5 & 28.6 & 24.6 & 0.11891 & & & $x^{2}$ & $X$ & X & & $\mathrm{X}$ & $\mathrm{X}$ & X & & $\mathrm{X}$ & & \\
\hline 7 & 35.2 & 32.0 & 17.9 & 0.11605 & $\mathrm{X}$ & $\mathrm{X}$ & & & 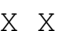 & & & & $\mathrm{X}$ & $\mathrm{X}$ & & & $\mathrm{X}$ \\
\hline 7 & 34.7 & 31.5 & 19.1 & 0.11651 & & & $x^{2}$ & $x 2$ & $X \quad X$ & $x$ & & $\mathrm{X}$ & $\mathrm{X}$ & & $\mathrm{X}$ & & \\
\hline 8 & 36.8 & 33.2 & 16.1 & 0.11503 & $\mathrm{X}$ & $\mathrm{X}$ & & & $X X$ & & & & $\mathrm{x}$ & $X$ & & $\mathrm{x}$ & $\mathrm{X}$ \\
\hline 8 & 36.3 & 32.7 & 17.3 & 0.11546 & & & $\mathrm{X} z$ & $x 2$ & $x \quad x$ & $x$ & & & X & & $\mathrm{X}$ & & $\mathrm{X}$ \\
\hline 9 & 38.0 & 34.1 & 15.1 & 0.11426 & & $\mathrm{X}$ & $x^{2}$ & $x>$ & $X \quad X$ & $x$ & & & $x$ & & $\mathrm{X}$ & & $\mathrm{X}$ \\
\hline 9 & 38.0 & 34.1 & 15.2 & 0.11428 & $\mathrm{X}$ & $\mathrm{X}$ & $x^{2}$ & $x>$ & 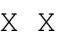 & & $\mathrm{X}$ & & $x$ & & & & $\mathrm{X}$ \\
\hline 10 & 40.3 & 36.1 & 11.7 & 0.11253 & $\mathrm{X}$ & $\mathrm{X}$ & $x^{2}$ & $x>$ & 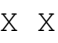 & $x$ & X & $\mathrm{X}$ & X & & & & $\mathrm{X}$ \\
\hline 10 & 40.3 & 36.0 & 11.8 & 0.11255 & $\mathrm{X}$ & $\mathrm{X}$ & $x_{2}$ & $x 2$ & $X \quad X$ & & X & $X$ & $x \quad x$ & & & & $\mathrm{X}$ \\
\hline 11 & 41.5 & 36.8 & 11.0 & 0.11184 & $\mathrm{X}$ & $\mathrm{X}$ & $x$ & $x>$ & $X \quad x$ & $x$ & X & $\mathrm{X}$ & $x \quad x$ & & & & $\mathrm{x}$ \\
\hline 11 & 41.2 & 36.5 & 11.7 & 0.11214 & $\mathrm{X}$ & $\mathrm{X}$ & $x^{2}$ & $x>2$ & $x \quad x$ & $x$ & & $\mathrm{X}$ & $x \quad x$ & & $\mathrm{X}$ & & $\mathrm{X}$ \\
\hline 12 & 42.3 & 37.3 & 11.1 & 0.11146 & $\mathrm{X}$ & $\mathrm{X}$ & $x^{2}$ & $x 2$ & 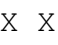 & $x$ & $\mathrm{X}$ & $\mathrm{X}$ & $x \quad x$ & & $\mathrm{x}$ & & $\mathrm{X}$ \\
\hline 12 & 42.3 & 37.2 & 11.2 & 0.11149 & $\mathrm{X}$ & $\mathrm{X}$ & $x$ & $X Y$ & $X \quad x$ & $x$ & $\mathrm{x}$ & $\mathrm{X}$ & $x \quad x$ & & & $\mathrm{x}$ & $\mathrm{X}$ \\
\hline
\end{tabular}




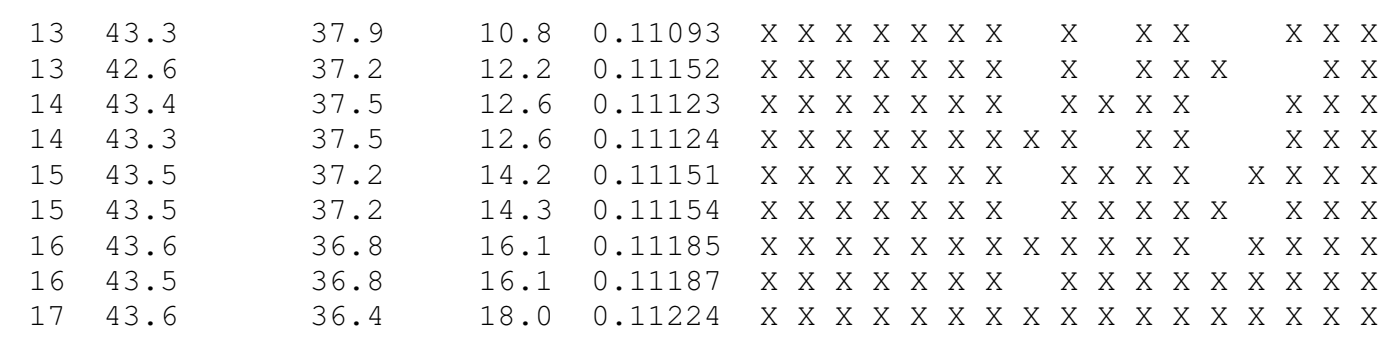

\section{General Regression Analysis: log los versus SD/SL(ft/s), Minor Speed , ...}

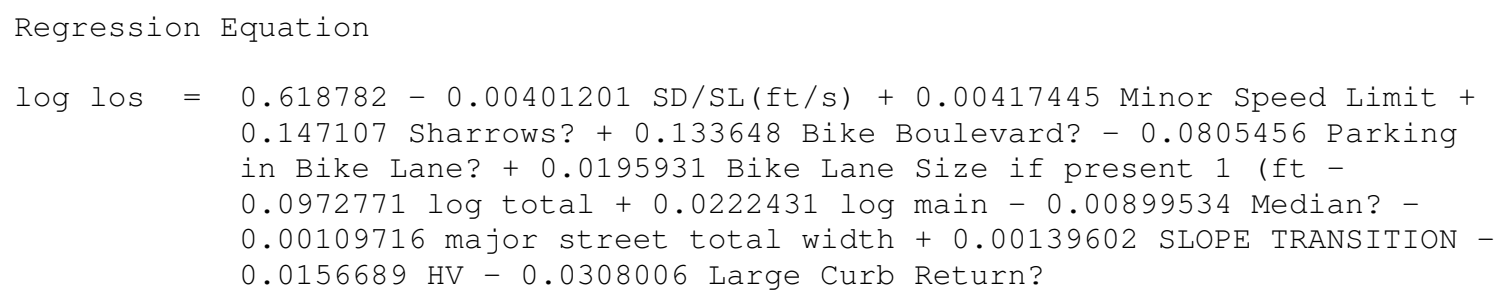

$\begin{array}{rrrr}\text { Coef } & \text { SE Coef } & T & P \\ 0.618782 & 0.106649 & 5.80204 & 0.000 \\ -0.004012 & 0.009452 & -0.42446 & 0.672 \\ 0.004174 & 0.002943 & 1.41840 & 0.159 \\ 0.147107 & 0.018928 & 7.77209 & 0.000 \\ 0.133648 & 0.029251 & 4.56902 & 0.000 \\ -0.080546 & 0.027295 & -2.95091 & 0.004 \\ 0.019593 & 0.002908 & 6.73741 & 0.000 \\ -0.097277 & 0.033272 & -2.92368 & 0.004 \\ 0.022243 & 0.026810 & 0.82965 & 0.408 \\ -0.008995 & 0.019660 & -0.45754 & 0.648 \\ -0.001097 & 0.000705 & -1.55701 & 0.122 \\ 0.001396 & 0.003037 & 0.45961 & 0.647 \\ -0.015669 & 0.002766 & -5.66521 & 0.000 \\ -0.030801 & 0.012898 & -2.38799 & 0.019\end{array}$

$\begin{array}{rrr}95 \% & C I & V I F \\ (0.407588, & 0.829976) & \\ (-0.022730, & 0.014706) & 2.67760 \\ (-0.001654, & 0.010003) & 2.02911 \\ (0.109625, & 0.184589) & 1.69820 \\ (0.075723, & 0.191573) & 1.67842 \\ (-0.134598, & -0.026494) & 1.30966 \\ (0.013834, & 0.025352) & 3.34497 \\ (-0.163165, & -0.031389) & 3.26619 \\ (-0.030849, & 0.075335) & 2.90920 \\ (-0.047928, & 0.029938) & 2.28226 \\ (-0.002493, & 0.000298) & 4.28302 \\ (-0.004619, & 0.007411) & 1.52922 \\ (-0.021146, & -0.010192) & 1.26798 \\ (-0.056342, & -0.005259) & 1.22637\end{array}$

Summary of Model 


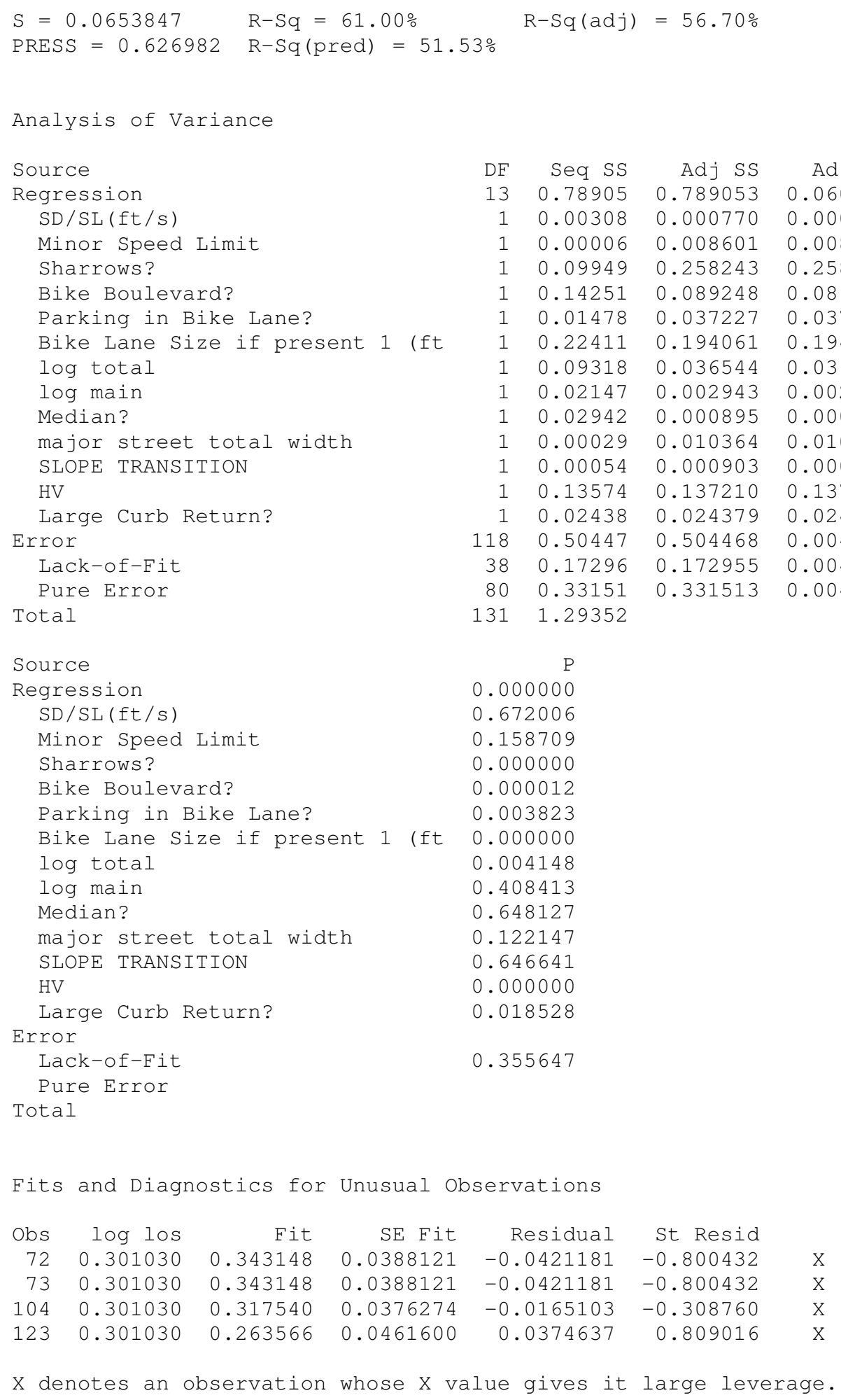

\section{Residual Plots for log los}




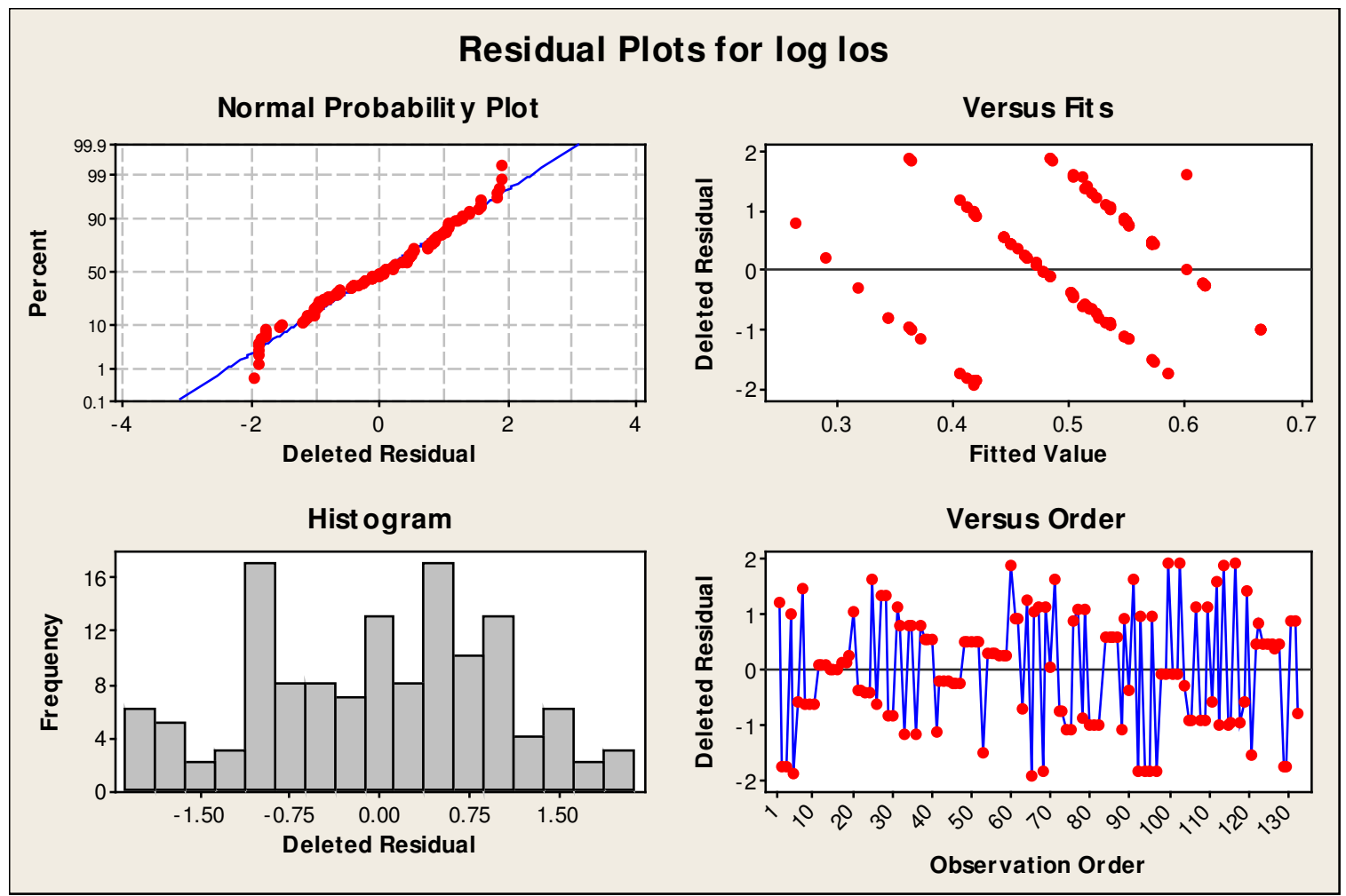

Combined Data Equation:

Best Subsets Regression: log los versus SD/SL(ft/s), Minor Speed , ...

Response is log los

334 cases used, 4 cases contain missing values

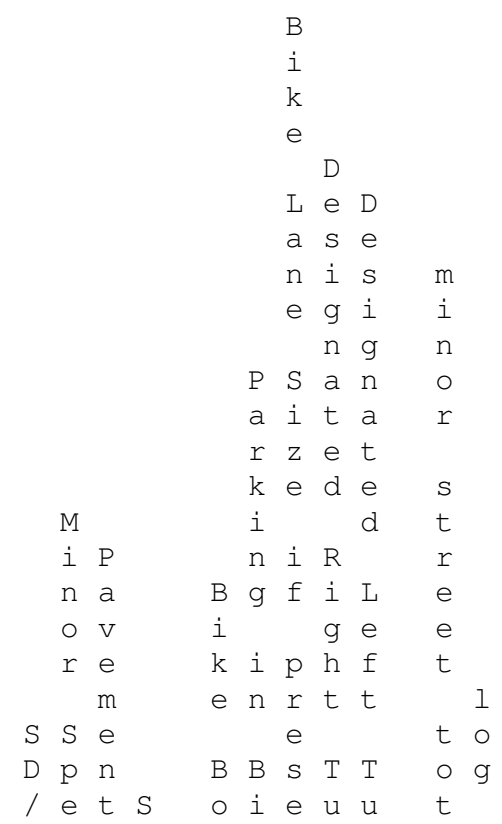




\begin{tabular}{|c|c|c|c|c|c|c|c|c|c|c|c|c|c|c|c|c|}
\hline & & & allows & & $\mathrm{s}$ & $i$ & t & $\mathrm{s}$ & e & & & e & e & $\mathrm{n}$ & t & C \\
\hline Vars & $\mathrm{R}-\mathrm{Sq}$ & $R-S q(a d j)$ & $\mathrm{Cp}$ & $\mathrm{S}$ & ) & t & $\mathrm{y}$ & $?$ & $?$ & ? & & ? & ? & ? & h & t \\
\hline 1 & 9.9 & 9.6 & 129.8 & 0.13112 & & & & & $\mathrm{X}$ & & & & & & & \\
\hline 1 & 6.8 & 6.5 & 145.7 & 0.13336 & & & $\mathrm{X}$ & & & & & & & & & \\
\hline 2 & 17.1 & 16.6 & 95.0 & 0.12595 & & & & & X & & & & & & $\mathrm{X}$ & \\
\hline 2 & 16.8 & 16.3 & 96.5 & 0.12618 & & & $\mathrm{X}$ & & $\mathrm{X}$ & & & & & & & \\
\hline 3 & 20.9 & 20.2 & 77.3 & 0.12317 & & & $\mathrm{X}$ & & $\mathrm{X}$ & & & & & & $\mathrm{X}$ & \\
\hline 3 & 20.3 & 19.6 & 80.7 & 0.12368 & & & & $\mathrm{X}$ & & & & $\mathrm{z}$ & & & $X$ & $\mathrm{X}$ \\
\hline 4 & 25.2 & 24.3 & 57.5 & 0.11998 & & & & $\mathrm{X}$ & & $x$ & & Y & & & $x$ & $\mathrm{x}$ \\
\hline 4 & 23.2 & 22.2 & 68.0 & 0.12161 & & & $\mathrm{X}$ & & $\mathrm{X}$ & & & z & $\mathrm{X}$ & & & \\
\hline 5 & 27.7 & 26.6 & 47.0 & 0.11818 & & & $\mathrm{X}$ & $\mathrm{X}$ & & $x$ & & $\mathrm{z}$ & $\mathrm{X}$ & & & \\
\hline 5 & 27.6 & 26.5 & 47.2 & 0.11821 & & & & $\mathrm{X}$ & & $x>2-2 y$ & & $\mathrm{x}$ & & & $x$ & $x$ \\
\hline 6 & 30.8 & 29.5 & 33.0 & 0.11576 & & & & $\mathrm{X}$ & & $x>$ & & Y & & $\mathrm{X}$ & 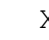 & $x$ \\
\hline 6 & 30.5 & 29.2 & 34.5 & 0.11601 & & & $\mathrm{X}$ & $\mathrm{X}$ & & $x>2-200$ & & $\mathrm{z}$ & $\mathrm{X}$ & & & \\
\hline 7 & 32.3 & 30.9 & 27.1 & 0.11463 & & & $\mathrm{x}$ & $\mathrm{X}$ & & $x>$ & & Y & $\mathrm{X}$ & & $\mathrm{X}$ & \\
\hline 7 & 32.3 & 30.9 & 27.1 & 0.11464 & & & $\mathrm{X}$ & $\mathrm{X}$ & & $x>$ & & Y & $\mathrm{X}$ & $\mathrm{X}$ & & \\
\hline 8 & 33.9 & 32.3 & 21.0 & 0.11346 & & & $\mathrm{X}$ & $\mathrm{X}$ & X & $x>2-200$ & & $\mathrm{x}$ & $\mathrm{X}$ & & $\mathrm{X}$ & \\
\hline 8 & 33.8 & 32.2 & 21.8 & 0.11358 & & & $\mathrm{X}$ & $\mathrm{X}$ & & $x>2-2 y$ & & $\mathrm{x}$ & $\mathrm{X}$ & $\mathrm{X}$ & $\mathrm{X}$ & \\
\hline 9 & 35.1 & 33.3 & 16.9 & 0.11260 & & & $\mathrm{X}$ & $\mathrm{X}$ & $\mathrm{X}$ & $x>2-2 y$ & & $\mathrm{r}$ & $\mathrm{X}$ & $\mathrm{X}$ & $\mathrm{X}$ & \\
\hline 9 & 35.0 & 33.2 & 17.4 & 0.11268 & $\mathrm{X}$ & $\mathrm{X}$ & & $\mathrm{X}$ & & $x>2-200$ & & $\mathrm{~K}$ & $\mathrm{X}$ & $\mathrm{X}$ & $\mathrm{r}$ & $\mathrm{X}$ \\
\hline 10 & 35.9 & 33.9 & 15.0 & 0.11209 & $\mathrm{X}$ & $\mathrm{X}$ & & $\mathrm{X}$ & & $\mathrm{x}$ & & $\mathrm{z}$ & $\mathrm{X}$ & $\mathrm{X}$ & $\times 2$ & $\mathrm{X}$ \\
\hline 10 & 35.7 & 33.8 & 15.8 & 0.11223 & $\mathrm{X}$ & & $\mathrm{x}$ & $\mathrm{X}$ & $\mathrm{X}$ & $x$ & & Y & $\mathrm{X}$ & $\mathrm{X}$ & $\mathrm{X}$ & \\
\hline 11 & 36.7 & 34.6 & 12.7 & 0.11153 & $\mathrm{X}$ & $\mathrm{X}$ & X & $\mathrm{X}$ & X & $x>$ & & $\mathrm{x}$ & $\mathrm{X}$ & $\mathrm{X}$ & $\mathrm{X}$ & \\
\hline 11 & 36.5 & 34.3 & 14.1 & 0.11178 & $\mathrm{X}$ & $\mathrm{x}$ & X & $\mathrm{X}$ & & $\times>$ & & r & $\mathrm{X}$ & $\mathrm{X}$ & X 2 & $\mathrm{x}$ \\
\hline 12 & 37.2 & 34.9 & 12.2 & 0.11127 & $\mathrm{X}$ & $\mathrm{x}$ & $\mathrm{X}$ & $\mathrm{X}$ & $\mathrm{X}$ & $\times>$ & & r & $\mathrm{X}$ & $\mathrm{X}$ & X 2 & $\mathrm{x}$ \\
\hline 12 & 36.8 & 34.4 & 14.6 & 0.11170 & $\mathrm{X}$ & $\mathrm{X}$ & X & $\mathrm{X}$ & X & $x$ & & $8 x$ & $\mathrm{X}$ & $\mathrm{X}$ & $\mathrm{X}$ & \\
\hline 13 & 37.3 & 34.7 & 14.0 & 0.11141 & $\mathrm{X}$ & $\mathrm{X}$ & $\mathrm{X}$ & $\mathrm{X}$ & $\mathrm{X}$ & $x>$ & & $x \quad x$ & $\mathrm{X}$ & $\mathrm{X}$ & $\mathrm{X}$ & $\mathrm{X}$ \\
\hline
\end{tabular}

\section{General Regression Analysis: log los versus SD/SL(ft/s), Minor Speed , ...}

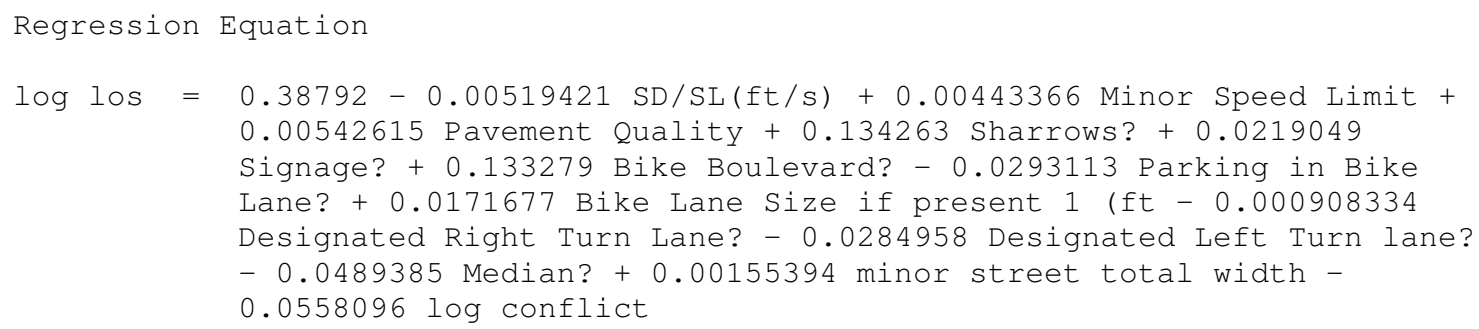

283 cases used, 4 cases contain missing values

Coefficients

$\begin{array}{lrrrr}\text { Term } & \text { Coef } & \text { SE Coef } & \text { T } & P \\ \text { Constant } & 0.387920 & 0.0604794 & 6.4141 & 0.000 \\ \text { SD/SL (ft/s) } & -0.005194 & 0.0043009 & -1.2077 & 0.228 \\ \text { Minor Speed Limit } & 0.004434 & 0.0014529 & 3.0516 & 0.003 \\ \text { Pavement Quality } & 0.005426 & 0.0071595 & 0.7579 & 0.449 \\ \text { Sharrows? } & 0.134263 & 0.0132480 & 10.1346 & 0.000 \\ \text { Signage? } & 0.021905 & 0.0091271 & 2.4000 & 0.017 \\ \text { Bike Boulevard? } & 0.133279 & 0.0190255 & 7.0053 & 0.000 \\ \text { Parking in Bike Lane? } & -0.029311 & 0.0171419 & -1.7099 & 0.088\end{array}$




$\begin{array}{lrrrr}\text { Bike Lane Size if present 1 (ft } & 0.017168 & 0.0015781 & 10.8786 & 0.000 \\ \text { Designated Right Turn Lane? } & -0.000908 & 0.0215296 & -0.0422 & 0.966 \\ \text { Designated Left Turn lane? } & -0.028496 & 0.0103896 & -2.7427 & 0.007 \\ \text { Median? } & -0.048939 & 0.0112300 & -4.3578 & 0.000 \\ \text { minor street total width } & 0.001554 & 0.0006505 & 2.3890 & 0.018 \\ \text { log conflict } & -0.055810 & 0.0140681 & -3.9671 & 0.000 \\ & & & \\ \text { Term } & 95 \% & \text { CI } & \\ \text { Constant } & (0.268847, & 0.506993) & \\ \text { SD/SL(ft/s) } & (-0.013662, & 0.003274) & 1.54680 \\ \text { Minor Speed Limit } & (0.001573, & 0.007294) & 1.72373 \\ \text { Pavement Quality } & (-0.008670, & 0.019522) & 1.90245 \\ \text { Sharrows? } & (0.108180, & 0.160346) & 2.13560 \\ \text { Signage? } & (0.003935, & 0.039875) & 1.66025 \\ \text { Bike Boulevard? } & (0.095822, & 0.170737) & 1.45249 \\ \text { Parking in Bike Lane? } & (-0.063061, & 0.004438) & 1.32638 \\ \text { Bike Lane Size if present 1 (ft } & (0.014061, & 0.020275) & 2.49603 \\ \text { Designated Right Turn Lane? } & (-0.043296, & 0.041480) & 1.50466 \\ \text { Designated Left Turn lane? } & (-0.048951, & -0.008041) & 2.10756 \\ \text { Median? } & (-0.071048,-0.026829) & 2.10432 \\ \text { minor street total width } & (0.000273, & 0.002835) & 1.59391 \\ \text { log conflict } & (-0.083507, & -0.028112) & 2.23475\end{array}$

Summary of Model

$\begin{array}{lll}S=0.0594975 & R-S q=59.05 \% & R-S q(\operatorname{adj})=57.08 \% \\ \text { PRESS }=1.04677 & R-S q(\text { pred })=54.99 \% & \end{array}$

Analysis of Variance

\begin{tabular}{|c|c|c|c|c|c|}
\hline Source & $\mathrm{DF}$ & Seq SS & Adj SS & Adj MS & $\mathrm{F}$ \\
\hline Regression & 13 & 1.37342 & 1.37342 & 0.105647 & 29.844 \\
\hline $\mathrm{SD} / \mathrm{SL}(\mathrm{ft} / \mathrm{s})$ & 1 & 0.02513 & 0.00516 & 0.005163 & 1.459 \\
\hline Minor Speed Limit & 1 & 0.02635 & 0.03296 & 0.032965 & 9.312 \\
\hline Pavement Quality & 1 & 0.10355 & 0.00203 & 0.002033 & 0.574 \\
\hline Sharrows? & 1 & 0.31694 & 0.36359 & 0.363586 & 102.709 \\
\hline Signage? & 1 & 0.23354 & 0.02039 & 0.020390 & 5.760 \\
\hline Bike Boulevard? & 1 & 0.11571 & 0.17372 & 0.173721 & 49.074 \\
\hline Parking in Bike Lane? & 1 & 0.01256 & 0.01035 & 0.010350 & 2.924 \\
\hline Bike Lane Size if present 1 (ft & 1 & 0.30166 & 0.41893 & 0.418931 & 118.344 \\
\hline Designated Right Turn Lane? & 1 & 0.00505 & 0.00001 & 0.000006 & 0.002 \\
\hline Designated Left Turn lane? & 1 & 0.08730 & 0.02663 & 0.026630 & 7.523 \\
\hline Median? & 1 & 0.04934 & 0.06723 & 0.067226 & 18.991 \\
\hline minor street total width & 1 & 0.04058 & 0.02020 & 0.020204 & 5.707 \\
\hline log conflict & 1 & 0.05571 & 0.05571 & 0.055711 & 15.738 \\
\hline Error & 269 & 0.95225 & 0.95225 & 0.003540 & \\
\hline Lack-of-Fit & 93 & 0.32956 & 0.32956 & 0.003544 & 1.002 \\
\hline Pure Error & 176 & 0.62268 & 0.62268 & 0.003538 & \\
\hline Total & 282 & 2.32566 & & & \\
\hline Source & & $\mathrm{P}$ & & & \\
\hline Regression & 0.0 & 0000 & & & \\
\hline $\mathrm{SD} / \mathrm{SL}(\mathrm{ft} / \mathrm{s})$ & 0.2 & 8224 & & & \\
\hline Minor speed Limit & 0.0 & 2504 & & & \\
\hline Pavement Quality & 0.4 & 9177 & & & \\
\hline Sharrows? & 0.0 & 0000 & & & \\
\hline Signage? & 0.0 & 7076 & & & \\
\hline Bike Boulevard? & 0.0 & 0000 & & & \\
\hline Parking in Bike Lane? & 0.0 & 8435 & & & \\
\hline Bike Lane Size if present 1 (ft & 0.0 & 0000 & & & \\
\hline Designated Right Turn Lane? & 0.9 & 6378 & & & \\
\hline
\end{tabular}




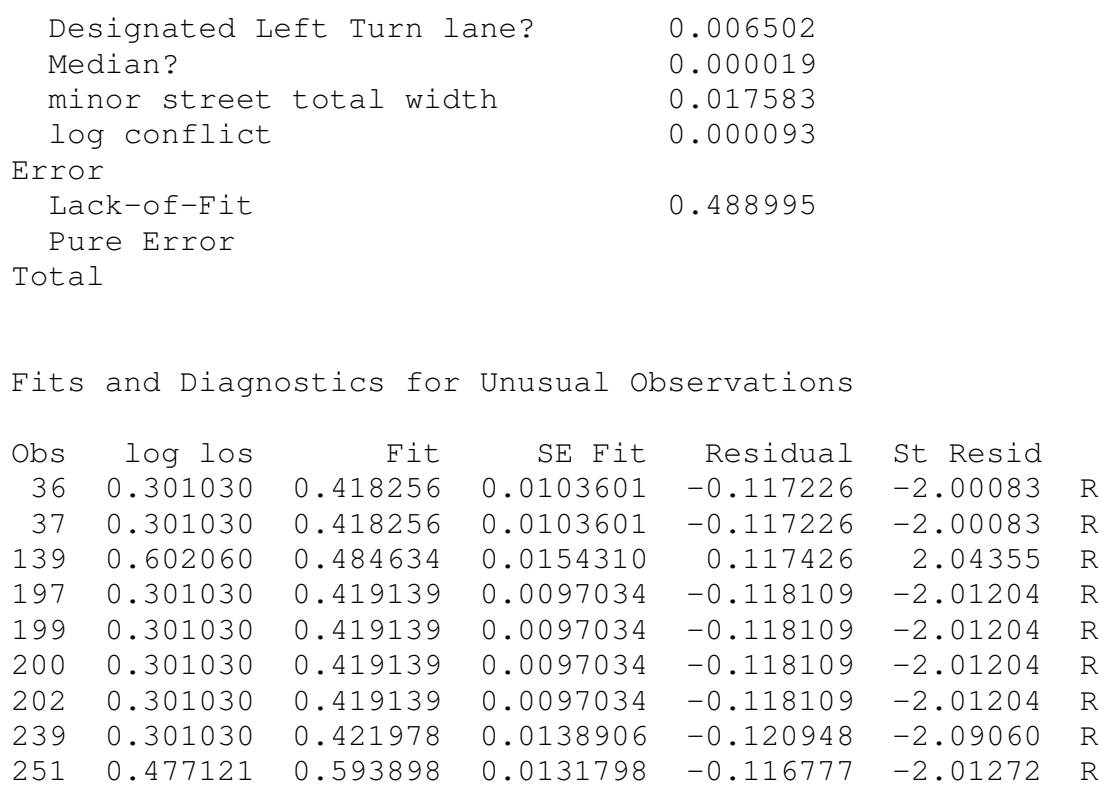

$\mathrm{R}$ denotes an observation with a large standardized residual.

\section{Residual Plots for log los}

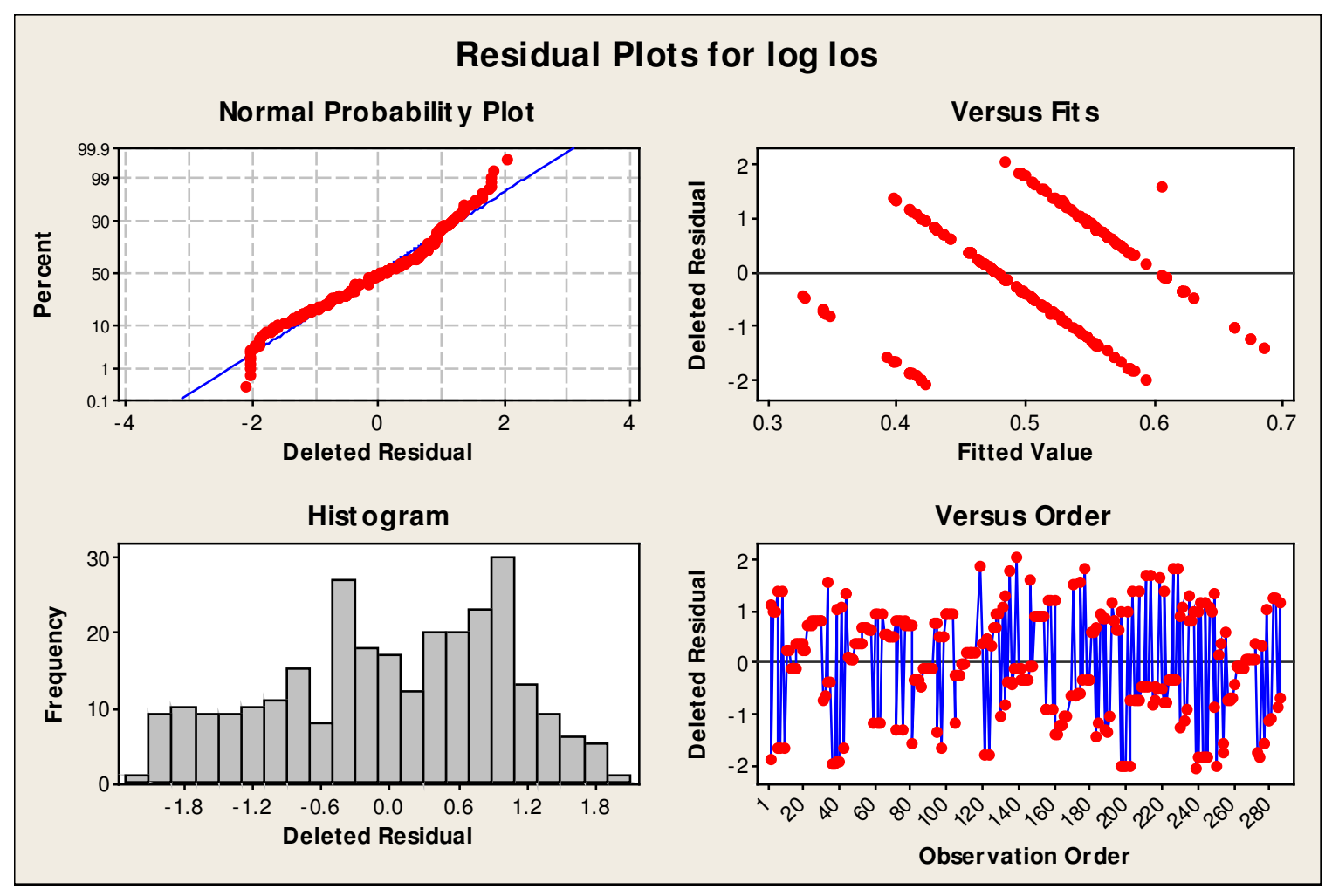




\section{Appendix M}

The following images are Google Earth ${ }^{\mathrm{TM}}$ screen shots of each surveyed intersection to clarify any confusion with the crude field drawings shown in the field data sheets provided in the above section. Please note that these images are only updated to the most recent Google Earth feed and some intersection images are out of date and do not show all current bicycle facilities present. 
Claremont Sites 


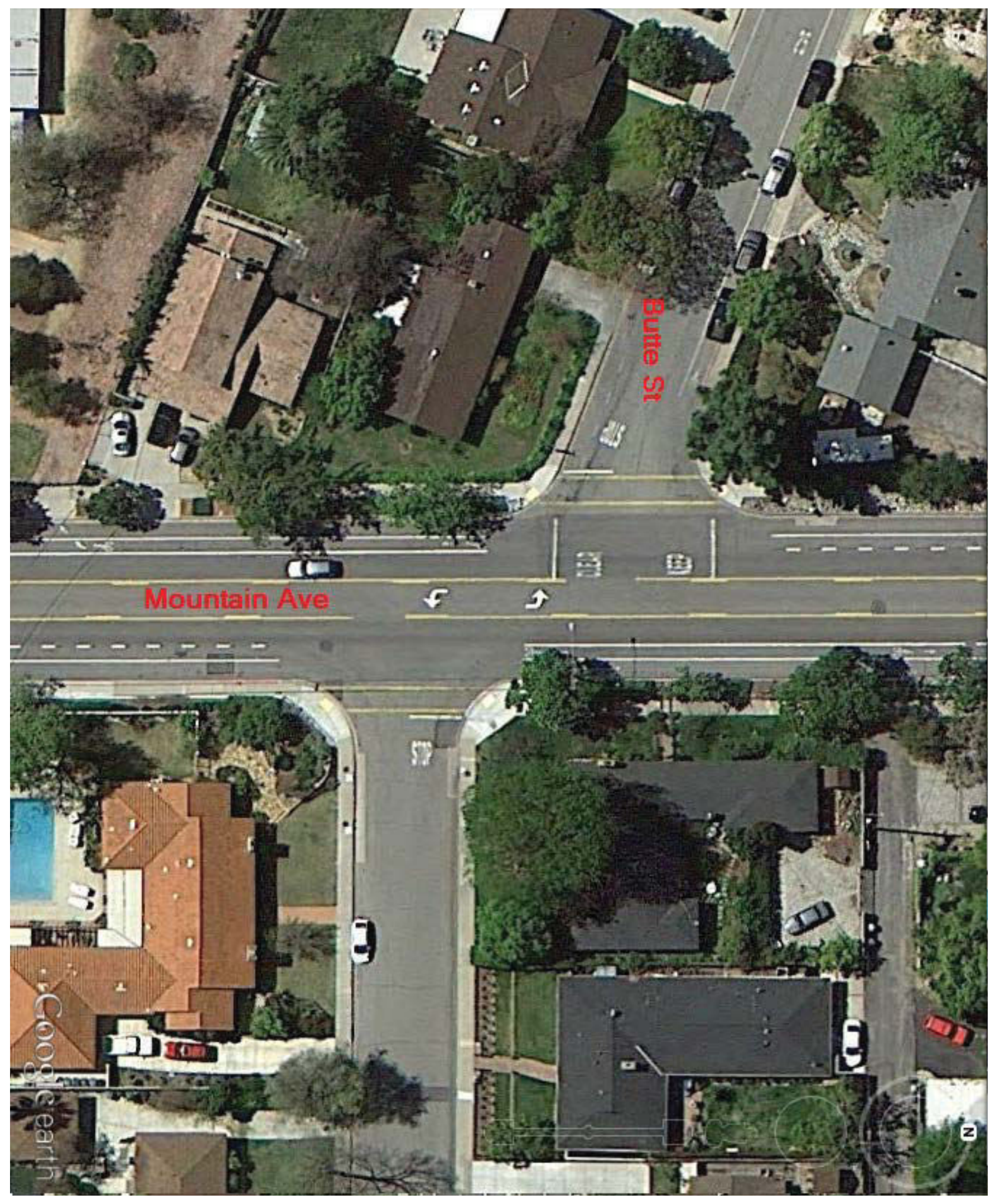




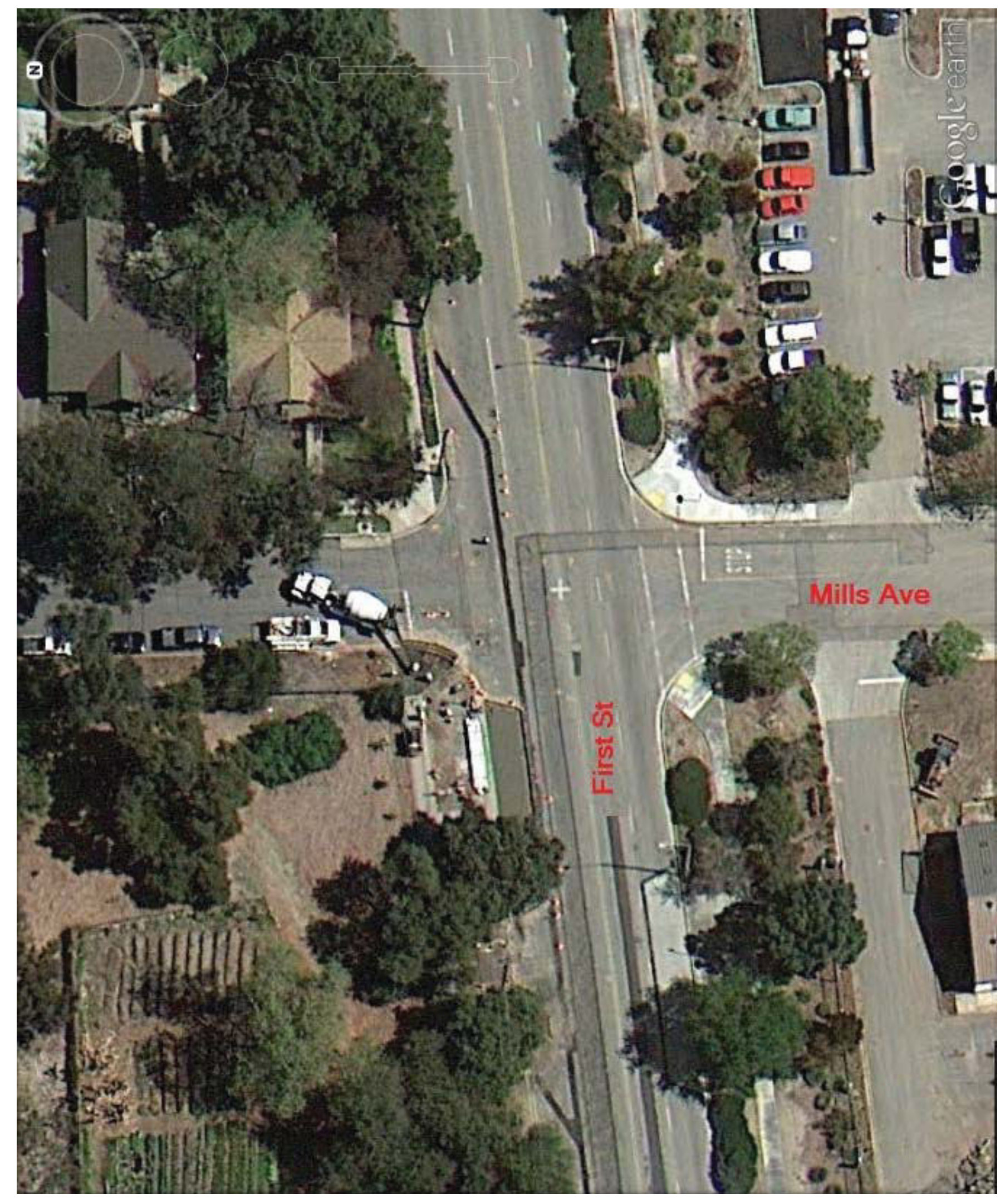




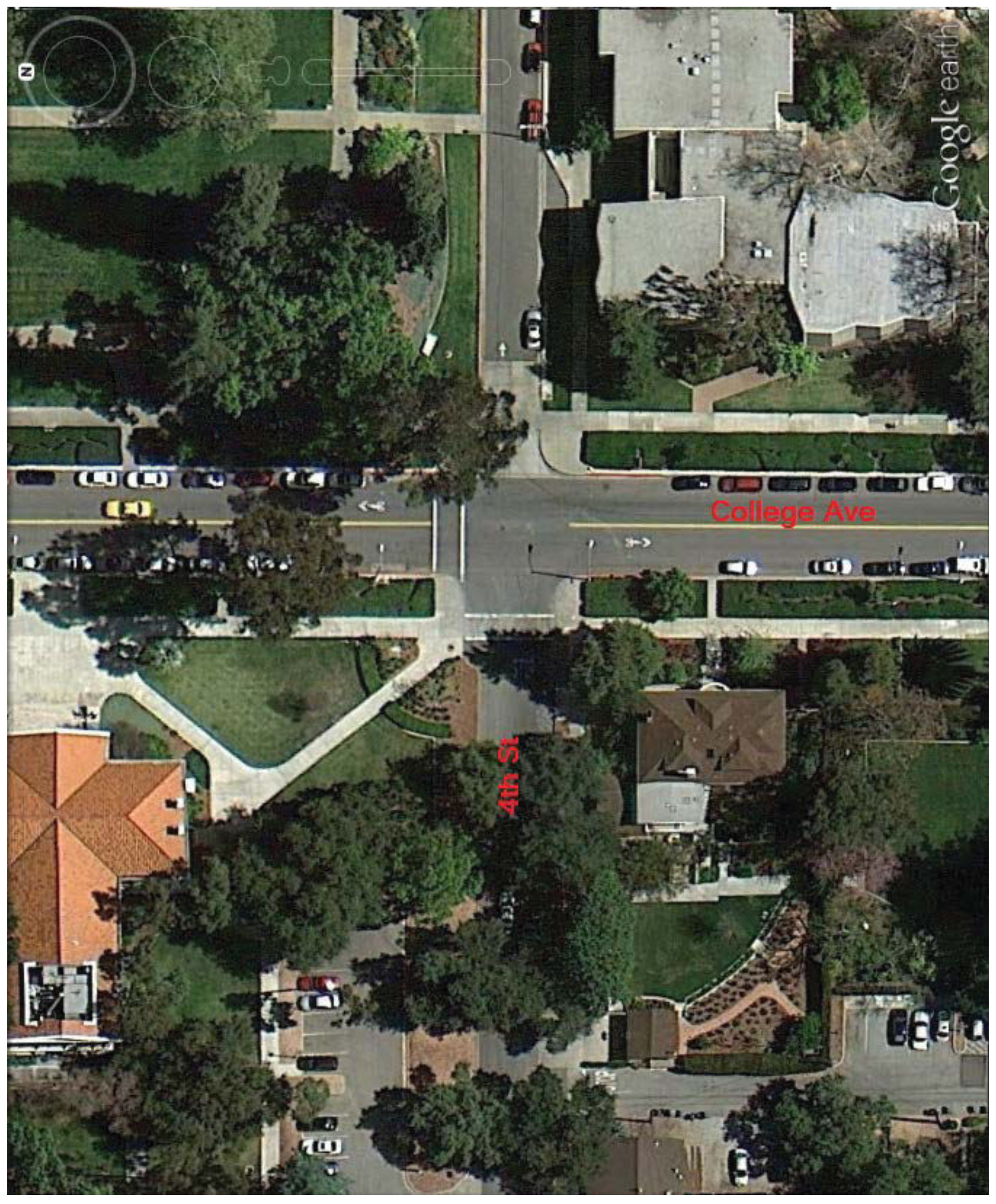




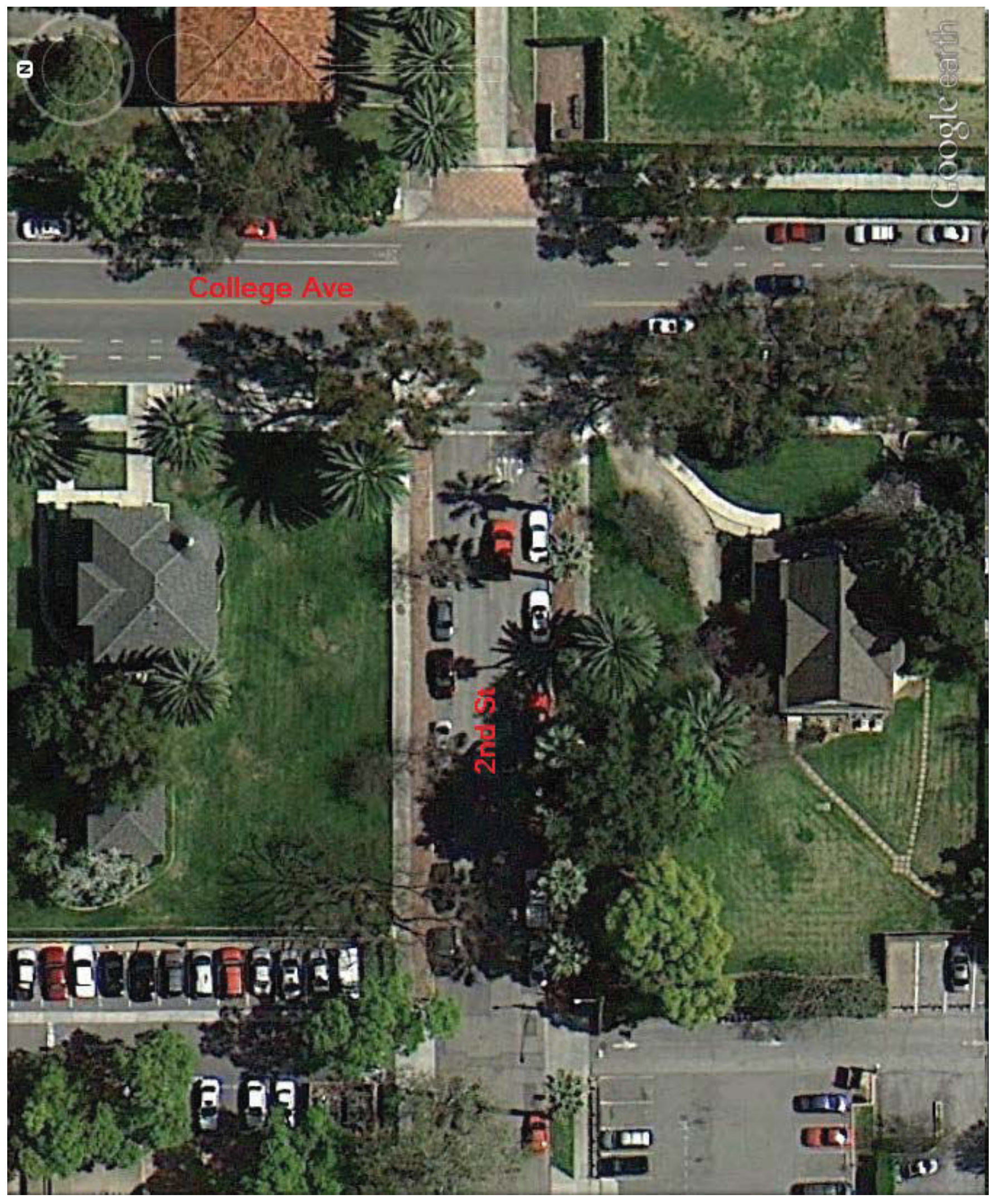




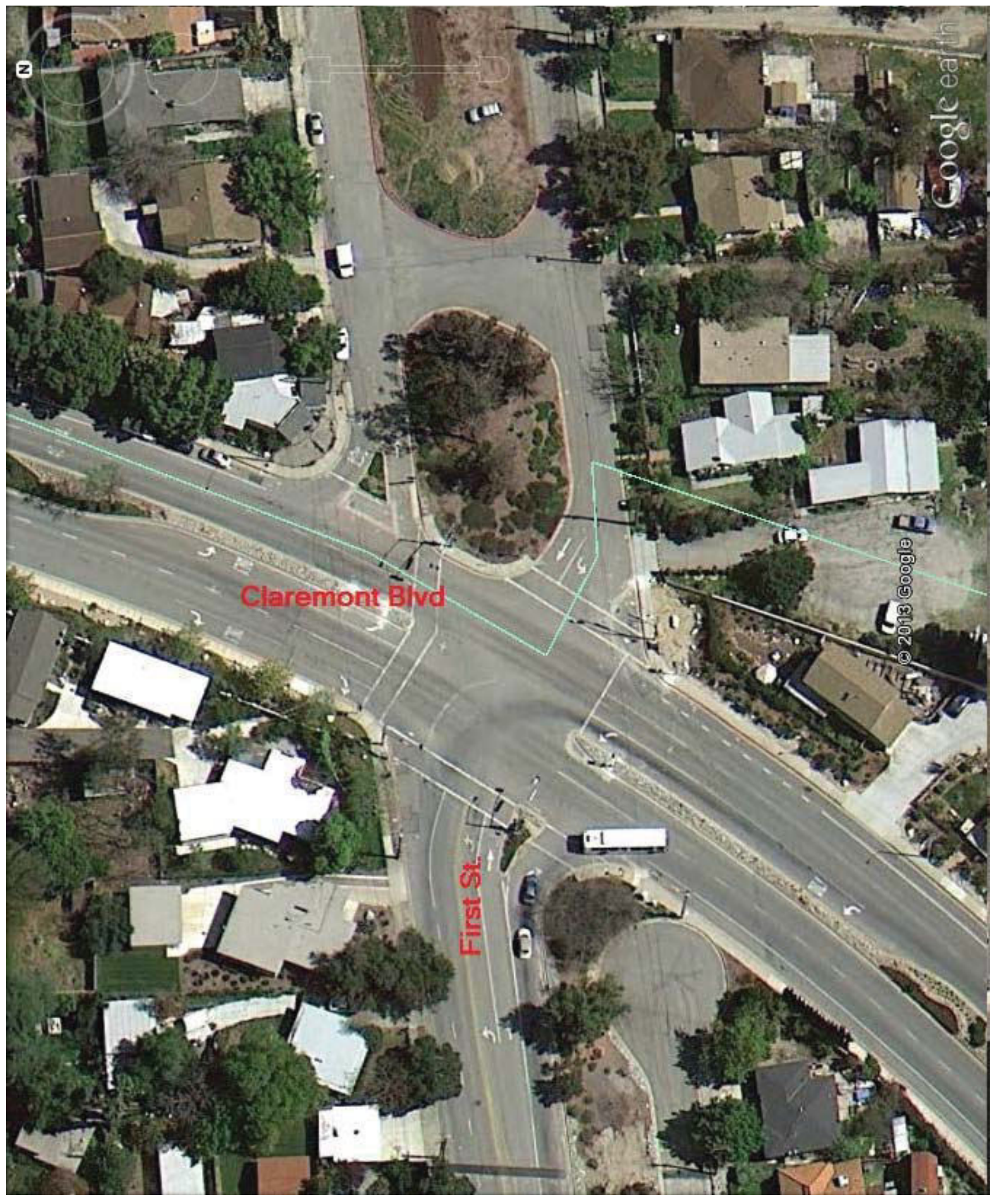




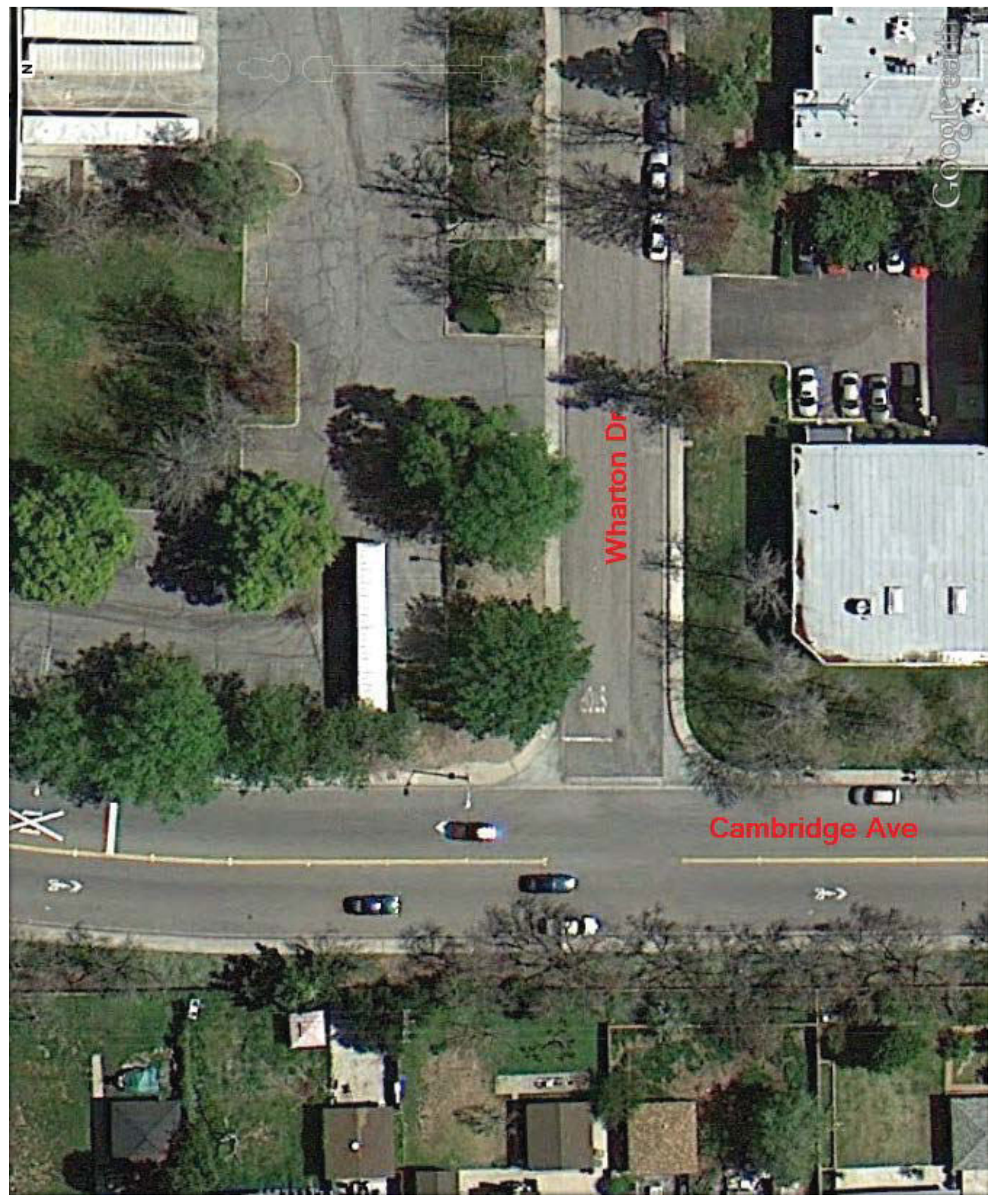




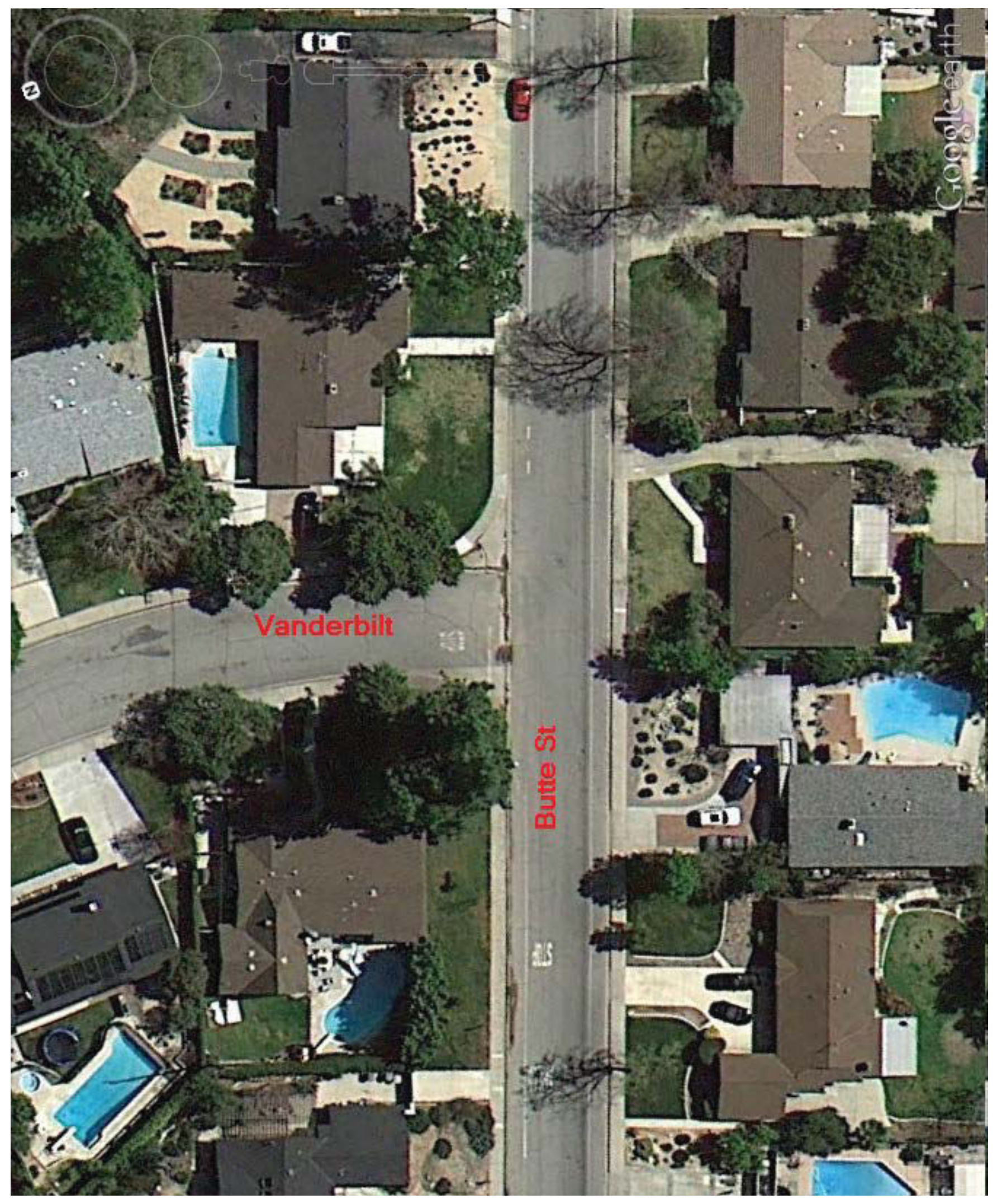




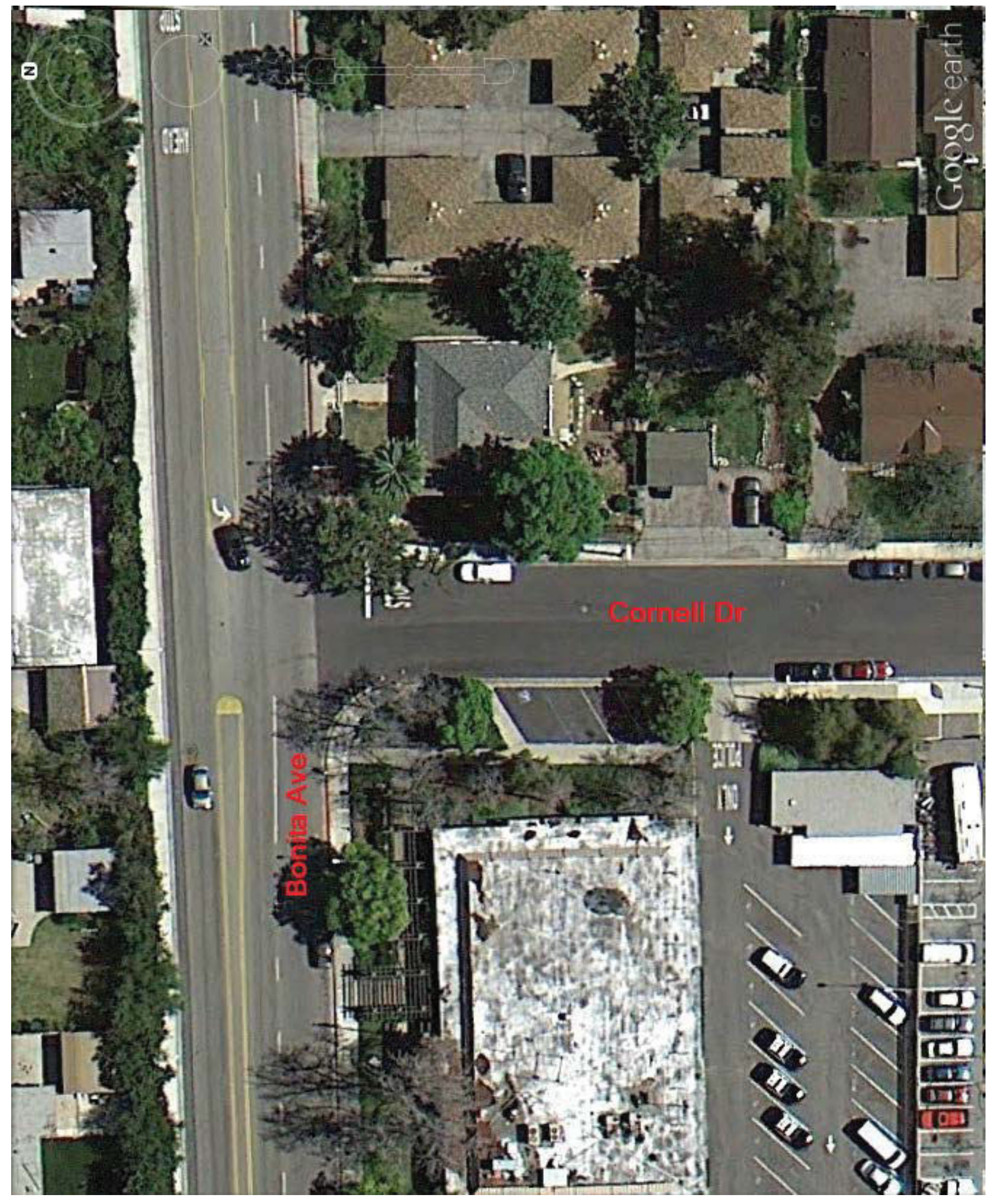




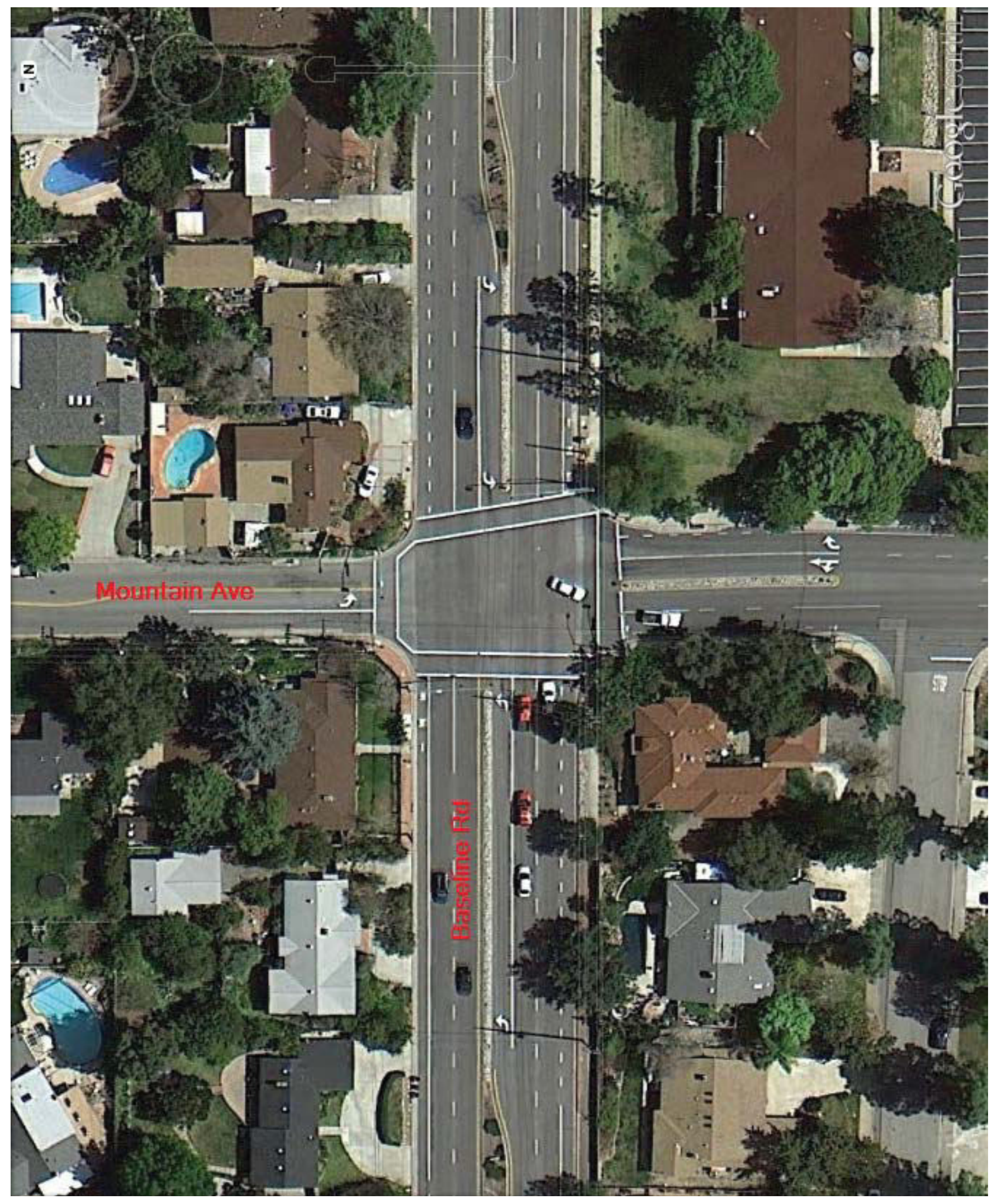




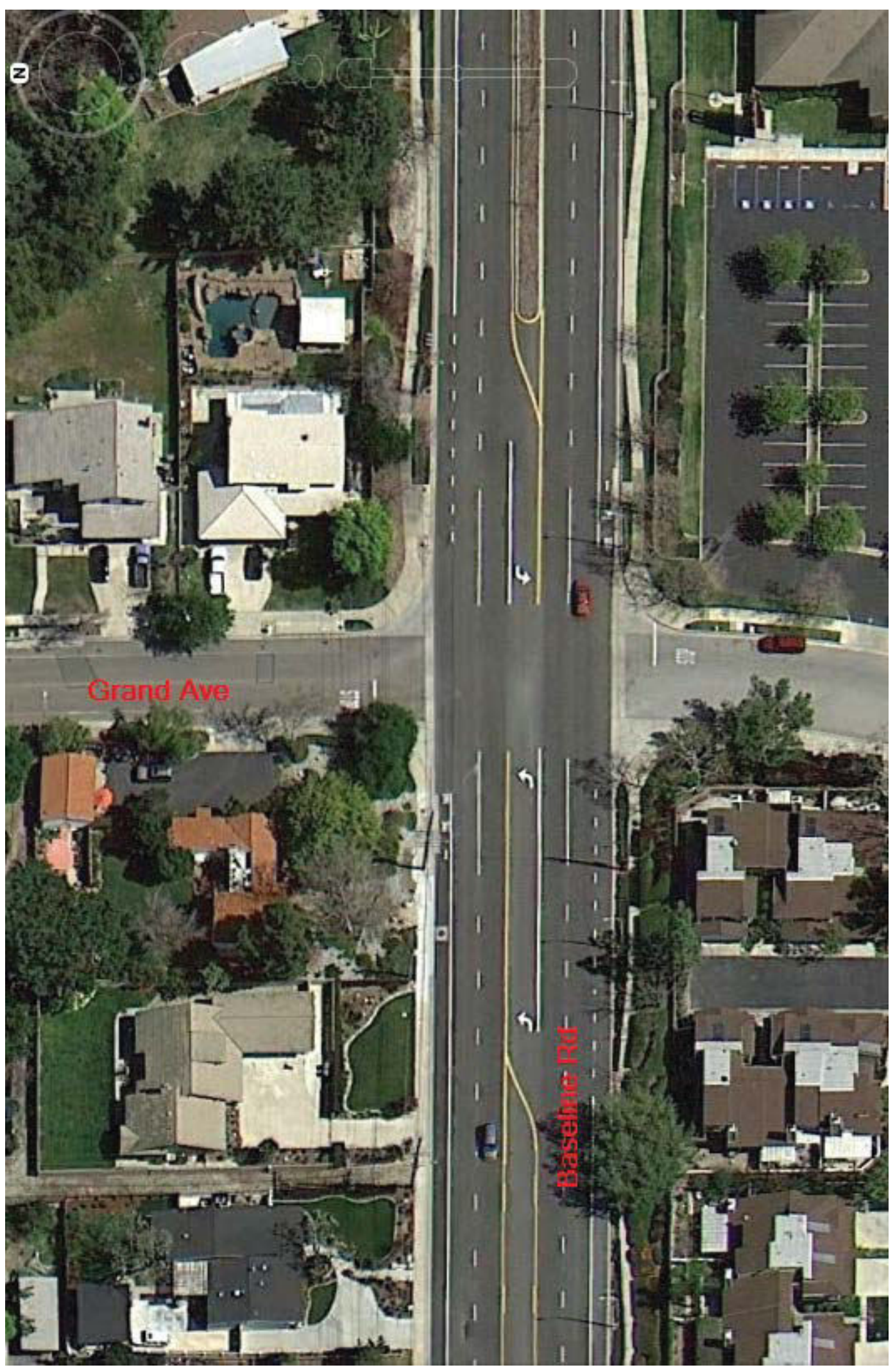




\section{Goleta Sites}




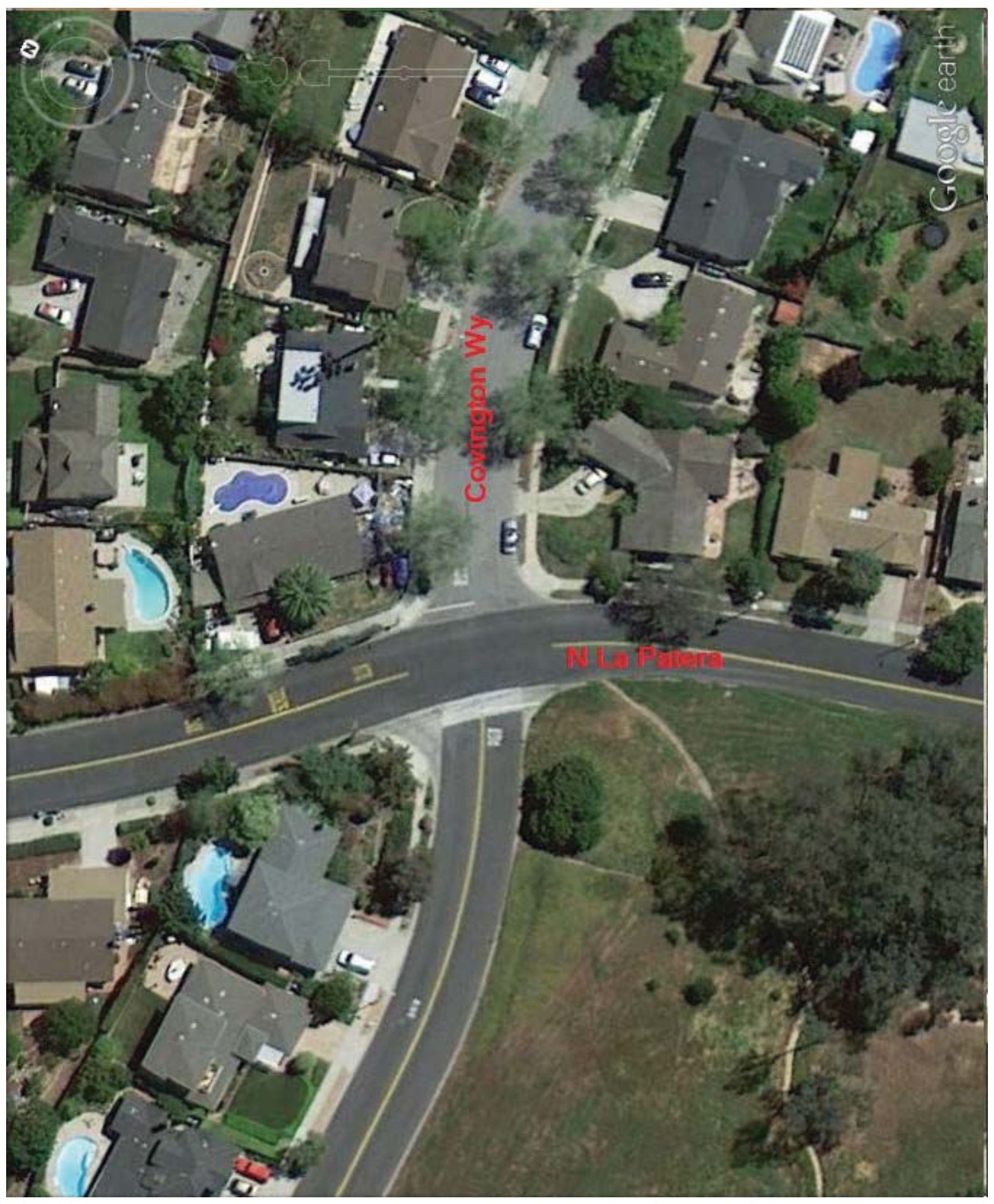




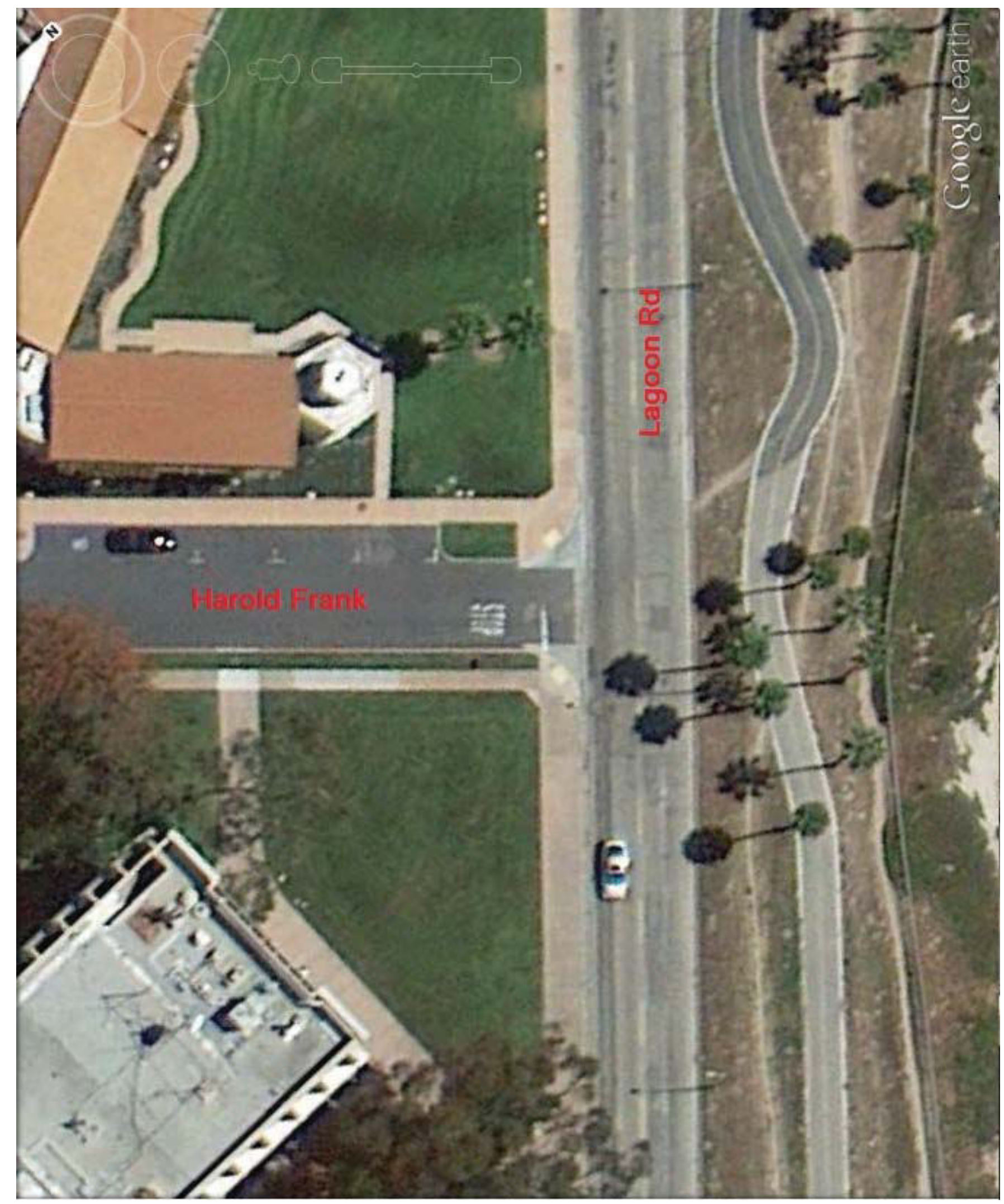




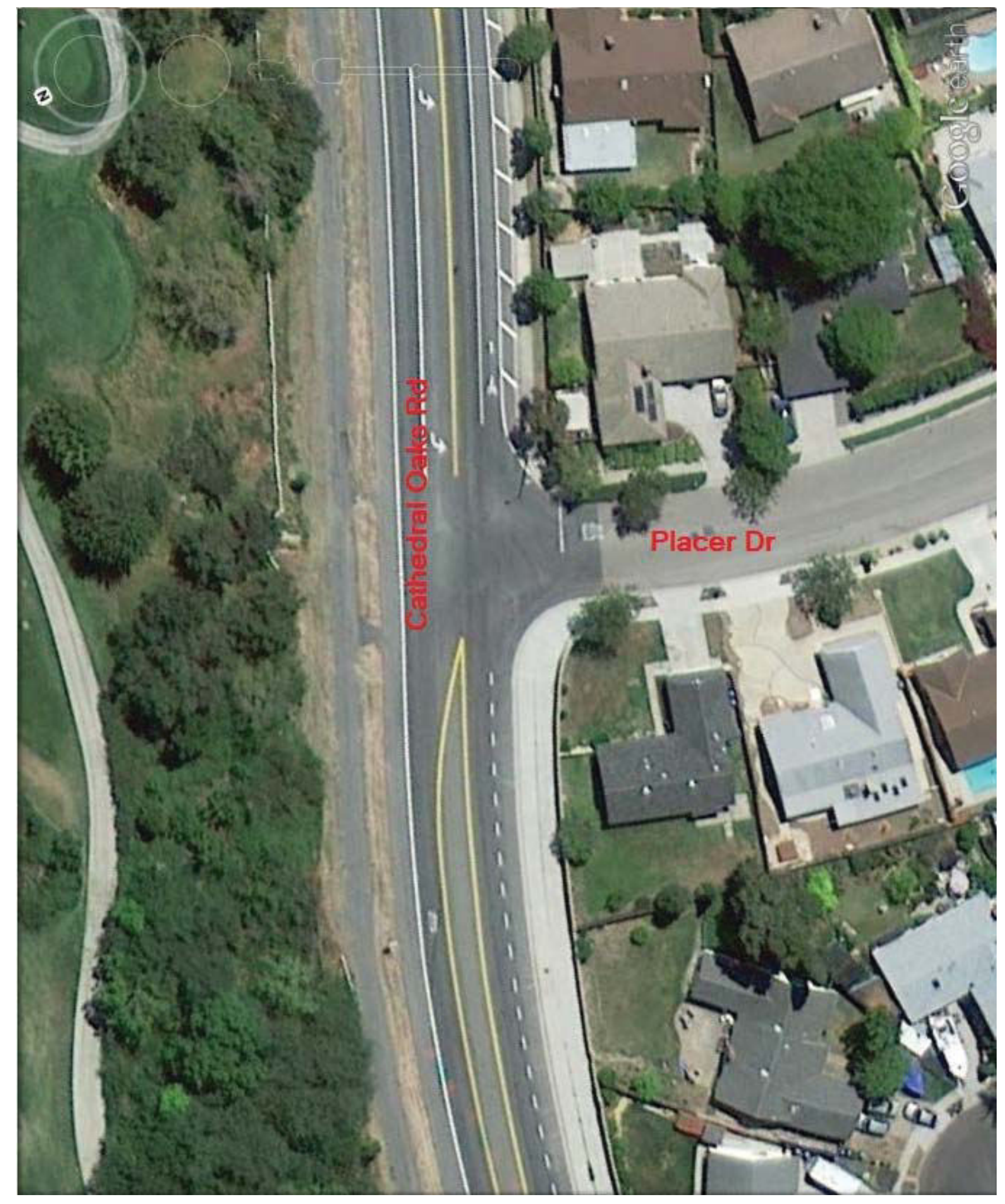




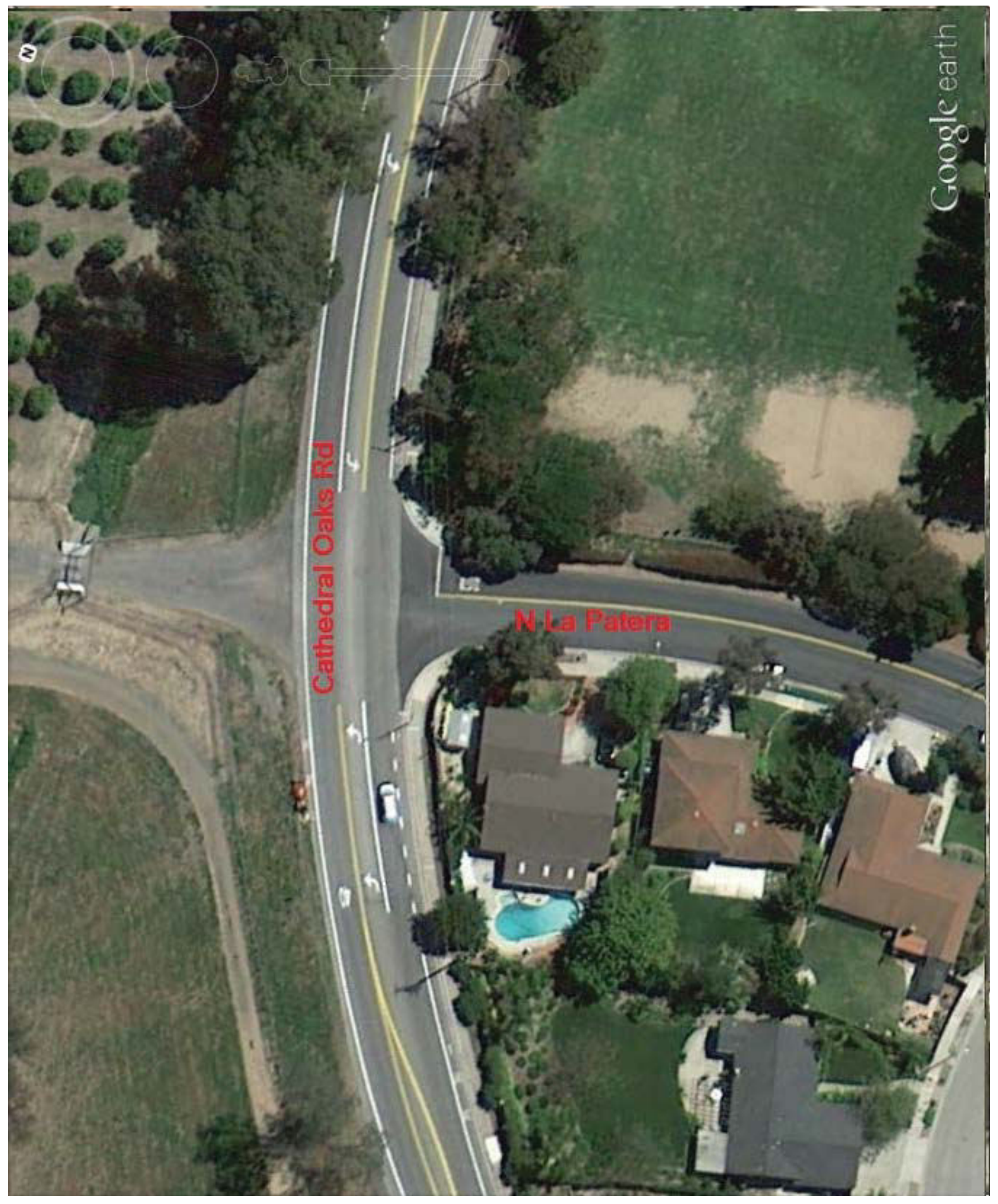




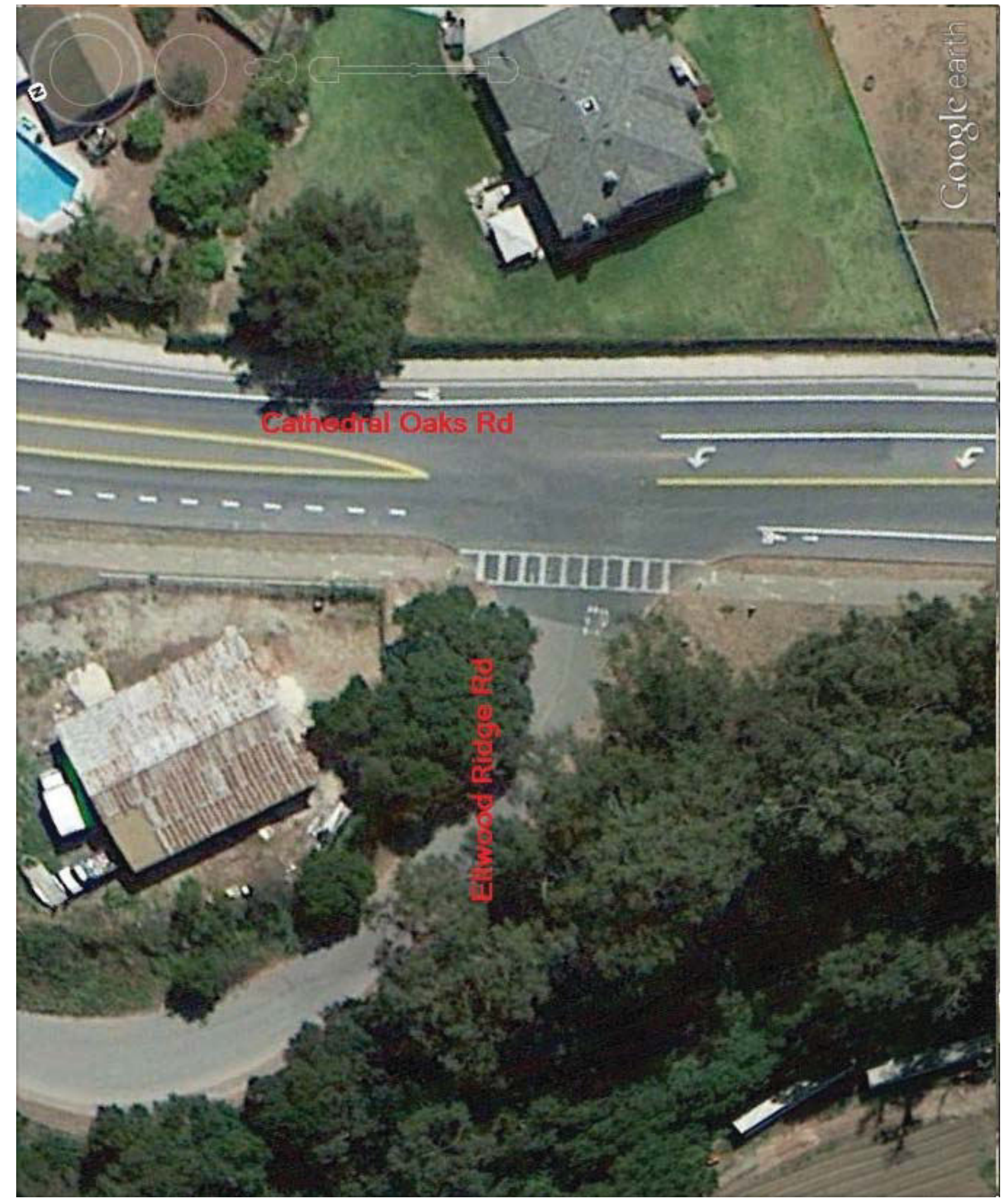


Irvine Sites 


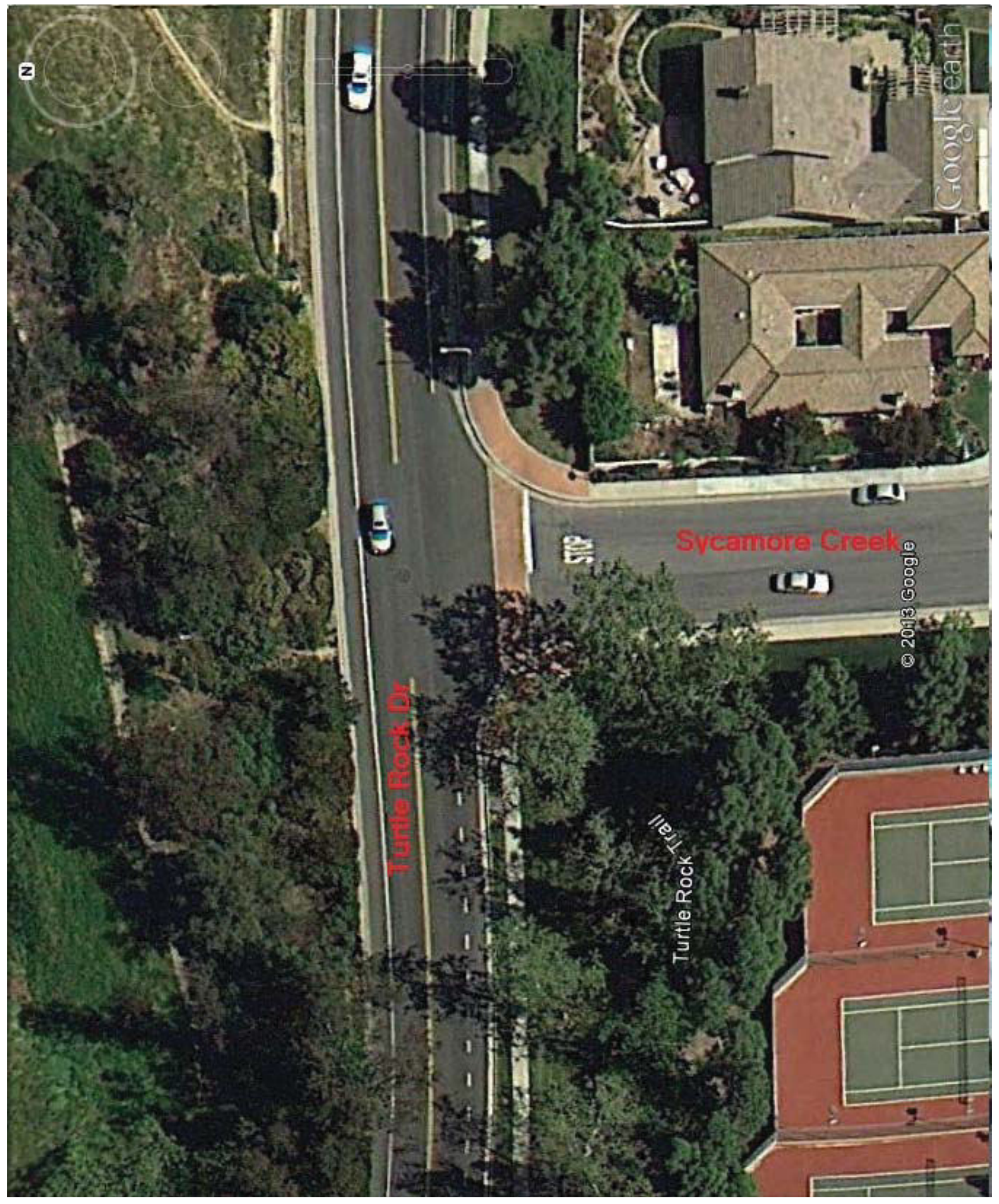




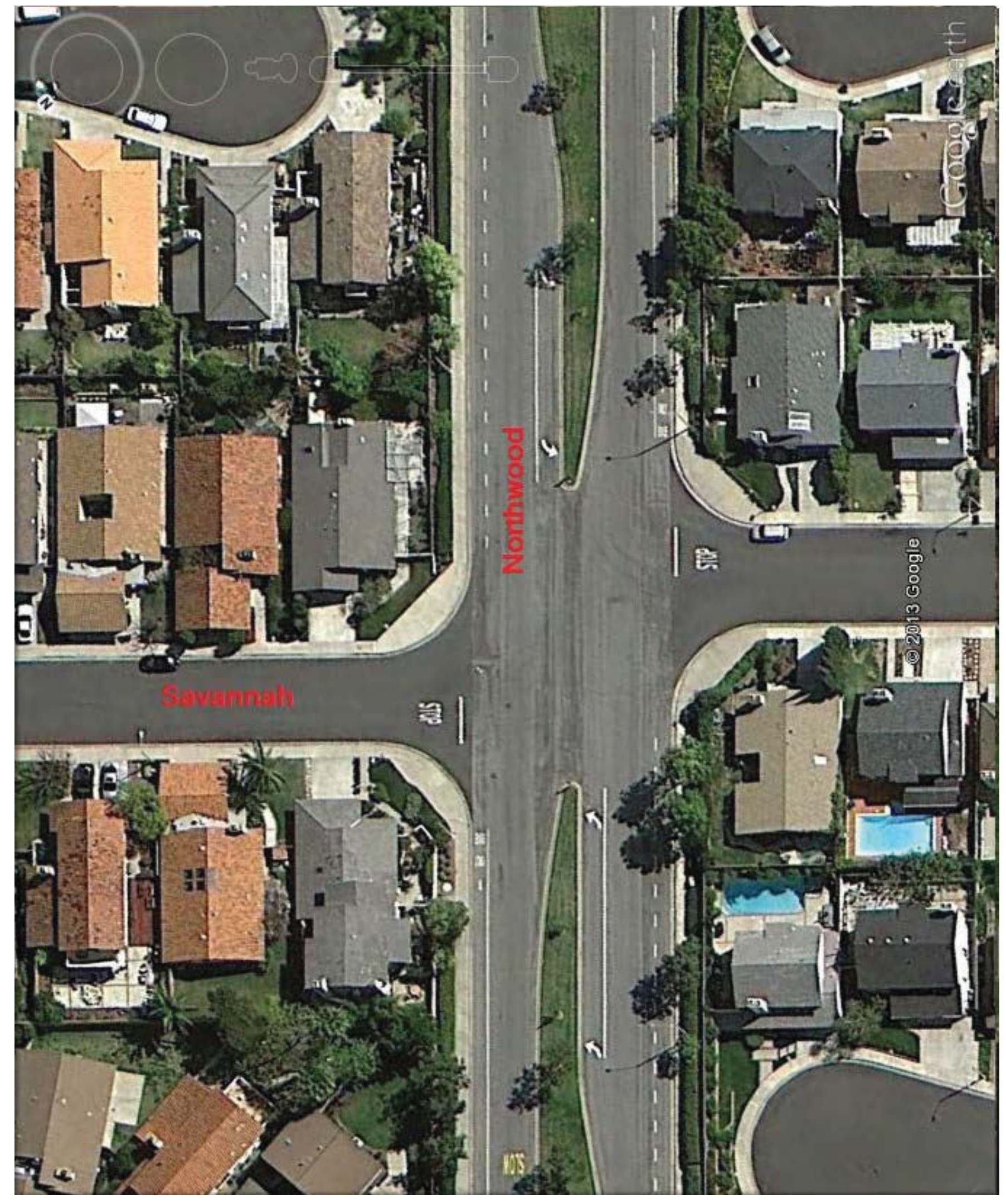




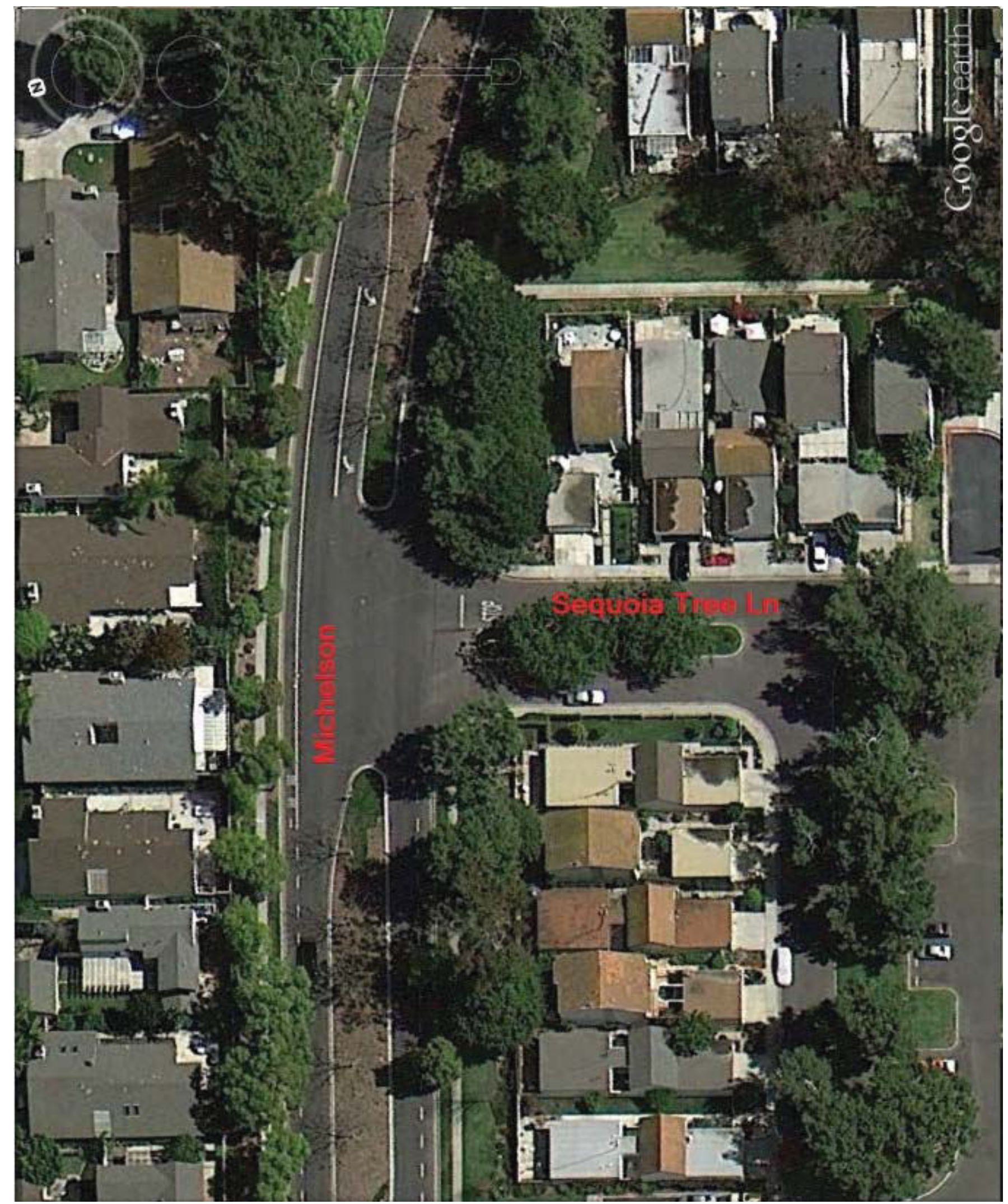




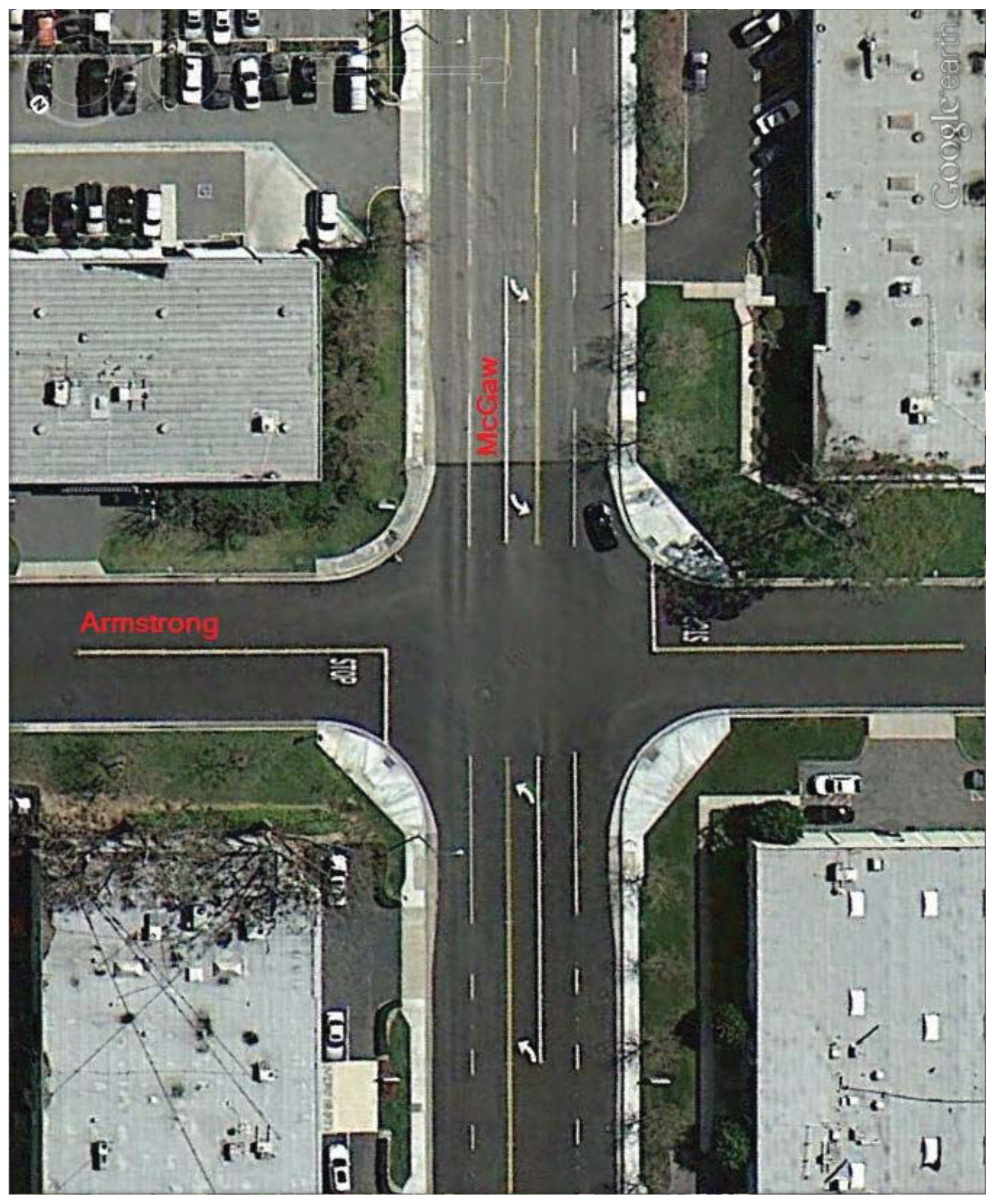




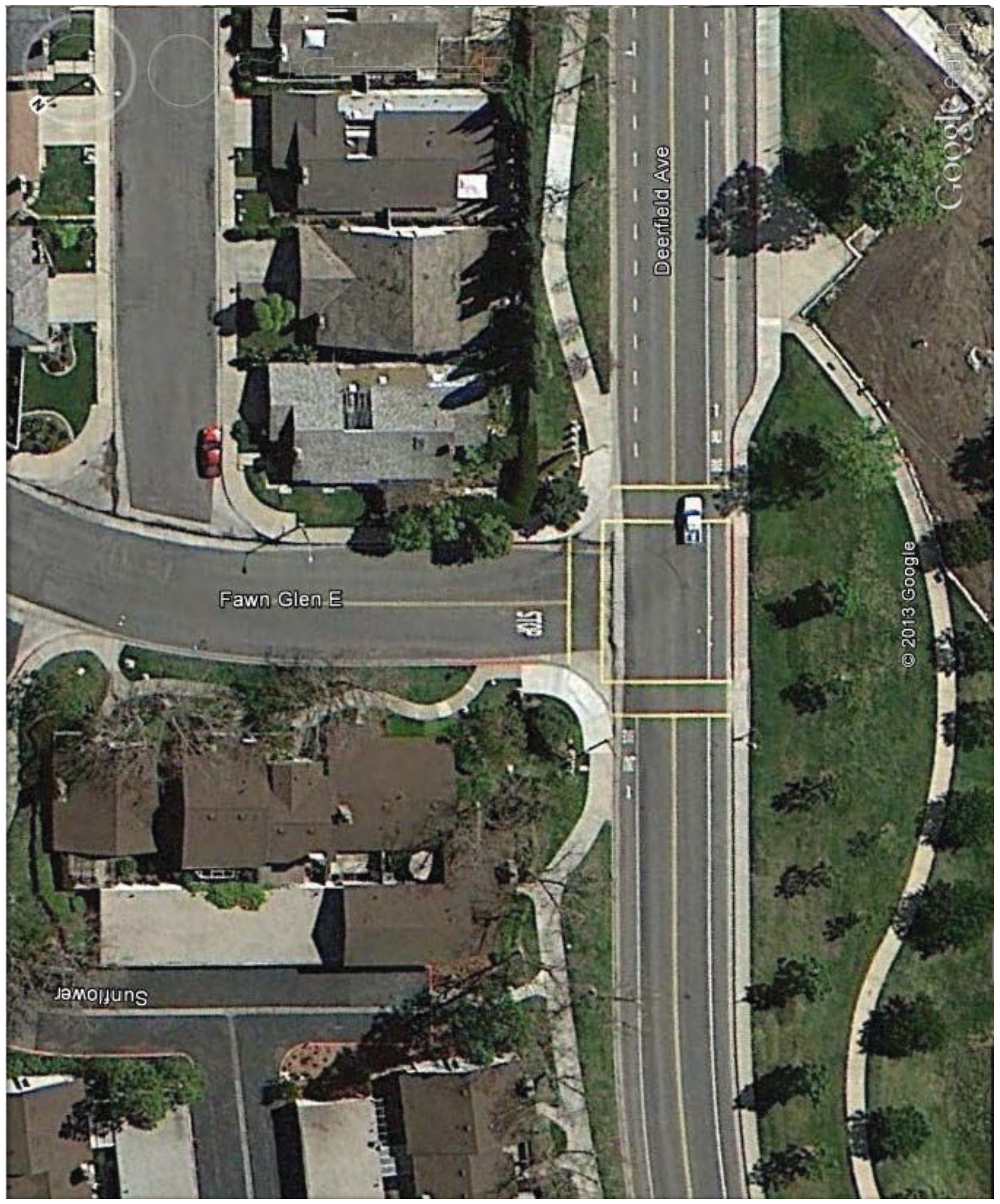


Riverside Sites 


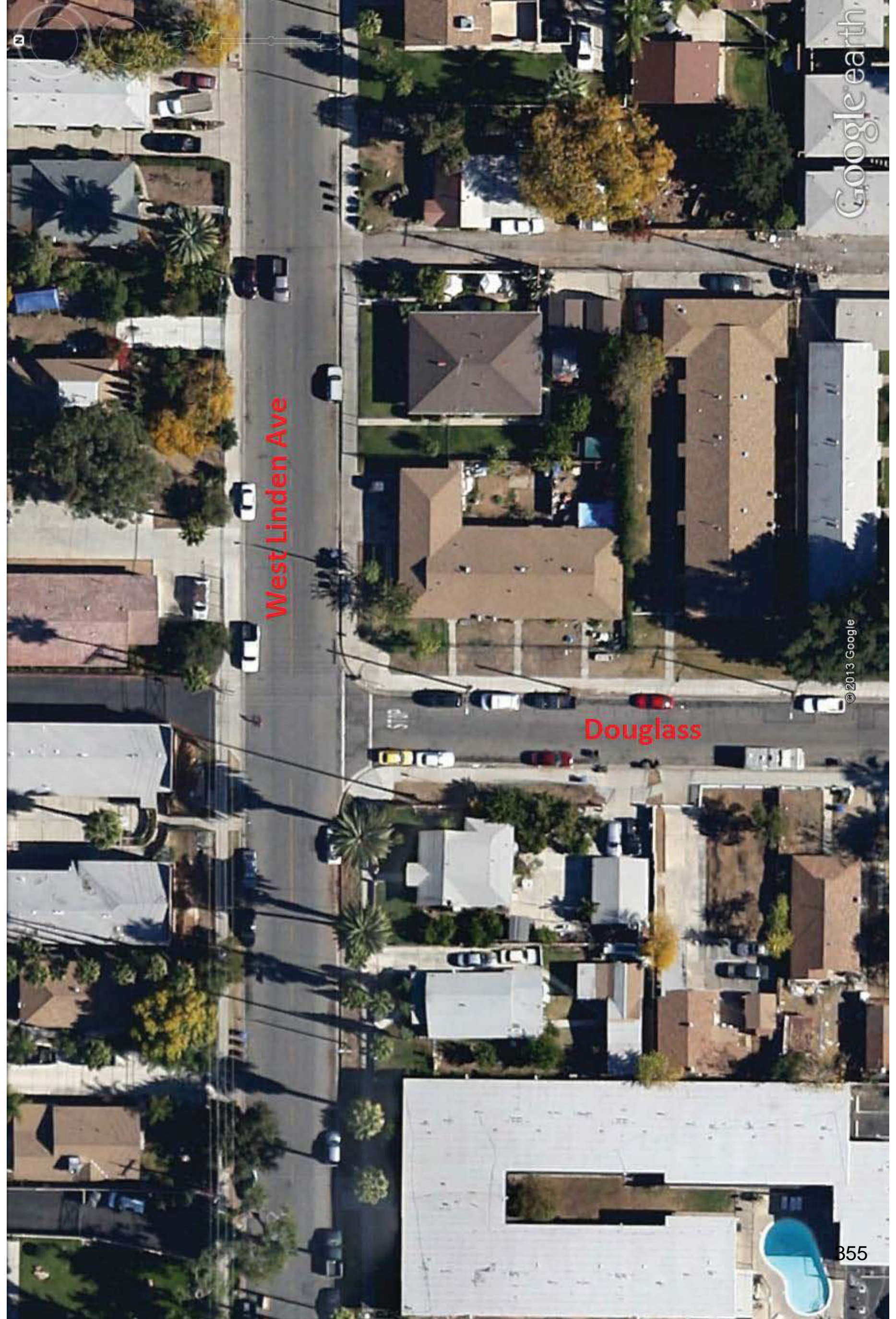




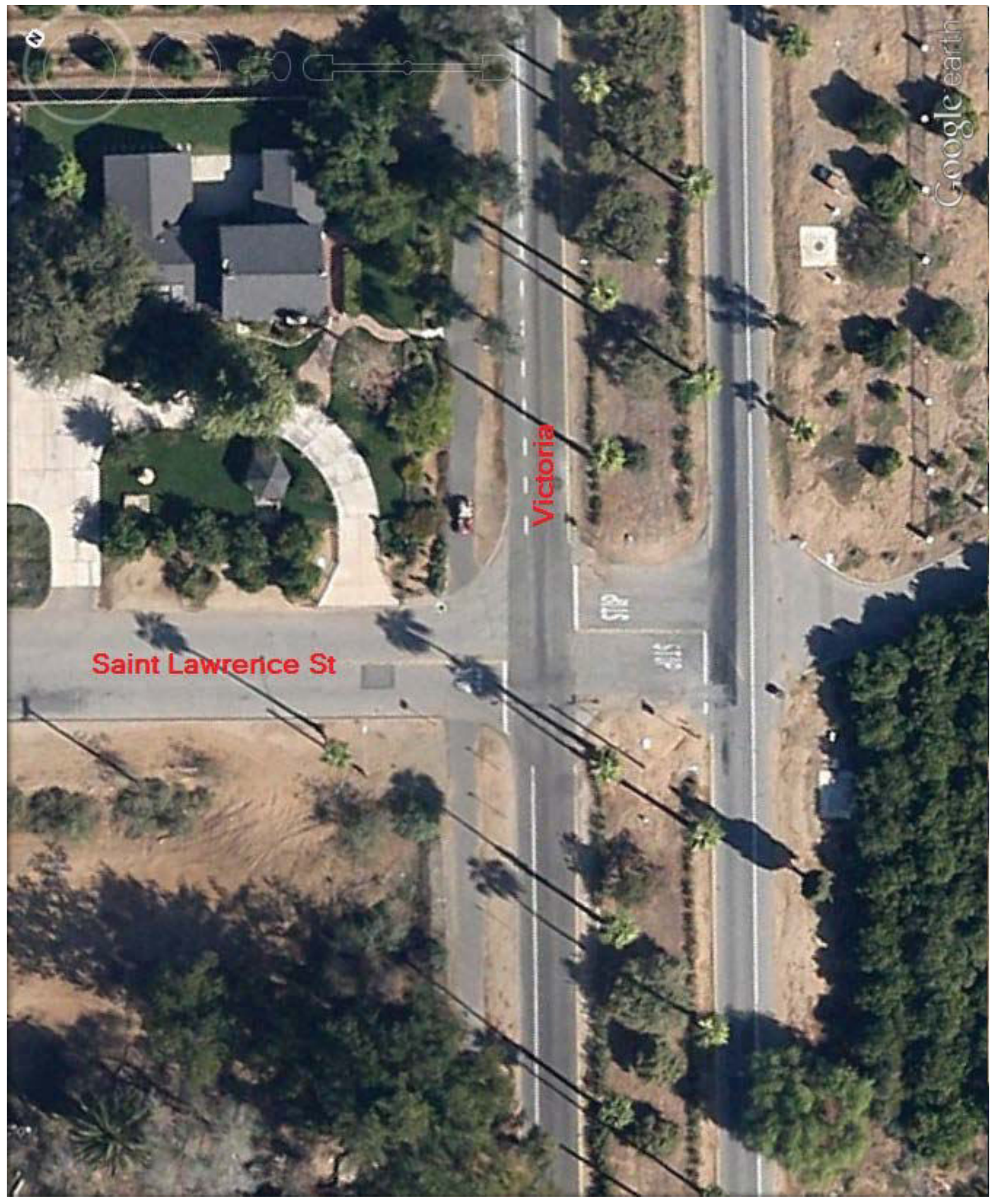




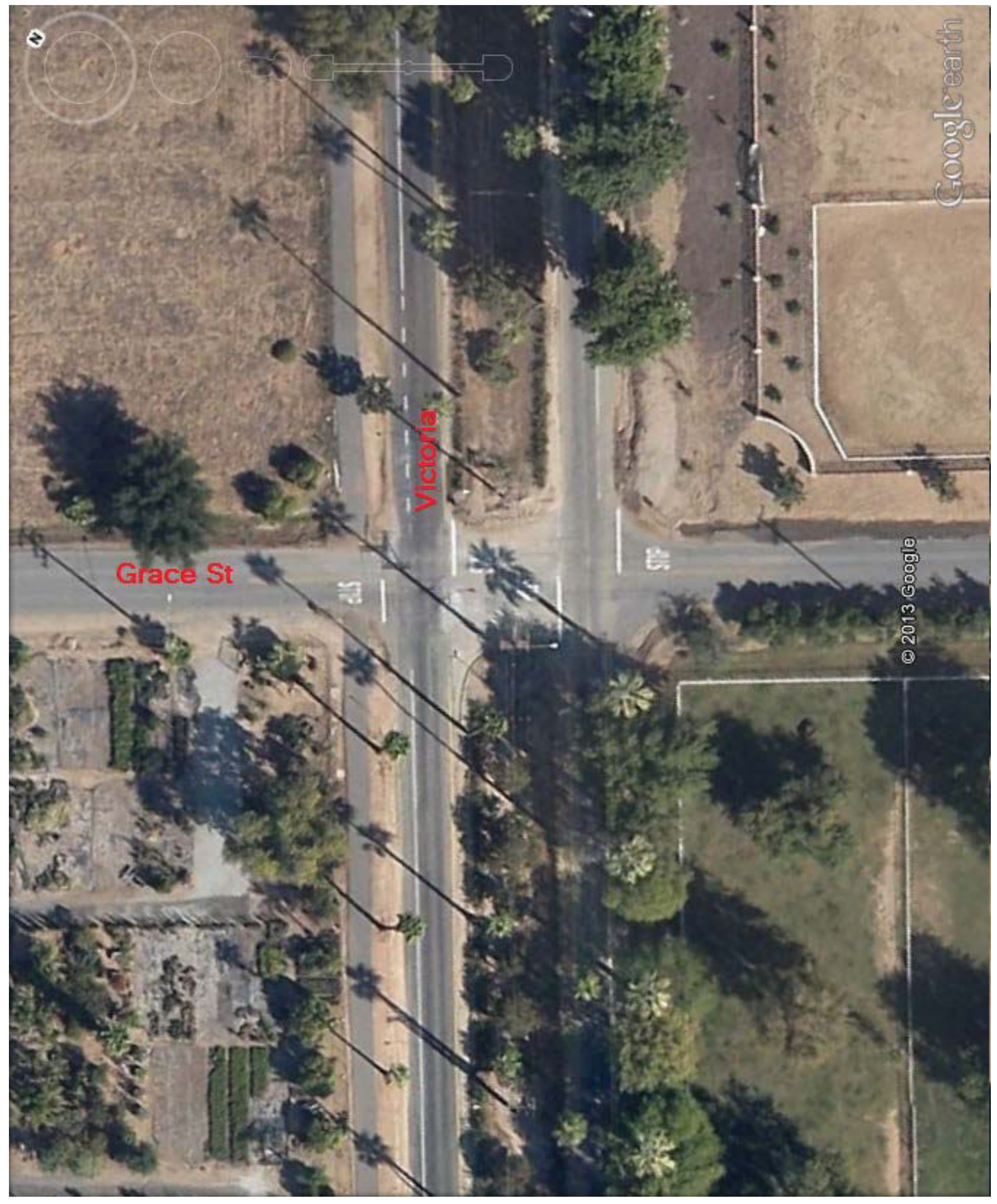




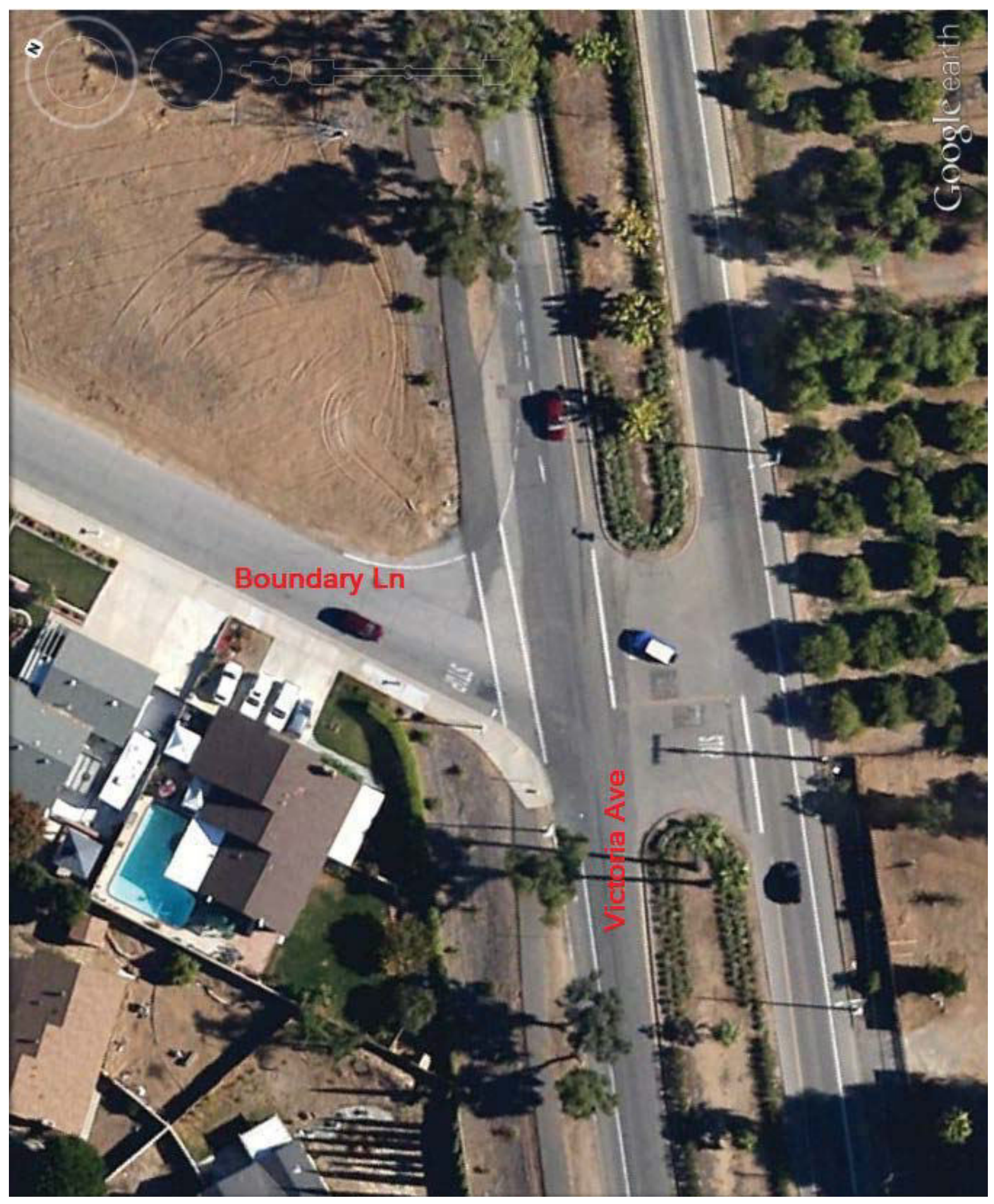




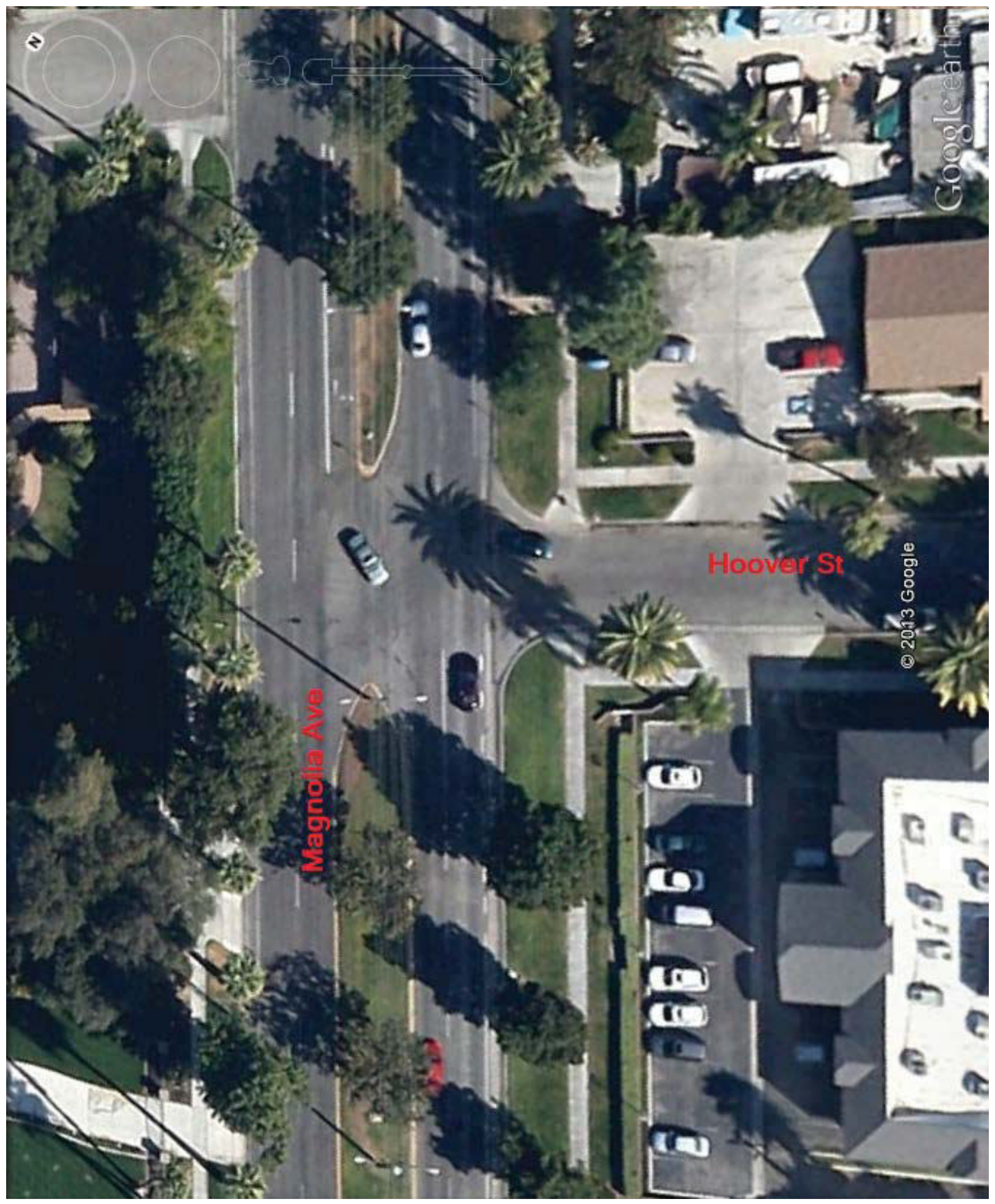




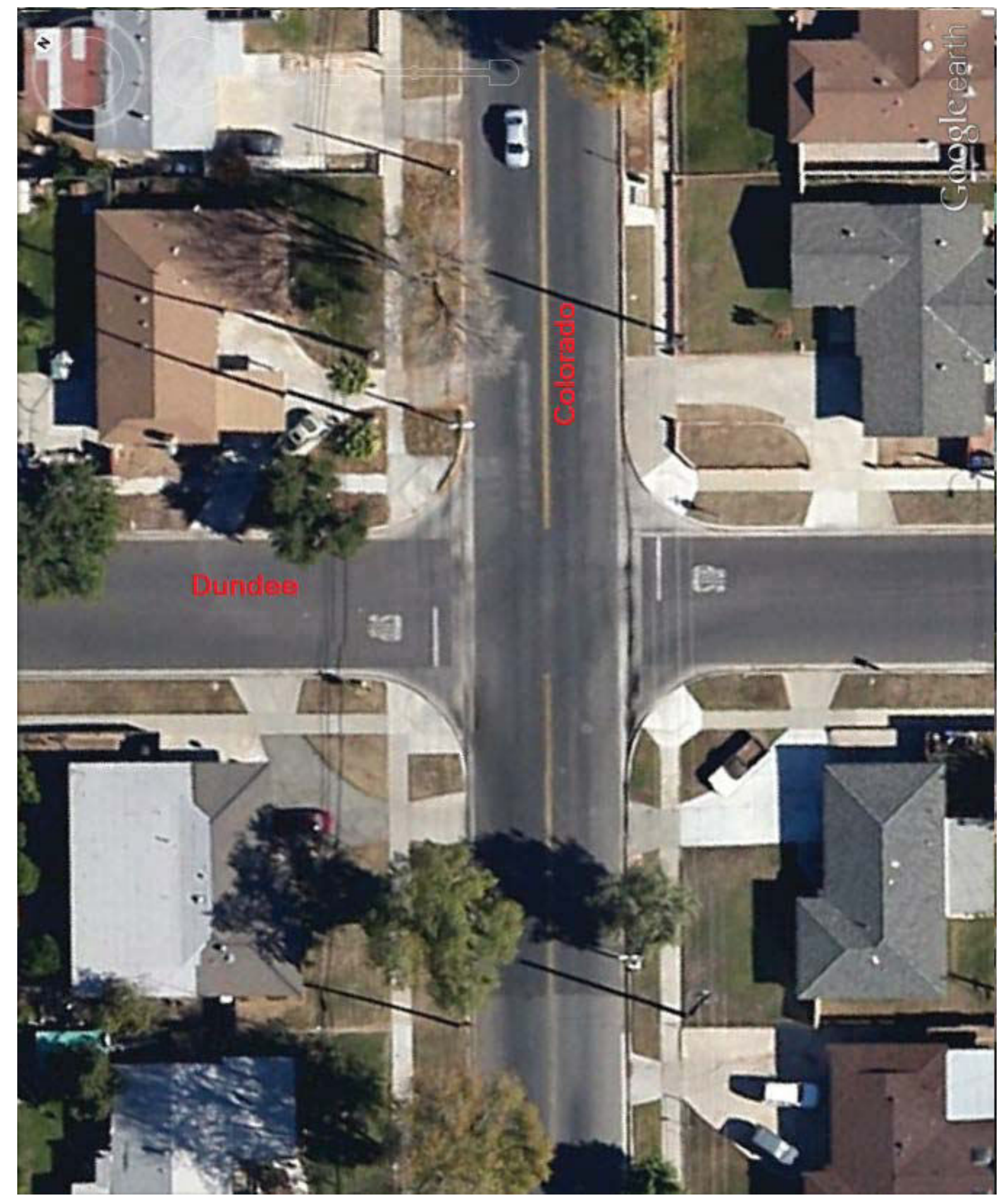




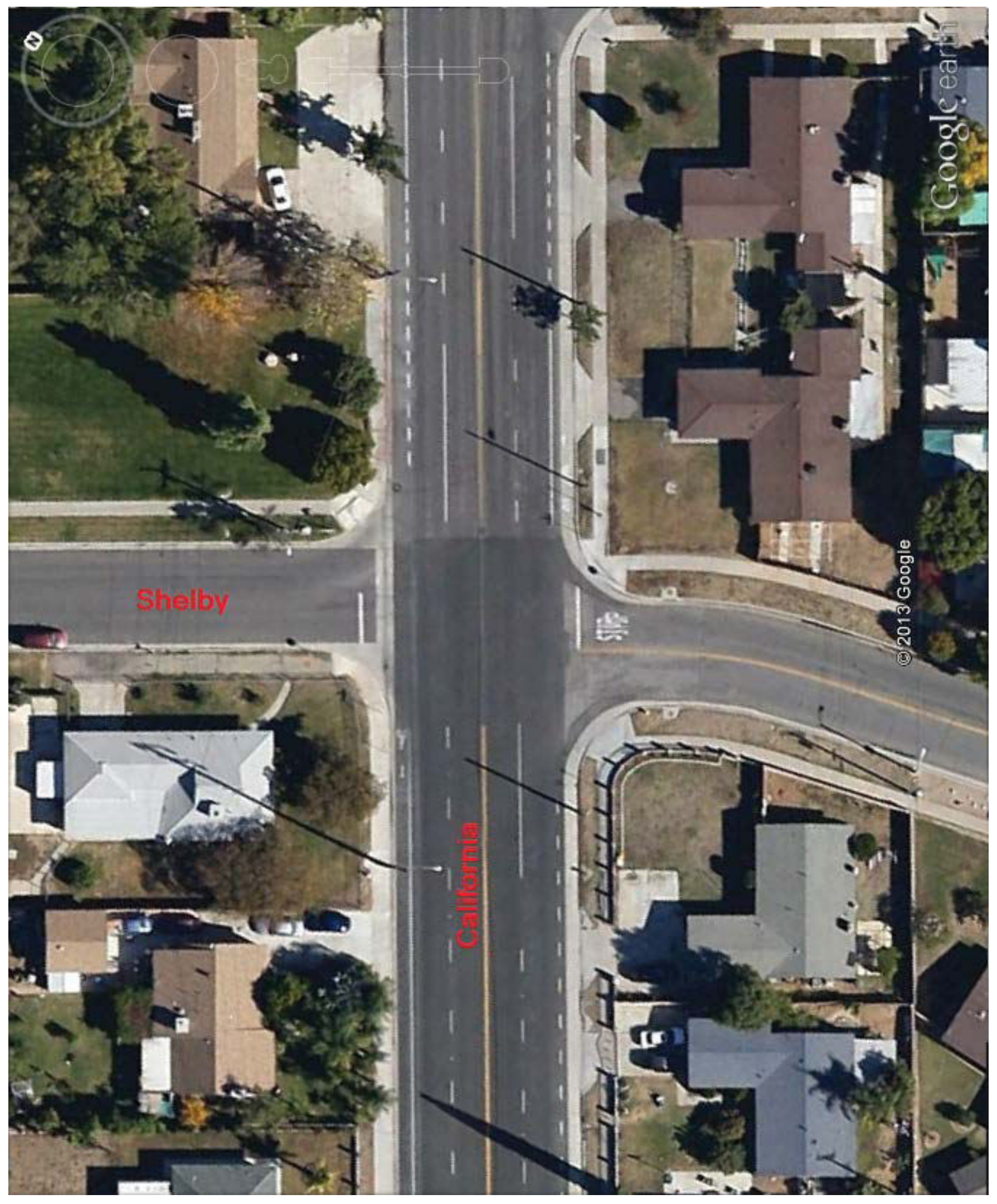




\section{San Luis Obispo Sites}




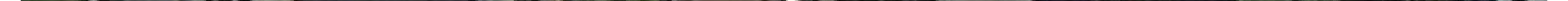




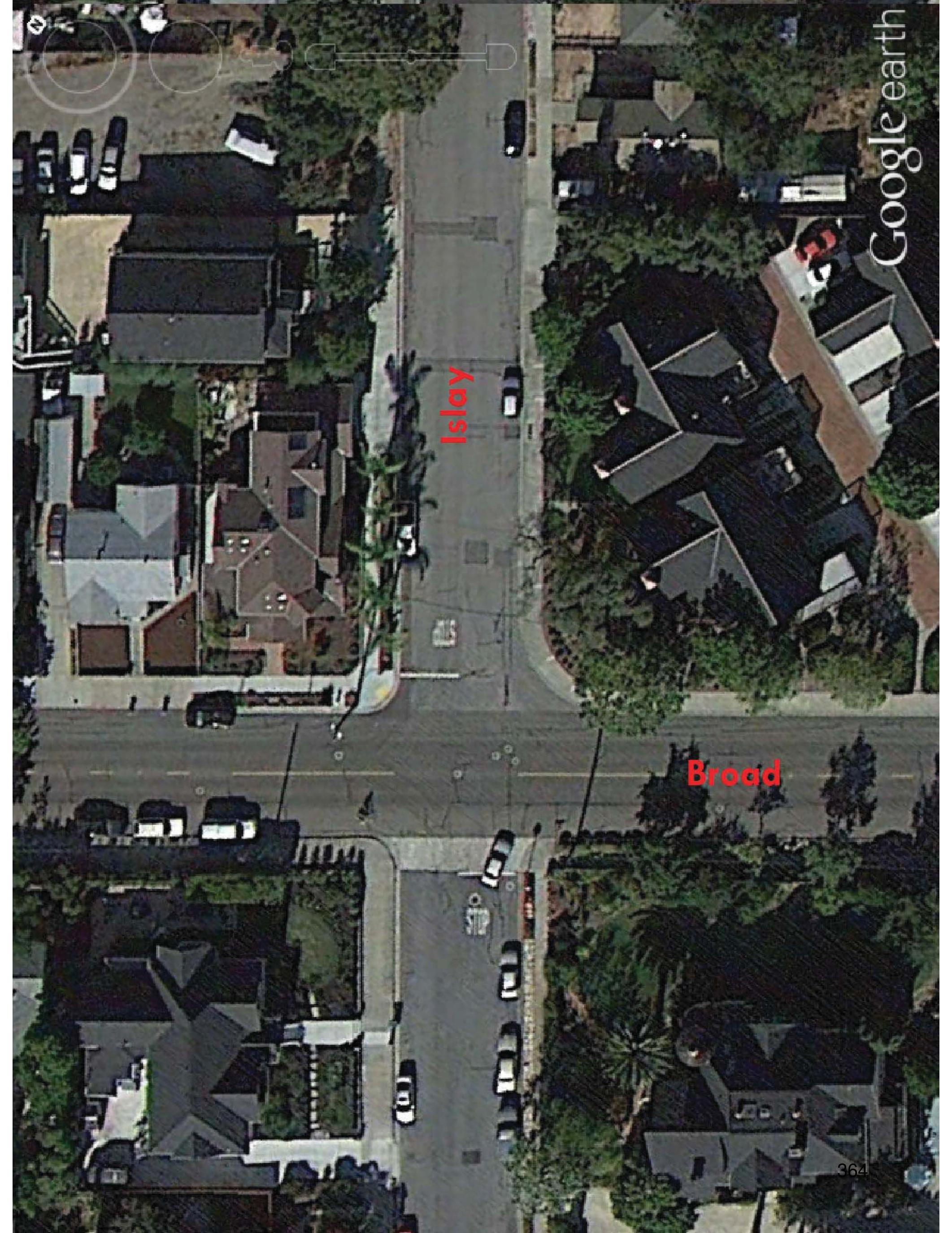




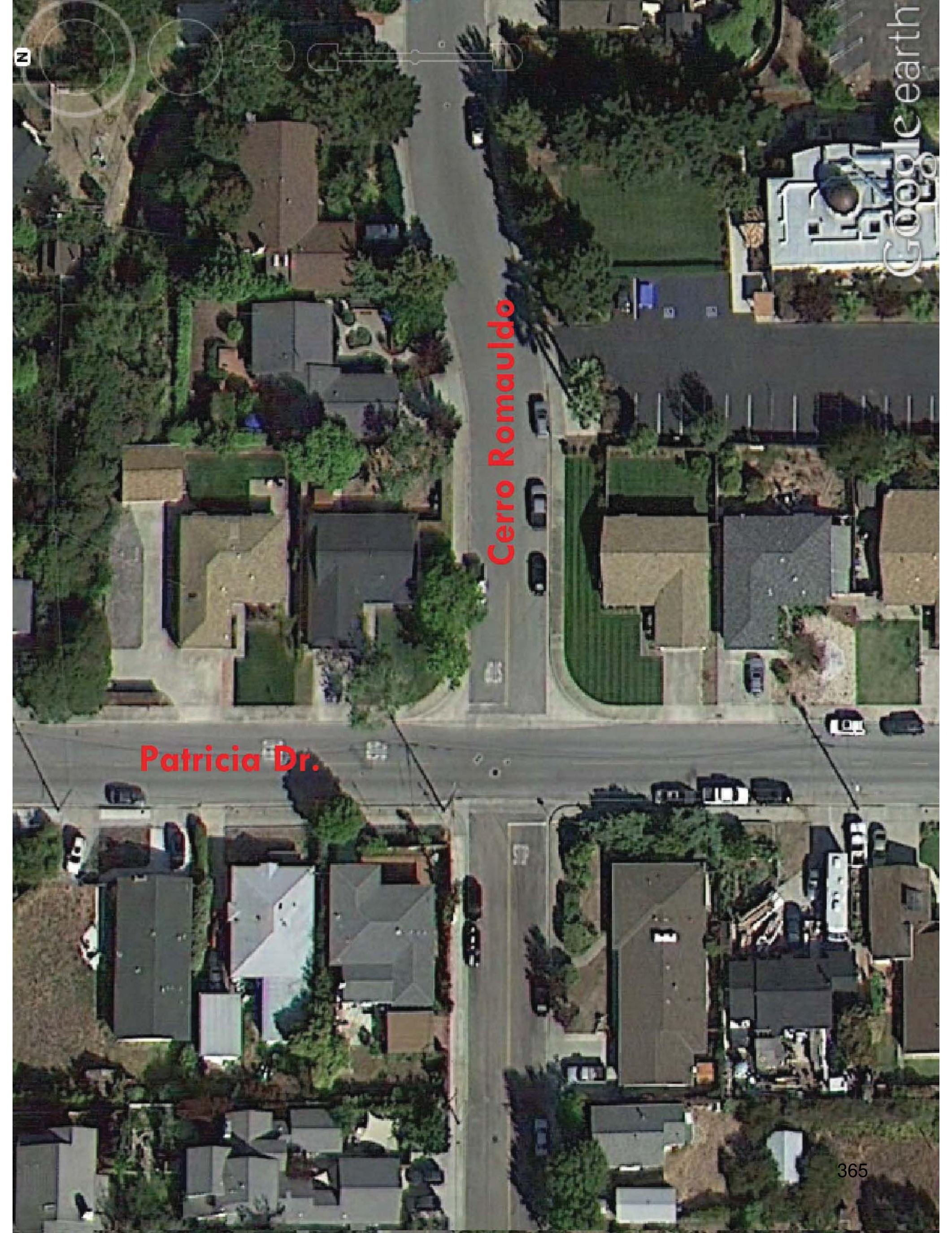




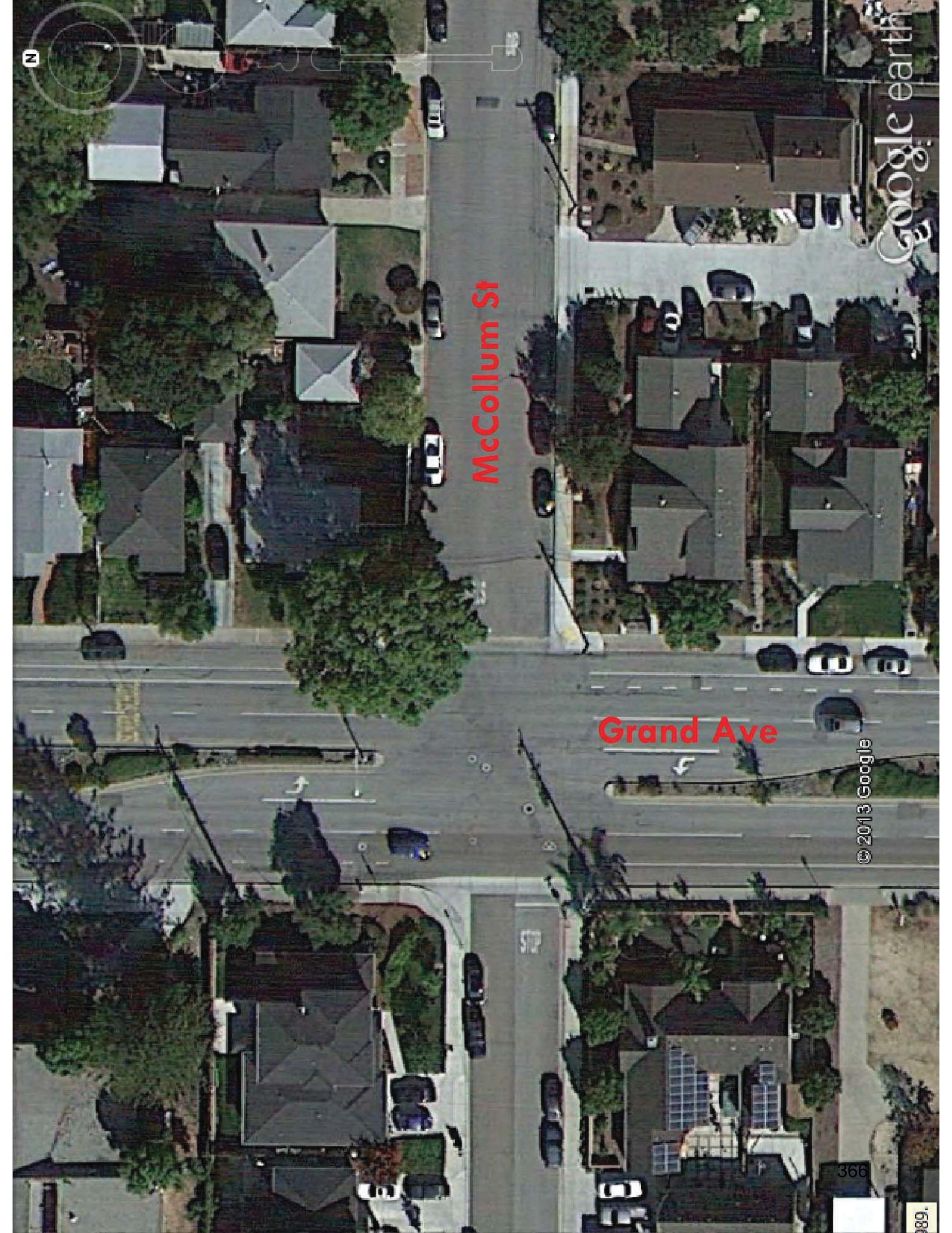




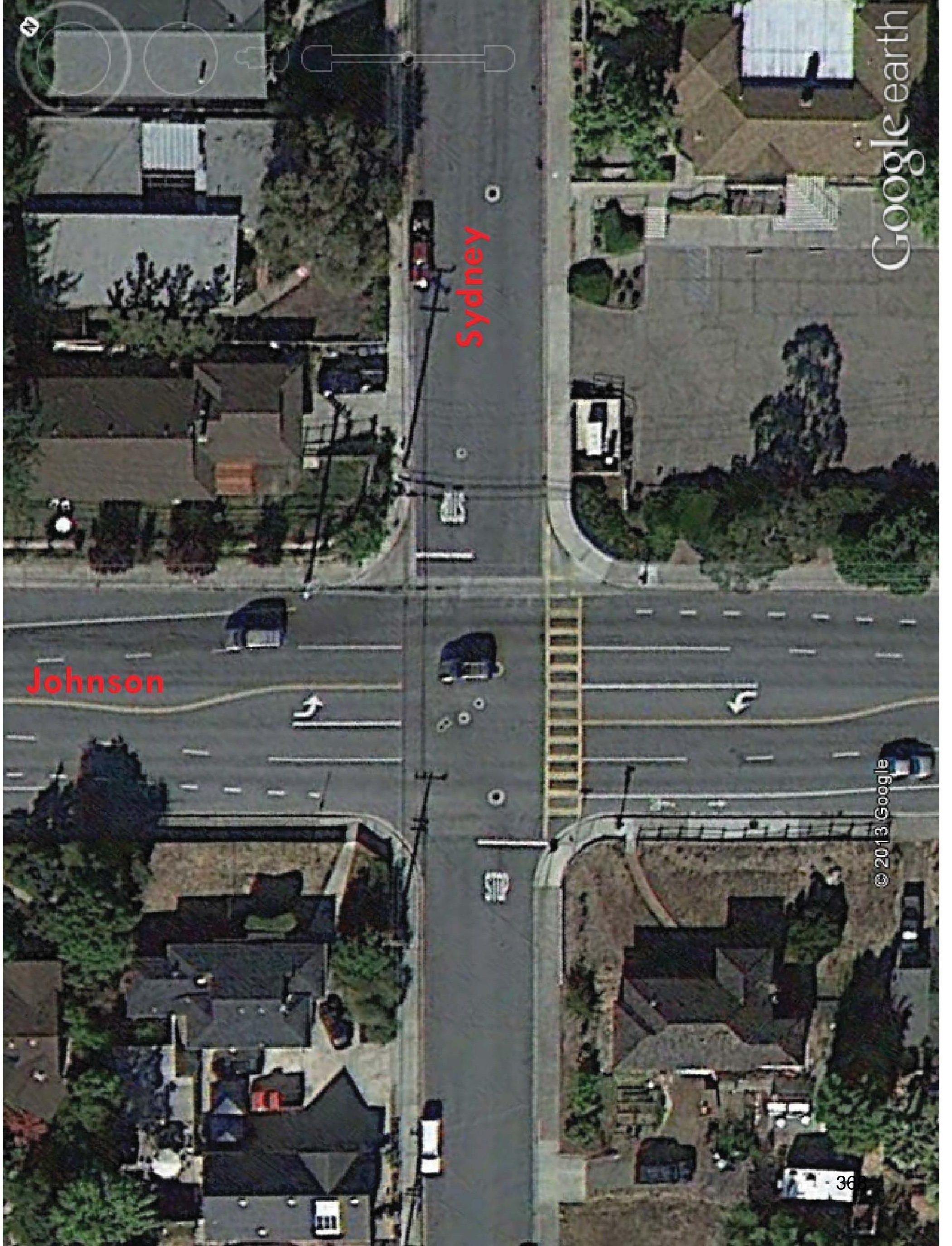




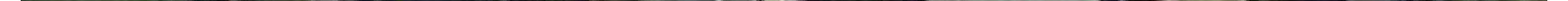




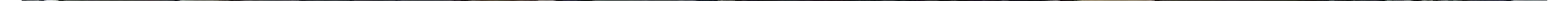




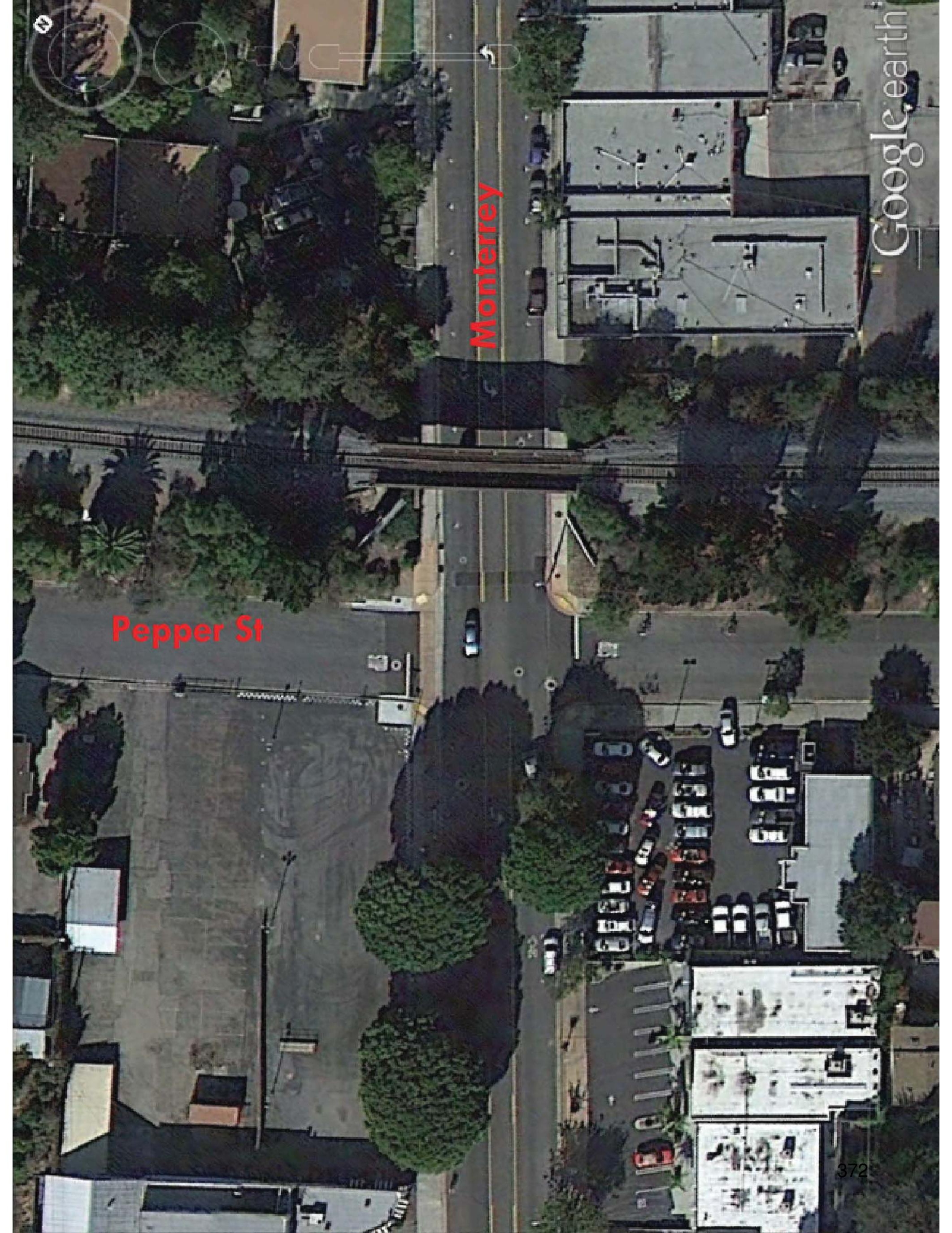




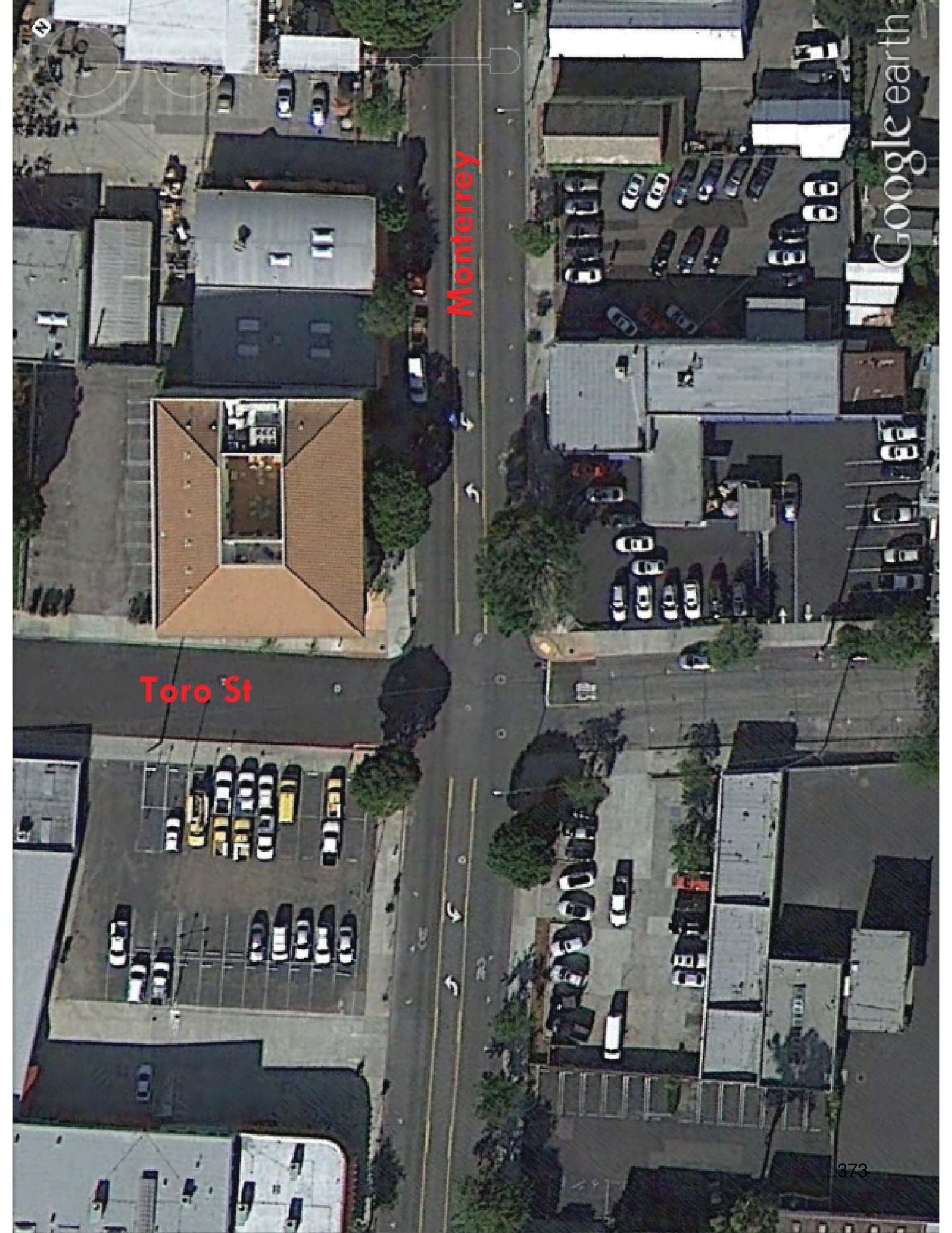




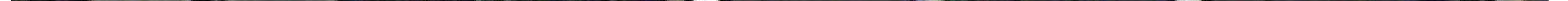




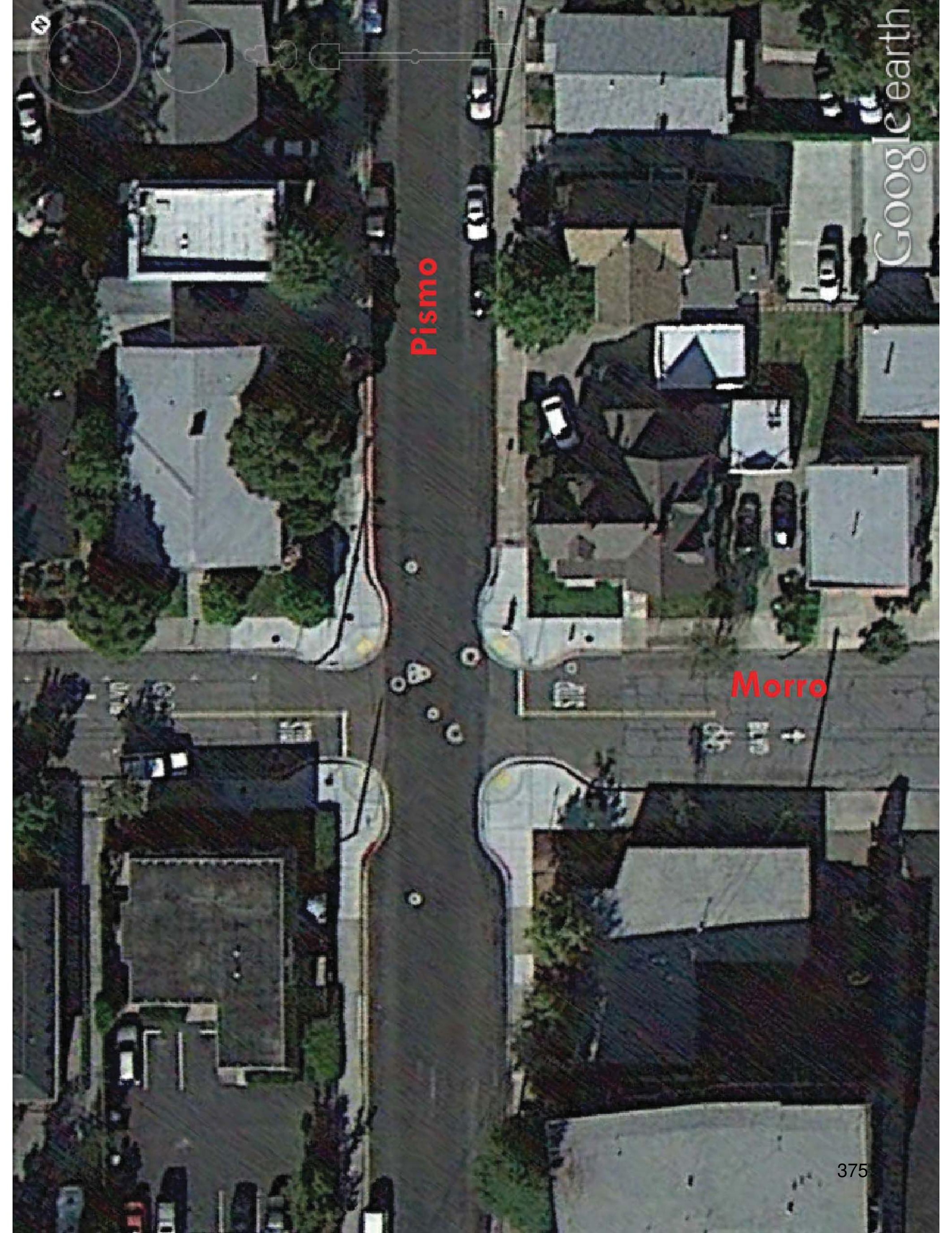




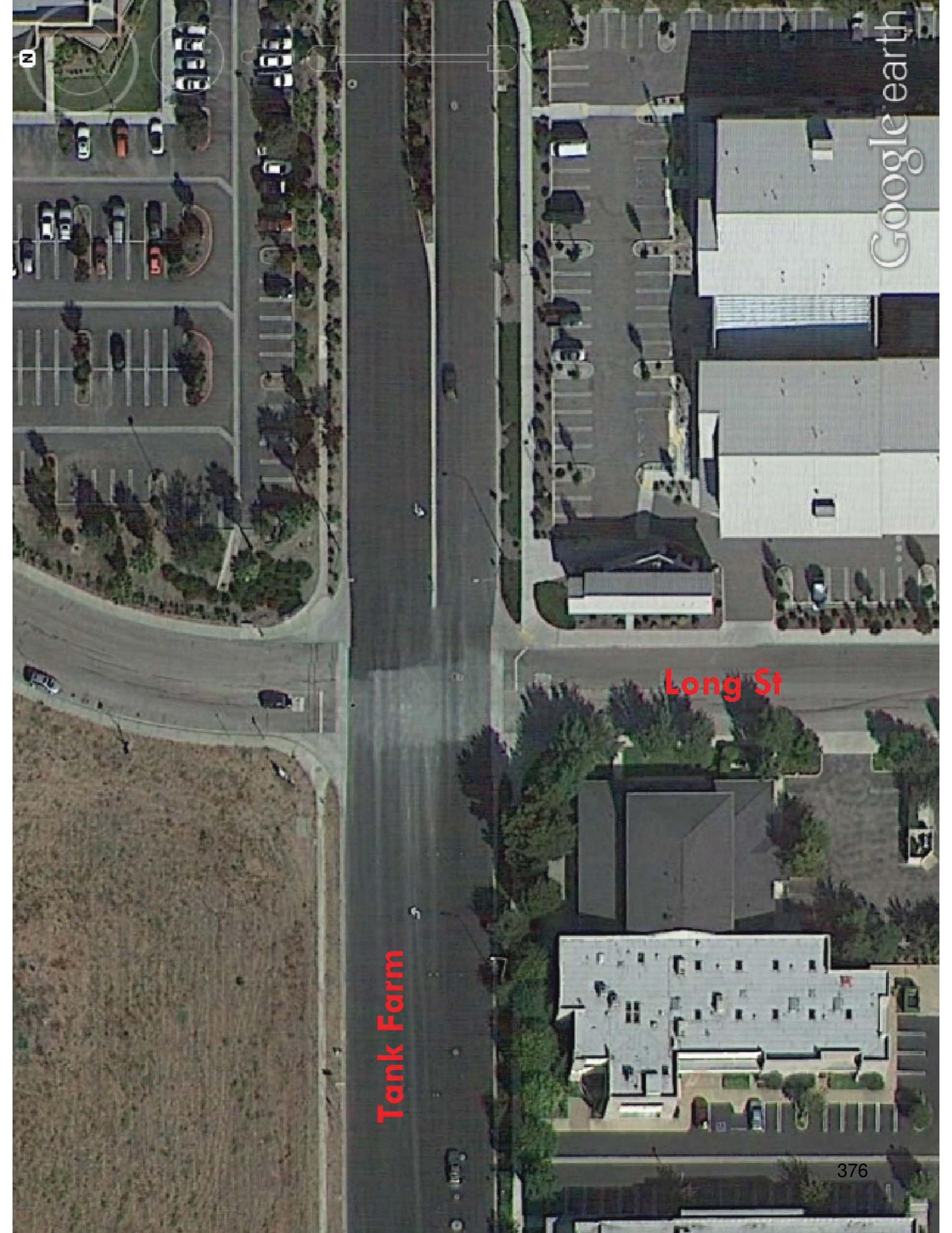




\section{Appendix N}

The following is a poster that was drawn up requesting volunteers to provide feedback on the collected videos. 


\section{Help CAL POLY Develop A System For Improving Intersections To Accomodate Bicycle Traffic}
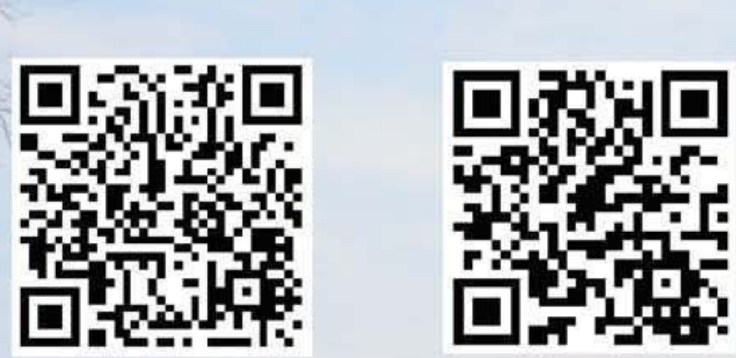

\section{We Need Your Opinion On Two Way Stop Controlled Intersections}

Simply Watch a Video on Youtube and Submit a Simple Response Survey- Its Easy!

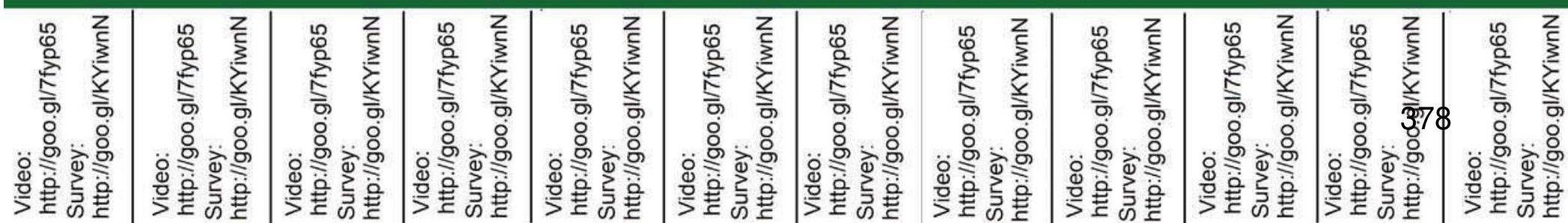

